UNIVERSIDAD NACIONAL DE LA PLATA

FACUlTad de Humanidades y Ciencias de LA

EDUCACIÓN

SECRETARÍA DE POSGRADO

\title{
La región Río de la Plata y el comercio ultramarino durante las últimas décadas del siglo XVIII: actores, circulación comercial y mercancías.
}

\section{Maximiliano Camarda}

Tesis para optar por el grado de Doctor en Historia

Director Dr. Fernando Jumar, Universidad Nacional de La Plata / Universidad Nacional de Tres de Febrero/ CONICET

La Plata, 16 de junio de 2015 


\section{AGRADECIMIENTOS}

Esta tesis es el resultado de intensos años de trabajo en los que fueron muchas las personas que me acompañaron y que intentaré mencionar en estas breves líneas, seguramente incompletas. No puedo dejar de pensar que en el entorno en que crecí, era casi imposible pensar en estudiar una carrera universitaria y menos aún continuar mis estudios de postgrado. Por ello mi agradecimiento no esta abocado solo a las personas que me ayudaron a concretar esta tesis, sino también a los que me apoyaron en los últimos 15 años que pasaron desde que decidí estudiar historia.

En primer lugar, un especial agradecimiento a Fernando Jumar quien me aceptó como dirigido desinteresadamente. Muchos de sus aportes, consejos y discusiones enriquecieron este trabajo.

A José Mateo quien, con generosidad me continuó acompañando desde aquel lejano 2005 ahora como codirector de beca. A Javier Kraselsky quien me codirigió mi tesis de maestría ayudándome acomprender el proceso político.

A los jurados de mi tesis de Maestría Mariana Canedo, Valeria Cilberto y Roberto Schmit por las sugerencias y comentarios.

A aquellos docentes que leyeron y comentaron mis trabajos, sugirieron fuentes, bibliografía y abrieron la posibilidad de nuevas preguntas: Valentina Ayrolo, Arturo Bentancur, Alex Borucky, Mariana Canedo, María Liliana Da Orden, Raúl Fradkin, Ana Frega, María Luz González, Antonio Ibarra, Silvia Mallo, Cristina Mazzeo, Eduardo Míguez, Emir Reitano y Mario Trujillo.

A la Universidad Nacional de Mar del Plata, donde realicé mis estudios de grado, así como la Maestría en Historia y la Universidad Nacional de La Plata dónde llevé a cabo mi formación doctoral. Una especial mención al CONICET sin cuyo financiamiento la concreción de esta tesis no hubiera sido posible.

Así también a los trabajadores de los diferentes archivos y bibliotecas, quienes cordialmente facilitaron la búsqueda de información e hicieron posible que pudiera aprovechar al máximo los días y horas de trabajo, principalmente del AGN de Argentina y de Uruguay y del Archivo de la ciudad de Barcelona. En especial a Fabian y Alejandro del AGN de Buenos Aires.

A mis compañeros del grupo de investigación de la Universidad Nacional de La Plata que me permitieron insertarme en un ámbito de trabajo, debate y amistad que me posibilitó la continuación de mi investigación durante estos años ${ }^{1}$.

Quiero reconocer en particular a Nicolás Biangardi, quien leyó atentamente esta tesis y con quien desde hace cinco años compartimos congresos, archivos y charlas sobre este proceso histórico en que nos embarcamos.

\footnotetext{
${ }^{1}$ Proyecto de Investigación: "Indagaciones en torno a la estructura socio-económica del Río de la Plata durante el largo siglo XVIII (1680-1820). La circulación mercantil revelada por las guías de aduana rioplatenses, 1779-1810”. Director: Fernando Jumar. Co-Directora: Silvia Mallo. Radicado en la Universidad Nacional de La Plata (Argentina).
} 
Esta tesis se enriqueció también con la atenta lectura de Lena Fugazza, Facundo García, Ana Laura Lanteri y Mara Petitti, a quienes agradezco por los comentarios y sugerencias que espero haber sabido capitalizar. En Mar del Plata las charlas con Facundo García, Alejandro Morea y Antonio Galarza sobre la sociedad del siglo XVII, XVIII y XIX fueron claves para comenzar a comprender.

No quiero dejar de agradecer a mis amigos y compañeros de Mar del Plata, Pedro Berardi, Romina Casalli, Guillermo Colombo, Silvana Ferreyra, Antonio Galarza, Facundo García, Laura Lanteri, Laura Mazoni, Alejandro Morea, Agustín Nieto, Alejo Reclusa, y muchos más, quienes desde hace más de diez años me marcaron y marcan en la vida y demuestran con acciones que la solidaridad y el cariño son posibles en este mundo. En especial a Noemí Suave quien me cobijó y enseñó como era esto de estudiar una carrera en la Universidad.

A mi abuela Mary quien me enseñó que de los momentos duros se puede salir más fuerte.

Por último a Mara con quien compartimos camino común, la persona de virtudes infinitas como el amor que te tengo. El conocerte, y compartir todas las experiencias en estos años (para enumerarlas es necesario un libro) y en los que vendrán me hicieron otra persona y a Amélie, la luz que me guía en cada paso. 
INDICE DE CONTENIDOS

\begin{tabular}{|c|c|}
\hline Indice & 4 \\
\hline Resumen & 11 \\
\hline INTRODUCCIÓN & 12 \\
\hline $\begin{array}{l}\text { CAPÍTULO I. Una aproximación a la región Río de la Plata a través } \\
\text { del cuero, la población y el mercado inmobiliario. }\end{array}$ & 26 \\
\hline 1. Introducción & 26 \\
\hline 2. La región Río de la Plata & 27 \\
\hline $\begin{array}{l}\text { 3. La dimensión de la región Rio de La Plata a partir del comercio interno } \\
\text { de los cueros }\end{array}$ & 29 \\
\hline 4. La región: zona sur y zona norte & 32 \\
\hline 5. El mercado inmobiliario: Buenos Aires y Montevideo. & 58 \\
\hline 6. Consideraciones finales & 64 \\
\hline $\begin{array}{l}\text { CAPÍTULO II. La Monarquía española y el comercio global en el siglo } \\
\text { XVIII }\end{array}$ & 66 \\
\hline 1. Introducción & 66 \\
\hline 2. El mercado externo español & 69 \\
\hline 3. El mercado interno español & 82 \\
\hline 4. La circulación de navíos del complejo portuario rioplatense & 93 \\
\hline 5. La salida de mercancías del complejo portuario rioplatense & 107 \\
\hline 6. Consideraciones finales & 112 \\
\hline CAPÍTULO III. EI comercio ultramarino de cueros & 116 \\
\hline 1. Introducción & 116 \\
\hline 2. La producción pecuaria & 117 \\
\hline 3. Fuentes trabajadas & 119 \\
\hline 4. Las cifras del comercio ultramarino de cueros & 121 \\
\hline 5. Los cargadores de cueros & 139 \\
\hline 6. Consideraciones finales & 157 \\
\hline $\begin{array}{l}\text { CAPÍTULO IV. La salida de metales preciosos por el complejo } \\
\text { portuario rioplatense. }\end{array}$ & 162 \\
\hline 1. Introducción & 162 \\
\hline 2. Antecedentes & 164 \\
\hline 3. Las cifras de la salida de metales & 170 \\
\hline 4. Los comerciantes ultramarinos, una posible conceptualización & 196 \\
\hline 5. El conflicto por la creación de la diputación en 1752 & 207 \\
\hline 6. Consideraciones finales & 210 \\
\hline CAPÍTULO V. EI comercio de esclavizados & 214 \\
\hline 1. Introducción & 214 \\
\hline 2. Antecedentes & 217 \\
\hline 3. La esclavitud en la Monarquía española & 219 \\
\hline 4. La circulación de navíos con esclavizados & 228 \\
\hline 5. Los esclavizados ingresados a la región Río de la Plata & 234 \\
\hline 6. Los actores regionales intervinientes & 241 \\
\hline $\begin{array}{l}\text { 7. La triangulación del comercio de esclavizados con el tasajo: el caso de } \\
\text { Mila de la Roca. }\end{array}$ & 245 \\
\hline 8. Conisderaciones finales & 252 \\
\hline
\end{tabular}


CONCLUSIONES

255

Fuentes

266

Bibliografía

270

Anexos

292 


\section{ÍNDICE DE MAPAS}

\begin{tabular}{|l|l|}
\hline Mapa I.1. La región Río de la Plata & 28 \\
\hline Mapa I.2. La región Río de la Plata y el complejo portuario rioplatense & 29 \\
\hline $\begin{array}{l}\text { Mapa I.3. Alcance del comercio de cueros llegados a Buenos Aires por el } \\
\text { Riachuelo (1792-1794) }\end{array}$ & 31 \\
\hline $\begin{array}{l}\text { Mapa I. 4. Procedencia de los cueros acopiados por Juan Pedro Aguirre, } \\
\text { noviembre de 1784 }\end{array}$ & 32 \\
\hline Mapa I. 5. División de la región Rio de la Plata & 33 \\
\hline $\begin{array}{l}\text { Mapa I. 6. Territorio de las Antiguas Misiones integradas a la región Río de } \\
\text { la Plata }\end{array}$ & 49 \\
\hline $\begin{array}{l}\text { Mapa I. 7. Principales estancieros de la campaña santafesina: pagos del } \\
\text { Salado, Los Saladillos, Rincón, Coronda, Arroyos y la Bajada }\end{array}$ & 50 \\
\hline Mapa I. 8. Estancias de los García Zúñiga & 51 \\
\hline Mapa I. 9. Ocupación territorial de Corrientes a fines de siglo & 53 \\
\hline $\begin{array}{l}\text { Mapa I. 10. Fundaciones de pueblos en la zona norte de la región Río de la } \\
\text { Plata a fines del siglo XVIII }\end{array}$ & 54 \\
\hline Mapa II-1. Circuito del Galeón de Manila & 78 \\
\hline Mapa II-2. La conexión de Manila con América & 80 \\
\hline $\begin{array}{l}\text { Mapa II-3. Flotas y galeones. Mercado interno siglo XVII hasta mediados } \\
\text { del XVIII. }\end{array}$ & 84 \\
\hline Mapa No II-4. Principales rutas comerciales de mediados del XVIII & 86 \\
\hline $\begin{array}{l}\text { Mapa II-5. Circuitos comerciales ultramarinos del complejo portuario } \\
\text { rioplatense 1779- 1806. }\end{array}$ & 97 \\
\hline $\begin{array}{l}\text { Mapa IV.1. Distribución de los grandes propietarios para 1763. Familia } \\
\text { Pérez }\end{array}$ & 205 \\
\hline Mapa V. 1. Costa africana atlántica meridional. & 223 \\
\hline
\end{tabular}




\section{ÍNDICE DE GRÁFICOS}

\begin{tabular}{|c|c|}
\hline ón de Montevideo (1760-1794). & 40 \\
\hline $\begin{array}{l}\text { Gráfico I. 2. Crecimiento poblacional, bautismos, casamiento y } \\
\text { defunciones de la Jurisdicción de Montevideo }(1757-1808) \text {. }\end{array}$ & 41 \\
\hline $\begin{array}{l}\text { Gráfico I. 3. Origen de la Población de la Jurisdicción de Montevideo } \\
\text { (1778) }\end{array}$ & 42 \\
\hline $\begin{array}{l}\text { Gráfico I. 4. Aproximaciones a la población total de la ciudad de Buenos } \\
\text { Aires (1744-1810). }\end{array}$ & 43 \\
\hline $\begin{array}{l}\text { Gráfico I. 5. Aproximación a los bautismos, defunciones y casamientos en } \\
\text { la ciudad de Buenos Aires (1730-60). }\end{array}$ & 44 \\
\hline Gráfico I. 6. Población de la Campaña de Buenos Aires (1744- 1815). & 46 \\
\hline Gráfico I. 7. Población de San Nicolás de los Arroyos (1726-1815). & 47 \\
\hline Gráfico I. 8. Población de las Misiones Jesuíticas durante el siglo XVIII. & 56 \\
\hline $\begin{array}{l}\text { Gráfico I. 9. Población de las Misiones Jesuíticas y de Yapeyú durante el } \\
\text { siglo XVIII. }\end{array}$ & 57 \\
\hline $\begin{array}{l}\text { Gráfico I. 10. Total de inmuebles vendidos y promedio del precio en la } \\
\text { ciudad de Buenos Aires. }\end{array}$ & 62 \\
\hline $\begin{array}{l}\text { Gráfico I. 11. Valores del total de inmuebles vendidos en la ciudad de } \\
\text { Montevideo }\end{array}$ & 63 \\
\hline Gráfico II-1. Total de navíos llegados a los puertos peninsulares (1793). & 71 \\
\hline Gráfico II-2.Total de navíos llegados al puerto de Barcelona (1793). & 72 \\
\hline Gráfico II-3. Total de navíos llegados al puerto de Cádiz (1793) & 73 \\
\hline Gráfico II-4. Azúcar comercializada de la Isla de Cuba (1760- 1819) & 90 \\
\hline Gráfico II-5. Total de navíos llegados a la península de América (1793) & 91 \\
\hline $\begin{array}{l}\text { Gráfico II-6. Circulación de navíos del puerto de Barcelona con América } \\
\text { española, (1792- 1804). }\end{array}$ & 92 \\
\hline Gráfico II-7. Entrada y salida de navíos del complejo portuario rioplatense & 93 \\
\hline $\begin{array}{l}\text { Gráfico II-8. Destinos de los navíos salidos del complejo portuario } \\
\text { rioplatense, }(1680-1760)\end{array}$ & 94 \\
\hline $\begin{array}{l}\text { Gráfico II-9. Destino de los navíos salidos del complejo portuario } \\
\text { rioplatense (1780-1806) }\end{array}$ & 95 \\
\hline $\begin{array}{l}\text { Gráfico II-10. Origen de los navíos llegados al complejo portuario } \\
\text { rioplatense (1779- 1806) }\end{array}$ & 99 \\
\hline $\begin{array}{l}\text { Gráfico II-11. Origen de los navíos provenientes de la península española } \\
\text { llegados al complejo portuario rioplatense (1779- 1806). }\end{array}$ & 100 \\
\hline $\begin{array}{l}\text { Gráfico II-12. Partida de navíos a puertos de la península española y otros } \\
\text { puertos. }\end{array}$ & 105 \\
\hline $\begin{array}{l}\text { Gráfico II-13. Partida de navíos a distintos puertos (exceptuando los de la } \\
\text { Península española). }\end{array}$ & 106 \\
\hline $\begin{array}{l}\text { Gráfico II-14. Metales y cueros salidos por el complejo portuario } \\
\text { rioplatense (1730-1789). }\end{array}$ & 109 \\
\hline Gráfico II-15. Mercancías salidas por el complejo portuario (1779- 1794). & 111 \\
\hline $\begin{array}{l}\text { Gráfico III. 1. Total de cueros comercializados en el mercado ultramarino } \\
\text { salidos del complejo portuario rioplatense (1720-1799). }\end{array}$ & 127 \\
\hline $\begin{array}{l}\text { Gráfico III. 2. Total de cueros salidos al comercio ultramarino desde el } \\
\text { complejo portuario rioplatense (1779- 1799). }\end{array}$ & 129 \\
\hline
\end{tabular}


\begin{tabular}{|l|l|}
\hline Gráfico III. 3. Total de cueros salidos al comercio ultramarino desde & 131
\end{tabular} Montevideo y Buenos Aires (1779- 1799).

Gráfico III. 4. Total de cueros salidos al comercio ultramarino a partir del 133 total de navíos y fiscales (1779-1796)

Gráfico III. 5. Total de cueros salidos por el complejo portuario 135 rioplatense (1779-1806)

Gráfico III. 6. Total de cargadores de cueros del complejo portuario 144 rioplatense (1720 -1799).

Gráfico III. 7. Total de cargadores salidos al comercio ultramarino desde 147 Montevideo. 1779- 1799

\begin{tabular}{|c|c|}
\hline Gráfico IV. 1. Metales preciosos salidos y llegados (1779- 1794) & 172
\end{tabular}

\begin{tabular}{|l|l|}
\hline Gráfico IV. 2. Salidas de metales preciosos (1725-1794) & 173
\end{tabular}

Gráfico IV. 3. Salida de metales preciosos hacia Cádiz, (1725- 1793) 175

Gráfico IV. 4. Salida de metales preciosos hacia Cádiz (1731-1793). 176

Gráfico IV. 5. Salida de mercancías de Buenos Aires según destino (1779- 1778 1783).

Gráfico IV. 6. Relación entre las guías de salida de Buenos Aires y Metales 179 preciosos enviados en forma directa (1779-1783)

\begin{tabular}{|c|c|} 
Gráfico IV. 7. La salida de metales preciosos y su distribución & 180
\end{tabular}

\begin{tabular}{|l|l}
\hline Gráfico IV. 8. Salida de metales preciosos (1715- 1794). & 182
\end{tabular}

\begin{tabular}{|l|l}
\hline Gráfico IV. 9. Distribución de los metales preciosos (1779- 1794) & 183
\end{tabular}

\begin{tabular}{|l|l}
\hline Gráfico IV. 10. Distribución de los metales preciosos (1779- 1794) & 184
\end{tabular}

\begin{tabular}{|l|l|}
\hline Gráfico IV. 11. Salida de metales para la Real Hacienda (1745-1793) & 186
\end{tabular}

Gráfico IV. 12. Presión fiscal per capita en Buenos Aires durante el siglo 188 XVIII

Gráfico IV. 13. Presión fiscal per capita en distintas ciudades y regiones 188 (1790)

\begin{tabular}{l|l}
\hline Gráfico IV. 14. Salida de metales preciosos según destino (1779- 1794). & 189
\end{tabular}

Gráfico IV. 15. Total de registros y promedio por año (1783-1794). 191

Gráfico IV. 16. Distribución de los cargadores por la suma enviada (1779- 193 1794)

Gráfico IV. 17. Total de metales enviados por grupo de cargadores (1779- 194 1794)

Gráfico IV. 18. Envíos de metales y cueros de Diego de Agüero, 1779- 202 1794

Gráfico V. 1. Procedencia de Esclavizados del comercio Atlántico (1451- 222 1870).

Gráfico V. 2. Población de la ciudad de Buenos Aires (1744-1810) 226

Gráfico V. 3. Lugares de arribo de los esclavizados salidos desde Buenos 227 Aires (1779-1783).

Gráfico V. 4. Rutas de los esclavizados salidos desde Buenos Aires (1779- 228 1783)

Gráfico V. 5. Entrada y salida de navíos con esclavizados del complejo 230 portuario rioplatense por origen (1777-1811).

Gráfico V. 6. Navíos llegados a la región Río de la Plata según bandera 231 (1779-1812)

Gráfico V. 7. Navíos comprados por rioplatenses (1787- 1805)

132


Gráfico V. 8. Esclavizados introducidos al Río de la Plata (1777-1812)

136

Gráfico V. 9. Esclavizados introducidos al Río de la Plata desde África y 237

Brasil (1777-1812)

Gráfico V. 10. Totales de esclavizados introducidos al Río de la Plata en 239 relación al origen del navío (1777-1812)

Gráfico V. 11. Exportación de tasajo a Cuba realizada por J. R. Milá de la 247 Roca (1792 a 1796)

Gráfico V. 12.

249

Comercio de esclavizados introducidos por Milá de la Roca (1797 a 1799). 


\section{ÍNDICE DE CUADROS}

\begin{tabular}{|c|c|}
\hline Cuadro I. 1. Origen de la población de Buenos Aires (1744-1810) & 45 \\
\hline Cuadro I. 2. Transacciones inmobiliarias de Buenos Aires (1700-1809) & 60 \\
\hline $\begin{array}{l}\text { Cuadro I. 3. Promedios de las transacciones inmobiliarias de Buenos Aires } \\
(1700-1809)\end{array}$ & 61 \\
\hline $\begin{array}{l}\text { Cuadro II-1. Máximo de comercio estipulado para la Ruta del Pacífico } \\
(1593-1815)\end{array}$ & 81 \\
\hline $\begin{array}{l}\text { Cuadro II-2. Tipos de navíos que ingresaron en el Complejo Portuarios } \\
\text { Rioplatense (1680-1800) }\end{array}$ & 103 \\
\hline $\begin{array}{l}\text { Cuadro II-3. Metales y cueros salidos por el complejo portuario rioplatense } \\
(1730-1789)\end{array}$ & 110 \\
\hline Cuadro III. 1. Cueros salidos de Montevideo y Buenos Aires (1779- 1799) & 130 \\
\hline $\begin{array}{l}\text { Cuadro III. 2. Totales de cargadores de Montevideo y Buenos Aires (1779- } \\
\text { 1799) }\end{array}$ & 147 \\
\hline $\begin{array}{l}\text { Cuadro III. 3. Total de cargadores de Buenos Aires y Montevideo según } \\
\text { cantidad de cuer.os comercializados (1779- 1799) }\end{array}$ & 148 \\
\hline $\begin{array}{l}\text { Cuadro III. 4. Total de cargadores de Montevideo según cantidad de } \\
\text { cueros comercializados (1779-1799) }\end{array}$ & 149 \\
\hline $\begin{array}{l}\text { Cuadro III. 5. Total de cargadores de Buenos Aires según cantidad de } \\
\text { cueros comercializados (1779- 1799) }\end{array}$ & 151 \\
\hline $\begin{array}{l}\text { Cuadro III. 6. Grandes cargadores de cueros según cantidad } \\
\text { comercializada (1779-1799) }\end{array}$ & 152 \\
\hline Cuadro IV. 1. Salida y entrada de metales preciosos (1779-1794) & 171 \\
\hline $\begin{array}{l}\text { Cuadro IV. 2. Salida de metales preciosos según forma de envío (1715- } \\
\text { 1794) }\end{array}$ & 181 \\
\hline $\begin{array}{l}\text { Cuadro IV. 3. Salida de metales preciosos para la Real Hacienda (1745- } \\
\text { 1794) }\end{array}$ & 187 \\
\hline Cuadro IV.4. Total de registros según destino (1779- 1794) & 190 \\
\hline $\begin{array}{l}\text { Cuadro IV. 5. Los cargadores de metales más importantes según cantidades } \\
\text { enviada (1779-1799) }\end{array}$ & 199 \\
\hline Cuadro IV. 6. Algunos de los cargadores por predominio de envíos & 200 \\
\hline $\begin{array}{l}\text { Cuadro IV.7. Envíos de metales por destino de Diego de Agüero (1779- } \\
\text { 1794) }\end{array}$ & 203 \\
\hline Cuadro IV. 8. Envíos de Manuel Diago (1779- 1794). & 205 \\
\hline $\begin{array}{l}\text { Cuadro IV. } 9 \text { Envíos de Metales y cueros por Domingo Belgrano Pérez } \\
(1755-1798) \text {. }\end{array}$ & 207 \\
\hline $\begin{array}{l}\text { Cuadro V. 1. Mayores propietarios de embarcaciones del Río de la Plata } \\
(1787-1806)\end{array}$ & 234 \\
\hline Cuadro V. 2. Permisos para ingresar esclavizados & 242 \\
\hline $\begin{array}{l}\text { Cuadro V. 3. Algunos de los grandes cargadores de esclavizados } \\
\text { rioplatenses }\end{array}$ & 244 \\
\hline
\end{tabular}




\section{Resumen}

El objetivo de esta tesis es analizar la economía de la región Río de la Plata durante las últimas décadas del siglo XVIII a partir del estudio de las cifras del comercio ultramarino y los actores que intervinieron. Operamos en el marco de una metodología que combinó un enfoque cuantitativo con el cualitativo y la escala macro analítica con la micro. Partimos del análisis de un conjunto amplio de documentación que registra no solo las cantidades y los tipos de mercancías sino también los actores vinculados al comercio.

Partimos del supuesto de que a mediados del siglo XVIII se produjo una serie de transformaciones en el comercio ultramarino global y en la región Río de la Plata que provocó que se sucediese un círculo virtuoso de crecimiento comercial. A partir de lo cual, un grupo de actores sociales habría logrado incrementar su actividad producto de que su renta principal era extraída de la comercialización ultramarina de cueros. Es decir, a partir del crecimiento del comercio de cueros, y su intercambio por mercancías europeas en lugar de metales preciosos, esto grupo de actores obtuvo una mayor ganancia que les permitió acumular estos metales para otras inversiones. Esta acumulación les permitió intervenir fuertemente en el mercado inmobiliario, comprar navíos, desarrollar protoindustrias como el tasajo y comprar esclavos en África.

Para mostrar este proceso desde distintos ángulos organizamos la tesis en cinco capítulos. El primero estudia la región Río de la Plata durante la segunda mitad del siglo XVIII a partir del análisis de la producción y comercialización interna, las características de la población y el mercado inmobiliario de sus principales ciudades: Buenos Aires y Montevideo. El segundo capítulo, examina las características y transformaciones del comercio ultramarino de la Monarquía española y su articulación con el complejo portuario rioplatense. A continuación estudiamos la participación de los actores comerciales en relación a la circulación de tres mercancías: los cueros, los metales preciosos y los esclavizados. Así, el tercer capítulo aborda la salida de cueros articulando el examen de sus cifras, actores y los conflictos en torno a la actividad. El capítulo cuatro focaliza en la salida de metales preciosos por el complejo portuario rioplatense, las cifras, origen, destino y actores que intervinieron. El último capítulo está dedicado al comercio de esclavizados llegados al complejo portuario rioplatense durante las últimas décadas del siglo XVIII y la participación de los rioplatenses en el mismo.

\section{Palabras claves}

Región Río de la Plata- comercio ultramarino- comerciantes- circuitos mercancías - Siglo XVIII 


\section{INTRODUCCIÓN}

I- El análisis y reflexión sobre las formas que adquirió la economía de fines de siglo XVIII y cuáles fueron sus actores más importantes ${ }^{2}$ acompañó las preocupaciones de la historiografía desde sus mismos orígenes. La piedra fundacional que supuso Bartolomé Mitre (1927) con su Historia de Belgrano, dio cuenta de este proceso, dividiendo a los grupos económicamente más importantes entre aquellos que estaban de acuerdo con la continuación del monopolio y los que consideraban fundamental un cambio orientado hacia el librecambio. Parte de considerar una nación argentina liberal oprimida por una España colonialista, siendo el objetivo de su estudio el revalorizar los supuestos valores argentinos y su destino inexorable.

La historiografía clásica ${ }^{3}$ continuó con los análisis de los sectores más poderosos de la región de fines del siglo XVIII, en donde se realizaron valiosos aportes y centraron su análisis en los conflictos comerciales. En particular, las variaciones estuvieron marcadas por dicotomías entre: monopolistas, españoles, argentinos y librecambistas. (Levene, 1949; Rosa, 1973; De Gandia, 1960)

Al calor de la renovación historiográfica que acompañó el regreso de la democracia en 1983, han aparecido varios trabajos relevantes que toman como punto de partida los planteos de Tulio Halperín Donghi. Como sostiene Raúl Fradkin este historiador registró procesos que habían pasado inadvertidos para la

\footnotetext{
${ }^{2}$ El análisis que se desarrolla a continuación no es exhaustivo, sino que busca establecer algunos de los lineamientos historiográficos más importantes, que nos permitieron delimitar esta investigación.

${ }^{3}$ Entendemos por historiografía clásica a los textos revisionistas y de la Nueva Escuela Histórica predominantes hasta la renovación historiográfica.
} 
historiografía como “...el carácter mercantil/ Burocrático de la élite tardocolonial porteña, la importancia del comercio y la exportación de plata, la presencia de la agricultura" (Fradkin, 2005: 172, 173).

A partir de entonces, las principales interpretaciones giraron en torno a establecer si los hacendados o los comerciantes eran los grupos sociales más importantes, recuperando y resignificando el debate entre producción o circulación como agente dinamizador del capitalismo ${ }^{4}$.

El análisis de Eduardo Azcuy Ameghino (2002), parte de establecer una sociedad “...dependiente -encadenada económicamente en su evolución- de las necesidades y designios de una potencia metropolitana hegemónica.” (Azcuy Ameghino, 2002: 17). En este contexto, dos grupos se encontraban en disputa, el de los comerciantes vinculados a la "metrópoli" y el de los hacendados, siendo estos últimos los predominantes a nivel regional.

En contraposición se encuentra la perspectiva en donde, por encima de la producción, el enfoque analítico se sitúa en la circulación. Juan Carlos Garavaglia y Jorge Gelman (1998), plantean que si bien los grandes propietarios tenían un rol importante ya que ocupaban gran parte del territorio, eran modestas sus explotaciones y

"Sin duda que la elite colonial hay que buscarla en otro lado, no en la campaña. Hay algunas grandes estancias propiedad de unos pocos miembros de la elite porteña, pero resulta evidente analizando las actividades de estos personajes- que su pertenencia a la elite no se fundaba en su actividad agropecuaria, sino en el comercio y en su participación en el poder político, siendo en todo caso la actividad rural un complemento a la diversificación de sus actividades principales" (1998: 34).

\footnotetext{
${ }^{4}$ En el número 40 de los Cuadernos de Pasado y Presente se plasmó distintas interpretaciones sobre el modo de producción en America Latina durante el siglo XVIII.
} 
Esta interpretación plantea que los comerciantes que intercambiaban metales por las mercancías provenientes de la península española era el sector más importante, estando atados a este sistema por las características mismas de la dominación colonial

...puesto que la Corona española por un lado y los comerciantes metropolitanos por el otro exigen que los pagos que se les efectúan (sea en concepto de diferentes impuestos para el primero o como pago de las importaciones para los segundos) sean sobre todo en moneda metálica y en particular en buena moneda (Gelman, 1996: 46).

Entonces, en esta perspectiva, como en la de Azcuy Ameghino, el sector más importante también se encontraba determinado por el sistema colonial, encontrándose la diferencia en el énfasis puesto en los comerciantes monopolistas.

Por el contrario Fernando Jumar sostiene que el modelo político no era el colonial, "entendida esta en tanto que mercado cautivo y fuente parasitaria de renta, de donde deriva la concepción del sistema de dominación”. (Jumar, 2010: 4). A su entender, el sector más influyente era entonces el los empresarios ganaderos, quienes
"desde el segundo tercio del siglo XVII y en función de las coyunturas cambiantes, asume diversas formas externas de articulación para lograr sus objetivos. Primero fue la de "vecinos accioneros", adaptando innovadoramente los usos y las normas sobre bienes del común. Luego, en tanto que "hacendados" que reivindican derechos de propiedad privada sobre las bestias dispersas y que llegaron a formalizar la exteriorización de sus intereses claramente desde el último tercio del siglo XVII (a través del Cabildo de Buenos Aires) y se refuerza con un gremio (informal pero reconocido como interlocutor por la Corona) desde el último cuarto del siglo XVIII.” (Jumar, 2010: 17).

Además, Jumar afirma que el Cabildo defendía en primer lugar los intereses de los empresarios ganaderos por sobre el de los comerciantes y cuando estos últimos comienzan a organizarse en juntas para presionar sobre los primeros, 
éstos se agrupan a su vez con su movimiento de agremiación, llegando a pedir formalmente la creación de la hermandad de la Mesta en 1790.

En esta línea, el objetivo de esta tesis es analizar la economía de la región Río de la Plata durante las últimas décadas del siglo XVIII a partir del estudio de las cifras del comercio ultramarino y los actores que intervinieron.

Tomamos para nuestro análisis cuatro ejes: el vínculo entre la región Río de la Plata y el comercio ultramarino; las cifras del comercio ultramarino del complejo portuario rioplatense; la participación de los actores regionales en él y la articulación entre la dinámica comercial y las reformas institucionales. Nos interesa integrar en un mismo análisis las transformaciones económicas internas de la región, la influencia externa, las cifras del comercio ultramarino, la participación de los actores y los conflictos comerciales. En líneas generales, examinamos los factores que confluyeron para incrementar, cuantitativa y cualitativamente, el comercio ultramarino de la región.

La intención es complejizar la mirada sobre los comerciantes, ya que una parte de los mismos mantuvieron los mismos intereses que los empresarios ganaderos. Para ello en primer lugar, establecemos las características de la región Río de la Plata y su vinculación comercial ultramarina y posteriormente desarrollamos las cifras, los circuitos y actores que intervinieron en ese comercio.

Consideramos que las transformaciones económicas en la región Río de la Plata se produjeron a partir de mediados del siglo XVIII a partir de una confluencia de cambios: dentro de la propia región, en el comercio interno y externo de la Monarquía española y en la dinámica comercial ultramarina del complejo portuario. En este contexto, nuestro análisis gira en torno a confirmar desde distintos ejes las transformaciones: el crecimiento de la producción y 
comercialización de los cueros, el incremento de la población regional, el aumento del mercado inmobiliario y naviero, la acentuación de los intercambios de mercancías provenientes de la península española por metales preciosos y el ingreso de esclavizados.

Aspectos poco conocidos al momento y que resultan centrales para profundizar el conocimiento sobre la economía de la región Río de la Plata y de los actores que intervinieron.

Partimos del supuesto de que estas transformaciones dieron lugar a un grupo de actores comerciales cuya renta principal era extraída de la comercialización ultramarina de cueros. Es decir, a partir del crecimiento del comercio de cueros, y su intercambio por mercancías europeas en lugar de metales preciosos, estos actores obtuvieron una mayor ganancia que les permitió acumular estos metales para otras inversiones. Esta acumulación les dio la posibilidad de intervenir fuertemente en el mercado inmobiliario, comprar navíos, desarrollar protoindustrias como el tasajo y comprar esclavos en África.

Este grupo fue el más dinámico comercialmente en las últimas décadas del siglo XVIII, participando en la compra de navíos, de tierras, inmuebles y de esclavizados. Para confirmar este supuesto definimos el grupo de actores que fueron los mayores cargadores de cueros y de metales preciosos y los reagrupamos en torno a sus características económicas. En relación a ello, analizamos algunos de los conflictos vinculados al comercio que se produjeron durante la segunda mitad del siglo XVIII con el objetivo estudiar la participación de los grupos de grandes comerciantes. 
II- Nuestro enfoque teórico-conceptual se orienta por los postulados de Fernando Jumar y del grupo de la tarea colectiva que realizamos junto a otros colegas bajo su dirección.

Jumar ha definido la región Río de la Plata como "un espacio acuático y térreo, articulado por un complejo portuario, sin solución de continuidad a hora de analizar los campos de fuerzas económicas que lo integran hacia dentro o de seguir el rastro de las que lo vinculan con otros espacios económicos." La región, continúa, “...estuvo conformada por los territorios dominados efectivamente por los europeos a ambas orillas del río, con fronteras difusas hacia el interior de las tierras, y el río mismo.” (Jumar, 2012: 123 y 124).

Una de las particularidades de la región estaba dada por la presencia del complejo portuario que articulaba los distintos circuitos mercantiles que la atravesaban. El complejo portuario, en su momento de mayor extensión (entre 1730- 1820), estuvo conformado por la ciudad de Buenos Aires, las ciudades puertos de Colonia do Sacramento y Montevideo, los apostaderos secundarios de Maldonado, Ensenada de Barragán y atracaderos con mayor o menor estructura y tránsito. Señala que fue el comercio ultramarino lo que puso en movimiento las fuerzas que generaron el complejo portuario en torno del cual se articuló la región (Jumar, 2011: 126, 127).

La tarea colectiva que emprendimos supone dividir y articular el análisis económico de la región considerando cuatro aspectos:

1- Como punto de contacto entre los mercados hispanoamericanos y extrahispanoamericanos, tanto americanos como ultramarinos.

2- Como consumidora de bienes del comercio ultramarino. 
3- Como poseedora de un complejo productivo regional que le permitió volcar excedentes a los mercados ultramarinos y americanos.

4- $\quad$ Como proveedora de bienes y servicios necesarios para la existencia de los distintos comercios.

En ese marco, esta tesis pretende realizar un aporte al estudio de la región como punto de contacto entre distintos mercados. Para analizar el comercio ultramarino pensamos que en la Monarquía española hubo dos tipos de comercio. Un mercado interno entre Filipinas, América y la península y un mercado externo que vinculó a los territorios de la Monarquía con otras unidades políticas a través de distintos puntos de conexión: Filipinas con Asia, América con Brasil y África y la península con Europa. El establecer como mercado interno el comercio en el interior de los territorios de la Monarquía española tiene como objetivo aportar a la ruptura con la mirada colonia- metrópoli.

Como es esperable para cualquier comunidad que esté abierta a comercializar con otros, estaba regulado y reglamentado y, también había circuitos comerciales que no estaban incluidos en las mismas. En este sentido la Monarquía española durante el siglo XVIII buscó dejar pocos canales de comercio modificándolo en tanto que las fuerzas internas y externas lograran un peso lo suficientemente importante como para que la presión surta efecto, como sostuvo Jaume Vicens i Vives

La causa de este progreso no debe buscarse en las medidas adoptadas por los ministros de Carlos III, como la trascendental cédula de libertad de comercio de cereales [...], sino en el tirón dado por la coyuntura económica internacional, francamente alcista, de 1765, a comienzos del siglo XIX (Vicens i Vives, 1958: 161 y 162).

Es decir, gran parte de las transformaciones económicas de la Monarquía española en cuanto al comercio ultramarino estuvo marcada por la presión externa 
para que eso suceda. Algunos ejemplos de ello, los encontramos en que a partir de la guerra con Inglaterra y el ataque a Portobelo en 1739, se extendieron los permisos para la circulación de navíos con registros sueltos, que hasta ese momento solo podían arribar al Río de la Plata. (Stern y Stern, 2000 y Lamikiz, 2007) Otro ejemplo, es que tras la perdida de la Habana, que cayó también en manos de los ingleses, en 1762 se reorganizó el comercio ultramarino habilitando progresivamente puertos en América y en la península española con el objetivo de una mayor consolidación económica, demográfica y militar en los territorios de la Monarquía ante las posibles invasiones. (Inglis y Kuethe, 1985)

También internamente se desarrollaron transformaciones que provocaron los cambios en la Monarquía española en el comercio ultramarino en el siglo XVIII. Un ejemplo de ello es el primer boom del comercio del cuero en la región Río de la Plata que muestra cómo a principio del siglo XVIII se comienzan a consolidar "intereses locales" que potenciaban las actividades productivas regionales (Jumar, 2008). Procesos similares se produjeron con distintas mercancías a lo largo de América, provocando, también, presión sobre las trasformaciones institucionales.

En este marco, resulta importante advertir al lector la manera en que precisamos conceptualmente la Monarquía española durante el siglo XVIII. En los últimos años se desarrollaron algunas nuevas perspectivas que tuvieron como eje el complejizar la mirada sobre este tema. La visión de una monarquía policéntrica (Cardim, Herzog, Ruiz Ibañez y Sabatini, 2012) es acaso la más sugerente. Este concepto se basa en la crítica a los modelos centrados en la tensión centroperiferia, los cuales si bien, como la monarquía compuesta, no establecen al monarca como al único eje del imperio sino una perspectiva que podríamos 
denominar en cuanto a la territorialidad y conducción como egocéntrica, en el sentido que todas las regiones y corporaciones negociaban en forma individual con el monarca. Esta unidireccionalidad resta capacidad de modificar las regulaciones y transformaciones encabezadas por la Corona ya que ante cada región, en la mayoría de los casos, la Corona tenía mayor capacidad de maniobra. Con la monarquía policéntrica esto es radicalmente opuesto ya que, como plantea Manuel Rivero Rodriguez, “...el poder nunca se expresa en términos bilaterales, circula por centros interconectados (interlinked centers). El sistema mantiene su estabilidad por medio de una negociación constante entre todas las partes y el espacio donde esto tiene lugar son los conflictos jurisdiccionales." (Rivero Rodriguez, 2013: 4) No tiene, por lo tanto un centro de poder, sino que la correlación de fuerzas va sopesando y las transformaciones se suceden producto del resultado de este entramado.

Este concepto nos permite estudiar los procesos generales poniendo el énfasis en el accionar de los actores para explicar las transformaciones comerciales de mediados del siglo XVIII.

En este sentido, consideramos al Antiguo Régimen como un conjunto plural y complejo de cuerpos sociales o comunidades y de vínculos personales y redes sociales. Como plantea José María Imízcoz Beunza: "se trata de un orden político plural, caracterizado por la diversidad de cuerpos sociales, por la realidad de poderes plurales y poli céntricos, y por la yuxtaposición y la concurrencia de los diversos poderes.” (Imizcoz Beunza, 1996: 19 y 20).

Durante el siglo XVIII, el desarrollo de las prácticas mercantilistas y el proceso de industrialización produjeron una búsqueda desenfrenada de territorios, materias primas y mercados de consumo de manufactura. En este contexto, la 
monarquía española tuvo que reorientar sus objetivos de expansión en torno a conservar los territorios propios. Por este motivo, la presión fiscal que se produjo estuvo íntimamente vinculada al desarrollo militar, he aquí la consolidación del estado fiscal militar español. Estamos en presencia de una monarquía que buscó, durante todo el siglo XVIII, mantener los territorios en base a distribuir sus recursos fiscales con fines defensivos. La contracción y derrotas sufridas aceleraron el proceso de reformas fiscales y la estrategia de resistencia territorial.

III- Operamos en el marco de una metodología que combinó un enfoque cuantitativo con el cualitativo y la escala macro analítica con la micro. Para analizar la economía de la región Río de la Plata a partir del estudio de las cifras del comercio ultramarino y los actores que intervinieron trabajamos con un conjunto amplio de documentación que registra no solo las cantidades y los tipos de mercancías sino también los actores vinculados al comercio.

Una vez que localizamos esta información realizamos un minucioso análisis de los registros fiscales que fueron volcados a planillas de Excel. Por un lado registros de salida de las mercancías. Para la salida de metales preciosos entre 1779- 1794 se procesaron 18.787 registros y para la salida de cueros en el período 1779- 1799 se procesaron 7.513. Por otro lado analizamos los registros de ingreso de esclavizados para el período 1779- 1806. Esta información nos permitió establecer datos sólidos del comercio legal y poder reconstruir las cifras totales del comercio, los circuitos comerciales.

Por otra parte desagregamos la totalidad de la carga de cada uno de los actores que intervinieron en los distintos tipos de comercio, con el fin de determinar cuáles fueron los más importantes y agruparlos en relación a las características del 
comercio y establecer su participación en los conflictos comerciales que se sucedieron durante las últimas décadas del siglo XVIII.

Trabajamos con cuatro grupos de fuentes. El primero tiene como fin analizar la circulación de navíos. El objetivo de ello, es observar la integración regional con otros territorios ya que si hubo más barcos pequeños o medianos muestra relaciones más dinámicas, con mayor velocidad de la circulación y por tanto mayor integración. En cambio, la presencia de algunos barcos grandes, si bien en el total pueden dar cuenta de un mayor volumen o valor, da cuenta relaciones más disgregadas. La fuente principal que se utilizó para analizar la circulación ultramarina de navíos del complejo portuario rioplatense fue el epistolario periódico entre el Gobernador de Montevideo y el Virrey, en el cual se especificaban los navíos que se aproximaron y las que partieron al Río de la Plata desde Maldonado. Para analizar la circulación de embarcaciones de la península española se utilizaron los diarios de Cádiz y de Barcelona en donde, para el periodo 1793-1808, se plasmó la salida e ingreso de todos los navíos de todos los puertos de la península.

El segundo grupo, constituido por las Alcabalas, fue examinado a fin de considerar algunos aspectos del mercado interno. En primer lugar trabajamos con los libros de "Alcabala de compra y venta de esclavos, tierras y casas" en donde se asentaba por fecha todas las transacciones que se realizaban, el escribano que la realizó, el nombre del vendedor y comprador, una descripción del bien, su coste y el impuesto que se debía pagar. Esta información fue fundamental para establecer el mercado inmobiliario para la ciudad de Buenos Aires y Montevideo. Por otra parte, para observar el alcance del comercio de cueros tomamos la alcabala de ingreso de cueros por el riachuelo en donde se establecía: quien los enviaba, el 
puerto de salida y la cantidad de los cueros. Por último, analizamos la alcabala de la ciudad de Montevideo en donde se puede apreciar la circulación de cueros provenientes de los territorios externos a la Jurisdicción de Montevideo y la compra y venta de casas y tierras.

Un tercer grupo se orientó a reconocer la salida de cueros. Dada la dificultad de encontrar la serie completa, buscamos los datos de Buenos Aires y Montevideo en forma separada. En relación a Montevideo, utilizamos las notas de aduana, es decir, aquellos documentos que entregaban los cargadores a los funcionarios fiscales en donde se describía el lugar, para comunicar su decisión de enviar fuera de la jurisdicción cualquier tipo de bien. Los datos de Buenos Aires, se encuentran completos en los libros de la Real Hacienda, donde figura quien enviaba cueros, la cantidad de los mismos y a cuenta y riesgo de quien.

El último grupo, constituido por los registros de navíos nos permitió reconstruir la salida de metales preciosos. Para ello continuamos el trabajo realizado por Fernando Jumar (2002b) para el período 1680-1778. Los registros de plata y oro constan del nombre de quien envía, a cuenta y riego de quien y el destinatario. Además, se establece el lugar de origen de quien lo envía y hacia que lugar debe llegar, la cantidad en su peso y al cambio en pesos de plata. La gran mayoría de los metales preciosos que partieron del complejo portuario rioplatense salieron por las fragatas correos ya que ofreció una serie de ventajas comparativas con el resto de embarcaciones. En primer lugar, mantuvieron una regularidad en su circulación que era una ventaja ya que no realizaban arribos a otros puertos. En segundo lugar, ofrecían una mayor seguridad de llegada producto de que eran acompañadas por navíos de guerra mientras que los barcos comerciales no. 
La mayoría de las fuentes trabajadas son institucionales, por lo tanto, el comercio directo y la ocupación de las tierras no se analizaron. En el caso del comercio de cueros, realizamos comparaciones con las estimaciones del comercio ilegal. Si bien la reconstrucción de las cifras generales se realiza en base a los datos registrados por los funcionarios y por lo tanto se trata de estimaciones, logran dar cuenta de una gran parte de este comercio.

IV- Organizamos el material en una secuencia temática en lugar de cronológica, para poder mostrar desde distintos ángulos el proceso analizado. Para ello la tesis se estructura en 5 capítulos.

El primero estudia la región Río de la Plata durante la segunda mitad del siglo XVIII. El objetivo de este capítulo es establecer algunas de las transformaciones que se produjeron en el interior de la región durante la segunda mitad del siglo XVIII. A partir de la conceptualización desarrollada por Fernando Jumar y Nicolás Biangardi, abordamos la producción y comercialización interna, las características de la población y el mercado inmobiliario de las ciudades de Buenos Aires y Montevideo.

El segundo capítulo, examina las características y transformaciones del comercio ultramarino de la Monarquía española y su articulación con el complejo portuario rioplatense. Dividimos el estudio del comercio de la Monarquía española en externo e interno en relación a los circuitos y las reformas institucionales, a fin de contemplar sus modulaciones e interacciones.

El tercer capítulo aborda la salida de cueros. Articulamos el examen de sus cifras, actores y los conflictos en torno a la actividad. En primer lugar, describimos la producción de cueros, su origen en la región y su desarrollo. En el segundo apartado analizamos las cifras del comercio ultramarino de cueros hacia 
la península española. Luego se trata sobre los cargadores de cueros en general y en particular profundiza en aquellos que concentraban gran parte del comercio. Por último, se da cuenta de los conflictos regionales que se produjeron en relación al permiso de comerciar cueros con territorios extranjeros durante los períodos de conflictos armados o como contrapartida por esclavizados.

El capítulo cuatro focaliza en la salida de metales preciosos por el complejo portuario rioplatense. Para ello dividimos las cifras en relación a las características de salida: lugar de salida, la finalidad de los mismos (para uso comercial, fiscal, para la iglesia, entre otros), el tipo de metales (amonedados o en pasta) y el destino de los mismos (Cádiz, los puertos del norte o del mediterráneo de la península española). Además, analizamos la participación de los actores circunscribiendo a los de mayor actividad, a partir de lo cual se ofrece una conceptualización sobre los mismos. Por último, abordamos el conflicto de mediados de siglo XVIII por los mercados internos entre el Consulado de Lima y los actores económicos más importantes de Buenos Aires.

El último capítulo está dedicado al comercio de esclavizados llegados al complejo portuario rioplatense durante las últimas décadas del siglo XVIII. En primer lugar abordamos algunos aspectos generales del comercio de esclavizados, el objetivo de este comercio y las regulaciones institucionales. Además, ya en el complejo portuario rioplatense estudiamos la entrada de navíos y las cifras de los esclavizados, por origen y bandera, haciendo especial hincapié en los actores regionales que intervinieron. Finalmente, a partir del estudio de un caso particular, el de Josep Ramón Milá de la Roca, analizamos la participación de los actores regionales en el comercio ultramarino de esclavizados. 


\section{CAPÍTULO I}

\section{Una aproximación a la región Río de la Plata a través del cuero, la población y el mercado inmobiliario (segunda mitad del siglo XVIII)}

\section{Introducción}

El objetivo de capítulo es analizar de qué manera durante la segunda mitad del siglo XVIII se produjo una reorientación comercial de la región Río de la Plata en su conjunto hacia el mercado ultramarino, particularmente a través de los cueros. Para ello, luego de delimitar la región a partir de la bibliografía que se ha dedicado a ello, abordaremos distintos aspectos vinculados a la producción de cueros, la población y el mercado inmobiliario.

Consideramos que durante este periodo se propició un círculo virtuoso en donde a mayor vinculación con el mercado ultramarino mayor incremento de la población. En este capítulo se dividirá la región Río de la Plata en dos sub zonas: la norte, en donde se consolidó una economía de cuero con escasa población, y la sur, con mucha mayor población y una producción mixta. Para ello tomaremos los datos de las investigaciones historiográficas que en las últimas décadas enriquecieron los conocimientos de esta región y que dan cuenta de cómo estaba constituida su producción y su población. Asimismo, como veremos en el último apartado, resta señalar que el crecimiento comercial y demográfico tuvieron como una de sus expresiones el incremento del mercado inmobiliario en las ciudades más importantes. 


\section{La región Río de la Plata}

La región Río de la Plata, que constituye el marco de nuestro estudio ha sido definida por Fernando Jumar como "un espacio acuático y férreo, articulado por un complejo portuario, sin solución de continuidad a la hora de analizar los campos de fuerzas económicas que lo integran hacia dentro o de seguir el rastro de las que lo vinculan con otros espacios económicos.” (Jumar, 2011: 123, 124). Para definir la región, el autor parte del análisis de la circulación mercantil, utilizando el concepto de Françoise Perroux. En este sentido, propone definir la región Río de la Plata como un espacio económico homogéneo. Este concepto, le permite abordar los flujos mercantiles sin las restricciones de los límites políticos y destacar el hecho de que la circulación interna es mayor que los intercambios con otros espacios. Además, la particularidad de ser homogéneo, implica que la región como un todo se pueda transformar en un polo de atracción de un espacio mayor (Jumar, 2011). 


\section{Mapa I.1}

La región Río de la Plata

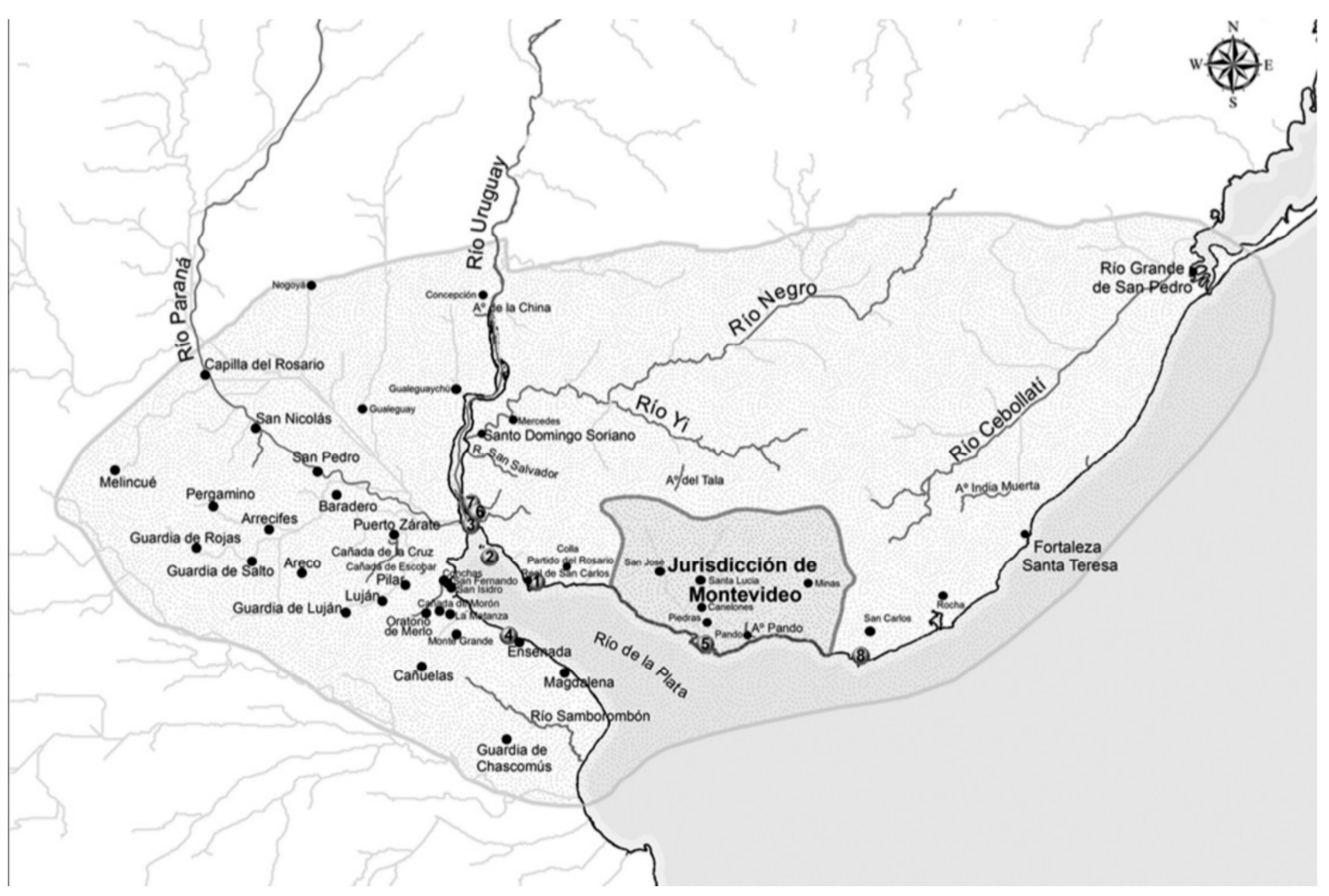

Fuente: Jumar (2011: 124).

En su tesis doctoral, Nicolás Biangardi (2015) sintetiza la definición que Fernando Jumar $(2000,2006,2011,2012)$ realizó sobre la región a lo largo de distintos trabajos. Si bien remitimos a su trabajo para un mayor detalle sobre la cuestión, para los fines de nuestra investigación cabe señalar que una de las particularidades de la región estaba dada por la presencia del complejo portuario que articulaba los distintos circuitos mercantiles que la atravesaban. El complejo portuario, en su momento de mayor extensión (entre 1730-1820), estuvo conformado por la ciudad de Buenos Aires, las ciudades puertos de Colonia do Sacramento y Montevideo, los apostaderos secundarios de Maldonado, Ensenada 
de Barragán y atracaderos con mayor o menor estructura y tránsito. Jumar señala que fue el comercio ultramarino lo que puso en movimiento las fuerzas que generaron el complejo portuario en torno del cual se articuló la región (Jumar, 2011: 126, 127).

\section{Mapa I.2}

La región Río de la Plata y el complejo portuario rioplatense

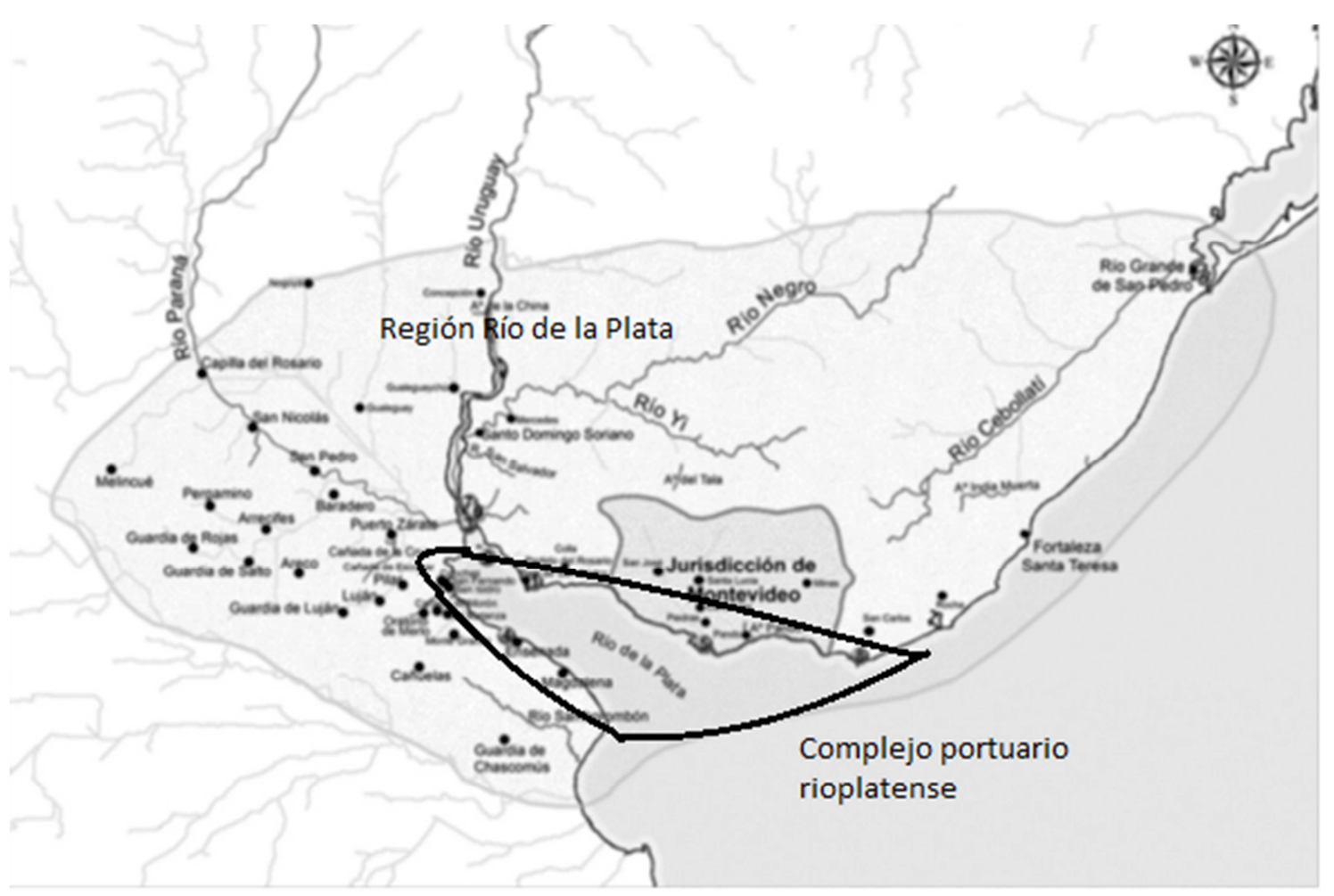

Fuente: Elaboración propia a partir de Jumar (2011:124).

\section{La dimensión de la región Rio de La Plata a partir del comercio}

\section{interno de los cueros}

Como decíamos más arriba, Fernando Jumar (2011) define el territorio ocupado por la región Río de la Plata teniendo en cuenta los datos de la intensidad y el tipo de tratos mercantiles vinculados a Buenos Aires. Esta propuesta ha sido 
comprobada en el trabajo de Nicolás Biangardi sobre la comercialización de cueros llegados a Montevideo (2015). El estudio del comercio interno de cueros de Buenos Aires que realizamos para esta tesis, coincide con esta delimitación de la región.

Las fuentes que describen los puntos de salida de los cueros hacia las zonas de concentración (Buenos Aires y Montevideo), previa su embarcación hacia mercados ultramarinos dan cuenta de que el alcance de la comercialización respetó aquellos límites. A partir de la sistematización de la alcabala del Riachuelo entre 1794 y $1796^{5}$, pudimos apreciar el origen de los cueros ingresados a Buenos Aires por vía fluvial: desde Goya y Arroyo la China en Corrientes, zona que se encontraba realizando una transición pasando del mercado paraguayo al rioplatense (esto se desarrollara más adelante en el capítulo), hasta la frontera sur, por ejemplo Luján y Chascomus, la zona costera norte del Río de la Plata y sus inmediaciones, Santo Domingo Soriano y Víboras, y, finalmente, en el noroeste, Rosario y Del Sauce. (Véase Mapa I.3) Encontramos que ingresaron unos 50.000 cueros al año, lo cual permite dar cuenta del mayor alcance de salida de cueros por vías fluviales. ${ }^{6}$

El resto de los cueros ingresados para el comercio ultramarino vía Buenos Aires, se produjo por tierra. Una parte importante provino de los vacunos que se faenaban para el consumo de carne de la ciudad. El análisis de Juan Carlos Garavaglia (1994) para el período estudiado estima en 50.000 cueros anuales producidos para ese fin. El resto de cueros ingresados, de los cuales no se tiene registro de ingreso (ya que no pagaba alcabala) sino de salida (en el capítulo tres

\footnotetext{
${ }^{5}$ Los libros de alcabala del Riachuelo que se encuentran en el AGN de Argentina comienzan en el año 1792 pero no contienen toda la información necesaria. En particular, el funcionario que completó esos dos años no siempre puso el lugar de origen de las mercancías.

${ }^{6}$ Como afirmó Claudia Wetzel (1988), Buenos Aires se nutría de la circulación de navíos de los ríos Uruguay y Paraná.
} 
se desarrollará en profundidad), se produjeron en la campaña de Buenos Aires (Wenzel, 1988). A pesar de que algunos cueros provinieron de Córdoba (Punta, 1994), debido a su escaso número (unos 3.500 anuales) no la incluimos en la región.

\section{Mapa I.3}

Alcance del comercio de cueros llegados a Buenos Aires por el Riachuelo (17921794)

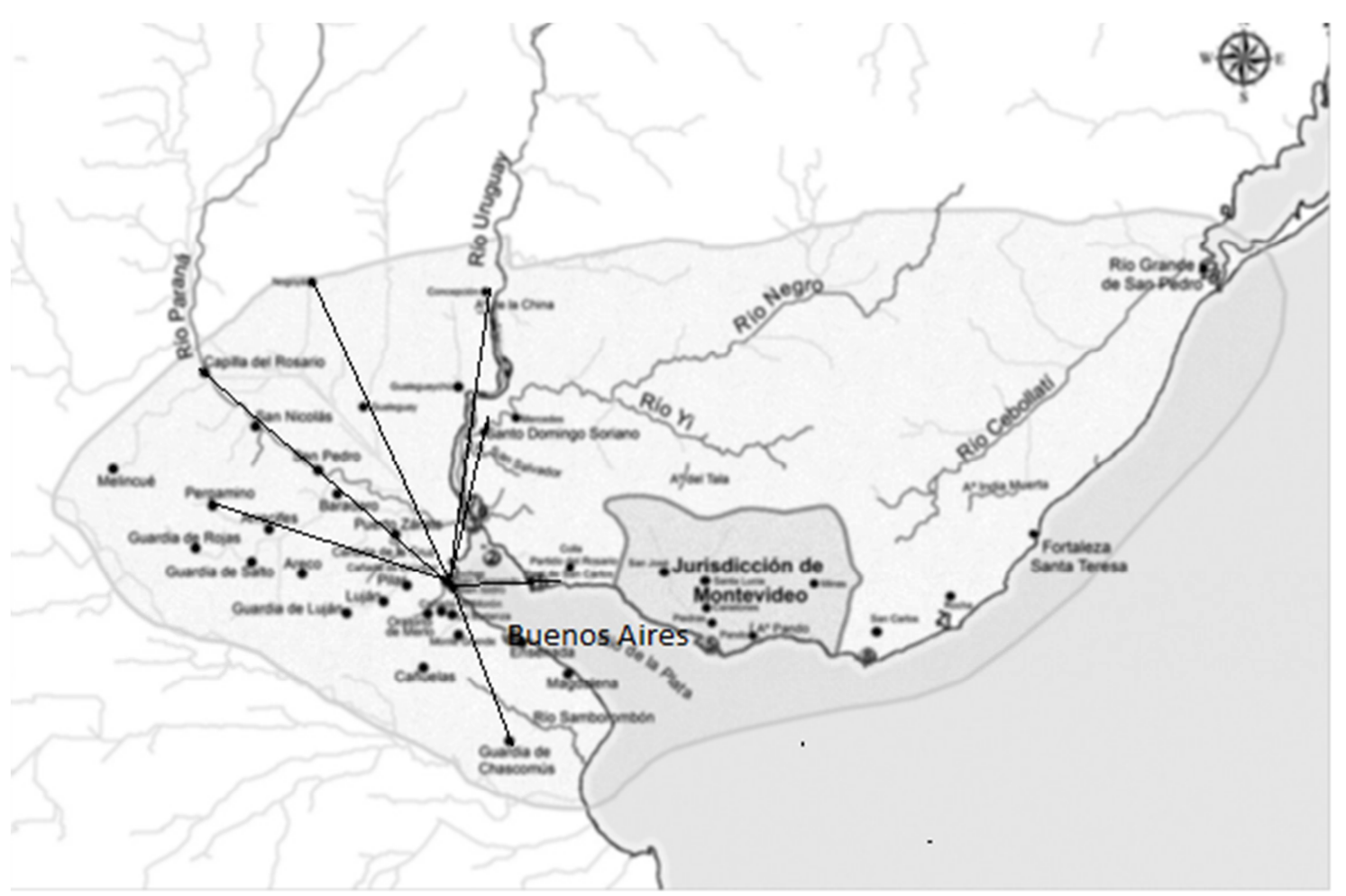

Fuente: Elaboración propia a partir de Jumar (2011:124)

Nicolás Biangardi (2015), a partir de los datos de unos de los principales lugares de almacenamiento, el de Juan Pedro Aguirre, estableció el lugar de faenamiento de los cueros llegados a esa plaza. Lo cual le sirve para demostrar la variedad de lugares de donde provenían los cueros, así como también la red de vínculos personales en las que se asentaba el exportador para adquirir, transportar y acopiar la mercancía exportable (Mapa I. 4). Asimismo, a partir de esa 
información, nosotros podemos ver que la mayor parte procedían de las faenas realizadas para la Administración de las Misiones. ${ }^{7}$

Mapa I. 4

Procedencia de los cueros acopiados por Juan Pedro Aguirre, noviembre de 1784

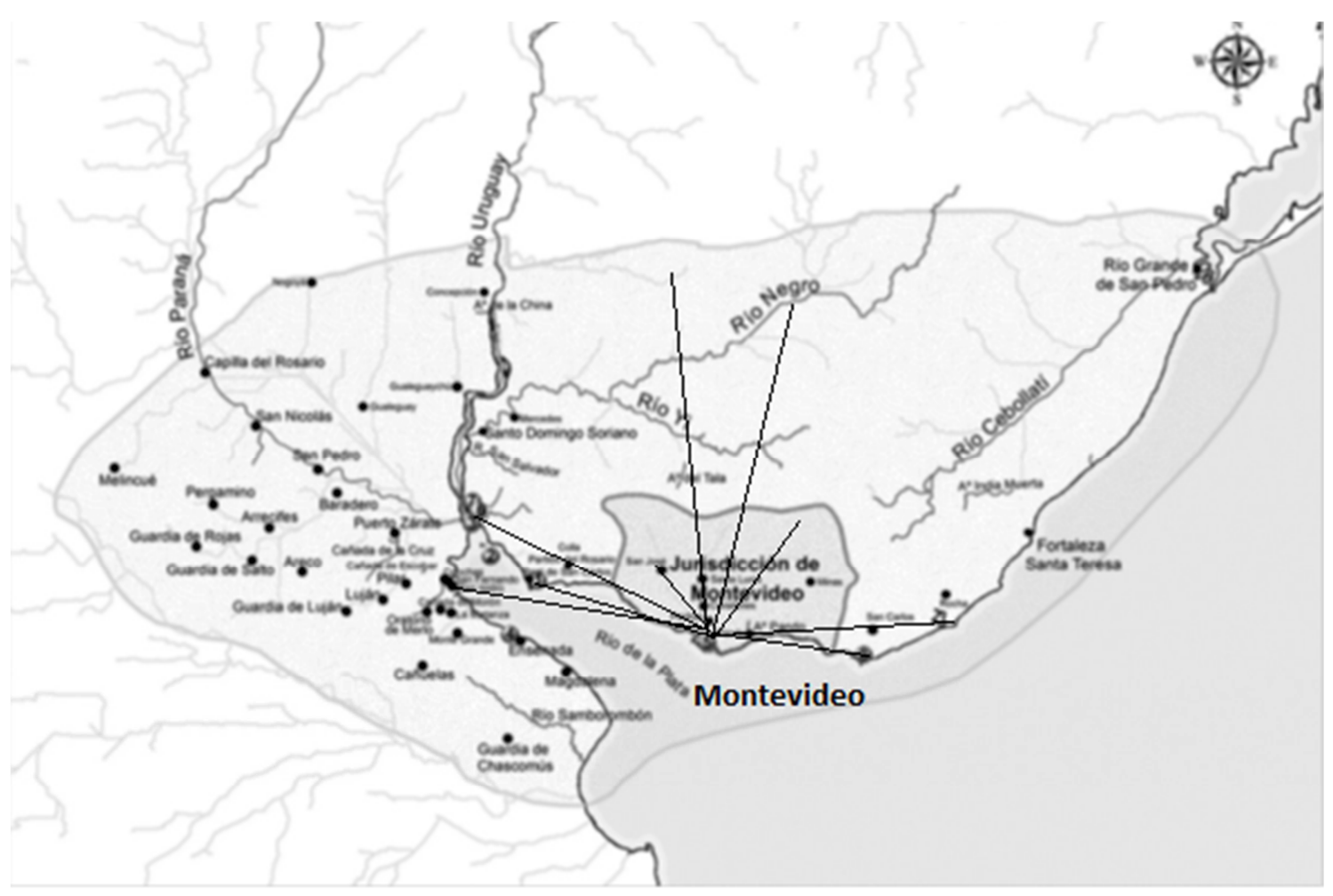

Fuente: Elaboración propia a partir de Jumar (2011:124), Biangardi (2015)

\section{La región: zona sur y zona norte}

Como ya se ha dicho, para los fines de este análisis hemos dividido la región en dos partes, una hacia el norte y otra hacia el sur (Mapa I.5). En el norte se hallaba el ganado, zona de menor densidad demográfica y con grandes

7 “...4906 procedían de las faenas realizadas por Antonio Pereyra para la Administración de las Misiones del otro lado del río Negro. Además, José Núñez introdujo 300 del consumo del fuerte de Santa Teresa (situado sobre la costa atlántica), Antonio Monasterio 130 comprados en Santa Lucía y Maldonado, Francisco Sánchez 82 también desde Maldonado, José Estreyte 80 comprados a vecinos de San José, Vicente Garzón 150 del matadero de Montevideo, Juan Trapani 635 de su propio matadero y María Francisca Alzaybar 277, Melchor de Viana 240 y José Llorens 240 procedentes de sus estancias.” (Biangardi, 2015: 64). 
estancias. En el sur, se condensaba una mayor cantidad de población, fundamentalmente, por encontrarse cercanas las dos ciudades más grandes, Buenos Aires y Montevideo. La producción de esta zona fue mixta, ya que la producción agraria fue muy rica, y si bien la gran propiedad fue muy significativa, hubo un número importante de pequeñas y medianas propiedades. A continuación se profundizara en los aspectos señalados de las subregiones.

\section{Mapa I. 5}

División de la región Rio de la Plata

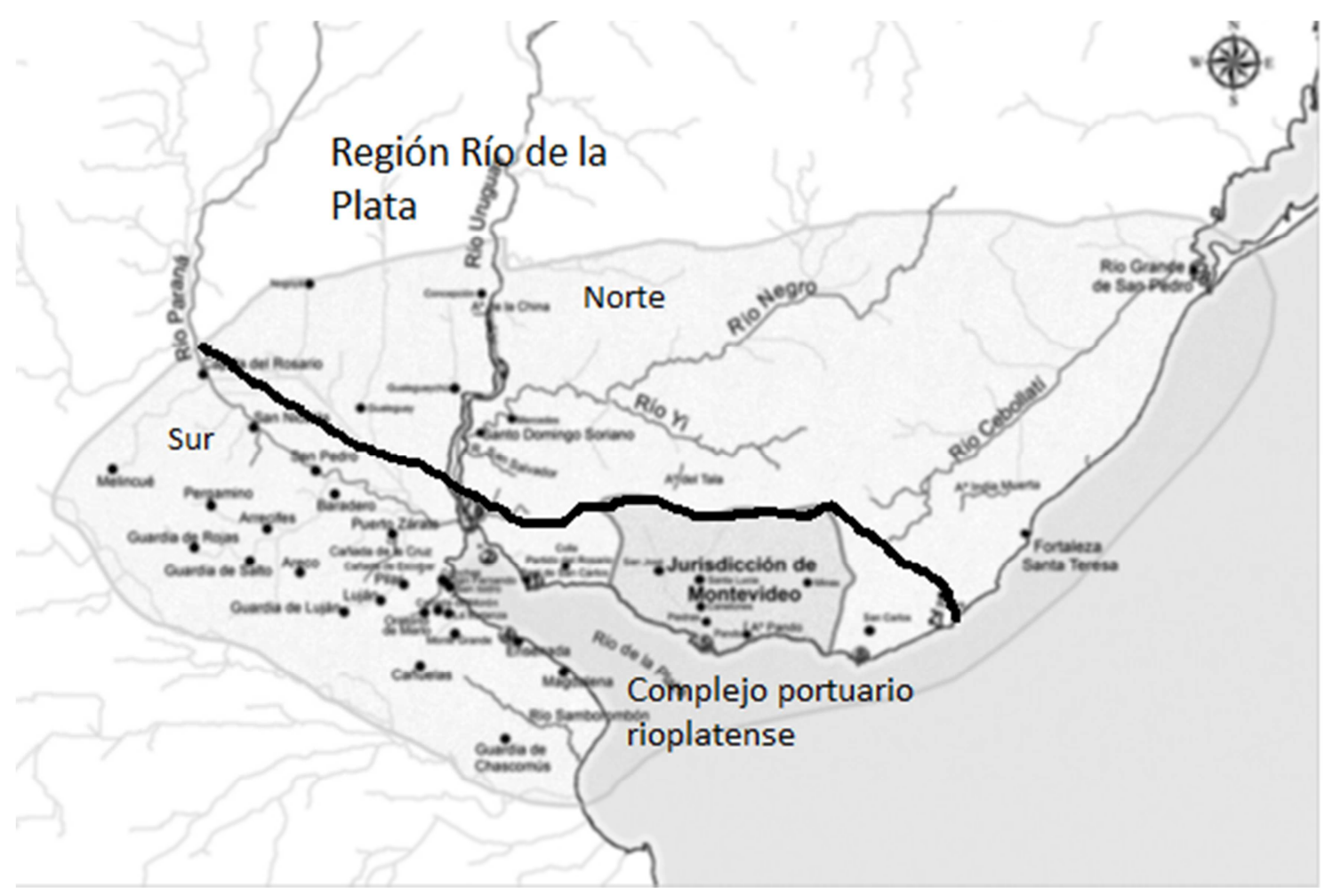

Fuente: Elaboración propia a partir de Jumar (2011:124).

Para el análisis de la producción regional se utilizaron los aportes de la bibliografía especializada en ello, con la cual se pudo desarrollar un breve panorama productivo de la región. Con respecto al análisis de la población también se abordó con la bibliografía, el cual fue combinado con estudios propios estadísticos de los padrones militares. La utilización de padrones militares para 
analizar la población es de gran utilidad ya que son los registros documentales más completos para observar la composición de la población, haciendo la salvedad que es un registro estático y no se puede observar las transformaciones año a año, pero si las transformaciones a largo plazo.

\section{La zona sur de la región: la producción.}

La zona sur se compone del territorio próximo a las ciudades más pobladas de la región, camino que comunicaba a Buenos Aires con el interior, las poblaciones que hacían de frontera con el indio, las zonas aledañas al Río de la Plata y al Río Paraná y la Jurisdicción de Montevideo. Esta última ha sido menos analizada por la historiografía, a diferencia del territorio que se encuentra entre el Río Paraná- el Río de la Plata- Pergamino.

Este último fue el más estudiado a partir de la renovación historiográfica de los estudios rurales, la cual centró sus hipótesis de trabajo en reafirmar la existencia de familias, de la pequeña propiedad y de la agricultura en la campaña porteña. Esta perspectiva hunde sus raíces en las investigaciones realizadas a lo largo de la década del sesenta y setenta del siglo XX por Tulio Halperín Donghi y José Carlos Chiaramonte.

En Revolución y Guerra, Halperín Donghi afirma que "La estancia es un núcleo de la producción ganadera, que en ella se combina en casi todas partes con la agricultura cerealera" (1972: 35). Esta visión de complementariedad entre la ganadería y la agricultura también se encuentra en el libro De la conquista a la independencia en donde Chiaramonte señala que, aunque limitada al mercado interno, la agricultura no debía ser ignorada: "De tal manera, mientras la agricultura estaba prácticamente limitada a un restringido mercado interno, la 
ganadería del litoral tenía ante sí un mercado exterior en permanente expansión.” (1972: 322).

La renovación que se produjo a partir del retorno de la democracia, a partir de la utilización de nuevas metodologías y fuentes dio mayor complejidad a estos aportes.

A partir de la publicación de un artículo de Carlos Mayo en la revista Desarrollo Económico que aborda las características de la población de la campaña en la segunda mitad del siglo XVIII, varios historiadores comenzaron a debatir algunas de sus conclusiones y a desarrollar nuevas aproximaciones que permitan establecer las características de los habitantes, lo que producían y establecer una explicación de su "funcionamiento económico". A partir de lo cual, se realizaron varias investigaciones que tomaron como eje central el estudio de una estancia en particular, tales como los realizados por el mismo Carlos Mayo (1984 a, b), Samuel Amaral (1987, 1984) y Jorge Gelman (1992). Estos autores tuvieron como preocupación central caracterizar la fuerza de trabajo utilizada y la producción.

Investigaciones posteriores han continuado en esta línea interpretativa, haciendo hincapié en la importancia de la agricultura y aquellos que la produjeron, siendo un hito el debate presentado en el Anuario del IEHS de 1987. Un completo estado de la cuestión sobre esta temática se puede observar en un trabajo de Garavaglia y Gelman (1998).

Si bien Garavaglia y Gelman (1998), no niegan la existencia de la gran propiedad rural, relativizan su importancia. Establecen que si bien ocupaban gran parte del territorio, eran modestas explotaciones y que la elite colonial hay que buscarla en otro lado, no en la campaña. Si bien, no niega que hubo algunas 
grandes estancias propiedad de unos pocos miembros de la elite porteña, su pertenencia a la elite, no se fundaba en su actividad agropecuaria, sino en el comercio y en su participación en el poder político, siendo en todo caso la actividad rural un complemento a la diversificación de sus actividades principales" (1998)

Otra interpretación sobre la importancia de la gran propiedad dialogó con esta interpretación (Azcuy Ameghino) ya que, a partir de un estudio minucioso del Gremio de Hacendados, de la propiedad de la tierra en algunas localidades, Navarro y Cañada de la Cruz y de las denuncias de la tierra considera que los hacendados tuvieron un rol central en la economía regional. Otra diferencia está marcada porque Azcuy Ameghino establece que el predominio de la producción ganadera para el comercio ultramarino fue predominante en relación a la agraria.

En relación a las características de los habitantes de la campaña, a partir de un análisis de los padrones de población Juan Carlos Garavaglia estableció que estuvo formada en su mayoría por familias:

El análisis demográfico nos ha mostrado de qué modo la región fue poblada fundamentalmente por familias nucleares y cómo ese doblamiento fue el resultado, en su mayor parte, de un movimiento migratorio desde el interior y el litoral (...) esto dio como resultado una sociedad campesina de labradores y pastores de ganado que mantenía complejas relaciones con los grandes propietarios (1999: 14).

Asimismo Juan Carlos Garavaglia y Jorge Gelman, señala que la población de la campaña durante este período se encontraba en claro crecimiento y estaba compuesta fundamentalmente por una población muy joven, 50\% del total eran menores de 20 años. Además "El fenómeno migratorio, es decir, el análisis de los flujos que llegaban desde el Tucumán y el Alto Litoral hacia la región pampeana y su extensión en la longue durée, fue uno de los aspectos más 
novedosos que surgió a partir de los nuevos Estudios" (Garavaglia, y Gelman, 1998: 32).

Anteriormente Juan Carlos Garavaglia (1989) realizó una conceptualización en torno a las características de la sociedad rural rioplatense, a partir del análisis de dos ecosistemas agrarios: el de la ciudad de Buenos Aires y el de San Antonio de Areco. En el primer caso, estableció que en los alrededores de la ciudad de Buenos Aires se encontraba un cordón fruti-hortícola-cerealero que producía aproximadamente la mitad de la producción regional que se comercializaba en Buenos Aires.

El segundo caso, el de San Antonio de Areco, el cual tuvo una producción mixta ganadera- cerealera, se produjo a partir de la existencia de una "oferta ilimitada de tierra" y la existencia de ciclos bien marcados de necesidad de brazos en la agricultura y en la ganadería con lo cual se produjo una suerte de armonía entre los ciclos permitiendo la pervivencia de ambos. Como plantea el autor: "Estamos aquí ante un ejemplo paradigmático resultado de la oferta casi ilimitada de tierras en un medio abiótico de gran fertilidad natural y con una formación de pradera. Un agrosistema ganadero y cerealero de alta productividad y alta movilidad humana." (Garavaglia, 1989: 569).

En suma, a partir de los importantes aportes que se realizaron para el territorio señalado en las últimas décadas, se puede afirmar que la producción agraria y pecuaria se complementó en la mayoría de los $\operatorname{casos}^{8}$. La producción de trigo y de carne para el mercado interno ha sido trabajada en forma sistemática,

\footnotetext{
${ }^{8}$ La mayoría de los estudios están teñidos de problemas de conceptualización de las relaciones espaciales ya que miran sólo la campaña de Buenos Aires y no ven que Río de la Plata está compuesto por las dos bandas, así, es cierto que en la de Buenos Aires en determinado momento prima el trigo, porque la producción de cueros está del otro lado del río y ambos espacios pertenecen a la misma región o se analizan solo las zonas del sur de Buenos Aires y no las zonas nortes.
} 
estableciendo la importancia de estos productos para el consumo interno (entre otros, Garavaglia, 1995, 1999a, 1999b, Gelman, 1993, 1998) y el mercado ultramarino (Sandrín, 2011). ${ }^{9}$

Como decíamos más arriba, la jurisdicción de Montevideo ha sido menos analizada que el territorio que venimos trabajando. La misma se conformó con una parte muy importante de la población de la región y, si bien contuvo grandes propiedades y se centró en la ganadería para la producción de cueros, también desarrolló la agricultura y la pequeña y mediana propiedad. El estudio minucioso de María Inés Moraes (2011) sobre las características económicas de este territorio a partir de los inventarios postmortem le permite aseverar que la jurisdicción se componía de chacras y estancias. Si bien no se encontraba en todo el territorio, en varias zonas la producción triguera era una actividad muy importante, ya que de 28 inventarios:

...10 no contaban con datos sobre su localización, mientras que de los restantes, 1 pertenecía a la ciudad de San Felipe y Santiago de Montevideo y 17 a diferentes pagos o partidos de la Jurisdicción de Montevideo. La localización de los inventarios post-mortem que incluyen trigo permite reconocer tres áreas trigueras: a) Miguelete, Arroyo Seco y Colorado, b) Brujas y Canelones grande y chico; y Pintado y Chamizo); c) Tala y Mataojo. (Moraes, 2011: 216).

El caso de Maldonado fue analizado por Nicolás Biangardi (2013), quien plantea que tras el crecimiento económico del área se produjo un excedente agropecuario para el abastecimiento de Montevideo y el comercio ultramarino:

En un primer momento, la producción estaba orientada principalmente al cultivo de cereales y leguminosas, incentivado por los repartos de semillas que los funcionarios hacían entre los nuevos habitantes con el fin de lograr el autoabastecimiento de los pobladores y las tropas asentadas en el lugar. Pero con el paulatino poblamiento y ocupación del espacio fue tornándose cada vez más

\footnotetext{
${ }^{9}$ Sandrín (2011) da cuenta de que la producción de trigo (galletas) para el mercado ultramarino fue mucho más alta de lo que se suponía.
} 
importante la frontera ganadera en expansión, profundamente ligada al comercio ultramarino (2013: 29).

\section{$\underline{\text { La zona sur de la región: la población }}$}

En el proceso de poblamiento de la zona sur de la región hubo dos periodos bien delimitados. Una primera etapa del proceso de poblamiento y de fundación de pueblos, villas y fuertes se desarrolló a partir de la fundación de Buenos Aires: en sus alrededores y hacia la ruta del Alto Perú (Mateo y Moreno: 1997). Este primer proceso de poblamiento estuvo vinculado al potencial económico que se desarrollaba a partir del abastecimiento de la ruta al Alto Perú y de la venta de productos agropecuarios en la ciudad para su abastecimiento. Además, durante esta primera etapa se produjeron poblamientos de las zonas aledañas al Río de la Plata y el Paraná desde el siglo XVII, por el impacto del comercio ultramarino y de la formación del complejo portuario rioplatense.

En la segunda etapa, el proceso de poblamiento de la ciudad y la zona cercana a Montevideo, en particular durante la segunda mitad del siglo XVIII, se produjo en forma paralela a partir del crecimiento comercial. En el gráfico I.1, se puede observar, el incremento sostenido de la población de la jurisdicción de Montevideo, de la ciudad y la línea en torno al avance indígena desde el sur. Las causas de esta tendencia se encuentran en las ventajas productivas y comerciales de este territorio que lo hacían muy atractivas a la migración y el crecimiento vegetativo. 
Gráfico I .1

Población de la Jurisdicción de Montevideo (1760-1794).

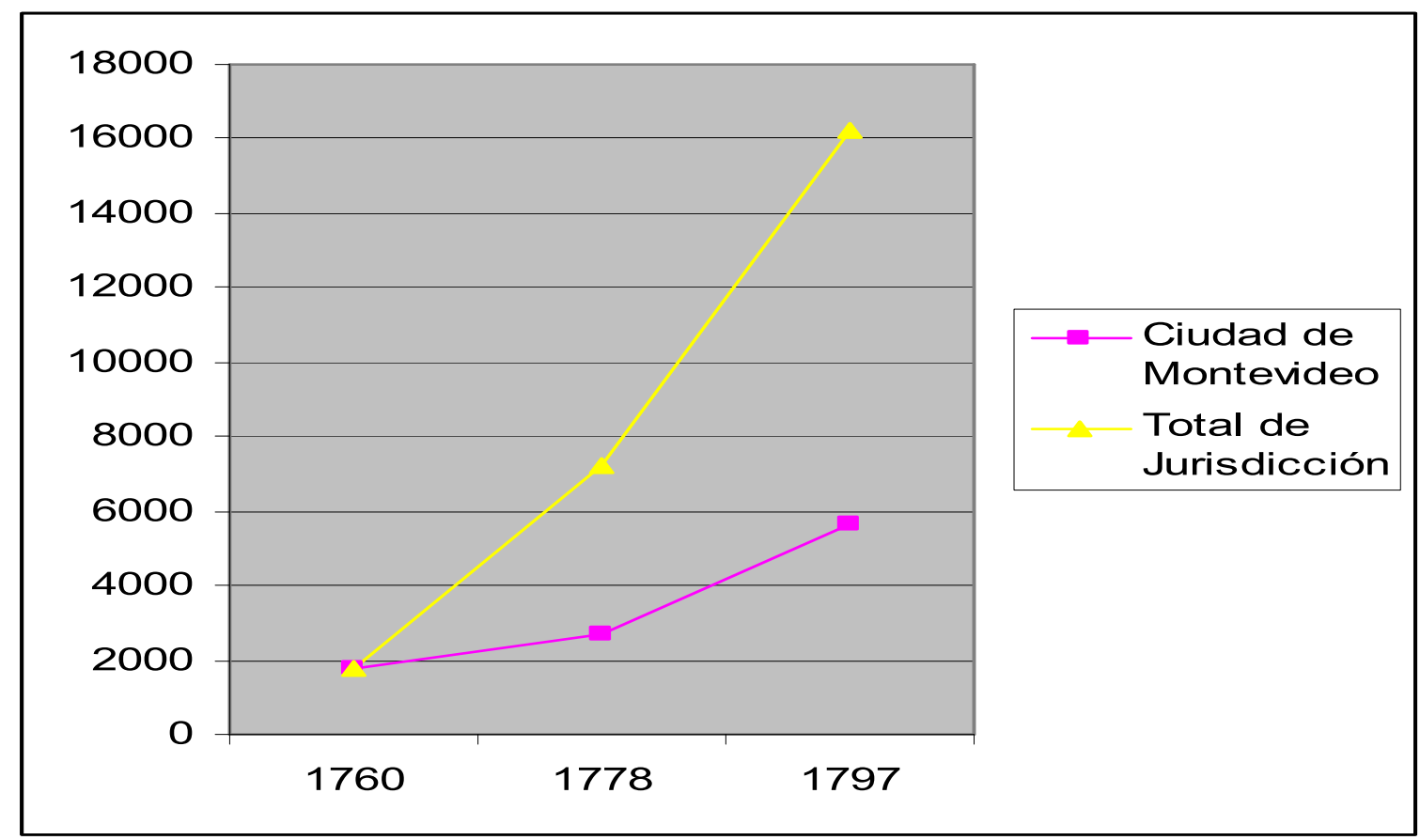

Fuente: elaboración propia a partir de los datos de Pollero y Vicario (2009).

El crecimiento vegetativo de la población fue constante y si bien, como se puede observar en el gráfico I.1, los nacimientos no siempre lograron estar por encima de las defunciones, mantuvieron un progresivo aumento. Las dos epidemias que incrementaron las defunciones tuvieron un efecto momentáneo en la dinámica general y no produjo un descenso de la población. La causa de que se mantuviera la tendencia al alza de la población, fue producto de la alta migración que complementó a la tendencia. 
Gráfico I. 2

Crecimiento poblacional, bautismos, casamiento y defunciones de la Jurisdicción de Montevideo (1757-1808).

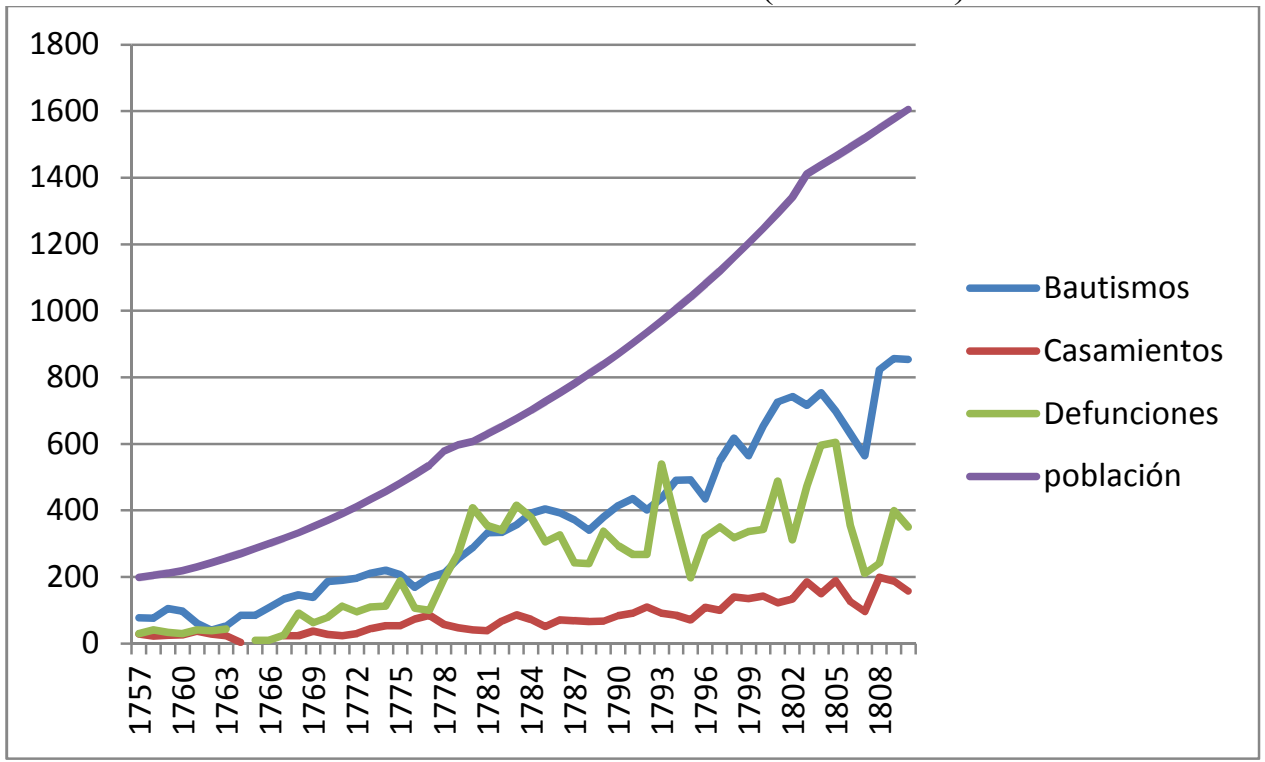

Fuente: elaboración propia a partir de los datos de Pollero y Vicario (2009).

El origen de los pobladores que observable en el gráfico I.3, a partir del Padrón Militar de 1778, da cuenta de una migración muy heterogénea en donde hubo un equilibrio en torno a la migración de la España peninsular y aquellos migrantes de otras regiones de Hispanoamérica. Esto da cuenta de una reestructuración de las corrientes migratorias, ya que en los siglos anteriores la mayor parte de los habitantes provinieron de la España peninsular. En cambio durante el siglo XVIII, cobró gran importancia la migración de otros territorios americanos y en particular de la región Río de la Plata, como es el caso de la ciudad de Buenos Aires, dando muestras de la pervivencia de la idea de que el Río de la Plata no constituyó una frontera sino que se encontraron integradas las dos bandas del río. 
Gráfico I. 3

Origen de la Población de la Jurisdicción de Montevideo en 1778

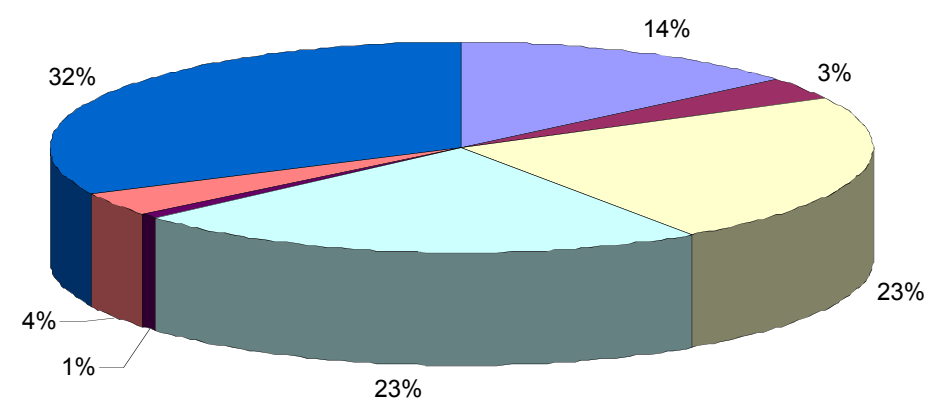

$\square$ Andalucía

- Mediterraneo

$\square$ Región Río de la Plata

$\square$ Virreinato

- Chile

$\square$ Extranjeros

- Atlantico Norte

Fuente: elaboración propia a partir de los datos de Pollero, Raquel y Vicario, Carolina. "Informe demográfico sobre la región platense (1760-1860)", Facultad de Ciencias Sociales, Universidad de la República, 2009.

Nota: Se denomina extranjeros a aquellos sujetos que no eran súbditos de la Monarquía española, especialmente provenientes de regiones "europeas".

Un caso similar a lo desarrollado para la Jurisdicción y ciudad de Montevideo para la segunda mitad del siglo XVIII, lo encontramos en la ciudad de Buenos Aires. La población, como podemos ver en el gráfico I.4, se multiplicó en el lapso de pocos años y, medio siglo después, pasó de menos de 10.000 a más de 40.000 habitantes. Siendo, en este período, la ciudad de Buenos Aires una de las más importantes dentro de la Monarquía española (Besio Moreno, 1939; Comadrán Ruiz, 1964; García Belsunce, 1976; Johnson y Socolow, 1980; Assadourian, Beato y Chiaramonte, 1986; Cuesta, 2012; Raitano, 2012). Este efecto de atracción en sujetos de distintos orígenes, da cuenta de la amplia circulación de personas dentro del espacio virreinal y regional motivado por el crecimiento económico. Este crecimiento poblacional se debió a la llegada de migrantes desde distintas regiones del Virreinato (Díaz, 1997), de la península española (De 
Cristóforis, 2001; 2002; García Belsunce, 1982; García Belsunce y

Frías, 1996; Rey Castelao, 2001) y de otros espacios (Reitano, 2010).

Gráfico I. 4

Aproximaciones a la población total de la ciudad de Buenos Aires de los años: 1744,1778 y 1810

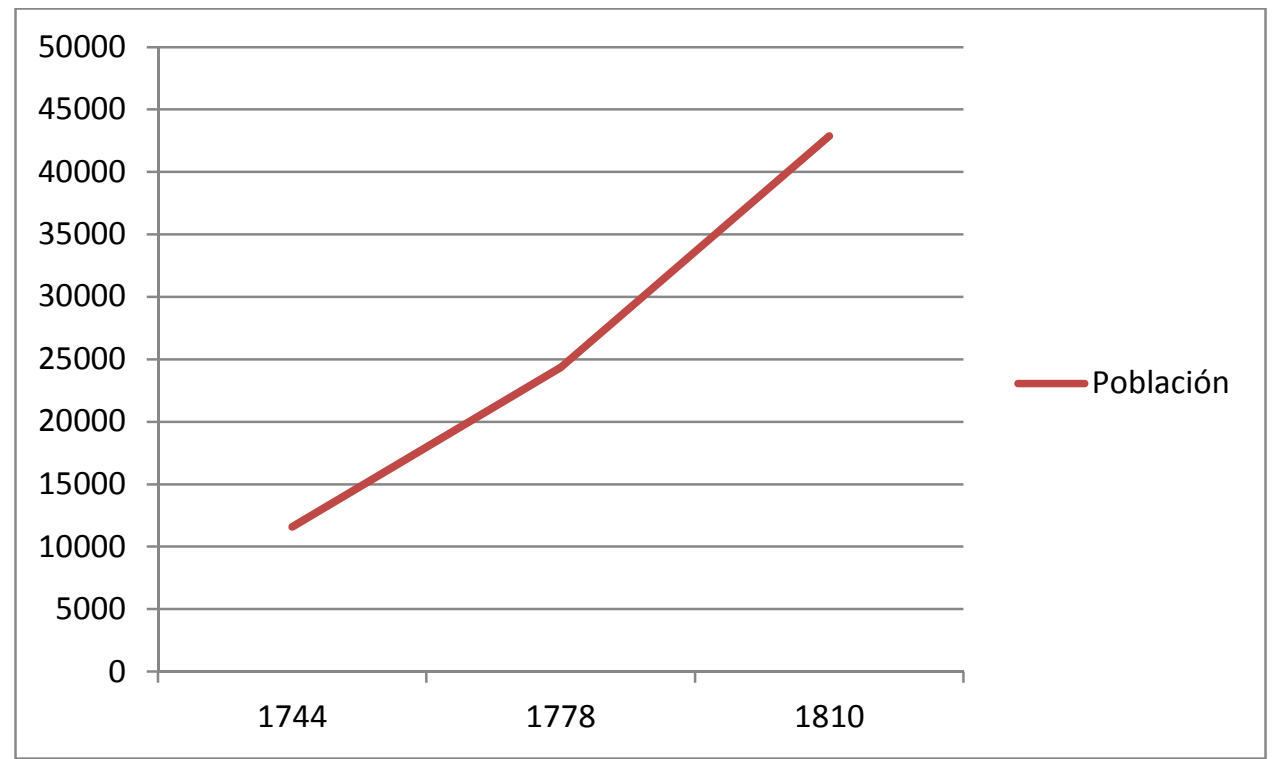

Fuente: elaboración propia a partir de Cuesta (2006).

Junto a la constante migración, el crecimiento de la ciudad de Buenos Aires se produjo a partir del incremento, del número de nacimientos que fueron en aumento como muestra el gráfico I.5. Las variaciones que observamos son producto tanto de la alta mortandad que asechaba a los recién nacidos en este período (resultado de las malas condiciones higiénicas en las que se encontraban), como de las epidemias (fundamentalmente durante los años 1734 a 1736). Por otra parte hay que tener en cuenta las inexactitudes lógicas de las fuentes ya que debemos recordar que no se encuentran todas las actas, como así también que las mismas son de bautismos y no de nacimientos ${ }^{10}$.

\footnotetext{
${ }^{10}$ Las diferencias son muy importantes ya que las familias podían bautizarlo en otras parroquias en las afueras de la ciudad, o en el caso que muriera el vástago no bautizarlo, o que no quede asentado en los registros todos los bautismos, etc.
} 


\section{Gráfico I. 5}

Aproximación a los bautismos, defunciones y casamientos en la ciudad de Buenos Aires desde 1730-60.

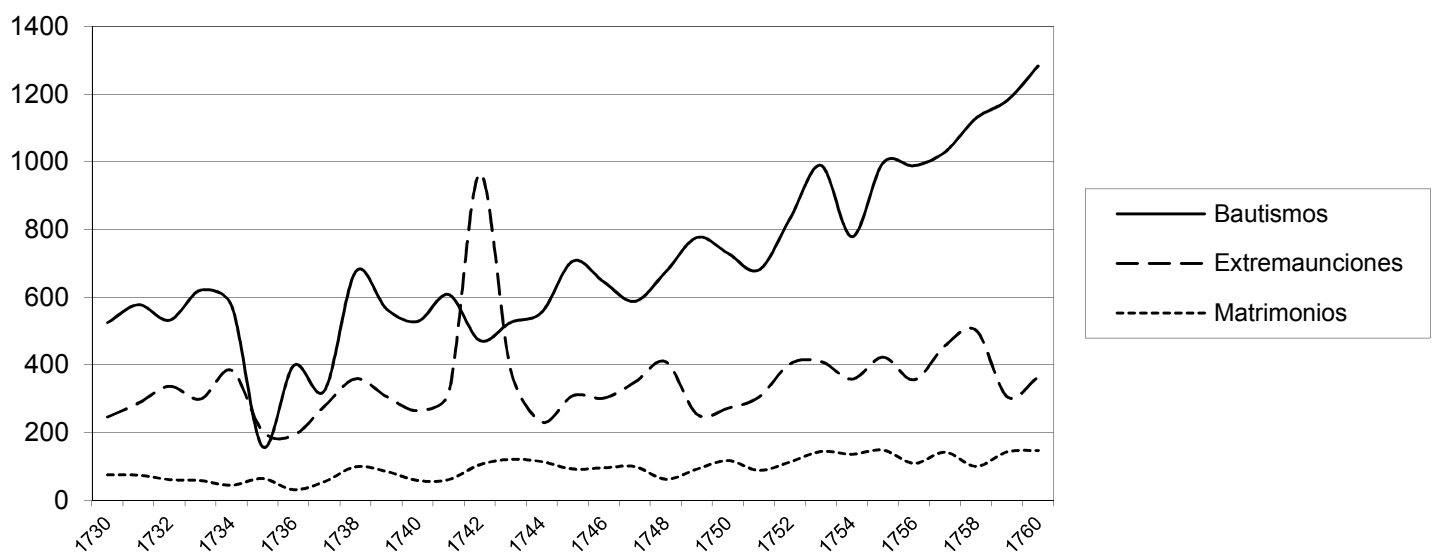

Fuente: Elaboración propia a partir de: Besio Moreno (1936).

Como afirman María Emilia Sandrín y Fernando Jumar (2011), Buenos Aires era una ciudad con un grado alto de "bienestar" en donde los salarios y beneficios no eran tan magros para gran parte de la población. Esto permitió una alta diversificación dentro de las actividades económicas que se realizaban a partir de un crecimiento de la intensa actividad del puerto, los circuitos económicos que entrelazaba y la baja densidad que aún tenía. A su vez, esto dio lugar al asentamiento e integración de la población recién llegada, que lejos de desentonar con el resto, se integraban a los ya asentados con anterioridad. 


\section{Cuadro I. 1}

Origen de la población de Buenos Aires (1744-1810)

\begin{tabular}{|l|r|r|r|r|}
\hline Origen & \multicolumn{2}{|c|}{ Población 1744} & \multicolumn{2}{c|}{ Población 1810} \\
\hline & Número & \multicolumn{1}{c|}{$\%$} & \multicolumn{1}{c|}{ Número } & \multicolumn{1}{c|}{$\%$} \\
\hline Buenos Aires & 697 & 10,2 & 5.766 & 18,5 \\
\hline $\begin{array}{l}\text { Península } \\
\text { Española }\end{array}$ & 253 & 3,7 & 2.290 & 7,3 \\
\hline $\begin{array}{l}\text { Brasil } \\
\text { Portugal }\end{array}$ & 40 & 0,6 & 283 & 0,9 \\
\hline Europa & & & & 385 \\
\hline América & 64 & 0,9 & 5.827 & 1,2 \\
\hline África & 1.490 & 21,8 & 7.610 & 24,3 \\
\hline S/D & 3.944 & 57,7 & 10.082 & 32,2 \\
\hline Total & 6833 & 100 & 31243 & 100 \\
\hline
\end{tabular}

Fuente: elaboración propia a partir de los datos de: Cuesta (2006), Moreno y Mateo (1997), Moreno (1965), Johnson (1979), Johnson y Socolow (1980).

La población de la zona aledaña a Buenos Aires tuvo un crecimiento constante durante la segunda mitad del siglo, pero producto de la falta de información para el periodo 1778- 1815 resulta dificultoso establecer la dinámica. Los trabajos que se realizaron sobre algunos de los pueblos que compusieron la campaña, dan cuenta de que el incremento estuvo marcado por la creación de la línea de fortines que consolidó un amplio territorio productivo en donde se asentaron familias provenientes de otros territorios del Virreinato (Santiago del Estero, Córdoba, San Luis y Mendoza) y de la región Río de la Plata en particular (Santa Fe, ciudad de Buenos Aires y su hinterland próximo, San Nicolás de los Arroyos, etc.). Se observa en este sentido que el proceso migratorio no fue homogéneo, sino que las corrientes migratorias estuvieron en estrecha vinculación con la dinámica económica y cada partido sufrió un proceso demográfico particular (Mateo y Moreno 1997).

La diversidad de procesos demográficos, que permite complejizar el análisis, no resta a la hora de ver una campaña en proceso de expansión poblacional y en constante movimiento, en donde proliferaron en gran medida las 
explotaciones de tipo familiar agrícola- ganadera y en donde era escaza la mano de obra dependiente (Moreno, 1989).

\section{Gráfico I. 6}

Población de la Campaña de Buenos Aires a partir de los padrones, 1744, 1778 y 1815.

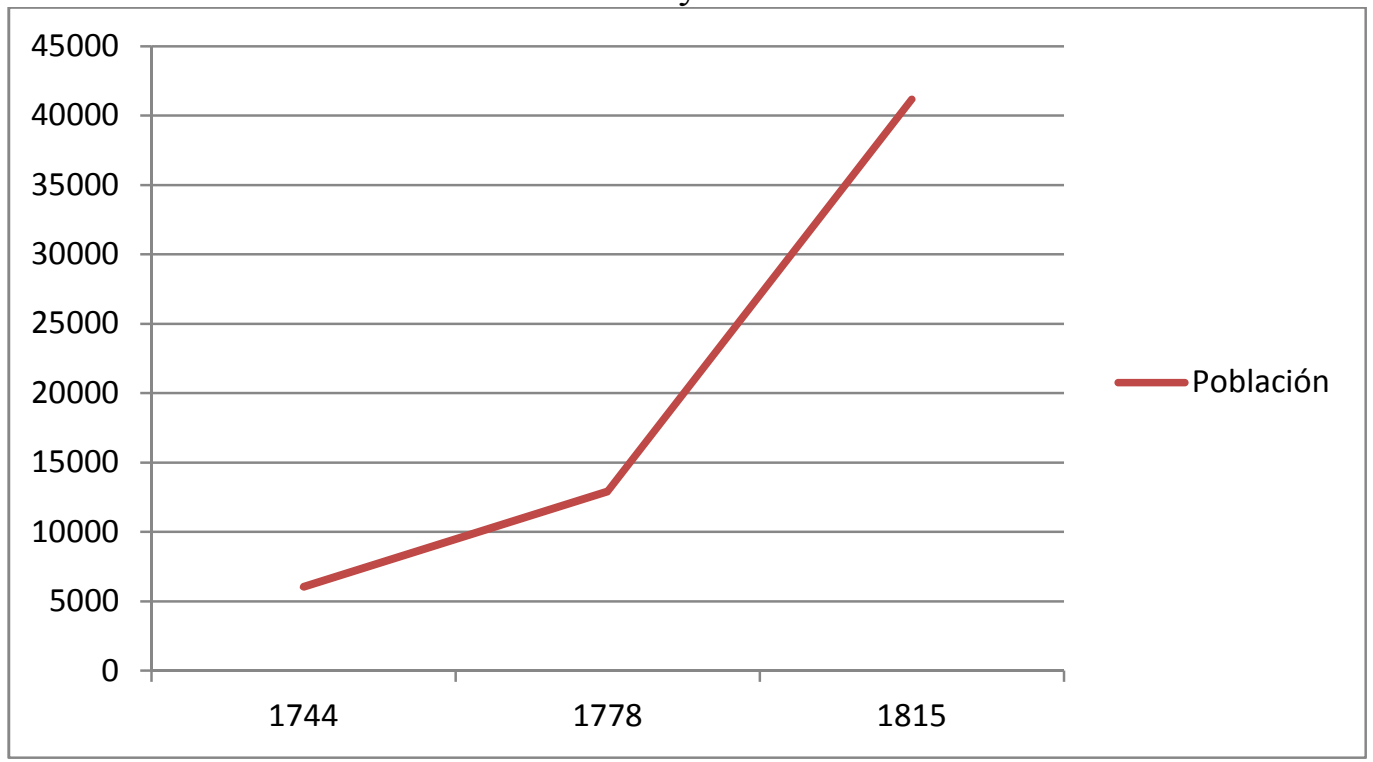

Fuente: elaboración propia a partir de los datos de: Cuesta (2006), Moreno y Mateo (1997), Moreno (1965), Johnson (1979), Johnson y Socolow (1980).

Un ejemplo del proceso señalado para la campaña es el de San Nicolás de los Arroyos, en la ribera sur del río Paraná, el cual fue estudiado en profundidad por Mariana Canedo (1999). La apropiación de tierras comenzó durante el siglo XVII a partir de dos Mercedes, pero no va a ser hasta el siglo XVIII que se produzca un proceso de poblamiento efectivo. Una de las características que señala Canedo como particulares es que los primeros asentamientos se produjeron a partir de la hostilidad que en la primera mitad del siglo XVIII tuvieron los Guaycurúes con las poblaciones asentadas al sur de Santa Fe, lo cual provocó la migración a la zona de San Nicolás. En la segunda mitad del siglo, en cambio, el crecimiento de la población se nutrió de las migraciones de personas provenientes de otros 
territorios dentro de la región Río de la Plata como de otros más alejados (como Santiago del Estero, Córdoba y Tucumán). En suma, “....al avanzar la segunda mitad del siglo XVIII, los elementos del ecosistema agro social no generan modificaciones estructurales al mismo, pero ponen en evidencia sus características específicas (crecimiento de población, aumento de la presencia de mujeres, asentamiento de las familias, continuidad del proceso de apropiación y fragmentación de la tierra, y de la utilización de la mano de obra familiar, etc.)" (Canedo, 1999: 130)

\section{Gráfico I. 7}

Población de San Nicolás de los Arroyos a partir de los padrones de 1726, 1744,1778 y 1815.

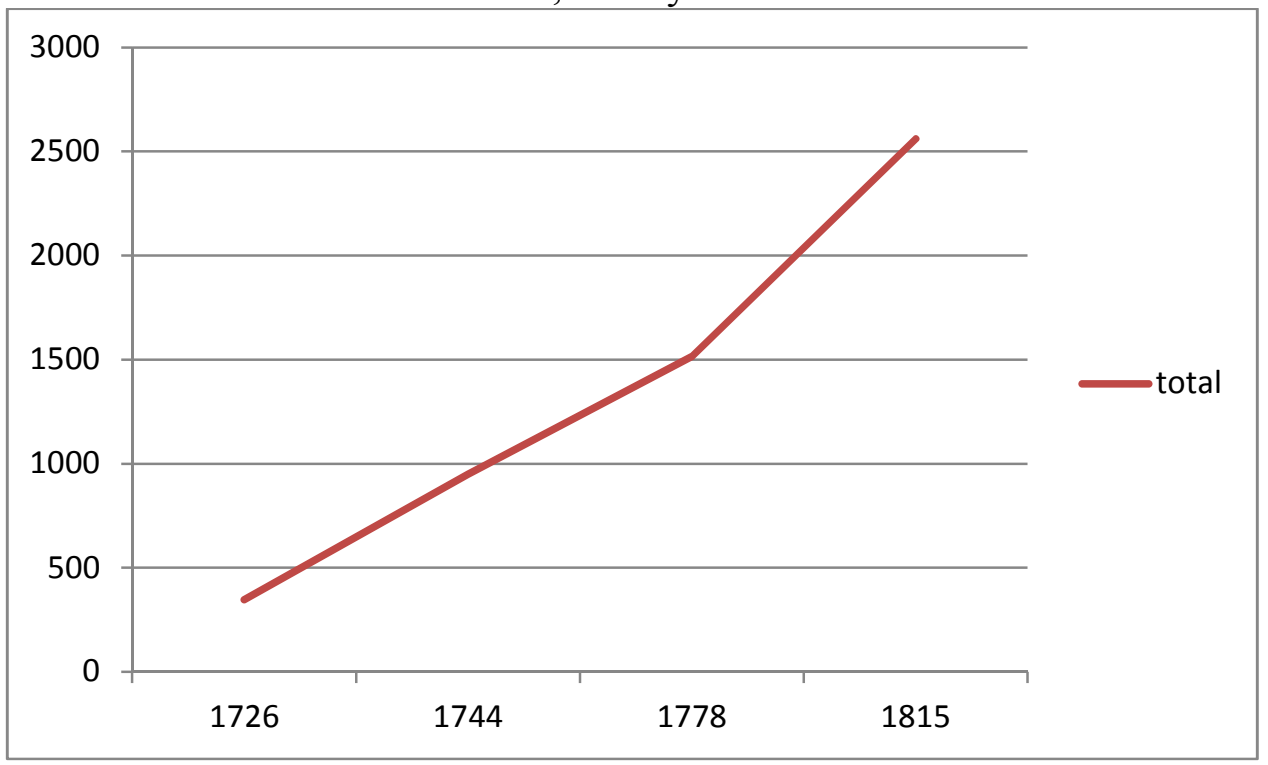

Fuente: Elaboración propia a partir de Canedo (1999).

La zona norte de la región: su producción.

El territorio de la zona norte de la región Río de la Plata se encontraba constituido por las zonas de producción de cueros. Contaba con el sur de la actual provincia de Santa Fe, Entre Ríos y el sur de los territorios de las Antiguas 
Misiones Jesuíticas. En términos generales, esta zona estuvo marcadas por una escasa población y grandes establecimientos productivos de cueros.

Al este, entre el río Uruguay, el Atlántico y el río de la Plata, la zona estuvo mayoritariamente en propiedad de los jesuitas, hasta su expulsión en 1767, a partir de lo cual fueron nombrados desde Buenos Aires dos gobernadores, ambos militares, para los pueblos misioneros. Cada uno de ellos tendría mando sobre los pueblos del río Uruguay y del río Paraná, respectivamente. Pero muy pronto este esquema fracasó y en 1769 se pasó a otro sistema, por el cual un gobernador único para todos los pueblos actuaría con ayuda de tres tenientes, cada uno de los cuales tendría jurisdicción sobre un sub-conjunto de pueblos. De esta forma, el territorio misionero y sus habitantes no se constituyó como provincia autónoma, quedando en carácter de distrito subordinado a la autoridad máxima de la provincia del Río de la Plata, con sede en Buenos Aires (Moraes, 2011: 57).

Este territorio compuso el paisaje pastoril misionero el cual, como plantea María Inés Moraes (2011), se fundó y desarrolló con el fin de producir carne y cueros vacunos para el resto de las misiones jesuíticas, las cuales tuvieron una alta tasa demográfica:

La base institucional del paisaje pastoril misionero era la propiedad comunal sobre tierras y ganados, y su sistema ganadero combinaba de manera original el arreo de ganados silvestre y la cría de animales mansos. Su destino se jugó entre el mercado interno colonial para el cual había nacido y el mercado atlántico que desde el último cuarto del siglo XVIII disputó su riqueza y acabó por disolver sus rasgos esenciales (Moraes 2011: 28) 


\section{Mapa I. 6}

Territorio de las Antiguas Misiones integradas a la región Río de la Plata

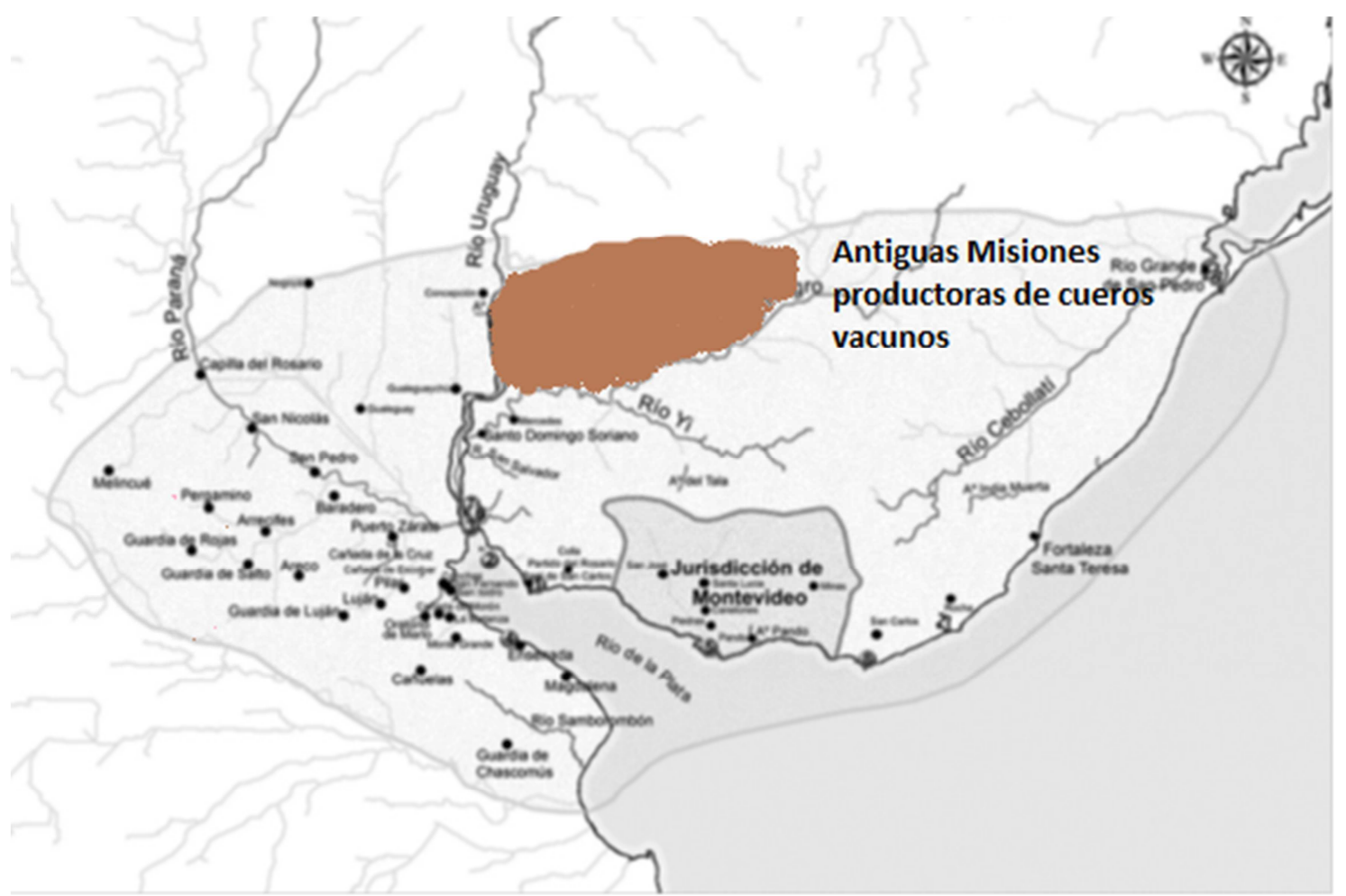

Fuente: Elaboración propia a partir de Jumar (2011:124), Moraes (2012).

Con respecto a la producción de cueros de esta región, la investigación de Julia Sarreal (2009) sobre el puerto de Yapeyú da cuenta que desde 1770 a 1806 se produjo un crecimiento muy importante a partir de la producción de cueros para el comercio atlántico. Además, establece que Yapeyú hizo una transición desde su condición de principal proveedor de carne para el consumo misionero, a principal exportador de cueros de la cuenca platense.

Por otro lado, en su tesis doctoral, María Inés Moraes (2011) observa que a partir de la expansión de la producción de cueros, desde 1760, se produjo:

Un proceso de re-localización de la actividad de corambre en dirección al Norte, cada vez más lejos del Río de la Plata, en busca de los ganados cimarrones. Aunque no fueron los únicos afectados, los territorios realengos comprendidos entre los ríos Uruguay y Negro, cobraron un renovado interés. Los territorios entre los ríos Yí y Negro constituyen una rinconada muy apreciada desde el punto de vista de las pasturas y de su ubicación geográfica, en la frontera del paisaje 
misionero pero muy cercana a Montevideo y a la antigua Vaquería del Mar. Se convirtió en el emplazamiento corambrero por excelencia del paisaje pastoril misionero después de 1770. Aunque con interpretaciones diversas, ha sido relatado por diversos autores el episodio que dio prerrogativas a los misioneros sobre los ganados de ese territorio (Moraes, 2011: 246).

En territorio comprendido en Entre Ríos y el sur de Santa Fe el predominio de las grandes estancias fue incuestionable, fueron las que mantuvieron la mayor parte de las tierras, como se puede observar en el mapa I-6. La distribución de la población se desarrolló en torno a pequeños pueblos como Las Víboras, Soriano, Arroyo la China que se encontraban, fundamentalmente, cerca de los ríos más importantes y eran los embarcaderos de los cueros producidos en las zonas aledañas.

\section{Mapa I. 7}

Principales estancieros de la campaña santafesina: pagos del Salado, Los Saladillos, Rincón, Coronda, Arroyos y la Bajada

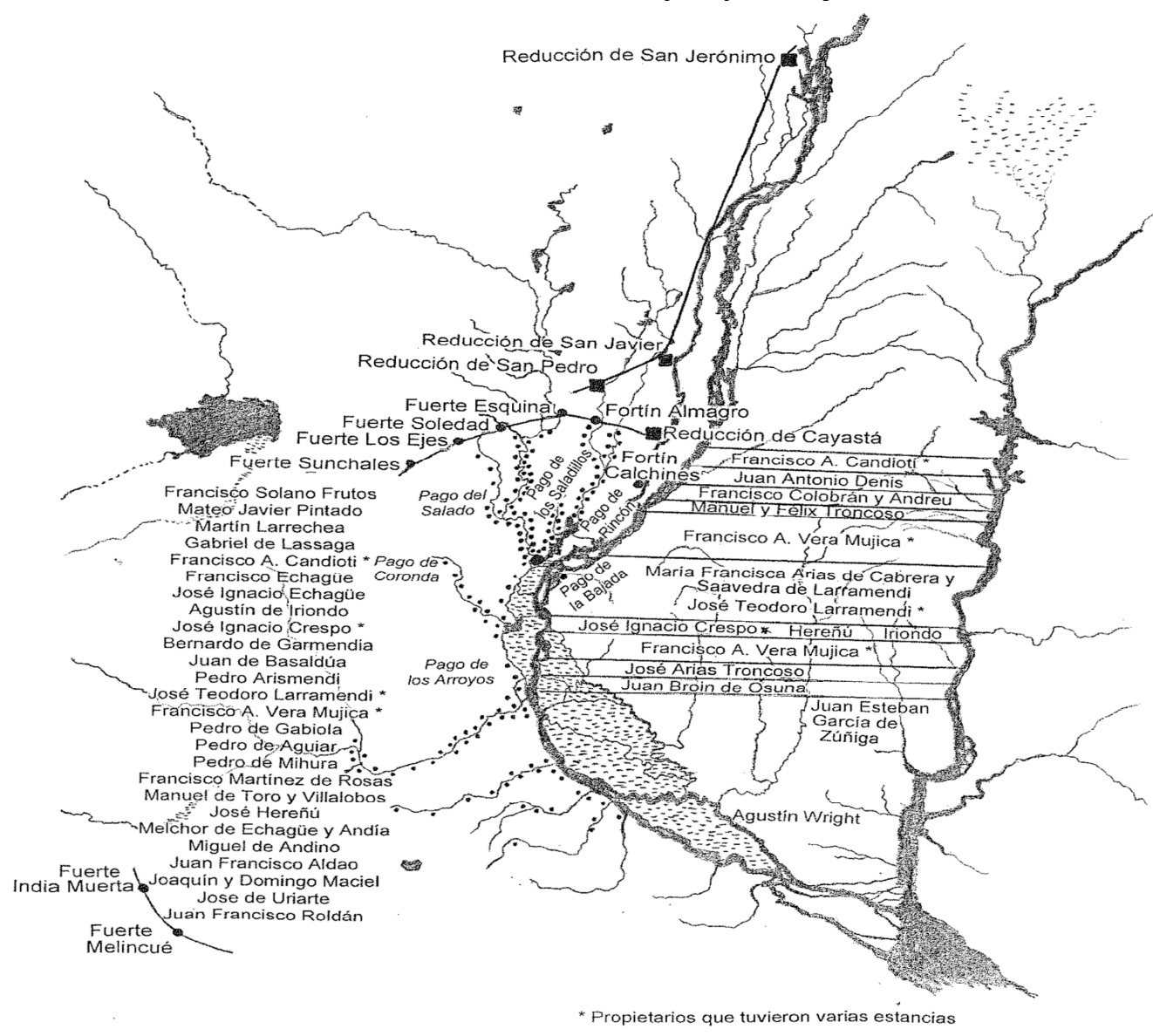


Fuente: Suarez y Tornay (2003: 538).

Julio Djenderedjian (2003, 2004 y 2011) analizó las características de dos de las estancias más importantes de este territorio, las cuales “....eran en promedio mucho más grandes y mucho más claramente especializadas en producción vacuna de exportación que las de Buenos Aires.” (Djenderedjian, 2011: 4).

En el mapa siguiente se puede observar el territorio que ocuparon estas dos estancias las cuales, sumadas abarcaban algo más de 350.000 hectáreas. Las mismas fueron compradas por Pedro García de Zuñiga en la década de 1760 y a partir de 1770 comenzó el proceso de poblamiento de lo que hoy es Gualeguaychú. El inventario del año 1803 registró 46963 cabezas de ganado manso y 25.300 de alzado o disperso (Djenderedjian, 2011: 10).

\section{Mapa I. 8}

Estancias de los García Zúñiga

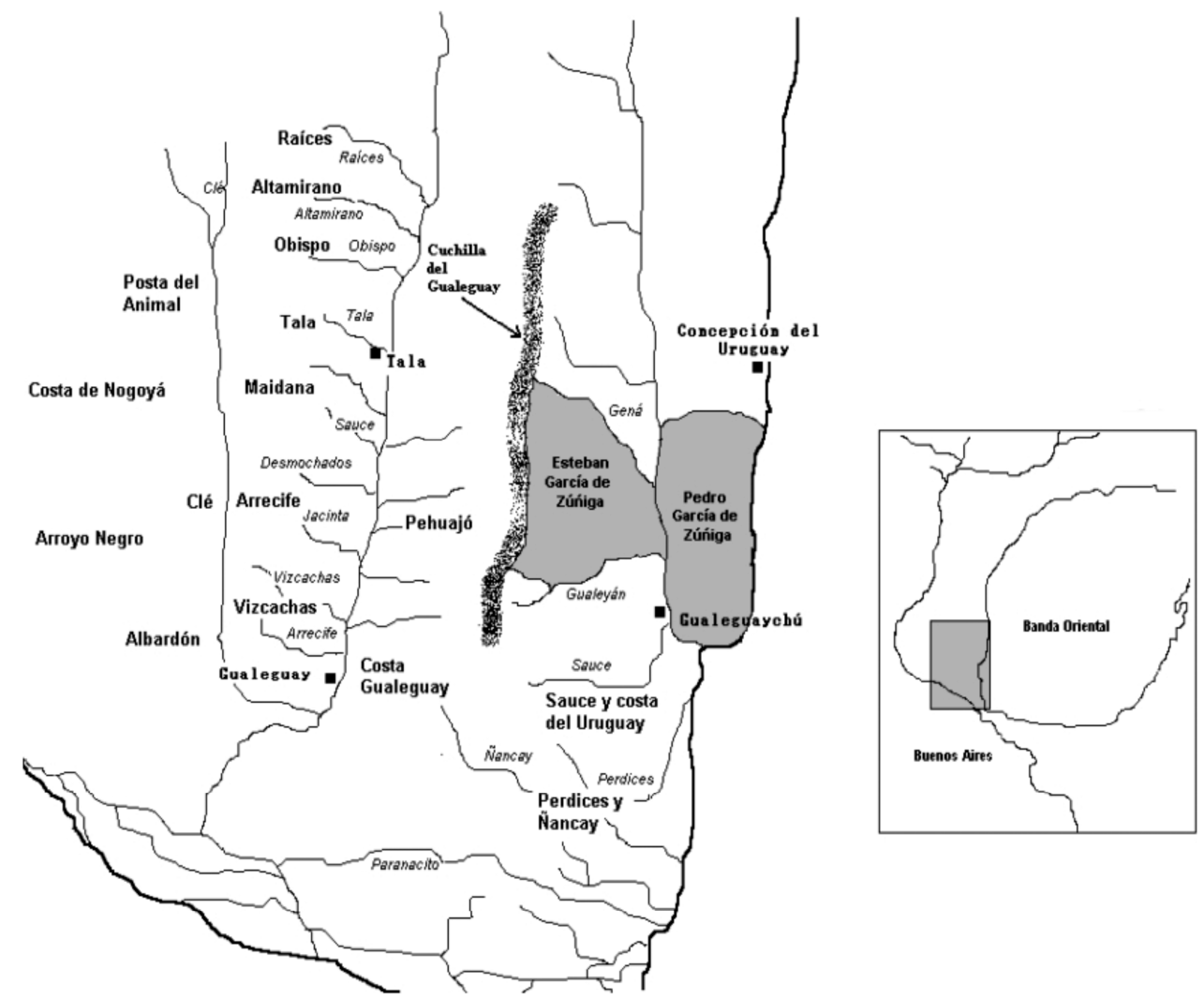

Fuente: Djenderedjian (2004) 
Las estancias de los García Zuñiga, si bien eran muy importantes, no eran las únicas (solo en la zona de Entre Ríos había unas diez estancias similares) con lo cual, se puede estimar que la existencia de ganado vacuno era muy importante, tanto el de cría como el alzado. Esto confirma que los ingresos de cueros por el Riachuelo eran certeros y que esta zona fue uno de los pilares del crecimiento comercial ultramarino de cueros salidos por Buenos Aires durante la segunda mitad de siglo.

En suma, como afirma Djenderedjian:

"Entre Ríos y la Banda Oriental fueron las áreas que mejor habían aprovechado las coyunturas favorables de la apertura del comercio atlántico. Es evidente que poseían envidiables condiciones para ello: tierras abundantes, movilidad social, capital en abundancia aportado por los grandes comerciantes porteños, pastos vírgenes, rebaños extensos; en suma, eran las áreas más prósperas en un momento de proverbial prosperidad para la producción pecuaria rioplatense..."(Djenderedjian, 2004: 17).

Por lo tanto, si bien los territorios del sur de las antiguas misiones y entre Ríos tuvieron un desarrollo pecuario muy importante, en otros (aunque en menor medida) también se desarrolló. Un ejemplo de ello se encuentra en el sur de Santa Fe, en donde se produjo una combinación entre la producción pecuaria extensiva y un desarrollo del puerto de Santa Fe, el cual fue paso obligado por disposición real, entre 1740 y 1780 el para la conexión entre el Río de la Plata y Paraguay (Suarez y Tornay, 2003).

Otro ejemplo, lo podemos encontrar en el territorio de la actual Misiones, la cual era un espacio que hasta las últimas décadas del siglo XVIII se encontraba articulado con Paraguay y, tras la crisis económica de este territorio y el auge comercial del cuero en la región Río de la Plata, giró su economía hacia el 
Atlántico. Sin embargo, tuvo una fortuna inversa a Entre Ríos y la zona sur de las Antiguas Misiones, ya que si logró impactar positivamente, las dificultades del transporte encarecieron su coste y ese espacio no logró consolidarse, como productor de cueros a largo plazo.

Mapa I. 9

Ocupación territorial de Corrientes a fines de siglo

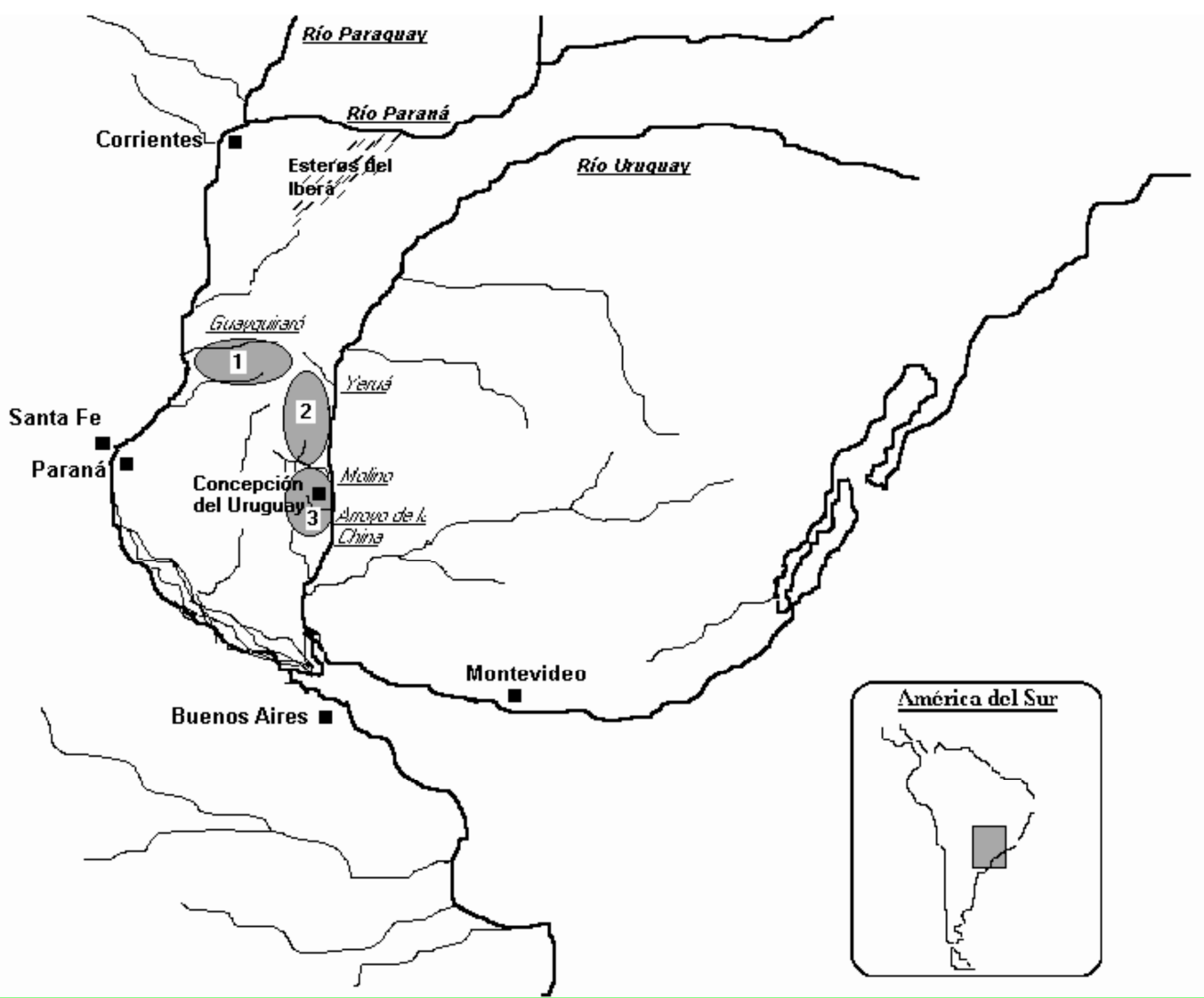

Fuente: Extraído de Djenderedjian (2004).

\section{La zona norte de la región: su población.}

Durante las últimas décadas del siglo XVIII, también en la zona norte se desarrollaron una serie de fundaciones de pueblos y fuertes en gran parte del territorio. Sin embargo, como se puede observar en el mapa siguiente, no logró consolidar e incrementar su población. El territorio de la zona norte, excluyendo el sur de las antiguas misiones, era un compendió de pequeños poblados de menos 
de 1.000 habitantes cada uno, con un crecimiento demográfico muy por debajo de la zona sur.

Las causas del bajo crecimiento poblacional en relación a la zona sur, se encuentran en los mecanismos productivos de este territorio. Como ya se señaló, frente a la producción mixta del sur regional que necesita gran cantidad de mano de obra, en la zona norte, el desarrollo de la gran propiedad con producción pecuaria no requirió de una población numerosa, siendo este un freno para su crecimiento demográfico.

\section{Mapa I. 10}

Fundaciones de pueblos en la zona norte de la región Río de la Plata a fines del siglo XVIII

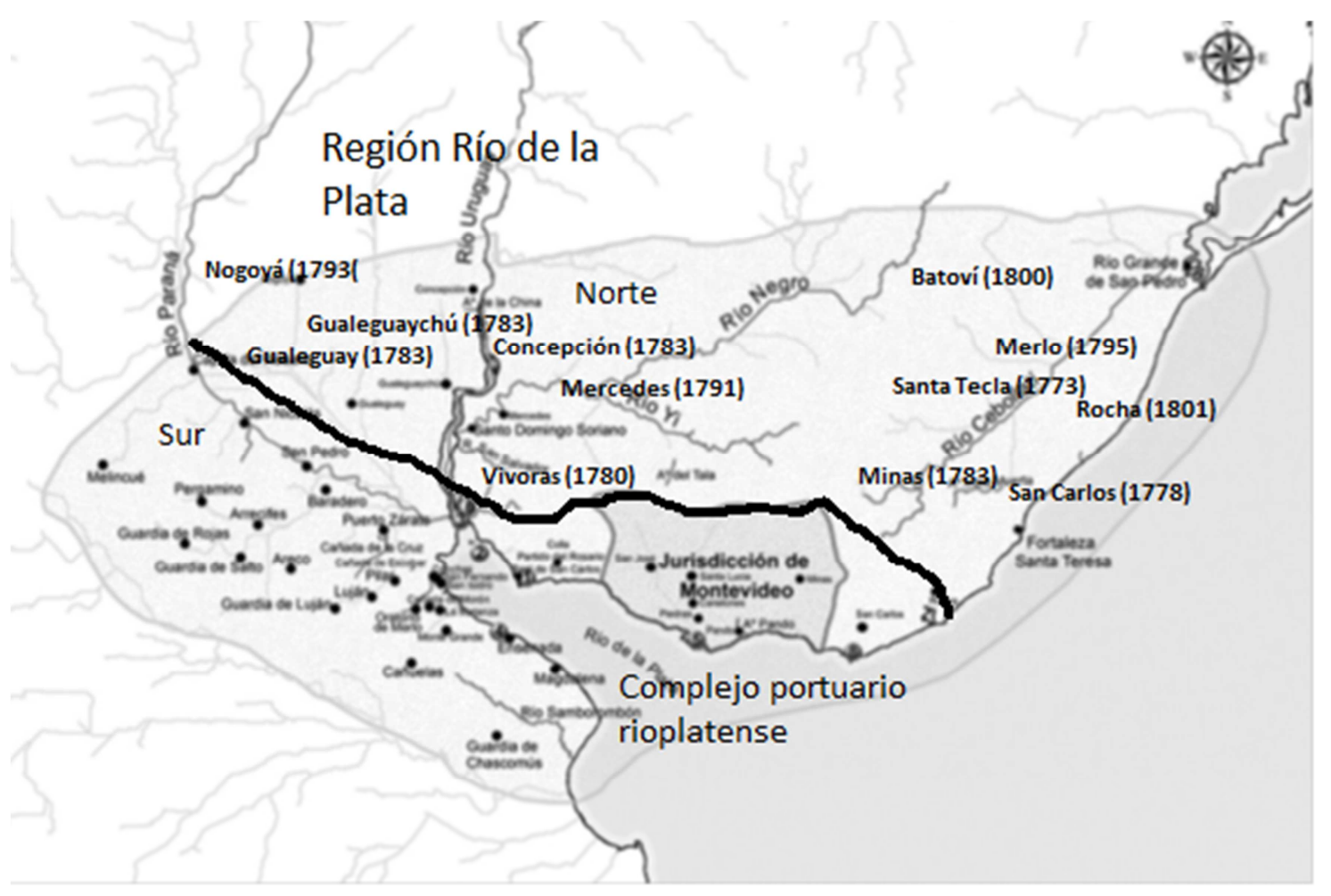

Fuente: Elaboración propia a partir de Jumar (2011), Djenderedjian (2004) y Román (2013) 
Un proceso divergente al analizado anteriormente, lo encontramos en el territorio sur de las antiguas misiones, ya que a partir de la expulsión de los jesuitas pasó de un entramado social a otro. Durante el apogeo de las misiones en el siglo XVIII, los jesuitas organizaron las treinta misiones en dos distritos. El primero comprendía las comunidades a ambos lados del río Paraná. Fueron San Ignacio Guazú, La Fe, Santa Rosa, Santiago, Encarnación de Itapúa, Candelaria, San Cosme y Damián, Santa Ana, Loreto, San Ignacio Mini, Corpus Christi, Jesús y Trinidad. El segundo abarcaba aquellas localizadas a ambos lados del río Uruguay. Este grupo incluía San José, San Carlos, Los Santos Apóstoles, Concepción, Santa María La Mayor, San Francisco Javier, Los Santos Mártires de Japón, San Nicolás, San Luis Gonzaga, San Lorenzo Mártir, San Miguel, San Juan Bautista, Santo Ángel Custodio, San Tomé, San Francisco de Borja, La Cruz y Yapeyú (Jackson, 2004). El crecimiento de la población estuvo dificultado por una serie de causas: epidemias, conflicto armado y la expulsión de los jesuitas.

La epidemia de 1738-1740 generó un severo aumento del índice de mortalidad. Además, producto de la firma del Tratado de Madrid en 1750 que intentó establecer los límites coloniales entre España y Portugal, estipulaba la transferencia del puesto avanzado portugués de Colonia do Sacramento, a cambio de territorio en lo que hoy es Río Grande do Sul, al norte de Uruguay. El área cedida incluía las siete misiones ubicadas al oriente del río Uruguay, junto con sus extensas estancias y Yapeyú, La Cruz y Santo Tomé. Los habitantes, que ascendían a 29.191, debían ser reubicados en territorio español, pero los guaraníes se resistieron y enfrentaron a las tropas españolas y portuguesas. Sin embargo, los guaraníes fueron derrotados y, mientras que los europeos tuvieron tres muertos y 10 heridos, estos sufrieron 1.511 bajas. Posteriormente, la expulsión de los 
jesuitas y el nombramiento de administradores civiles provocó una ruptura entre el sistema económico jesuita que compartía recursos entre las comunidades y el nuevo sistema que hacía un gran énfasis en la producción de cada misión individual con muy poco o ningún intercambio entre ellas (Sarreal, 2012).

Gráfico I. 8

Población de las Misiones Jesuíticas durante el siglo XVIII.

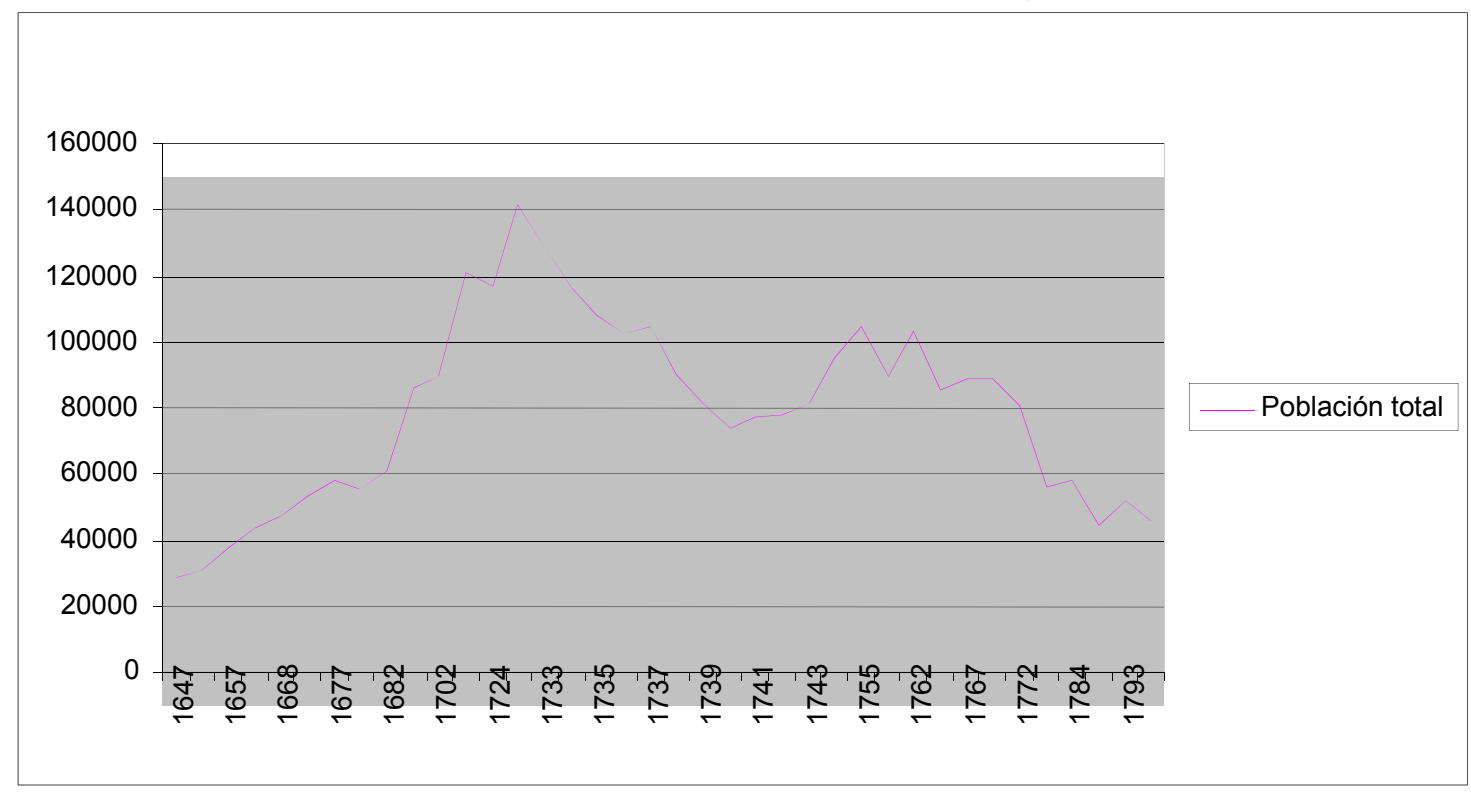

Fuente: elaboración propia a partir de Jackson (2004).

Esto implicó una reconversión de unidades de un todo articulado internamente, en donde cada comunidad cumplía una función, a un modelo orientado a la división de las comunidades y su integración en distintos circuitos ya establecidos. Por lo tanto, en términos generales, el descenso de la población fue muy importante y dejó diezmadas a muchas de las florecientes comunidades. 
Gráfico I. 9

Población de las Misiones Jesuíticas y de Yapeyú durante el siglo XVIII.

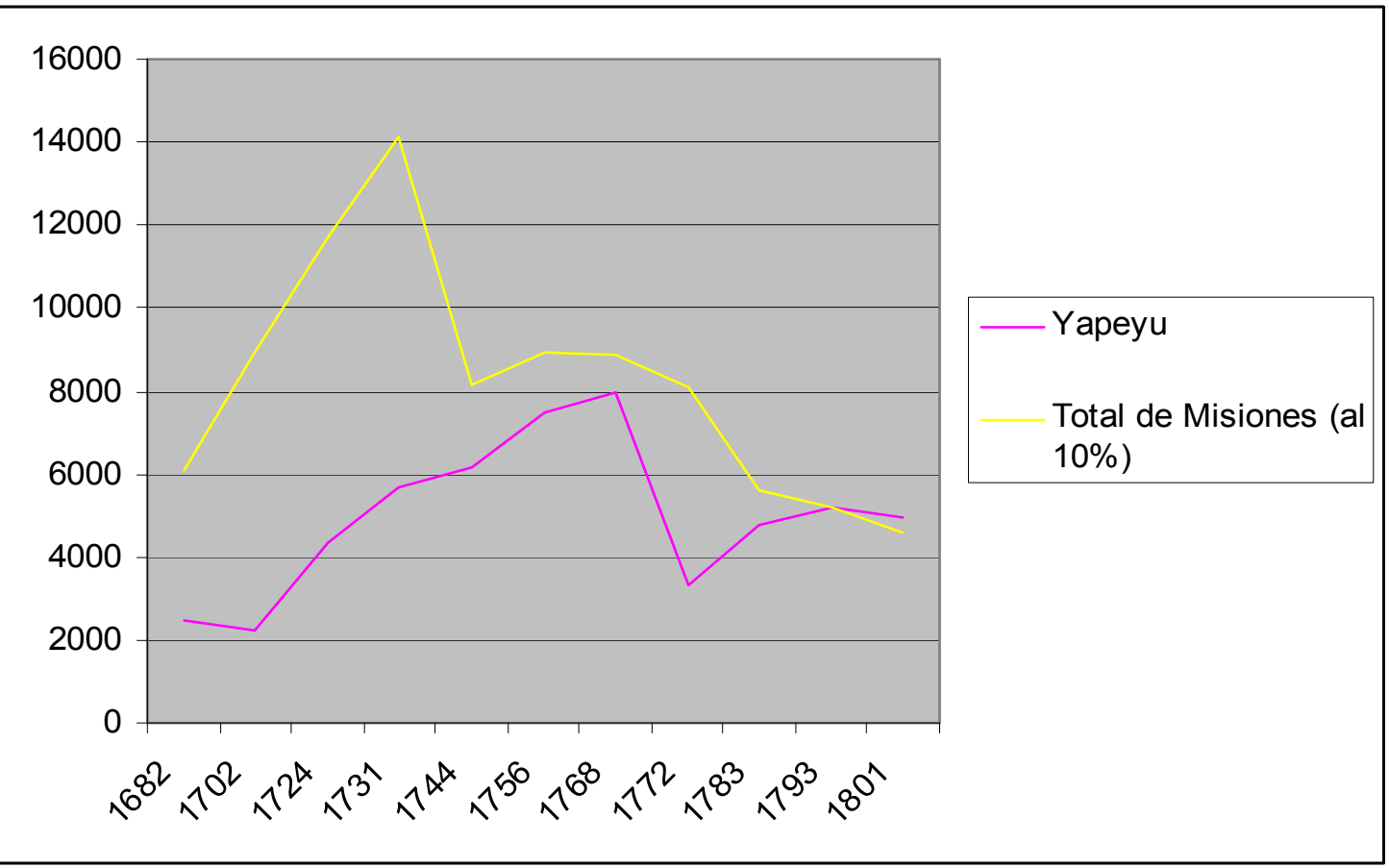

Fuente: elaboración propia a partir de Jackson (2004).

Como ya se dijo, la comunidad que se integró a la región Río de la Plata a partir de la expulsión de los Jesuitas fue la de Yapeyú. La misma tuvo un descenso poblacional muy importante después de los jesuitas pero, a partir de allí, como producto de la rápida integración al mercado ultramarino de cueros, estabilizó su población durante las décadas siguientes.

Resumiendo, la división en dos subregiones, sur y norte, responde a la dinámica económica y su correlato en la población. Sin embargo, si bien contuvo diferencias, se puede hablar de una complementariedad entre ambas. La zona norte estuvo orientada a la producción de cueros que salían por los puertos de Montevideo y Buenos Aires y su población se mantuvo estable en algunos de los casos y en otros creció a un nivel pobre en relación a la zona sur (estando este 
crecimiento vinculado a la promoción de Villas y poblados por parte de la Monarquía en este espacio en particular).

\section{El mercado inmobiliario: Buenos Aires y Montevideo.}

Una de las expresiones del crecimiento económico y demográfico de la región Río de la Plata de la zona sur, se puede observar en el mercado inmobiliario de las dos ciudades más importantes: Buenos Aires y Montevideo. En este apartado se analizará la dinámica del mercado inmobiliario, tanto en relación a la cantidad de transacciones como los valores por año.

Eduardo Saguier (1995), analizó el mercado inmobiliario urbano para la ciudad de Buenos Aires. A partir de los protocolos notariales rastreó las transacciones comerciales durante 120 años, desde 1700 a 1820, con el objetivo de establecer la movilidad social de la población de la ciudad. Para el caso de Montevideo, un trabajo similar al de Saguier fue el realizado bajo la dirección de Pivel Devoto en donde se plasman las cifras del mercado inmobiliario. En ambos casos, el objetivo era determinar, los totales de transacciones realizadas, que acompañarían el desarrollo económico del período, y sus costes sin detenerse en los actores que las realizaron.

Para complementar los datos de Saguier y Pivel tomamos los datos expresados en libros de Alcabala, para el período 1783- 1794. La compra y venta de tierras, casas, navíos, tahonas, entre otros, solían registrarse en un libro titulado "Alcabala de compra y venta de esclavos, tierras y casas" donde se asentaba por fecha todas las transacciones que se realizaban, el escribano que la realizó, el nombre del vendedor y comprador, una descripción del bien ${ }^{11}$, su coste y el impuesto que se

\footnotetext{
${ }^{11}$ En el caso de tierra: su tamaño, ubicación, si contaba con edificación, limites; en el caso de las casas su ubicación, material de construcción, tamaño y si contaba con quinta y/o esquina, en el caso de los navíos, el tipo, origen, nombre, tonelaje, año de construcción.
} 
debía pagar. A partir de este corpus documental se puede establecer no solo las cantidades de compras y ventas sino también los actores que intervinieron pudiendo aislarse a aquellos actores que intervinieron con mayor regularidad y que acumularon en su patrimonio más cantidades de estos bienes.

En el cuadro I. 2, se puede observar el total de las transacciones que se desarrollaron durante el período que va desde 1700 a 1810 . Es posible dividir, a su vez, este período en cinco etapas. La primera de 1700 a 1720 en donde el nivel no pasó del $2 \%$ del total de transacciones. La segunda etapa que abarca las dos siguientes décadas y que no superó el 5\%. La tercera de 1740 a 1770 y que se mantuvo alrededor de un $8 \%$. La cuarta para las tres siguientes que rondan alrededor del 10\%. Finalmente una quinta etapa que llega casi al $25 \%$.

El crecimiento de las transacciones fue entonces, en términos generales, constante. Década a década se incrementó producto de la afluencia de migrantes que habitaron la ciudad y que, probablemente, lograron adquirir en un período relativamente corto de tiempo el dinero suficiente para la compra de un terreno o una casa. Sin embargo, la década que representa un cambio con respecto a esta tendencia fue la primera del siglo XIX la cual casi duplica las transacciones de la década anterior. Siendo que en esta década no se produjo una “explosión demográfica" y el comercio ultramarino bajó sensiblemente debido a la guerra con Inglaterra, las invasiones inglesas y la invasión francesa a la península española, las respuestas a este proceso seguramente se encuentren en un cambio en los patrones de inversión. 
Cuadro I. 2

Transacciones inmobiliarias de Buenos Aires (1700-1809)

Fuente: elaboración propia a partir de Saguier (1995).

\begin{tabular}{|l|l|l|}
\hline Años & Número & $\%$ \\
\hline $1700-1709$ & 162 & 1,5 \\
\hline $1710-1719$ & 207 & 1,9 \\
\hline $1720-1729$ & 519 & 4,8 \\
\hline $1730-1739$ & 516 & 4,8 \\
\hline $1740-1749$ & 876 & 8,2 \\
\hline $1750-1759$ & 867 & 8,1 \\
\hline $1760-1769$ & 821 & 7,7 \\
\hline $1770-1779$ & 1.138 & 10,7 \\
\hline $1780-1789$ & 1.410 & 13,2 \\
\hline $1790-1799$ & 1.475 & 13,8 \\
\hline $1800-1809$ & 2.656 & 24,9 \\
\hline Total & 10.647 & 100 \\
\hline
\end{tabular}

En el mismo sentido, se puede observar que la fluctuación del promedio de coste de un inmueble fue mucho mayor. Mientras que en las primeras décadas fue mucho más alto que en las tres siguientes luego, con ciertos altibajos, no se incrementó, aumentando previsiblemente, según lo expuesto en la última década analizada. Con respecto al alto coste del promedio del inmueble en las primeras décadas, es probable que esté vinculado al alto nivel de monetarización de la sociedad, sumado al escaso número de habitantes, lo que produciría un incremento en alto coste de la mano de obra para la construcción de viviendas. Tendencia que, con el correr de las décadas, fue variando ya que las oleadas migratorias redujeron sensiblemente el coste de la mano de obra. Como en el cuadro anterior, el aumento de las transacciones incrementó el precio de las mismas notablemente. 
Cuadro I. 3

Promedios de las transacciones inmobiliarias de Buenos Aires (1700-1809)

\begin{tabular}{|l|l|}
\hline Años & Promedio \\
\hline $1700-1709$ & 652,9 \\
\hline $1710-1719$ & 502,2 \\
\hline $1720-1729$ & 324,5 \\
\hline $1730-1739$ & 450,5 \\
\hline $1740-1749$ & 368,3 \\
\hline $1750-1759$ & 744,8 \\
\hline $1760-1769$ & 725,7 \\
\hline $1770-1779$ & 688,6 \\
\hline $1780-1789$ & 873,1 \\
\hline $1790-1799$ & 895,3 \\
\hline $1800-1809$ & 1383,9 \\
\hline
\end{tabular}

Fuente: elaboración propia a partir de Saguier (1995).

En este contexto de crecimiento demográfico y comercial, durante la segunda mitad del siglo XVIII se observa un incremento en las transacciones inmobiliarias vinculadas a esta tendencia. A partir del cambio del siglo, se produjo un trastrocamiento de la misma ya que aumentaron notablemente las inversiones y el coste promedio. Las causas de esta variación probablemente se encuentren vinculadas a un giro en las inversiones de algunos sectores de la sociedad producidas por las dificultades en el comercio, lo que generó que se centre la mirada en los inmuebles como mecanismo de extraer una renta sin un riesgo alto. 
Gráfico I. 10

Total de inmuebles vendidos y promedio del precio por décadas en la ciudad de Buenos Aires.

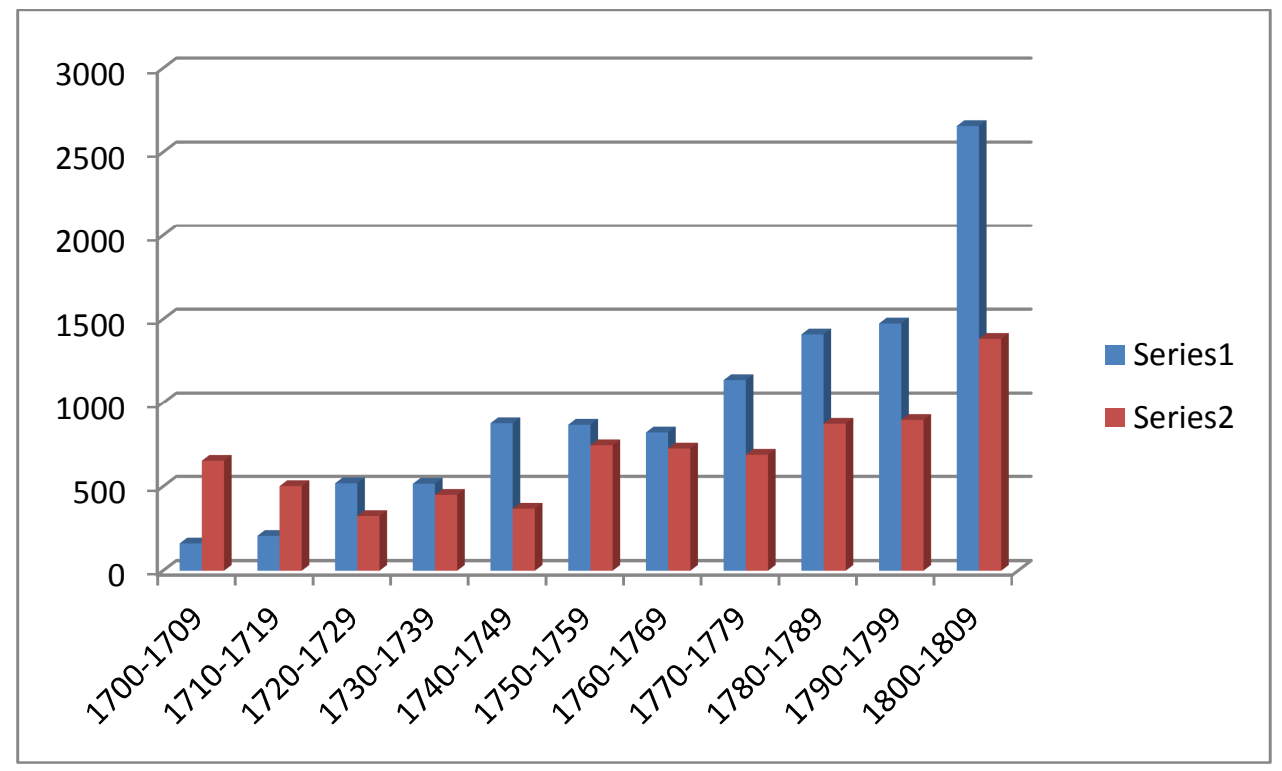

Fuente: elaboración propia a partir de Saguier (1995).

El caso de Montevideo es similar al de Buenos Aires en relación al crecimiento de los inmuebles. A partir de la década de 1760 se triplicaron las ventas lo que vincularía el crecimiento comercial y poblacional. 


\section{Gráfico I. 11}

Total de inmuebles vendidos del precio por décadas en la ciudad de Montevideo.

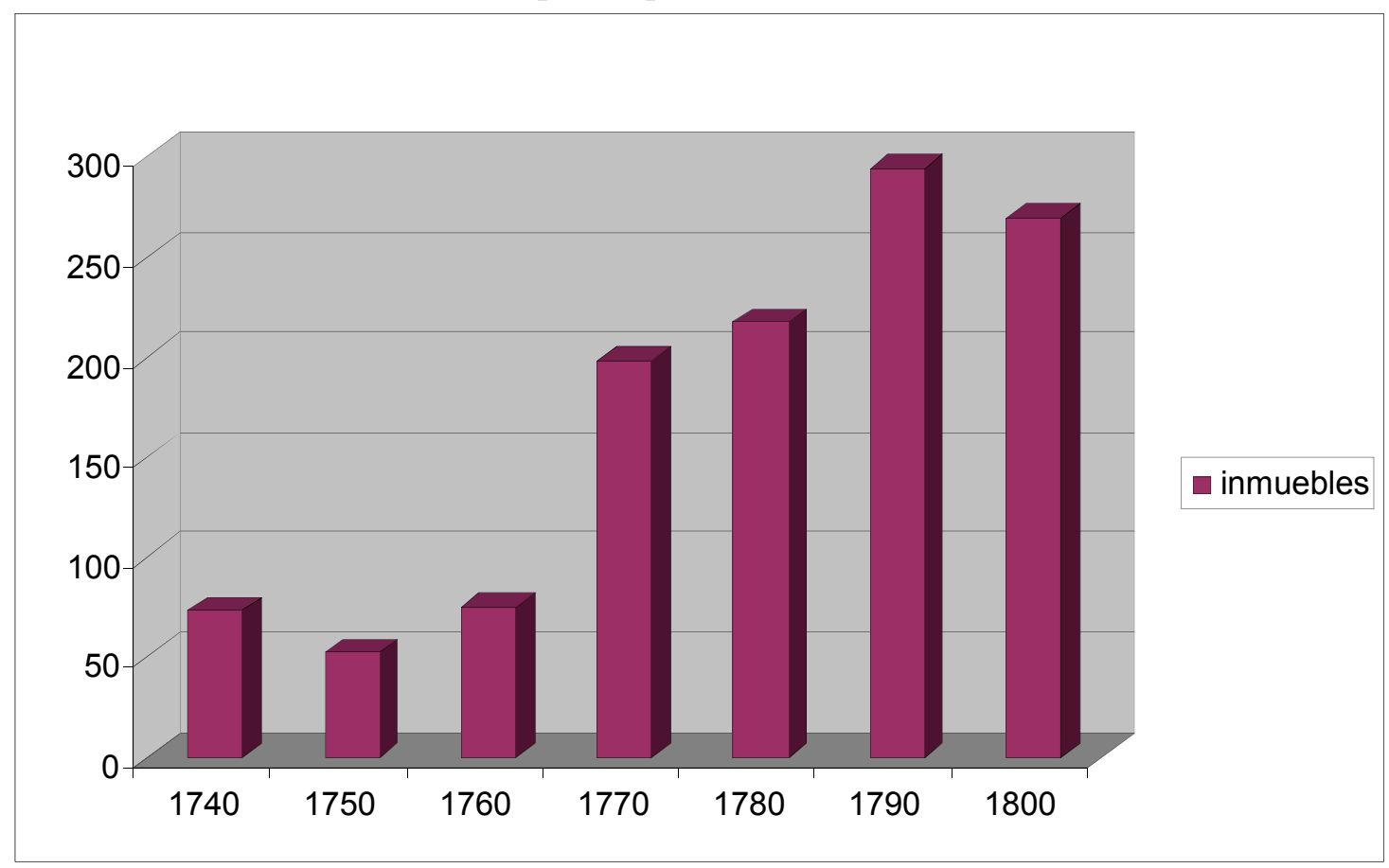

Fuente: elaboración propia a partir de Pivel Devoto (1964).

El crecimiento de los mercados inmobiliarios de Buenos Aires y Montevideo es una expresión más de la pujanza económica de esta región que articula dos ejes, uno como puerta de entrada de las mercancías a distribuir en Paraguay, Chile, Alto Perú, Córdoba, etc. Pero también de la dinámica del comercio del cuero producido en la región. Esta dinámica hizo que, cada vez más, se afinquen migrantes en las ciudades más importantes, Buenos Aires y Montevideo, y que logren tener, por ejemplo trabajando como carpintero en el puerto, una importante capacidad de ahorro y, en poco tiempo, pudiera casarse y comprar un terreno con edificación, rancho o casa. ${ }^{12}$

\footnotetext{
${ }^{12}$ Maria Emilia Sandrín (2014) afirma que un carpintero, toma el ejemplo de J. A. Embil, con las ganancias de su trabajo podria alquilar una casa digna de un gran comerciante porteño.
} 


\section{Consideraciones finales}

En este capítulo se abordaron los aspectos vinculados a la delimitación de la región Río de La Plata y sus características económicas y demográficas en el periodo trabajado. La problematización que planteamos busca eliminar las fronteras nacionales en las problemáticas, logrando conformar una contrageografía que nos permita encontrar elementos que conecten determinados espacios sin encontrar en los estados fronteras para delimitar procesos que, tal vez, sean más amplios.

En este sentido, partimos de analizar la región dentro de un entramado mayor de regiones dentro de la Monarquía y en articulación con el análisis de lo global. Para definir las características de la región observamos no sólo sus particularidades internas, sino, también, con qué otros espacios y regiones se vinculó y cómo lo hizo. A partir de ello es que establecimos como medio para delimitar la región Río de la Plata la mercancía producida regionalmente para ser comercializada en el ultramar: el cuero.

Durante las últimas décadas del siglo XVIII, se incrementó la comercialización de cueros hacia el mercado ultramarino provocada por una serie de transformaciones en cuanto a los mecanismos de producción y el aumento del consumo producto del desarrollo de la industrialización. Esto, sumado a una serie de transformaciones internas como la expulsión de los jesuitas, generó una reconfiguración espacial, consolidando así una región. Esta región se articuló en torno a dos espacios, una hacia el norte y otra al sur, con algunas particularidades y complementariedades.

La zona norte, comprendida por la zona sur de las misiones jesuíticas, Santa Fe y entre Ríos, se caracterizó por concentrar gran parte de su producción al 
comercio del cuero, el cual bajaba por los ríos Paraná y Uruguay hacia los puertos de Buenos Aires y de Montevideo. En términos generales, en este espacio se produjo un crecimiento moderado o un mantenimiento de la población, siendo en algunos de los casos potenciados su desarrollo por el empuje de la monarquía basada en fundaciones de Villas y Poblados.

La zona sur, en cambio, se caracterizó por mantener una producción mixta y un incremento poblacional muy importante. El crecimiento económico provocó que fuera necesaria una mayor producción de carne y trigo tanto para consumo de la creciente población como para los navíos. Sumado a esto, también en este espacio se produjeron grandes cantidades de cuero. Por lo tanto, el crecimiento comercial atrajo un gran número de migrantes que favorecieron el aumento comercial, dando lugar, a su vez, a un incremento poblacional. Es decir, más comercio, más población y más comercio, repercutiendo en el crecimiento del mercado inmobiliario.

En suma, a partir de una serie de transformaciones en la economía global (la necesidad de mercancías como insumos para el proceso de industrialización), en el régimen monárquico (la expulsión de los Jesuitas, la creación de milicias, la fundación de Villas y Poblados, entre otros) y en lo regional, se dio una reconfiguración espacial en donde la región Río de la Plata se orientó hacia el mercado ultramarino. La mercancía que acusó de eslabón imprescindible fue el cuero vacuno, el cual permitió el desarrollo económico de la región. A partir de ello, se produjo entonces un círculo virtuoso de crecimiento comercial y demográfico constante. 


\section{CAPÍTULO II}

\section{La Monarquía española y el comercio global y en el siglo XVIII}

\section{Introducción}

Horst Pietchmann en un texto de 1985, planteó que los estudios sobre el comercio entre la península española ${ }^{13}$ e Hispanoamérica tienen un enfoque marcadamente bilateral, entre dos regiones o entre un puerto y su relación con la región principal hacia dónde iba dirigido su comercio. Esto se debe a que "el comercio en el Atlántico era una cosa absolutamente internacional o, si se quiere, resulta muy claro que hay varios circuitos comerciales que se entrecruzan de una forma sumamente complicada" (Horst Pietchmann, 1985: 248).

Según señala González tomando el concepto de Globalización Soft acuñado por Gerard De Vries (2010), a partir del "descubrimiento" de América se produjo un proceso de globalización e integración resultado de "intercambios de especies animales y vegetales, de flujos migratorios, voluntarios o no, y de enfermedades entre el Nuevo (América) y el Viejo Mundo (Eurasia y África)" (González, 2014: 4).

De esta forma, la Monarquía española consolidó un modelo de circuito comercial que articulaba los distintos espacios tanto interna y como externamente. Como hemos dicho anteriormente, nuestro objetivo consiste en estudiar el impacto del comercio ultramarino en la región Río de la Plata sin desatender las relaciones de esta región con los mercados externos. Por ello en este capítulo

\footnotetext{
${ }^{13}$ En este trabajo se denomina península española a la actual España sin Ceuta y Melilla. Se define de esta forma ya que denominarla España en el siglo XVIII constituiría un anacronismo.
} 
analizaremos el comercio ultramarino de la monarquía española con otros territorios.

Para ello, en una primera instancia abordaremos la circulación de navíos desde y hacia la península española a través del análisis de todos los puertos peninsulares para el año 1793. El año 1793 es tomado como media debido a que no tuvo guerra ni conflicto que variara los destinos. Se cuenta con más de tres mil registros para ese año. Esta selección tuvo como fin dar cuenta de una imagen congelada de los circuitos que mantuvieron cada puerto en un período sin conflicto bélico. Además daremos cuenta de las explicaciones existentes en la bibliografía sobre el papel del comercio con América para la industrialización, reseñando las distintas posturas. Esto lo consideramos importante ya que el proceso de industrialización de algunas zonas de la península justifica parte del incremento de la demanda de cueros.

Luego de ello, analizaremos la forma en que se desarrolló el mercado interno español durante el siglo XVIII a partir de las transformaciones institucionales. En el ámbito comercial ultramarino este proceso se centraba desde la vinculación con la península y con los dominios extra-europeos entre sí. En particular, veremos cómo en el Atlántico se produjo el paso del monopolio de cuatro puertos a la apertura de cuarenta.

Por último, abordaremos la circulación de navíos y mercancías salidas por el complejo portuario rioplatense. Analizaremos la cantidad de navíos y su procedencia, la articulación del complejo con otras regiones, los tipos de embarcaciones que ingresaron y su variación a la largo del siglo XVIII. Finalmente, estableceremos la proporción de cueros y de metales preciosos que partieron del complejo portuario durante la segunda mitad del siglo. 
En términos generales, se puede afirmar que a comienzos del siglo XVIII se dio inicio a la consolidación de un modelo económico global basado en la apertura de nuevos tráficos, de mayor volumen, siendo los productos más importantes a comercializar el tejido, el té, el café y el azúcar (Fontana y Delgado Ribas, 2000). Durante la segunda mitad del siglo XVIII se afianzaría la producción y comercialización de estas mercancías y otras utilizadas como insumos para la producción textil: por ejemplo, los cueros rioplatenses destinados a los telares, la grana cochinilla y el palo Campeche como tintura para las telas o el tasajo para la alimentación de los esclavos de las plantaciones de azúcar, entre otros. $^{14}$

La demanda externa produjo una transformación muy importante en cuanto al sistema comercial ultramarino. Como se verá más adelante, a nivel institucional se pasó de un sistema de gran concentración en tres puertos y grandes comerciantes vinculados a Cádiz, a la apertura (siempre dentro del monopolio) de 40 puertos, una masiva circulación de navíos y una participación de nuevos pequeños y medianos comerciantes, asentados tanto en la península ibérica como en Hispanoamérica (Stein y Stein, 2000; Lamikiz, 2007). Esta tendencia no correspondió a lo sucedido en el complejo portuario rioplatense ya que, como demostró Jumar $(2000,2001)$ desde 1720 gran parte de la población tuvo participación en el comercio ultramarino en forma directa. Posiblemente la llegada de registros sueltos durante gran parte del siglo XVIII y las Fragatas Correos a partir de 1767 produjo esta variación con respecto al resto de territorios.

\footnotetext{
${ }^{14}$ En el capítulo cinco se abordará el comercio de esclavizados ingresados por el complejo portuario rioplatense.
} 


\section{El mercado externo español}

El sistema comercial desarrollado durante el siglo XVIII, que se proyectaba del XVI, establecía que los puertos de la península española eran la conexión entre el mercado interno español con los mercados bajo control de otras unidades políticas. Las causas de ello eran, por ejemplo, la posibilidad de un mayor control fiscal, el favorecer a ciertas zonas por sobre otras y la cercanía con los mercados de intercambio.

Sin embargo, si bien este era el modelo establecido, varios aspectos escapaban al control institucional, por ejemplo, el comercio de esclavizados o el comercio de mercancías de amigos y/o neutrales a la Monarquía en tiempos de guerra. Sumado a esto, se encuentra el comercio directo:

Es cierto que en España y en América el contrabando era una acción ilegal y punible, y que por lo tanto sus actores trataban de dejar pocas huellas. Pero hay que tener en cuenta que en los puertos de origen, europeos y americanos (no pertenecientes al imperio español) esta actividad, la mayor parte de las veces era legal (Malamud, 1981: 31).

Zacarías Moutoukias (1988) sostiene, entre otros valiosos aportes, que la

práctica del contrabando de metales fue un aspecto central para la economía del Río de la Plata en el siglo XVII:

....sobre todo, gracias al comercio ilegal, la ruta Potosí- Buenos Aires ofrecía posibilidades lo suficientemente atractivas como para aceptar dichos transportes e incluso pagar a la Corona fuertes sumas en concepto de licencia e indulto. De modo que la Corona mantenía a los representantes locales de su poder estimulando y apoyándose en una corriente comercial que sus leyes, supuestamente, intentaban contener. Pero el contrabando no sólo financió el aparato burocrático- militar local, los protagonistas de aquél fueron los cuadros de éste, le dieron vida $\mathrm{y}$, hasta cierto punto, lo modelaron. (Moutoukias, 1988: 204, 205).

Para el período, 1778- 1810, Fernando Jumar sostiene que 
...posiblemente, el fraude podría no haber sido muy importante en los navíos de registro españoles del período 1716-1777: para ese tipo de negocios estaba enfrente la Colonia del Sacramento, que suponía una notable reducción de costos y riesgos. Y para el período 1778-1810 manejo como hipótesis, emergente del trabajo de investigación relacionado con la circulación legal de bienes desde Buenos Aires hacia los mercados regionales y algunas aún groseras estimaciones sobre consumo, que tras 1778 el fraude y el contrabando "puro" tuvieron un peso cuantitativo menor en el mercado que el que les suele atribuir la historiografía. (Jumar, 2012: 64).

Entonces, según lo planteado por Jumar, se puede sostener que durante el siglo XVIII el comercio directo bajó progresivamente su intensidad, producto de la dinámica económica.

Desde la perspectiva de los circuitos comerciales, podemos señalar que dentro de la Monarquía española los dos extremos comerciales que estaban institucionalmente regulados (Manila en el Pacífico y la península española en el Atlántico) se conectaron con mercados bajo control de otras organizaciones políticas (China y el resto de Europa). Además de estos dos grandes circuitos se desarrollaba el comercio con Brasil, el cual tuvo una especial vinculación con la región Río de la Plata (Jumar, 2002).

Una aproximación exploratoria a la circulación de navíos llegados a la península española la realizamos a partir del diario de Cádiz. Para ello, analizamos la circulación de navíos de todos los puertos de la península española para el año 1793, en donde se puede observar: puerto de salida y de llegada, tipo y nombre del navío, capitán, a quien iban consignadas y el tipo de mercancías transportadas.

En el gráfico II-1, se puede apreciar, que los puertos del Mediterráneo gozaron durante este período de mayor preponderancia, en especial el de Barcelona que concentró el 29 \% de los navíos llegados. En segundo lugar, se 
encuentra el de Cádiz, el cual, como se ha dicho anteriormente, fue el puerto de mayor conexión con América, siendo por ello fundamental dentro del comercio ultramarino. Por último, los puertos peninsulares españoles del Atlántico Norte.

\section{Gráfico II-1}

Total de Navíos llegados a los puertos peninsulares (1793).

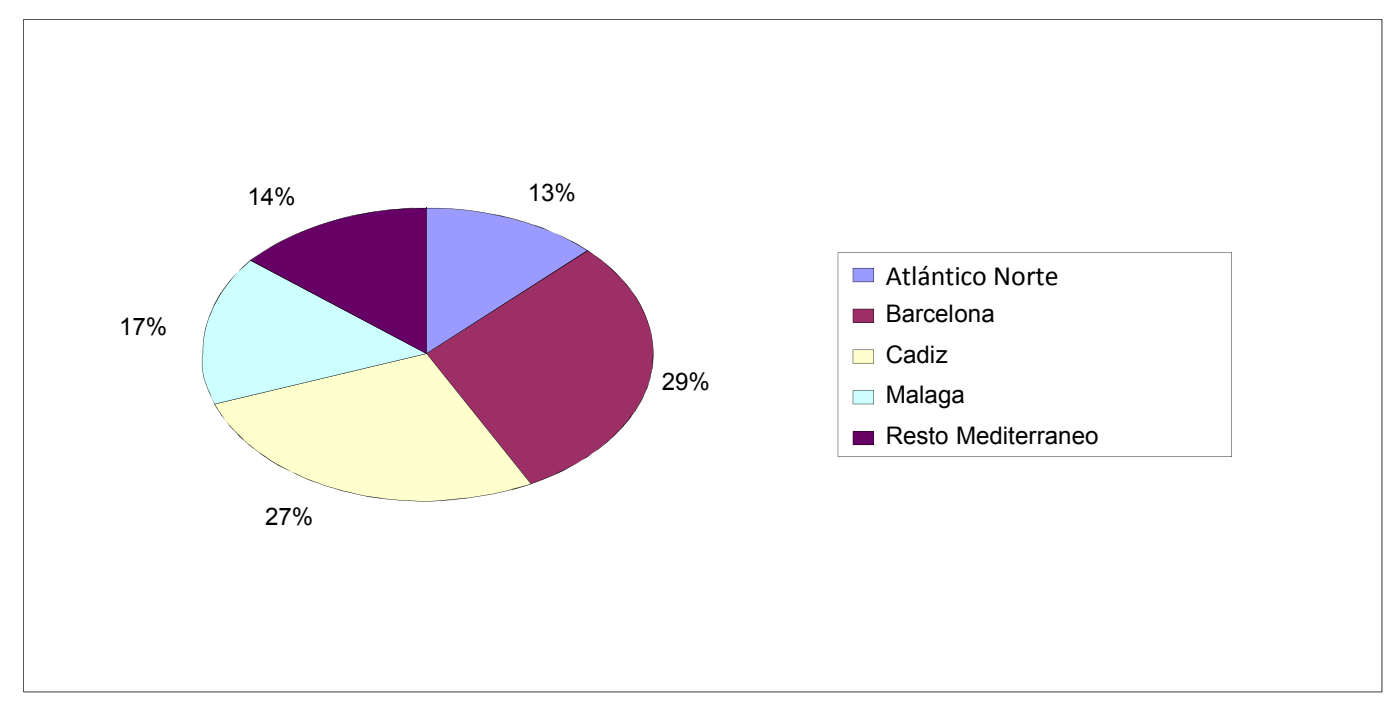

Fuente: Elaboración propia a partir del "El diario Mercantil de España y sus Indias" Año 1793. Biblioteca Nacional de España.

Con respecto al proceso de industrialización de la península en el siglo XVIII, la producción historiográfica es muy basta. El caso catalán ha sido el más estudiado ya que representó un modelo de industrialización, siendo el comercio ultramarino el sector en donde se focalizaron las investigaciones. El debate central giró en torno al papel de América en la industrialización catalana. Como afirmó Ricardo Franch Benavent (1988: 101), hay que tener en cuenta que la creciente orientación atlántica del tráfico no implicó la desvinculación del comercio mediterráneo, como ha puesto de manifiesto el análisis de las actividades de importantes casas comerciales. Este historiador establece que:

El tráfico se centra fundamentalmente en el Mediterráneo Occidental, destacando los contactos con Italia, Francia y España, y siendo muy escasos los vínculos con el Atlántico. Incluso los productos de origen colonial eran adquiridos en gran medida a través de las relaciones con Génova y Marsella, que actuaban como 
grandes centros redistribuidores tanto de las mercancías mediterráneas como de las de origen atlántico. También el comercio catalano-musulmán experimentó una considerable expansión durante el siglo XVIII (Benavent, 1988: 102).

Como se observa en el gráfico II- 2, existió un equilibrio en Barcelona entre la llegada de navíos procedentes de América y el Mediterráneo, siendo muy menor, en relación a estos dos, los provenientes de los puertos peninsulares españoles del Atlántico Norte.

\section{Gráfico II-2.}

Total de Navíos llegados al puerto de Barcelona para el año 1793.

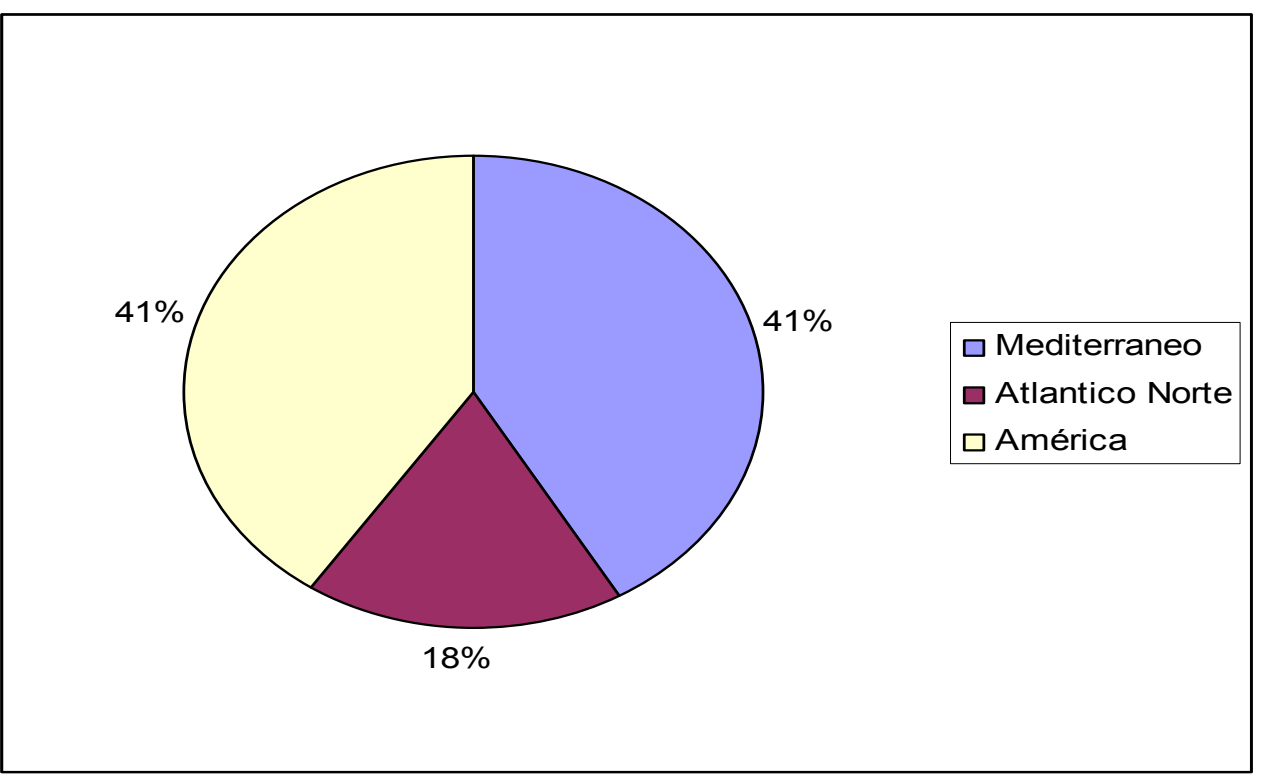

Fuente: Elaboración propia a partir de "El diario Mercantil de España y sus Indias" Año 1793. Biblioteca Nacional de España.

Otro objetivo de los trabajos que analizaron la circulación de navíos fue establecer el papel del comercio ultramarino en el desarrollo industrial de la península española. Así, el puerto de Cádiz fue estudiado en el siglo XVIII en el contexto de la industrialización española sin tomar en cuenta el potencial desarrollo de la vinculación con otras regiones. En el Gráfico II-3, se puede apreciar cómo Cádiz era un puerto de enlace entre distintas economías, la americana-española con las del norte de Europa y Estados Unidos. 
Gráfico II-3

Total de Navíos llegados al puerto de Cádiz para el año 1793

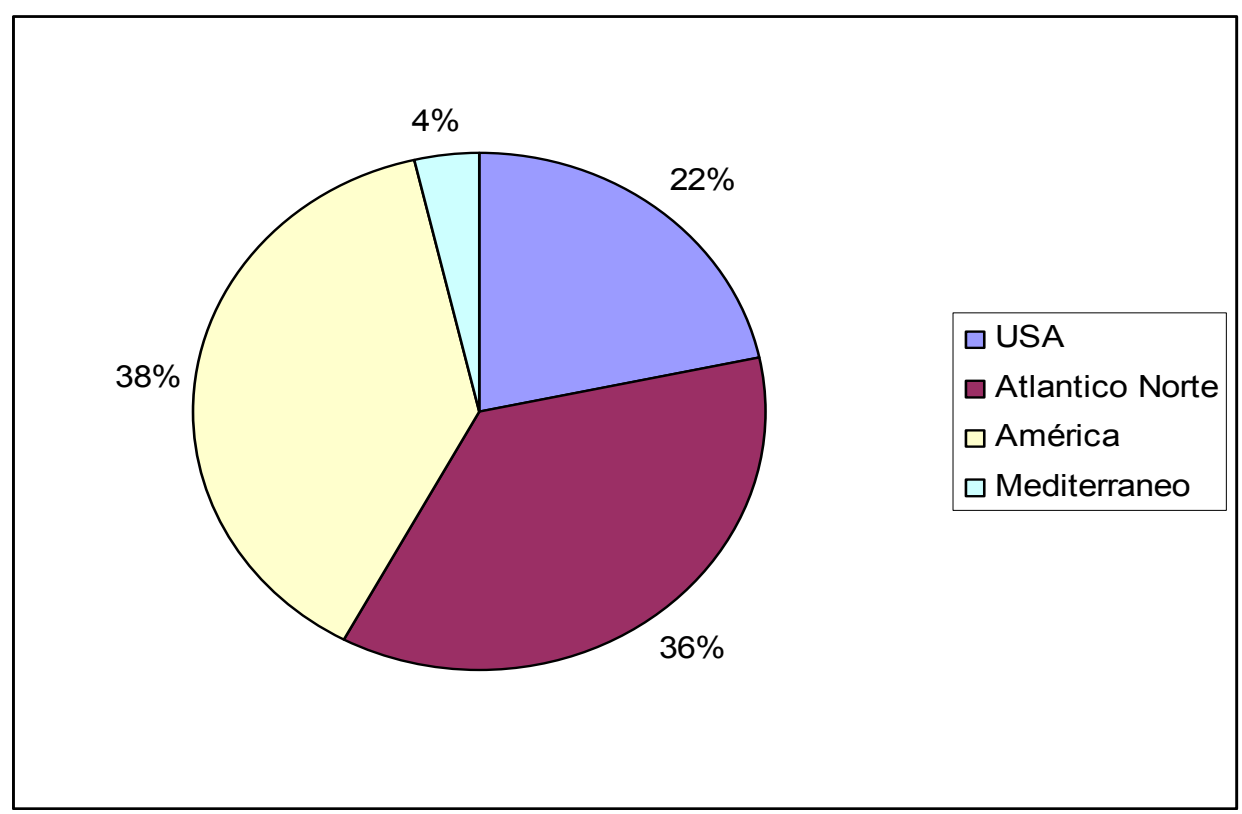

Fuente: Elaboración propia a partir de "El diario Mercantil de España y sus Indias" Año 1793. Biblioteca Nacional de España.

Como ya planteaba Vicens i Vives (1974 [1969]: 146), la industrialización se produjo mediante dos mecanismos: el oficial o de la Monarquía y el privado. En el primer caso no se llegó a generar elementos perdurables que permitan hablar de industrialización, sin embargo, en el segundo caso sí se produjeron, siendo Cataluña la única región en que perduró este proceso durante los siglos siguientes.

Hubo zonas que no participaron de la industrialización, como los casos de Extremadura (Llopis Agelán, 1996) o Castilla y León (Palacio Atard, 1960; Miguel López, 2000). Pero, igualmente, fueron beneficiadas por el proteccionismo económico en América, lo que les permitió vender sus limitados excedentes agropecuarios a precios mucho más altos. De todas formas, este beneficio no fue suficiente para lograr una industrialización que excediera el 
marco local o regional y que impidiera, tal vez, el perjuicio posterior generado por las reformas borbónicas. Finalmente, se produjo entonces el deterioro comercial de estas regiones, a partir de la pérdida comercial de la mayor parte de América, durante la segunda mitad del siglo XVIII, y el ingreso masivo en ese período de los productos catalanes (Palacio Atard, 1960, Llopis Agelán, 1996, Miguel López, 2000).

Un proceso similar se encontró en la región de Galicia (Alonso Álvarez 1984; 1999) donde si bien tuvo puerto habilitado para la producción de telas por parte del campesinado, esta actividad se desarrolló solamente en los hogares siendo complementaria a la producción agraria. Sin embargo, el aumento en el ingreso de telas extranjeras evitó un desarrollo mayor de su producción. Con respecto al excedente agrario, este mantuvo un proceso similar al de las zonas interiores de la península.

En lo que respecta a las zonas que tuvieron intentos de industrialización con algo más de suerte, las investigaciones se centran en analizar por qué no lograron un proceso como el catalán. En este grupo se sitúan el País Vasco, Andalucía y Valencia.

Las investigaciones sobre el País Vasco plantean las grandes ventajas que tuvo la región producto de la extracción del hierro, sumado, según Basurto Larrañaga (1983), al bacalao y la lana que, en menores cantidades, también generaban beneficios que podrían haber permitido una industrialización no efectuada por diversas causas. Por ejemplo, para Azcona Guerra (1996), los conflictos con Inglaterra desestabilizaron el comercio y la falta de infraestructura y las barreras aduaneras no permitieron tal proceso. Fernández Albadalejo (1975) establece que los comerciantes vascos realizaban, fundamentalmente, 
contrabando que era más beneficioso y que, por ello, no hubo inversiones para mejorar la infraestructura y, consecuentemente, para la industrialización. Fue el aumento arancelario, la respuesta gubernamental al contrabando.

Por otro lado, un espacio históricamente favorecido a nivel institucional por la Monarquía fue la costa andaluza, ya que mantuvo el monopolio del puerto único hasta mediados del siglo XVIII, siendo la liberación de varios puertos la causa probable de la caída de los beneficios y del estancamiento de la región. Sumado a esto, García-Baquero González $(1972 ; 1974)$ plantea que las mercancías manufacturadas eran extranjeras en su mayor parte (sólo se realizaban leves modificaciones en ellas para que pasen a ser de producción española). También señala que la mayoría de los bienes exportados producidos en la región eran agropecuarios y que tras la liberalización de los puertos se perjudicaron notablemente.

La zona que, en principio, tuvo un desarrollo similar al catalán fue la valenciana, en donde "la industria de la seda, sin lugar a dudas, [era] la más importante [...] durante el siglo XVIII, tanto por el volumen de su producto, como el número de fábricas y de obreros empleados" (Ardite Lucas, 1977: 28). Joan Fuster (1962), a su vez, determina que en el siglo XVIII las condiciones dadas por la exportación de seda a América permitieron algunos pasos en la industrialización. Por otra parte, Ernest Lluch (2003), determina que es motivo de controversia entre los investigadores las causas por las cuales no prosperó a lo largo del tiempo la industrialización en el Valencia, teniendo en cuenta que, $a$ priori, las similitudes con Cataluña son notables. Sin embargo, a principios del siglo XIX, se truncó producto de la imposibilidad de desarrollar la industria pesada (por la falta de materia prima y de fuentes de energía) y debido a que la 
industria liviana no se desarrolló por las características de su burguesía, que, finalmente, con la caída de la producción de la seda, realizó un giro hacia el campo que floreció con el impulso de la producción de naranjas (Giralt, 1970).

Giralt (1970) planteó que el siglo XVIII fue positivo, a pesar de que la industrialización no se produjo debido a causas externas (enfermedad de la seda y un sistema financiero perjudicial) e internas (una aristocracia ausentista que vivía en Madrid, que controlaba el estado regional y que comenzó a invertir en el campo produciendo el "boom" de la naranja"). Finalmente, Vicent Ribes (1985: 11) asevera que "la falta de solidaridad clasista existente entre los burgueses valencianos" es lo que interrumpió el proceso de industrialización. Esto se debe a que, en vez de unirse, las burguesías de las dos principales ciudades, Valencia y Alicante, se dificultaban mutuamente el desarrollo, impidiendo un proceso similar al catalán.

Retomando el proceso catalán, el debate de las últimas décadas se concentró en evaluar la incidencia, en el proceso de industrialización, de la apertura comercial de 1778 del puerto de Barcelona hacia América. La aclaración del mismo, echaría luz a su vez en la incidencia de la Corona en dicho proceso “modernizador". Es por ello que se intensificaron las investigaciones desde 1970 surgiendo dos posicionamientos contrapuestos, aquellos que plantean que sí tuvo incidencia y aquellos proponen que la tuvo de modo directo.

Durante el período anterior a la reglamentación de libre comercio, Pierre Vilar (1988) plantea que a partir de la década del treinta del siglo XVIII los herederos de los mercaderes barceloneses descubren la inversión industrial moderna (con el hilado de algodón) pero sin dejar la extracción señorial pura. Asimismo afirma que lo que causó el arranque de una industria y una sociedad 
nueva "fueron los núcleos de negocios internacionales desarrollados por la producción de un excedente exportable de vino y aguardiente desde 1760 hasta 1805, siendo los mercados coloniales los que más beneficien" (Pierre Vilar, 1988: 449). Estas afirmaciones son la base de estudios posteriores en torno al origen y características de la temprana industrialización catalana ampliada por un grupo de notables historiadores.

A su vez, Carlos Martínez Shaw (1975: 4) determina que "los catalanes parecen haber intervenido, con mayor o menor intensidad en la carrera de Indias desde la apertura misma del mercado americano, a pesar de la vigencia del monopolio de la ciudad de Sevilla" ya que se realizaban escalas portuarias en Sevilla, Lisboa, y Cádiz y por medio de "la Reial Companyia de Comerç de Barcelona a Índies.” Desde un comienzo, entonces, la flota mercante catalana fue de vital importancia para el desarrollo del comercio Atlántico.

Se ha afirmado, desde la década de 1970, que la aplicación del libre comercio permitió un desarrollo más rápido de la industria textil tanto del algodón como de la seda (García-Baquero González, 1975: 268- 294; Fisher, 1992).

Las investigaciones realizadas por Josep Delgado Ribas (1983), en cambio, lo llevan a plantear que el libre comercio se convirtió en una herramienta gubernamental para amparar la industria tradicional (que se caracteriza por ser corporativista y dispersa) frente al avance de la manufactura moderna centrada en la industria algodonera que era incompatible con el orden social del feudalismo tardío. 
Mapa II-1

Circuito del Galeón de Manila.

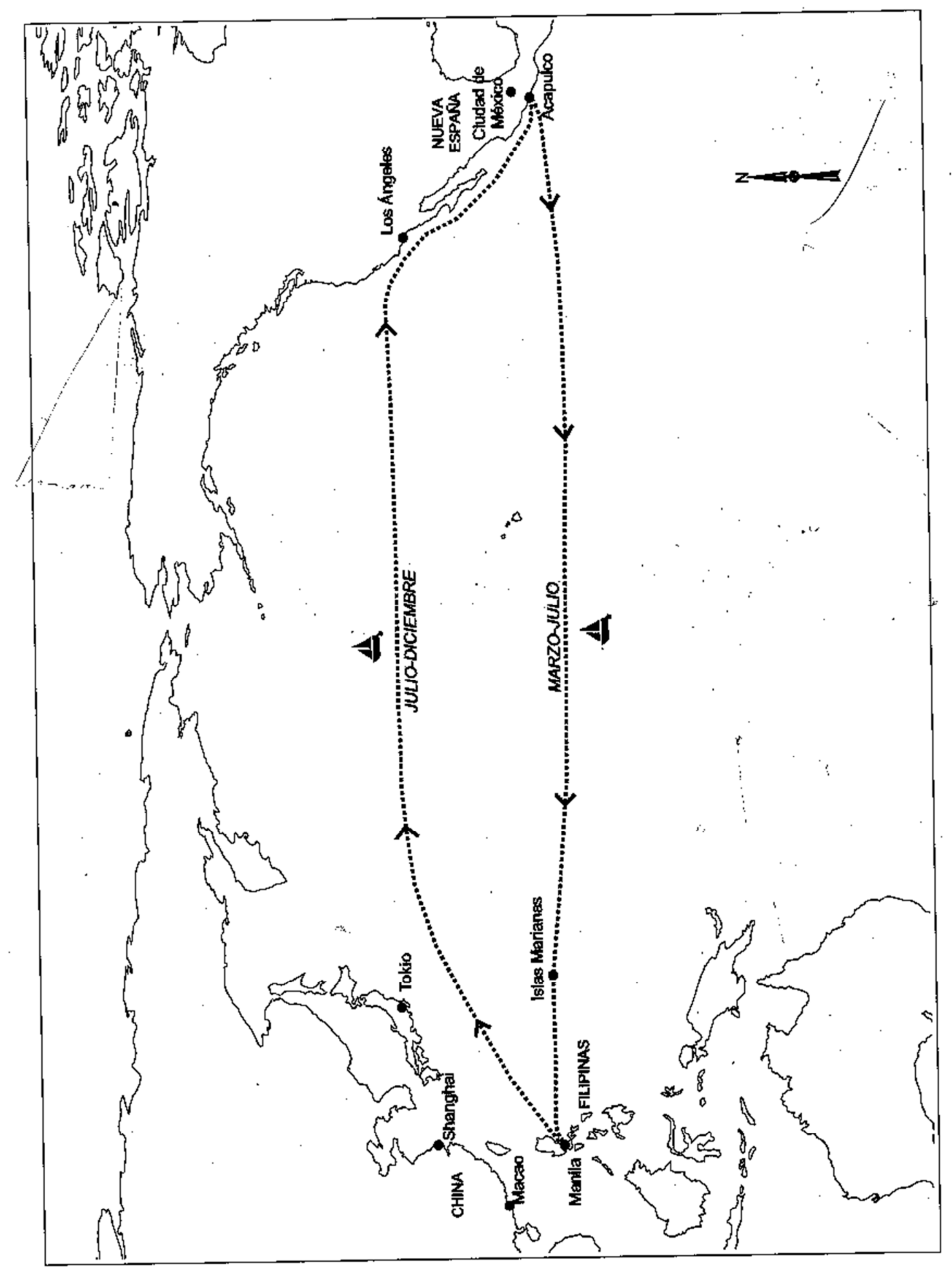

Fuente: Bonialian (2012).

Martínez Shaw (1987) plantea que si bien existió por parte de la Corona el apoyo a la industria tradicional, esto no bastó para impedir que se produjera un 
desarrollo de la manufactura moderna, que fue mucho menos optimista de lo que se pensaba, pero aun así muy importante. En respuesta Delgado Ribas (1987) introdujo investigaciones sobre una treintena de fabricantes en las que, además de reafirmar las conclusiones de investigaciones previas, abre una serie de interrogantes en torno a los estímulos de la producción algodonera catalana bastante lejanos a los vaivenes comerciales con América.

El circuito del Pacífico si bien no tuvo la atención historiográfica del comercio en el Atlántico fue gravitante durante el siglo XVIII (Alfonso Mola y Martínez Shaw, 2000; Delgado Barrado, 1997; Bonialian, 2012, entre otros). La conexión entre Filipinas y Acapulco era el nexo entre tres grandes espacios: China, América y Europa. Durante la segunda mitad del siglo XVI, este sistema se articuló en torno al Galeón de Manila el cual no tuvo restricciones en cuanto a la posibilidad de comerciar las mercancías y podía establecer nuevas rutas con la América española. 
Mapa II-2

La conexión de Manila con América

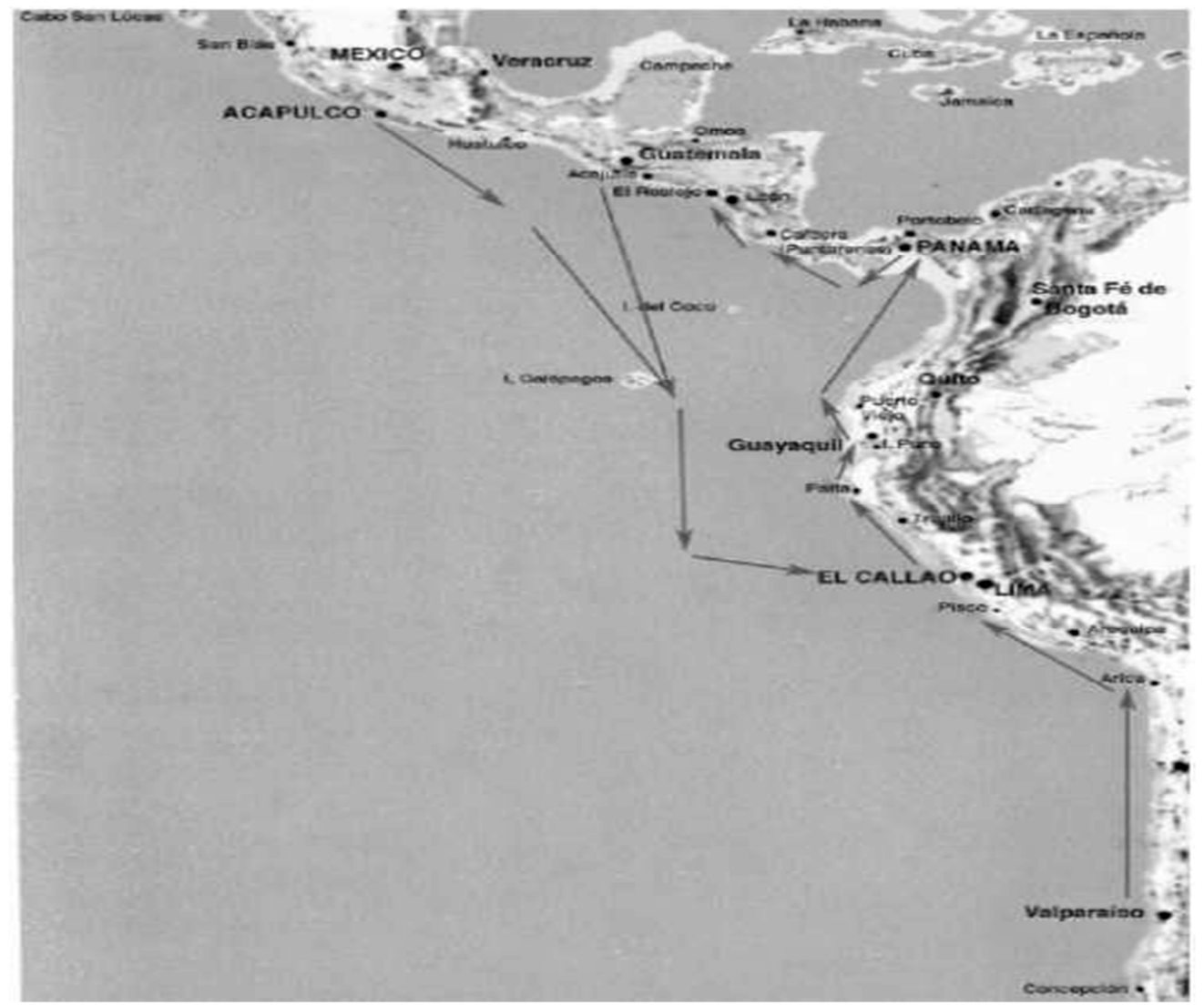

Fuente: Extraído de http://www.afehc-historiacentroamericana.org/?action=fi_aff\&id=2529 [última fecha de consulta: 8 de abril de 2015].

A partir de enero de 1593 se reguló este circuito permitiendo el comercio sólo con el puerto de Acapulco, con una periodicidad de dos viajes anuales, y cada Galeón no debía sobrepasar las trescientas toneladas. Además no se permitía el control del comercio por parte de los americanos, ya que en la conexión ManilaAcapulco debían ser filipinos y en la de China- Manila, chinos.

En 1680 comenzaron a transformarse las regulaciones institucionales a la luz del gran comercio directo que se desarrollaba. Lentamente, se fueron eliminando las trabas legales y, para la segunda década del siglo XVIII, el sistema 
de regulaciones institucionales comenzó a dar señales de apertura del tráfico de sedas asiáticas. Como plantea Mariano Bonialian:

Al menos desde la segunda mitad del siglo XVII y durante gran parte de la centuria siguiente el Pacífico se convirtió en un lago indiano, universo mercantil que resultó ser plenamente americano. La noción intenta rescatar la propia especificidad del área, reevaluando la capacidad que presentaron los agentes económicos para generar sus propias redes y estrategias mercantiles. En otros términos, la categoría de lago indiano se amolda muy bien al Pacífico por una razón fundamental: todos los circuitos mercantiles de corta, media y larga distancia, en particular los que llegaron a enlazar a la América española con Filipinas y el Oriente, fueron impulsados por los más reconocidos mercaderes, capitanes y autoridades de la ciudad de México y del Perú. (Bonialian, 2012: 20).

Cuadro II-1

Máximo de comercio estipulado para la Ruta del Pacífico (1593-1815) (en pesos de 8 reales)

\begin{tabular}{|l|l|l|}
\hline Periodo & $\begin{array}{l}\text { De Manila a } \\
\text { Acapulco }\end{array}$ & $\begin{array}{l}\text { De Acapulco a } \\
\text { Manila }\end{array}$ \\
\hline $1593-1701$ & 250.000 & 500.000 \\
\hline $1702-1733$ & 300.000 & 600.000 \\
\hline $1734-1769$ & 500.000 & 1.000 .000 \\
\hline $1769-1815$ & 750.000 & 1.500 .000 \\
\hline
\end{tabular}

Fuente: Bonialian, (2012: 66).

Como afirmó Rafael González (2014) hasta 1591 el puerto de Manila comercializaba en forma directa con los puertos de El Callao, Realejo y Huatulco. El circuito que se estableció a partir de allí fue la conexión Manila- Acapulco- El Callao. La plata novohispana y peruana llegó así en forma regular a China durante los siglos XVI, XVII y XVIII (Marichal, 2006).

En 1785 se conformó la Real Compañía de Filipinas que se sumó a las ya conformadas: Real Compañía Guipuzcoana de Caracas, de La Habana, Barcelona, Honduras, Galicia, entre otras. Como señala Delgado Barrado (1998: 104), estas 
compañías "fueron elementos políticos, económicos, defensivos y culturales, en manos del Estado y de una minoría comerciante. En España intentaron establecerse a imitaciones de las grandes compañías holandesas, inglesas y francesas, aunque con diversos resultados”. Fue a partir de la Real Compañía que se produjo el monopolio del comercio del Pacífico por parte de la Monarquía española.

\section{El mercado interno español}

El comercio ultramarino desarrollado por la Monarquía en el Atlántico durante los siglos XVI y XVII mantenía una estructura simple, dividida en relación al mercado interno (se entiende por tal el que vinculaba a todos los espacios de la Monarquía española) y externo (el comercio desarrollado por la Monarquía española con otras potencias Internamente la conexión era entre un puerto de salida y tres de llegada y externamente el comercio se encontraba ubicado en la península ${ }^{15}$. A partir de allí, los ajustes se desarrollaron para la apertura de nuevas rutas y casos particulares a partir de: permisos para navíos de registros, permisos para la trata de esclavos, reales compañías, asientos, entre otros. Un ejemplo de ello es el Rioplatense, como plantea Jumar:

"Una vieja imagen que es difícil de desterrar es que la Corona española se empecinó en mantener la región rioplatense cerrada al comercio ultramarino debido al llamado sistema de flotas y galeones. Sin embargo, cuando se puso en pie el tan mentado sistema, entre 1561 y 1566 , Buenos Aires no existía y desde que existió el poder real rápidamente entendió que, si deseaba que la segunda fundación de la ciudad tuviera mejor suerte que la primera, debería permitir que se abasteciera de otro modo y también comprendió que por el comercio practicado allí podría obtener

\footnotetext{
${ }^{15}$ Somos consciente que con en distintos momentos históricos los territorios que compusieron la Monarquía española y las demás formaciones políticas. Además, tenía una serie de particularidades: tuvieron distintas legislaciones, con diversas moneadas y sistemas de unidades de medida. Estas particularidades hacían, a veces tan dificultoso el comercio interno como el externo.
} 
recursos por la vía fiscal. Así, primero se concedieron unas licencias de comercio con las costas del Brasil, entre 1588 y 1618 , y desde 1622 se abrió lo que en algunas fuentes aparece como la Carrera de Buenos Aires, es decir, una ruta de comercio legal y directo entre Andalucía y el río de la Plata, independiente del sistema de convoyes, aunque igualmente guiada por la idea de control monopólico de la circulación, y que estuvo activa de allí en más, con la regular irregularidad del conjunto de la Carrera de Indias".(Jumar 2011: 132).

El sistema de comercio y navegación que se estableció, durante el siglo XVI, fue el de "Flotas y Galeones" el cual consistía en el arribo regular a algunos puertos americanos habilitados (Portobelo, Veracruz y La Habana) de una flota de navíos mercantes junto a galeones de guerra destinados a proteger las mercancías y la plata ${ }^{16}$. Además desde el siglo XVI se utilizaban los llamados registros sueltos, que consistían en permisos particulares que se otorgaba a ciertos navíos para llegar al complejo portuario rioplatense. El Río de la Plata siempre escapó a los convoyes: entre 1588 y 1618 a través de licencias de comercio con las costas del Brasil y desde 1622 con la ruta directa Buenos Aires-Sevilla (Jumar, 2002).

La llegada y salida de mercancías por medios terrestres a Buenos Aires, no fueron las únicas ya que se encontraron las llamadas "arribadas forzosas", los navíos de registro y los asientos. Las arribadas forzosas fueron una práctica habitual, en la cual el Capitán del navío daba aviso a las autoridades del puerto más cercano de la necesidad de desviar el rumbo establecido y de atracar en sus costas. Una vez que autorizaba el acercamiento al puerto, se pedía comerciar ciertas mercancías y una vez solucionado el desperfecto se continuaba con el camino ya establecido.

\footnotetext{
${ }^{16}$ El circuito a realizar por el sistema de flotas y galeones en el marco de la Carrera de Indias estuvo totalmente ligado al monopolio que Castilla ejercía sobre sus tierras de Ultramar. Un monopolio que se asienta sobre dos pilares: a) El derecho a comerciar y residir en las Indias quedaría establecido como derecho privativo de los castellanos; b) Toda la navegación y el comercio con las Indias Occidentales se canalizará desde la metrópoli a través de un solo puerto, Sevilla y luego desde Cádiz. Para una mayor profundización de este proceso véase entre otros: García Fuentes (1980); García-Baquero González (1976, 1992); Haring (1979); Lorenzo Sanz (1980); Veitia Linaje (1982).
} 
Con respecto al comercio de esclavos (siempre en manos de las potencias extranjeras y, por ello, la única vinculación legal de América con estas), durante la primera mitad del siglo XVIII se desarrollaron los asientos del comercio de esclavos de Francia (La compañía francesa de Guinea) e Inglaterra (la South Sea Company) en Hispanoamérica.

\section{Mapa II-3}

Flotas y galeones. Mercado interno siglo XVII hasta mediados del XVIII.

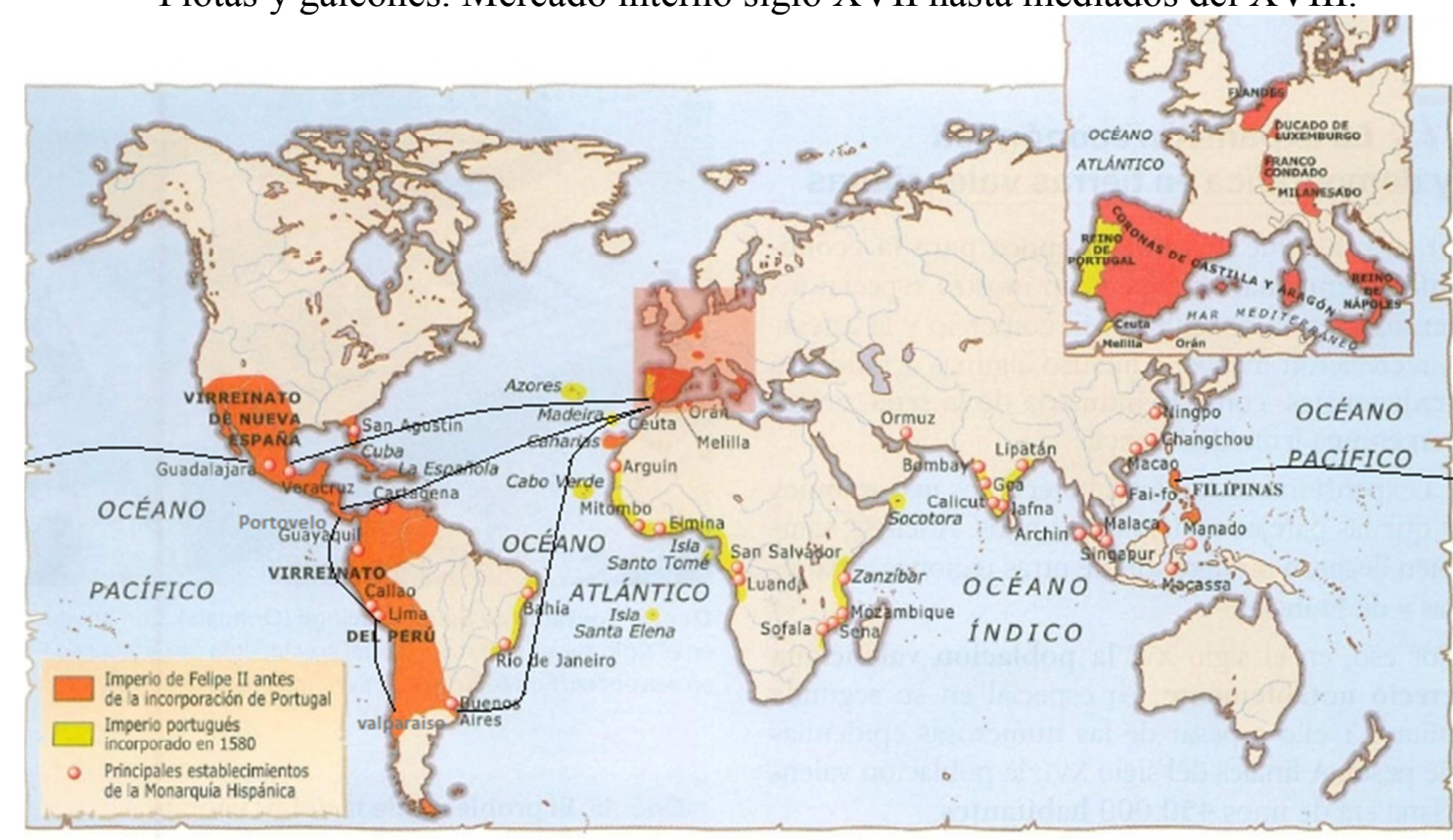

Fuente: elaboración propia a partir de http://angelluisgonzalez.blogspot.com.ar/2013_10_01_archive.html [última fecha de consulta: 8 de abril de 2015]

El sistema de flotas y galeones tuvo como objetivo el establecer rutas con una gran previsibilidad, siendo resguardado militarmente. Fue pensado para pequeños enclaves urbanos con cierta autarquía y para consolidar un comercio que estuviera en pocas manos y en donde se trasladaran grandes cantidades de mercancías. En este modelo se dejaba librado al azar el comercio de esclavos y las zonas que se encontraban alejadas de los puertos de llegadas. La forma de solventarlo ya para el siglo XVIII, como en el caso del Complejo Portuario 
Rioplatense, fue a partir de los registros sueltos y de los acuerdos para el abastecimiento de esclavos.

La historiografía lo ha analizado, en términos generales, como un modelo comercial restrictivo ya que no permitía la circulación marítima hacia otras zonas americanas. Ahora bien, si pensamos en que los centros más importantes se encontraban "cubiertos" por la llegada de la flota protegida por varios navíos de guerra, que en el resto del territorio la población era exigua y que el sistema era de fácil ejecución y control, cabe preguntar hasta qué punto constituyó un modelo negativo para el desarrollo durante los siglos XVI y XVII.

No obstante, con el proceso de industrialización europeo y el crecimiento poblacional urbano del siglo XVIII, la necesidad de insumos para el uso industrial y de más mercados para abastecer de manufacturas y los cambios en el consumo urbano, impulsarían la modificación de este modelo comercial.

A partir de la Guerra con Inglaterra de 1739, se comenzaron a producir, lentamente, algunos cambios en la forma de defensa de los territorios al calor de los constantes conflictos. Este proceso entró en una aceleración a partir de la Guerra de los Siete Años de la década siguiente e ingresó en una etapa de irreversibilidad con la toma de La Habana en 1762. 


\section{Mapa II-4}

Principales rutas comerciales de mediados del XVIII

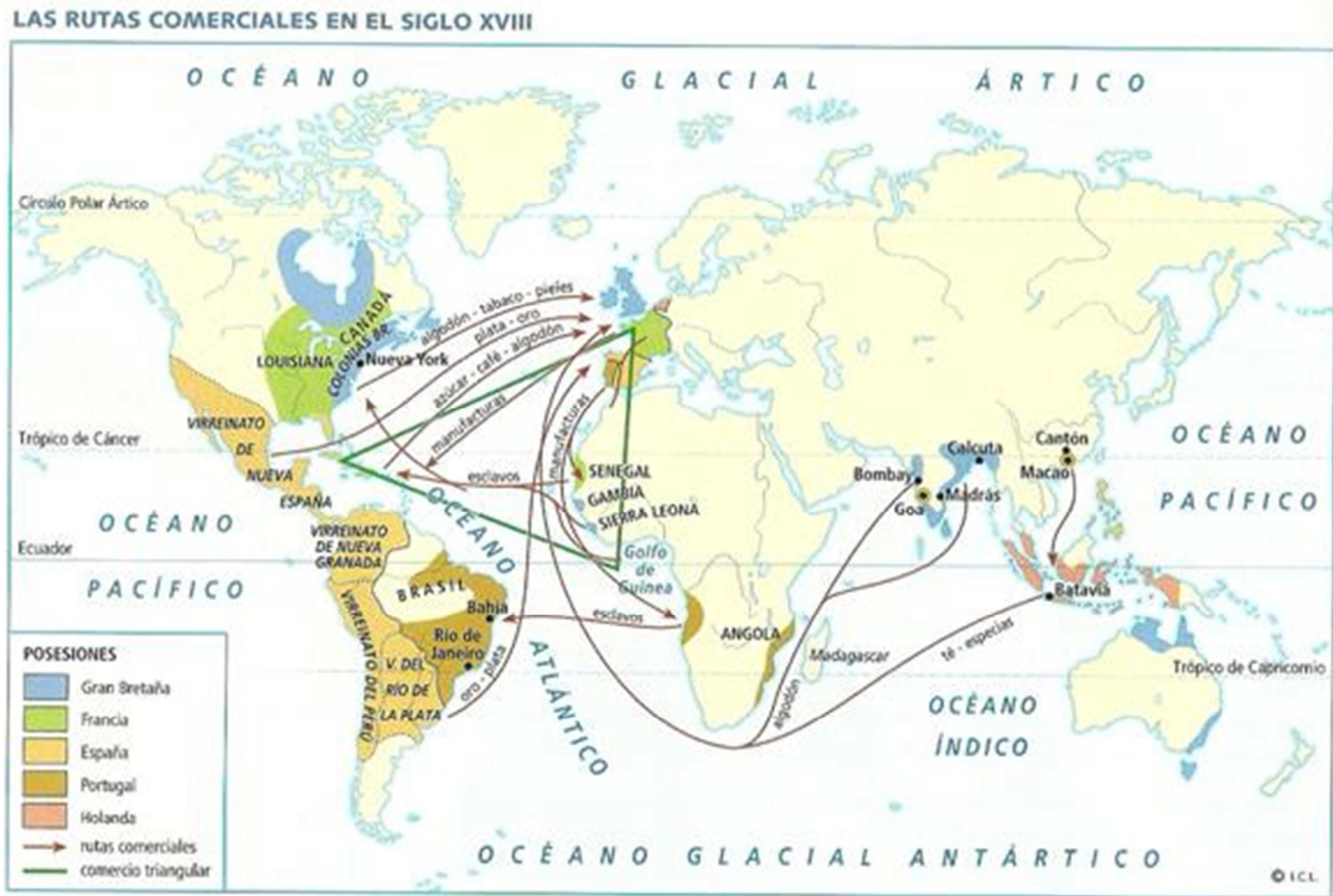

Fuente:http://esodelahistoriacontemporanea.wikispaces.com/EL+SIGLO+DE+L AS+LUCES.+LA+CRISIS+DEL+ANTIGUO+REGIMEN+EN+EL+SIGLO+XV III. [Última fecha de consulta: 8 de abril de 2015].

En este contexto, asimismo, desde la década de 1760 se produjo un primer proceso de transformaciones institucionales ${ }^{17}$. En 1764 se creó un servicio regular de Correos Marítimos, "cada mes debía salir un navío de "aviso" hacia la América septentrional, y cada dos meses otro para la meridional. Tres años más tarde, el servicio se hacía extensivo a Buenos Aires con frecuencia de cuatro navíos anuales" (Villalobos, 1965: 48). En forma simultánea, en 1765, se decretó el comercio libre entre Cuba, Santo Domingo, Puerto Rico, Isla Margarita y Trinidad, y entre estos y los de Cádiz, Sevilla, Alicante, Cartagena, Málaga,

\footnotetext{
${ }^{17} \mathrm{Si}$ bien anteriormente se produjeron transformaciones, las reformas borbónicas se dieron a partir de la llegada de los Borbones al trono español a principios del siglo XVIII. Sin embargo, entendemos que las reformas no significaron un cambio sustancial en la dinámica económica y, de producir alguna transformación, fue esporádica y no prosperaron a lo largo del tiempo en particular para la región Río de la Plata.
} 
Barcelona, Santander, La Coruña y Gijón. Además, en 1774 y en 1776 se promulgaron Reales Ordenes que permitieron el comercio entre las distintas regiones de América. ${ }^{18}$

El 12 de octubre de 1778 se sancionó el documento denominado "Reglamento y Aranceles Reales para el Comercio Libre de España e Indias" que establecía la apertura de diversos puertos americanos y españoles para comerciar con un registro de salida y un puerto o varios de llegada. Los puertos de América habilitados fueron San Juan de Puerto Rico, Santo Domingo, y de Monte-Chisti en la Isla Española; Santiago de Cuba, y la Habana en la Isla de Cuba; las dos de Margarita y Trinidad; Campeche en la provincia de Yucatán; el Golfo de Santo Tomás de Castilla, y el Puerto de Omoa en el Reino de Guatemala; Cartagena, Santa Marta, Río de el hacha, Portobelo, y Chagre en el destino de Santa Fe, y Tierra Firme; Montevideo, y Buenos Aires en el Río de la Plata; Valparaíso, y la Concepción en el Reino de Chile; y los Arica, Callao, y Guayaquil en el Reino del Perú y Costas de la Mar del Sur. ${ }^{19}$

También fueron habilitados puertos de la Península española que hasta entonces no habían podido participar de forma directa en el comercio ultramarino o, en el mejor de los casos, lo habían hecho de forma escueta y limitada. Los puertos habilitados fueron los de Sevilla, Cádiz, Málaga, Almería, Cartagena, Alicante, Alfaques de Tortosa, Barcelona, Santander, Gijón, y Coruña; y los de Palma, y Santa Cruz de Tenerife en las Islas de Mallorca y Canarias. ${ }^{20}$

\footnotetext{
${ }^{18}$ La ocupación británica de La Habana entre 1762 y 1763 fue uno de los factores que determinó los cambios institucionales que se desarrollaron. Esto se debe a que, a partir del ingreso de mercancías a menor precio, el retorno al sistema del monopolio de Cádiz resultó inviable (García Del Pino, 2002; Marrero, 1978).

${ }^{19}$ Reglamento y Aranceles Reales para el Comercio Libre de España e Indias de 12 de Octubre de 1778. Madrid. Imprenta de Pedro Marin. 1778. pp. 5 y 6.

${ }^{20}$ Reglamento y Aranceles Reales para el Comercio Libre de España e Indias de 12 de Octubre de 1778. Madrid. Imprenta de Pedro Marin. 1778, p.7.
} 
En el Reglamento se establece, además, como plantearon Pierre Vilar (1962) y Hernán Asdrúbal Silva (1993) a partir de varios cuadernos de bitácora, que los navíos pueden descender y ascender mercancías en varios de los puertos habilitados pudiendo, a su vez, variar los destinos. Los autores antes mencionados, dieron muestras de los circuitos comerciales ultramarinos donde los navíos cargaban y descargaban en varios puertos de la península española y también en diversos puertos americanos. Por ello, se trataba de un circuito muy dinámico que permitía la llegada al complejo portuario rioplatense no sólo de mercaderías provenientes de Europa sino también de bienes de otras latitudes de América, fundamentalmente, cacao y azúcar ${ }^{21}$.

Las reformas institucionales que se desarrollaron en las últimas décadas del siglo XVIII aceleraron el crecimiento, a partir de que se permitió el desarrollo de nuevas rutas y mercancías favorecidas por una baja fiscalidad. Un ejemplo de ello son las transformaciones en el comercio de esclavizados.

El comercio de esclavos durante el siglo XVIII se desarrolló bajo control de extranjeros $\mathrm{y}$, en las últimas décadas, también de hispanoamericanos. A comienzos del siglo, la Corona institucionalizó el asiento del comercio de esclavos de Francia (La compañía francesa de Guinea) e Inglaterra (la South Sea Company) en el territorio americano. Por otro lado, se desenvolvió el comercio directo en manos de los portugueses quienes, a partir de los puertos de Río de Janeiro y de Porto Alegre, introdujeron, en todo el territorio, esclavizados provenientes de África.

Recién en las últimas décadas los iberoamericanos intentaron tomar el control de este comercio. Con dificultades para su realización, en la década de

${ }^{21}$ La circulación de metales provenientes de América fue la principal mercancía, en términos de valor, que llegaban a la península española. No se analiza en profundidad ya que requeriría un desarrollo minucioso que excede los objetivos de esta tesis. 
1770, la Corona permitió a la Compañía Gaditana de Negros y a la Real Compañía de Filipinas comprar en África esclavizados, transportarlos a Hispanoamérica y comercializarlos. ${ }^{22}$ Arturo Bentancur (1997) planteó que, dada la falta de experiencia, estas compañías sólo se ofrecieran de intermediarios entre los consumidores y los comerciantes extranjeros. En la Real Cedula del 24 de noviembre de 1791 se decretó la libre introducción de esclavos permitiendo, por lo tanto, que cualquier español y extranjero pudiera comercializar. A partir de esta Reglamentación, se dio permiso entonces a los hispanoamericanos para que, a través de la renta de navíos o por medio de los suyos propios, pudieran comercializar esclavizados en África y Brasil.

A partir de lo que hemos visto podemos señalar que la intención de la Monarquía al realizar modificaciones en el comercio, si bien pudo haber existido algún interés fiscal, era salvaguardar los territorios americanos a partir de la consolidación de importantes núcleos de población (especialmente en las zonas portuarias) y defender el territorio ante una potencial invasión. Por ese motivo, se crearon, desde la década de 1760, cuerpos de voluntarios en América. (Kuethe, $1986 ; 1991)$

En este proceso, el papel de las mercancías americanas tuvo un rol central ya que permitieron el crecimiento poblacional señalado, dando lugar a la formación de enclaves comerciales. Un ejemplo de ello es el del azúcar en la isla de Cuba, en donde se pasó de 60 ingenios a fines del siglo XVII a 600 un siglo después.

\footnotetext{
${ }^{22}$ Si bien ya desde mediados de siglo se dieron licencias, como desarrollaremos en el capítulo 5, no tuvieron efecto para la región el Río de la Plata.
} 


\section{Gráfico II-4}

Azúcar comercializada de la Isla de Cuba 1760- 1819

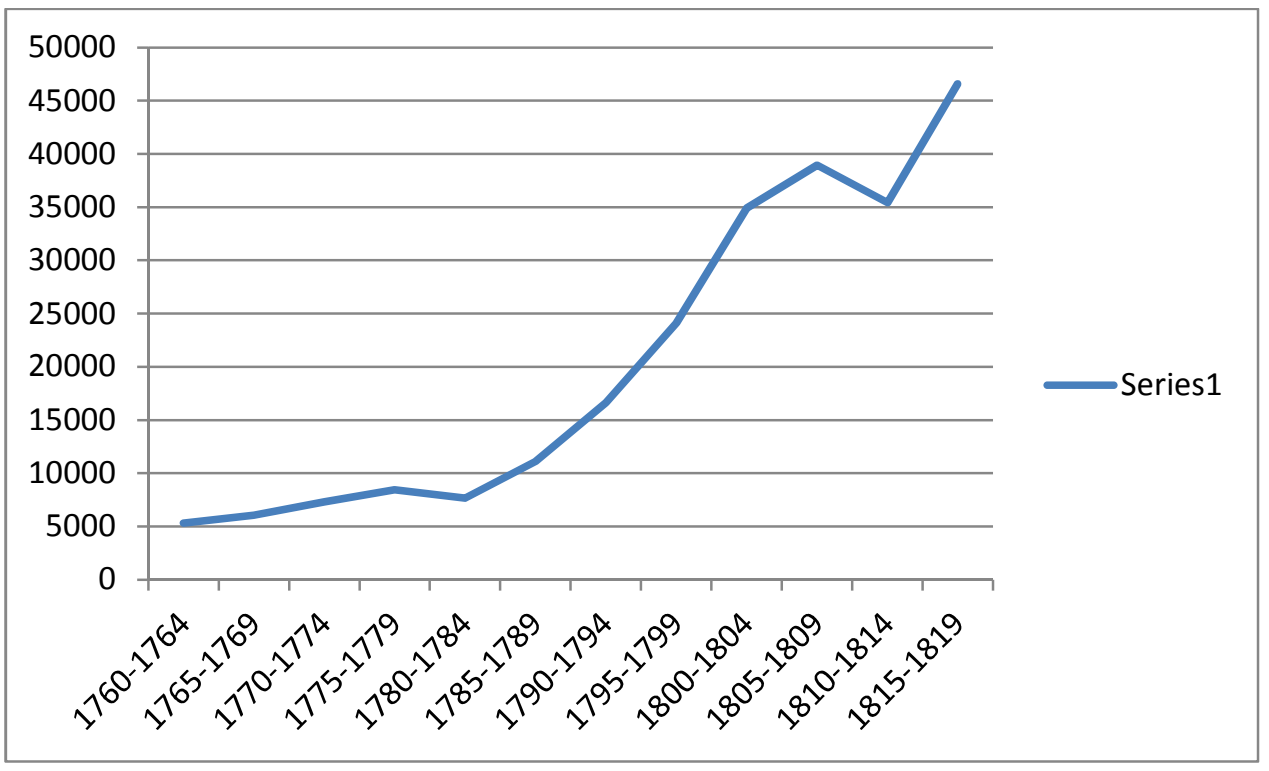

Fuente: Elaboración propia a partir de los datos de Santamaría García (2005).

Este crecimiento de las producciones regionales no sólo tuvo como consecuencia una reestructuración espacial de la población que se afincó especialmente en las zonas portuarias, sino que también posibilitó que se implementara el impuesto municipal de guerra, posibilitando así la creación de las milicias que permitieron la autodefensa regional, para los cuales se ampliaron los fueros militares (Kuethe, 1986; 1991).

Las mercancías americanas, en general y centrando la mirada en el circuito legal español, tuvieron un circuito marcado por el paso previo de las mismas por la península española para luego ser destinadas al comercio global. Por ejemplo, el azúcar pasaba de la producción a la comercialización en la Isla de Cuba, luego a la península y de allí se recomercializaba a otras regiones europeas. 


\section{Gráfico II-5}

Total de Navíos llegados a la península de América (1793)

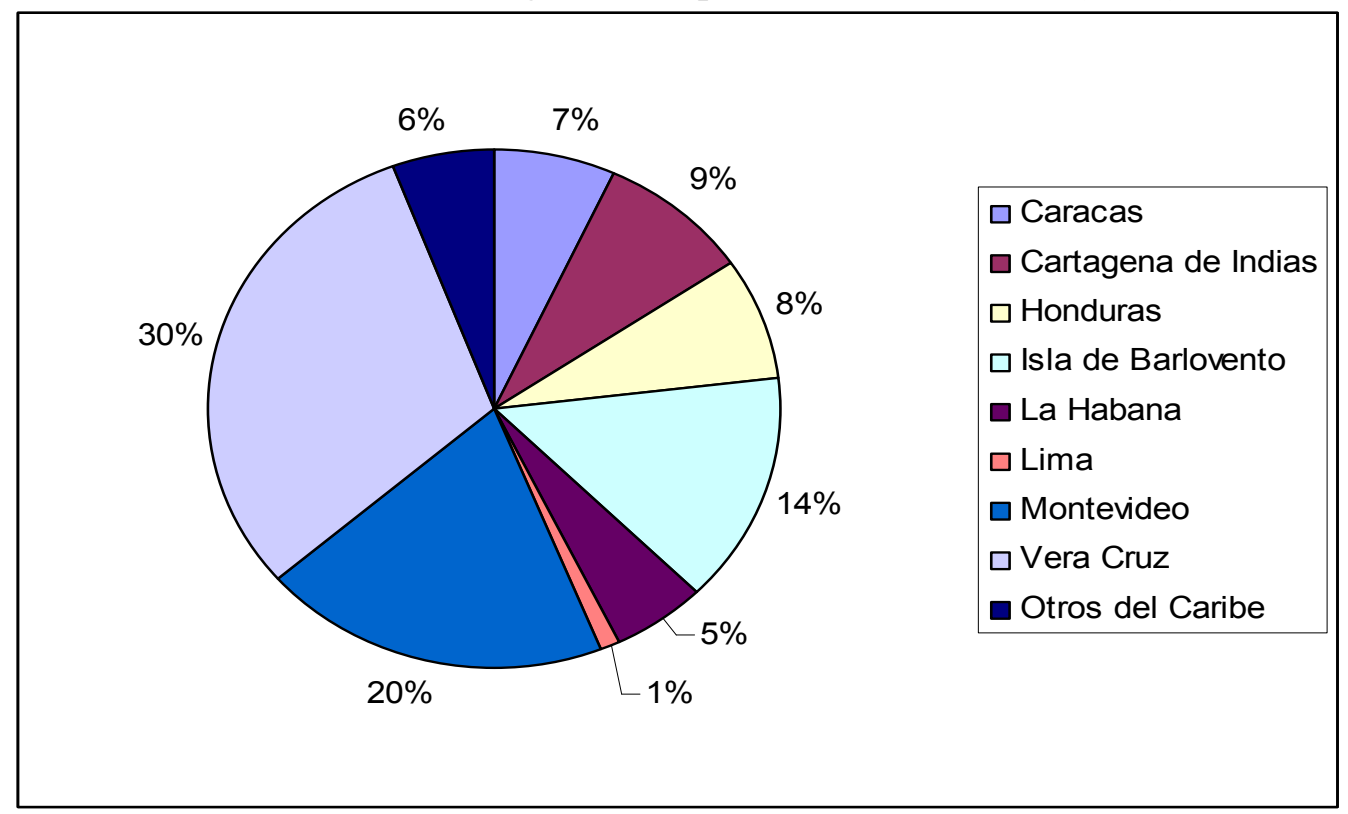

Fuente: Elaboración propia a partir de "El diario Mercantil de España y sus Indias" Año 1793. Biblioteca Nacional de España.

La llegada de los navíos a la península desde América se diversificó notablemente en distintos puertos. En el gráfico II- 5 se puede apreciar cómo se mantuvo la importancia de los puertos, que anteriormente habían sido los únicos que tuvieron permiso para comercializar, pero la diversificación de destinos fue la constante. La mayor transformación en cuanto al comercio se produjo fundamentalmente en los puertos de salida de Montevideo y Buenos Aires, ya que el $20 \%$ de los navíos llegados a la península provenían de dichos puertos. Esto se originó a partir de la importancia que cobraron como puerta de entrada de mercancías producidas en Europa y de salida de plata y cueros (Camarda, 2013).

Así, la división del comercio americano del Atlántico se dio, fundamentalmente, en torno a tres grandes bloques: Veracruz como puerto de México, los diversos puertos de Caribe y el complejo portuario rioplatense. 
Circulación de navíos del puerto de Barcelona con América española, 1792- 1804

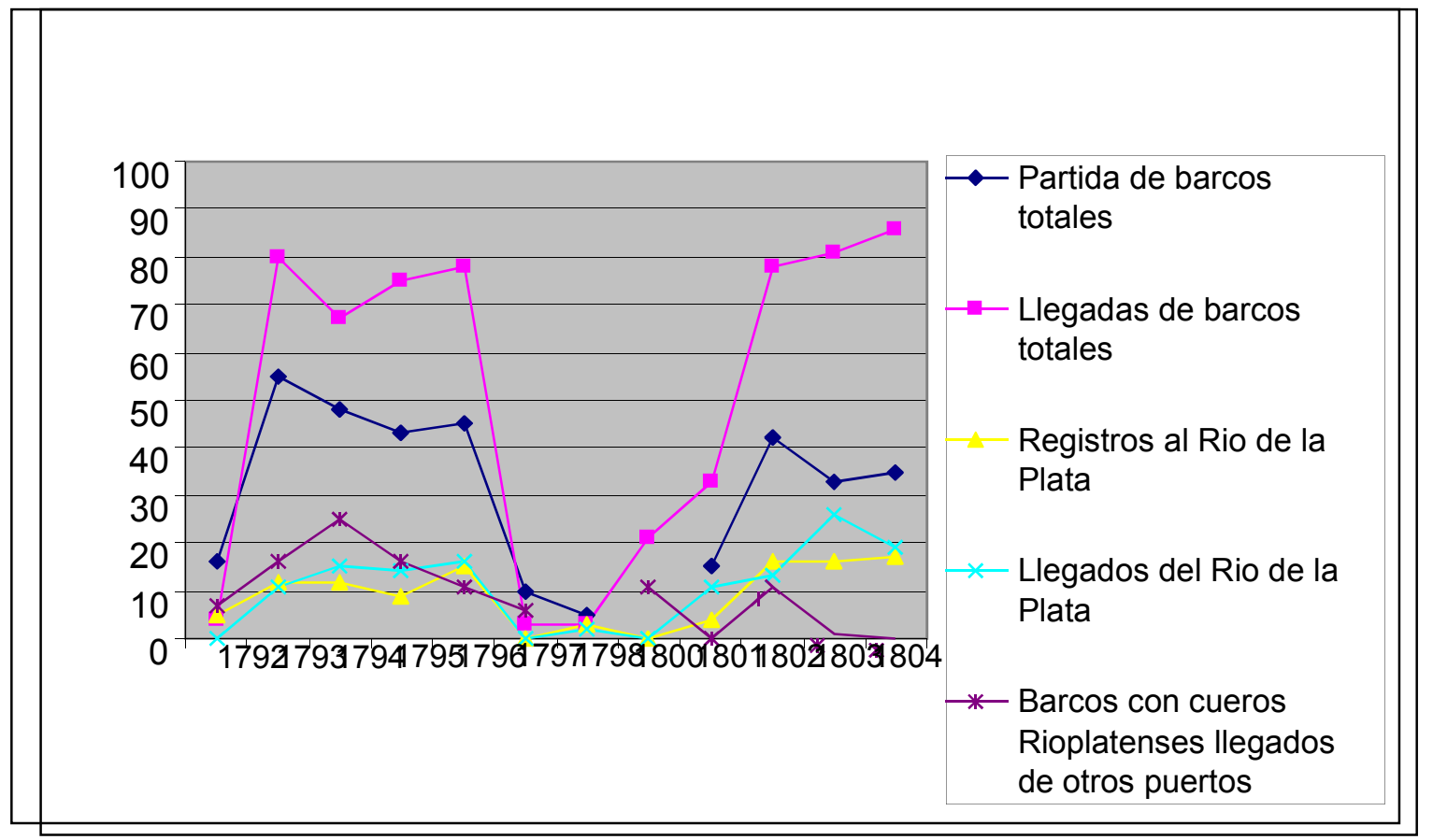

Fuente: Elaboración propia a partir de los datos del Diario de Barcelona. Arxiu de la Ciutat de Barcelona (1792-1804).

Nota: denominamos barcos con cueros rioplatenses, a aquellos provenientes del complejo portuario rioplatense.

En el gráfico II-6, analizamos la circulación de navíos del puerto de Barcelona con América española entre 1792 y 1804 a partir del Diario de Barcelona. Con estos datos podemos ver que la cantidad de barcos provenientes del complejo portuario rioplatense fluctuó acorde al movimiento general del comercio con el resto de América. La cantidad de barcos con registro directo a América desde el puerto de Barcelona fue de 347, de los cuales 100, el 28,8\%, provinieron desde el complejo portuario rioplatense. Si se toman los navíos que incluían dentro de su carga cueros rioplatenses, este porcentaje se incrementa a un 35,4\%. La importancia de la vinculación de la región Río de la Plata con Cataluña 
dentro del comercio ultramarino fue muy importante, no sólo a partir de la vinculación directa sino también del comercio indirecto.

\section{La circulación de navíos del complejo portuario rioplatense}

El movimiento naviero del complejo portuario rioplatense, durante el siglo XVIII, tuvo una dinámica progresivamente ascendente. Como se puede observar en el gráfico II-7, la llegada y salida de los navíos legales comenzó a incrementarse en forma acelerada durante la década de 1760 y no volvió a bajar a cifras de décadas previas durante el resto del período estudiado.

Sin analizar la legalidad o ilegalidad de los navíos de otras banderas (francesa, holandesa, portuguesa e inglesa), nos centraremos en analizar el porqué de este crecimiento sostenido en la cantidad de navíos del circuito legal español que arribaron de nacionalidad española a estas costas.

\section{Gráfico II-7}

Entrada y salida de navíos del complejo portuario rioplatense

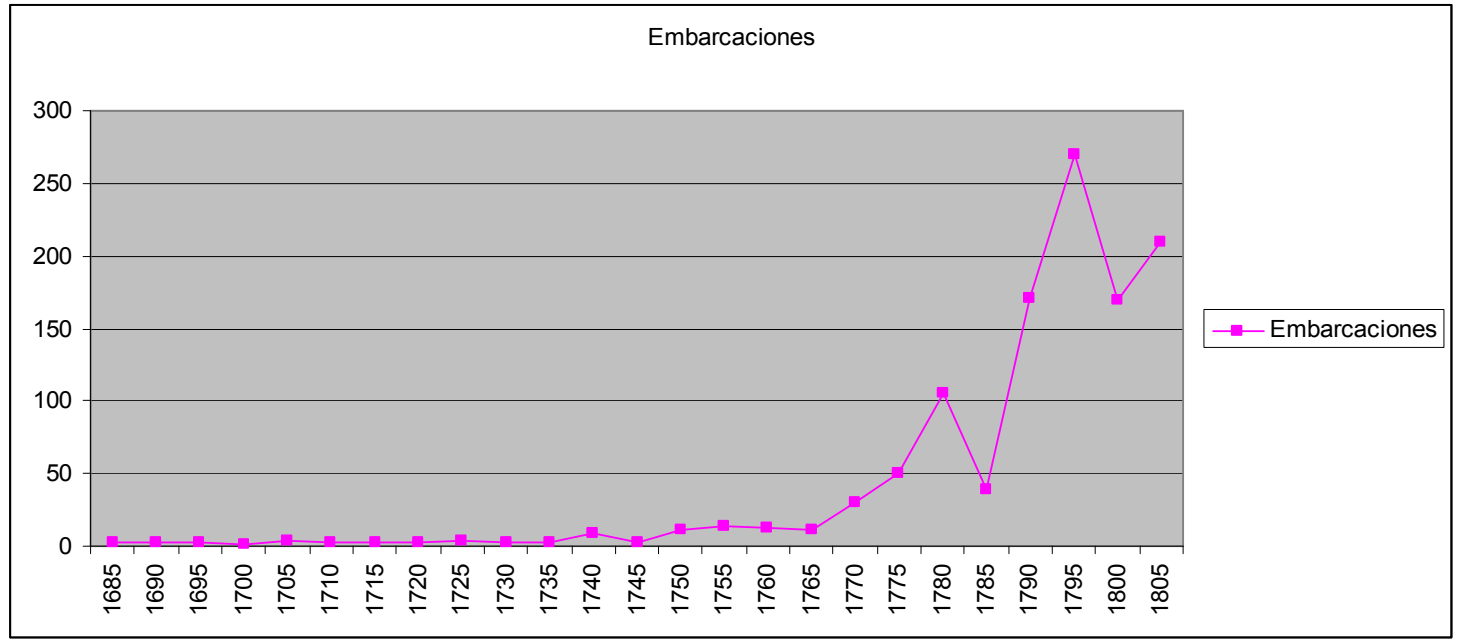

Fuente: Elaboración propia a partir de los datos de Jumar (2002). 2 Vols. / A partir de 1779: AGN Sala IX 02-03-03; 02-03-04; 02-03-05; 02-03-06; 02-03-07; 02-04-01; 02-04-02; 02-04-03; 02-04-04; 02-04-05; 02-04-06; 02-05-01; 02-0502 ; 02-05-03; 02-05-04; 02-05-05; 02-05-06; 02-06-01; 02-06-02; 02-06-03; 0206-04; 02-06-05; 02-06-06; 02-06-07; 02-06-08; 02-07-01; 02-07-02; 02-07-03; 02-07-04; 02-07-05; 02-07-06; 02-07-07; 02-08-01; 02-08-02; 02-08-03; 02-0804; 02-08-05; 02-08-06; 02-08-07; 02-08-08; 02-09-01; 02-09-02; 02-09-03; 0209-04; 02-09-05; 02-09-06; 02-09-07; 02-09-08; 02-10-01; 02-10-02; 02-10-03; 
02-10-04; 02-10-05; 02-10-06; 02-10-07; 03-01-01; 03-01-02; 03-01-03; 03-0104; 03-01-05; 03-01-06; 03-01-07; 03-01-08; 03-02-01; 03-02-02; 03-02-03.

Como se puede observar en el gráfico II- 8 , durante el período que va desde 1680 a 1760 la mayor parte de los navíos partieron de Sevilla y Cádiz. Esto cambió a partir de la década de 1760 debido al surgimiento de distintas dinámicas económicas que fueron acompañadas por cambios institucionales.

\section{Gráfico II-8}

Destinos de los Navíos salidos del complejo portuario rioplatense, 1680-1760

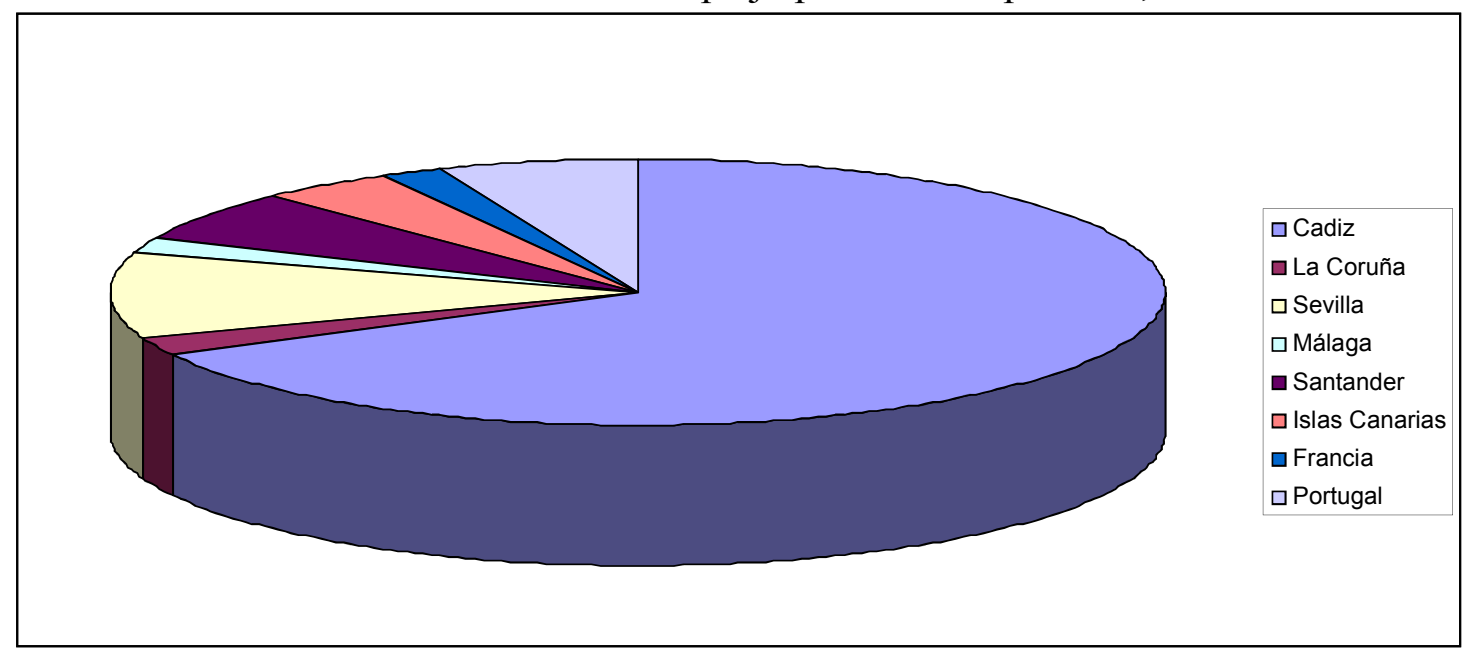

Fuente: Elaboración propia a partir de los datos de Jumar (2000).

Entre 1760 y 1780 se produjo un cambio de los destinos de los navíos que partieron del complejo portuario rioplatense. Si bien la mayoría continuaron dirigiéndose a Cádiz, un tercio aproximadamente partió a los puertos de La Coruña (en donde llegaban las Fragatas Correo) y al puerto de Ferrol.

A partir de 1780 los navíos llegados al complejo portuario rioplatense provenientes de la Península española dejaron de salir mayoritariamente desde Cádiz. De esta manera, se incrementaron notablemente los puertos implicados en el comercio ultramarino con América de forma directa. La variedad de los puertos de salida obliga a abordar esta cuestión bajo agrupaciones geográficas que permitan establecer los grandes lineamientos de los circuitos, por ello, 
dividiremos los puertos en tres grandes grupos (Silva: 1993): Cádiz, puertos peninsulares españoles del Atlántico Norte y del Mediterráneo. Los porcentajes que reflejan la cantidad de barcos que llegan de cada uno de los destinos son:

-Cádiz 36\%.

-Atlántico Norte: los Puertos de Vigo, La Coruña, Santander, Ferrol y Gijón. 27\%.

-Mediterráneo: los Puertos de Málaga, Barcelona, Tarragona, Algeciras, Mallorca y Tortosa. 37\%.

\section{Gráfico II-9}

Destino de los Navíos salidos del complejo portuario rioplatense (1780-1806)

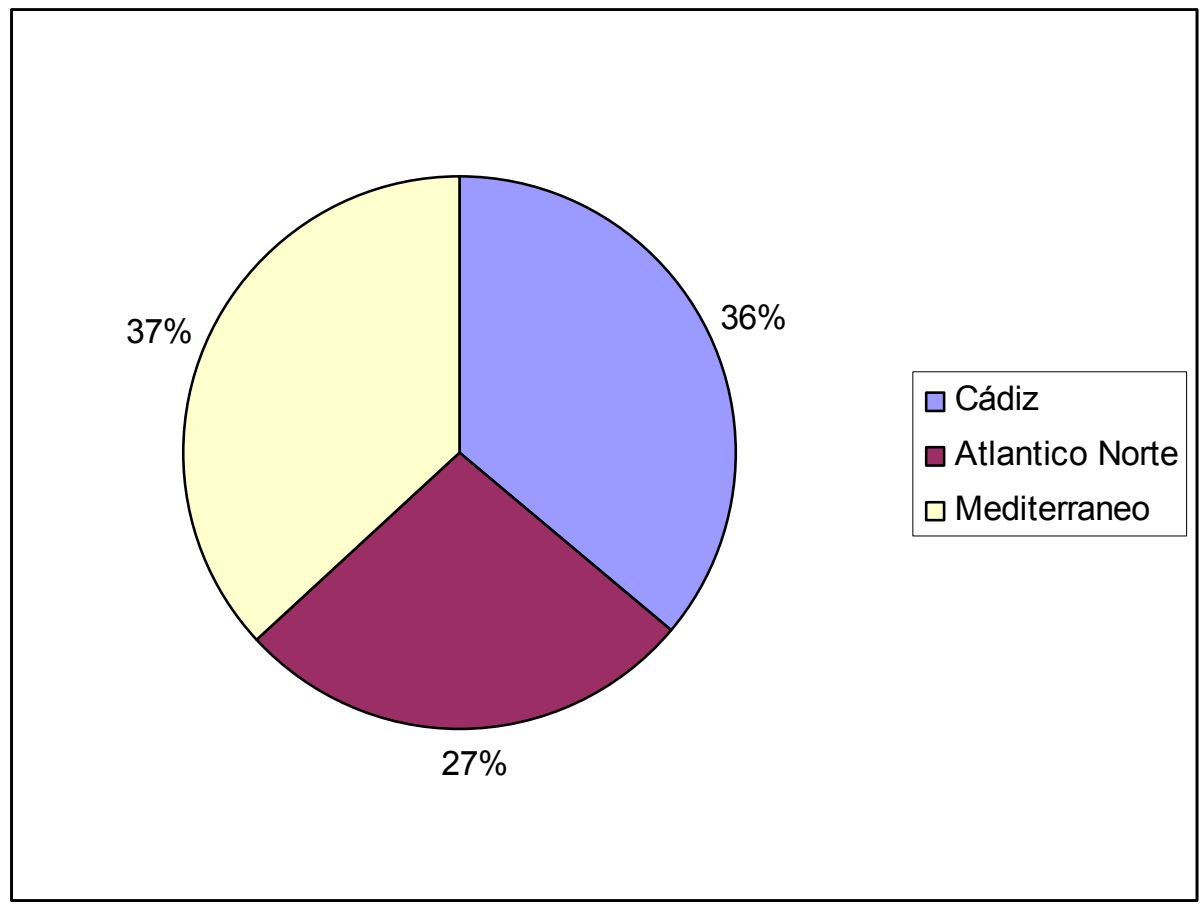

Fuente: Elaboración propia a partir de los datos de: AGN Sala IX 02-03-03; 0203-04; 02-03-05; 02-03-06; 02-03-07; 02-04-01; 02-04-02; 02-04-03; 02-04-04; 02-04-05; 02-04-06; 02-05-01; 02-05-02; 02-05-03; 02-05-04; 02-05-05; 02-0506 ; 02-06-01; 02-06-02; 02-06-03; 02-06-04; 02-06-05; 02-06-06; 02-06-07; 0206-08; 02-07-01; 02-07-02; 02-07-03; 02-07-04; 02-07-05; 02-07-06; 02-07-07; 02-08-01; 02-08-02; 02-08-03; 02-08-04; 02-08-05; 02-08-06; 02-08-07; 02-0808; 02-09-01; 02-09-02; 02-09-03; 02-09-04; 02-09-05; 02-09-06; 02-09-07; 0209-08; 02-10-01; 02-10-02; 02-10-03; 02-10-04; 02-10-05; 02-10-06; 02-10-07; 03-01-01; 03-01-02; 03-01-03; 03-01-04; 03-01-05; 03-01-06; 03-01-07; 03-01$08 ; 03-02-01 ; 03-02-02 ; 03-02-03$. 
En el Gráfico II-9 se puede observar la distribución de los navíos que salieron desde los puertos de la península española al complejo portuario rioplatense. En relación a la circulación de los barcos se puede afirmar entonces que Cádiz perdió la preeminencia frente a los puertos del Norte y del Mediterráneo los cuales, especialmente Barcelona, mantenían un crecimiento económico pujante motivado por el proceso de industrialización que se estaba desarrollando.

A partir de estos datos, es posible afirmar que la importancia del puerto de Cádiz en relación al complejo portuario rioplatense bajó notablemente como producto del empuje de otras regiones que vieron canalizadas sus necesidades en reglamentos que, desde la década de 1760 , se re- direccionaron para su beneficio.

A partir de la década de 1760 se produjo un incremento de la cantidad de navíos que llegaron y partieron del complejo portuario rioplatense, mientras que en el período anterior la salida y llegada de navíos desde otros puertos (por ejemplo Ferrol) se produjo en forma excepcional. Esto constituye un argumento para señalar que el crecimiento se debió no sólo a la aplicación del reglamento de 1778 sino también a la necesidad de aumentar los intercambios de diversas zonas de la península española que, con la creciente industrialización, necesitaban introducir sus manufacturas y acceder a mercados para la compra de insumos y materias $\operatorname{primas}^{23}$.

Como se puede observar en el mapa II-5, los circuitos comerciales ultramarinos fueron modificando su estructura a la largo del período desarrollado en este trabajo. Por un lado, como ya analizamos en el apartado anterior, se

\footnotetext{
${ }^{23}$ Fernando Jumar propuso que ello se debe a que desde los años 1760 se controla más y mejor el tráfico de Colonia del Sacramento y el salto desde el 78 se debe a la desaparición de Colonia del Sacramento en manos portuguesas que concentra el tráfico en los puertos españoles. Estas causas se suman a las que se plantean en esta tesis.
} 
produjo una modificación en cuanto a los puertos de origen de los navíos que llegaban y el destino de los que salían del complejo portuario rioplatense hacia la península española. Por otro lado, fue la posibilidad del contacto ultramarino con otras regiones americanas lo que permitió en algunos casos una alternativa a las vinculaciones terrestres ya establecidas desde antaño, como en el caso de Lima, Guayaquil y la costa de la Capitanía General de Chile. En otros casos, se establecieron nuevas vinculaciones que florecieron a la luz de la oferta y la demanda de productos derivados del vacuno, como en el caso de Cuba (Silva, 1994).

\section{Mapa II-5}

Circuitos comerciales ultramarinos del complejo portuario rioplatense 1779- 1806.

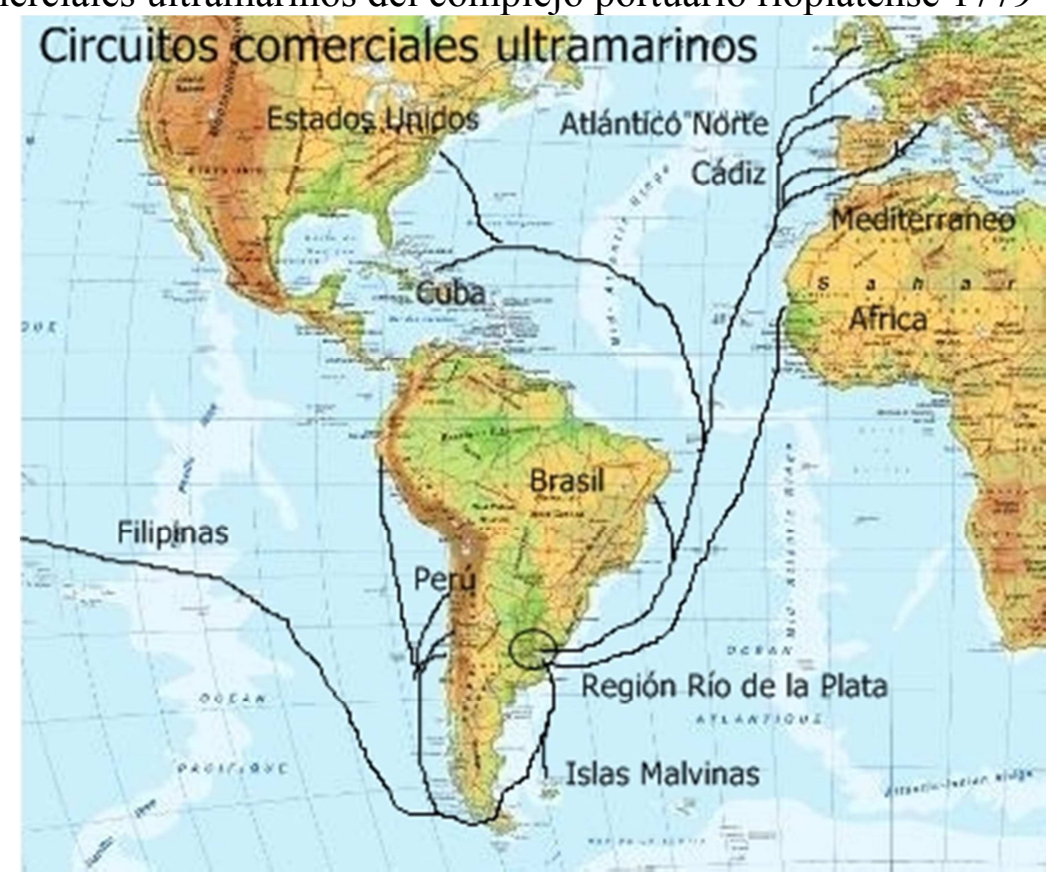

Fuente: Elaboración propia a partir de: http://mapas.owje.com/6877_mapa-fisicodel-mundo-2003.html [última fecha de consulta: 8 de abril de 2015].

Si bien el comercio de esclavos en el complejo portuario rioplatense se desarrolló desde muchos años atrás (los distintos asientos y el comercio con Brasil 
así lo atestiguan), fue a partir de la posibilidad de operar directamente en las costas Áfricanas, que los habitantes americanos pudieron comprar esclavos y trasladarlos para su posterior distribución por las regiones americanas ${ }^{24}$. Es en este sentido que durante este período se permite avanzar en el eslabón de la compra y traslado hasta América cosa vedada hasta este período.

También se produjo una diversificación de los navíos "extranjeros" los cuales incrementaron su llegada, en especial los de origen norteamericano, a partir del comercio con neutrales desde 1796. En cambio, la circulación de navíos de origen brasileño continuó, con altibajos, un proceso que recorre todo el período del complejo portuario rioplatense.

Por último, entre los navíos que conectaban puertos del virreinato sobresalen aquellos que conectaron al complejo portuario rioplatense con las Islas Malvinas a partir del establecimiento de un presidio en este lugar instalada en 1780 y que, periódicamente, se vinculaba para llevar o traer presos, militares y mercancías.

Es importante remarcar que si bien la preeminencia de los puertos de la península española fue mayoritaria con un $68 \%$, la llegada desde Brasil y desde otros puertos americanos pertenecientes a la monarquía española mantuvo una importancia relativa dando muestras del proceso de integración intrarregional que se consolidaba. Esta integración que mantuvo antiguas rutas de comercio directo, produjo el desarrollo de otras que reemplazaban rutas para el transporte terrestre (Sovarzo, 2014) y generó la inauguración de otras nuevas de mayor lejanía que permitieron la llegada de nuevas mercancías o, por lo menos, de menor coste.

\footnotetext{
${ }^{24}$ Los trabajos sobre la esclavitud en la región Rio de la Plata son de antigua data y se han multiplicaron desde distintas perspectivas. Véase entre otros AA. VV (2012) Mallo, S. (1991), Mallo, S. (1997), Mayo, C. (1993), Goldberg y Mallo (1994), Saguier (1989), Guzmán (1993), Klein (1986).
} 
Por otra parte, si bien el resto de los destinos no tuvo un gran predominio o distinción, lo cierto es que bajo determinadas circunstancias prosperaron, esencialmente a partir de las facilidades para el envío de tasajo a Cuba que se produjo en la década de 1790, lo mismo con los contactos con África y la entrada de navíos desde Estados Unidos que se potenció a partir del permiso de ingreso de navíos neutrales casi con el cambio de centuria.

\section{Gráfico II-10}

Origen de los navíos llegados al complejo portuario rioplatense 1779- 1806

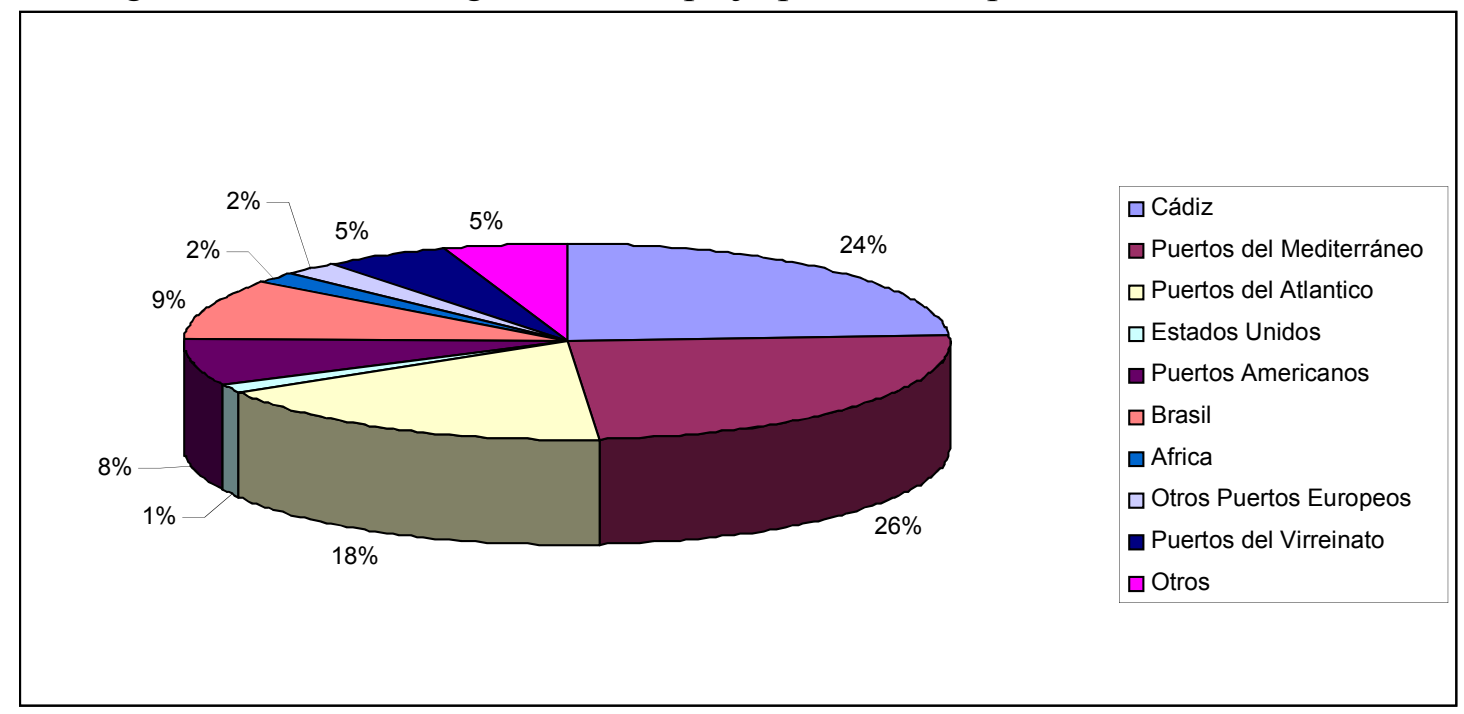

Fuente: Elaboración propia a partir de los datos de: AGN Sala IX 02-03-03; 0203-04; 02-03-05; 02-03-06; 02-03-07; 02-04-01; 02-04-02; 02-04-03; 02-04-04; 02-04-05; 02-04-06; 02-05-01; 02-05-02; 02-05-03; 02-05-04; 02-05-05; 02-0506 ; 02-06-01; 02-06-02; 02-06-03; 02-06-04; 02-06-05; 02-06-06; 02-06-07; 0206-08; 02-07-01; 02-07-02; 02-07-03; 02-07-04; 02-07-05; 02-07-06; 02-07-07; 02-08-01; 02-08-02; 02-08-03; 02-08-04; 02-08-05; 02-08-06; 02-08-07; 02-0808; 02-09-01; 02-09-02; 02-09-03; 02-09-04; 02-09-05; 02-09-06; 02-09-07; 02$09-08 ; 02-10-01 ; 02-10-02 ; 02-10-03 ; 02-10-04 ; 02-10-05 ; 02-10-06 ; 02-10-07$; 03-01-01; 03-01-02; 03-01-03; 03-01-04; 03-01-05; 03-01-06; 03-01-07; 03-0108; 03-02-01; 03-02-02; 03-02-03.

Nota: Los puertos americanos fueron: Callao, La Habana y Valparaíso. Otros puertos Europeos: Hamburgo, El Havre, Marsella, Poole, entre otros. Los puertos del virreinato fueron Puerto Deseado e Islas Malvinas.

En el gráfico II-10 se puede apreciar cómo en los primeros años Cádiz mantuvo una preeminencia que sólo recuperaría esporádicamente entre 1794 y 1796. En cambio, los puertos del Mediterráneo conservaron, durante el resto del 
período analizado, un crecimiento importante. Esto se debe en parte a la industrialización, es decir, a la doble necesidad de consumir cueros para el desarrollo de la industria y de comerciar con las mercancías que se producían. Finalmente, este crecimiento está vinculado al desarrollo de la marina catalana. El avance y aumento del comercio mediterráneo puede rastrearse en la cantidad de comerciantes venidos de esos lugares. Podría decirse que Cádiz seguiría manteniendo la hegemonía porque contaba con los agentes comerciales que eran los ricos del consulado ${ }^{25}$. Es decir, en una época de cambios y transformaciones, Cádiz y sus comerciantes contaban con las redes mercantiles para mantener el comercio, pero no para incrementarlo, en relación al desarrollo que durante este período se produjo.

\section{Gráfico II-11}

Origen de los navíos provenientes de la península española llegados al complejo portuario rioplatense $1779-1806$

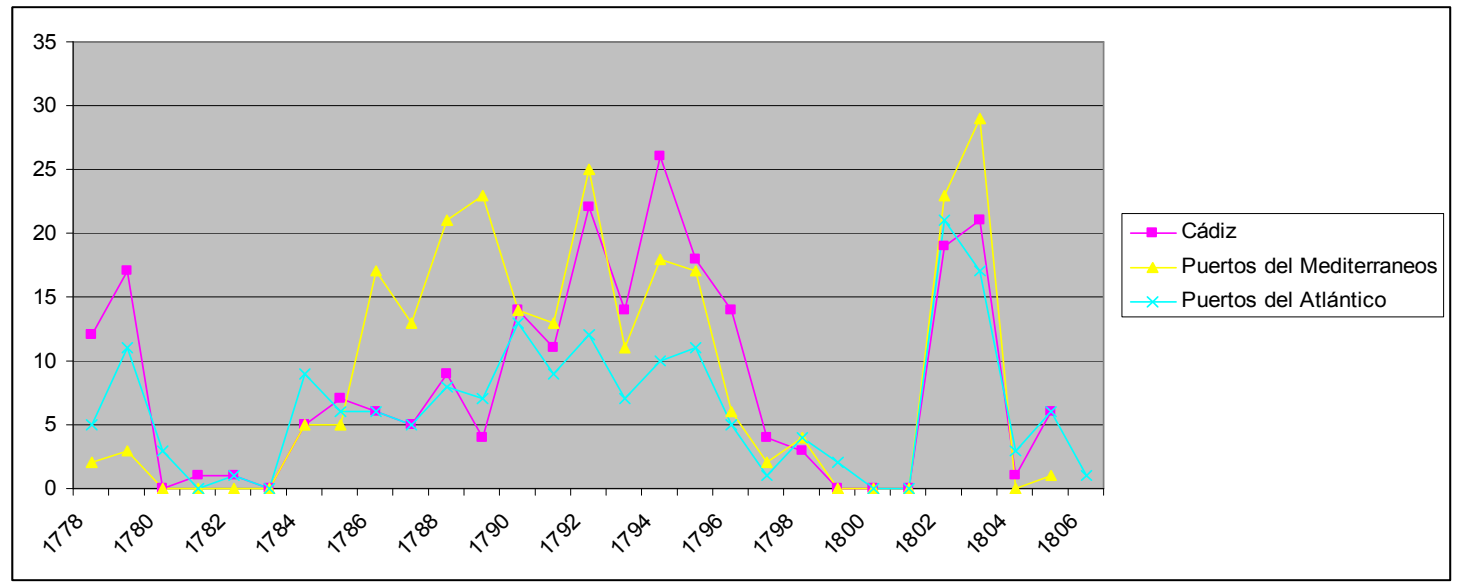

Fuente: Elaboración propia a partir de los datos de: AGN Sala IX 02-03-03; 0203-04; 02-03-05; 02-03-06; 02-03-07; 02-04-01; 02-04-02; 02-04-03; 02-04-04; 02-04-05; 02-04-06; 02-05-01; 02-05-02; 02-05-03; 02-05-04; 02-05-05; 02-0506 ; 02-06-01; 02-06-02; 02-06-03; 02-06-04; 02-06-05; 02-06-06; 02-06-07; 0206-08; 02-07-01; 02-07-02; 02-07-03; 02-07-04; 02-07-05; 02-07-06; 02-07-07; 02-08-01; 02-08-02; 02-08-03; 02-08-04; 02-08-05; 02-08-06; 02-08-07; 02-0808; 02-09-01; 02-09-02; 02-09-03; 02-09-04; 02-09-05; 02-09-06; 02-09-07; 0209-08; 02-10-01; 02-10-02; 02-10-03; 02-10-04; 02-10-05; 02-10-06; 02-10-07; 03-01-01; 03-01-02; 03-01-03; 03-01-04; 03-01-05; 03-01-06; 03-01-07; 03-01$08 ; 03-02-01 ; 03-02-02 ; 03-02-03$.

\footnotetext{
${ }^{25}$ Ver anexo II en donde se puede observar, a partir de los datos de Eduardo Saguier, los más grandes cargadores de metales del período.
} 
Josep Delgado Ribas (1987: 66) establece que sólo a través de la marina es que puede inducirse un beneficio de la apertura comercial ya que "por su eficiencia y reducción de costes, la marina colonial catalana se impuso a la de todo el Estado Español” siendo sus características más importantes:

a) Una menor incidencia de los salarios en los costes de explotación ya que se les daba a quienes trabajaban una parte proporcional de las ganancias.

b) Se reducía al máximo la estadía del barco en el puerto ya que mantenían un circuito de transporte de mercancías con fletes.

c) Se realizaban registros múltiples que permitían la carga y descarga en varios puertos españoles.

d) La expedición atlántica constaba de paradas en varios puertos americanos hasta la venta total de la mercadería.

Estos factores hicieron que la marina catalana contara a principios del siglo XIX "con 200 buques solamente en la carrera de América, con 6.000 tripulantes" (Ruiz i Pablo, 1994: 178) y, por lo tanto, se entiende que haya sido la más perjudicada por los conflictos con Inglaterra que culminaron con la derrota militar de España (Llimargas, 1992) y la imposibilidad de continuar realizando el comercio con buques propios.

Pese a ello, como señala Delgado Ribas (1982: 158), el comercio con América continuó con "el regreso a formas de gestión comercial utilizadas durante las dos primeras décadas del siglo XVIII; una vez más, Lisboa, Gibraltar y Filadelfia adquirirán un puesto fundamental en el circuito de distribución colonial catalán: el de intermediarios”. Esta coyuntura prevaleció hasta la invasión francesa a la península ibérica de 1808, unos pocos años después, situación que 
complicó aún más el comercio pero que motivó a los comerciantes catalanes a emigrar durante este período a las Islas Baleares desde donde operaban, realizando las transacciones desde puertos pequeños (los puertos más grandes estaban ocupados por los franceses) y con barcos de pequeño calado.

Se puede realizar una aproximación a algunos elementos característicos de los navíos a partir de los cuadernos de bitácora, que se encuentran en el Archivo de la Ciudad de Barcelona. Las siete embarcaciones para las que se dispone de esta fuente son de fabricación catalana, la mayoría de sus marineros eran de ese mismo origen y el período que abarcan es de 1775 a $1802 .{ }^{26}$ Los destinos de los circuitos de cada viaje, como ya plantearon Pierre Vilar (1962), Josep Delgado Ribas (1987) y Hernán Asdrúbal Silva (1993), variaron y tendieron a no marcar una ruta fija, sino a realizar un sistema de carga y descarga en cada puerto visitado.

Es interesante remarcar que el hecho de que sean marineros de origen catalán, como el hecho de que las embarcaciones tengan ese mismo origen da cuenta de una especialización de los astilleros en elaborar navíos que resistan la travesía del Atlántico y marineros lo suficientemente experimentados que hicieran llevarlos a puerto. Esto da cuenta de un giro radical ya que el comercio que anteriormente se enfocaba en el Mediterráneo posó su mirada en el Atlántico.

Este giro explicaría el cambio en cuanto a la variación de los tamaños de los navíos, la parte proporcional de las ganancias que se repartían entre los tripulantes y el origen de los barcos y de sus tripulantes.

${ }^{26}$ Arxiu de la Ciutat d Barcelona. Diarios de Bitácora. Barcelona. 


\section{Cuadro II-2}

Tipos de Navíos que ingresaron en el Complejo Portuarios Rioplatense (16801800)

\begin{tabular}{|c|c|c|c|c|c|}
\hline \multirow[b]{2}{*}{ Navío } & \multicolumn{3}{|c|}{ Período } & \multirow[t]{2}{*}{ Tamaño } & \multirow[t]{2}{*}{ Origen- Utilización } \\
\hline & $1680-1760$ & $1760-1780$ & $1780-1800$ & & \\
\hline Fragata & 22 & 107 & 308 & Grande & Generalizado \\
\hline Buque & 39 & 36 & 11 & Grande & Generalizado \\
\hline Paquebot & 9 & 24 & 45 & Pequeña & Mar del Norte \\
\hline Corbeta & 1 & 0 & 27 & Grande & Generalizado \\
\hline Patache & 6 & 0 & 0 & Pequeña & Guerra \\
\hline Urca & 1 & 6 & 4 & Grande & Generalizado \\
\hline Aviso & 2 & 0 & 0 & Pequeña & Guerra \\
\hline Tartana & 1 & 1 & 1 & Pequeña & Mediterráneo \\
\hline Goleta & 1 & 0 & 9 & Pequeña & Generalizado \\
\hline Polacra & 2 & 5 & 68 & Grande & Mediterráneo \\
\hline Saetía & 0 & 34 & 31 & Grande & Mediterráneo \\
\hline Pingüe & 0 & 1 & 1 & Pequeño & Mediterráneo \\
\hline Bergantín & 0 & 4 & 207 & Grande & Generalizado \\
\hline Zumaca & 0 & 5 & 36 & Pequeña & Con Brasil \\
\hline Balandra & 0 & 0 & 9 & Pequeña & Generalizado \\
\hline Falucho & 0 & 0 & 3 & Pequeña & Mediterráneo \\
\hline
\end{tabular}

Fuente: Elaboración propia a partir de los datos de: AGN Sala IX 02-03-03; 0203-04; 02-03-05; 02-03-06; 02-03-07; 02-04-01; 02-04-02; 02-04-03; 02-04-04; $02-04-05$; 02-04-06; 02-05-01; 02-05-02; 02-05-03; 02-05-04; 02-05-05; 02-0506 ; 02-06-01; 02-06-02; 02-06-03; 02-06-04; 02-06-05; 02-06-06; 02-06-07; 0206-08; 02-07-01; 02-07-02; 02-07-03; 02-07-04; 02-07-05; 02-07-06; 02-07-07; 02-08-01; 02-08-02; 02-08-03; 02-08-04; 02-08-05; 02-08-06; 02-08-07; 02-0808; 02-09-01; 02-09-02; 02-09-03; 02-09-04; 02-09-05; 02-09-06; 02-09-07; 0209-08; 02-10-01; 02-10-02; 02-10-03; 02-10-04; 02-10-05; 02-10-06; 02-10-07; 03-01-01; 03-01-02; 03-01-03; 03-01-04; 03-01-05; 03-01-06; 03-01-07; 03-01$08 ; 03-02-01 ; 03-02-02 ; 03-02-03$.

En el cuadro II-2 se establecen los distintos tipos de embarcaciones, el período en el cual llegaron al complejo portuario rioplatense, su tamaño y el origen de las mismas. Se puede observar que, mayoritariamente, las embarcaciones que llegaron fueron los bergantines y las fragatas los cuales durante el siglo XVIII fueron los navíos, de distintos orígenes, que navegaron en el Atlántico. Estos barcos tuvieron como beneficio el hecho de ser de gran tamaño y, pese a ello, desarrollar una gran velocidad. También podían auto defenderse, ya 
que eran utilizados como buque de guerra. A su vez, a partir de la década de 1760, ingresaron en el complejo portuario rioplatense algunos tipos de embarcaciones no vinculadas anteriormente al comercio ultramarino Atlántico como, por ejemplo, saetías y polacras modificadas, que eran embarcaciones fabricadas y utilizadas para el Mar Mediterráneo desde el siglo XVI.

Una parte importante de estos navíos fue construida en los astilleros de Cataluña. Además, los paquebotes también generalizaron su uso a partir de la década de 1760 en el complejo portuario rioplatense, siendo esta embarcación de uso común anteriormente en los circuitos del Mar del Norte y en el Atlántico Norte de la Península española (La Piñera y Rivas, 2002; Hormaechea, 2012; Oliva Melgar, 1996).

Por lo tanto, se puede afirmar que el proceso de comercio, a partir de la década de 1760, entre las diversas regiones de la península española y el complejo portuario rioplatense, se produjo en forma paralela a una readaptación de los navíos y las prácticas marítimas que se realizaban en otras latitudes. Estas transformaciones y el permiso de comerciar con otras regiones permitieron el desarrollo de fletes durante los periodos de guerra, entre España y otras potencias, que dificultaban la llegada de los navíos a los puertos de la península.

Como se puede observar en el Gráfico II-12, durante el período estudiado, el comercio no vinculado a la península española gravitó fundamentalmente en los momentos en los cuales los conflictos militares no permitieron la circulación de navíos hacia la misma. Fue en estos espacios de tiempo que se realizó la mayoría de los fletes. Igualmente, es interesante remarcar que tímidamente en sus comienzos, pero con crecimiento constante, a partir de 1793 se produjo una consolidación de estos vínculos. De todas formas, los puertos de la península 
española continuaron teniendo una mayor cantidad de navíos recibidos en el complejo portuario, lo cual nos muestra cuán sólidos se mantuvieron los vínculos comerciales con los puertos del Mediterráneo y del Atlántico Norte (que, como se dijo anteriormente, fueron mayoritarios en este período) como consecuencia de la necesidad mutua de conservarlos pese a los bloqueos militares.

\section{Gráfico II-12}

Partida de navíos a puertos de la península española y otros puertos.

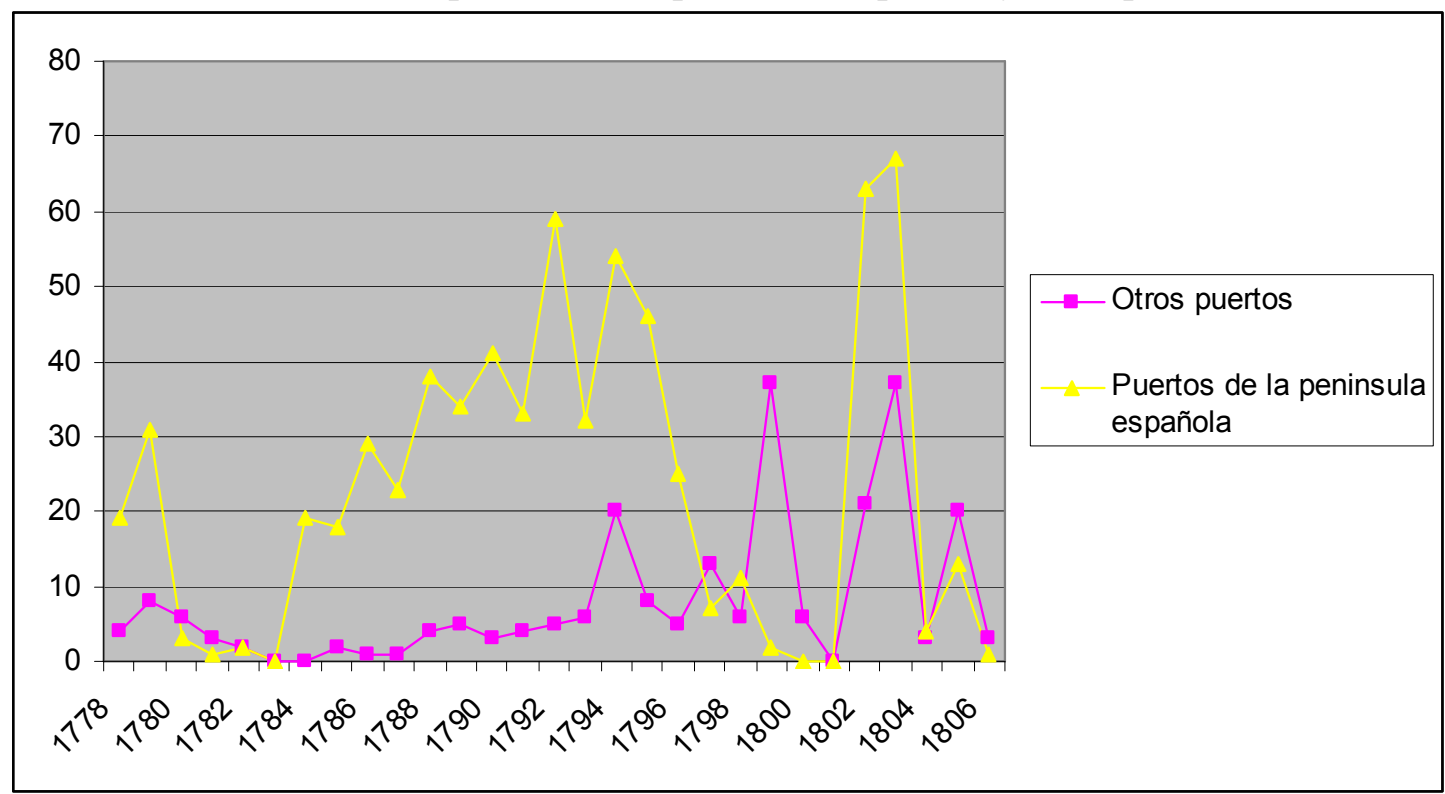

Fuente: Elaboración propia a partir de los datos de: AGN Sala IX 02-03-03; 0203-04; 02-03-05; 02-03-06; 02-03-07; 02-04-01; 02-04-02; 02-04-03; 02-04-04; 02-04-05; 02-04-06; 02-05-01; 02-05-02; 02-05-03; 02-05-04; 02-05-05; 02-0506; 02-06-01; 02-06-02; 02-06-03; 02-06-04; 02-06-05; 02-06-06; 02-06-07; 0206-08; 02-07-01; 02-07-02; 02-07-03; 02-07-04; 02-07-05; 02-07-06; 02-07-07; 02-08-01; 02-08-02; 02-08-03; 02-08-04; 02-08-05; 02-08-06; 02-08-07; 02-0808 ; 02-09-01; 02-09-02; 02-09-03; 02-09-04; 02-09-05; 02-09-06; 02-09-07; 0209-08; 02-10-01; 02-10-02; 02-10-03; 02-10-04; 02-10-05; 02-10-06; 02-10-07; 03-01-01; 03-01-02; 03-01-03; 03-01-04; 03-01-05; 03-01-06; 03-01-07; 03-01$08 ; 03-02-01 ; 03-02-02 ; 03-02-03$.

Con respecto a la llegada de navíos de los diversos puertos que no eran de la península española nos encontramos, como se puede observar en el gráfico II13, con que la mayor regularidad comercial se mantuvo con Brasil, lo cual habla 
de la perduración de los circuitos ya construidos con anterioridad. ${ }^{27}$ El comercio con Brasil se estableció en torno a la compraventa de esclavos intercambiados por plata o cueros. Durante los bloqueos comerciales hubo un crecimiento del comercio de esclavos con Brasil a partir de la imposibilidad por la guerra de realizar viajes cruzando el Atlántico. Desde 1792 el aumento del tráfico fue constante, probablemente, debido al mantenimiento de las redes construidas en el periodo belicoso previo. Luego, se produjo la cesión de su primacía en 1745, a raíz del incremento del comercio con la Isla de Cuba, ya que a partir del conflicto por Terranova (que generó la imposibilidad de intercambiar el bacalao salado) se incrementó la demanda de tasajo para el mantenimiento de la población esclava de la Isla (Silva, 1993; 1994).

\section{Gráfico II-13}

Partida de navíos a distintos puertos (exceptuando los de la Península española)

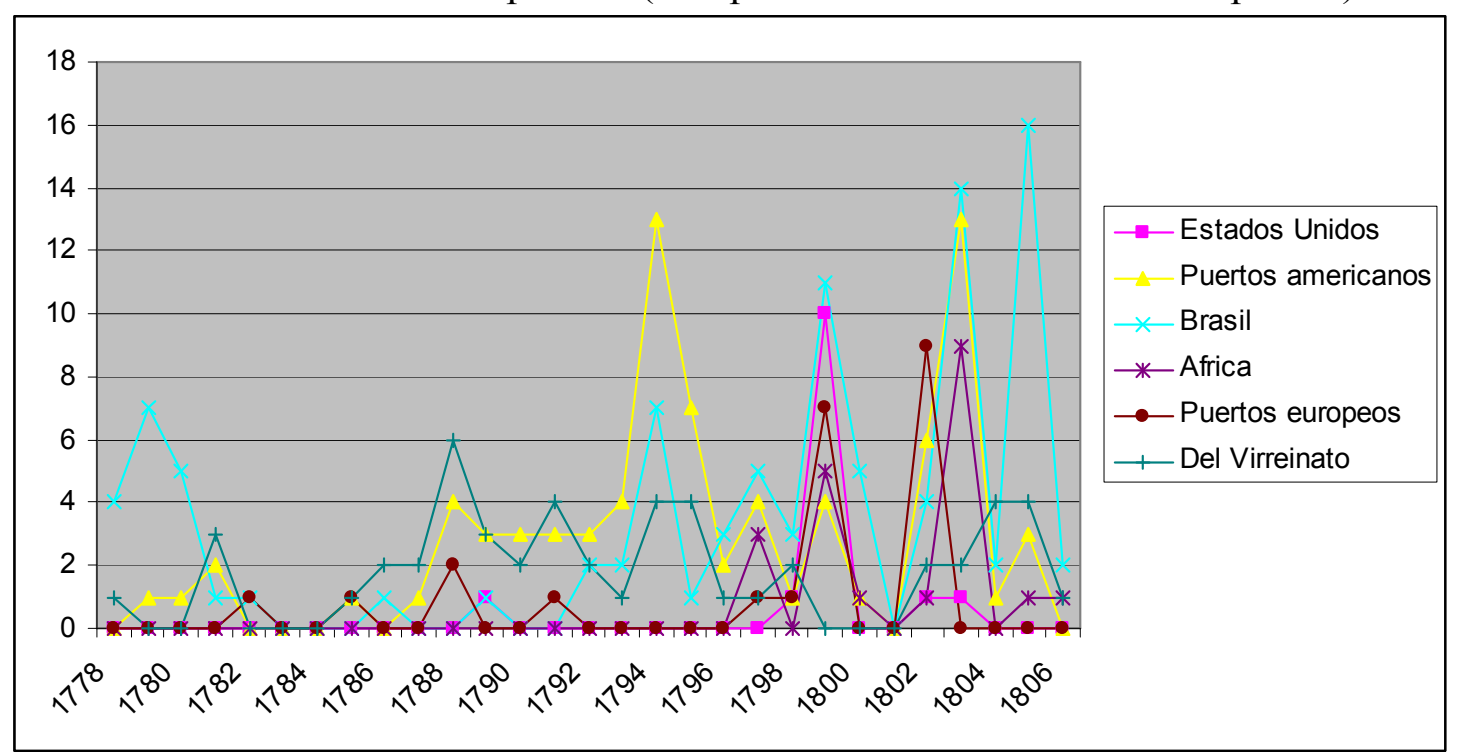

Fuente: Elaboración propia a partir de los datos de: AGN Sala IX 02-03-03; 0203-04; 02-03-05; 02-03-06; 02-03-07; 02-04-01; 02-04-02; 02-04-03; 02-04-04; 02-04-05; 02-04-06; 02-05-01; 02-05-02; 02-05-03; 02-05-04; 02-05-05; 02-0506 ; 02-06-01; 02-06-02; 02-06-03; 02-06-04; 02-06-05; 02-06-06; 02-06-07; 0206-08; 02-07-01; 02-07-02; 02-07-03; 02-07-04; 02-07-05; 02-07-06; 02-07-07; 02-08-01; 02-08-02; 02-08-03; 02-08-04; 02-08-05; 02-08-06; 02-08-07; 02-08-

\footnotetext{
${ }^{27}$ Sobre el análisis de los circuitos legales y de comercio directo con la región Río de la Plata antes de 1779 véase: Reitano, E. (2003); Tejerina (2002); Jumar (2000).
} 
08; 02-09-01; 02-09-02; 02-09-03; 02-09-04; 02-09-05; 02-09-06; 02-09-07; 0209-08; 02-10-01; 02-10-02; 02-10-03; 02-10-04; 02-10-05; 02-10-06; 02-10-07; 03-01-01; 03-01-02; 03-01-03; 03-01-04; 03-01-05; 03-01-06; 03-01-07; 03-01$08 ; 03-02-01 ; 03-02-02 ; 03-02-03$.

Tanto el comercio con la Isla de Cuba como con África se produjo en la década de 1790. Para que se desarrollase se necesitó construir un círculo virtuoso, triangular, en donde se llevaba tasajo a Cuba y se compraban esclavizados en África. Los navíos debían pertenecer a los afincados en el complejo portuario ${ }^{28}$, los esclavizados debían ser vendidos en la región Río de la Plata, a su vez, era necesario desarrollar una mejora en la técnica del salado, ya que hasta este período se realizaba para el consumo en los barcos y en este momento se debía producir en mayor escala y conservar mejor para un uso posterior.

\section{La salida de mercancías del complejo portuario rioplatense}

Este apartado está dedicado a analizar, en términos generales, las mercancías que salieron por el complejo portuario rioplatense ${ }^{29}$. Para este análisis sólo se tomarán los metales preciosos y los cueros ya que, si bien en pequeñas cantidades se comercializaron otras mercancías (plumeros, cobre, astas, sebo, grasa, tasajo, cecina, cueros de lobos marinos, entre otros) no generaron una variación sustancial, representando menos de un $1 \%{ }^{30}$ En los capítulos tres, cuatro y cinco

\footnotetext{
${ }^{28}$ Ver anexo III en donde su puede observar el número de navíos en propiedad de vecinos de la región Río de la Plata.

${ }^{29}$ El desarrollo en profundidad la salida de mercancías se realizó en los siguientes capítulos, pero a efectos prácticos para la comprensión de la tesis entendemos que se debía realizar una contextualización general.

${ }^{30} \mathrm{Si}$ bien para esta investigación en particular, no son significativos en el conjunto, lo son a la hora de analizar las economías productoras americanas y pudiendo revelar la extensión de los circuitos que se vinculaban con Río de la Plata. No se incluyo el comercio de tasajo hacia Cuba, la cual comenzó en 1785 y mantuvo una regularidad hasta 1796, en donde se produjo un crecimiento significativo. Asdrubal Silva (1994) encontró que 50 navios partieron hacia La Habana entre 1790 y 1796, estableciendo la importancia que tuvo a nivel regional. Las escasas huellas que dejaron en los depósitos documentales analizados no nos permitió reconstrir las cifras totales y los actores que intervinieron hasta 1794. Por ese motivo no se incluyó en los datos vertidos en este
} 
de esta tesis se desarrollará, en profundad, un análisis de las mercancías producidas a nivel regional y aquellas que provinieron desde el interior del espacio.

Juan Carlos Garavaglia realizó estimaciones en torno a la comercialización ultramarina y señaló que entre 1779 y 1784 solo un $15 \%$ correspondía a los cueros, mientras que el $82 \%$ era de metálico y derivados vacunos. El resto correspondía a mercancías de otras regiones -cascarilla, cobre, etc.- (1987: 74). Mientras que Miguel Rosal y Roberto Schmit señalaron que el 20\% de la exportación total fueron productos pecuarios y el $80 \%$ metales preciosos $(2004$, 166).

Como planteó Jumar, existió una diferencia muy importante entre la salida de metales preciosos y los cueros, “...en los análisis de esas exportaciones se suele poner al mismo nivel los metales preciosos y los cueros, olvidándose que los primeros son testimonio de transacciones entre un complejo rosario de economías regionales entrelazadas y parcialmente superpuestas unas con otras y, los segundos, dan cuenta de la principal actividad productiva de una de esas economías y que su comercialización indirectamente se vincula a las dinámicas del polo Lima-Potosí." (Jumar, 2010: 16). Pese a ello, nos parece interesante analizar las proporciones de metales preciosos y cueros que salieron del complejo portuario para poder dar cuenta de las transformaciones que se sucedieron internamente y las variaciones de la demanda externa.

En el gráfico II-14 se puede observar que, a partir de mediados del siglo XVIII, la dinámica naviera fue acompañada por un crecimiento del comercio, tanto en metales preciosos como en cueros.

capítulo. En el capítulo V, se describe el derrotero comercial de Josep Milá de la Roca, quien fuera un gran productor de tasajo y se profundiza en este aspecto. 
Gráfico II-14

Metales y cueros (en pesos de 8 reales) salidos por el complejo portuario rioplatense (1730-1789)

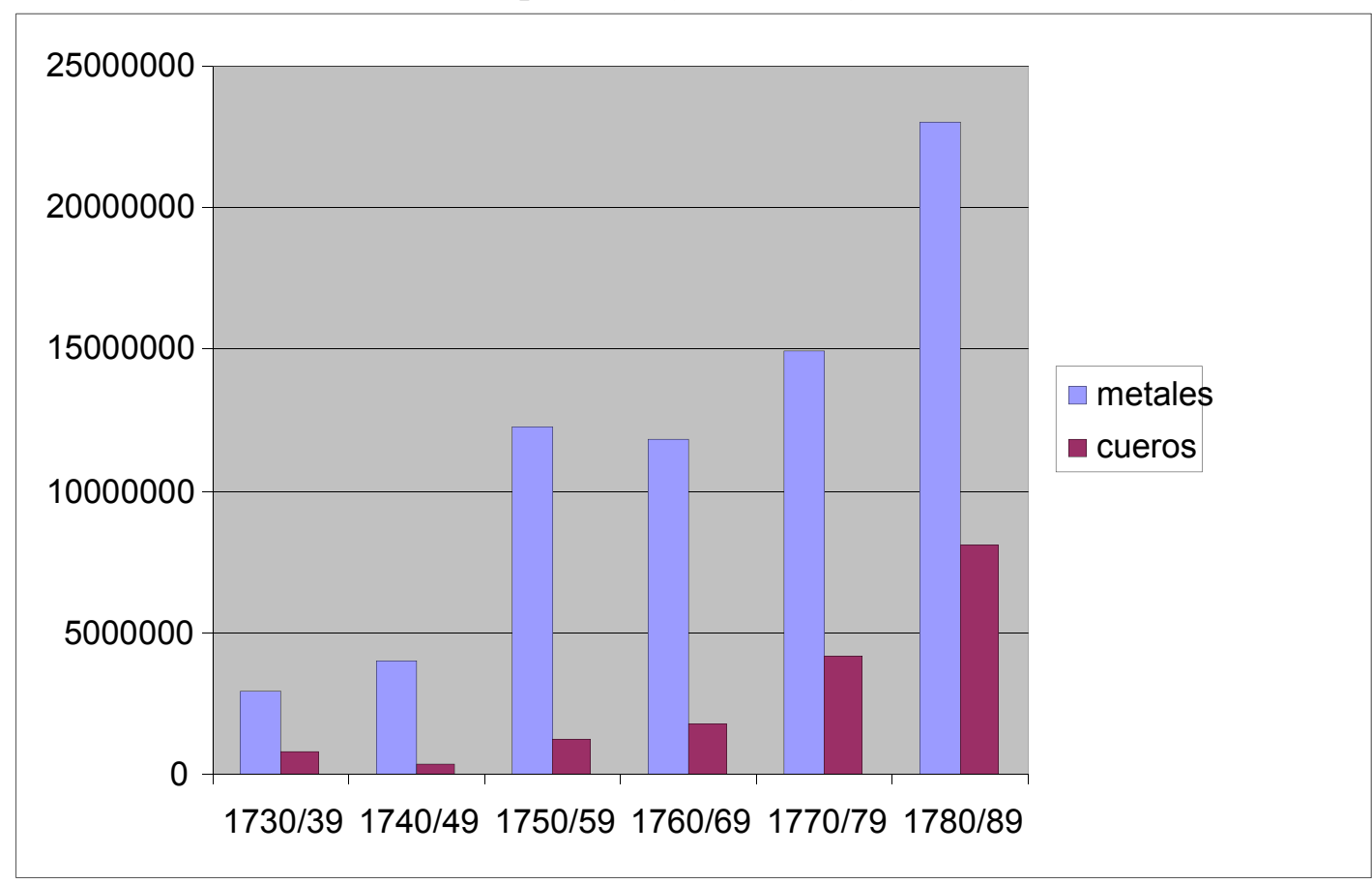

Fuente: Elaboración propia a partir de los datos de Jumar (2002). A partir de 1779 los datos son tomados de: AGN Argentina: Sala XIII: 15-10-3; 37-6-4; 37-10-5; $37-10-6-; 38-8-3$; 38-8-4; 38-1-1; 38-1-3; 38-2-3; 38-3-4; 38-4-4; 38-5-3; 38-6-4; $38-1-3$; 39-1-3; 39-2-1; 39-2-2; 39-3-1; 39-3-2; 39-3-3; 39-4-3; 39-5-4; 39-6-2; $39-8-4 ; 39-9-3 ; 39-10-1 ; 39-10-4 ; 39-7-4 ; 15-10-3 ; 37-9-3 ; 37-9-4 ; 38-10-3$; 38-63. $14-9-5 ; 14-10-1 ; 14-10-2 ; 14-10-3 ; 14-10-4 ; 15-10-1 ; 15-10-2 ; 15-10-3$. Sala IX 43- 05- 11 ; 43- 06- 01; 43- 06- 02; 43- 06- 03; 43- 06- 04; 43- 06- 05; 43- 0606; 43- 06- 07; 43- 06- 08; 43- 06- 09; 43- 07- 01 ; 43- 07- 02; 43- 07- 03; 43- 0704; 43- 07- 05; 43- 07- 06; 43- 07- 07; 43- 07- 08; 43- 07- 09; 43- 07- 10; 43- 0711 ; 43- 07- 12 ; 43- 08- 01 ; 43- 08- 02; 43- 08- 03; 43- 08- 04; 43- 08- 05; 43- 0806; 43- 08- 07; 43- 08- 08; 43- 08- 09; 43- 08- 10; 43- 08- 11 ; 43- 08- 12; 43- 0901; 43- 09- 02; 43- 09- 03; 43- 09- 04; 43- 09- 05; 43- 09- 06; 43- 09- 07; 43- 0908; 43- 09- 09; 43- 09- 10; 43- 09- 11. AGN Uruguay: Fondo Documental ex "Archivo y Museo Histórico Nacional": Legajos con Registros de Navíos desde el 218 a 270.

La proporción de cueros en relación a los metales preciosos, fue en aumento progresivo desde la década del treinta, la década anterior se podría denominar como excepcional ya que fue producto del primer "boom del cuero" (Jumar, 2008) y una baja salida de metales. A partir de la década de 1750 la proporción de cueros fue creciendo en forma acelerada dando cuenta de la 
demanda de otras regiones, en particular de las zonas en proceso de industrialización.

\section{Cuadro II-3}

Metales y cueros salidos por el complejo portuario rioplatense (1730-1789)

(Totales en pesos de 8 reales y porcentajes)

\begin{tabular}{|l|l|l|l|l|}
\hline Periodo & Plata & Cueros & \\
\hline $1730 / 39$ & 2.893 .802 & $79 \%$ & 792.361 & $21 \%$ \\
\hline $1740 / 49$ & 3.995 .823 & $92 \%$ & 326.522 & $8 \%$ \\
\hline $1750 / 59$ & 12.286 .298 & $91 \%$ & 1.250 .145 & $9 \%$ \\
\hline $1760 / 69$ & 11.812 .039 & $87 \%$ & 1.740 .652 & $13 \%$ \\
\hline $1770 / 79$ & 14.908 .704 & $78 \%$ & 4.198 .099 & $22 \%$ \\
\hline $1780 / 89$ & 23.056 .016 & $74 \%$ & $8.106 .031,3$ & $26 \%$ \\
\hline Total & 68.952 .682 & $83,5 \%$ & $16.413 .810,3$ & $16,5 \%$ \\
\hline
\end{tabular}

Fuente: Elaboración propia a partir de los datos de Jumar (2002). A partir de 1779 los datos son tomados de: AGN Argentina: Sala XIII: 15-10-3; 37-6-4; 37-10-5; $37-10-6-; 38-8-3$; 38-8-4; 38-1-1; 38-1-3; 38-2-3; 38-3-4; 38-4-4; 38-5-3; 38-6-4; $38-1-3 ; 39-1-3 ; 39-2-1 ; 39-2-2 ; 39-3-1 ; 39-3-2 ; 39-3-3 ; 39-4-3 ; 39-5-4 ; 39-6-2$; $39-8-4 ; 39-9-3 ; 39-10-1 ; 39-10-4 ; 39-7-4 ; 15-10-3 ; 37-9-3 ; 37-9-4 ; 38-10-3$; 38-63. $14-9-5 ; 14-10-1 ; 14-10-2 ; 14-10-3 ; 14-10-4 ; 15-10-1 ; 15-10-2 ; 15-10-3$. Sala IX 43- 05- 11 ; 43- 06- 01; 43- 06- 02; 43- 06- 03; 43- 06- 04; 43- 06- 05; 43- 0606; 43- 06- 07; 43- 06- 08; 43- 06- 09; 43- 07- 01; 43- 07- 02; 43- 07- 03; 43- 0704; 43- 07- 05; 43- 07- 06; 43- 07- 07; 43- 07- 08; 43- 07- 09; 43- 07- 10; 43- 0711 ; 43- 07- 12 ; 43- 08- 01 ; 43- 08- 02 ; 43- 08- 03 ; 43- 08- 04 ; 43- 08- 05; 43- 0806; 43- 08- 07; 43- 08- 08; 43- 08- 09; 43- 08- 10; 43- 08- 11 ; 43- 08- 12; 43- 0901; 43- 09- 02; 43- 09- 03; 43- 09- 04; 43- 09- 05; 43- 09- 06; 43- 09- 07; 43- 0908; 43- 09- 09; 43- 09- 10; 43- 09- 11. AGN Uruguay: Fondo Documental ex "Archivo y Museo Histórico Nacional": Legajos con Registros de Navíos desde el 218 a 270.

La relación entre metales preciosos y cueros entre 1730 y 1789 estuvo marcada por un crecimiento constante de ambas mercancías y un progresivo aumento de la salida de cueros. Luego del primer boom de salida de cueros pasó de representar un $8 \%$ a un $26 \%$ del comercio total en las cuatro décadas posteriores. Este incremento en la salida de cueros fue producto de las transformaciones en la demanda externa y la nueva economía del cuero que se implementó y que permitió aumentar la oferta. 


\section{Gráfico II-15}

Mercancías salidas por el complejo portuario $(1779-1794)^{31}$

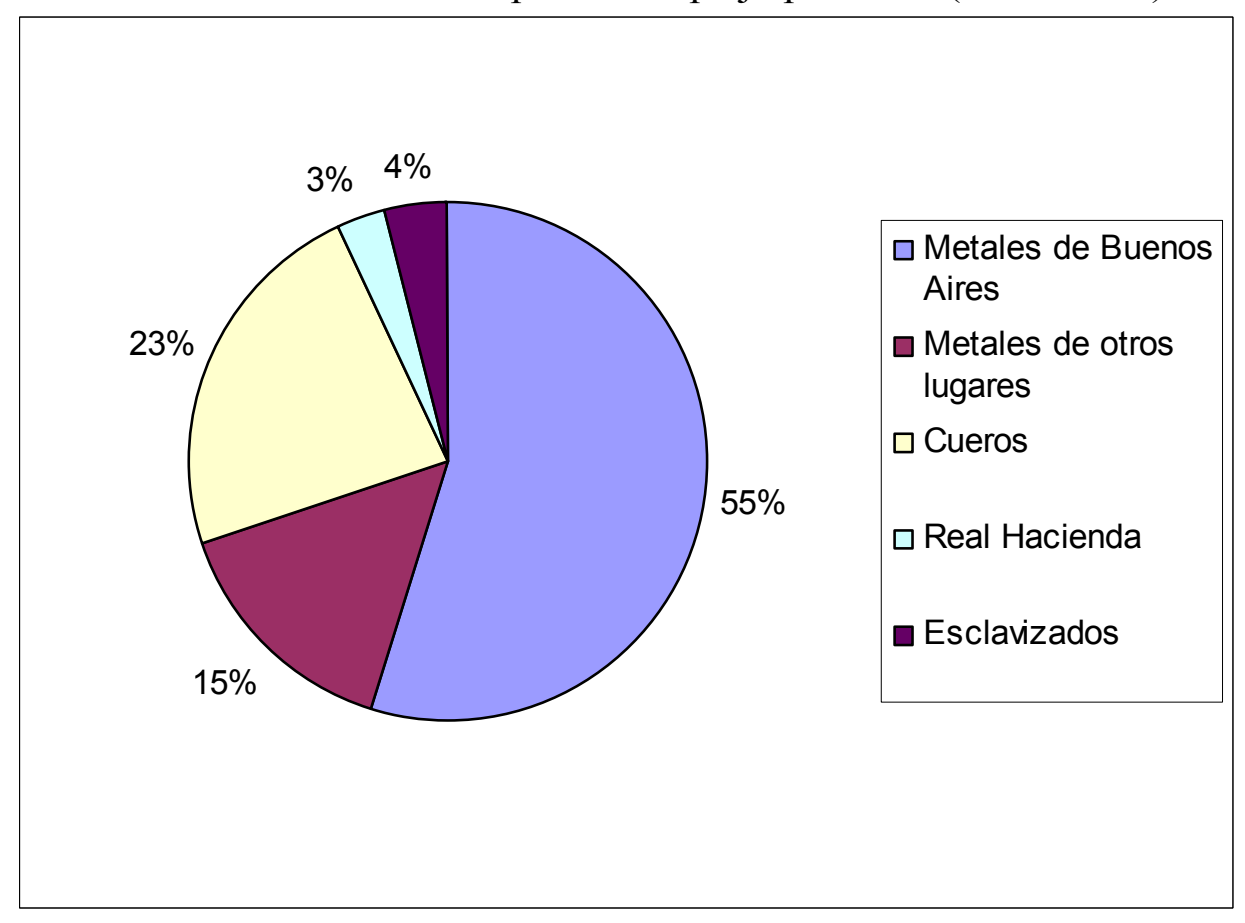

Fuente: AGN Argentina: Sala XIII: $15-10-3 ; 37-6-4 ; 37-10-5 ; 37-10-6-; 38-8-$ 3 ; 38-8-4; 38-1-1; 38-1-3; 38-2-3; 38-3-4; 38-4-4; 38-5-3; 38-6-4; 38-1-3; 39-1-3; $39-2-1 ; 39-2-2 ; 39-3-1 ; 39-3-2 ; 39-3-3 ; 39-4-3 ; 39-5-4 ; 39-6-2 ; 39-8-4 ; 39-9-3$; $39-10-1 ; 39-10-4 ; 39-7-4 ; 15-10-3 ; 37-9-3 ; 37-9-4 ; 38-10-3 ; 38-6-3$. 14-9-5; $14-$ $10-1 ; 14-10-2 ; 14-10-3 ; 14-10-4 ; 15-10-1 ; 15-10-2 ; 15-10-3$. Sala IX 43- 05- 11; 43- 06- 01; 43- 06- 02; 43- 06- 03; 43- 06- 04; 43- 06- 05; 43- 06- 06; 43- 06- 07; 43- 06- 08; 43- 06- 09; 43- 07- 01; 43- 07- 02; 43- 07- 03; 43- 07- 04; 43- 07- 05; 43- 07- 06; 43- 07- 07; 43- 07- 08; 43- 07- 09; 43- 07- 10; 43- 07- 11; 43- 07- 12; 43- 08- 01 ; 43- 08- 02; 43- 08- 03; 43- 08- 04; 43- 08- 05; 43- 08- 06; 43- 08- 07; 43- 08- 08; 43- 08- 09; 43- 08- 10; 43- 08- 11 ; 43- 08- 12; 43- 09- 01; 43- 09- 02; 43- 09- 03; 43- 09- 04; 43- 09- 05; 43- 09- 06; 43- 09- 07; 43- 09- 08; 43- 09- 09; 43- 09- 10; 43- 09- 11. AGN Uruguay: Fondo Documental ex "Archivo y Museo Histórico Nacional”: Legajos con Registros de Navíos desde el 218 a 270.

En el gráfico II-15 se puede observar la composición de las mercancías salidas por el complejo portuario para el período 1779- 1794. Si bien la mayor parte de los metales que partieron eran enviados por los rioplatenses (55\%), se puede apreciar la importancia que tuvieron los enviados por actores de otras regiones (15\%), siendo muy minoritario lo enviado por la Real Hacienda y en el

\footnotetext{
${ }^{31}$ Metales de Buenos Aires da cuenta de lo registrados por vecinos de Buenos Aires en la ciudad.
} 
comercio de esclavizados. Además, si bien representaba un alto porcentaje de metales preciosos enviados por los rioplatenses, de los mismos, solo un 8 a $10 \%$ quedaba en propiedad de los mismos en concepto de comisión, muy pocos envíos eran a cuenta y riesgo propio en general las transacciones estaban a cargo de un tercero residente en la península española.

La salida de cueros, fue muy significativa para este período ya que, si bien representó un $23 \%$ del total de mercancías salidas, si se toma las cifras de los enviados por los rioplatenses se dispara a casi un 30\%. Además, los cueros, son mercancías producidas íntegramente en la región y, por ello, su crecimiento impactó profundamente en su desarrollo económico y demográfico.

\section{Consideraciones finales}

El objetivo de este capítulo fue analizar la inserción del comercio del complejo portuario rioplatense en la Monarquía española y en el comercio global. Para ello dividimos el comercio en dos grandes sectores: el exterior y el interior. El exterior de la Monarquía española se desarrolló a partir de dos grandes puertas: Manila con el comercio con China y la península española con el resto de Europa. Estas eran las fronteras comerciales impuestas por la Monarquía.

La vinculación de Manila con China tuvo como eje central la establecida previamente con Acapulco que se ofrecía como conector entre la ruta del Pacífico y el resto de América. Hasta fines del siglo XVIII, el control de esta ruta estuvo en manos de los hispanoamericanos asentados en Nueva España y los intercambios más importantes eran entre la plata americana y los tejidos y cerámica china. La península española constituyó el nexo comercial exterior de las mercancías que circulaban por el Atlántico, donde se concentraban las europeas y americanas. 
Hasta mediados de siglo XVIII el puerto de Cádiz tuvo preeminencia y posteriormente se sumaron una gran mayoría de los puertos peninsulares.

En torno al comercio del Atlántico, hasta inicios de la segunda mitad del siglo XVIII, el sistema comercial ultramarino de la Monarquía se encontraba atado al circuito Cádiz- Portovelo- Veracruz- La Habana, logrando conectarse el resto de las regiones a partir de algunos registros sueltos o compañías comerciales que obtuvieron permisos especiales por algunas décadas.

En la segunda mitad del siglo, se produjeron transformaciones económicas globales que afectaron directamente a Iberoamérica. Por un lado, tenemos el proceso de industrialización que provocó la búsqueda de nuevas mercancías como insumos (palo Brasil, cueros, etc.) y otras para su consumo (te, café, azúcar, etc). Por otro lado, la invasión de Inglaterra a la Isla de Cuba que forzó a establecer cambios defensivos en los territorios. Esto permitió el desarrollo de varias regiones hispanoamericanas tanto en lo económico como en lo demográfico.

Las regiones productoras de materias primas volcadas al comercio ultramarino, tuvieron un proceso de aceleración económico que sedujo la llegada de migrantes que aumentaron la densidad de la población regional e insertaron a estas regiones en un círculo virtuoso: a mayor demanda externa, más producción, más migración y más población. El hecho de tener una mayor cantidad de habitantes permitió una mejor defensa regional ya que los sujetos que estuvieron a su cargo conformaron milicias.

Para que este proceso se produjese era necesario que ingresaran al comercio ultramarino nuevos actores y se vinculasen mucho más las distintas regiones. Los pequeños y medianos (y no tan medianos) productores industriales que no podían comercializar en Cádiz por lo costoso de mantener una casa 
comercial allí, sumado a los productores hispanoamericanos que tenían la capacidad de producir más, fueron los artífices y beneficiados de las reformas comerciales que se desarrollaron. Esto se debe a que lograron insertarse en un circuito que hasta ese momento les había sido vedado y con la oposición de quienes hasta ese momento concentraban este comercio. Este es el motivo por el cual se produjo la apertura a otros puertos que ocuparon una porción muy grande del comercio de América con la península.

El reflejo de este proceso se puede observar en el complejo portuario rioplatense, en donde se generó un crecimiento de la llegada de navíos a partir de la década de 1760. Este incremento estuvo marcado por la pluralidad de puertos de destino ya que se pasó de la centralidad previa de Cádiz, a una atomización de los destinos. Esta transformación se vio también en los tipos de navíos que comenzaron a surcar el Atlántico y las prácticas comerciales que desarrollaron.

En este capítulo, al establecer la proporción de metales preciosos y de cueros que partieron desde el complejo portuario rioplatense hacia la península española durante la segunda mitad del XVIII, encontramos que pese al crecimiento progresivo de los metales preciosos, el aumento de los cueros fue mucho mayor en términos absolutos. Además, se puede ver que una parte de los metales que partían no eran enviados por rioplatenses sino que los cargadores eran vecinos de otras regiones.

Se puede observar entonces que, en las últimas décadas el porcentaje de venta de cueros fue mayor al $20 \%$ que se tenía como media, llegando casi a un $30 \%$ sobre el total de lo enviado por los rioplatenses. Las causas de este crecimiento estuvieron marcadas por la oferta y demanda de esta mercancía que se 
producía en la región Río de la Plata. Los siguientes tres capítulos estarán dedicados a analizar esta dinámica. 


\section{CAPÍTULO III}

\section{El comercio ultramarino de cueros}

\section{Introducción}

"A la oración se da muchas veces carne de balde, como en los mataderos, porque todos los días se matan muchas reses, más de las que necesita el pueblo, sólo por el interés del cuero". (Concolocorvo 1997).

Esta afirmación de Corcolocorvo da cuenta de la importancia que tuvieron los cueros en la región Río de la Plata. Es en este sentido que, en el presente capítulo, se analizará el comercio ultramarino de cueros salidos por el complejo portuario rioplatense.

Durante la segunda mitad del siglo XVIII, a partir de la consolidación de nuevos tráficos comerciales de mayor volumen, se fue desarrollando la producción y comercialización de los productos pecuarios en la región Río de la Plata. Fundamentalmente se incrementó la producción de cueros ya que era un insumo muy necesario para poner en funcionamiento las maquinas textiles. En menor medida, se produjo tasajo, alimento para los esclavizados destinados a las plantaciones de azúcar de Cuba y Brasil. ${ }^{32}$

En esta tesis establecemos que los cargadores eran aquellos actores que intervenían como nexo entre los productores locales ${ }^{33}$ y los consumidores

\footnotetext{
${ }^{32}$ La proporción de cueros en relación a otros productos pecuarios varió a lo largo del período, dando cuenta de la progresiva diversificación productiva que la ganadería fue experimentando. Rosal y Roberto Schmit señalan que "entre 1779 y 1784, los cueros vacunos ocupan el 95\% del valor de las exportaciones agropecuarias; años más tarde, entre 1792 y 1796, el porcentaje bajó al $87 \%$ y hacia la década de 1820, el mismo se situó en el 69\%" (2004: 166). Como ya se señaló, en esta tesis no se analizará la dinámica de las distintas mercancías de menor cuantía ya que nos centramos en el cuero en particular.

${ }^{33}$ Hasta ahora la historiografía ha señalado que los grandes productores ganaderos, salvo algunos ejemplos, no participaron directamente del comercio durante este período, falta realizar un estudios sistemático de los productores para establecer sus vinculaciones, en ello se encuentra encaminada la investigación de Nicolás Biangardi (2013).
} 
ultramarinos. ${ }^{34}$ La perspectiva desarrollada en este capítulo es partir de la totalidad de los cargadores para luego analizar aquellos que tuvieron una actividad mayor en cuanto al número total de cueros cargados a su nombre en los navíos. En algunos casos los cueros los comerciaban a su cuenta y riesgo y, en otros, a cuenta y riesgo de terceros

El capítulo está dividido en cuatro apartados. El primer apartado es una descripción de la producción de cueros, su origen en la región y desarrollo. El segundo apartado analiza las cifras del comercio ultramarino de cueros hacia la península española. El tercer apartado es sobre los cargadores de cueros en general y en particular se analiza aquellos que concentraban gran parte del comercio. Por último, se da cuenta de los conflictos regionales que se produjeron en relación al permiso de comerciar cueros con territorios extranjeros durante los períodos de conflictos armados o como contrapartida por esclavizados.

\section{La producción pecuaria}

La llegada de los vacunos a la región Río de la Plata se originó desde distintos espacios y en distintos periodos. Durante el siglo XVI se produjo el asentamiento de vacunos traídos por Juan de Garay en 1573 y 1580 en Buenos Aires y Santa Fe. Desde Cabo Verde pasando por Brasil llegaron a Paraguay y también se movilizó desde Santiago del Estero y Córdoba. Las condiciones naturales (clima templado, abundante pastura, inexistencia de depredadores, entre otras) y la escasa población provocó que en los siguiente dos siglos se multiplicara el ganado alzado. Pese a ello, no se extendió por toda la región por la falta de agua dulce ${ }^{35}$.

\footnotetext{
${ }^{34}$ Tomamos como consumidores no solo a aquellos que consumieron efectivamente los cueros, sino también a aquellos actores que los recibieron para su fraccionamiento y posterior venta y que se encontraban en las regiones ultramarinas de llegada de los navíos.

${ }^{35}$ Una extensa bibliografía da cuenta de este proceso. Véase entre otros Giberti (1954), Levene (1952), Montoya (1957).
} 
Las expediciones que se realizaban podían tener dos objetivos, el de recoger y aquerenciar el ganado alzado, es decir, reunirlo, marcarlo y llevarlo a las estancias y el de cuerear y sebear que consistía en la cacería del ganado para la extracción de los cueros y sebo. Como plantea María Inés Moraes, este tipo de producción se basaba en la existencia de reservorios de animales cimarrones. Para armar las expediciones eran necesarios caballos y el dinero que había que darlo de antemano. La mano de obra era reclutada en la población criolla de la región Río de la Plata. A partir de considerarse un bien común intervenían los cabildos, los cuales tenían el monopolio de la explotación. A su vez, los preemisarios eran los agentes privados que adelantaban el capital para que se realicen las expediciones.

Se ha indicado en el capítulo 1 que en el primer tercio del siglo XVIII se agotaron las reservas de ganado en las zonas aledañas y que, por ello, se produjo la expansión del sistema de rodeos. Las actividades que se desarrollaban en el “calendario ganadero eran la aparición de las vacas -agosto/octubre- y la yerra (marcar y castrar los animales del último procreo), generalmente en julio si se trata de ganado vacuno de rodeo (Garavaglia, 1989: 567).

A este sistema se le sumó, a mediados del siglo XVIII, la nueva economía del cuero (NEC), la cual se caracterizó, a partir del auge comercializador y el avance de la propiedad privada, por la generalización de:

[...] la tipificación de "alzados" hacia cualquier bovino no sometido a rodeo, como parte de una estrategia de apropiación de animales ajenos por parte de los hacendados interesados en la producción masiva de cueros. En estos casos los hacendados o bien violaban directamente los derechos de propiedad de sus vecinos desconociendo su marca, o bien cazaban animales realengos alegando que sus animales se habían alzado antes de ser herrados [...] en el marco del furor exportador nació un tipo de estancia cuya actividad principal no era la cría sino la explotación esporádica de los planteles salvajes capturados bajo el 
expediente de haberse "alzado" del rodeo manso. En ese caso, la propiedad de la tierra daba derecho, o se pretendía que diera derecho, a organizar reiteradas expediciones sobre presuntos "alzados" que sencillamente eran ajenos. (Moraes, 2011: 240).

El desarrollo de esta práctica, sumado a lo señalado en los capítulos anteriores, da cuenta del grado de atlantización del mercado regional, en donde la producción y comercialización de los cueros ocupó un rol central.

\section{Fuentes trabajadas}

En este capítulo, para llegar a las cifras y la participación de los actores en el comercio ultramarino, se procesaron las fuentes fiscales que dan cuenta de cada uno de los envíos cueros desde el complejo portuario rioplatense.

Varios historiadores han dado cuenta que las fuentes que permiten realizar series para el periodo 1779-1809 son fragmentarias y se produce, en general, un corte abrupto de ellas en 1796 (Rosal y Schmit, 1999 y 2004). Con estos recaudos se realicé la búsqueda de las fuentes para hacer la serie. Una primera que comencé a trabajar para este fin, fueron los registros de los navíos, los cuales se encuentran en el AGN de Buenos Aires (hasta 1799) y en Montevideo (desde 1800 a 1809). Tras la enumeración de los navíos, se concluyó que no se encontraban completos por lo que no permitía una aproximación certera ni de las cifras ni de los actores.

Finalmente indagué en documentos que daban cuenta del comercio de Buenos Aires y Montevideo en forma separada. Ahí comencé a trabajar con las notas de aduana, las cuales son documentos que escribieron aquellos actores con el fin de poner en circulación determinados bienes, quedando en el lugar de origen y entregándose la guía de aduana que era el documento que se enviaba con la mercancía en cuestión. Como ya ha desarrollado Fernando Jumar para el caso de Buenos Aires, las notas de aduana se generaban cuando un particular (persona 
física o moral) se dirigía a la autoridad recaudadora local para comunicar su decisión de enviar fuera de la jurisdicción cualquier tipo de bien. La nota original era utilizada por los funcionarios para aforar los bienes y aplicar las tasas correspondientes, transformándolas así en base de las guías de aduana y de los asientos de los diversos libros de la administración. Luego se generaba una copia (la guía) que debía ser entregada en el destino, lo que daba lugar a nuevos gravámenes y el envío al origen de un documento -la tornaguía en donde se anunciaba la entrada de los bienes, el pago de los gravámenes correspondientes y el fin de la circulación prevista (Jumar, 2002). Esta información era pasada "en limpio" en un cuaderno con casi toda la información y finalmente a los libros de la administración de la Real Hacienda. Para este caso, trabaje con las notas de aduana y con el primer libro, específicamente el apartado del impuesto Ramo de Guerra.

Para extraer los datos de Buenos Aires, se encuentran completos los libros de la Real Hacienda, en donde figura quien enviaba cueros, la cantidad de los mismos y a cuenta y riesgo. Es importante remarcar que solo se detalla la información con respecto a los cueros, y en algunos años otros "productos de la tierra" ${ }^{36}$, sin especificar el resto de mercancías, en cuyo caso es necesario acudir a las notas y guías de aduana (Jumar, Zurdo, Sandrín, Biangardi, Bogosian, Errecart, Tappatá, 2009). Estos datos fueron triangulados con los aportados por la circulación de navíos a partir del epistolario que mantuvieron el Gobernador de Montevideo con el Virrey del Río de la Plata.

La importancia de la información que proporcionan estas fuentes está dada al menos por dos cuestiones. En primer lugar, se puede establecer las cantidades

\footnotetext{
${ }^{36}$ Son aquellas mercancías producidas regionalmente.
} 
de cueros que salieron del Complejo Portuario Rioplatense por medio de sus dos puertos habilitados para ese fin, Buenos Aires y Montevideo, en el comercio legal, sus destinos y regularidades. En segundo lugar, se puede vincular las mercancías con los actores intervinientes, a través de lo cual se extraerían los totales de los actores y los períodos en que comerciaron.

\section{Las cifras del comercio ultramarino de cueros}

\section{$\underline{\text { Antecedentes }}$}

El crecimiento del comercio ultramarino de cueros salidos por el complejo portuario rioplatense en las últimas décadas del siglo XVIII fue expuesto en los primeros textos de la historiografía clásica. El objeto de estudio estuvo centrado en determinar el momento en el cual comenzó a producirse el crecimiento del comercio ultramarino de cueros y las causas del mismo.

Bartolomé Mitre (1927) otorgó un lugar central a la aplicación del Reglamento de Libre Comercio de 1778. En el mismo sentido, los trabajos de Emilio Ravignani (1952) aportan cifras a partir de notas sueltas sobre ello, mientras que Eduardo Azcuy Ameghino (1997) contribuye en sus trabajos lo descripto por cronistas y funcionarios que alababan las virtudes del Reglamento ${ }^{37}$. Para el caso del puerto de Montevideo, el estudio de Arturo Bentancur (1999) establece similitudes con los trabajos de Azúa (1991) Pivel Devoto (1952). Por último, Hernán Asdrúbal Silva (1993) a partir de resúmenes de funcionarios albergados en el Archivo General de Indias, aporta datos en relación al tráfico entre el Río de la Plata y la península española para un período determinado.

\footnotetext{
${ }^{37}$ Algunos de los cronistas trabajados son: Félix de Azara "Viajes por la América Meridional.". Madrid, Ed. Espasa. 1969.; Anónimo "Noticias sobre los campos de Buenos Aires y Montevideo para su arreglo, 1794”. Estudio preliminar de Rogelio Brito Stefano, En Revista Histórica. Tomo XVIII. Montevideo, 1953.
} 
En líneas generales, estas interpretaciones plantean que, producto de la aplicación del Reglamento, se generó un crecimiento del comercio ya que se permitió la afluencia permanente de navíos que llegaban con manufacturas europeas y eran intercambiadas, en primer lugar, por plata y, en segundo lugar, por cueros. Los trabajos antes mencionados establecieron como lugar de análisis especifico el puerto de Buenos Aires y el crecimiento que se produjo en torno a éste. Al mantener sólo los datos de algunos años aislados, se torna complejo determinar si los años que se exponen no son una excepción y se dificulta establecer la forma en que se elaboraron los mismos. Esto se debe a que al ser notas aisladas sin datos de su autor o notas de viajeros la crítica de fuentes los torna endebles. Finalmente, establecer que un crecimiento económico se produjo a partir de un reglamento requiere evaluar la economía anterior al mismo e instituir las transformaciones que se sucedieron a partir de su promulgación y puesta en vigencia efectiva.

Otra línea interpretativa, más reciente, minimiza el papel del Reglamento pero, como planteo María Inés Moraes, "ratificaron la imagen de un temprano despegue rioplatense, ahora desplegado a lo largo de la segunda mitad del siglo XVIII” (2011: 11). Estas investigaciones basaron sus análisis en la construcción de series a partir de diversos corpus documentales, encontrando las causas de ese crecimiento en procesos internos.

El primer trabajo dentro de esta interpretación es el desarrollado por Juan Carlos Garavaglia quien en Economía, Sociedad y Regiones analizó la salida de cueros desde los puertos de Buenos Aires y Montevideo durante el período 17791784. Las fuentes que utilizó fueron los libros diarios de la aduana de Buenos Aires y Montevideo. Si bien el análisis comienza en 1779, Garavaglia estima que 
el crecimiento comercial es previo. Este trabajo es muy importante en cuanto al aporte metodológico ya que la utilización de los libros de aduana (los cuales a partir de 1785 no se encuentran completos) permitió no solo establecer las cifras sino también los actores intervinientes. Además, da cuenta de la dinámica de los dos puertos y sus respectivos espacios productores.

Por otro lado, el análisis de Zacarías Moutoukias (1995) está orientado a estudiar el comercio ultramarino de cueros centrado en el puerto de Buenos Aires. El autor plantea “entre 1760 y 1796 la sucesión de acontecimientos que mostraba, en efecto, una aceleración hasta entonces inédita." (2000: 373). Establece que durante el período 1760- 1796 el valor y volumen de las mercancías intercambiadas aumentó $\mathrm{y}$, a partir de 1780, creció en forma explosiva la fiscalidad de estos intercambios, repercutiendo en los totales del comercio. Establece que lo que sí cambió a partir de 1779 fue la participación relativa de los distintos tráficos (2000: 394), por lo cual la aplicación del Reglamento de Libre Comercio habría tenido un éxito indudable.

En términos absolutos hubo una clara expansión del comercio entre Buenos Aires y España, la cual se tradujo en un aumento notable de la participación de la navegación española. No hay dudas de que en ese breve lapso la Corona logró imponer el predominio de su intermediación comercial en el Río de la Plata. Sin embargo, lo perdería rápidamente tras las turbulencias en las que se vio envuelta después de 1796. Pese a ello, establece Moutoukias que la aplicación del Reglamento fue un episodio que no alteró sustancialmente ni el volumen ni las características de la demanda externa sino que, por la presión fiscal, una parte importante de lo que anteriormente era comercio directo pasó a ser "legal". 
Para llevar a cabo el análisis Moutoukias estima que el contrabando continuó teniendo un papel importante. Por ello, para la consecución de la cantidad de cueros exportados por año no extrajo los datos de una fuente en particular sino que realizó un cálculo a partir del total de navíos que salieron del complejo portuario. Para ello, computa primero a partir de treinta y cinco navíos, el tonelaje promedio de carga de cueros (entre 300 y 500 toneladas) y el peso de cada cuero en 35 libras y, así, establece una aproximación a la salida de cueros. Para separar la salida de los distintos puertos, calculó que un 40\% eran desde Buenos Aires. La causa del crecimiento se encontraría en el funcionamiento de complejos circuitos mercantiles que vinculaban los metales preciosos con las producciones regionales.

Miguel Rosal y Roberto Schmit ${ }^{38}$ estudiaron el comercio ultramarino de cueros a lo largo de casi cien años, 1756- 1852, tomando las cifras de Zacarías Moutoukias, Juan Carlos Garavaglia y de Osvaldo Pérez. Plantean entonces que un $20 \%$ de las salidas eran de productos pecuarios, variando a su vez su composición, entre el vacuno, el predominante, de baguala, lobo marino y a partir de la década de 1790 de tasajo.

Recientemente, María Inés Moraes (2011) aporta datos a lo analizado por Moutoukias sobre Buenos Aires, para la otra banda del Río. En su tesis donde analiza sobre la producción de cueros de las antiguas misiones, estableció que el crecimiento del comercio de cueros se produjo a partir del incremento de la oferta ya que, desde 1760, hubo un proceso de re-localización de la actividad de

\footnotetext{
${ }^{38}$ Rosal, Miguel Ángel y Schmit, Roberto. "Del reformismo colonial borbónico al libre comercio: las exportaciones pecuarias del Río de la Plata (1768-1854)", En: Boletín del Instituto de Historia Argentina Dr. Emilio Ravignani, Tercera Serie, núm. 20, Bs. As., 1999; Rosal, Miguel y Roberto Schmit. "Las exportaciones pecuarias bonaerenses y el espacio mercantil rioplatense (17681854)". En Juan Carlos Garavaglia y Raúl Fradkin (ed.) En busca del tiempo perdido. La economía de Buenos Aires en el país de la abundancia 1750- 1865. Buenos Aires. Prometeo. 2004.
} 
corambre en dirección al Norte, cada vez más lejos del Río de la Plata, en busca de los ganados cimarrones. Aunque no fueron los únicos afectados, los territorios realengos comprendidos entre los ríos Uruguay y Negro cobraron un renovado interés.

Por otro lado, Fernando Jumar (2002) realiza un corte temporal de casi cien años desde 1680 a $1778 \mathrm{y}$, si bien toma un amplio abanico de fuentes, los registros de navíos ocupan un lugar central, siendo estos una fuente que permite reconstruir el envío de bienes y caudales dentro del circuito legal, las cantidades, quiénes lo efectuaban y a qué lugares se dirigía. El autor establece que el primer proceso de comercialización de cueros a gran escala se produjo en las primeras décadas del siglo XVIII sosteniendo que los años de la Guerra de Sucesión marcaron un primer boom exportador.

Jumar sostiene que, tras el establecimiento del libre comercio de cueros de 1677, los cabildantes perdieron el control del negocio y se concentraron en la producción. Sin embargo, en 1708 recuperaron su control de un modo más completo por lo cual, a partir de esos años, se combinaron los efectos de la concentración de la producción en menos manos y el control del circuito comercial. En este sentido, afirma el autor: "se llegó a un grado de eficacia empresarial que permitió responder a la demanda, hasta se extendió la zona de caza de bovinos a la Banda Oriental hasta entonces en barbecho" (2002b: 127).

Daniel Santilli (2013) relativiza la idea de la aplicación del reglamento como único factor de crecimiento económico, ya que le otorga un papel fundamental en torno al crecimiento del comercio ultramarino de cueros de Buenos Aires y su entorno. La hipótesis central de su artículo es que a partir de las transformaciones institucionales desarrolladas en la década de 1770, en particular 
la creación del Virreinato del Río de la Plata y el Reglamento, se produjo un crecimiento de la potencia del mercado urbano de Buenos Aires y su entorno. Este mercado se integró, por ende, en torno a dos frentes:

"Por un lado, hacia el interior de la campaña requiriendo bienes de consumo, alimentos sobre todo, que pudieran llegar a un precio competitivo a la ciudad [...] Por otro lado, en el frente externo se realizó el proceso de integración requiriendo bienes pasibles de ser exportados, como los cueros. Así se integraba el litoral, que formaba parte del espacio económico rioplatense y cuyas pieles curtidas llegaban a precios competitivos a Buenos Aires." Santilli (2013: 16-17).

Con el fin de contribuir a esta temática, el presente capítulo se propone integrar las cifras del comercio ultramarino de cueros fiscalizados de las últimas décadas del siglo XVIII e relacionar a las causas internas del crecimiento con las necesidades externas de esta mercancía.

\section{El comercio ultramarino de cueros}

Como ya se planteó, la historiografía reciente ha establecido que en la segunda mitad del siglo XVIII se produjo un crecimiento del comercio ultramarino. En este apartado se analizaran las cantidades de cueros salidos desde el complejo portuario rioplatense y la importancia que adquirió esta mercancía en algunas regiones de la península español. Se parte del análisis que realizó Fernando Jumar (2002) para el período 1680-1778, en donde plasma las cifras de salida y las características de los cargadores. Además, como ya se dijo, establece cómo a principio de siglo se produjo un primer boom de salida de cueros, relacionándolo con un proceso de transformaciones que se comenzaron a producir desde fines del siglo XVII. (Jumar, 2008) A partir de este antecedente, desde mediados del siglo XVIII, se consolido la tendencia de crecimiento del comercio ultramarino de cueros. 


\section{Gráfico III. 1}

Total de cueros comercializados en el mercado ultramarino salidos del complejo portuario rioplatense (1720-1799)

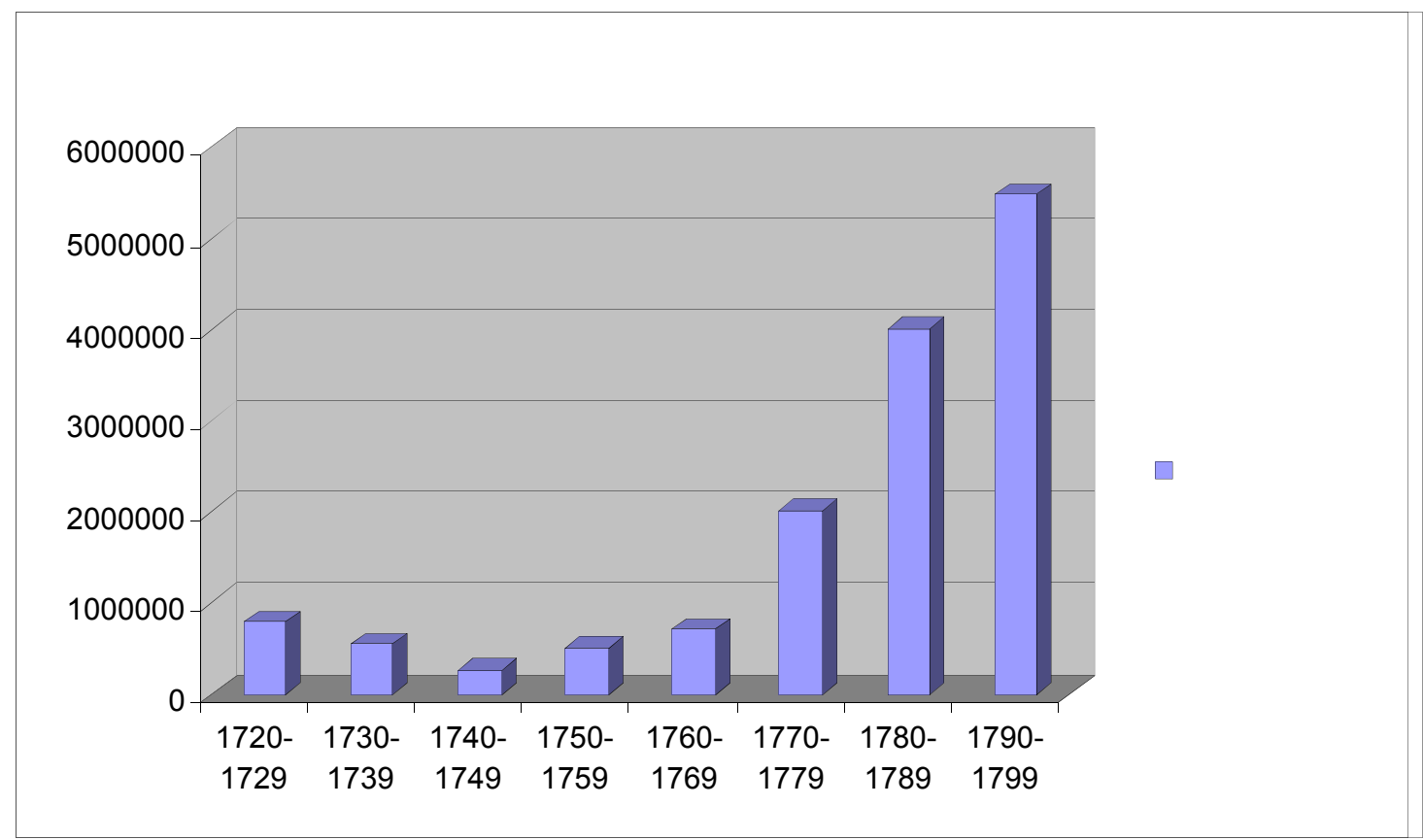

Fuente: Elaboración propia a partir de los datos extraídos de Jumar (2002) y AGN Sala XIII: $15-10-3 ; 37-6-4 ; 37-10-5 ; 37-10-6-; 38-8-3 ; 38-8-4 ; 38-1-1 ; 38-1-3 ; 38-$ $2-3$; 38-3-4; 38-4-4; 38-5-3; 38-6-4; 38-1-3; 39-1-3; 39-2-1; 39-2-2; 39-3-1; 39-32 ; 39-3-3; 39-4-3; 39-5-4; 39-6-2; 39-8-4; 39-9-3; 39-10-1; 39-10-4; 39-7-4; 15$10-3 ; 37-9-3 ; 37-9-4 ; 38-10-3$; 38-6-3. 14-9-5; 14-10-1; 14-10-2; 14-10-3; 14-10$4 ; 15-10-1 ; 15-10-2 ; 15-10-3$.

En el gráfico III.1 se puede apreciar la importancia de las primeras décadas del siglo XVIII, ya que las cifras de este período recién se recuperarán treinta años después, en la década de 1760. A partir de entonces comienza a incrementarse el comercio en forma paulatina. Según María Inés Moraes (2011), ello se debió a una transformación en los mecanismos de la producción. Durante la primera mitad del siglo XVIII, se producen circunstancias específicas que incrementan la salida de cueros como el asentamiento de la Campagnie de Guinée et de 1'Assiento (1703-1715), la South Sea Company (1715-1738, con interrupciones) y el comercio con Brasil, sin embargo fueron insuficientes para mantener ese nivel e incrementarlo. 
En 1779, la salida de cueros del complejo portuario rioplatense continuó aumentando manteniendo la tendencia ya desarrollada durante el siglo XVIII a partir de 1760. La guerra con Inglaterra, que comenzó precisamente en 1779, no permitió que se reflejara esta tendencia. Sin embargo, a partir del acuerdo de paz en 1783, se produjo un incremento sustancial que compensó la caída de la salida previa, con más de un millón unidades en 1783 y casi setecientas mil durante el año siguiente. Como se puede observar en el gráfico III.2, salvo en el período de guerra con Inglaterra, el comercio de cueros no bajó ningún año de las trescientas cincuenta mil unidades, hasta el nuevo conflicto militar de finales de siglo, en donde se vuelve a exportar mínimas cantidades.

Es interesante remarcar que la oferta, durante este último conflicto armado, se mantuvo disponible, siendo la pauta de salida marcada por la dinámica externa (contexto bélico) a partir del ingreso de navíos neutrales de distintos orígenes que transportaban cueros. Estos navíos eran de origen angloamericano en su mayoría y no sólo fletaban mercancías desde y hacia la península española, sino que también comerciaban con otros lugares, como Estados Unidos o Hamburgo (Silva, 1979), estableciendo así redes de relaciones con los productores locales y demás actores ávidos de consumición de cueros e inserción de mercancías manufacturadas propias. Esta oferta de cueros fue lo que permitió el mantenimiento del precio durante todo el período ya que, mientras que la demanda creció lentamente, siempre se mantuvo la oferta en las dos bandas del río. ${ }^{39}$

\footnotetext{
39 María Inés Moraes (2011) analiza los precios de los cueros en Buenos Aires y Ámsterdam llegando a la conclusión de que no se produjeron cambios sustantivos.
} 


\section{Gráfico III. 2}

Total de cueros (en unidades) salidos al comercio ultramarino desde el complejo portuario rioplatense 1779 - 1799

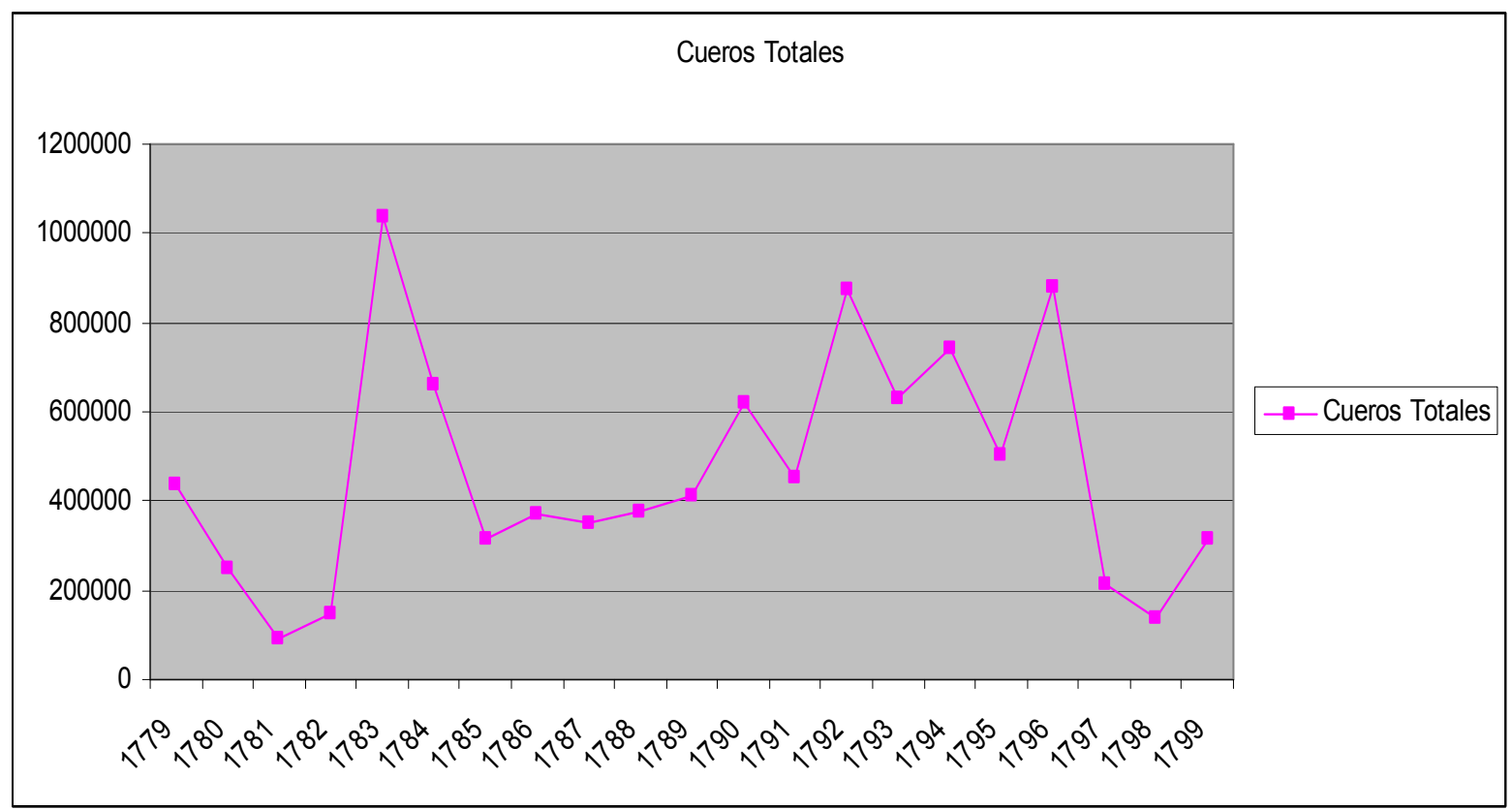

Fuente: Elaboración propia a partir de los datos extraídos de AGN Sala XIII: $15-$ 10-3; 37-6-4; 37-10-5; 37-10-6-; 38-8-3; 38-8-4; 38-1-1; 38-1-3; 38-2-3; 38-3-4; $38-4-4 ; 38-5-3 ; 38-6-4 ; 38-1-3 ; 39-1-3 ; 39-2-1 ; 39-2-2 ; 39-3-1 ; 39-3-2 ; 39-3-3$; $39-4-3 ; 39-5-4 ; 39-6-2 ; 39-8-4 ; 39-9-3 ; 39-10-1 ; 39-10-4 ; 39-7-4 ; 15-10-3 ; 37-9-$ 3 ; 37-9-4; 38-10-3; 38-6-3. 14-9-5; 14-10-1; 14-10-2; 14-10-3; 14-10-4; 15-10-1; $15-10-2 ; 15-10-3$.

La salida de cueros de los dos puertos habilitados de la región Río de la Plata da un total de casi diez millones en estos veinte años y un promedio de casi quinientos mil al año. Este importante número de cueros comercializados en el mercado ultramarino salió en forma relativamente equilibrada de dichos puertos, si bien desde Buenos Aires su número fue mayor que desde Montevideo. Esto se pudo haber debido a dos causas. En primer lugar, el incremento de la población de Montevideo y del comercio y, en segundo lugar, la expansión de la producción pecuaria en las antiguas posesiones de los Jesuitas. 
Cuadro III. 1

Cueros salidos de Montevideo y Buenos Aires (1779- 1799).

(en unidades)

\begin{tabular}{|c|c|c|c|}
\hline & Total de cueros & Porcentaje \% & $\begin{array}{c}\text { Por año } \\
\text { media }\end{array}$ \\
\hline Montevideo & 4.414 .630 & 44,50 & $220.731,5$ \\
\hline Buenos Aires & 5.504 .185 & 55,49 & $275.209,25$ \\
\hline Total & 9.918 .815 & $100 \%$ & $495.940,75$ \\
\hline
\end{tabular}

Fuente: Elaboración propia a partir de los datos extraídos de AGN Sala XIII: 15$10-3$; 37-6-4; 37-10-5; 37-10-6-; 38-8-3; 38-8-4; 38-1-1; 38-1-3; 38-2-3; 38-3-4; $38-4-4 ; 38-5-3 ; 38-6-4 ; 38-1-3 ; 39-1-3 ; 39-2-1 ; 39-2-2 ; 39-3-1 ; 39-3-2 ; 39-3-3$; $39-4-3 ; 39-5-4 ; 39-6-2 ; 39-8-4 ; 39-9-3 ; 39-10-1 ; 39-10-4 ; 39-7-4 ; 15-10-3 ; 37-9-$ 3 ; 37-9-4; 38-10-3; 38-6-3. 14-9-5; 14-10-1; 14-10-2; 14-10-3; 14-10-4; 15-10-1; $15-10-2 ; 15-10-3$.

Las fronteras de la zona norte de la región Río de la Plata se tornaron difusas en este período, con lo cual, no es posible establecer certeramente el lugar de donde provinieron los vacunos. Sin embargo, es para remarcar el hecho de que lleguen a cada uno de los puertos. En primer lugar, la cercanía del puerto de salida ya establece que, probablemente, el transporte de cueros por el río se tornaba innecesario $^{40}$. En segundo lugar, el paso de cueros hacia la zona de Buenos Aires se vuelve improbable ya que la mayoría de los envíos se encontraba cercana a Montevideo por las facilidades que deja ese puerto. Por último, dado el fluido contacto entre los actores comerciales se dificultaba la posibilidad de que fueran transportados para realizarse las transacciones comerciales. Todas las investigaciones coinciden en que la mayor producción de cueros está en la Banda Oriental y, sin embargo, salen por Buenos Aires. Como se analizó en el capítulo 1, otro motivo posible es que fuera más barato moverlos por botes desde Víboras, Colonia, etc. a Buenos Aires que por tierra a Montevideo. 
En el gráfico III-3 se puede observar cómo durante el período estudiado de los dos puertos el comercio se produjo, en términos generales, con armonía en relación al porcentaje. Así todo, es remarcable el hecho de que se cumple la conocida premisa de que en los conflictos militares se produce un descenso marcado y en los años de paz, se incrementa sustancialmente el comercio.

Gráfico III. 3

Total de Cueros (en unidades) salidos al comercio ultramarino desde Montevideo y Buenos Aires 1779- 1799

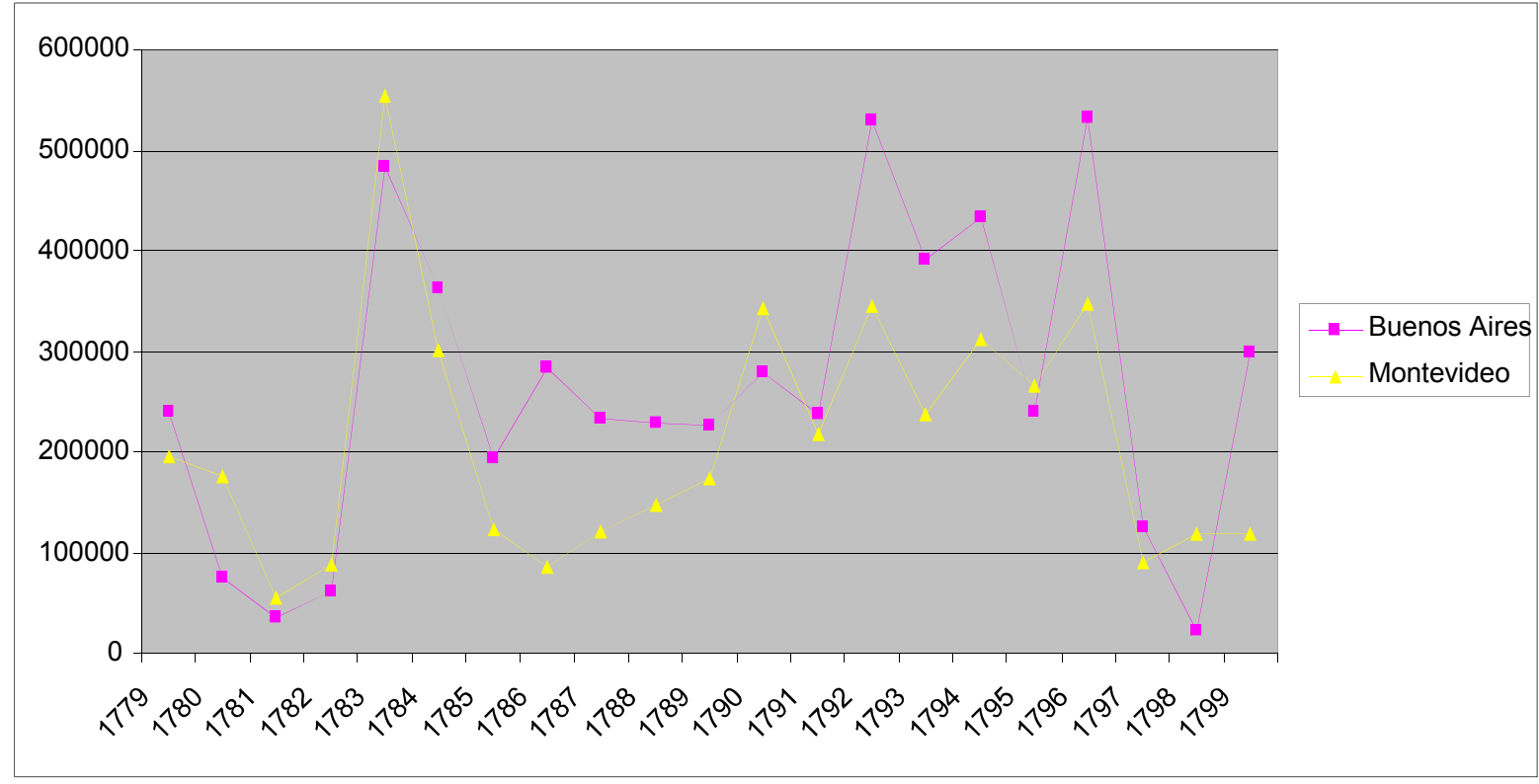

Fuente: Elaboración propia a partir de los datos extraídos de AGN Sala XIII: 1510-3; 37-6-4; 37-10-5; 37-10-6-; 38-8-3; 38-8-4; 38-1-1; 38-1-3; 38-2-3; 38-3-4; $38-4-4 ; 38-5-3 ; 38-6-4 ; 38-1-3 ; 39-1-3 ; 39-2-1 ; 39-2-2 ; 39-3-1 ; 39-3-2 ; 39-3-3$; $39-4-3 ; 39-5-4 ; 39-6-2 ; 39-8-4 ; 39-9-3 ; 39-10-1 ; 39-10-4 ; 39-7-4 ; 15-10-3 ; 37-9-$ 3 ; 37-9-4; 38-10-3; 38-6-3. 14-9-5; 14-10-1; 14-10-2; 14-10-3; 14-10-4; 15-10-1; $15-10-2 ; 15-10-3$.

En el gráfico III.3 se puede observar como en los primeros años estudiados, el predominio de Buenos Aires no es claro sino todo lo contrario, ya que en algunos años desde Montevideo salieron más cueros que desde Buenos Aires. Sin embargo, esta tendencia pronto se truncó y el predominio de Buenos Aires se hizo notable y con cierta regularidad. Una posible causa de esta tendencia 
es que en Buenos Aires se concentraban los cueros del litoral, siendo su única salida el puerto bonaerense. En cambio, en el caso de Montevideo, la existencia de la frontera con Brasil permitía la posibilidad de otra salida de los mismos. Ésta posible salida "ilegal" de los cueros, entra en el plano de lo incierto.

Sumado al incremento de la cantidad de navíos que ingresaron y salieron en forma regular del complejo portuario rioplatense, se encuentra el aumento de productos regionales comercializados. Esto nos da un cambio producido en la economía regional que fue acompañado de una política de homogeneización durante el siglo XVIII.

Como ya se aclaró, en este trabajo las fuentes analizadas son fiscales, lo que nos permite poder establecer sólo la salida de cueros legales, sin poder dar cuenta de aquellos no registrados. No obstante, para el caso de Buenos Aires, Zacarías Moutoukias (1995) realizó un recorrido distinto. Partiendo de los navíos que salieron desde los puertos habilitados y de la carga total posible, traducida a un número de cueros promediado por su peso, el autor plantea un mecanismo que evade el potencial fraude existente. Estima así que una parte importante de los cueros no fueron declarados, pero cargados igualmente. En este sentido, al reconstruir la cantidad total de la carga, se plantea un máximo de la carga estableciendo un número de cueros que no refleja la salida real sino una tendencia alcista en cuanto a lo más cercano a lo real, ya que el peso real de la carga, en su mayoría eran cueros.

Fernando Jumar sostiene que el contrabando se realizaba en el mercado interno a partir de la compra de cueros para su acopio, el contrabando hormiga (Jumar y Paredes, 2008) peros plantea la imposibilidad de cargar los navíos para el comercio ultramarino: 
"El interés de los empresarios ganaderos en el comercio ultramarino es que, dadas las modalidades de la actividad, la exportación de cueros requiere que los navíos del tráfico tengan acceso legal a los puertos y amarraderos del complejo portuario rioplatense. Es imposible cargar 70.000 cueros de contrabando, tarea que a lo largo de un par de meses requería muchos de trajines de embarcaciones menores y la intervención de mano de obra con y sin especialización (arrumadores, estibadores, etc.). Es decir, que ante cualquier bloqueo de la circulación legal, su reclamo siempre fue el mismo: abrir puertas a la legalización del comercio de amigos, neutrales o de quien sea." (Jumar, 2010: 20)

\section{Gráfico III. 4}

Comparativo de total de Cueros (en unidades) salidos al comercio ultramarino a partir del total de navíos y fiscales. 1779- 1796

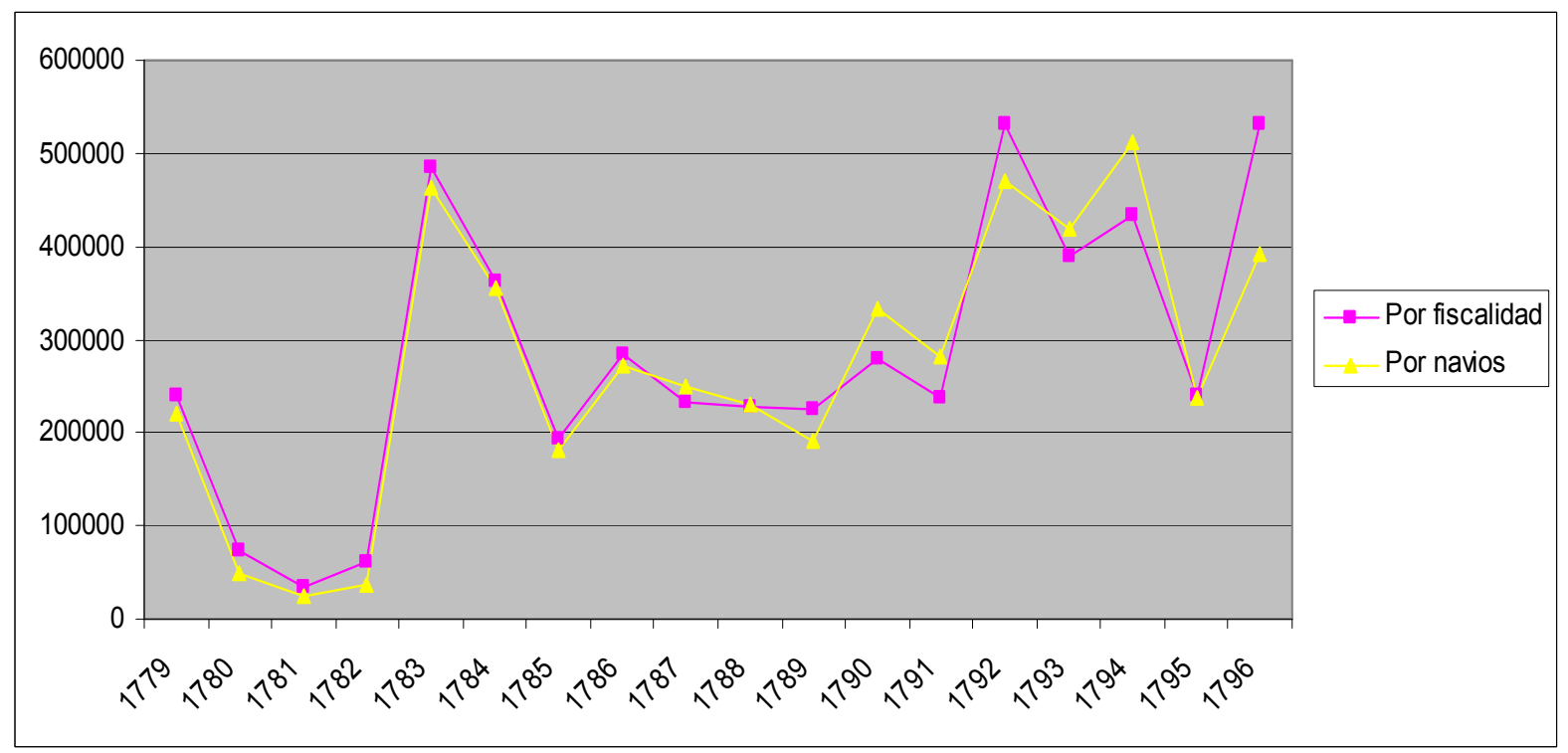

Fuente: Por fiscalidad: Elaboración propia a partir de los datos extraídos de AGN Sala XIII: $15-10-3 ; 37-6-4 ; 37-10-5 ; 37-10-6-; 38-8-3 ; 38-8-4 ; 38-1-1 ; 38-1-3$; 38$2-3 ; 38-3-4 ; 38-4-4 ; 38-5-3 ; 38-6-4 ; 38-1-3 ; 39-1-3 ; 39-2-1 ; 39-2-2 ; 39-3-1 ; 39-3-$ $2 ; 39-3-3 ; 39-4-3 ; 39-5-4 ; 39-6-2 ; 39-8-4 ; 39-9-3 ; 39-10-1 ; 39-10-4 ; 39-7-4 ; 15-$ $10-3$; 37-9-3; 37-9-4; 38-10-3; 38-6-3. 14-9-5; 14-10-1; 14-10-2; 14-10-3; 14-10$4 ; 15-10-1 ; 15-10-2 ; 15-10-3$. A partir de los navíos: Moutoukias (1995).

En el gráfico III.4, podemos observar una comparación de las cifras obtenidas a partir de las fuentes fiscales y aquellas estimadas en relación a los navíos. En términos generales existe un equilibrio en cuanto al número total de cueros, sin embargo, por momentos se puede observar un leve desfasaje producto 
de la utilización de fuentes distintas. Vemos que en el año en el cual se impuso el pago de los impuestos a la carga, la brecha o desfasaje es mayor entre las cifras obtenidas por las fuentes fiscales y las estimadas a partir de la carga de los navíos.

Por lo tanto, si las cifras del comercio que se encontraba fiscalizado y las sumadas a ellas del comercio directo por el mecanismo realizado por Moutoukias son similares, entonces el contrabando ultramarino no significó un porcentaje alto en relación al total de cueros que salieron por año. En otras palabras, podemos decir que no hubo contrabando ultramarino de cueros a gran escala ya que las cifras de la carga de la bodega, que en principio retornaba completa de cueros, y las fiscalizadas son similares. En este sentido, las similitudes del comercio legal y el directo nos aproximan al trabajo de Fernando Jumar quien plantea esta dificultad.

Como se puede apreciar en el gráfico siguiente a partir de la guerra de 1796 con Inglaterra, se produjo un descenso de la salida de cueros pero, como en la guerra anterior, se recuperó velozmente una vez concluida. Por lo tanto, si bien los conflictos armados generaron dificultades en este comercio en particular, no produjeron un declive pronunciado sino que, todo lo contrario, una vez firmada la paz, continuaron saliendo masivamente cueros desde el complejo portuario. 
Gráfico III. 5

Totales de cueros salidos por el complejo portuario rioplatense, 1779- 1806

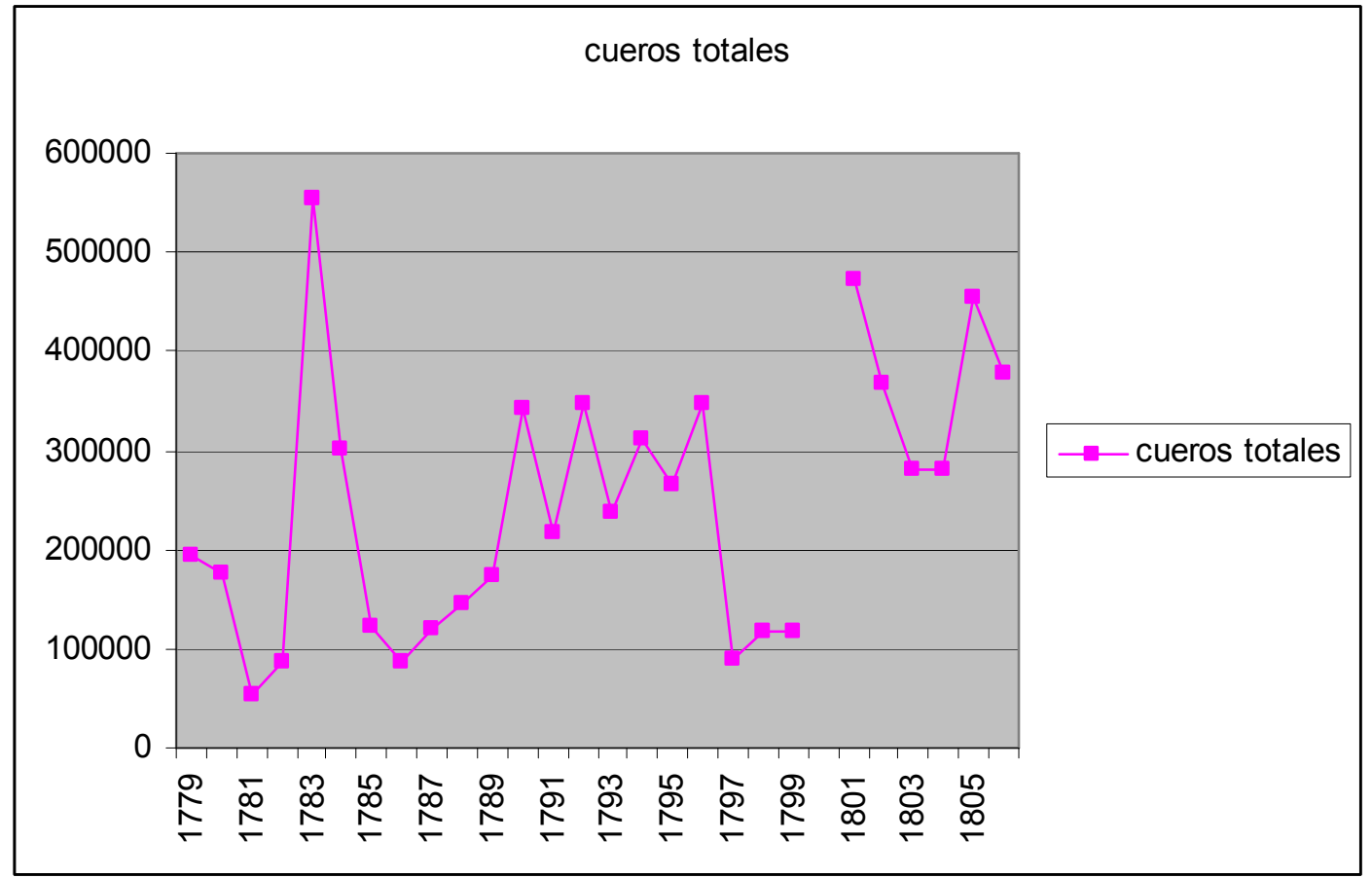

Fuentes: Elaboración propia a partir de los datos extraídos de AGN Sala XIII: $15-10-3$; 37-6-4; 37-10-5; 37-10-6-; 38-8-3; 38-8-4; 38-1-1; 38-1-3; 38-2-3; 38-34 ; 38-4-4; 38-5-3; 38-6-4; 38-1-3; 39-1-3; 39-2-1; 39-2-2; 39-3-1; 39-3-2; 39-3-3; $39-4-3 ; 39-5-4 ; 39-6-2 ; 39-8-4 ; 39-9-3 ; 39-10-1 ; 39-10-4 ; 39-7-4 ; 15-10-3 ; 37-9-$ 3 ; 37-9-4; 38-10-3; 38-6-3. 14-9-5; 14-10-1; 14-10-2; 14-10-3; 14-10-4; 15-10-1; 15-10-2; 15-10-3. AGI, Buenos Aires 848.

Este crecimiento del comercio ultramarino, desde la década de 1760 en adelante no solo fue producto del aumento de la oferta sino que era un insumo imprescindible para la industrialización. Se ha planteado que el cuero era un lastre conveniente para la circulación de los navíos ya que las piedras que se utilizaban habitualmente para ello eran vendidas en Buenos Aires (ya que tenían un alto costo producto de la falta crónica de ese material en la zona) y se retornaba, para el mantenimiento del nivel de flotación, con cueros (Amaral, 1998; Rosal y Schmit, 2004). A continuación, se desarrollarán algunos ejemplos para vislumbrar la vital importancia que tuvieron los cueros para las regiones de destino. 
En el epistolario comercial de varios de los comerciantes que se encuentra en el Arxiu de la Ciutat de Barcelona se pueden observar los mecanismos utilizados para ese fin. El desarrollo industrial descentralizado y el claro crecimiento de la segunda mitad del siglo XVIII produjeron que se incrementara el número de pequeños industriales que intentaban mantener un contacto directo con algún actor instalado en la región Río de la Plata. La carta de Francisco Ribas y Cía., fechada el 7 de febrero de 1804, destinada a Juan Larrea vecino de Buenos Aires, es un claro ejemplo de este proceso:

Muy estimado, por unos amigos los Francisco Manxuach y Antonio José Cot, vecinos y del comercio de Mataró, nos han dado conocimiento de la casa de usted nos hallamos informados de las circunstancias de ella, lo que estamos deseosos de establecer parte de nuestro giro con esa plaza, nos anima a valernos de ella confiados tendría usted el bien de aceptar una comisión y manejar nuestros intereses como si propios, asegurando por una parte que si el existió de este ensayo, es como deseamos, y esperamos continuaremos los envíos de los pintados de nuestra fabrica, y por consiguiente, entablaremos una correspondencia seguida, que nos sea respectivamente utilosa. A consecuencia de lo dicho, hemos registrado, en la Polacra Santos Inocentes, del Capitán Juan Basten, vecino de Blanes 90 piezas finas, condicionadas en 3 tercios marcados con unas iniciales [...] Sobre los retornos, anhelamos la brevedad y siendo los cueros baratos, que usted conozca puedan de sernos alguna utilidad, y en estación de invierno, que no estén sujetos a apolillarse, los preferimos al metálico, pero no siendo en esto, venga en efectivo. ${ }^{41}$

El ejemplo señalado da cuenta de varios elementos para resaltar. En primer lugar, el mecanismo de acceso a los actores insertos en América, el cual se produce a partir de la cercanía de otro "industrial” que había instalado el contacto. Como plantea Jaume Torras Elías (2007), los mecanismos de expansión comercial se daban a partir de una especie de "don y contra don" entre familiares o personas del mismo pueblo. No se producía por una pertenencia regional, sino local. Es

\footnotetext{
${ }^{41}$ Aria de la Cauta de Barcelona. Fondo Comercial. Ignacio Parera y Cía. Cartas, pp. 16 y 17.
} 
decir, se mantenía una vinculación comercial con actores del mismo pueblo y su región cercana y, a partir de ello, se extendía a otros interesados en insertar sus mercancías en la región Río de la Plata.

En segundo lugar, vemos que muchos tenían la posibilidad de comerciar pequeñas cantidades. Durante el período en el cual se encontraba como único medio regulado y estable las flotas y galeones y el monopolio de Cádiz, el número de comerciantes que podían actuar era escaso y sólo podían enviar mercancías manufacturadas aquellos que tenían una conexión en Cádiz. En cambio, durante la segunda mitad del siglo XVIII, con la generalización de los navíos de registro y las fragatas correos al complejo portuario rioplatense desde distintos puertos, se produjo una ampliación de la cantidad de actores que intervinieron ya que no fue necesario enviar grandes cantidades como así tampoco lo fue tener un contacto en Cádiz.

Por último, en esta carta se puede apreciar cómo el lugar que ocupa el cuero tiene preeminencia en relación al que ocupan los metales preciosos. Con esto no se quiere decir que el lugar de la plata no fuera en mayoritario, sino que los cueros eran un insumo necesario y vital para el desarrollo industrial.

En el censo de la Riqueza Territorial e Industrial de España del año $1799^{42}$ se puede observar la escasa cantidad de vacunos en la península española en relación a la población. En este censo se puede ver entonces que el número de vacunos es lo suficientemente bajo como para que los cueros rioplatenses cobren una importancia vital dado que varias zonas, con desigual desarrollo, se encontraban en un proceso de industrialización.

${ }^{42}$ Censo de la Riqueza Territorial e Industrial de España en el año de 1799. Madrid. Imprenta Real, 1803. 
En el caso de Cataluña, la industrialización se encontraba vinculada a la producción de distintos tipos de textiles y aguardiente. Isabel Miguel López (1996) realizó un análisis del Censo de Manufacturas de 1784 de Cataluña, en donde establece geográficamente las principales industrias de la región. La manufactura lanera, de lino/cáñamo, algodonera y sedera se encontraba distribuida por todo el territorio. El subsector del cuero era actividad consolidada:

cuyos núcleos más notables se ubicaban en algunos de aquellos que también lo eran en quehaceres textiles. Así ocurría en Barcelona, Vic, Olote, Igualada, y en menor medida Reus y Valls, con la nota sobresaliente de Horta. Localidades que merecen resaltarse por el número de sus tenerías, el empleo movilizado y la variedad de sus productos. (Miguel López, 1996: 128).

La importancia de la industrialización se reflejaba también en las medidas/propuestas/ideas de los funcionarios españoles. Un ejemplo de ello es el Corregidor del Talarn quien, en 1784, plantea que:

si se evitara la entrada de lienzos extranjeros pintados, si se rebajaran los derechos de aduana de pelo de camello, lana de vicuña y castor, se propiciara la venida de cueros de Buenos Aires y los becerrillos del exterior tuvieran franquicia de derecho por la escasez que tienen en nuestra España, se estimularían los subsectores correspondientes (Sánchez Suarez, 1988: 18).

La Coruña, a partir de la década de 1760, tuvo en el complejo portuario rioplatense un mercado privilegiado en donde colocar su producción y la reexportación. Como plantea Ofelia Rey Castelao: "En ese período predominó el mercado de Buenos Aires/Montevideo - dos tercios de las exportaciones- y el mejor momento se alcanzó entre 1767 y 1778. El 63,4\% de las exportaciones eran productos textiles primarios y el 30,2\% del textil secundario, pero menos de la mitad eran productos gallegos $(44,6 \%)$ y el resto eran reexportaciones." (Rey Castelao, 2013: 12). Siendo el cuero rioplatense la principal mercancía 
intercambiada, encontramos, por ejemplo, casos como el del comerciante Jerónimo Hijosa que entre 1762 y 1772 adquirió 56.580 cueros y en 1782 100.000.

La mayoría de los cueros, luego de su llegada al puerto de la península española, eran reenviados a otros lugares de Europa. Los arribados a Santander, por ejemplo, eran reenviados en su mayoría a Bayona, Burdeos, Ostende y Londres (Miguel López: 2004).

\section{Los cargadores de cueros}

\section{$\underline{\text { Antecedentes }}$}

Hay una gran producción historiográfica en torno al análisis de los actores que intervinieron en el comercio del complejo portuario rioplatense. Estos trabajos estuvieron marcados por el estudio de los actores particulares o grupos con el objetivo de establecer las estrategias comerciales predominantes.

El libro de Susan Socolow (1991), tiene como objetivo establecer los mecanismos de ascenso de los comerciantes en el entramado social del siglo XVIII. En primer lugar, trabajó con los padrones militares de 1744 y de 1778 con el fin de establecer las características ocupacionales de la población, extrayendo los datos de aquellos que denominaron comerciantes (Johnson y Socolow 1979). Por otro lado, a partir de un estudio minucioso de las testamentarias, se concentró en los comerciantes de mayor riqueza. Llega así a la conclusión de que a partir de un proceso de asimilación de las redes instaladas, que van desde la conformación de la familia, religiosa y por similar origen, se produjo una consolidación de los actores ya establecidos y la incorporación de nuevos, los cuales, a partir de 
demostrar sus "aptitudes" para el comercio, eran asimilados dentro de esta elite (Socolow, 1991).

Según establece la autora esta forma de ascenso social, en la cual los nuevos actores se incorporaron a la elite comercial, no fue producto del libre acceso al mercado sino que se originó por medio de dos mecanismos: el trabajo con algún gran comerciante que los formaba y les permitía ingresar en el selecto grupo o, la consolidación de redes relaciones en Cádiz (que podían durar más de una generación), que les permitía viajar a Buenos Aires con una parte del camino ya realizado.

En varios textos, Zacarías Moutoukias se concentró en analizar las redes de los comerciantes $(1995,1999$ y 2000), señalando que la importancia de las redes de relaciones personales fue una característica central del comercio del siglo XVIII en América. En primer lugar, relaciona la importancia de los excedentes y la extensión geográfica de las transacciones. En segundo lugar, expone que, en condiciones de producción estables, la comunidad de comerciantes competía por un número igualmente equitativo de oportunidades. De este modo, la carrera ascendente de un comerciante se confundía con la incorporación de nuevas actividades y el progresivo control de un territorio, el único medio por el cual se podía obtener economías de escala y rendimientos crecientes, con la particularidad de que cada nueva actividad se agregaba a las anteriores.

Finalmente, la ausencia de instituciones formales que asegurasen la fluidez de las transacciones y del crédito a lo largo de tan vasto territorio, permitía el éxito de quienes lograban construir sólidos y flexibles tejidos de relaciones personales. El crédito era rudimentario, de donde se comprende la importancia del adelanto de mercancías a fiado. Los instrumentos con los que se contaba eran las 
libranzas, el préstamo con seguros y las compañías. Pero sólo parcialmente se podía sancionar el eventual incumplimiento de las obligaciones contractuales implícitas en esos instrumentos recurriendo al sistema judicial. La vida cotidiana de los negocios transcurría gracias a un engorroso sistema de compensación de cuentas que sólo la confianza o el temor a la sanción del grupo hacían funcionar. Por eso, las redes de relaciones personales, su identificación con formas políticas de autoridad, aseguraban el cumplimiento de los contratos y brindaban el esqueleto de las estructuras empresariales (Moutoukias, 1999).

Los estudios dedicados a analizar un actor en particular se caracterizan por tomar un caso "exitoso" y analizar las estrategias comerciales que aplicaron para ese fin ${ }^{43}$. En el estudio dedicado a la actividad económica de Domingo Belgrano Pérez, Jorge Gelman, (1996) ahondó en los mecanismos comerciales y las redes de este personaje. Considera centrales dos elementos: las alianzas familiares y las redes comerciales. La búsqueda de mayores beneficios se establece a partir de la diversificación de destinos de las relaciones comerciales. Esto se lograba por un lado, a partir de mantener vínculos con familiares, empleados y comisionistas en el interior. Por otro lado, se conseguía siendo comisionista de grandes comerciantes establecidos en Cádiz. Los intercambios se producían con el objetivo de vender diversas mercancías en el interior, manufacturas europeas o de otras regiones del interior, minimizando el uso de plata, la cual sólo era utilizada para el comercio ultramarino. Las ganancias, a su vez, eran invertidas en la compra de bienes inmuebles rurales, urbanos y semi-rurales.

\footnotetext{
${ }^{43}$ En los últimos años se ha desarrollado una importante producción historiogáfica que tomó como objeto de estudio los actores desde distintas perspectivas que han enriquecido el análisis del siglo XVIII en la región Río de la Plata. En torno a la participación de las mujeres en el comercio véase el trabajo de Marcela Aguirrezabala (2001, 2003, 2010, 2011). Sobre la relación de las pautas comerciales y familiares véase los trabajos de Elsa Caula $(2002,2007,2011)$ y Griselda Tarragó (1994, 2006), entre otros.
} 
Hugo Galmarini (2000) analizó la aplicación de las reformas borbónicas a partir de un caso en particular: Tomas Romero. Plantea que para que fueran exitosas las reformas:

Requerían de hombres identificados con sus objetivos, leyes que las instrumentaran y mercaderes dispuestos a comprometerse con las empresas que se presentaran. Como vimos, la instrucción consideraba importante el desarrollo de la explotación de los recursos naturales del mar para lo cual era necesario el fortalecimiento de la marina y de la flota pesquera, el comercio de negros, el auspicio de la industria de la salazón y la protección de la explotación minera lo que hacía imprescindible contar con el abastecimiento del azogue (Galmarini, 2000: 39).

Tomas Romero identificado con ese proceso diversificó sus inversiones en el comercio de cueros, esclavos y tasajo, entre otras mercancías (Galmarini, 2000).

Centrado en el análisis en un actor en particular también, pero desde otra perspectiva, se encuentra el trabajo de Mariano Schlez $(2010,2014)$ quien trabajó exhaustivamente sobre la participación económica y política de Diego de Agüero. ${ }^{44}$ Tomó como ejemplo este actor para dar cuenta de las características de los comerciantes monopolistas, los cuales tenían

“...como fundamento la existencia de relaciones sociales atrasadas. $\mathrm{Su}$ acumulación fue posible por el lugar de privilegio que poseían en la sociedad colonial, basada en un poder político feudal.(...) Estamos en presencia, entonces, de un caso de comercio inmerso en la dinámica feudal: Diego de Agüero formó parte de una burguesía subsidiaria de la nobleza peninsular, dependiente de la reproducción del Estado feudal español, y reprodujo sus intereses en el Río de la Plata, combatiendo a quien amenaza las condiciones que hacían posible su reproducción social.” (Schlez, 2010: 65).

Dentro de los trabajos focalizados en los actores, Fernando Jumar (2001, 2002), parte desde otro punto de vista metodológico ya que desde un estudio

\footnotetext{
${ }^{44}$ A partir de su trabajo se tomo como ejemplo para el análisis de los actores agrupados en torno al envio de metales preciosos en particula.
} 
exhaustivo del comercio establece qué papel cumplieron los cargadores en general y distintos actores en particular. Con respecto al análisis de los comerciantes en general, plantea que el comercio rioplatense durante el siglo XVIII, en sus aspectos ultramarino y local, distaba mucho de estar concentrado por un grupo cualquiera, cosa que tal vez sí sucedía con la rama más importante del comercio, es decir, lo que se dirigía a los mercados interiores del Virreinato del Perú y al Reino de Chile. Jumar advierte la existencia de diversos grupos que defienden sus propios intereses en la medida de lo posible sin considerar los de los otros grupos. Por ello establece:

Básicamente se ve desde el comienzo una cierta separación entre los comerciantes y los productores de cueros y, dentro de los comerciantes, entre aquellos que se afanan en el tráfico ultramarino, el local y el interior. Esto no descarta la posibilidad de que algunos personajes pudieran concentrar todas estas actividades, pero, tal vez éstos sean casos de excepción y no la norma. (Jumar, 2001: 6).

Además, a partir de ello analizó algunos casos particulares: los Basavilbaso y Juan de Eguía. En este sentido, los trabajos se centran en indagar las redes que fueron construidas alrededor de los comerciantes. El mecanismo de abordaje de estos casos particulares, como ya planteamos, se produce a partir de los datos que aportan los registros de los navíos. Mediante ello, establece las particularidades de un comerciante "exitoso" y de otro que no lo fue tanto, especialmente con respecto a su derrotero, señalando que el comercio ultramarino no fue el objetivo fundamental de los grandes comerciantes, sino que fue el camino para asentarse y realizar otras actividades menos redituables pero a la vez menos riesgosas.

Siguiendo esta línea, en este trabajo se parte de la elaboración de una base de datos sobre la carga de cueros, en donde figuran los nombres de los cargadores 
y en relación a ello se puede establecer las cantidades y períodos de cada uno de ellos.

$\underline{\text { Análisis de los cargadores de cueros }}$

Analizamos a los cargadores de cueros con el fin de establecer cuál fue su impacto en el comercio ultramarino en general y si, en las últimas décadas del siglo XVIII, se produjeron modificaciones a la luz del crecimiento del comercio iniciado en 1760.

\section{Gráfico III. 6}

Total de cargadores de cueros del complejo portuario rioplatense $(1720$ - 1799).

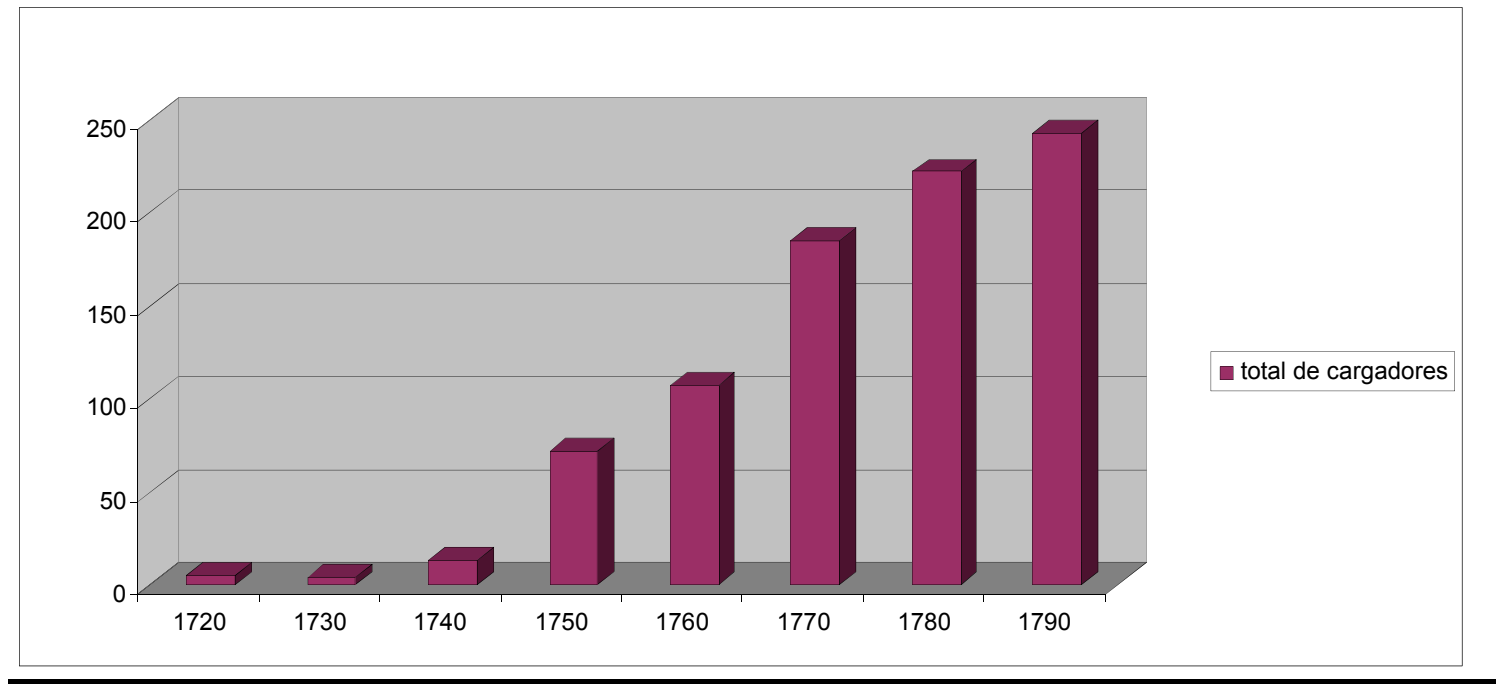

Fuente: Elaboración propia a partir de los datos extraídos de Jumar (2002) y AGN Sala XIII: $15-10-3 ; 37-6-4 ; 37-10-5 ; 37-10-6-; 38-8-3 ; 38-8-4 ; 38-1-1 ; 38-1-3 ; 38-$ $2-3 ; 38-3-4 ; 38-4-4 ; 38-5-3 ; 38-6-4 ; 38-1-3 ; 39-1-3 ; 39-2-1 ; 39-2-2 ; 39-3-1 ; 39-3-$ 2 ; 39-3-3; 39-4-3; 39-5-4; 39-6-2; 39-8-4; 39-9-3; 39-10-1; 39-10-4; 39-7-4; 15$10-3 ; 37-9-3 ; 37-9-4 ; 38-10-3$; 38-6-3. 14-9-5; 14-10-1; 14-10-2; 14-10-3; 14-10$4 ; 15-10-1 ; 15-10-2 ; 15-10-3$.

En el Gráfico III-6 se puede observar el incremento del número de cargadores que se dedicaron al comercio ultramarino de cueros entre 1720 y 1790 . A partir de la década de 1750 comenzaron a llegar nuevos actores con redes de 
distintas regiones de la península española, los cuales se vincularon específicamente al comercio de cueros como consecuencia del incremento de la demanda externa de esta mercancía. Por ello, aumentó el número de actores dedicados a esta actividad durante las décadas siguientes que, además, se vio reforzada con las transformaciones institucionales que permitieron que no fuera necesario el paso por Cádiz como nexo obligatorio para el comercio de cueros.

La llegada de las fragatas correos desde mediados de la década del sesenta y el Reglamento de Libre Comercio fueron las respuestas de la Corona al proceso económico regional y global abierto, dando su apoyo a estos actores, restringiendo el peso de los monopolistas ${ }^{45}$ en el comercio de esta mercancía.

Al observar el movimiento de personas revelado por las fuentes se vislumbra que, en la mayoría de los casos, tras la llegada al Río de la Plata comienzan a comerciar como comisionistas de alguna casa y envían remesas de metales preciosos. Unos años después, empiezan progresivamente a incorporar envíos de cueros, que con el tiempo se continúa incrementando en detrimento de los metales preciosos. ${ }^{46} \mathrm{El}$ aumento de la competencia de quienes comercializaban manufacturas europeas a partir de la apertura progresiva de puertos y de la especialización de más regiones en el área, produjo un cambio en cuanto a la correlación de negociación entre aquellos que enviaban las mercancías desde la península española y quienes debían venderlas en la región Río de la Plata u otra región americana.

\footnotetext{
${ }^{45}$ Lo se establece como monopolistas en esta tesis son los actores que estuvieron vinculados con Cádiz durante el siglo XVIII.

${ }^{46}$ En el anexo I y II se puede apreciar las cifras totales de los máximos cargadores, la diferencia entre los actores que no fueron grandes cargadores de cueros con aquellos que solo enviaron plata es que los primeros lentamente aumentaron la cantidad de cueros y descendió la cantidad de plata enviada.
} 
Otro de los cambios que se produjo fue el surgimiento de las Juntas de Comercio, siendo una práctica política diferente a los organismos tradicionales como el Cabildo. En la tesis doctoral de Javier Kraselsky (2011) se plantea que a partir de 1749 se dio comenzó a la primera etapa de las Juntas de Comerciantes, definidas como un periodo inmaduro o inorgánico:

Los comerciantes llevaron adelante estrategias para obtener mayores privilegios, y la conformación de su estructura permanente fue una de ella. Esta conformación de esta estructura jerárquica mercantil surge como consecuencia de un proceso dual en el que participa la Corona estimulando nuevas relaciones y los actores locales, que potencian y promueven su corporización. (2011: 174).

El número total de cargadores que intervinieron entre 1779 y 1799 fue de 1.386, lo que nos habla de que una parte importante de la población se dedicó, en mayor o menor medida, a esta actividad. Esto permite ver la falta de monopolio en cuanto al acceso al comercio. Es decir, un gran número de pobladores tuvieron el contacto con productores y consumidores/intermediarios ultramarinos gracias a la facilidad de cargar en forma legal cueros y a la llegada masiva de navíos destinados para ese fin. Como se puede observar en el cuadro III-2, algo más de dos tercios de los cargadores operaban desde Montevideo ${ }^{47}$. Esto probablemente estuviera dado como producto de una permeabilidad mayor al pequeño comerciante por el reciente poblamiento de la ciudad y la cercanía entre el puerto y las zonas de producción de cueros. En el caso de Buenos Aires, dado que las zonas de producción se encontraron más alejadas y al tener una estructura comercial con mayor articulación, el número de actores intervinientes fue menor.

\footnotetext{
${ }^{47}$ En este caso dividimos el análisis entre los dos puertos también, para complejizar el análisis y establecer las diferencias y similitudes entre los dos puertos más importantes y determinar las zonas de producción.
} 
Cuadro III. 2

Totales de cargadores de Montevideo y Buenos Aires (1779- 1799)

\begin{tabular}{|c|c|}
\hline Puerto & Cargadores \\
\hline Montevideo & 928 \\
\hline Buenos Aires & 458 \\
\hline Total & 1386 \\
\hline
\end{tabular}

Fuente: Elaboración propia a partir de los datos extraídos de AGN Sala XIII: 15$10-3$; 37-6-4; 37-10-5; 37-10-6-; 38-8-3; 38-8-4; 38-1-1; 38-1-3; 38-2-3; 38-3-4; $38-4-4 ; 38-5-3 ; 38-6-4 ; 38-1-3 ; 39-1-3 ; 39-2-1 ; 39-2-2 ; 39-3-1 ; 39-3-2 ; 39-3-3$; $39-4-3$; 39-5-4; 39-6-2; 39-8-4; 39-9-3; 39-10-1; 39-10-4; 39-7-4; 15-10-3; 37-93 ; 37-9-4; 38-10-3; 38-6-3. 14-9-5; 14-10-1; 14-10-2; 14-10-3; 14-10-4; 15-10-1; $15-10-2 ; 15-10-3$.

Los cargadores operaron en forma desigual durante este período. Como se puede observar en el gráfico III.7 las fluctuaciones estuvieron dadas en Buenos Aires y Montevideo en líneas generales de igual manera. Tanto en los momentos de aumento de los cargadores como en los momentos de descenso, en los dos puertos la actividad estuvo sincronizada. Respondiendo a la dinámica comercial ultramarina, los dos momentos de descenso se produjeron a partir de los conflictos militares y de ascenso, en los tiempos de paz, produciendo un incremento de la cantidad de actores que intervinieron como cargadores.

\section{Gráfico III. 7}

Total de Cargadores (en unidades) salidos al comercio ultramarino desde Montevideo. 1779- 1799

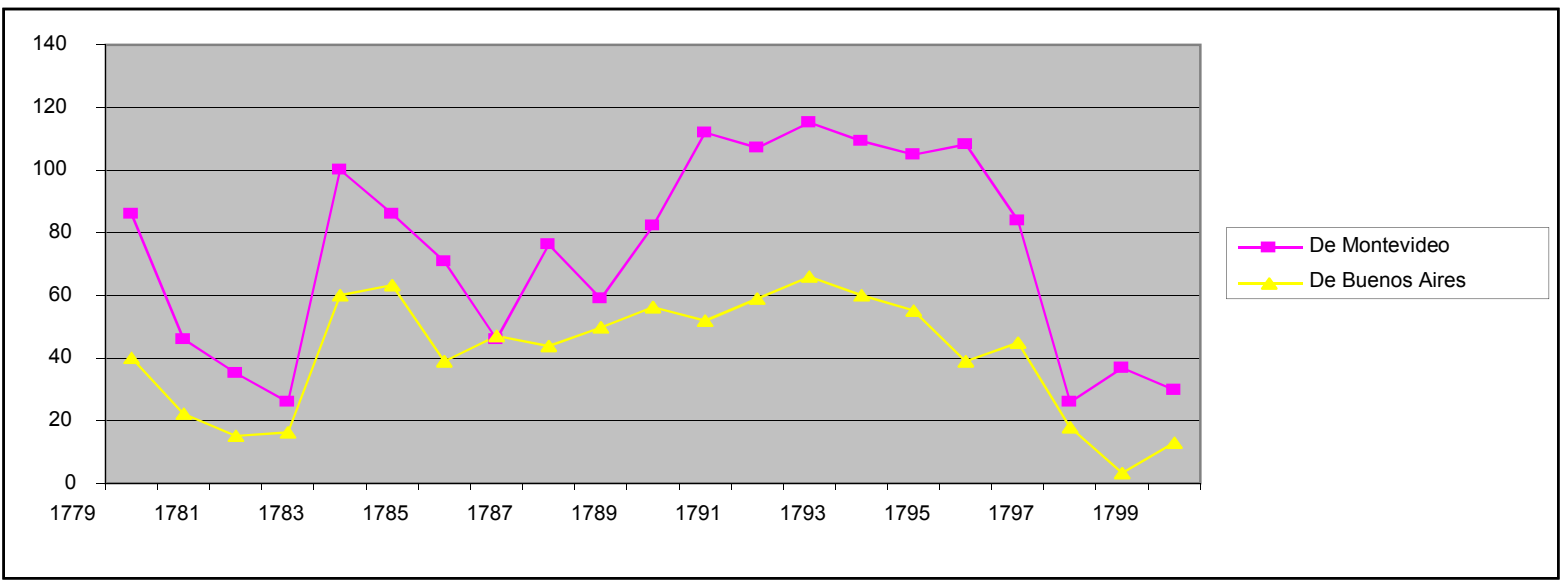


Fuente: Elaboración propia a partir de los datos extraídos de AGN Sala XIII: 15$10-3$; 37-6-4; 37-10-5; 37-10-6-; 38-8-3; 38-8-4; 38-1-1; 38-1-3; 38-2-3; 38-3-4; $38-4-4 ; 38-5-3 ; 38-6-4 ; 38-1-3 ; 39-1-3 ; 39-2-1 ; 39-2-2 ; 39-3-1 ; 39-3-2 ; 39-3-3$; $39-4-3 ; 39-5-4 ; 39-6-2 ; 39-8-4 ; 39-9-3 ; 39-10-1 ; 39-10-4 ; 39-7-4 ; 15-10-3 ; 37-9-$ 3 ; 37-9-4; 38-10-3; 38-6-3. 14-9-5; 14-10-1; 14-10-2; 14-10-3; 14-10-4; 15-10-1; $15-10-2 ; 15-10-3$.

La cantidad total de cueros que enviaron cada uno de los cargadores varió notablemente, como se observa en el cuadro 3. Por un lado, tenemos que el mayor número de cargadores, más de mil, enviaron menos de cinco mil cueros $\mathrm{y}$, sumados, representaron algo más de un catorce por ciento del total de cueros exportados. Por otro lado, durante el período sólo treinta y cuatro cargadores enviaron más de cincuenta mil cueros fueron, quienes concentraron algo más de la mitad del comercio de cueros. Esto da cuenta de una gran concentración del comercio en muy pocas manos $\mathrm{y}$, si bien el número de cargadores fue alto, la mayoría no tuvo una participación importante en el comercio.

\section{Cuadro III. 3}

Total de Cargadores de Buenos Aires y Montevideo según cantidad de cueros comercializados (1779- 1799)

\begin{tabular}{|c|c|c|c|c|}
\hline & \multicolumn{2}{|c|}{ Cargadores } & \multicolumn{2}{c|}{ Cueros } \\
\hline - de 1.000 & 616 & $44,5 \%$ & 344.739 & $3,5 \%$ \\
\hline - de 5.000 & 499 & $36,1 \%$ & 1.107 .949 & $11,2 \%$ \\
\hline - de 10.000 & 110 & $7,8 \%$ & 813.856 & $8,2 \%$ \\
\hline - de 50.000 & 126 & $9,1 \%$ & 2.640 .023 & $26,6 \%$ \\
\hline + de 50.000 & 34 & $2,5 \%$ & 5.012 .248 & $50,5 \%$ \\
\hline Total & 1.386 & $100 \%$ & 9.918 .815 & $100 \%$ \\
\hline
\end{tabular}

Fuente: Elaboración propia a partir de los datos extraídos de AGN Sala XIII: 15$10-3$; 37-6-4; 37-10-5; 37-10-6-; 38-8-3; 38-8-4; 38-1-1; 38-1-3; 38-2-3; 38-3-4; $38-4-4 ; 38-5-3 ; 38-6-4 ; 38-1-3 ; 39-1-3$; 39-2-1; 39-2-2; 39-3-1; 39-3-2; 39-3-3; $39-4-3 ; 39-5-4 ; 39-6-2 ; 39-8-4 ; 39-9-3 ; 39-10-1 ; 39-10-4 ; 39-7-4 ; 15-10-3 ; 37-9-$ 3 ; 37-9-4; 38-10-3; 38-6-3. 14-9-5; 14-10-1; 14-10-2; 14-10-3; 14-10-4; 15-10-1; $15-10-2 ; 15-10-3$.

En este sentido, se puede observar que un grupo determinado se mantuvo como núcleo del comercio de cueros, estos cargadores bajaban la 
actividad mercantil por las circunstancias adversas pero la mantenían en el tiempo. A su vez, se encuentra otro grupo mayoritario, fluctuante, que a partir de las oportunidades que se brindaban con la reapertura comercial, actuaban de forma intermitente.

\section{Cuadro III. 4}

Total de cargadores de Montevideo según cantidad de cueros comercializados (1779- 1799)

\begin{tabular}{|c|c|c|c|c|}
\hline & \multicolumn{2}{|c|}{ Cargadores } & \multicolumn{2}{c|}{ Cueros } \\
\hline - de 1.000 & 511 & $55,0 \%$ & 171.344 & $3,9 \%$ \\
\hline - de 5.000 & 294 & $31,7 \%$ & 642.310 & $14,5 \%$ \\
\hline - de 10.000 & 55 & $5,9 \%$ & 407.558 & $9,2 \%$ \\
\hline - de 50.000 & 54 & $5,9 \%$ & 1.072 .237 & $24,3 \%$ \\
\hline + de 50.000 & 14 & $1,5 \%$ & 2.121 .181 & $48,1 \%$ \\
\hline Total & 928 & $100 \%$ & 4.414 .630 & $100 \%$ \\
\hline
\end{tabular}

Fuente: Elaboración propia a partir de los datos extraídos de AGN Sala XIII: 15$10-3$; 37-6-4; 37-10-5; 37-10-6-; 38-8-3; 38-8-4; 38-1-1; 38-1-3; 38-2-3; 38-3-4; $38-4-4 ; 38-5-3 ; 38-6-4 ; 38-1-3 ; 39-1-3 ; 39-2-1 ; 39-2-2 ; 39-3-1 ; 39-3-2 ; 39-3-3$; $39-4-3 ; 39-5-4 ; 39-6-2 ; 39-8-4 ; 39-9-3 ; 39-10-1 ; 39-10-4 ; 39-7-4 ; 15-10-3 ; 37-9-$ 3 ; 37-9-4; 38-10-3; 38-6-3. 14-9-5; 14-10-1; 14-10-2; 14-10-3; 14-10-4; 15-10-1; $15-10-2 ; 15-10-3$.

Para el caso de Montevideo, en donde se encontraba el número mayor de cargadores $^{48}$, dos tercios del total, la concentración del comercio de los cueros fue altísima, sólo 14 comerciantes concentraron casi la mitad y 805 el $17 \%$ de la cantidad de cueros. Como veníamos desarrollando, la cercanía con las zonas de producción de cueros probablemente permitió a una parte importante de la población con algún vínculo con la península española, el envío de pequeñas cantidades de cueros, sin el mantenimiento de un vínculo permanente como forma de pago de mercancías enviadas previamente o para el pago de deudas contraídas.

\footnotetext{
${ }^{48}$ El alto número de cargadores que realizaron su operación en Montevideo no acredita que sean vecinos de la localidad, podrían ser del espacio regional, comerciantes asentados provisoriamente o capitanes de navíos. Para determinar que un número importante de estos cargadores se mantuvo un periodo relativamente prolongado en la región, se tomó algunos cargadores al azar y se rastreó su participación. El análisis puntilloso de todos los actores, es una tarea a futuro que realizaremos mediante el estudio de los padrones militares y demás fuentes que den cuenta de la totalidad, o gran parte, de la población que se encontraba en la región.
} 
La población de Montevideo en este período pasó de 2.420 personas para el año 1773 a 7.200 en $1797 .^{49}$ Si especulamos con la cantidad de unidades domésticas que se encontrarían en este período, casi todas estuvieron implicadas en el comercio de cueros de forma intermitente, pero no les fue ajena, probablemente, a ninguna.

Para el espacio de Colonia Jorge Gelman plantea que la inmensa mayoría no tenía más remedio que vender sus cueros localmente a intermediarios, que luego los enviarían a los lucrativos circuitos de comercio exterior. (Gelman, 1993). Por lo tanto, establece que casi la totalidad de los pequeños y medianos "campesinos-pastores" no participaban plenamente en la producción mercantil. En cambio, si ponemos la atención en los registros de salida de Montevideo, observamos que el número de cargadores fue muy alto en relación a la población que potencialmente podía realizar esta actividad. Por ello, es posible poner en consideración en qué medida el acceso al mercado ultramarino estuvo cerrado para los "campesinos-pastores"

Para el caso de Buenos Aires se aprecian notables diferencias ya que se parte de un número muy inferior de cargadores pese a existir en la ciudad un número mucho mayor de habitantes. Esto podría ser producto de la dificultad de acceder a los lugares de producción y/o a la existencia de un grupo de cargadores que se especializaron sin dejar lugar a aquellos que desearan enviar pequeñas cantidades. El número de grandes cargadores, si bien porcentualmente es mayor,

\footnotetext{
${ }^{49}$ Ver anexo $\mathrm{N}^{\mathrm{o}} \mathrm{I}$.

${ }^{50}$ Para llegar a una conclusión en este aspecto es necesario un análisis puntilloso de los padrones de las ciudades y campaña para determinar el lugar y la actividad de los actores que participaron como cargadores. Lo cierto es que pertenezcan a cualquiera de esos lugares, les vendan los pequeños productores a los pulperos como sostiene Gelman o no, la posibilidad de realizarlo fue muy importante y el número de comerciantes que estaban predispuestos a comprarle sus cueros fue muy alto.
} 
no deja de ser un pequeño grupo que concentra más de la mitad del comercio en sus manos, manteniendo en menos de cien personas el $80 \%$ de la producción total.

\section{Cuadro III. 5}

Total de cargadores de Buenos Aires según cantidad de cueros comercializados (1779- 1799)

\begin{tabular}{|c|c|c|c|c|}
\hline & \multicolumn{2}{|c|}{ Cargadores } & \multicolumn{2}{c|}{ Cueros } \\
\hline - de 1.000 & 106 & $23,1 \%$ & 173.395 & $3,1 \%$ \\
\hline - de 5.000 & 205 & $44,8 \%$ & 465.639 & $8,4 \%$ \\
\hline - de 10.000 & 55 & $12 \%$ & 406.298 & $7,4 \%$ \\
\hline - de 50.000 & 72 & $15,8 \%$ & 1.567 .786 & $28,5 \%$ \\
\hline + de 50.000 & 20 & $4,3 \%$ & 2.891 .067 & $52,6 \%$ \\
\hline Total & 458 & $100 \%$ & 5.504 .185 & $100 \%$ \\
\hline
\end{tabular}

Fuente: Elaboración propia a partir de los datos extraídos de AGN Sala XIII: 1510-3; 37-6-4; 37-10-5; 37-10-6-; 38-8-3; 38-8-4; 38-1-1; 38-1-3; 38-2-3; 38-3-4; $38-4-4 ; 38-5-3 ; 38-6-4 ; 38-1-3 ; 39-1-3 ; 39-2-1 ; 39-2-2 ; 39-3-1 ; 39-3-2 ; 39-3-3$; $39-4-3 ; 39-5-4 ; 39-6-2 ; 39-8-4 ; 39-9-3 ; 39-10-1 ; 39-10-4 ; 39-7-4 ; 15-10-3 ; 37-9-$ 3 ; 37-9-4; 38-10-3; 38-6-3. 14-9-5; 14-10-1; 14-10-2; 14-10-3; 14-10-4; 15-10-1; $15-10-2 ; 15-10-3$.

En términos generales, se podría afirmar que en el comercio ultramarino de cueros el número de actores que intervino activamente no fue reducido, pero sí se logró una gran concentración ya que en un pequeñísimo grupo de treinta y cuatro comerciantes se manejó algo más de la mitad de la comercialización total.

Aquellos cargadores que comerciaron grandes cantidades de cueros lograron cierta regularidad durante algunos años. Solo 34 cargadores concentraron casi la mitad de los cueros comercializados, esto daría cuenta de que si bien muchos actores participaron comercializando, aquellos que se dedicaron y enriquecieron fueron pocos. Esto sucede en igual medida tanto en Buenos Aires y Montevideo, lo que permite predecir una cierta homogeneidad en los dos puertos en cuanto a la capacidad de actuar de este grupo. 
Cuadro III. 6

Grandes cargadores de cueros según cantidad comercializada (1779-1799)

\begin{tabular}{|c|c|c|}
\hline Nombre & cantidad & periodo \\
\hline Belgrano, Domingo & 89.740 & $84-93$ \\
\hline Ugarte, Julián & 95.834 & $86-92$ \\
\hline Monfort, Miguel & 96.699 & 84 \\
\hline Conet, Miguel & 102.911 & $89-96$ \\
\hline De la Peña, Francisco & 109.020 & $86-97$ \\
\hline Romero, Tomas & 113.792 & $88-99$ \\
\hline Ugarte, Francisco & 129.947 & $84-96$ \\
\hline Dobal, Pedro & 159.329 & $88-99$ \\
\hline Lesica, Juan & 168.101 & $84-97$ \\
\hline Balanzategui, Tomas & 180.493 & $84-97$ \\
\hline González Bolaños, José & 197.973 & $79-99$ \\
\hline Arguibel, Felipe & 214.533 & $79-96$ \\
\hline Belaustegui, Francisco & 305.412 & $86-97$ \\
\hline Necochea, Casimiro & 585.701 & $84-99$ \\
\hline Silva, José & 69.031 & $88-97$ \\
\hline Pascuali, Ramón & 76.512 & $84-96$ \\
\hline Balvin Vallejos, Juan & 85.157 & $79-97$ \\
\hline Pereyra, Zacarías & 87.496 & $85-95$ \\
\hline Martínez, Juan Ignacio & 174.360 & $79-98$ \\
\hline Ulibarri, Lorenzo & 295.297 & $80-96$ \\
\hline Balvastro, Isidro & 113.624 & \\
\hline Diago, M & 174.245 & $79-97$ \\
\hline Echeñique, J & 132.115 & $79-87$ \\
\hline Aguirre, Agustín/ José & 316.990 & $79-92$ \\
\hline
\end{tabular}

Fuente: Elaboración propia a partir de los datos extraídos de AGN Sala XIII: 15$10-3$; 37-6-4; 37-10-5; 37-10-6-; 38-8-3; 38-8-4; 38-1-1; 38-1-3; 38-2-3; 38-3-4; $38-4-4 ; 38-5-3 ; 38-6-4 ; 38-1-3 ; 39-1-3 ; 39-2-1 ; 39-2-2 ; 39-3-1 ; 39-3-2 ; 39-3-3$; $39-4-3 ; 39-5-4 ; 39-6-2 ; 39-8-4 ; 39-9-3 ; 39-10-1 ; 39-10-4 ; 39-7-4 ; 15-10-3 ; 37-9-$ 3 ; 37-9-4; 38-10-3; 38-6-3. 14-9-5; 14-10-1; 14-10-2; 14-10-3; 14-10-4; 15-10-1; $15-10-2 ; 15-10-3$.

El sector de grandes cargadores de cueros tuvo algunas cuestiones en común. En primer lugar, la mayoría de ellos llegó a partir de la década de 1760, envió remesas de plata durante los primeros años e invirtió en diversas actividades vinculadas a los eslabones de producción y comercialización de productos vacunos. 
Dentro de este grupo, varios de ellos invirtieron, a su vez, en grandes extensiones de tierra (Jumar y Kraselsky, 2007). Algunos adquirieron sus tierras mediante compra y otros, tras lograr una cierta posición social, mediante el casamiento. De una u otra forma, producir cueros propios reducía el coste de los mismos e incrementaba las ganancias. Por otro lado, a los empresarios ganaderos les permitía mantenerse dentro del otro grupo poderoso a nivel económico además de los comerciantes, es decir, desarrollando una gran capacidad política dentro de las instituciones.

Por último, también se dedicaron a la actividad naviera. Este sector, expandió el eslabonamiento comercial, lo que les permitía aumentar sus ganancias a partir de bajar los costes de transporte. Estos, no sólo transportaban cueros o plata, sino que la mayoría de los navíos adquiridos por actores locales fueron destinados al comercio con Brasil, Cuba o África. El comercio del tasajo y de los esclavos en manos de actores regionales permitió expandir el circuito comercial produciendo una triangulación que generó un espiral ascendente. Se enviaban cueros a la península española o a otras regiones, el tasajo a Cuba y se proveía de esclavos de Brasil o de las costas Áfricanas. Los casos más renombrados en este sentido fueron los de Antonio Romero y Pedro Dubal, quienes incrementaron sus riquezas a partir de estas dos actividades, la pecuaria y esclavista, en donde las dos piezas fundamentales eran las redes comerciales y la tenencia de navíos.

Por otra parte durante este periodo, los cargadores señalados tuvieron participación política. Algunos de los actores estuvieron vinculados a las Juntas de Comercio y de Hacendados y la gran mayoría al Consulado de Comercio. La disputa entre comerciantes y empresarios ganaderos fue, a nivel económico, el gran conflicto por la hegemonía comercial. La creación del Consulado se 
transformó en otro de los espacios en donde los intereses de los comerciantes "monopolistas", los que participaban de la ampliación de monopolio y los hacendados, disputaron beneficios económicos. El conflicto entre los comerciantes y hacendados, que durante un breve período se inclinó hacia una victoria de los comerciantes, finalizó en 1797 cuando se incorporó a los empresarios ganaderos al Consulado de Comercio. Esto se produjo a causa de una reformulación de las alianzas entre los comerciantes vinculados al comercio de cueros y los hacendados. Esto aumentó el declive del sector menos afín a ellos, que eran los comerciantes monopolistas, quienes hasta ese momento se habían mantenido como un grupo de poder importante ante la división de los otros dos.

El Consulado, se transformó, para los comerciantes de cueros, en algo central ya que les permitió ocupar este espacio como un lugar de negociación corporativa con la Corona. En el resto de instituciones políticas, como el Cabildo, su presencia no fue muy visible. Sin embargo, al compartir intereses con los hacendados, esta institución no les era un lugar hostil.

\section{$\underline{\text { Salida de cueros fuera de los territorios de la Monarquía }}$}

La salida de cueros hacia destinos externos a la Monarquía tuvo, en las últimas décadas del siglo XVIII, dos móviles centrales: la guerra (1779- 1783 y 17961802) y el comercio con África para intercambiar por esclavizados. Este proceso no se dio ajeno a conflictos sino todo lo contrario, a partir de la aprobación por parte de la Corona de los pedidos de los actores implicados, se sucedieron una serie de

Durante el conflicto armado con Inglaterra, entre 1779 y 1783, se permitió el ingreso de navíos de bandera portuguesa que realizaban el trayecto con la 
península española. En líneas generales, y como se afirmó en el capítulo 2, la circulación de navíos durante este período fue escasa, como la salida de cueros y de metales preciosos (cuestión que se verá en el próximo capítulo) y, por lo tanto, su impacto fue minoritario. Sin embargo, hubo varios permisos para transportar cueros y metales, como el otorgado al Marqués de Echaudia luego transferido a Juan Bautista de Ustáriz para extraer un millón de pesos y 80.000 cueros $^{51}$.

Si bien se aplicó el mismo sistema de embarcaciones neutrales para el conflicto armado posterior, en los territorios de la Monarquía los resultados fueron muy distintos. A partir de 1799, se mantuvo el comercio mediante el ingreso de navíos neutrales, en particular norteamericanos, que continuaron las conexiones establecidas y promovieron otras nuevas. Como afirmó Arturo Bentancur:

Predominó en general la marina mercante norteamericana. Única verdaderamente neutral en la mayor parte del período, puede decirse que se adueñó del comercio exterior de las Indias Españolas, y realizó un tráfico provechoso para sus intereses. Esa preponderancia se mantuvo al menos hasta 1807, cuando la situación internacional le impuso un repliegue por medio de la Embargo Act que sólo permitió la navegación de cabotaje (1997: 347).

El actor social que tuvo mayor vinculación entre el complejo portuario rioplatense con Estados Unidos fue Martín Sarratea quien envió la mayoría de los navíos que unieron la ruta: complejo portuario rioplatense- Filadelfia.

En relación a la compra de esclavizados, la misma era realizada, en términos generales, por medio de plata y en algunas ocasiones cueros, si bien esto generó debates internos. A partir de la década de 1790, con los permisos para ingresar esclavizados desde África, comenzaron a producirse pedidos para que

${ }^{51}$ Documentos para la Historia Argentina; tomo V, Comercio de Indias, Antecedentes Legales (1713-1778); tomo VI, Comercio de Indias, Comercio Libre (1778-1791); Facultad de Filosofía y Letras, Universidad de Buenos Aires, Buenos Aires, 1915-1916. 
una parte de la compra se realizara con cueros y no solo con plata. Quien comenzó con el pedido fue Tomas Romero y los integrantes en calidad de diputados del Consulado plantearon que los cueros no eran frutos del país y, por lo tanto, no se podían comercializar en ese sentido.

Por un lado se encontraban Diego de Agüero, José Martínez de Hoz y Jaime Alsina y Verges, por otro Tomas Romero, comerciantes portugueses afincados en Buenos Aires, el cuerpo de Hacendados, Manuel Herrero y Miguel de Azcuenaga. Este conflicto en relación a la inclusión de cueros en el comercio de esclavizados consta de varias idas y vueltas institucionales lo que da cuenta de un problema mucho mayor a lo discursivo. Elena Studer afirma:

Hacía constar el administrador interino de la Aduana que en 1792 y 1793 habían entrado en Buenos Aires 2787 negros, introducidos una tercera parte por comerciantes nacionales y las otras dos por mercaderes extranjeros. Estos esclavos "corridos a los mismos precios y regulas" habían importado 557.400 pesos, o sea 278700 pesos en cada año "para importarlos y considerarlos separados del comercio común". La salida de cueros llevada a cabo en esos años en virtud del comercio de negros ascendió a 5930 unidades, completándose el resto con exportación de sebo, carnes, harinas y dinero. Se extrajeron en cambio para España, en el mismo lapso, 1.580.274 cueros. Resulta pues ridículo que los comerciantes invocaran los graves perjuicios que se le ocasionaría a la economía del virreinato permitiendo la exportación de corambre a los negreros y se indignaba Izquierdo que después de pasados tres años de permiso, los apoderados del Comercio pretendieran que, al incluir los cueros en la denominación de frutos, alternaba la fe de la Real palabra. (Studer, 1958: 283).

Así todo, este conflicto no es baladí, si se lo contextualiza en un proceso de conflictos mucho mayor, en donde ciertos grupos que tenían un control de los circuitos comerciales en la segunda mitad del siglo vio cómo su reproducción estuvo limitada por la dinámica económica global y el arribo de actores con otras lógicas, más cercanas a las transformaciones comerciales e institucionales. 
Por lo tanto, este conflicto particular debe insertarse en un proceso de transformaciones de la región Río de la Plata (como se planteó en el capítulo 1) del mercado global (como se argumentó en el capítulo 2) y en el comercio de cueros como se desarrolló en este capítulo. En los siguientes capítulos se analizaran otros conflictos que se sucedieron que formaron parte de este proceso.

\section{Consideraciones finales}

Durante la segunda mitad del siglo XVIII se produjo un crecimiento del comercio ultramarino de cueros salidos del complejo portuario rioplatense. Esto fue resultado de causas internas y externas que permitieron el ingreso de la región Río de la Plata en un círculo virtuoso económico. Durante el período señalado, se generó en distintos espacios una aceleración de la industrialización que trajo aparejada la necesidad de consumir grandes cantidades de cueros (dentro del proceso industrial el cuero vacuno es un elemento indispensable) provocando el incremento de la demanda de esta mercancía.

Además, como se sostuvo en el capítulo 1, a partir de la aplicación de la “nueva economía del cuero" se incrementó la oferta de cueros para el comercio ultramarino. Sumado a ello, se produjeron reformas institucionales que favorecieron este desarrollo, como la llegada de las fragatas correros, el reglamento de libre comercio, entre otras. Con el incremento del comercio de cueros, progresivamente aumentó la llegada de migrantes que se distribuyeron por la región y produjeron la duplicación de los habitantes de las ciudades más importantes lo que, a su vez, favoreció el crecimiento del comercio ultramarino.

La salida de cueros del complejo portuario rioplatense durante las últimas décadas del siglo XVIII aceleró el proceso de crecimiento de la tendencia alcista. 
Entre 1779 y 1783 y entre 1796 y 1799, durante los conflictos bélicos, se produjo un descenso del comercio, recuperando y estabilizándose a partir de la paz, compensando así las caídas previas. Los dos puertos gozaron de una importancia similar en relación al comercio ultramarino ya que mantuvieron una cierta paridad durante todo el período estudiado.

Durante las décadas siguientes se consolidó este proceso económico en las dos riberas del río, siendo el cuero la producción económica más importante durante las primeras décadas del siglo XIX tanto en el litoral argentino (marcada por la expansión territorial hacia el sur) como en Uruguay.

Por otro lado, este capítulo estuvo orientado a analizar a aquellos actores cuya actividad fue la de vincular comercialmente a los productores de cueros con los consumidores ultramarinos de dicha mercancía. Se puede observar en forma paralela al crecimiento del comercio ultramarino el aumento exponencial del número de cargadores. Durante el siglo XVIII, se pasó de un número muy reducido de cargadores, vinculados al monopolio comercial de Cádiz, a una segunda mitad del siglo marcada por el incremento del comercio con los puertos españoles y del número de cargadores que intervinieron. Lo más importante que debía tener un cargador para poder comercializar los cueros era el mantener un vínculo entre los productores locales y los consumidores en las regiones de $\operatorname{destino~}^{52}$.

Durante la segunda mitad del siglo XVIII se generaron transformaciones orientadas en este sentido. A partir de las necesidades regionales de cueros tanto para el desarrollo industrial como para otras actividades (por ejemplo, toda la suspensión de los medios de transporte se hacía con cueros) y el crecimiento de la

\footnotetext{
52 Tomamos este modelo explicativo que no agota las causas de todos los cargadores ya que se interpreta que fue el más recurrente de los casos.
} 
producción, se suma una reglamentación que potencia este desarrollo en detrimento del monopolio gaditano. La circulación de las fragatas correo, el aumento de los navíos de registro, establecimiento de "asientos" comerciales y el reglamento de libre comercio estuvo enfocado a acompañar las transformaciones económicas.

El alto número de cargadores involucrados en el comercio ultramarino de cueros acompaña lo descrito. La llegada de navíos de diversa procedencia y destino final, la posibilidad de cargas con exiguas cantidades y el hecho de que fueran migrantes recientes con lazos fuertes en otras regiones, permitió que muchos actores que se asentaran en el complejo portuario rioplatense y desarrollaran esta actividad. Hay que marcar algunos matices en relación a los puertos de Buenos Aires y Montevideo. En el primero hay un número menor de cargadores de cueros que en el segundo, tal vez por ser un asentamiento más antiguo, por la lejanía de las zonas de extracción y/o la vinculación de los grandes propietarios de ganado y tierras con grandes comerciantes. En Montevideo, en cambio se produjo todo lo contrario, el alto número de migrantes recientes y la cercanía a las zonas de producción hizo que un número mayor de actores intervengan en el comercio.

Si bien hubo muchos actores que intervinieron en el comercio, hay un gran número de comerciantes que intercambiaron pocas cantidades de cueros y durante un breve período de tiempo. En cambio, un número muy reducido de actores comercializaron la mitad de los cueros, siendo este fenómeno de concentración una característica común a los dos puertos, pero las cifras muestran que así y todo el comercio no era exclusivo de unos pocos. Entre estos dos grupos, uno de muchos cargadores con pocas cantidades y otros de pocos con muchas, se 
encuentra una franja media que, en términos generales, comercializaron un número importante de cueros distribuidos en varios años. Este grupo de cargadores estaba constituido, probablemente, por hombres que no llegaban a ser grandes comerciantes y para quienes la venta de cueros era la actividad más importante o era complementaria a otra actividad económica como el comercio interno (redistribución de las mercancías en el Virreinato del Río de la Plata) o el pago alternativo al de las remesas de plata.

Aquellos cargadores que comerciaron grandes cantidades de cueros lograban cierta regularidad durante algunos años. Sólo treinta y cuatro cargadores concentraron casi la mitad de los cueros comercializados, esto daría cuenta de que si bien muchos actores participaron comercializando, aquellos que se dedicaron y enriquecieron fueron pocos. En igual medida tanto en Buenos Aires y Montevideo, lo que se permite predecir una cierta homogeneidad en los dos puertos en cuanto a la capacidad de este grupo de actuar.

A partir de aumentar la producción y la necesidad de consumir esta mercancía es que se incrementó el número de actores que intervinieron como cargadores. Desde la continua migración se establecieron un número importante de sujetos que mantenían contacto con actores de otras latitudes. Por lo tanto, algunos actuaron de cargadores en forma esporádica a partir de las facilidades que se produjeron para tal fin, otros se dedicaron durante un período mayor a esta actividad y, por último, un número reducido concentró gran parte del comercio.

Las transformaciones que se produjeron en la segunda mitad del siglo XVIII, como no podía ser de otra forma, no beneficiaron a todos los actores económicos sino a un sector de comerciantes, fundamentalmente comisionistas de mercancías llegadas desde Cádiz cuyos proveedores, que pedían por sus 
mercancías solo metales preciosos, intentaron frenar este proceso. Varias fueron las estrategias adoptadas, la creación del Consulado de Comercio, los pedidos de no reconocer los cueros como frutos del país, las limitaciones a la llegada y carga de los navíos neutrales, entre otras.

Como se ha mencionado, este sector era el que intercambiaba mercancías que luego distribuía por todo el espacio a cambio de metales preciosos. El siguiente capítulo estará dedicado al análisis de esta actividad en particular. 


\title{
CAPÍTULO IV
}

\section{La salida de metales preciosos por el complejo portuario}

\author{
rioplatense.
}

El descubrimiento de los yacimientos de oro y plata de América, la cruzada de exterminio, esclavización y sepultamiento en las minas de la población aborigen, el comienzo de la conquista y el saqueo de las Indias

Orientales, la conversión del continente Áfricano en cazadero de esclavos negros: son todos hechos que señalan los albores de la era de producción capitalista. Estos procesos idílicos representan otros tantos factores fundamentales en el movimiento de la acumulación originaria. Tras ellos, pisando sus huellas, viene la guerra comercial de las naciones europeas, cuyo escenario fue el planeta entero.

(Marx, 2002: 633)

\section{Introducción}

La frase de Marx arriba citada sobre el papel de la plata americana en el desarrollo del capitalismo condensa los debates de la historiografía europea, ya que tanto para los períodos de crecimiento como de crisis en Europa se analizó el ingreso de metales preciosos. También en la historiografía latinoamericana estuvo presente el análisis de la salida de metales para evaluar su impacto en Europa. Posteriormente a ello la salida de metales se investigó para responder a problemáticas americanas.

En este capítulo se analizará la salida de metales preciosos del complejo portuario rioplatense entre 1779- 1794 con el objetivo de establecer las cifras, los destinos y los actores que intervinieron. Para ello trabajamos con los registros de 
los navíos durante el período mencionado, durante el cual se contabilizaron 18.787 partidas. La información que esta fuente nos provee da cuenta de: el año de partida, la embarcación en donde fue cargada, el nombre y procedencia de quien la cargó, a cargo y cuenta de quien, el destinatario, la cantidad de metales preciosos y el destino.

La hipótesis de este capítulo es que a mediados del siglo XVIII se dio un crecimiento de la salida de metales preciosos continuado en el resto del siglo que fue producto de una serie de dinámicas económicas interrelacionadas. Ese crecimiento estuvo acompañado por una modificación en los destinos. Mientras que en un primer momento mayoritariamente circulaban hacia unidades políticas externas a la Monarquía española, con el tiempo se fueron dirigiendo a Cádiz y finalmente al resto de puertos de la península española. Este proceso, fue acompañado con el incremento de la salida de cueros al comercio ultramarino y a la incorporación de migrantes ultramarinos que modificaron la fisonomía comercial regional. En relación al comercio ultramarino consideramos que podemos diferenciar a los grandes comerciantes en tres grupos: uno que solo enviaba metales preciosos, otro que solo intercambiaba cueros y un tercero que combinaba ambas actividades.

En este capítulo, luego de analizar los antecedentes historiográficos, a partir del procesamiento de los datos procedentes de los registros de los navíos, estableceremos las cifras de metales preciosos salidos por año. Además de ello tendremos en qué proporción estaba dirigida para la Real Hacienda y qué proporción correspondía los envíos realizados por actores de otras regiones.

A continuación teniendo en cuenta que la fuente mencionada proporciona los nombres propios de cada uno de los actores que realizaron los envíos 
abordaremos la participación de los actores regionales y la identificación de los más importantes en cuanto a las cantidades de metales que enviaban. Para terminar, estableceremos algunas de las características de los grupos de cargadores ultramarinos más importantes y su participación en el conflicto con el consulado de Lima.

\section{Antecedentes}

Las primeras investigaciones relacionadas al estudio de los flujos comerciales ingresados a la Península española, provenientes de América, se concentraron en la llegada de metales preciosos que arribaban anualmente y en los efectos que produjeron en Europa. Su fin era determinar el papel de América en la acumulación originaria que permitió el desarrollo capitalista. Un investigador pionero en este sentido fue Earl J. Hamilton, quien en su libro editado en 1934, llamado El tesoro Americano y la revolución de los precios en España 1501-1650 se centró en establecer la cantidad de oro y plata importadas a través de España durante un siglo y medio. Las fuentes que utilizó fueron las cartas de la Casa de Contratación, los registros de carabelas y galeones y los diarios de entradas y salidas que llevó el tesorero de la Casa de Contratación llamado "La cuenta y razón”.

En la misma línea, se encuentra el monumental trabajo realizado por Pierre y Hugette Chaunu quienes a partir del volumen y la cantidad de navíos que ingresaron al puerto de Sevilla, en términos generales, reafirman las cifras desarrolladas por Hamilton. Estos autores, plantean que el siglo XVI fue un período de desarrollo económico y que en el XVII, en cambio, producto de la saturación de mercancías europeas comienza el declive del comercio, 
fundamentalmente a partir de 1620. Otros trabajos, como los primeros realizados por Antonio García Baquero aportan nuevos datos, sin establecer diferencias significativas con "la ley general" establecida. Un ejemplo de ello es su trabajo “Andalucía y la Carrera de Indias, 1492-1824” en donde cuestiona el crecimiento de Andalucía durante el período la primera centuria. Este historiador planteó que la falta de materias primas, mano de obra especializada, capitales y el desajuste de salarios y precios no permitió que se produjese una transformación que permitiera hacerse cargo de la demanda americana, además determina que los beneficios obtenidos no se reinvirtieron en actividades productivas.

Ya en los artículos del historiador francés Michel Morineau, en donde analizan el comercio entre Europa y América, se pueden rastrear críticas al modelo explicativo sobre los análisis del comercio ultramarino realizados desde la década del sesenta del siglo pasado, fue a partir de la publicación de su libro en 1985, cuando la crítica tuvo eco en los especialistas y en los espacios institucionales. Tomando como punto de partida el análisis de unas fuentes como las Gazettes Holandesas, que hasta ese momento no habían sido utilizadas para analizar la entrada de metales preciosos a Europa provenientes de América, el autor realizó un cambio más que sustancial en la idea que se tenía hasta ese momento de las características del comercio. Esto le permitió determinar que, a diferencia de lo que se había planteado hasta entonces, no existió una crisis de los metales durante el siglo XVII, siendo un "etrange hallucination provoquée par une lacune de l'information" (Jumar, 2002). Determinó que tanto en el siglo XVII como en el siglo XVIII, la tendencia fue al alza. El autor se centra en el comercio legal, tomando una fuente no oficial, Gazettes Holandesas, pero que cuenta con un abordaje exhaustivo, lo que le permite reconstruir el comercio poniendo la mirada 
en Europa. Así determina que no solo era importante la llegada de metales preciosos, sino que también era necesario analizar cómo estaba organizado el comercio, los flujos circulatorios y el stock. Por otra parte, amplía el panorama al aseverar en su trabajo que los metales preciosos eran solo una mercancía más en el comercio existente entre Europa y América.

Este trabajo sirvió de impulso para que durante la misma década, un florecimiento de investigaciones se volcara a estudiar los espacios americanos y su relación con el comercio europeo. Su objetivo, era profundizar en discutir la hipótesis de la crisis del siglo XVII. Específicamente en el Río de la Plata su objetivo fue el dar cuenta del aumento de la cantidad de navíos y de las cifras totales de plata y oro que salió a partir de la aplicación del Reglamento de Libre Comercio, que vincularon los puertos de Montevideo y Buenos Aires con los puertos de la España peninsular. Con ese fin, se utilizaron como fuentes resúmenes sueltos de funcionarios que dan cuenta del número total de embarcaciones que entraron en los puertos del Complejo o, en el mejor de los casos, incluyendo los nombres de los mismos, por periodos cortos de tiempo, haciendo especial hincapié en los cuatros o cinco años siguientes a 1778.

Además, un gran número de autores comienzan a discutir la existencia o no de la crisis del siglo XVII en América, entre estos cabe destacar la labor de Ruggiero Romano. Este autor devela el “eurocentrismo" de las investigaciones desarrolladas, ya que se centraron en la llegada de metales preciosos a Europa, cuando, desde la realidad americana, lo importante era lo que quedó en el espacio americano, esto es lo que el autor denominó coyunturas opuestas. Nuevas investigaciones de la década del ochenta relativizaron la existencia de la crisis en América a partir de los estudios de Juan Carlos Super (1983) quien se centra en la 
región del Bajío Oriental en Nueva España y el trabajo de TePaske y Klein (1982) quienes abordan la dinámica económica a partir del análisis de los ingresos fiscales.

El libro de Zacarías Moutoukias (1988), reconstruye a partir del análisis de las fuentes, entre otras, extraídas del Archivo Municipal de Ámsterdam, un trabajo en donde su objetivo es colocar a Buenos Aires en el sistema ya descripto por Assadourian de la articulación de las economías regionales. En donde Buenos Aires, se encuentra como punto de conexión a partir del “... comercio ultramarino basado en la exportación de metales preciosos, gravitación de la administración en la vida comercial...". Por otra parte, aborda el tema del contrabando, tomando la mirada renovada iniciada por Carlos D. Malamud (1982), quien ve contradicciones en la legalidad vigente y un cierto "acuerdo implícito con la Corona" para este tipo de tráfico.

John Robert Fisher (1993) es quien comenzó a elaborar a partir de los registros de los buques que los funcionarios de aduana redactaban en los puertos de salida un trabajo sistemático sobre el comercio entre América y la España peninsular posteriormente a la promulgación del Real decreto de Libre Comercio de 1778. En su estudio, encuentra que gracias a la promulgación de este decreto se incrementó notablemente el intercambio durante el período solo descendiendo en aquellos momentos de guerra o bloqueo. Esta explicación generó críticas por parte de varios historiadores. Josep Delgado Ribas (2002), por ejemplo le cuestionó el año que se toma por medida 1778 , el cual fue de menor flujo comercial por los problemas militares con Inglaterra y por el impacto de la inminente declaración del reglamento. En cambio, García Baquero (2003) plantea la insuficiencia del corpus de fuentes analizado por Fisher para sus afirmaciones e inserta dos nuevas 
fuentes, los derechos contribuidos a la Real Hacienda y las notas de carga, con las que relativiza el espectacular crecimiento y que los datos aportados solo representan un $20 \%$ del total. A partir del análisis de los registros de los navíos García Baquero afirma que

"...la imagen que hasta ahora teníamos de dicho período, como una fase de signo inequívocamente alcista, en la que se producía un incremento extraordinario de los valores del tráfico $\mathrm{y}$, muy en particular, de los correspondientes a las importaciones (que registraban porcentajes de crecimiento de indudable espectacularidad), experimenta un vuelco radical." (García Baquero, 2003: 16).

En lo concerniente al Río de la Plata, en las últimas décadas, aumentó notablemente la producción de trabajos, siendo en su mayoría abocada a realizar estudios de caso, centralmente a partir de un actor o un grupo reducido de actores, inmigrante de la península, su derrotero y relaciones establecidas, por lo tanto, tres trabajos abordaron la relación comercial entre el Espacio Portuario Rioplatense y la España Peninsular.

La primera es la de María Jesús Arázola Corvera (1998) quien desarrolló en su investigación un recorte temporal de veinte años 1737 a 1757 . Si bien realiza un amplio tratamiento de fuentes, en especial las licencias otorgadas para partir al Río de la Plata, no ofrece un cambio sustantivo en las apreciaciones ya desarrolladas en el pasado.

La tesis inédita en castellano de Fernando Jumar (2002a) realiza un corte temporal de algo menos de cien años desde 1680 a 1778, toma un amplio abanico de fuentes, en donde los Registros de los Navíos ocuparon un lugar central, que se realizaba cuando un sujeto se dirigía a la autoridad recaudadora para informarle que iba a enviar algún bien fuera de la jurisdicción, siendo ese registro una fuente que permite reconstruir el envío de mercancías, las cantidades, quienes lo 
efectuaban y a donde. Las conclusiones a las que llega Jumar están centralmente orientadas al espacio rioplatense en el cual plantea, entre otras cosas, dos elementos fundamentales. El primero de ellos está relacionado al contrabando ya que relativiza la importancia del mismo al plantear que

Ese aplica al estudio de las realidades americanas del siglo XVIII con el contenido que tiene actualmente. En el siglo XVIII pude detectar que el límite de tolerancia para los actos que hoy se relevan de corrupción era diferente, mientras que la Corona recibía su parte los individuos son enjuiciados por cometer excesos, pero no por el hecho mismo de aceptar regalos que tienen como efecto la suspensión temporaria de las disposiciones reales en cuanto al comercio. (Jumar, 2002b).

El análisis que se desarrolló continúa la línea investigativa de Fernando Jumar ya que se trabajó con la misma fuente, los registros de navíos. Si bien, no se encuentra completa esta fuente, faltan algunos registros de navíos comerciales que dificultaron el abordaje de la salida de cueros, para el caso de los metales preciosos si se pudo llevar a cabo.

Los trabajos sobre la salida de metales preciosos durante las últimas décadas del siglo XVIII desde el complejo portuario rioplatense estuvieron orientados a esclarecer procesos desarrollados en la península española o en Europa, en particular el impacto de la aplicación del reglamento de libre comercio y la industrialización.

Desde el Río de la Plata, para el período analizado no se realizaron trabajos sistemáticos de las cifras de salida de metales preciosos, el trabajo que analizo este aspecto lo realizo a partir del estudio de un actor: Domingo Belgrano Perez. Si bien no aporta los datos de las transacciones comerciales de todos los años, da cuenta de los circuitos comerciales y las características de los intercambios. Plantea dos etapas del crecimiento comercial de este actor. Un primer período 
desde 1756 que llego al Río de la Plata hasta el casamiento de su hija, María Florencia, en 1776 con un estanciero Julián Gregorio Espinosa, el cual ayudo a potenciar el comercio minorista de Domingo Belgrano, llevarlo al comercio mayorista y multiplicar sus redes hacia el interior americano y con la península española. Establece que internamente Belgrano privilegió el intercambio de mercancías por otras mercancías de otras regiones y que la plata se enviaba hacia la península.

\section{Las cifras de la salida de metales}

En el trabajo de Morineau da cuenta de la llegada de metales preciosos proveniente de América durante el siglo XVIII, aportando los totales por año y por puerto de salida. Fernando Jumar, advierte la variación que observa al tomar los datos de salida y los de ingreso de Morineau para el período 1680- 1778 y sus posibles causas:

\footnotetext{
"Toutefois, nous ne voulons pas affirmer que les informations des gazetiers ne sont pas valables pour le reste de la Carrera de Indias et même nous présentons nos doutes par rapport à celles concernant le Río de la Plata avec bien d'hésitations. Il est fort probable que les informations concernant les retours de Buenos Aires ont été recueillies par les gazetiers avec un peu moins d'attention que pour le reste, en fin de comptes, nous sommes devant des arrivées en provenance d'un lieu -encore- marginale. Quelle est la signification des 19625000 pesos -chiffre qui reflète, ne l'oublions pas, des métaux précieux mais aussi des productions américaines... dans l'ensemble de la Carrera ? Bien peu. Ces 35 années de commerce légal espagnol dans le Río de la Plata arrivent seulement à dépasser de peu les 19 millions de la seule flotte de la Nouvelle-Espagne arrivée en 1688 d'après les informations fournies par La Lande Magon..." (Jumar 2002a: 131).
}

Continuando lo expresado por Jumar para el periodo 1680- 1778, para el período 1779- 1794 se puede observar en el gráfico número uno, no hubo gran diferencia entre los datos que expresó Morineau con los elaborados para esta tesis, 
la mayor diferencia se encuentra en los años 1784- 85 que tras la firma de la paz se produjo una gran afluencia de plata americana en la península. Como se planteó, en el libro de Morineau no se ofrece más datos que los totales del origen y destino con lo cual se dificulta establecer si hubo una gran variación en cuanto a navíos que partieron en tiempos de paz y que luego producto de la guerra tuvieron que quedarse durante el conflicto en otro puerto americano hasta la paz.

La explicación que entiendo correcta para la variación de esos años es que la salida de navíos en los años 1777 y 1778 no llegaron a destino inmediatamente, producto de la declaración de guerra, y si lo hicieron en los años posteriores. En las cifras expresadas por Fernando Jumar para los años 1776 a 1778 es casi seis millones y medio de pesos. En los cuadernos de bitácora que se analizaron en el capítulo 2 se puede apreciar que la práctica habitual cuando se enteraban de la declaración de guerra (por lo general en altamar) era ir al puerto más cercano y esperar allí la evolución del conflicto armado.

\section{Cuadro IV. 1}

Salida y entrada de metales preciosos (1779-1794)

\begin{tabular}{|r|r|r|}
\hline \multicolumn{1}{|l|}{ Años } & Entrada & \multicolumn{1}{l|}{ Salida } \\
\hline 1779 & 78747 & 438588 \\
\hline 1780 & 0 & 42444 \\
\hline 1781 & 0 & 14148 \\
\hline 1782 & 0 & 38146 \\
\hline 1783 & 1800000 & 2981406 \\
\hline 1784 & 8709452 & 5570620 \\
\hline 1785 & 4184633 & 2487564 \\
\hline 1786 & 4001936 & 4081532 \\
\hline 1787 & 3502709 & 2731691 \\
\hline 1788 & 474897 & 2572232 \\
\hline 1789 & 4117883 & 3022798 \\
\hline 1790 & 1994372 & 2964131 \\
\hline 1791 & 2993701 & 2873445 \\
\hline 1792 & 3218215 & 2878475 \\
\hline 1793 & 2150704 & 1731165 \\
\hline 1794 & 3741890 & 1996595 \\
\hline
\end{tabular}

Fuente: Elaboración propia a partir de Morineau, Michel. Incroyables Gazettes et fabuleux métaux. Les retours des trésors américains dans les gazettes 
hollandaises XVI $I^{e}$-XVIII siècles, Paris, Maison des Sciences de l'Homme et Cambridge University Press, 1984-1985.AGN Argentina: Sala XIII: 15-10-3; $37-6-4$; 37-10-5; 37-10-6-; 38-8-3; 38-8-4; 38-1-1; 38-1-3; 38-2-3; 38-3-4; 38-4-4; $38-5-3$; 38-6-4; 38-1-3; 39-1-3; 39-2-1; 39-2-2; 39-3-1; 39-3-2; 39-3-3; 39-4-3; $39-5-4 ; 39-6-2 ; 39-8-4 ; 39-9-3 ; 39-10-1 ; 39-10-4 ; 39-7-4 ; 15-10-3 ; 37-9-3$; 37-94 ; 38-10-3; 38-6-3. 14-9-5; 14-10-1; 14-10-2; 14-10-3; 14-10-4; 15-10-1; 15-10-2; 15-10-3. Sala IX 43- 05- $11 ; 43-06-01 ; 43-06-02 ; 43-06-03 ; 43-06-04$; 4306- 05; 43- 06- 06; 43- 06- 07; 43- 06- 08; 43- 06- 09; 43- 07- 01; 43- 07- 02; 4307- 03; 43- 07- 04; 43- 07- 05; 43- 07- 06; 43- 07- 07; 43- 07- 08; 43- 07- 09; 4307- 10 ; 43- 07- 11 ; 43- 07- 12 ; 43- 08- 01 ; 43- 08- 02; 43- 08- 03; 43- 08- 04; 4308- 05; 43- 08- 06; 43- 08- 07; 43- 08- 08; 43- 08- 09; 43- 08- 10; 43- 08- 11 ; 4308- 12; 43- 09- 01; 43- 09- 02; 43- 09- 03; 43- 09- 04; 43- 09- 05; 43- 09- 06; 4309- 07; 43- 09- 08; 43- 09- 09; 43- 09- 10; 43- 09- 11. AGN Uruguay: Fondo Documental ex "Archivo y Museo Histórico Nacional": Legajos con Registros de Navíos desde el 218 a 270.

Gráfico IV. 1

Comparación de los metales preciosos salidos y llegados 1779- 1794

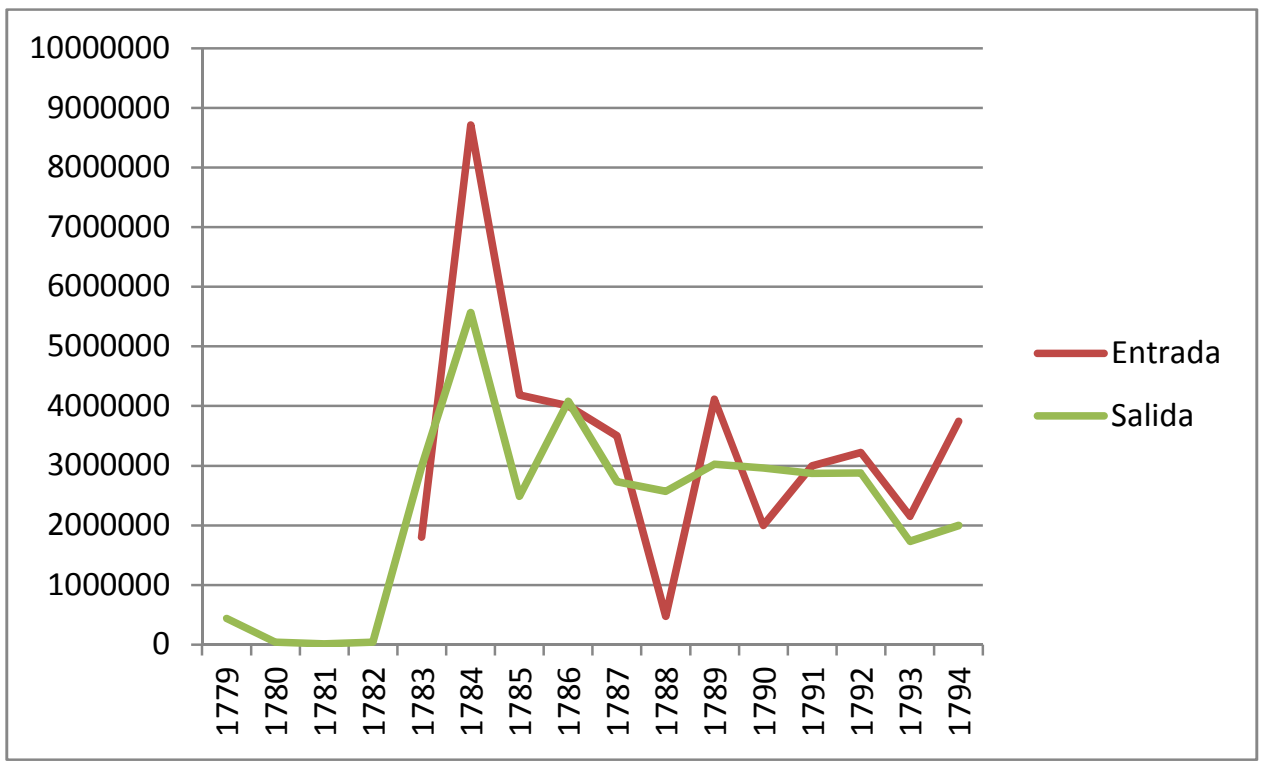

Fuente: Elaboración propia a partir del Cuadro IV. 1.

Continuado lo planteado en la tesis de Fernando Jumar (2002) se parte del análisis de los registros de los navíos para lograr reconstruir las cantidades de metales que salieron. La utilización de los registros de los navíos permite separar 
los envíos fiscales y privados y dentro de los privados aquellos que eran para herencias y donaciones para iglesias de los que se efectuaban para el comercio.

Como ya dijimos en la introducción de este capítulo, el total de metales preciosos salidos registrados comenzó a crecer en forma paulatina desde mediados del siglo XVIII, producto de una serie de dinámicas económicas interrelacionadas. En primer lugar, la consolidación del complejo portuario como punto de vinculación entre el interior americano y, en principio Brasil y luego la península española. En un solo trienio, 1746- 48, partieron desde el complejo portuario 9.188.275 pesos hacia territorios de la Monarquía portuguesa. Este intercambio fue perdiendo peso progresivamente en pos de la vinculación con la península española, en particular a partir de la posibilidad de la conexión con la Coruña por medio de las fragatas correos y la apertura de otros puertos de la península española.

\section{Gráfico IV. 2}

Salidas de metales preciosos 1725-1794

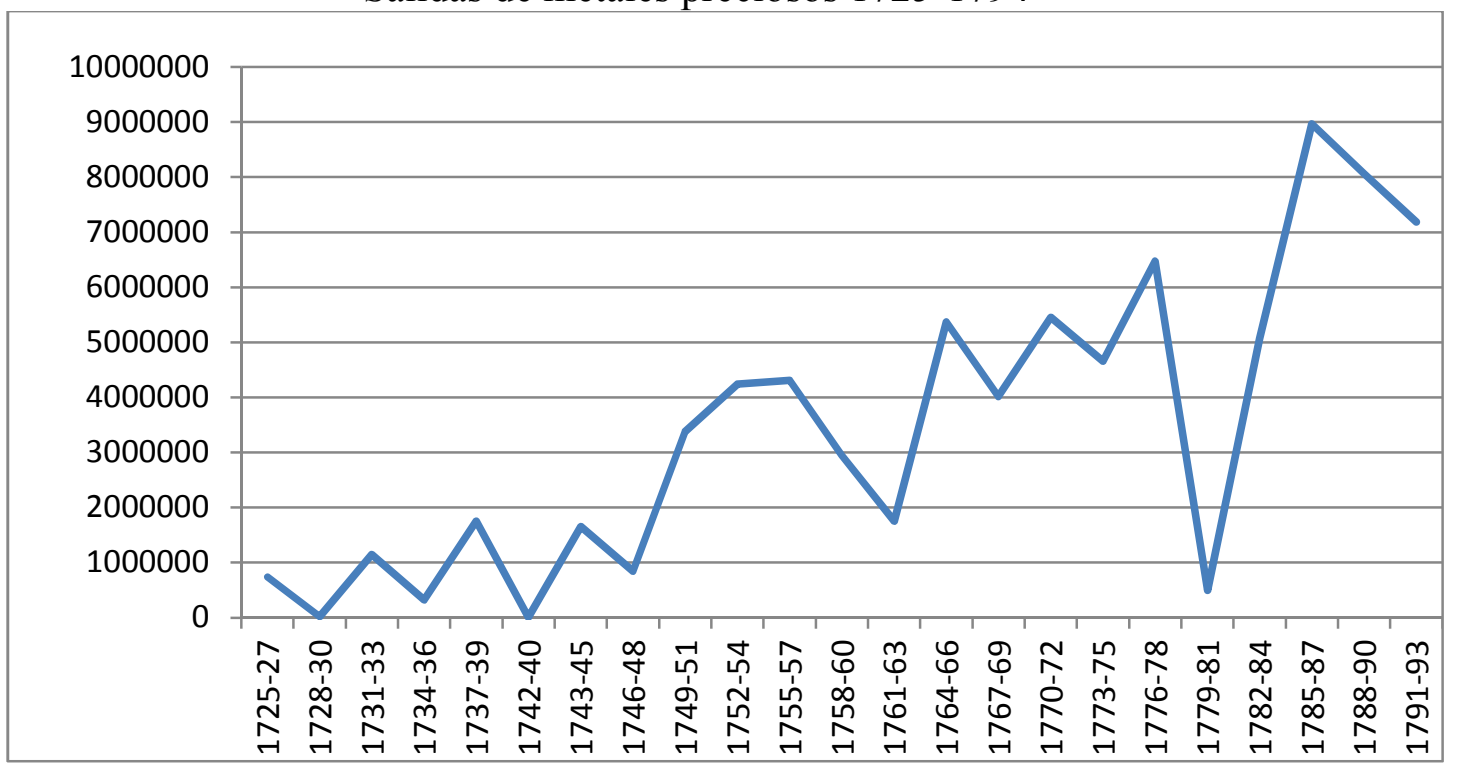

Fuente: elaboración propia en base a Jumar (2002)..AGN Argentina: Sala XIII: 15-10-3; 37-6-4; 37-10-5; 37-10-6-; 38-8-3; 38-8-4; 38-1-1; 38-1-3; 38-2-3; 38-34 ; 38-4-4; 38-5-3; 38-6-4; 38-1-3; 39-1-3; 39-2-1; 39-2-2; 39-3-1; 39-3-2; 39-3-3; $39-4-3 ; 39-5-4 ; 39-6-2 ; 39-8-4 ; 39-9-3 ; 39-10-1 ; 39-10-4 ; 39-7-4 ; 15-10-3 ; 37-9-$ 3 ; 37-9-4; 38-10-3; 38-6-3. 14-9-5; 14-10-1; 14-10-2; 14-10-3; 14-10-4; 15-10-1; 
15-10-2; 15-10-3. Sala IX 43- 05- $11 ; 43-06-01 ; 43-06-02 ; 43-06-03$; 43- 0604; 43- 06- 05; 43- 06- 06; 43- 06- 07; 43- 06- 08; 43- 06- 09; 43- 07- 01; 43- 0702; 43- 07- 03; 43- 07- 04; 43- 07- 05; 43- 07- 06; 43- 07- 07; 43- 07- 08; 43- 0709; 43- 07- 10 ; 43- 07- 11 ; 43- 07- 12 ; 43- 08- 01 ; 43- 08- 02; 43- 08- 03; 43- 0804; 43- 08- 05; 43- 08- 06; 43- 08- 07; 43- 08- 08; 43- 08- 09; 43- 08- 10; 43- 0811 ; 43- 08- 12 ; 43- 09- 01; 43- 09- 02; 43- 09- 03; 43- 09- 04; 43- 09- 05; 43- 0906; 43- 09- 07; 43- 09- 08; 43- 09- 09; 43- 09- 10; 43- 09- 11. AGN Uruguay: Fondo Documental ex "Archivo y Museo Histórico Nacional”: Legajos con Registros de Navíos desde el 218 a 270.

En la historiografía que analizó el papel de Cádiz y del resto de puertos a partir de la aplicación del reglamento de libre comercio hubo un consenso en que Cádiz mantuvo el predominio como puerto de llegada de los metales preciosos americanos, siendo hasta beneficiado por las reformas y el resto de puertos mantuvo un lugar testimonial sin producir gran incidencia (Fisher, 1993, García Baquero, 2003).

En el gráfico siguiente se puede apreciar que la salida de metales preciosos hacia Cádiz se incrementó a mediados de siglo, solo bajando en el período del conflicto armado iniciado en 1779 y manteniendo la salida en las décadas siguientes. Si se compara, por lo tanto, la salida total y las enviadas a Cádiz encontramos que el impacto de las reformas institucional fue mínimo y que el incremento se produjo a partir del ascenso del comercio de mediados de siglo. 
Gráfico IV. 3:

Salida de metales preciosos con destino Cádiz, 1725- 1793

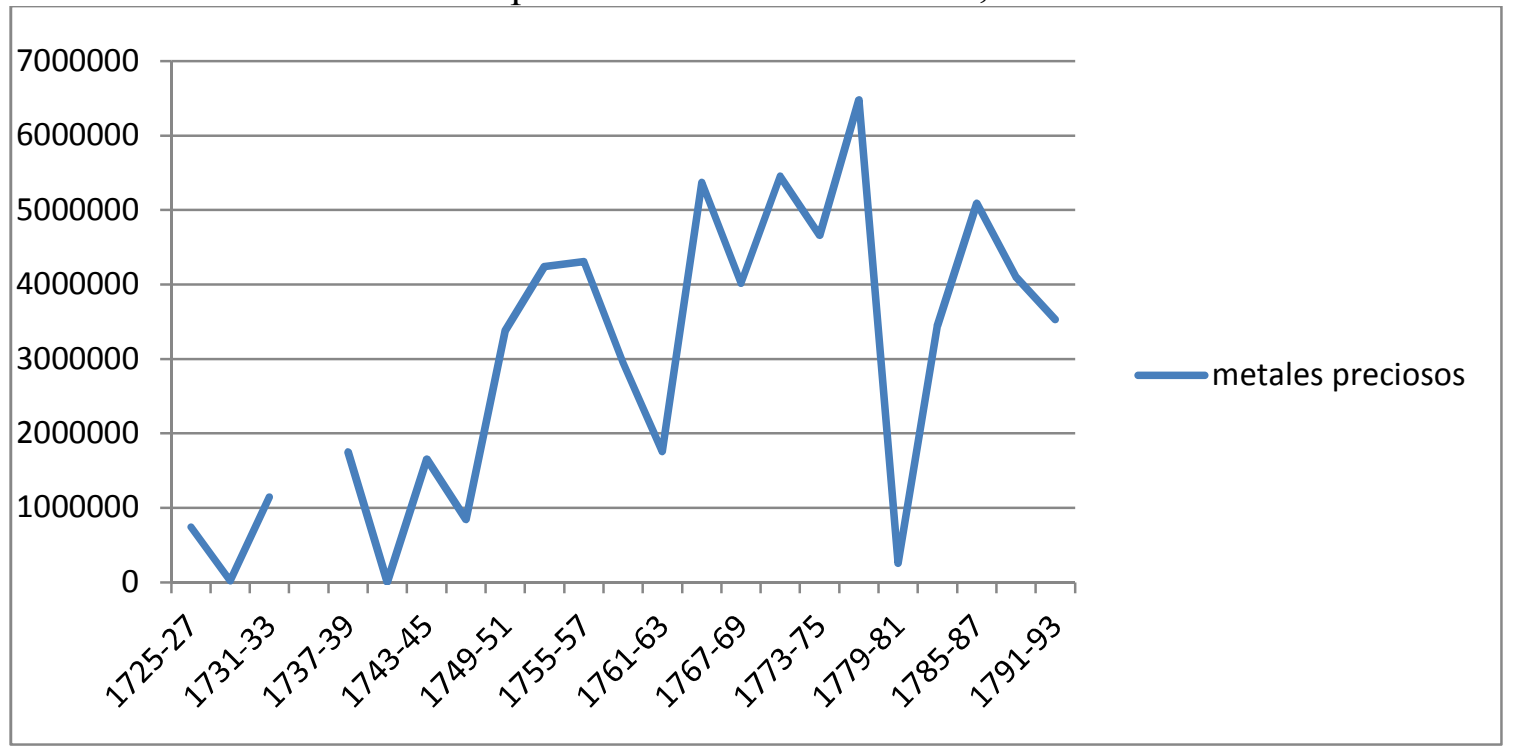

Fuente: elaboración propia en base a Jumar (2002a).AGN Argentina: Sala XIII: $15-10-3$; 37-6-4; 37-10-5; 37-10-6-; 38-8-3; 38-8-4; 38-1-1; 38-1-3; 38-2-3; 38-34 ; 38-4-4; 38-5-3; 38-6-4; 38-1-3; 39-1-3; 39-2-1; 39-2-2; 39-3-1; 39-3-2; 39-3-3; $39-4-3 ; 39-5-4 ; 39-6-2 ; 39-8-4 ; 39-9-3 ; 39-10-1 ; 39-10-4 ; 39-7-4 ; 15-10-3 ; 37-9-$ 3 ; 37-9-4; 38-10-3; 38-6-3. 14-9-5; 14-10-1; 14-10-2; 14-10-3; 14-10-4; 15-10-1; $15-10-2 ; 15-10-3$. Sala IX 43- 05- $11 ; 43-06-01 ; 43-06-02 ; 43-06-03 ; 43-06-$ 04; 43- 06- 05; 43- 06- 06; 43- 06- 07; 43- 06- 08; 43- 06- 09; 43- 07- 01; 43- 0702; 43- 07- 03; 43- 07- 04; 43- 07- 05; 43- 07- 06; 43- 07- 07; 43- 07- 08; 43- 0709; 43- 07- 10 ; 43- 07- 11 ; 43- 07- 12 ; 43- 08- 01 ; 43- 08- 02; 43- 08- 03; 43- 0804; 43- 08- 05; 43- 08- 06; 43- 08- 07; 43- 08- 08; 43- 08- 09; 43- 08- 10; 43- 0811 ; 43- 08- 12 ; 43- 09- 01; 43- 09- 02; 43- 09- 03; 43- 09- 04; 43- 09- 05; 43- 0906; 43- 09- 07; 43- 09- 08; 43- 09- 09; 43- 09- 10; 43- 09- 11. AGN Uruguay: Fondo Documental ex "Archivo y Museo Histórico Nacional": Legajos con Registros de Navíos desde el 218 a 270.

La salida de metales preciosos hacia Cádiz tuvo un crecimiento muy marcado a mediados del siglo XVIII. Este crecimiento, probablemente este marcado por la consolidación comercial que se produjo a partir de que el complejo portuario rioplatense se encontraba en expansión interna en detrimento de Lima como lugar de ingreso de mercancías del circuito legal español. El crecimiento del complejo portuario, estuvo marcado por la guerra con Inglaterra y el ataque sobre Portobelo que forzó el incremento de navíos de registro sueltos. La circulación de embarcaciones de esta característica entre Cádiz y el complejo portuario rioplatense, como se desarrolló en el primer capítulo se incrementó a partir de este 
período. Esto consolidó los lazos entre los comerciantes de estos dos espacios en detrimento de los de Lima (Kraselsky, 2010).

\section{Gráfico IV. 4}

Salida de metales preciosos hacia Cádiz (1731-1793).

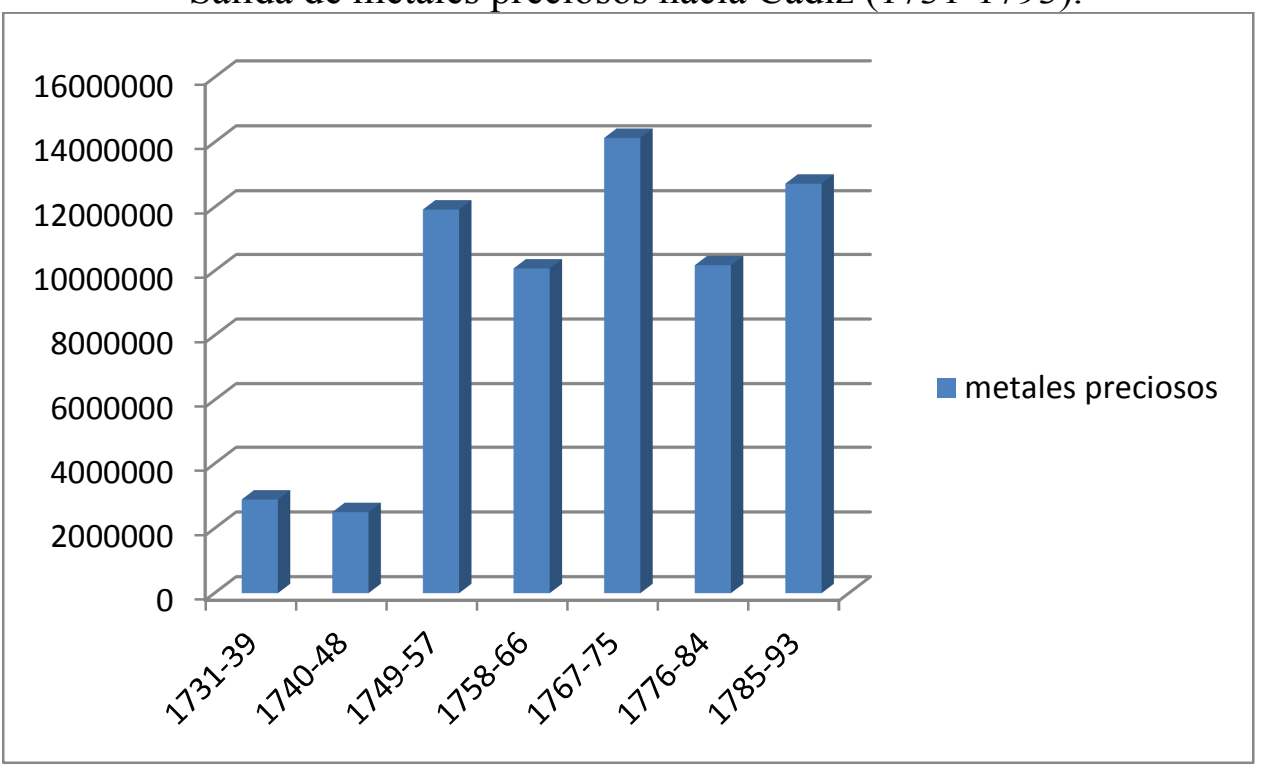

Fuente: elaboración propia en base a Jumar (2002a).AGN Argentina: Sala XIII: $15-10-3 ; 37-6-4 ; 37-10-5 ; 37-10-6-; 38-8-3 ; 38-8-4 ; 38-1-1 ; 38-1-3$; 38-2-3; 38-34 ; 38-4-4; 38-5-3; 38-6-4; 38-1-3; 39-1-3; 39-2-1; 39-2-2; 39-3-1; 39-3-2; 39-3-3; $39-4-3 ; 39-5-4 ; 39-6-2 ; 39-8-4 ; 39-9-3 ; 39-10-1 ; 39-10-4 ; 39-7-4 ; 15-10-3 ; 37-9-$ 3 ; 37-9-4; 38-10-3; 38-6-3. 14-9-5; 14-10-1; 14-10-2; 14-10-3; 14-10-4; 15-10-1; 15-10-2; 15-10-3. Sala IX 43- 05- 11 ; 43- 06- 01; 43- 06- 02; 43- 06- 03; 43- 0604; 43- 06- 05; 43- 06- 06; 43- 06- 07; 43- 06- 08; 43- 06- 09; 43- 07- 01; 43- 0702; 43- 07- 03; 43- 07- 04; 43- 07- 05; 43- 07- 06; 43- 07- 07; 43- 07- 08; 43- 0709; 43- 07- 10 ; 43- 07- 11 ; 43- 07- 12; 43- 08- 01; 43- 08- 02; 43- 08- 03; 43- 0804; 43- 08- 05; 43- 08- 06; 43- 08- 07; 43- 08- 08; 43- 08- 09; 43- 08- 10; 43- 0811; 43- 08- 12; 43- 09- 01; 43- 09- 02; 43- 09- 03; 43- 09- 04; 43- 09- 05; 43- 0906; 43- 09- 07; 43- 09- 08; 43- 09- 09; 43- 09- 10; 43- 09- 11. AGN Uruguay: Fondo Documental ex "Archivo y Museo Histórico Nacional": Legajos con Registros de Navíos desde el 218 a 270.

El impacto de las reformas se produjo a partir del ingreso de nuevos puertos, los cuales represento el $44,7 \%$ de la salida de metales preciosos para el período 1779- 1794. Esto fue producto, como se planteó para el comercio ultramarino de cueros, por la descentralización que esto provocó. Si se suma los cueros a los metales se puede establecer que, gran parte de la producción de todo 
el espacio fue hacia otros puertos. Si bien, no modificó directamente el comercio con Cádiz, produjo el descenso de los precios y una mayor competencia, dejando atrás la edad dorada de los monopolistas de Cádiz.

En suma, durante el siglo XVIII se tendría tres etapas con respecto a la salida de metales, una primera marcada por los Asientos francés e inglés y el comercio con Brasil. Un segundo período marcado por el predominio de Cádiz, anteriormente presente pero minoritario y un tercero con la apertura de los puertos peninsulares al comercio. Tenemos por lo tanto que Cádiz, mantuvo hasta la década de 1780 una tendencia creciente en su vinculación con el área vinculada al complejo portuario rioplatense y a partir de allí, se estancó, creciendo la vinculación con otras regiones de la península. Si bien la salida se produjo desde el Río de la Plata no todos los envíos se producían por actores afincados allí.

\section{$\underline{\text { Procedencia de los registros de los metales preciosos }}$}

La salida de metales preciosos por el complejo portuario rioplatense refleja en gran medida el ingreso de mercancías distribuidas sobre el interior americano. A partir del análisis de la salida de metales preciosos se puede analizar el lugar de donde se envía en forma directa hacia la península. Es decir, en las fuentes analizadas se puede establecer el lugar de donde se envía en forma directa hacia la península española.

Carlos Sempat Assadourian (1983) estableció que en los siglos XVI y XVII, los límites del espacio peruano se encontraban en superposición a la jurisdicción del Virreinato del Perú. Los intercambios tenían como objetivo proveer de mercancías por oro y plata al centro extractor de metales. Lima era el centro político y el organizador de las transacciones y el Río de la Plata era el 
espacio en donde ingresaban ilegalmente mercancías desde Europa. Este contexto para la segunda mitad del siglo XVIII se modificó notablemente producto de la intensificación de los intercambios dentro de la región Río de la Plata y de la zona de Cuyo y Chile. Como se puede apreciar en el gráfico siguiente la mayoría de los envíos de mercancías se distribuían en la región Río de la Plata, en segundo lugar hacia Chile y Mendoza y en tercero desde Córdoba hasta el Alto Perú.

\section{Gráfico IV. 5}

Salida de mercancías de Buenos Aires según destino (1779- 1783).

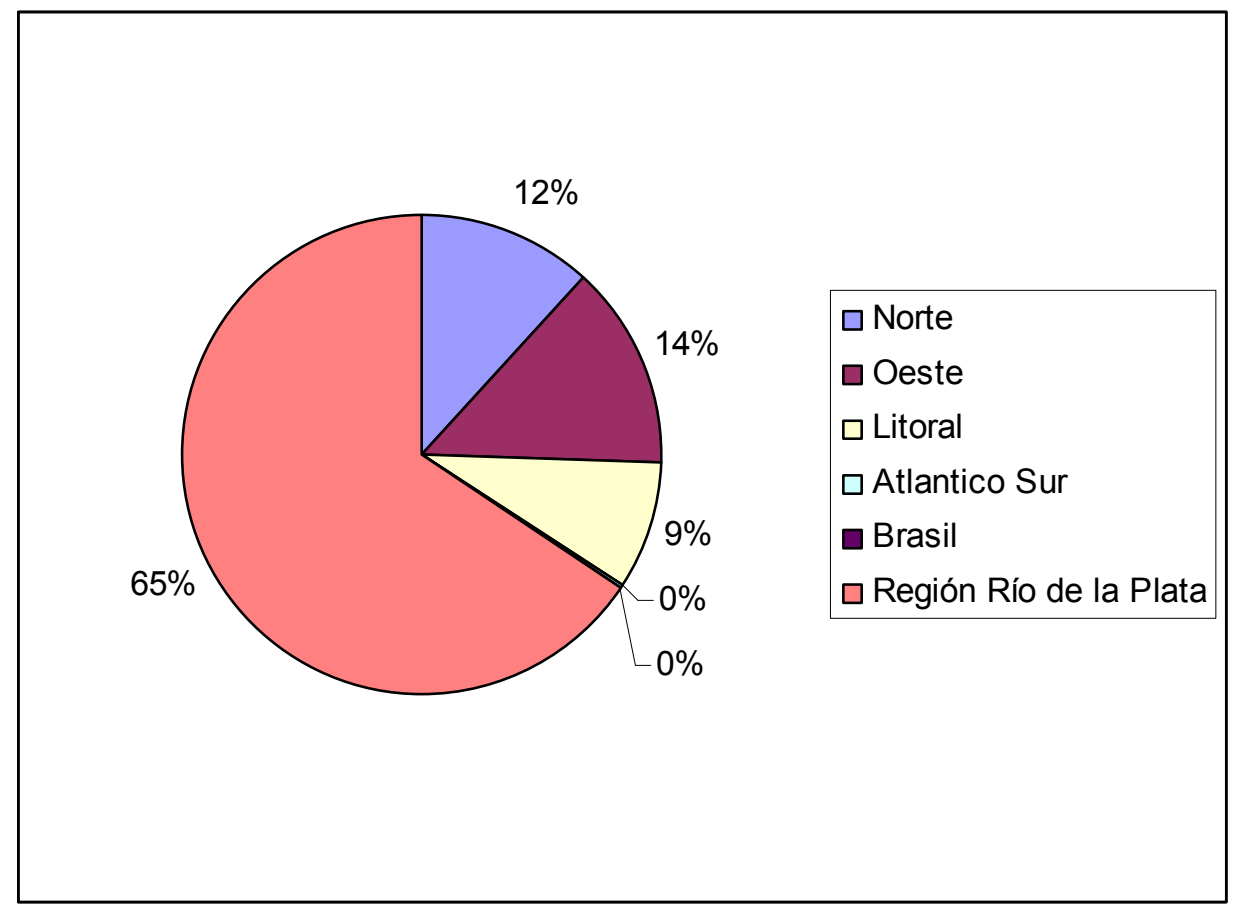

Fuente: Elaboración propia a partir de los datos de Sovarzo (2014).

La salida de mercancías por fuera de la región Río de la Plata se dividió entre los que partían hacia el Norte, Chile y el Litoral. Si se toma la relación entre la importancia del circuito y la salida de metales se puede apreciar que mientras que en el Litoral no hubo prácticamente envíos por las mercancías que llegaban, en el Norte se produjeron algunos y en Chile mucho más. La inexistencia de envíos de actores afincados en el Litoral da cuenta de que aquellos que vincularon 
estos espacios con el mercado ultramarino eran los comerciantes de Buenos Aires, en cambio, los envíos de metales preciosos de Chile, por ejemplo, da cuenta de que un grupo de comerciantes asentados en este territorio mantuvo un contacto directo con la península española.

\section{Gráfico IV. 6}

Relación entre las guías de salida de Buenos Aires y Metales preciosos enviados en forma directa (1779-1783)

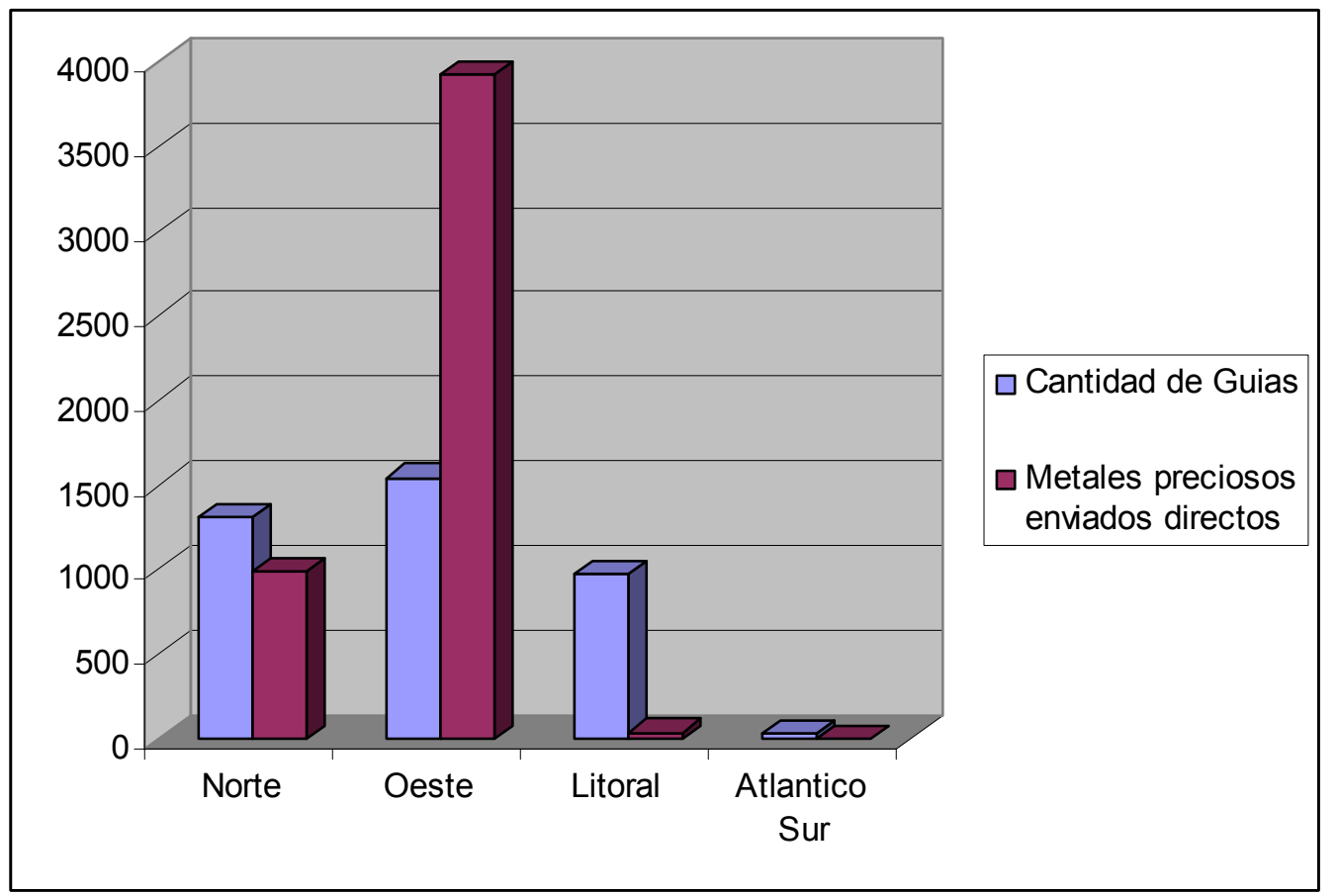

Fuente: elaboración propia en base a Sovarzo (2014) AGN Argentina: Sala XIII: $15-10-3$; 37-6-4; 37-10-5; 37-10-6-; 38-8-3; 38-8-4; 38-1-1; 38-1-3; 38-2-3; 38-34 ; 38-4-4; 38-5-3; 38-6-4; 38-1-3; 39-1-3; 39-2-1; 39-2-2; 39-3-1; 39-3-2; 39-3-3; $39-4-3 ; 39-5-4 ; 39-6-2 ; 39-8-4 ; 39-9-3 ; 39-10-1 ; 39-10-4 ; 39-7-4 ; 15-10-3 ; 37-9-$ 3 ; 37-9-4; 38-10-3; 38-6-3. 14-9-5; 14-10-1; 14-10-2; 14-10-3; 14-10-4; 15-10-1; 15-10-2; 15-10-3. Sala IX 43- 05- 11 ; 43- 06- 01; 43- 06- 02; 43- 06- 03; 43- 0604; 43- 06- 05; 43- 06- 06; 43- 06- 07; 43- 06- 08; 43- 06- 09; 43- 07- 01; 43- 0702 ; 43- 07- 03; 43- 07- 04; 43- 07- 05; 43- 07- 06; 43- 07- 07; 43- 07- 08; 43- 0709; 43- 07- 10 ; 43- 07- 11 ; 43- 07- 12 ; 43- 08- 01 ; 43- 08- 02 ; 43- 08- 03; 43- 0804; 43- 08- 05; 43- 08- 06; 43- 08- 07; 43- 08- 08; 43- 08- 09; 43- 08- 10; 43- 0811 ; 43- 08- 12; 43- 09- 01; 43- 09- 02; 43- 09- 03; 43- 09- 04; 43- 09- 05; 43- 0906; 43- 09- 07; 43- 09- 08; 43- 09- 09; 43- 09- 10; 43- 09- 11. AGN Uruguay: Fondo Documental ex "Archivo y Museo Histórico Nacional": Legajos con Registros de Navíos desde el 218 a 270. 
La centralidad de Buenos Aires y, en menor medida, Montevideo, de los envíos de metales preciosos por casi todas las mercancías que ingresaron a la región Río de la Plata da cuenta de la consolidación de esta región a partir de los dos puntos que lo vinculaban con el Atlántico, en donde no solo era un eje territorial o político sino también económico. En cambio, para las zonas articuladas en torno al camino del norte: Córdoba, Tucumán, Salta, Jujuy y el Alto Perú, si bien hubo envíos de actores asentados en esos territorios la centralidad de Buenos Aires es muy marcado, que puede dar cuenta de una vinculación con control de los rioplatenses previa a la creación del Virreinato. En oposición, una parte muy importante de los envíos de mercancías hacia Chile era a cuenta y riesgo de actores asentados allí. Esto da cuenta de que esta ruta, posiblemente era bastante menos controlada que las anteriores por los afincados en el Río de la Plata.

\section{Gráfico IV. 7}

La salida de metales preciosos y su distribución

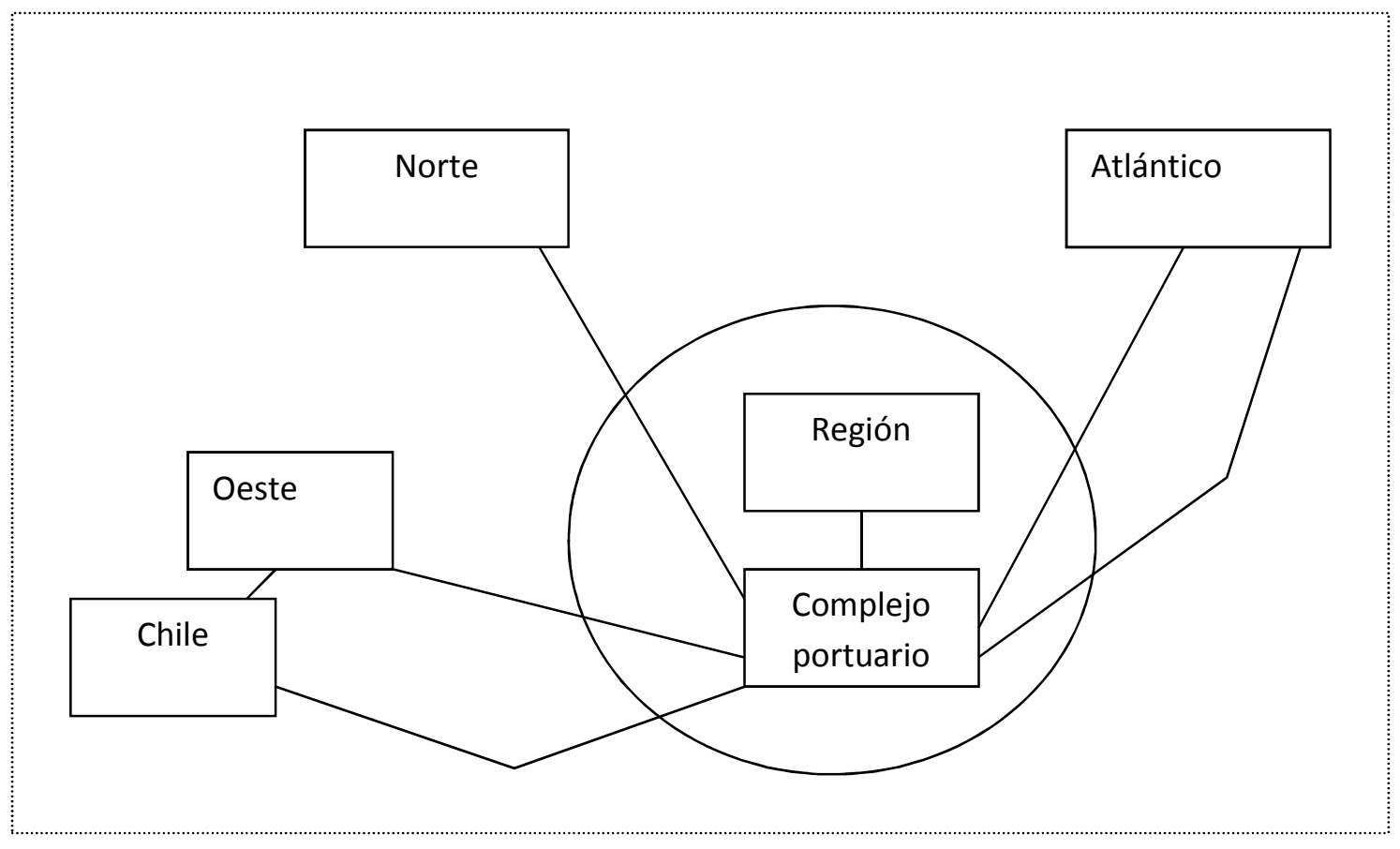


$\underline{\text { Tipos de Metales preciosos que partieron hacia la península }}$

Los metales preciosos, tanto plata como el oro, se enviaban de distintas formas: amonedada, labrada o en pasta. En general, los envíos que se realizaban en oro y plata amonedada era producto del comercio y en muchos de los envíos en pasta o labrada era por otros motivos y el valor era simbólico. Como plantea Fernando Jumar: "A veces se precisa, por ejemplo, que un par de candelabros fueron expendidos para ser entregados al párroco de una iglesia perdida en las provincias vascas. En estos casos el valor simbólico era mucho mayor que el que resulta de la aplicación de 8 pesos de a 8 reales por marco de plata declarada" (Jumar, 2002b: 4).

Durante el periodo que va desde 1715 a 1794 la mayor parte de los envíos fueron en monedas amonedadas, un setenta de plata y un quince de oro, y minoritariamente en pasta o labrada. Es decir, la mayor parte de la salida de metales preciosos estuvo vinculada al comercio y pasó previamente por las casas de amonedación.

\section{Cuadro IV. 2}

Salida de metales preciosos según forma de envío (1715-1794)

\begin{tabular}{|l|r|r|r|r|l|}
\hline Años & $\begin{array}{l}\text { Plata } \\
\text { Amonedada }\end{array}$ & Plata Pasta & $\begin{array}{l}\text { Oro } \\
\text { Amonedado }\end{array}$ & Oro pasta & Total \\
\hline $1715-1778$ & 43291756 & 1128810 & 4708667 & 7478944 & 56608177 \\
\hline $1779-1794$ & 18995480 & 3206497 & 8544101 & 1100478 & 31846556 \\
\hline Total & 62287236 & 4335307 & 13252768 & 8579422 & 88454733 \\
\hline
\end{tabular}

Fuente: elaboración propia en base a Jumar (2002); AGN Argentina: Sala XIII: $15-10-3$; 37-6-4; 37-10-5; 37-10-6-; 38-8-3; 38-8-4; 38-1-1; 38-1-3; 38-2-3; 38-34 ; 38-4-4; 38-5-3; 38-6-4; 38-1-3; 39-1-3; 39-2-1; 39-2-2; 39-3-1; 39-3-2; 39-3-3; $39-4-3$; 39-5-4; 39-6-2; 39-8-4; 39-9-3; 39-10-1; 39-10-4; 39-7-4; 15-10-3; 37-93 ; 37-9-4; 38-10-3; 38-6-3. 14-9-5; 14-10-1; 14-10-2; 14-10-3; 14-10-4; 15-10-1; 15-10-2; 15-10-3. Sala IX 43- 05- 11; 43- 06- 01; 43- 06- 02; 43- 06- 03; 43- 0604; 43- 06- 05; 43- 06- 06; 43- 06- 07; 43- 06- 08; 43- 06- 09; 43- 07- 01; 43- 0702; 43- 07- 03; 43- 07- 04; 43- 07- 05; 43- 07- 06; 43- 07- 07; 43- 07- 08; 43- 0709; 43- 07- 10; 43- 07- 11 ; 43- 07- 12; 43- 08- 01; 43- 08- 02; 43- 08- 03; 43- 0804; 43- 08- 05; 43- 08- 06; 43- 08- 07; 43- 08- 08; 43- 08- 09; 43- 08- 10; 43- 0811 ; 43- 08- 12; 43- 09- 01; 43- 09- 02; 43- 09- 03; 43- 09- 04; 43- 09- 05; 43- 0906; 43- 09- 07; 43- 09- 08; 43- 09- 09; 43- 09- 10; 43- 09- 11. AGN Uruguay: 
Fondo Documental ex "Archivo y Museo Histórico Nacional": Legajos con Registros de Navíos desde el 218 a 270.

Gráfico IV. 8

Salida de metales preciosos (1715- 1794).

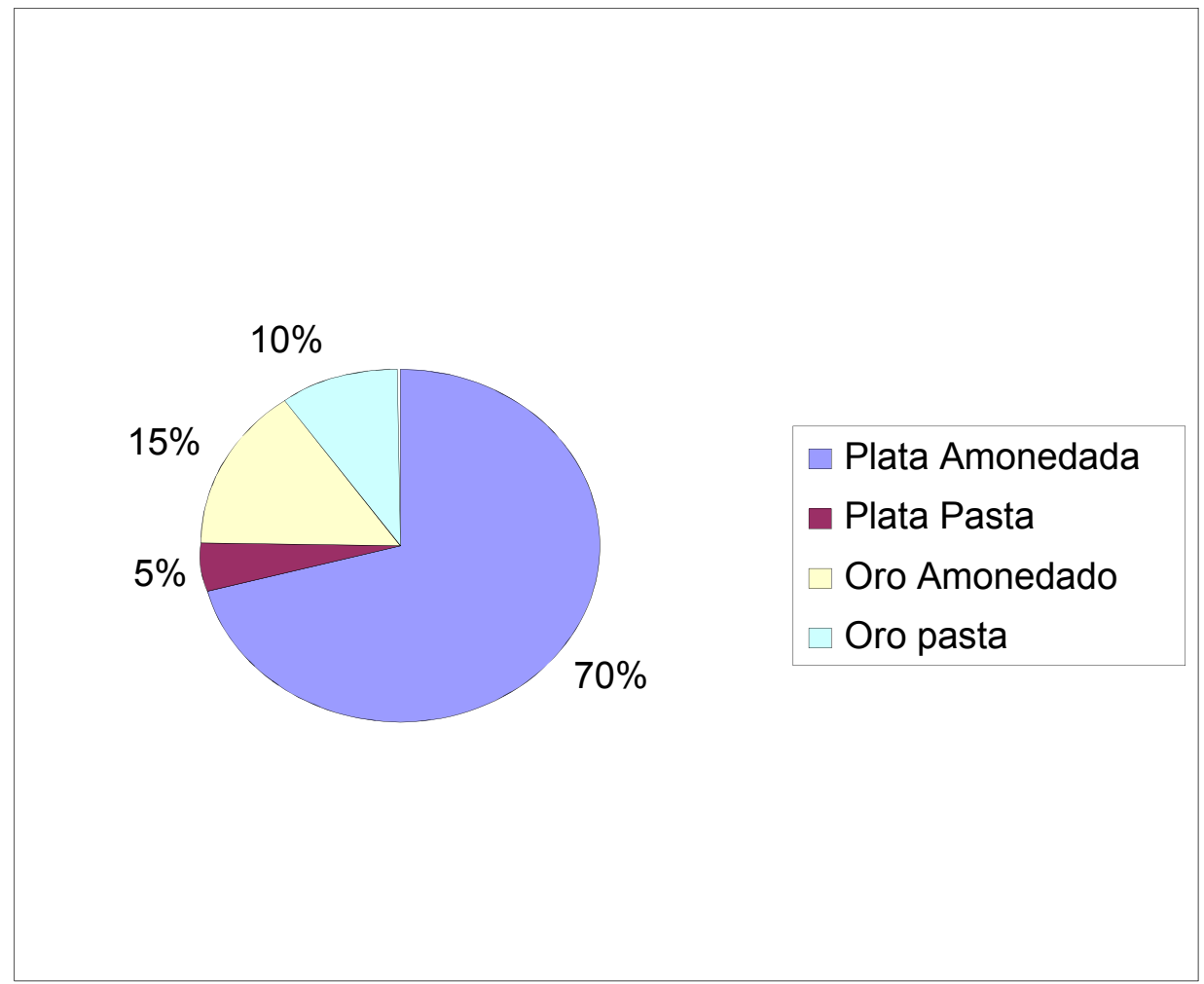

Fuente: elaboración propia en base cuadro IV. 2

En las últimas décadas del siglo XVIII se modificó levemente la proporción de salida de plata amonedada $\mathrm{y}$ oro. En términos absolutos no descendió la circulación de plata amonedada. De hecho creció producto de que las minas de plata alto y bajo peruanas en general incrementaron su producción y se expandió aún más el circuito con el complejo portuario, sino que la expansión del comercio con Chile que tenía en su territorio un desarrollo de la extracción del oro por encima de la plata. 
Gráfico IV. 9

Distribución de los metales preciosos (1779- 1794)

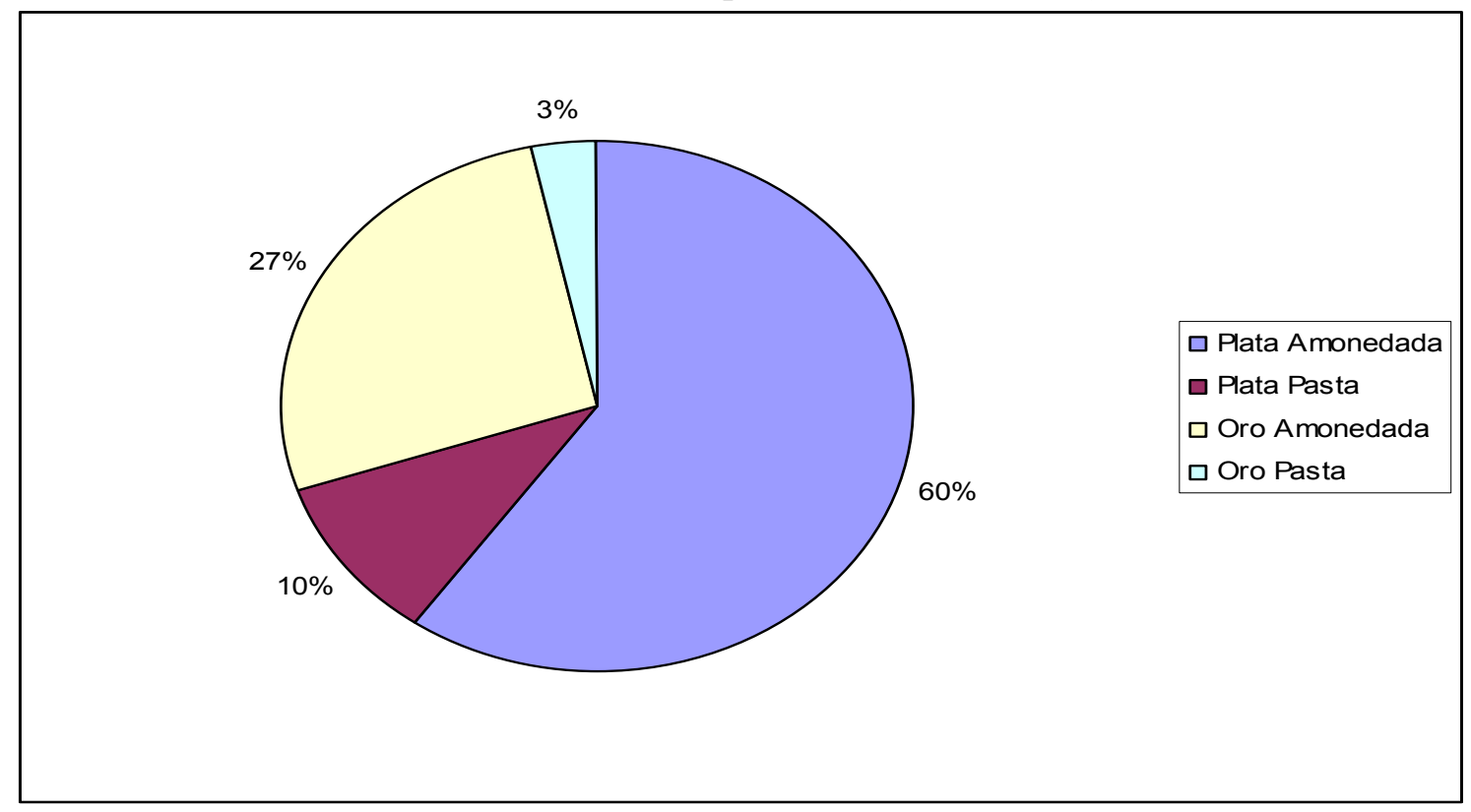

Fuente: elaboración propia en base a AGN Argentina: Sala XIII: 15-10-3; 37$6-4$; 37-10-5; 37-10-6-; 38-8-3; 38-8-4; 38-1-1; 38-1-3; 38-2-3; 38-3-4; 38-4-4; $38-5-3$; 38-6-4; 38-1-3; 39-1-3; 39-2-1; 39-2-2; 39-3-1; 39-3-2; 39-3-3; 39-4-3; $39-5-4 ; 39-6-2 ; 39-8-4 ; 39-9-3 ; 39-10-1 ; 39-10-4 ; 39-7-4 ; 15-10-3 ; 37-9-3 ; 37-9-$ 4 ; 38-10-3; 38-6-3. 14-9-5; 14-10-1; 14-10-2; 14-10-3; 14-10-4; 15-10-1; 15-10-2; 15-10-3. Sala IX 43- 05- 11 ; 43- 06- 01 ; 43- 06- 02; 43- 06- 03; 43- 06- 04; 4306- 05; 43- 06- 06; 43- 06- 07; 43- 06- 08; 43- 06- 09; 43- 07- 01; 43- 07- 02; 4307- 03; 43- 07- 04; 43- 07- 05; 43- 07- 06; 43- 07- 07; 43- 07- 08; 43- 07- 09; 4307- 10 ; 43- 07- 11 ; 43- 07- 12 ; 43- 08- 01 ; 43- 08- 02; 43- 08- 03; 43- 08- 04; 4308- 05; 43- 08- 06; 43- 08- 07; 43- 08- 08; 43- 08- 09; 43- 08- 10 ; 43- 08- 11 ; 4308- 12; 43- 09- 01; 43- 09- 02; 43- 09- 03; 43- 09- 04; 43- 09- 05; 43- 09- 06; 4309- 07; 43- 09- 08; 43- 09- 09; 43- 09- 10; 43- 09- 11. AGN Uruguay: Fondo Documental ex "Archivo y Museo Histórico Nacional”: Legajos con Registros de Navíos desde el 218 a 270.

Este crecimiento fue de la mano del incremento de la producción de plata del Alto Perú. En su texto clásico sobre la minería y el comercio de Potosí, Enrique Tandeter, Vilma Miletich y Roberto Schmit, plantean que no hubo un descenso en la producción y comercio sino más bien un incremento, además "A pesar del continuado peso de los mercados del Pacífico, el abasto de Potosí en mercancías ultramarinas provendría fundamentalmente de Buenos Aires." (1994: 104). 


\section{Gráfico IV. 10}

Distribución de los metales preciosos a lo largo del periodo, 1779- 94

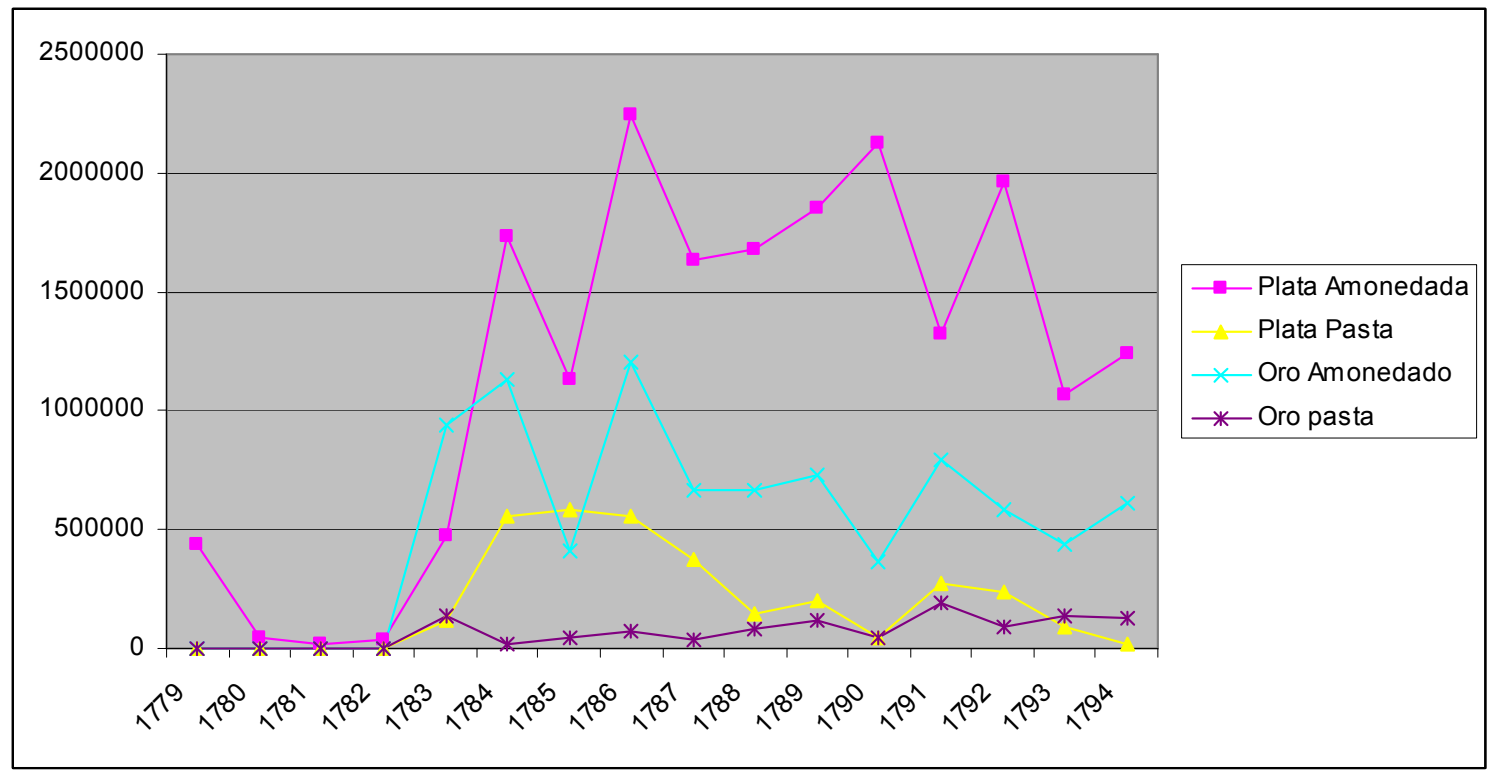

Fuente: elaboración propia en base a AGN Argentina: Sala XIII: 15-10-3; $37-$ $6-4$; 37-10-5; 37-10-6-; 38-8-3; 38-8-4; 38-1-1; 38-1-3; 38-2-3; 38-3-4; 38-4-4; $38-5-3$; 38-6-4; 38-1-3; 39-1-3; 39-2-1; 39-2-2; 39-3-1; 39-3-2; 39-3-3; 39-4-3; $39-5-4 ; 39-6-2 ; 39-8-4 ; 39-9-3 ; 39-10-1 ; 39-10-4 ; 39-7-4 ; 15-10-3 ; 37-9-3 ; 37-9-$ 4 ; 38-10-3; 38-6-3. 14-9-5; 14-10-1; 14-10-2; 14-10-3; 14-10-4; 15-10-1; 15-10-2; 15-10-3. Sala IX 43-05- 11 ; 43- 06- 01 ; 43- 06- 02; 43- 06- 03; 43- 06- 04; 4306- 05; 43- 06- 06; 43- 06- 07; 43- 06- 08; 43- 06- 09; 43- 07- 01 ; 43- 07- 02; 4307- 03; 43- 07- 04; 43- 07- 05; 43- 07- 06; 43- 07- 07; 43- 07- 08; 43- 07- 09; 4307- 10 ; 43- 07- 11 ; 43- 07- 12 ; 43- 08- 01 ; 43- 08- 02; 43- 08- 03; 43- 08- 04; 4308- 05 ; 43- 08- 06; 43- 08- 07; 43- 08- 08; 43- 08- 09; 43- 08- 10 ; 43- 08- 11 ; 4308- 12; 43- 09- 01; 43- 09- 02; 43- 09- 03; 43- 09- 04; 43- 09- 05; 43- 09- 06; 4309- 07; 43- 09- 08; 43- 09- 09; 43- 09- 10; 43- 09- 11. AGN Uruguay: Fondo Documental ex "Archivo y Museo Histórico Nacional": Legajos con Registros de Navíos desde el 218 a 270.

En suma, se puede estimar que el complejo portuario rioplatense continuó siendo la puerta que conectaba la plata altoperuana a los mercados ultramarinos. Sumado a ello, se produjo un incremento cada vez mayor del mercado trasandino que contaba con la particularidad de que una parte muy importante de las mercancías que ingresaban formaban parte de una conexión directa entre los actores sociales asentados en Santiago de Chile y los de la península española. 


\section{$\underline{\text { Salida de metales para fiscalidad }}$}

La historiografía sobre la fiscalidad de Buenos Aires se ha debatido sobre el carácter deficitario o no de la misma y si las reformas borbónicas influyeron positivamente en la recaudación. El aporte de esta tesis es en torno a la salida de metales preciosos con el fin de la Administración de la Real Hacienda. Como ya se desarrolló hay un consenso historiográfico que durante el siglo XVIII la economía de la región Río de la Plata creció, por ello, en principio la recaudación también, pero ¿cuánto de esos metales preciosos partieron hacia la península española como recaudación fiscal?

El trabajo más completo sobre los ingresos de la Caja Real de Buenos Aires durante el siglo XVIII fue realizado por Martín Cuesta (2009) quien, planteó que el crecimiento más importante de la recaudación de la caja de Buenos Aires se produjo a mediados de siglo, siendo autosustentable y creciendo, a su vez, en forma progresiva al gasto interno, en particular, militar. Este incremento en el gasto aportó al crecimiento económico regional, ya que se volcaba al consumo interno. El éxito de que este espacio perdure como territorios de la Monarquía da cuenta de que su defensa, en principio fue exitoso, lo cual, como se analizó en el capítulo primero, era el motivo más importante de las reformas durante la segunda mitad de siglo.

El crecimiento de la salida de metales preciosos hacia la Corona no fue tan sustancial como la recaudación. Entre 1745 y 1784 la salida de metales preciosos para la Real Hacienda fue de 4.484.641 pesos, siendo hasta 1.779 un promedio de $87.851,2$ pesos y para el período posterior $105.703,5$ pesos. La cifra general es muy pobre si tomamos en cuenta que en principio este espacio, como el resto americano, era un "fuente parasitaria de renta" que tenía como fin incrementar las 
arcas reales. Además, las reformas borbónicas, no lograron incrementar la salida anualmente, sin dudas durante todo el periodo la recaudación se quedó en América y sus incremento fue producto de la aceleración comercial y no del aumento de la presión fiscal, la cual durante todo el período fue alta en comparación a otros espacios tanto dentro de la Monarquía como fuera.

Gráfico IV. 11

Salida de metales para la Real Hacienda (1745-1793)

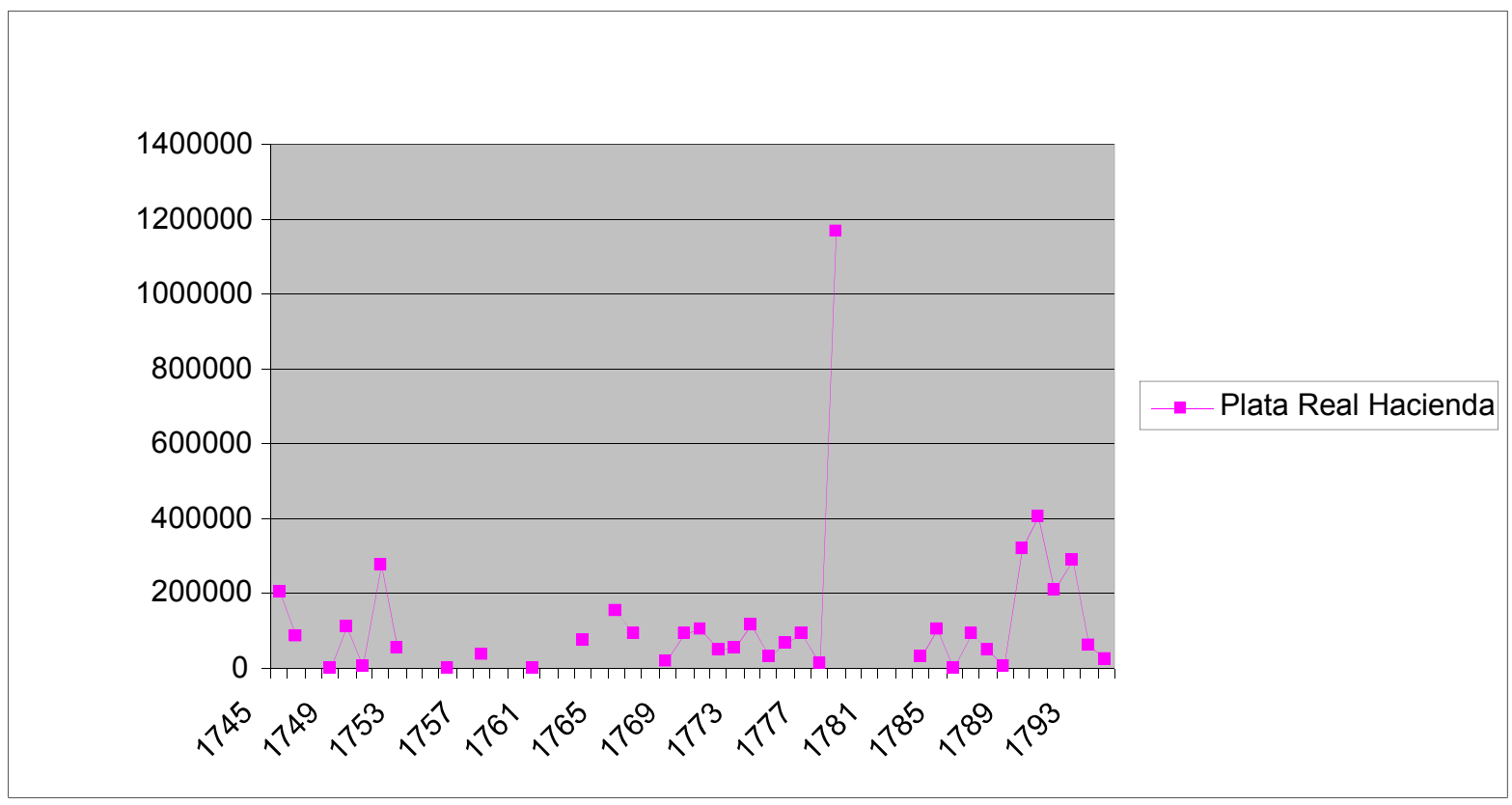

Fuente: elaboración propia en base a AGN Argentina: Sala XIII: 15-10-3; 37$6-4$; 37-10-5; 37-10-6-; 38-8-3; 38-8-4; 38-1-1; 38-1-3; 38-2-3; 38-3-4; 38-4-4; $38-5-3 ; 38-6-4 ; 38-1-3 ; 39-1-3 ; 39-2-1 ; 39-2-2 ; 39-3-1 ; 39-3-2 ; 39-3-3 ; 39-4-3$; $39-5-4 ; 39-6-2 ; 39-8-4 ; 39-9-3 ; 39-10-1 ; 39-10-4 ; 39-7-4 ; 15-10-3 ; 37-9-3 ; 37-9-$ 4 ; 38-10-3; 38-6-3. 14-9-5; 14-10-1; 14-10-2; 14-10-3; 14-10-4; 15-10-1; 15-10-2; 15-10-3. Sala IX 43-05- 11 ; 43- 06- $01 ; 43-06-02 ; 43-06-03 ; 43-06-04 ; 43-$ 06- 05; 43- 06- 06; 43- 06- 07; 43- 06- 08; 43- 06- 09; 43- 07- 01; 43- 07- 02; 4307- 03; 43- 07- 04; 43- 07- 05; 43- 07- 06; 43- 07- 07; 43- 07- 08; 43- 07- 09; 4307- 10 ; 43- 07- 11 ; 43- 07- 12 ; 43- 08- 01 ; 43- 08- 02; 43- 08- 03; 43- 08- 04; 4308- 05; 43- 08- 06; 43- 08- 07; 43- 08- 08; 43- 08- 09; 43- 08- 10; 43- 08- 11 ; 4308- 12; 43- 09- 01; 43- 09- 02; 43- 09- 03; 43- 09- 04; 43- 09- 05; 43- 09- 06; 4309- 07; 43- 09- 08; 43- 09- 09; 43- 09- 10; 43- 09- 11. AGN Uruguay: Fondo Documental ex “Archivo y Museo Histórico Nacional”: Legajos con Registros de Navíos desde el 218 a 270. 
Cuadro IV. 3

Salida de metales preciosos para la Real Hacienda (1745-1794)

\begin{tabular}{|c|c|c|}
\hline Periodo & Metales & promedio \\
\hline $1745-78$ & 2899089 & 87851,2 \\
\hline $1779-1794$ & 1585552 & 105703,5 \\
\hline total & 4484641 & 93430,1 \\
\hline
\end{tabular}

Fuente: elaboración propia en base a AGN Argentina: Sala XIII: 15-10-3; $37-$ $6-4$; 37-10-5; 37-10-6-; 38-8-3; 38-8-4; 38-1-1; 38-1-3; 38-2-3; 38-3-4; 38-4-4; $38-5-3$; 38-6-4; 38-1-3; 39-1-3; 39-2-1; 39-2-2; 39-3-1; 39-3-2; 39-3-3; 39-4-3; $39-5-4 ; 39-6-2 ; 39-8-4 ; 39-9-3 ; 39-10-1 ; 39-10-4 ; 39-7-4 ; 15-10-3 ; 37-9-3 ; 37-9-$ 4 ; 38-10-3; 38-6-3. 14-9-5; 14-10-1; 14-10-2; 14-10-3; 14-10-4; 15-10-1; 15-10-2; 15-10-3. Sala IX 43- 05- 11 ; 43- 06- 01 ; 43- 06- 02 ; 43- 06- 03; 43- 06- 04; 4306- 05; 43- 06- 06; 43- 06- 07; 43- 06- 08; 43- 06- 09; 43- 07- 01; 43- 07- 02; 4307- 03 ; 43- 07- 04; 43- 07- 05; 43- 07- 06; 43- 07- 07; 43- 07- 08; 43- 07- 09; 4307- 10 ; 43- 07- 11 ; 43- 07- 12 ; 43- 08- 01 ; 43- 08- 02; 43- 08- 03; 43- 08- 04; 4308- 05; 43- 08- 06; 43- 08- 07; 43- 08- 08; 43- 08- 09; 43- 08- 10; 43- 08- 11 ; 4308- 12 ; 43- 09- 01; 43- 09- 02; 43- 09- 03; 43- 09- 04; 43- 09- 05; 43- 09- 06; 4309- 07; 43- 09- 08; 43- 09- 09; 43- 09- 10; 43- 09- 11. AGN Uruguay: Fondo Documental ex “Archivo y Museo Histórico Nacional”: Legajos con Registros de Navíos desde el 218 a 270.

En el año 1778 se produjo un incremento anómalo en relación a la dinámica del siglo en relación a los envíos fiscales hacia la península. La posible causa de esto, tal vez sea la salida de la expedición de Don Pedro de Cevallos hacia Cádiz, lo que probablemente llevó consigo una parte importante de la recaudación de un espacio mayor para contribuir a los gastos generados por la salida de la expedición, Martín Cuesta da cuenta de un ingreso muy importante para ese año del situado. Durante la segunda mitad del siglo XVIII, entonces, se puede apreciar una cierta regularidad de los envíos, produciéndose los aumentos en los periodos que seguían de los conflictos armados en donde no se realizaban envíos, similar proceso sucedió con los metales de los privados 


\section{Gráfico IV. 12}

Presión fiscal per capita en Buenos Aires durante el siglo XVIII

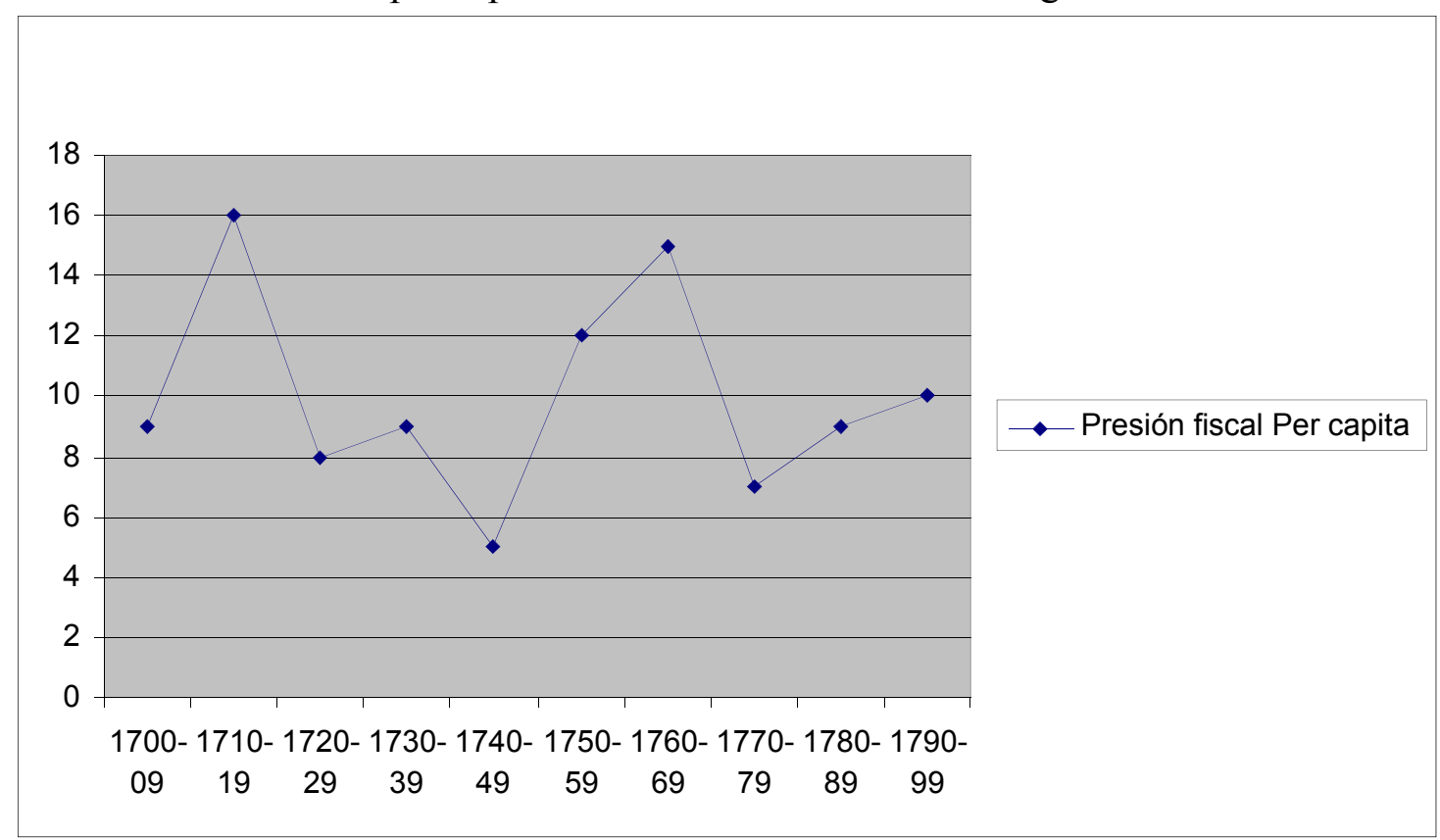

Fuente: Elaboración propia a partir de Cuesta (2009)

Gráfico IV. 13

Presión fiscal per capita en distintas ciudades y regiones (1790)

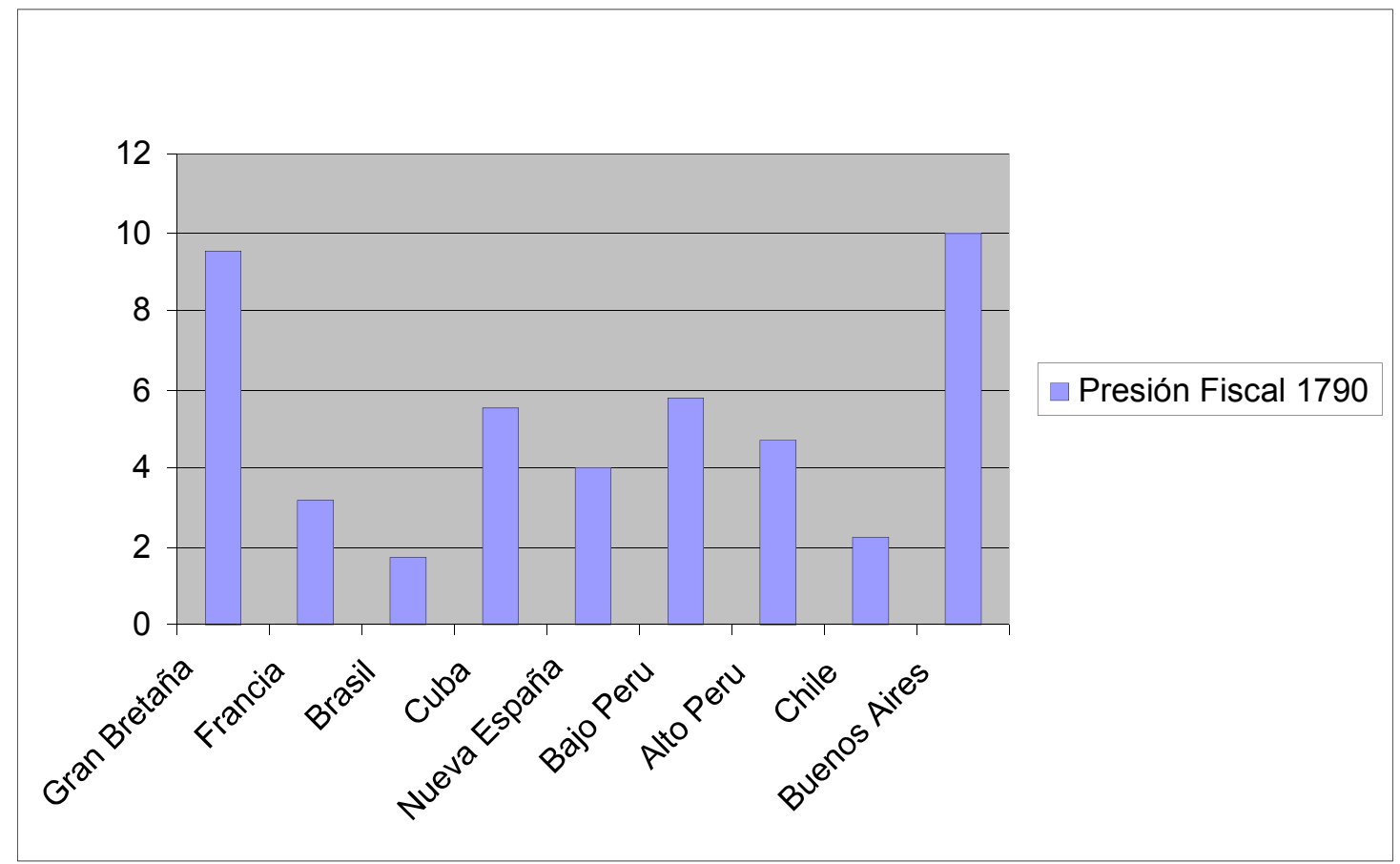

Fuente: Elaboración propia a partir de Cuesta (2009). 
La presión fiscal de la ciudad de Buenos Aires, fue singularmente alta, la respuesta se encuentra en que el mayor ingreso fiscal se producía producto del comercio, tanto interno como ultramarino, y dado que era una puerta de ingreso fiscal que vinculaba las mercancías europeas y americanas, se disparaba, en promedio, la presión sobre la población (Cuesta, 2009).

En suma, se puede observar que producto del crecimiento comercial de la segunda mitad del siglo XVIII, se incrementó la recaudación fiscal, la cual fue volcada en gran medida a la defensa promoviendo, por ello, al consumo interno y al crecimiento regional. Los envíos hacia la península española se mantuvieron estables durante este período, sin impactar en este aspecto las reformas fiscales que se desarrollaron durante las últimas décadas.

\section{Gráfico IV. 14}

Salida de metales preciosos según destino (1779- 1794).

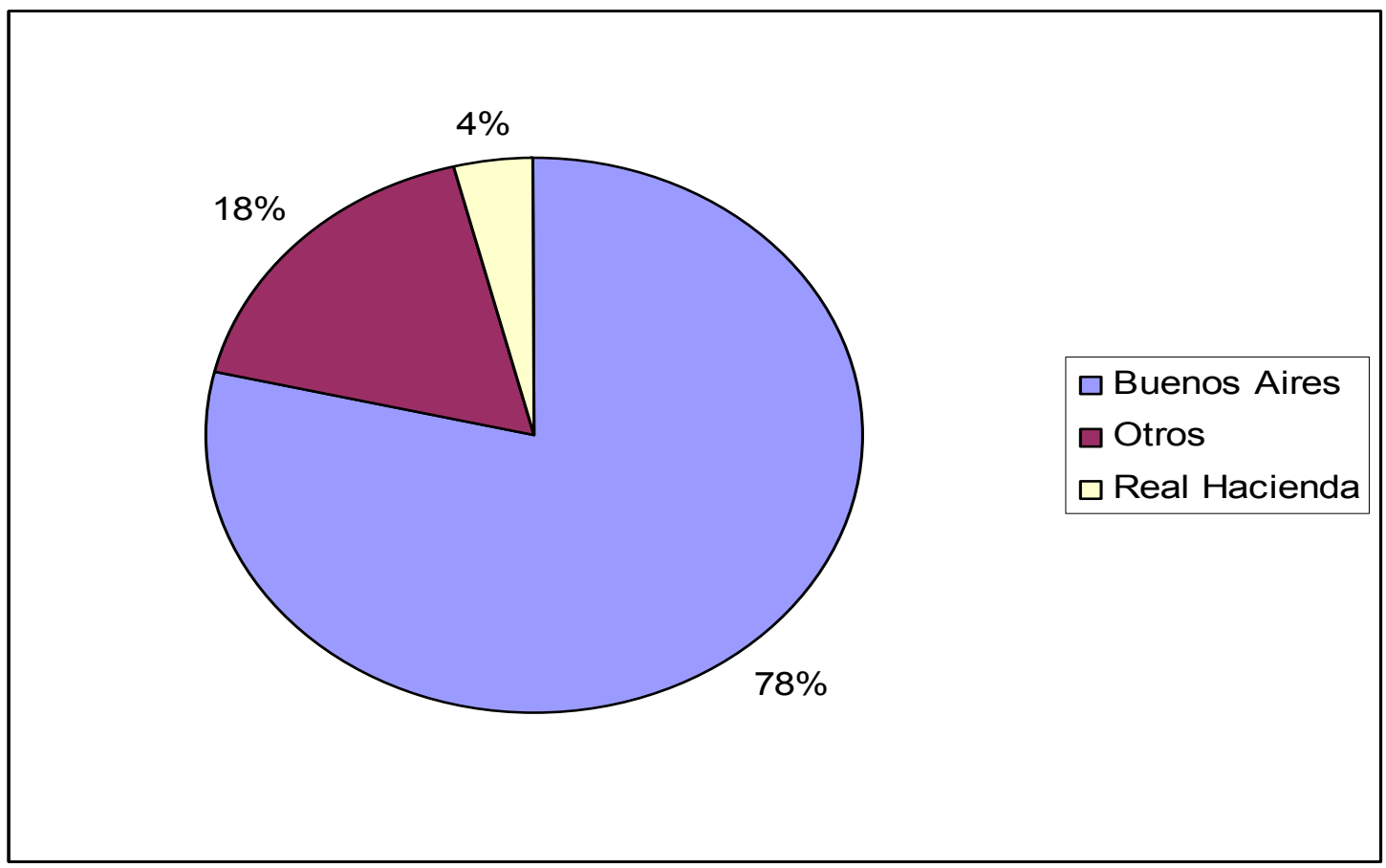

Fuente: elaboración propia en base a AGN Argentina: Sala XIII: 15-10-3; 37$6-4$; 37-10-5; 37-10-6-; 38-8-3; 38-8-4; 38-1-1; 38-1-3; 38-2-3; 38-3-4; 38-4-4; $38-5-3$; 38-6-4; 38-1-3; 39-1-3; 39-2-1; 39-2-2; 39-3-1; 39-3-2; 39-3-3; 39-4-3; $39-5-4 ; 39-6-2 ; 39-8-4 ; 39-9-3 ; 39-10-1 ; 39-10-4 ; 39-7-4 ; 15-10-3 ; 37-9-3$; 37-94 ; 38-10-3; 38-6-3. 14-9-5; 14-10-1; 14-10-2; 14-10-3; 14-10-4; 15-10-1; 15-10-2; 15-10-3. Sala IX 43-05- 11; 43- 06- 01; 43- 06- 02; 43- 06- 03; 43- 06- 04; 43- 
06- 05 ; 43- 06- 06; 43- 06- 07; 43- 06- 08; 43- 06- 09; 43- 07- 01 ; 43- 07- 02; 4307- 03; 43- 07- 04; 43- 07- 05; 43- 07- 06; 43- 07- 07; 43- 07- 08; 43- 07- 09; 4307- 10 ; 43- 07- 11 ; 43- 07- 12 ; 43- 08- 01 ; 43- 08- 02; 43- 08- 03; 43- 08- 04; 4308- 05 ; 43- 08- 06; 43- 08- 07; 43- 08- 08; 43- 08- 09; 43- 08- 10 ; 43- 08- 11 ; 4308- 12; 43- 09- 01; 43- 09- 02; 43- 09- 03; 43- 09- 04; 43- 09- 05; 43- 09- 06; 4309- 07; 43- 09- 08; 43- 09- 09; 43- 09- 10; 43- 09- 11. AGN Uruguay: Fondo Documental ex "Archivo y Museo Histórico Nacional": Legajos con Registros de Navíos desde el 218 a 270.

\section{Los comerciantes ultramarinos, una posible conceptualización}

Durante el periodo 1779- 1794, 633 actores enviaron en 18.787 registros los metales preciosos hacia la península española. La relación entre las cantidades y los registros permiten apreciar como vario la cantidad de metales por envío, por lo tanto si hubo tendencia a la concentración. Para su realización lo dividimos en los envíos por destino, Cádiz y resto de puertos, y su transformación durante el período.

En el gráfico siguiente se puede apreciar como varió anualmente la cantidad de envíos y el promedio de metales enviados. Durante los primeros años, producto de que no se enviaban navíos hacia la península, los metales preciosos se concentraron y una vez firmada la paz, en pocos envíos se enviaba más cantidad. Una vez estabilizado el proceso, la afluencia de envíos fue mayor y, por ende bajaron los montos de cada uno.

\section{Cuadro IV.4}

Total de registros según destino (1779- 1794)

\begin{tabular}{|l|r|r|}
\hline Destino & \multicolumn{1}{|c|}{ Registros } & promedio \\
\hline Cádiz & 10.568 & $1.662,9$ \\
\hline Otros & 8.219 & $1.728,4$ \\
\hline
\end{tabular}

Fuente: elaboración propia en base a AGN Argentina: Sala XIII: 15-10-3; $37-$ $6-4$; 37-10-5; 37-10-6-; 38-8-3; 38-8-4; 38-1-1; 38-1-3; 38-2-3; 38-3-4; 38-4-4; $38-5-3$; 38-6-4; 38-1-3; 39-1-3; 39-2-1; 39-2-2; 39-3-1; 39-3-2; 39-3-3; 39-4-3; $39-5-4 ; 39-6-2 ; 39-8-4 ; 39-9-3 ; 39-10-1 ; 39-10-4 ; 39-7-4 ; 15-10-3 ; 37-9-3 ; 37-9-$ 
$4 ; 38-10-3 ; 38-6-3.14-9-5 ; 14-10-1 ; 14-10-2 ; 14-10-3 ; 14-10-4 ; 15-10-1 ; 15-10-2$; 15-10-3. Sala IX 43- 05- 11; 43- 06- 01 ; 43- 06- 02; 43- 06- 03; 43- 06- 04; 4306- 05; 43- 06- 06; 43- 06- 07; 43- 06- 08; 43- 06- 09; 43- 07- 01; 43- 07- 02; 4307- 03; 43- 07- 04; 43- 07- 05; 43- 07- 06; 43- 07- 07; 43- 07- 08; 43- 07- 09; 4307- 10 ; 43- 07- 11 ; 43- 07- 12 ; 43- 08- 01 ; 43- 08- 02; 43- 08- 03; 43- 08- 04; 4308- 05; 43- 08- 06; 43- 08- 07; 43- 08- 08; 43- 08- 09; 43- 08- 10 ; 43- 08- 11 ; 4308- 12; 43- 09- 01; 43- 09- 02; 43- 09- 03; 43- 09- 04; 43- 09- 05; 43- 09- 06; 4309- 07; 43- 09- 08; 43- 09- 09; 43- 09- 10; 43- 09- 11. AGN Uruguay: Fondo Documental ex "Archivo y Museo Histórico Nacional": Legajos con Registros de Navíos desde el 218 a 270.

Gráfico IV. 15

Total de registros y promedio por año (1783-1794)

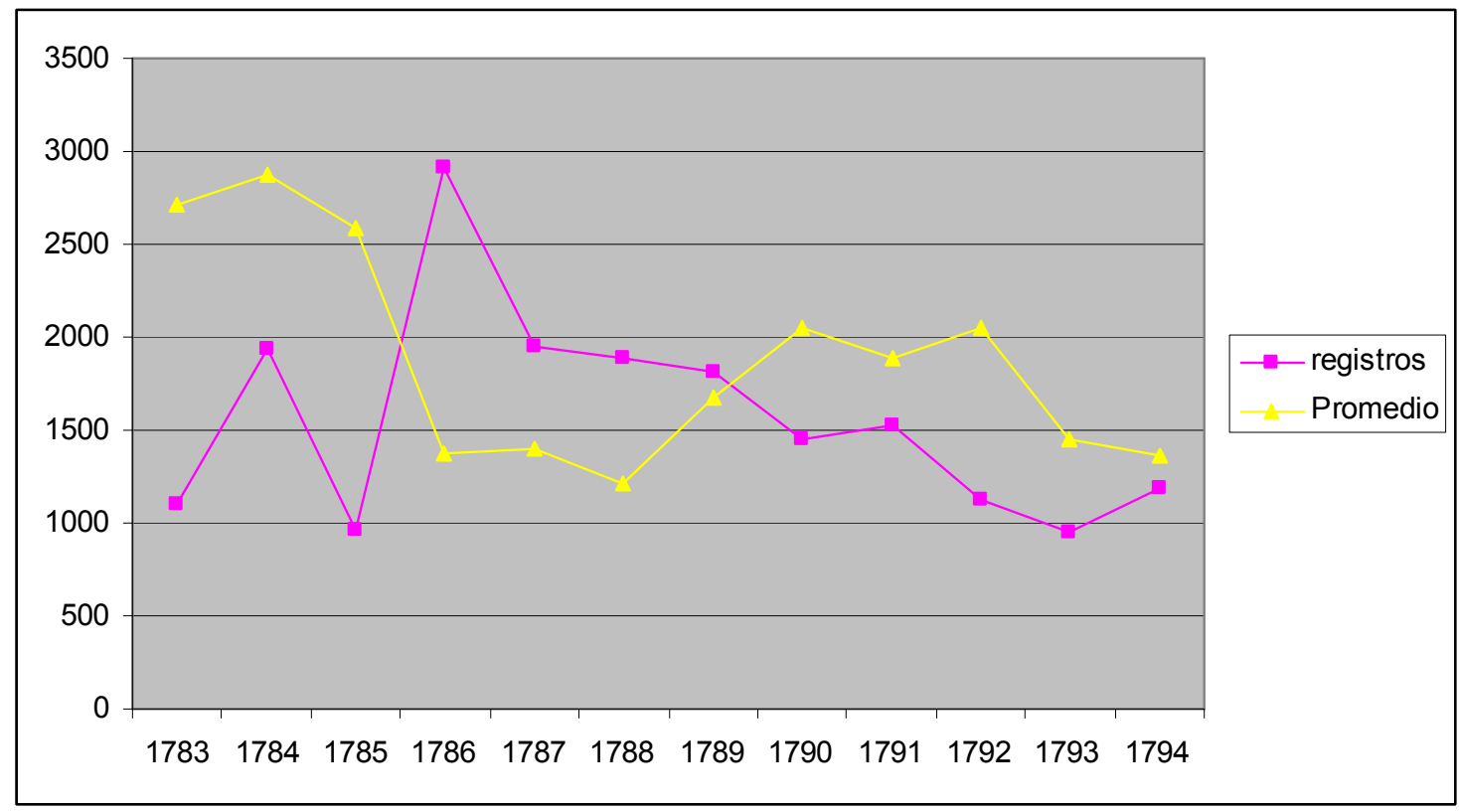

Fuente: elaboración propia en base a AGN Argentina: Sala XIII: 15-10-3; $37-$ $6-4$; 37-10-5; 37-10-6-; 38-8-3; 38-8-4; 38-1-1; 38-1-3; 38-2-3; 38-3-4; 38-4-4; $38-5-3$; 38-6-4; 38-1-3; 39-1-3; 39-2-1; 39-2-2; 39-3-1; 39-3-2; 39-3-3; 39-4-3; $39-5-4 ; 39-6-2 ; 39-8-4 ; 39-9-3 ; 39-10-1 ; 39-10-4 ; 39-7-4 ; 15-10-3 ; 37-9-3 ; 37-9-$ 4 ; 38-10-3; 38-6-3. 14-9-5; 14-10-1; 14-10-2; 14-10-3; 14-10-4; 15-10-1; 15-10-2; 15-10-3. Sala IX 43-05- 11 ; 43- 06- 01 ; 43- 06- 02; 43- 06- 03; 43- 06- 04; 4306- 05; 43- 06- 06; 43- 06- 07; 43- 06- 08; 43- 06- 09; 43- 07- 01; 43- 07- 02; 4307- 03; 43- 07- 04; 43- 07- 05; 43- 07- 06; 43- 07- 07; 43- 07- 08; 43- 07- 09; 4307- 10 ; 43- 07- 11 ; 43- 07- 12 ; 43- 08- 01 ; 43- 08- 02; 43- 08- 03; 43- 08- 04; 4308- 05; 43- 08- 06; 43- 08- 07; 43- 08- 08; 43- 08- 09; 43- 08- 10 ; 43- 08- 11 ; 4308- 12; 43- 09- 01; 43- 09- 02; 43- 09- 03; 43- 09- 04; 43- 09- 05; 43- 09- 06; 4309- 07; 43- 09- 08; 43- 09- 09; 43- 09- 10; 43- 09- 11. AGN Uruguay: Fondo Documental ex “Archivo y Museo Histórico Nacional": Legajos con Registros de Navíos desde el 218 a 270.

En el período 1779 a 1794 enviaron metales preciosos legalmente desde el complejo portuario rioplatense hacia la península española un total de 931 
cargadores particulares. Una parte de estos cargadores se dedicaban a enviar metales preciosos como intercambio por mercancías, desarrollando esta actividad durante un período de tiempo en particular. Otro sector, en cambio, por diversas causas solo realizaban un envío en el período señalado, si bien muchos de ellos era como intercambio comercial, la ocupación de los actores señalados no se dedicaban al comercio ultramarino.

De la totalidad de los cargadores, una leve mayoría fueron cargadores circunstanciales, 499, en detrimento de aquellos que podríamos denominar comerciantes, 440, la causa de ello se encuentra en que gran parte de los migrantes ultramarinos traían consigo mercancías para vender en el Río de la Plata con el fin de que esa venta le permita instalarse y obtener un pequeño capital para invertir en otras actividades. Otros envíos se realizaban, por ejemplo, para testamentos, iglesias, familiares, entre otros.

En cambio, aquellos que realizaban más envíos, sin evaluar las cuantías de cada uno, se puede plantear que eran actores que mantenían una vinculación estrecha con comerciantes o industriales afincados en la península. Si bien es un número importante de comerciantes, en relación a la potencial población que se podría dedicar a esta actividad no es mayoritaria. Si se toma la totalidad de cargadores, como se planteó para los cargadores de cueros, no hubo una restricción en cuanto a la posibilidad de enviar metales preciosos pero no era la actividad elegida mayoritariamente.

La distribución de los cargadores en relación a la suma total de metales enviados da cuenta de un cierto equilibrio entre los pequeños, medianos y grandes cargadores. A Diferencia de los cargadores de cueros, que casi todos los cargadores eran pequeños (un $80 \%$ ) siendo solo 34 (un 2,5\%) eran grandes. 
Menos de la mitad de los cargadores de metales eran pequeños, un cuarto medianos y el resto grandes.

Si bien, se encuentra una mayor distribución entre los pequeños, medianos y grandes cargadores en relación a los de cuero, se produce una mayor concentración de la carga en menos manos, solo 86 cargadores concentraban el 82 $\%$ de los envíos.

Gráfico IV. 16

Distribución de los cargadores por la suma enviada (1779-1794)

\begin{tabular}{|l|l|}
$\square-500$ \\
$\square-1000$ \\
$\square-2000$ \\
$\square-5000$ \\
$\square-10000$ \\
$\square-20000$ \\
$\square-50000$ \\
$\square 50000$
\end{tabular}

Fuente: elaboración propia en base a AGN Argentina: Sala XIII: 15-10-3; $37-$ $6-4 ; 37-10-5 ; 37-10-6-; 38-8-3 ; 38-8-4 ; 38-1-1 ; 38-1-3 ; 38-2-3 ; 38-3-4 ; 38-4-4$; $38-5-3 ; 38-6-4 ; 38-1-3 ; 39-1-3 ; 39-2-1 ; 39-2-2 ; 39-3-1 ; 39-3-2 ; 39-3-3 ; 39-4-3$; $39-5-4 ; 39-6-2 ; 39-8-4 ; 39-9-3 ; 39-10-1 ; 39-10-4 ; 39-7-4 ; 15-10-3 ; 37-9-3 ; 37-9-$ 4 ; 38-10-3; 38-6-3. 14-9-5; 14-10-1; 14-10-2; 14-10-3; 14-10-4; 15-10-1; 15-10-2; 15-10-3. Sala IX 43- 05- 11; 43- 06- 01; 43- 06- 02; 43- 06- 03; 43- 06- 04; 4306- 05; 43- 06- 06; 43- 06- 07; 43- 06- 08; 43- 06- 09; 43- 07- 01; 43- 07- 02; 4307- 03; 43- 07- 04; 43- 07- 05; 43- 07- 06; 43- 07- 07; 43- 07- 08; 43- 07- 09; 4307- 10 ; 43- 07- 11 ; 43- 07- 12 ; 43- 08- 01 ; 43- 08- 02; 43- 08- 03; 43- 08- 04; 4308- 05; 43- 08- 06; 43- 08- 07; 43- 08- 08; 43- 08- 09; 43- 08- 10; 43- 08- 11 ; 4308- 12 ; 43- 09- 01; 43- 09- 02; 43- 09- 03; 43- 09- 04; 43- 09- 05; 43- 09- 06; 4309- 07; 43- 09- 08; 43- 09- 09; 43- 09- 10; 43- 09- 11. AGN Uruguay: Fondo 
Documental ex "Archivo y Museo Histórico Nacional": Legajos con Registros de Navíos desde el 218 a 270.

Gráfico IV. 17

Total de metales enviados por grupo de cargadores (1779-1794)

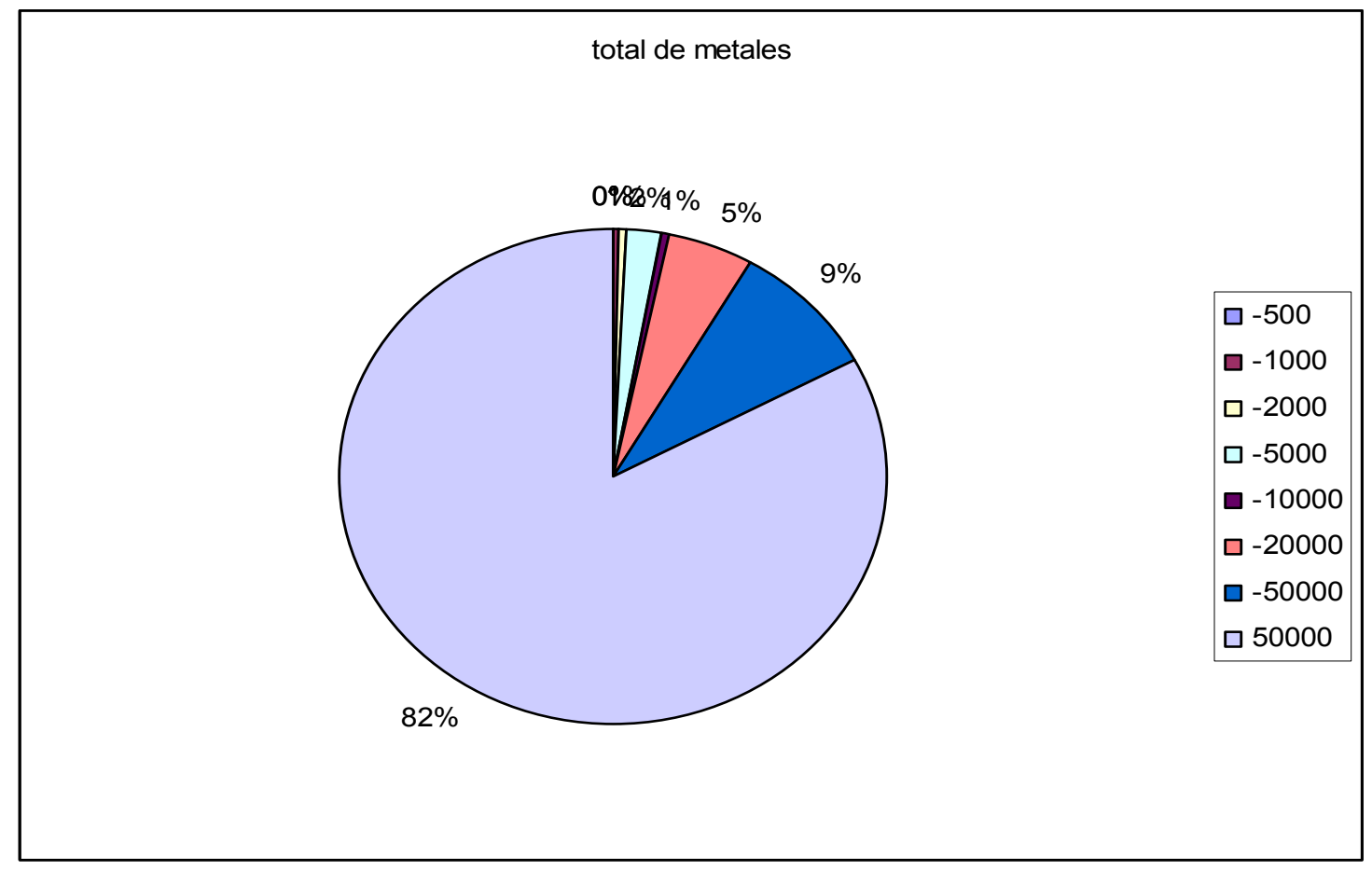

Fuente: elaboración propia en base a AGN Argentina: Sala XIII: 15-10-3; $37-$ $6-4$; 37-10-5; 37-10-6-; 38-8-3; 38-8-4; 38-1-1; 38-1-3; 38-2-3; 38-3-4; 38-4-4; $38-5-3$; 38-6-4; 38-1-3; 39-1-3; 39-2-1; 39-2-2; 39-3-1; 39-3-2; 39-3-3; 39-4-3; $39-5-4 ; 39-6-2 ; 39-8-4 ; 39-9-3 ; 39-10-1 ; 39-10-4 ; 39-7-4 ; 15-10-3 ; 37-9-3 ; 37-9-$ $4 ; 38-10-3 ; 38-6-3.14-9-5 ; 14-10-1 ; 14-10-2 ; 14-10-3 ; 14-10-4 ; 15-10-1 ; 15-10-2$; 15-10-3. Sala IX 43- 05- 11 ; 43- 06- 01 ; 43- 06- 02; 43- 06- 03; 43- 06- 04; 4306- 05; 43- 06- 06; 43- 06- 07; 43- 06- 08; 43- 06- 09; 43- 07- 01; 43- 07- 02; 4307- 03; 43- 07- 04; 43- 07- 05; 43- 07- 06; 43- 07- 07; 43- 07- 08; 43- 07- 09; 4307- 10 ; 43- 07- 11 ; 43- 07- 12 ; 43- 08- 01 ; 43- 08- 02; 43- 08- 03; 43- 08- 04; 4308- 05; 43- 08- 06; 43- 08- 07; 43- 08- 08; 43- 08- 09; 43- 08- 10; 43- 08- 11; 4308- 12; 43- 09- 01; 43- 09- 02; 43- 09- 03; 43- 09- 04; 43- 09- 05; 43- 09- 06; 4309- 07; 43- 09- 08; 43- 09- 09; 43- 09- 10; 43- 09- 11. AGN Uruguay: Fondo Documental ex “Archivo y Museo Histórico Nacional”: Legajos con Registros de Navíos desde el 218 a 270.

En suma, hubo una gran cantidad de cargadores y pequeños comerciantes que enviaron pequeñas cantidades y un sector reducido que concentraban gran 
parte de los envíos. En el cuadro siguiente se puede apreciar los mayores cargadores de metales preciosos del periodo 1779- 1794 .

Los mayores cargadores de metales, como se afirmó anteriormente eran 86. Dentro de este grupo encontramos algunos actores que realizaban un número reducido de envíos, por lo general esto se producía producto de ser consignatario de alguna gran casa de Cádiz, lo que provocaba que acumulara gran cantidad de metales preciosos para enviar en un período de tiempo y que se produzca un envío a la casa matriz. Estos casos, han sido los menos estudiados y de los que se carece de información, ya que solo eran comisionistas con un enriquecimiento menor a la mayoría y solían quedarse un tiempo relativamente corto de tiempo ya que estaban a disposición de los cambios que le indicaran de Cádiz.

La mayoría de los grandes cargadores de metales eran consignatarios de varias casas comerciales y de particulares, con una red de vínculos amplios que le permitía conectar las necesidades de mercancías de las distintas regiones americanas con los peninsulares, en algunos casos, por la solidez y enriquecimiento que garantizaba, solo enviaban metales preciosos que era la demanda de las casas más importantes de Cádiz, ya que estas utilizaban el metálico para la compra de las mercancías en otras plazas comerciales como Londres, Ámsterdam o Marsella, las cuales estuvieron vinculadas al comercio americano durante todo el siglo XVIII y, por ejemplo no permitieron el establecimiento de una compañía comercial en Buenos Aires a mediados de siglo.

Finalmente, otros combinaban la salida de metales con cueros, desarrollando una actividad más lucrativa para el período que analizado, pero para ello era necesario el tener o desarrollar una gran red comercial de pequeños y medianos industriales y comerciantes en la península. En el apartado siguiente se 
desarrollará una descripción mayor de esta clasificación profundizándose con ejemplos.

\section{Cuadro IV. 5}

Los cargadores de metales más importantes según cantidades enviadas (17791799)

\begin{tabular}{|l|r|c|c|}
\hline Nombre & Total & Años & Envíos \\
\hline Abaroa Barrena, Matias & 176.526 & $1.783-1794$ & 77 \\
\hline Agüero, Diego & 513.587 & $1.783-1794$ & 205 \\
\hline Aguirre, Agustín Casimiro & 258.755 & $1.783-1789$ & 93 \\
\hline Aguirre, Cristóbal & 181.048 & $1.783-1790$ & 87 \\
\hline Aguirre, Juan & 108.727 & $1.785-1791$ & 27 \\
\hline Alsina, Jaime & 188.201 & $1.783-1794$ & 153 \\
\hline Alvarado, Pedro & 125.145 & $1.783-1793$ & 101 \\
\hline Álvarez, Saturnino & 59.454 & $1.783-1794$ & 80 \\
\hline Alaga, Martin & 192.858 & $1.784-1790$ & 53 \\
\hline Amenábar, Josep & 66.777 & $1.783-1794$ & 63 \\
\hline Anchorena, Juan Esteban & 321.179 & $1.783-1794$ & 58 \\
\hline Aramburu, Adrián & 52.776 & $1.783-1790$ & 90 \\
\hline Arana, Joaquín & 176.026 & $1.783-1794$ & 57 \\
\hline Arana, Manuel & 975.440 & $1.783-1794$ & 223 \\
\hline Arguibel, Felipe & 84.234 & $1.783-1794$ & 83 \\
\hline Avecilla, Cristóbal & 123.990 & $1.786-1793$ & 107 \\
\hline Belanzategui, Tomas & 424.587 & $1.783-1794$ & 170 \\
\hline Balvastro, Isidro & 428.372 & $1.783-1794$ & 168 \\
\hline Basavilbaso, Manuel & 3.877 .686 & $1.783-1794$ & 2050 \\
\hline Basualdo, Manuel & 127.279 & $1.783-1790$ & 37 \\
\hline Baudrix, Juan & 61.850 & $1.783-1786$ & 30 \\
\hline Belgrano Pérez, Domingo & 94.230 & $1.783-1792$ & 61 \\
\hline Bosch, Francisco & 71.499 & $1.784-1794$ & 87 \\
\hline Cerro Sanz, Manuel & 83.208 & $1.783-1793$ & 80 \\
\hline Díaz de Vivar, Pedro & 133.240 & $1.783-1794$ & 93 \\
\hline Díaz Velez, Francisco & 211.147 & $1.783-1794$ & 101 \\
\hline Dubal, Pedro & 107.268 & $1.783-1794$ & 114 \\
\hline Echeñique, Juan & 161.246 & $1.783-1793$ & 95 \\
\hline Arezcan, Agustín & 161.439 & $1.783-1794$ & 100 \\
\hline Euba, Juan & 208.836 & $1.783-1794$ & 133 \\
\hline Ezcurra, Juan & 99.521 & $1.783-1793$ & 57 \\
\hline Fernández, Tomas & 91.636 & $1.783-1793$ & 69 \\
\hline Flotat, Santiago & 69.454 & $1.783-1794$ & 43 \\
\hline Gainza, Josep & 129.085 & $1.783-1794$ & 267 \\
\hline García López, Antonio & & & 27 \\
\hline Gardeazabal, Luis & & $1.783-1793-1794$ & 169 \\
\hline González Bolaños, Josep & & $1.783-1794$ & 200 \\
\hline González Cortina, Pedro & & 24 \\
\hline
\end{tabular}




\begin{tabular}{|c|c|c|c|}
\hline González, Domingo & 53.804 & $1.783-1794$ & 64 \\
\hline González, Gregorio & 88.639 & $1.783-1794$ & 57 \\
\hline González, Josep & 74.878 & $1.783-1794$ & 62 \\
\hline Hernández, Julián & 54.309 & $1.783-1789$ & 49 \\
\hline Insua, Tomas & 150.510 & $1.783-1794$ & 91 \\
\hline Lagraba, Juan & 60.532 & 1.784-1794 & 17 \\
\hline Larrea, Bernardo & 185.856 & $1.783-1786$ & 53 \\
\hline Larrea, Miguel & 87.365 & $1.783-1791$ & 27 \\
\hline Las Heras, Bernardo & 205.302 & $1.783-1794$ & 103 \\
\hline Lerdo de Tejada, Eugenio & 245.878 & $1.783-1791$ & 120 \\
\hline Lesica, Josep & 235.501 & $1.783-1794$ & 77 \\
\hline Lesica, Juan & 2.396 .590 & $1.783-1794$ & 1072 \\
\hline Llano, Francisco & 73.776 & $1.783-1794$ & 88 \\
\hline Llorente Romero, Ventura & 52.279 & $1.783-1791$ & 44 \\
\hline Martínez de Hoz, Josep & 187.303 & $1.784-1794$ & 73 \\
\hline Maza, Mateo & 287.256 & $1.783-1791$ & 71 \\
\hline Molino, Julián & 197.117 & $1.784-1794$ & 118 \\
\hline Nadal y Guarda, Jaime & 191.902 & $1.784-1794$ & 165 \\
\hline Necochea, Casimiro & 622.205 & $1.783-1794$ & 367 \\
\hline Novales, Manuel & 86.399 & $1.783-1788$ & 33 \\
\hline Obligado, Antonio & 191.346 & $1.783-1794$ & 84 \\
\hline Orueta, Luis & 80.530 & $1.784-1790$ & 24 \\
\hline Osorio, Juan & 55.292 & $1.783-1790$ & 19 \\
\hline Pinto, Joaquín & 594.062 & $1.783-1794$ & 177 \\
\hline Pita de la Vega, Pascual & 51.554 & $1.783-1790$ & 24 \\
\hline Pueyrredón, Juan & 119.421 & $1.783-1791$ & 63 \\
\hline Quintana, Antonio & 52.025 & 1.784 & 12 \\
\hline Rodriguez de V., Manuel & 460.258 & $1.783-1794$ & 135 \\
\hline Romero, Tomas & 112.413 & $1.783-1794$ & 150 \\
\hline Ruiz de Gaona, Pablo & 260.901 & $1.783-1794$ & 180 \\
\hline Santa Coloma, Gaspar & 884.810 & $1.783-1794$ & 246 \\
\hline Sanz, Miguel & 92.822 & $1.783-1794$ & 56 \\
\hline Sarasa, Saturnino & 95.158 & $1.783-1790$ & 44 \\
\hline Sarratea, Martin & 349.758 & $1.783-1794$ & 141 \\
\hline Segurola, Francisco & 523.255 & $1.783-1794$ & 224 \\
\hline Ugarte, Francisco & 792.535 & $1.783-1794$ & 147 \\
\hline Ugarte, Julián & 144.623 & $1.785-1792$ & 106 \\
\hline Ugarteche, Josep & 96.128 & $1.784-1794$ & 34 \\
\hline Villaboa, Juan & 58.401 & $1.784-1794$ & 54 \\
\hline Villanueba, Esteban & 116.248 & 1.784- 1794 & 83 \\
\hline Zelaya, Juan & 173.511 & $1.784-1794$ & 103 \\
\hline Zubiria, Miguel & 57.948 & $1.783-1792$ & 23 \\
\hline Total & 22.352 .704 & & 10612 \\
\hline
\end{tabular}

Fuente: elaboración propia en base a AGN Argentina: Sala XIII: 15-10-3; $37-$ $6-4 ; 37-10-5 ; 37-10-6-; 38-8-3 ; 38-8-4 ; 38-1-1 ; 38-1-3 ; 38-2-3 ; 38-3-4 ; 38-4-4$; $38-5-3 ; 38-6-4 ; 38-1-3 ; 39-1-3 ; 39-2-1 ; 39-2-2 ; 39-3-1 ; 39-3-2 ; 39-3-3 ; 39-4-3$; $39-5-4 ; 39-6-2 ; 39-8-4 ; 39-9-3 ; 39-10-1 ; 39-10-4 ; 39-7-4 ; 15-10-3 ; 37-9-3 ; 37-9-$ 
4 ; 38-10-3; 38-6-3. 14-9-5; 14-10-1; 14-10-2; 14-10-3; 14-10-4; 15-10-1; 15-10-2; 15-10-3. Sala IX 43- 05- 11 ; 43- 06- 01 ; 43- 06- 02; 43- 06- 03; 43- 06- 04; 4306- 05; 43- 06- 06; 43- 06- 07; 43- 06- 08; 43- 06- 09; 43- 07- 01; 43- 07- 02; 4307- 03; 43- 07- 04; 43- 07- 05; 43- 07- 06; 43- 07- 07; 43- 07- 08; 43- 07- 09; 4307- 10 ; 43- 07- 11 ; 43- 07- 12 ; 43- 08- 01 ; 43- 08- 02; 43- 08- 03; 43- 08- 04; 4308- 05; 43- 08- 06; 43- 08- 07; 43- 08- 08; 43- 08- 09; 43- 08- 10; 43- 08- 11; 4308- 12; 43- 09- 01; 43- 09- 02; 43- 09- 03; 43- 09- 04; 43- 09- 05; 43- 09- 06; 4309- 07; 43- 09- 08; 43- 09- 09; 43- 09- 10; 43- 09- 11. AGN Uruguay: Fondo Documental ex “Archivo y Museo Histórico Nacional”: Legajos con Registros de Navíos desde el 218 a 270.

\section{$\underline{\text { Cargadores más importantes de metales preciosos y cueros }}$}

Los cargadores de metales preciosos era el grupo de actores sociales que articulaban la conexión entre los mercados ultramarinos y del interior. En la mayoría de los casos era a cuenta y riesgo de terceros, los cuales, por lo general, eran quienes recibían los metales en la península. Se estableció quienes eran los más grandes cargadores y se los relacionó con los grandes cargadores de cueros, a partir de allí se identificó tres grupos de cargadores:

1- Cargadores de metales preciosos: este grupo de actores estuvo solo vinculado a la carga de metales, en particular vinculados a Cádiz y que no realizaban grandes inversiones en otros aspectos económicos.

2- Mixtos: son el grupo de actores que enviaban tanto metales como cueros hacia la península, en general además diversificaban sus inversiones en tierras, navíos y propiedades urbanas. Son los que algunos investigadores establecen como hacendados y otros como comerciantes.

3- Cueros: son los actores que cargaron casi prácticamente cueros y muy pocos metales preciosos, llegados en la década de 1780 en adelante y operaban fundamentalmente en la región Río de la Plata. 


\section{Cuadro IV. 6}

Algunos de los cargadores por predominio de envíos

\begin{tabular}{|c|c|c|}
\hline Metales preciosos & Mixtos & Cueros \\
\hline Arana, Manuel & Lesica, Juan & De la Peña, Francisco \\
\hline Gainza, Josep & Necochea, Casimiro & Conet, Miguel \\
\hline Agüero, Diego & Balbastro, Isidro & Monfort, Miguel \\
\hline Gardeazabal, Luis & Belanzategui, Tomas & Martínez, Juan Ignacio \\
\hline Lerdo de Tejada, Eugenio & González Bolaños, Josep & Ulibarri, Lorenzo \\
\hline Díaz Vélez, Francisco & $\begin{array}{c}\text { Aguirre, Agustín } \\
\text { Casimiro }\end{array}$ & Diago, Manuel \\
\hline Euba, Juan & Echeñique, Juan & Ugarte, Julián \\
\hline
\end{tabular}

Fuente: Elaboración propia

En la primera mitad del siglo XVIII, había dos grandes grupos de actores económicos, los comerciantes monopolistas y los hacendados. El primer grupo era aquel que se dedicaba a introducir las mercancías en el interior a cambio de una comisión de un gran comerciante asentado en Cádiz, eran que aseguraban el flujo de metales al puerto. El otro sector era el de los empresarios ganaderos que concentraban gran parte de la producción de cueros y su llegada al puerto. Estos dos grupos eran los que disputaban el control del Cabildo y el predominio económico regional.

En la segunda mitad del siglo XVIII, en cambio, por las transformaciones de la economía global, de la Monarquía española y de la región, llegaron actores que intervinieron económicamente en forma diferente, el comercio dejó de estar vinculado a Cádiz y creció notablemente la salida de cueros. Por ello se diversificaron las actividades económicas y los grupos de comerciantes que operaban. Estos nuevos sectores fueron favorecidos por las transformaciones institucionales comerciales que se llevaron a cabo y no mantuvieron en cada conflicto la misma posición. Un ejemplo es su alianza con los comerciantes monopolistas en el conflicto con el consulado de Cádiz y con los hacendados para que ingresen en el consulado de Buenos Aires. 
En el primer grupo se tomara como ejemplo el caso estudiado por Mariano Schlez: Diego de Agüero. Este actor nació en Santander en el año 1738, dejo la península a mediados del siglo XVIII. Una vez instalado en Buenos Aires se casó con Doña Petrona de Gregorio Espinoza en el año 1769 (hermana de Julián marido de la hija de Domingo Belgrano Perez).

EL mecanismo de enriquecimiento de este actor era el ser comisionista de las mercancías que le llegaban desde la península española y su redistribución en el interior de América. El intercambio era de metales preciosos por mercancías europeas y los actores contactados se encontraban en Cádiz, siendo casas comerciales ya establecidas desde antaño. Como sostiene Mariano Schlez, el éxito de este actor estaba marcado por el mantenimiento de Cádiz como único puerto de contacto y el establecer el mayor número de redes en el interior.

\section{Cuadro IV.7}

Envíos de metales por destino de Diego de Agüero (1779- 1794)

\begin{tabular}{|l|r|r|}
\hline Cádiz & 614.000 & $99,1 \%$ \\
\hline Otros puertos & 5.408 & $0,9 \%$ \\
\hline Total & 619.408 & $100 \%$ \\
\hline
\end{tabular}

Fuente: elaboración propia en base a AGN Argentina: Sala XIII: 15-10-3; $37-$ $6-4$; 37-10-5; 37-10-6-; 38-8-3; 38-8-4; 38-1-1; 38-1-3; 38-2-3; 38-3-4; 38-4-4; $38-5-3 ; 38-6-4 ; 38-1-3 ; 39-1-3 ; 39-2-1 ; 39-2-2 ; 39-3-1 ; 39-3-2 ; 39-3-3 ; 39-4-3$; $39-5-4 ; 39-6-2 ; 39-8-4 ; 39-9-3 ; 39-10-1 ; 39-10-4 ; 39-7-4 ; 15-10-3 ; 37-9-3 ; 37-9-$ 4 ; 38-10-3; 38-6-3. 14-9-5; 14-10-1; 14-10-2; 14-10-3; 14-10-4; 15-10-1; 15-10-2; 15-10-3. Sala IX 43- 05- 11; 43- 06- 01; 43- 06- 02; 43- 06- 03; 43- 06- 04; 4306- 05; 43- 06- 06; 43- 06- 07; 43- 06- 08; 43- 06- 09; 43- 07- 01; 43- 07- 02; 4307- 03; 43- 07- 04; 43- 07- 05; 43- 07- 06; 43- 07- 07; 43- 07- 08; 43- 07- 09; 4307- 10 ; 43- 07- 11 ; 43- 07- 12 ; 43- 08- 01 ; 43- 08- 02; 43- 08- 03; 43- 08- 04; 4308- 05; 43- 08- 06; 43- 08- 07; 43- 08- 08; 43- 08- 09; 43-08- $10 ; 43-08-11$; 4308- 12; 43- 09- 01; 43- 09- 02; 43- 09- 03; 43- 09- 04; 43- 09- 05; 43- 09- 06; 4309- 07; 43- 09- 08; 43- 09- 09; 43- 09- 10; 43- 09- 11. AGN Uruguay: Fondo Documental ex “Archivo y Museo Histórico Nacional”: Legajos con Registros de Navíos desde el 218 a 270. 
El éxito de las primeras décadas de la segunda mitad de siglo, también fue el causal de su decadencia. Un ejemplo de ello es la fuerte vinculación comercial que mantuvo con Ignacio Díaz Saravia, quien era uno de los comerciantes más importantes afincados en Cádiz y cuya familia se encontraba afincada desde principios de siglo en esta ciudad. Este comerciante participaba activamente en el Consulado de Comercio de Cádiz, el cual fue el principal opositor de que se realice una Real Compañía Guipuzcoana que vinculara Bilbao con Buenos Aires. El haber sido el comisionista de este comerciante le permitió en tiempos en que Cádiz era el único puerto legal comercial una gran ventaja por sobre el resto de comerciantes, lo que le permitió un gran enriquecimiento durante décadas, reflejado en la construcción de una de las casas más caras de la ciudad de Buenos Aires, pero lo invalidó para buscar otras estrategias que acompañen los cambios comerciales e institucionales de las últimas décadas del siglo XVIII.

Las reformas institucionales producidas en la década de 1770 fueron perjudiciales para su desarrollo, como se puede apreciar en el gráfico siguiente el descenso de los envíos de metales precioso fueron producto de ello. 
Gráfico IV. 18

Envíos de metales y cueros de Diego de Agüero, 1779- 1794

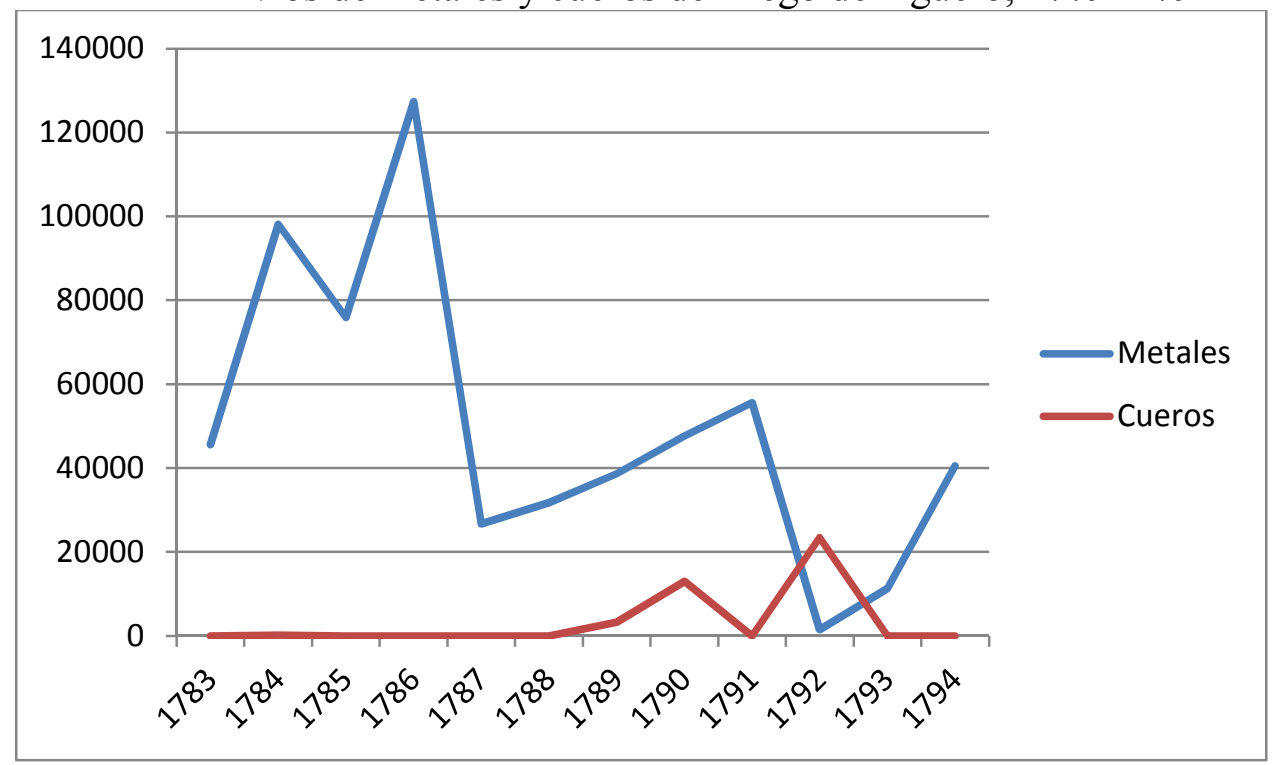

Fuente: elaboración propia en base a AGN Argentina: Sala XIII: 15-10-3; $37-$ $6-4$; 37-10-5; 37-10-6-; 38-8-3; 38-8-4; 38-1-1; 38-1-3; 38-2-3; 38-3-4; 38-4-4; $38-5-3 ; 38-6-4 ; 38-1-3$; 39-1-3; 39-2-1; 39-2-2; 39-3-1; 39-3-2; 39-3-3; 39-4-3; $39-5-4 ; 39-6-2 ; 39-8-4 ; 39-9-3 ; 39-10-1 ; 39-10-4 ; 39-7-4 ; 15-10-3 ; 37-9-3 ; 37-9-$ 4 ; 38-10-3; 38-6-3. 14-9-5; 14-10-1; 14-10-2; 14-10-3; 14-10-4; 15-10-1; 15-10-2; 15-10-3. Sala IX 43- 05- 11 ; 43- 06- 01 ; 43- 06- 02; 43- 06- 03; 43- 06- 04; 4306- 05; 43- 06- 06; 43- 06- 07; 43- 06- 08; 43- 06- 09; 43- 07- 01; 43- 07- 02; 4307- 03; 43- 07- 04; 43- 07- 05; 43- 07- 06; 43- 07- 07; 43- 07- 08; 43- 07- 09; 4307- 10 ; 43- 07- 11 ; 43- 07- 12 ; 43- 08- 01 ; 43- 08- 02; 43- 08- 03; 43- 08- 04; 4308- 05; 43- 08- 06; 43- 08- 07; 43- 08- 08; 43- 08- 09; 43- 08- 10; 43- 08- 11; 4308- 12; 43- 09- 01; 43- 09- 02; 43- 09- 03; 43- 09- 04; 43- 09- 05; 43- 09- 06; 4309- 07; 43- 09- 08; 43- 09- 09; 43- 09- 10; 43- 09- 11. AGN Uruguay: Fondo Documental ex “Archivo y Museo Histórico Nacional”: Legajos con Registros de Navíos desde el 218 a 270. 
Cuadro IV. 7

Envío año a año de metales y cueros por Diego de Agüero

\begin{tabular}{|c|c|c|}
\hline \multicolumn{3}{|c|}{ Diego de Agüero } \\
\hline Años & Metales & Cueros \\
\hline 1.783 & 45.593 & 0 \\
\hline 1.784 & 98.124 & 186 \\
\hline 1.785 & 75.868 & 0 \\
\hline 1.786 & 127.794 & 0 \\
\hline 1.787 & 26.684 & 0 \\
\hline 1.788 & 31.721 & 0 \\
\hline 1.789 & 57.112 & 3.220 \\
\hline 1.790 & 47.674 & 12.920 \\
\hline 1.791 & 55.630 & 0 \\
\hline 1.792 & 1.424 & 23.390 \\
\hline 1.793 & 11.310 & 0 \\
\hline 1.794 & 40.474 & 0 \\
\hline Total & 619.408 & 39.716 \\
\hline
\end{tabular}

Fuente: elaboración propia en base a AGN Argentina: Sala XIII: 15-10-3; $37-$ $6-4$; 37-10-5; 37-10-6-; 38-8-3; 38-8-4; 38-1-1; 38-1-3; 38-2-3; 38-3-4; 38-4-4; $38-5-3$; 38-6-4; 38-1-3; 39-1-3; 39-2-1; 39-2-2; 39-3-1; 39-3-2; 39-3-3; 39-4-3; $39-5-4 ; 39-6-2 ; 39-8-4 ; 39-9-3 ; 39-10-1 ; 39-10-4 ; 39-7-4 ; 15-10-3 ; 37-9-3 ; 37-9-$ 4 ; 38-10-3; 38-6-3. 14-9-5; 14-10-1; 14-10-2; 14-10-3; 14-10-4; 15-10-1; 15-10-2; 15-10-3. Sala IX 43- 05- 11; 43- 06- 01 ; 43- 06- 02; 43- 06- 03; 43- 06- 04; 4306- 05; 43- 06- 06; 43- 06- 07; 43- 06- 08; 43- 06- 09; 43- 07- 01; 43- 07- 02; 4307- 03; 43- 07- 04; 43- 07- 05; 43- 07- 06; 43- 07- 07; 43- 07- 08; 43- 07- 09; 4307- 10 ; 43- 07- 11 ; 43- 07- 12 ; 43- 08- 01 ; 43- 08- 02; 43- 08- 03; 43- 08- 04; 4308- 05; 43- 08- 06; 43- 08- 07; 43- 08- 08; 43- 08- 09; 43- 08- 10 ; 43- 08- 11 ; 4308- 12; 43- 09- 01; 43- 09- 02; 43- 09- 03; 43- 09- 04; 43- 09- 05; 43- 09- 06; 4309- 07; 43- 09- 08; 43- 09- 09; 43- 09- 10; 43- 09- 11. AGN Uruguay: Fondo Documental ex “Archivo y Museo Histórico Nacional": Legajos con Registros de Navíos desde el 218 a 270.

Manuel Diago en 1777 firmó un acuerdo con su hermano Francisco para generar un vínculo comercial entre el Río de la Plata y La Coruña. En el acuerdo se estableció que Manuel partía con mercancías a ser vendidas y se enviarían a Francisco su coste y el $75 \%$ de las ganancias. Arturo Bentancur asevera que el objetivo de Manuel no era quedarse en América sino, establecer los vínculos necesarios para que el proyecto prospere en el tiempo y él volver a la península española una vez logrado este objetivo, no se produjo con lo esperado en la 
partida. Se convirtió en uno de los comerciantes más prósperos de la región y en 1796 contrajo matrimonio con una de las hijas de Marcos Pérez, quien tenía una estancia (en el mapa siguiente el señalado con el № 9 de la familia Pérez).

Se explicitaba en el acuerdo que los envíos debían ser cueros y no metales preciosos por las mercancías provenientes de la península. Durante el período 1779 a 1797 envió a la península española, todos sus envíos fueron a La Coruña, 174.245 cueros y solo 4027 pesos en monedas de plata. El mecanismo de capitalización que ejerció fue la recepción de mercancías de la península, prontamente no enviadas por su hermano ya que este falleció en 1780, las cuales intercambiaba por cueros o plata, siendo los cueros enviados a la península y la plata utilizada para otras operaciones comerciales regionales. Los cueros también eran adquiridos a partir de la compra en las cercanías a Montevideo, en espacios más alejados. Unos diez años después consolido su posición económica expresada en la compra de esclavizados y de un navío, la Fragata San Francisco de Asís (alias) el Tártaro en 10.000, siendo uno de los primeros actores regionales que adquirió una embarcación para realizar viajes ultramarinos. Con el nuevo siglo, continuó con una posición económica privilegiada, como nos mostraría la compra de un de las casas más caras de Montevideo y ser uno de los principales impulsores de la creación del Consulado de Montevideo, siendo su primer Prior entre 1812- 1814 . 
Distribución de los grandes propietarios para 1763. Familia Pérez

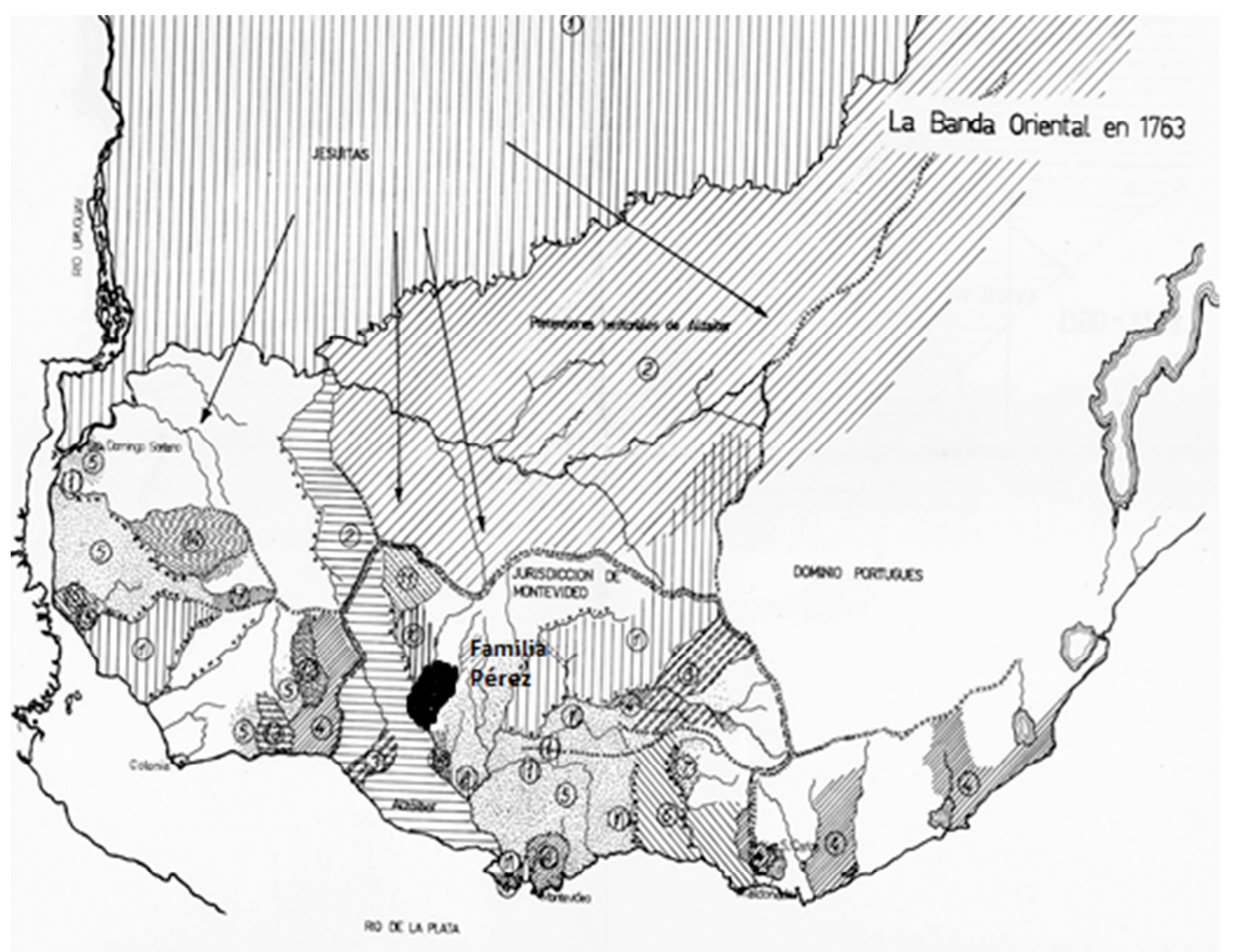

Cuadro IV. 8

Envíos de Manuel Diago (1779- 1794).

\begin{tabular}{|c|c|c|}
\hline Periodo & Mercancía & Cantidad \\
\hline $1779-1797$ & Cueros & 174.245 \\
\hline $1783-1784$ & Plata & 4.027 \\
\hline
\end{tabular}

Fuente: elaboración propia en base a AGN Argentina: Sala XIII: 15-10-3; $37-$ $6-4$; 37-10-5; 37-10-6-; 38-8-3; 38-8-4; 38-1-1; 38-1-3; 38-2-3; 38-3-4; 38-4-4; $38-5-3 ; 38-6-4 ; 38-1-3 ; 39-1-3 ; 39-2-1 ; 39-2-2 ; 39-3-1 ; 39-3-2 ; 39-3-3 ; 39-4-3$; $39-5-4 ; 39-6-2 ; 39-8-4 ; 39-9-3 ; 39-10-1 ; 39-10-4 ; 39-7-4 ; 15-10-3 ; 37-9-3 ; 37-9-$ 4 ; 38-10-3; 38-6-3. 14-9-5; 14-10-1; 14-10-2; 14-10-3; 14-10-4; 15-10-1; 15-10-2; 15-10-3. Sala IX 43-05- 11; 43-06- 01; 43- 06- 02; 43- 06- 03; 43- 06- 04; 4306- 05; 43- 06- 06; 43- 06- 07; 43- 06- 08; 43- 06- 09; 43- 07- 01; 43- 07- 02; 4307- 03; 43- 07- 04; 43- 07- 05; 43- 07- 06; 43- 07- 07; 43- 07- 08; 43- 07- 09; 4307- 10 ; 43- 07- 11 ; 43- 07- 12 ; 43- 08- 01 ; 43- 08- 02; 43- 08- 03; 43- 08- 04; 4308- 05; 43- 08- 06; 43- 08- 07; 43- 08- 08; 43- 08- 09; 43- 08- 10; 43- 08- 11 ; 4308- 12; 43- 09- 01; 43- 09- 02; 43- 09- 03; 43- 09- 04; 43- 09- 05; 43- 09- 06; 4309- 07; 43- 09- 08; 43- 09- 09; 43- 09- 10; 43- 09- 11. AGN Uruguay: Fondo 
Documental ex "Archivo y Museo Histórico Nacional": Legajos con Registros de Navíos desde el 218 a 270.

El actor ejemplo elegido del tercer grupo es Domingo Belgrano Pérez, quien migró desde Oneglia, Italia hacia Cádiz en el año 1750 y pocos años después viajo hacia el Río de la Plata. En el año 1757 se casó con María Josefa González Casero quien provenía de una familia no muy rica de Santiago del Estero. Las operaciones de Belgrano durante las primeras décadas de su estadía en la región eran de pequeñas y medianas cuantías, el crecimiento comercial se produjo a partir del casamiento de su hija con Julián Gregorio Espinosa, un gran hacendado, como planteó Jorge Gelman "La alianza familiar con Espinosa va a ser importante en la carrera posterior de Belgrano y la primer prueba de ello la encontramos en que en el mismo año que se casa su hija con Espinosa, éste va a otorgar a su suegro, fiado y en condiciones muy ventajosas (a dos años sin interés y a pagar con cueros) 18331 ps $13 / 4$ rls en efectos de Castilla y ferreterías para que Belgrano pueda incrementar el hasta entonces magro volumen de sus operaciones comerciales".

La inyección monetaria que recibió hizo posible ampliara sus relaciones comerciales en América y que reactivara las redes comerciales de la península española. Los envíos que realizó por las mercancías europeas, eran en gran parte cueros y en menor medida metales preciosos. Entre 1783 hasta 1792 más de noventa mil pesos distribuidos entre varios puertos peninsulares y gran parte de ellos a cuenta y riesgo propio. Los cueros que envió, los cuales eran casi todos a su cuenta y riesgo, fueron enviados en su mayoría a La Coruña, contando con un total, para el periodo $1779-1794$ de casi cien mil cueros. 


\section{Cuadro IV. 9}

Envíos de Metales y cueros por Domingo Belgrano Pérez (1755- 1798).

\begin{tabular}{|c|c|c|}
\hline \multicolumn{3}{|c|}{ Domingo Belgrano Pérez } \\
\hline Periodo & Mercancía & Cantidad \\
\hline $1755-92$ & Metales & 96.451 \\
\hline $1779-98$ & Cueros & 89.740 \\
\hline
\end{tabular}

Fuente: elaboración propia en base a AGN Argentina: Sala XIII: 15-10-3; $37-$ $6-4$; 37-10-5; 37-10-6-; 38-8-3; 38-8-4; 38-1-1; 38-1-3; 38-2-3; 38-3-4; 38-4-4; $38-5-3 ; 38-6-4 ; 38-1-3 ; 39-1-3 ; 39-2-1 ; 39-2-2 ; 39-3-1 ; 39-3-2 ; 39-3-3 ; 39-4-3$; $39-5-4 ; 39-6-2 ; 39-8-4 ; 39-9-3 ; 39-10-1 ; 39-10-4 ; 39-7-4 ; 15-10-3 ; 37-9-3 ; 37-9-$ 4 ; 38-10-3; 38-6-3. 14-9-5; 14-10-1; 14-10-2; 14-10-3; 14-10-4; 15-10-1; 15-10-2; 15-10-3. Sala IX 43- 05- $11 ; 43-06-01 ; 43-06-02 ; 43-06-03 ; 43-06-04$; $43-$ 06- 05; 43- 06- 06; 43- 06- 07; 43- 06- 08; 43- 06- 09; 43- 07- 01; 43- 07- 02; 4307- 03; 43- 07- 04; 43- 07- 05; 43- 07- 06; 43- 07- 07; 43- 07- 08; 43- 07- 09; 4307- 10 ; 43- 07- 11 ; 43- 07- 12 ; 43- 08- 01 ; 43- 08- 02; 43- 08- 03; 43- 08- 04; 4308- 05; 43- 08- 06; 43- 08- 07; 43- 08- 08; 43- 08- 09; 43- 08- 10; 43- 08- 11 ; 4308- 12; 43- 09- 01; 43- 09- 02; 43- 09- 03; 43- 09- 04; 43- 09- 05; 43- 09- 06; 4309- 07; 43- 09- 08; 43- 09- 09; 43- 09- 10; 43- 09- 11. AGN Uruguay: Fondo Documental ex “Archivo y Museo Histórico Nacional”: Legajos con Registros de Navíos desde el 218 a 270.

A partir de los datos expresados se puede deducir que la acumulación de este actor se produjo a partir del intercambio de mercancías europeas por cueros y metales preciosos, los cuales luego intercambiaba en el interior por metales preciosos. El enviar un número importante de cueros, los cuales eran extraídos desde sus propias estancias, da cuenta de la clave de la capitalización de este actor, ya que gran parte de los metales preciosos que ingresaba en el interior americano no era enviado por las mercancías europeas sino que pagaba con cueros. Esta dinámica es la que le permitió logran adquirir propiedades urbanas, más de 20 casas alquiladas en Buenos Aires, dos chacras y dos estancias y que al morir conservase un capital de 370.000 pesos 5 5/8 reales. 
Desde mediados de siglo XVIII, como se ha sostenido, se produjo un crecimiento muy importante del comercio ultramarino. Para que esto se produzca era necesario que previamente la demanda de mercancías ultramarinas desde el interior americano se expanda. La dinámica comercial que se fue imponiendo lentamente provocó que el complejo portuario rioplatense fuera ganando cada vez más mercados al interior en detrimento de los comerciantes de Lima. A diferencia de los conflictos que se sucederán a partir de la década de 1770, en la década de 1750 se encontraban los representantes de Cabildo (hacendados en su mayoría) y comerciantes monopolistas del mismo lado en la batalla por mercados del interior.

En el año 1748 y 49 comienza a producirse una ofensiva de los comerciantes de Lima para limitar la expansión comercial de los rioplatenses a partir de diversas prohibiciones de introducción de mercancías hacia el interior realizadas por el Virrey Conde de Superunda. La respuesta a ello fueron realizadas por el apoderado de Buenos Aires en la Corte Domingo de Marcoleta quien solicita el fomento de Buenos Aires como puerto por las ventajas que genera para la Monarquía, la presión da efecto y se permite para el año 1749 la salida de las mercancías de Buenos Aires hacia el interior.

El segundo momento de esta disputa se produjo a partir de que el Gobernador de Buenos Aires José Andonaegui el 3 de agosto de 1752 envió al Virrey Conde de Superunda una carta en donde planteaba la necesidad de un tribunal mercantil o un juez de comercio, posiblemente era para limitar el contrabando desde este ciudad hacia el interior que el Gobernador realizaba este pedido. La aceptación de la creación de la Diputación de Buenos Aires quedo supeditada a la elección de los diputados desde Lima y no desde la propia ciudad, como ocurría con las ya creadas en Potosí y Santiago de Chile. 
A partir de allí se sucedieron una serie de conflictos entre las autoridades de Lima, los comerciantes y el cabildo de Buenos Aires, que se saldó con un triunfo de la alianza rioplatense, como planteó Javier Kraselsky:

De este modo, y ante todos estos inconvenientes, el Virrey de Perú quitó apoyo al Diputado enunciando que sería un cargo electivo como en Potosí o Santiago. Así, a principios de 1756, comenzaba la última etapa de la Diputación en Buenos Aires, y con ello el quiebre de la alianza y el inicio de conflictos entre los actores: Cabildo y comerciantes en proceso de constitución corporativa. En conclusión, la alianza establecida entre Cabildo y comerciantes triunfó desestabilizando la institución de la Diputación de Comercio y exigiendo nuevas pautas a las autoridades de Lima. Por extensión, tal triunfo revela el poder real de los actores locales frente a imposiciones sin su consenso. Esto fortalece la visión de pluralidad de la Monarquía borbónica y su imposibilidad de sostener la armonía y el equilibrio de poderes mediante la imposición arbitraria de su voluntad." (Kraselsky, 2011: 97).

La resolución de este conflicto en favor de los rioplatenses fue el puntapié inicial a un predominio de las mercancías ingresadas por el complejo portuario en la zona sur americana. Su desarrollo no fue solo por la habilidad de los rioplatenses para la resolución, sino por la presión de la economía global para la integración de esta región desde otro lugar, la necesidad de la monarquía de consolidar un proceso interno para la conservación de los territorios y porque ya para ese periodo la fortaleza comercial era mucho mayor de lo que se esperaría para una zona de frontera.

A diferencia de los conflictos planteado en el capítulo 3, en este caso, no hubo, en principio disidencias internas entre los comerciantes monopolistas y los empresarios ganaderos y sus comerciantes afines, sino que se unieron para disputarles los mercados del interior a los comerciantes en Lima. Esto es producto de que la hegemonía comercial no se había producido. Con el correr de los años las disputas internas se intensificaron cada vez más, mientras que un sector quedó cada vez más marginal en el entramado comercial, el otro, con una mayor 
diversificación económica y redes externas consolido su peso a nivel regional logrando la resolución de los conflictos a su favor. En el próximo capítulo, dedicado al comercio ultramarino de esclavizados se podrá observar la participación de este sector hegemónico en las últimas dos décadas de participación en expediciones hacia África con navíos propios y a su cuenta y riesgo.

\section{Consideraciones finales}

En este capítulo se analizaron las cifras de la salida de metales preciosos y los actores que intervinieron durante las últimas décadas del siglo XVIII. A partir de la segunda mitad del siglo, se produjo un crecimiento de la salida de metales preciosos legales, esto se encadena a lo planteado con respecto al comercio de cueros ya que las causas se encuentran en la consolidación del comercio con Brasil y luego, tras la apertura de la conexión con La Coruña por medio de las fragatas correo y la apertura de otros puertos.

La salida de metales hacia Cádiz tuvo en la década de 1760 y 1770 su momento de mayor crecimiento, tras lo cual, se estanca y baja levemente. Las décadas señaladas son un interregno entre la salida hacia otras potencias y otras regiones. En ese contexto, Cádiz logró consolidar una posición predominante debido a la falta de mercancías llegadas desde otros lugares. Este predominio se encontraba vinculado a un grupo de comerciantes en particular, los cuales a partir de allí comenzaron a perder dominio comercial en la región.

El crecimiento de la salida de metales a partir de 1783 fue consecuencia del ingreso de mercancías de pequeños y medianos comerciantes e industriales 
que anteriormente no podían ingresar al mercado americano por las dificultades que se presentaba en el puerto de Cádiz.

La salida de metales no se encontraba vinculada solamente a actores afincados en la región Río de la Plata, como así tampoco era solo de particulares. Aproximadamente un $20 \%$ de los metales que partieron eran enviados por actores afincados en Chile y del Norte (Alto Perú, Salta, Jujuy, entre otros), esto permite establecer que el Río de la Plata no era la fuente de enriquecimiento comercial de actores asentados ahí y que las redes comerciales eran mucho más amplias y complejas.

Los actores que participaron no fueron solamente comerciantes, sino que una parte importante eran cargadores esporádicos, sujetos que en la travesía marítima que los deposito en la región traían consigo algunas mercancías para su venta y que, tras realizarla enviaban hacia la península el coste. Otra parte de los actores, eran pequeños comerciantes que mantenían contactos comerciales con pequeños y medianos industriales o comerciantes peninsulares y que lograban una actividad comercial modesta. Finalmente, se encontraban los grandes comerciantes que, concentraban la mayoría de los metales enviados. Para su análisis se incorporó los datos del capítulo anterior sobre los cargadores de cueros, y a partir de allí se dividió en tres grandes grupos, los cargadores de metales, de cueros y los mixtos.

Los grandes cargadores de metales preciosos eran aquellos actores que se ofrecían como intermediarios entre los grandes comerciantes de Cádiz y los mercados consumidores, por lo general eran comisionistas, rara vez los envíos los realizaban a su cuenta y riesgo, y no enviaban cueros por las características de los gaditanos que operaban con metales preciosos. 
El segundo grupo, era el de los cargadores de cueros, estos actores eran en su mayoría de arribo en la década de 1760 y 1770, provenían de regiones en un proceso insipiente de industrialización, lograron consolidar una posición importante a nivel regional ya que eran en vínculo entre los productores agrarios y el comercio ultramarino y muchos de ellos una vez consolidada su posición económica se inclinaron por invertir en tierras rurales o navíos ya que de esa forma lograban incrementar su patrimonio.

El último grupo era el de los comerciantes mixtos, estos actores eran los que mantenían una mayor diversificación comercial, ya que enviaban grandes cantidades de metales preciosos y de cueros. Además, en varios de los casos tenían inversiones de tierras y de casas en Buenos Aires y Montevideo. Este sector, probablemente era el más importante, ya que en las disputas institucionales que se desarrollaron en el periodo estudiado mantenían un vínculo estrecho con el resto de grupos de actores. En el conflicto que desarrollaron con los comerciantes de Lima, por ejemplo, los unifico.

El conflicto analizado de mediados de siglo considero que es importante ya que fue el inicio de la consolidación institucional de la región Río de la Plata como eje articulador comercial de todo el espacio. Para que esto se produzca, fueron claves los elementos analizados en los capítulos anteriores. Es decir, las transformaciones de la economía global y Regional son la clave para comprender el porqué de la victoria de los comerciantes y empresarios ganaderos rioplatenses en detrimento de los, en principio, más poderosos limeños. Una vez que se produjo esta victoria comercial, florecieron con mayor fuerza los conflictos internos, entre los monopolistas, el primer grupo de comerciantes, y los comerciantes y hacendados. 
La intensificación de los conflictos entre estos dos grupos se desarrolló en toda la segunda mitad del siglo, como se señaló en el capítulo anterior, uno de los conflictos más sostenidos se encontraba en los posibles destinos de los cueros rioplatenses. En realidad, lo que estaba en juego era el predominio económico y político regional, el cual se encontraba decididamente orientado a prevalecer del segundo grupo de actores, por ello, los monopolistas intentaban sistemáticamente frenar todas las reformas institucionales que se desarrollaban. Dentro de las trabas que se intentaron imponer, sin efecto, estuvo la posibilidad de que los rioplatenses puedan realizar expediciones hacia África para comprar esclavizados y que se entreguen cueros como forma de pago, esta problemática se profundizará en el capítulo siguiente. 


\section{CAPÍTULO 5}

\section{EI comercio de esclavizados ${ }^{53}$}

\section{Introducción}

En el año 1855 Herman Melville escribió una novela corta titulada Benito Cereno inspirado en el diario de un Capitán de Navío ballenero quien, en 1799, se encontró, sobre las costas de la Capitanía General de Chile, con una embarcación española que transportaba esclavizados amotinados. Jorge Luis Borges en un mítico prólogo a esta obra, escribió que, probablemente: "Herman Melville se propuso la escritura de un texto deliberadamente inexplicable que fuera un símbolo cabal de este mundo, también inexplicable.” (Borges, 1985: 9-10).

Es factible que Borges interprete que lo inexplicable del mundo que le tocó vivir a Melville fuera la posibilidad de que un hombre deliberadamente deje de ser hombre y pase a ser una mercancía, en términos económicos, políticos y jurídicos. El mundo de Melville, mediados del siglo XIX, se debate entre la plena ciudadanía de los habitantes y la consecuente abolición de la esclavitud, y el mantenimiento de esta práctica.

El misterio que significa ese mundo para este autor, continúa siendo muy difícil de comprender para las ciencias sociales. En las páginas siguientes no se buscará dilucidar sobre las causas de la esclavitud, si bien brevemente se da cuenta de ello, sino de establecer el impacto que esta actividad económica produjo en la región Río de la Plata. Para ello, en primer lugar, se abordarán las investigaciones más relevantes vinculadas al comercio de esclavizados en la

\footnotetext{
${ }^{53}$ Agradezco los artículos y fuentes que me entregaron los doctores Alex Borucky y Silvia Mallo que me permitió reconstruir las cifras de este comercio.
} 
región Río de la Plata, luego se analizará la circulación de navíos, las cifras de esclavizados $^{54}$ ingresados, la mercancía salida para su compra y, finalmente, un análisis de los actores rioplatenses que intervinieron tomando el caso de Milá de la Roca como ejemplo.

Como hemos visto en el segundo capítulo, durante el período estudiado, los contactos comerciales del complejo portuario rioplatense con regiones no pertenecientes a la monarquía fueron, principalmente, las islas Áfricanas dedicadas al comercio de esclavizados y Brasil (que, como se verá, proveía también de esclavizados). Como ya se desarrolló, en los territorios de esta unidad política durante gran parte del siglo XVIII se ofrecían pocas puertas de entrada y salida de mercancías, esto se modificó durante las últimas décadas.

Los intercambios de mercancías americanas por esclavizados tuvieron, a fines del siglo XVIII, una importancia vital ya que permitieron el florecimiento de actores económicos que, gracias al crecimiento económico de la segunda mitad de siglo, pudieron invertir sus ganancias en embarcaciones y en la compra de esclavizados.

La historiografía sobre la esclavitud en América abordó gran parte de las problemáticas vinculadas a esta temática, por un lado, desde los mecanismos de apropiación de los potenciales esclavizados en África, su venta, transporte, alimentación, destinos, las cifras de llegados, mortandad, etc. Por otro lado, se ha evaluado el impacto económico, social y cultural de los esclavizados en América. Uno de los aspectos menos trabajados es el papel de los americanos en este comercio. Los trabajos vinculados a esta temática se desarrollaron a partir del

\footnotetext{
${ }^{54}$ Se utiliza el concepto de esclavizados ya que un hombre no nace esclavo sino que se produce el sometimiento de un sujeto a esa condición en un contexto determinado. No es un concepto histórico sino analítico ya que su utilización intenta describir, en la actualidad, un proceso del pasado (Beckles, 2002).
} 
análisis de un actor en particular, para el caso rioplatense Tomás Romero es un caso paradigmático, o a partir del origen de ciertos grupos sociales (dando por hecho que el origen geográfico fue determinante).

La hipótesis de este capítulo es que la dinámica comercial de las últimas décadas del siglo XVIII estuvo determinada por la acción de los comerciantes ultramarinos de esclavizados regionales, los cuales participaron del comercio de cueros, tasajo e invirtieron en navíos.

En este capítulo se analizarán algunos aspectos generales del comercio de esclavizados como las zonas de salida, el objetivo de este comercio y las regulaciones institucionales. Además, se estudiará la entrada de navíos y las cifras de los esclavizados, por origen y bandera, haciendo especial hincapié en los actores regionales que intervinieron. Finalmente, a partir del estudio de un caso particular, Josep Ramón Milá de la Roca, se abordará la articulación del comercio de esclavizados y el tasajo ${ }^{55}$.

La posibilidad de establecer las cifras de los esclavizados ingresados se pueden encontrar en la web Voyages Database en donde se halla un gran número de navíos llegados de África. Con respecto a aquellos provenientes desde Brasil se encuentra en el Archivo Histórico Ultramarino series documentales ${ }^{56}$ que dan cuenta de los navíos que ingresaron desde Río de Janeiro, Bahía y Río Grande. Un análisis detallado y con descripción de las fuentes fue realizada por Corcino Medeiros dos Santos (2005). Por último, en relación a los análisis de los comerciantes asentados en la región Río de la Plata se encuentra un corpus documental en el AGN de Argentina en donde, con fines recaudatorios, se

\footnotetext{
${ }^{55} \mathrm{Si}$ bien el comercio del tasajo fue importante en los últimos años del siglo XVIII y la primera década del XIX (aunque con respecto a las cifras generales es un porcentaje muy pequeño), las fuentes para trabajarlo con profundidad son escasas y no permiten una sistematización. Por ese motivo, si bien se dan algunos datos generales, nos centraremos en un caso en particular.

${ }^{56}$ AHU, Rio Grande do Sul, caixa 10, doc. 19,27,33,39 y 43
} 
desglosa la participación de todos los individuos, las cantidades, los precios de los esclavizados y los navíos en donde fueron transportados. ${ }^{57}$

\section{Antecedentes}

Las investigaciones en torno al comercio de esclavizados en el Río de la Plata son de larga data, ya que a los estudios específicamente dedicados a ello se suman gran parte de las investigaciones vinculadas al comercio en general ${ }^{58}$. La primera investigación seriada del comercio ultramarino de esclavizados fue realizada por Elena Studer, quien en 1958 publicó un libro llamado La trata de negros en el Río de la Plata durante el siglo XVIII. En este texto, la investigadora da cuenta de las transformaciones institucionales que llevó a cabo la Monarquía en torno al comercio de esclavizados, a partir del análisis de las series de navíos ingresados, con los totales y el origen de esclavizados, las banderas de los barcos y los nombres de sus capitanes y dueños. Estas fuentes constituyeron hasta hace unos pocos años como la única base de datos sobre el comercio de esclavizados.

A partir de su estudio, los historiadores se dedicaron a analizar la presencia de los esclavizados en el Río de la Plata desde distintas perspectivas y abordajes ${ }^{59}$. Un primer trabajo en este sentido fue el desarrollado por Ceferino Garzón Maceda y José Dorflinger (1961), quienes analizaron la población esclava en una hacienda jesuítica a partir del examen de los libros de Registros de Bautismos, Casamientos

\footnotetext{
${ }^{57}$ Agradezco al Dr. Alex Borucky por proporcionarme su base de datos sobre el comercio ultramarino de esclavizados.

${ }_{58}$ Miguel Ángel Rosal realizó un recuento de los trabajos dedicados al análisis de los esclavizados en el que hoy es argentina. https://geala.files.wordpress.com/2011/04/sucinta bibliografc3ada.pdf. [Última fecha de consulta: 8 de abril de 2015].

Este apartado no busca agotar las interpretaciones sino dar cuenta de las de mayor vinculación con esta investigación.

${ }^{59}$ La presencia de estudios vinculados a la esclavitud y al papel de los esclavizados en los últimos sesenta años fue constante, un ejemplo es el lugar que le dio a ello Ricardo Rodríguez Molas, quien escribió, de 1957 al 2000, varios artículos desde un abordaje descriptivo. Algunos de ellos: Rodríguez Molas, 1958, 1959; 1961, 1970, 1988, 1999, 2000.
} 
y Entierros de Esclavos y otros, que contiene asientos desde 1754 hasta $1799^{60}$. Dentro de la misma perspectiva se encuentran los trabajos de Marta Goldberg (1976) y George Reid Andrew (1980) quienes abordaron la población Áfricana (esclavizada y no esclavizada) en Buenos Aires a partir de padrones e informes poblacionales, con el objetivo de reubicar historiográficamente el lugar que ocuparon los esclavizados dentro de la población. Desde otra perspectiva, Lyman Johnson se introdujo en el debate suscitado en la década del 60 en Estados Unidos sobre el "grado de humanismo" de los españoles e ingleses con respecto al trato que propinaron a los esclavizados, para ello un factor determinante era la facilidad con la que se otorgó la manumisión.

Alex Borucky, Karla Chagas y Natalia Stalla (2005) dan cuenta de los avances historiográficos de los últimos treinta años con respecto a los estudios sobre la esclavitud en Argentina, Uruguay y Brasil. Se desprende del texto que se profundizó notablemente en una serie de elementos vinculados a la relación entre los esclavizados y el resto de la población, su inserción social y económica interna.

La historiografía económica rioplatense, a partir de la renovación de la década de 1980, se orientó a analizar la fuerza de trabajo rural y en particular que impacto tuvieron los esclavizados en la economía. En la última década, en cambio, se retornó a los estudios sobre los flujos comerciales ultramarinos.

En su tesis doctoral, Fernando Jumar retoma el análisis de Elena Studer sobre el comercio ultramarino, centrándose en el período 1680- 1778, en particular, los Asientos y la integración en el complejo portuario rioplatense de Colonia do Sacramento que conectaba con el comercio de Brasil. En términos

\footnotetext{
${ }^{60}$ Un estudio detallado de la historiografía cordobesa sobre la esclavitud, ver: Becerra (2008).
} 
generales, plantea que el comercio ultramarino se encontraba en manos extranjeras a partir de los Asientos y acuerdos establecidos por la Monarquía y por medio de Colonia, controlando los rioplatenses el comercio interno. En este sentido en la conclusión afirma:

De leur côté, les rioplatenses n'ont aucune liberté dans le choix des partenaires externes: s'ils souhaitent agir en dehors du cadre légal espagnol, ils doivent se contenter de s'allier avec la puissance commerciale qui se présente dans le fleuve. Je n'ai trouvé aucun indice qui me permettrait d'affirmer que les rioplatenses ont entamé une action quelconque pour attirer sur le marché un partenaire autre que celui qui s’y était présenté. (Jumar, 2002a: 532).

Desde la historiografía brasileña se continuó con el análisis del periodo trabajado por Jumar, centrándose en la vinculación de Brasil y el Río de la Plata a partir de Colonia (Santos, 2011, 2005). Sus principales aportes fueron establecer los flujos comerciales que se realizaron y su impacto en la economía de Brasil.

Finalmente, los trabajos de Alex Borucky $(2009,2011)$ avanzan, para el período 1779- 1812, en relación al análisis de las cifras de esclavizados ingresados, el origen y a cargo de quien se produjo. La hipótesis central es que gran parte del comercio se desarrolló a través de las interacciones permanentes de los españoles y portugueses en el Atlántico sur iberoamericano. Este tráfico sirvió como plataforma desde donde los comerciantes rioplatenses se lanzaron hacia África. Además plantea que las guerras modificaron los circuitos y actores intervinientes, fundamentalmente, por el ingreso de los norteamericanos.

\section{La esclavitud en la Monarquía española}

A partir de 1513, comenzaron a sancionarse reglamentos que propiciaron el tráfico de esclavos. Se cobraba por primera vez el impuesto de dos ducados por cada esclavo que entrara a las Indias y se implementaba también la obtención de 
una licencia para ello. Pese a ello, no se otorgaron nuevas licencias y el comercio de esclavizados quedó en manos de la Casa de Contratación y el Consulado de Sevilla.

A fines del siglo XVI, entró en crisis el sistema monopólico de comercio y el comercio de esclavizados en sí mismo. Tras la unión de las Coronas de Portugal y España se dio comienzo al control portugués. Los portugueses eran entonces quienes controlaban las fuentes de extracción de los esclavizados.

A partir del conflicto entre España y Portugal, en 1640, el comercio de esclavizados fue aprovechado por Holanda que, a partir de 1668, se hizo cargo de la trata, y de los fletes del Atlántico. Desde fines del siglo XVII, Inglaterra comenzó a tener una ubicación favorable en este comercio producto de su capacidad marítima, de los territorios que poseía en África y América y de la forma de organizarse económicamente. El punto culmine de ese proceso se produjo con la paz de Utrech en 1713, por la cual se desarrolló el asiento de la South Sea Company que, a su vez, garantizaba la provisión de esclavos mediante un contrato particular con la Royal Áfrican Company. El compromiso era el ingreso de 144.000 esclavizados en los siguientes treinta años y los puertos de entrada incluidos en el tratado fueron, fundamentalmente, los del Caribe, incluidos Veracruz y Campeche, a los que se sumaron Caracas y Buenos Aires, y a partir de 1721 a través de Panamá se sumaron el Alto Perú y Chile.

En 1739 se inició una serie de conflictos armados entre la monarquía española e inglesa y se produjo el rompimiento del contrato del Asiento. El inglés fue el último de los asientos monopólicos internacionales concedidos por la Corona Española que, en 1788, por efecto del tratado del Pardo, recibió de Portugal las islas de Fernando Poo y Annabón en las costas Áfricanas, que le 
permitieron iniciar el comercio negrero que no había ejercido con anterioridad. Además para ese entonces contaba con una flota comercial, a lo que se sumaban proyectos para desarrollar un sistema de haciendas y plantaciones azucareras en Cuba, La Española y Veracruz (De la Serna, 2004).

Por otro lado, en 1780 se permitió a los súbditos españoles traficar con los neutrales, salvo en los territorios del Río de la Plata, Chile y Perú. En 1789 se declaró el comercio libre de esclavos como de pública utilidad para Caracas, Cuba, Santo Domingo y Puerto Rico y, en 1791, se incluyó en este comercio a los virreinatos de Buenos Aires y Santa Fe. Por último, en 1793, se concedió la libertad irrestricta de comercio para los súbditos americanos.

En este contexto, el comercio de esclavizados ocupó un rol central en cuanto a la utilización de los mismos como mano de obra y como mercancía que otorgaba prestigio. Uno de los interrogantes con respecto a este comercio es el porqué de su flujo constante. Si se viera desde una perspectiva actual, atemporal, y sin un análisis profundo, se podría llegar a pensar que, una vez que se habían asentado unos miles de esclavos en cada una de las regiones, el crecimiento vegetativo haría el resto. Claro está que, para ello, en primer lugar sería necesario que ingresara un número equilibrado de mujeres y hombres o, en su defecto, más mujeres que hombres. Sin embargo, Herbert Klein estableció que dos tercios de los esclavizados eran hombres y que este desequilibrio se daba como producto de la alta demanda de mujeres nativas en el interior de África. Sumado a esto, se encontraba la mortandad existente en la travesía y el promedio de vida relativamente bajo (que, si bien no era mucho más bajo que del resto de la población, la capacidad de reproducción si se encontraba mermada). Este proceso 
tuvo entonces como consecuencia que la incorporación de un gran número esclavizados en América.

Como se puede observar en el gráfico V-1, el comercio de esclavizados durante más de cuatro siglos giró en torno a la alta concentración de esclavizados en territorio americano. Por lo tanto, consideramos imprescindible para el estudio de la economía atlántica del siglo XVIII el impacto de los esclavizados en América.

Gráfico V. 1

Procedencia de Esclavizados del comercio Atlántico (1451- 1870).

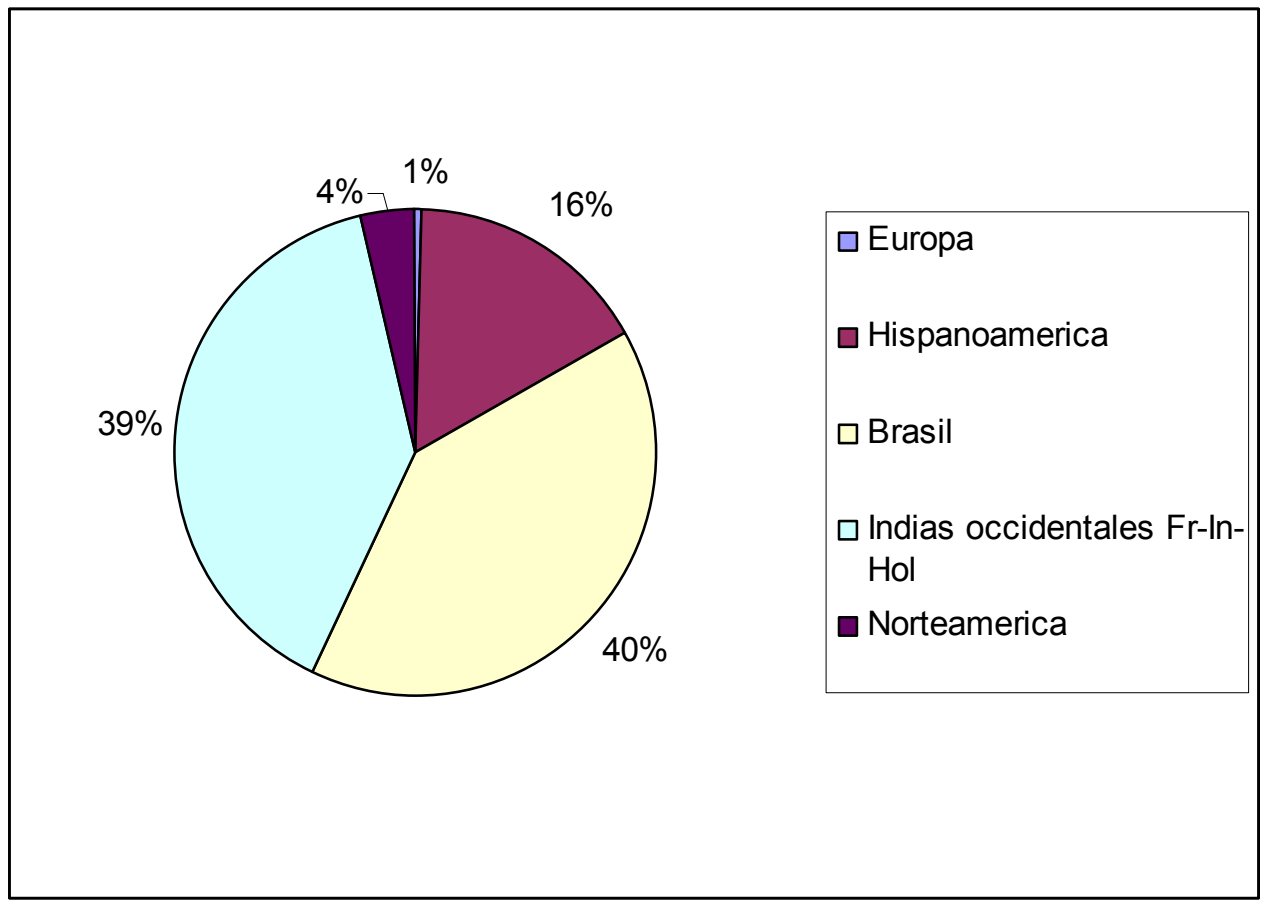

Fuente: Elaboración propia a partir de los datos de Klein (1993).

La zona en donde se efectuaron las transacciones comerciales con los esclavizados era en África Occidental, desde la actual Sierra Leona a República del Congo. Se estima que el origen de los esclavizados era muy variado ya que provenían desde gran parte de África Central. Lo cierto es que se torna muy dificultoso establecer el origen de los esclavizados ya que, como plantea Herbert Klein "Todos los estudios indican que, salvo los portugueses en Angola y 
Mozambique, el resto de los europeos prácticamente desconocía la naturaleza de las sociedades con las que comercializaban. En la mayoría de los casos se designaba a los Áfricanos según el puerto de procedencia, sin tener en cuenta ningún rasgo distintivo de lenguaje, grupo o nacionalidad.” Klein (1993: 23).

\section{Mapa V. 1}

Costa Áfricana atlántica meridional.

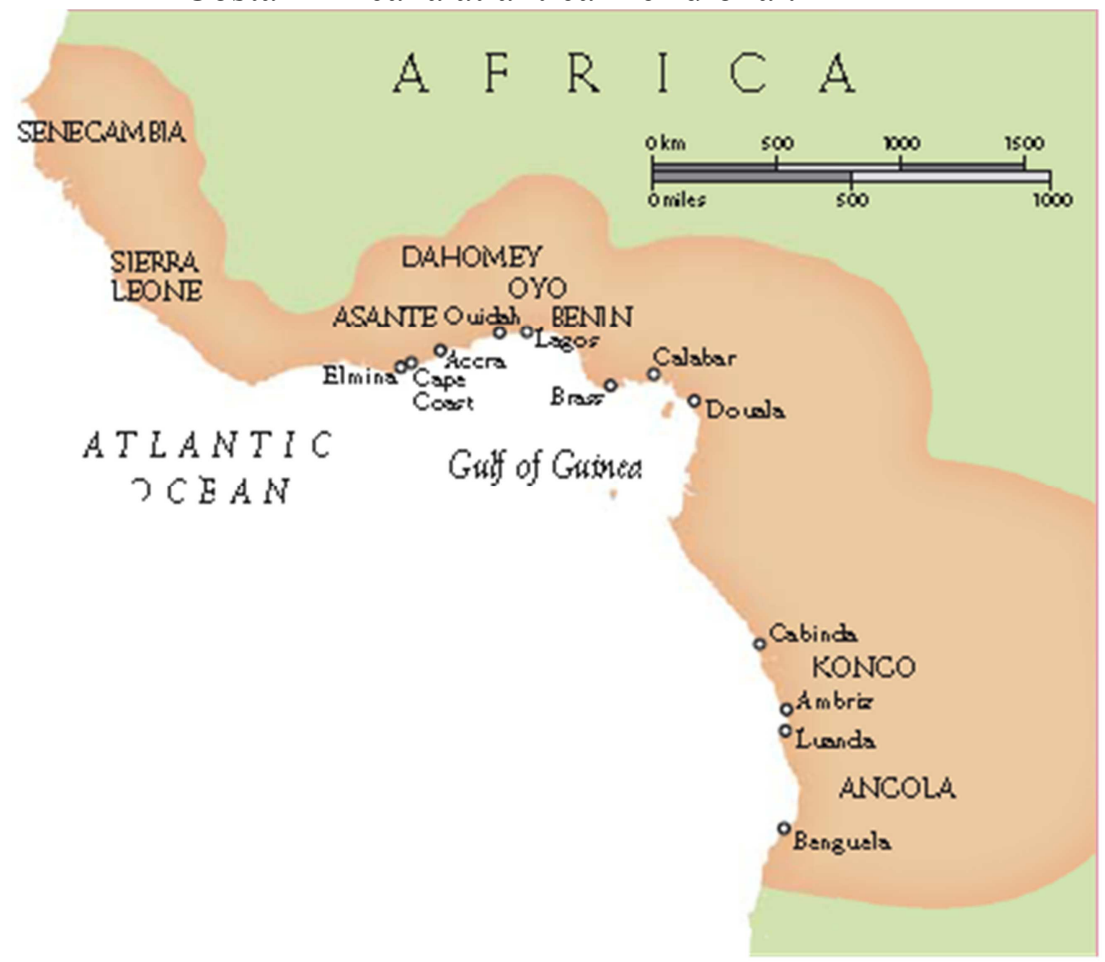

Fuente: http://history-peru.blogspot.com.ar/2013 0801 archive.html [última fecha de consulta: 8 de abril de 2015].

La vinculación de África con el complejo portuario rioplatense, planteó Alex Borucky (2011), se desarrolló en torno al Golfo de Guinea, el Golfo de Biafra y Mozambique. Esta diversidad se produjo por las distintas banderas que operaron en este espacio, en cambio, a Río de Janeiro y Bahía llegaban navíos provenientes exclusivamente de Angola y el Golfo de Benín. 
La costa Áfricana era un gran circuito comercial en donde se produjo una gran cantidad de intercambios a costa de los esclavizados vinculando a actores Áfricanos con europeos y americanos. Eran innumerables las mercancías que se intercambiaban: telas asiáticas, hierro, armas, pólvora, entre otros.

El principal uso que se daba a los esclavizados durante el siglo XVIII era como mano de obra para las plantaciones; durante la segunda mitad del siglo, se destinaron especialmente a Cuba y a Puerto Rico, por ser zonas que necesitaban trabajadores/esclavizados de forma masiva para poder perdurar. Los usos que se destacaron para los ingresados por el Río de la Plata fueron el trabajo en las minas y tareas agrícolas y urbanas. Finalmente cabe señalar que, la tenencia de esclavizados fue una fuente de prestigio, por lo tanto, no se compraban solo por lo rentable que pudiesen ser sino también por el mantenimiento de un status social determinado. Por ese motivo, una parte importante de los esclavizados se encontraba en las ciudades realizando actividades domésticas. Como afirma Silvia Mallo "Desde el punto de vista de la sociedad, la rioplatense se define en Hispanoamérica como una sociedad multirracial con esclavos. En este tipo de sociedades la necesidad de la esclavitud es incidental o superficial y no una parte integral de la economía.” (2013: 5).

Si tomamos el caso de Buenos Aires, una parte importante de la población de las ciudades estuvo constituida por esclavizados. En el gráfico V-2 se puede observar que para 1744 el 27,4\% de los habitantes eran esclavos, porcentaje que se eleva al $35,5 \%$ en 1778 , hasta llegar al $43,1 \%$ en 1810 . Es decir, no solo el crecimiento de los esclavizados acompañó al de la población en general, sino que fue incrementando su porcentaje en relación a la cantidad total de habitantes. La causa de este ascenso en cuanto al porcentaje de esclavizados que habitaron la 
ciudad no la deberíamos buscar en un mayor crecimiento vegetativo ya que, como se ha planteado, los nacimientos eran relativamente pocos en la población esclavizada de América.

Fue precisamente el crecimiento comercial de la región Río de la Plata el que generó un gran incremento de la población esclavizada en la ciudad por diferentes razones. Por un lado, la escasa mano de obra rentada existente implicó la utilización de esclavizados para compensar estas circunstancias. ${ }^{61}$ Por otro lado, hay que considerar la gran circulación monetaria que se sumaba a que la compra de esclavizados fuera relativamente barata. Por último, no es menor el hecho de que un número considerable de la población poseía sujetos en condiciones de esclavitud que les significaba un incremento de su renta y prestigio. Pese a que algunos esclavizados ingresados del mercado ultramarino permanecían en el puerto de Buenos Aires, la mayoría de ellos tuvieron como destino otras regiones del sur de América.

\footnotetext{
${ }^{61}$ María Emilia Sandrín da cuenta en sus trabajos de la alta renta que adquirían aquellos sujetos que se dedicaban a los trabajos manuales.
} 
Gráfico V. 2

Población de la ciudad de Buenos Aires (1744-1810)

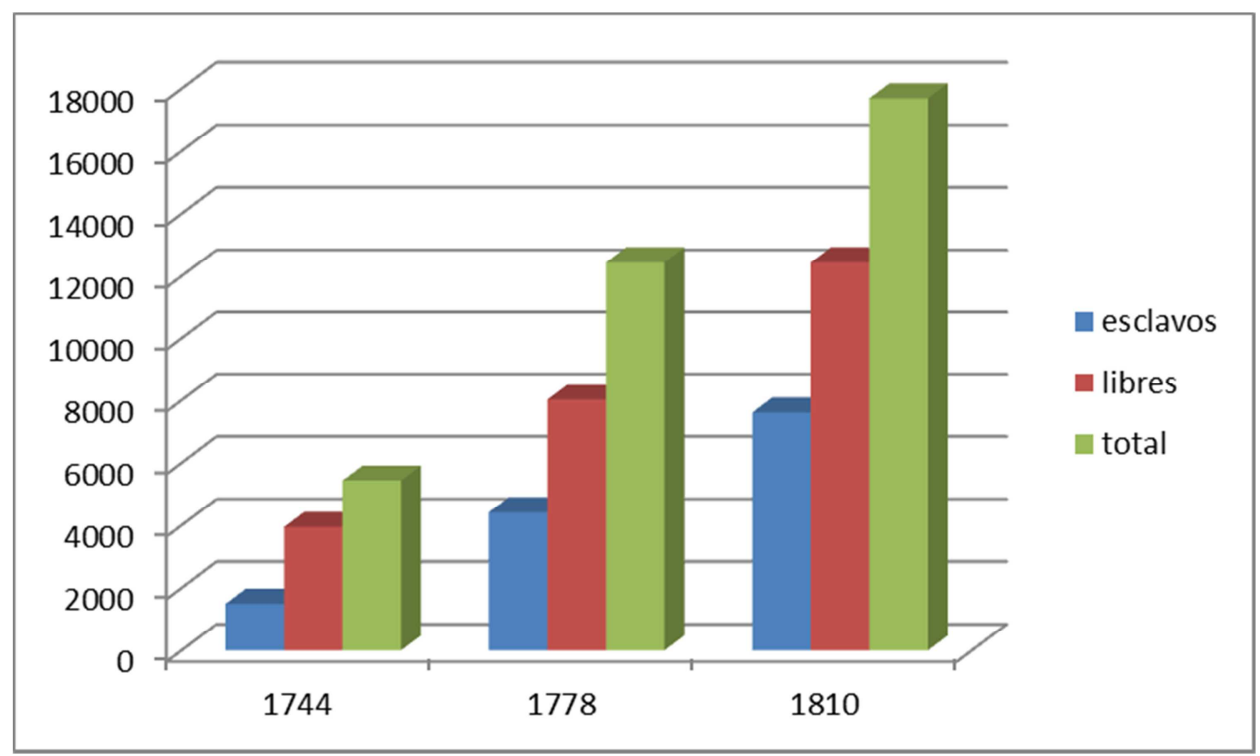

Fuente: Padrones de 1744, 1778 y 1810.

Consideramos que esto representó una modificación debido a que durante el siglo XVII y la primera mitad del siglo XVIII el ingreso de esclavizados tuvo como fin la redistribución espacial de los mismos, siendo el complejo portuario el lugar de ingreso y enclave de redistribución. Florencia Guzmán establece que las regiones en donde se redistribuyeron fueron la región del Tucumán, Chile, Paraguay y Alto Perú. Producto de la escasa mano de obra regional, el comercio de esclavizados fue fundamental, siendo el Alto Perú el gran "consumidor". Las rutas, que conducían desde Buenos Aires hacia Córdoba, Tucumán y Salta y la que iba hacia Mendoza, Chile y Lima mantenían una afluencia constante de esclavizados que permitía la distribución de los mismos en las distintas regiones (Guzmán, 2006). Un ejemplo de ello es, tomando al padrón Militar de 1778, el Obispado del Tucumán en el cual un 44,5 \% de la población total eran negros, mulatos, pardos y zambos, un 36,5\% eran indígenas y los blancos un $19 \%$, esto da cuenta de la notable inserción forzosa de esta población migrante en este espacio. 
Pese al crecimiento de la importancia de Buenos Aires como lugar de concentración de los esclavizados, gran parte de los mismos continuó partiendo hacia otras regiones. José Sovarzo, establece que entre los años 1779 y 1783 salieron desde Buenos Aires un total de 4.238 esclavizados, produciéndose así un equilibrio en el consumo entre los destinados hacia el Alto Perú y Mendoza/Chile. Esto refleja la gran importancia que cobraron Mendoza y Chile como lugar de consumo de esclavizados.

\section{Gráfico V. 3}

Lugares de arribo de los esclavos salidos desde Buenos Aires (1779-1783).

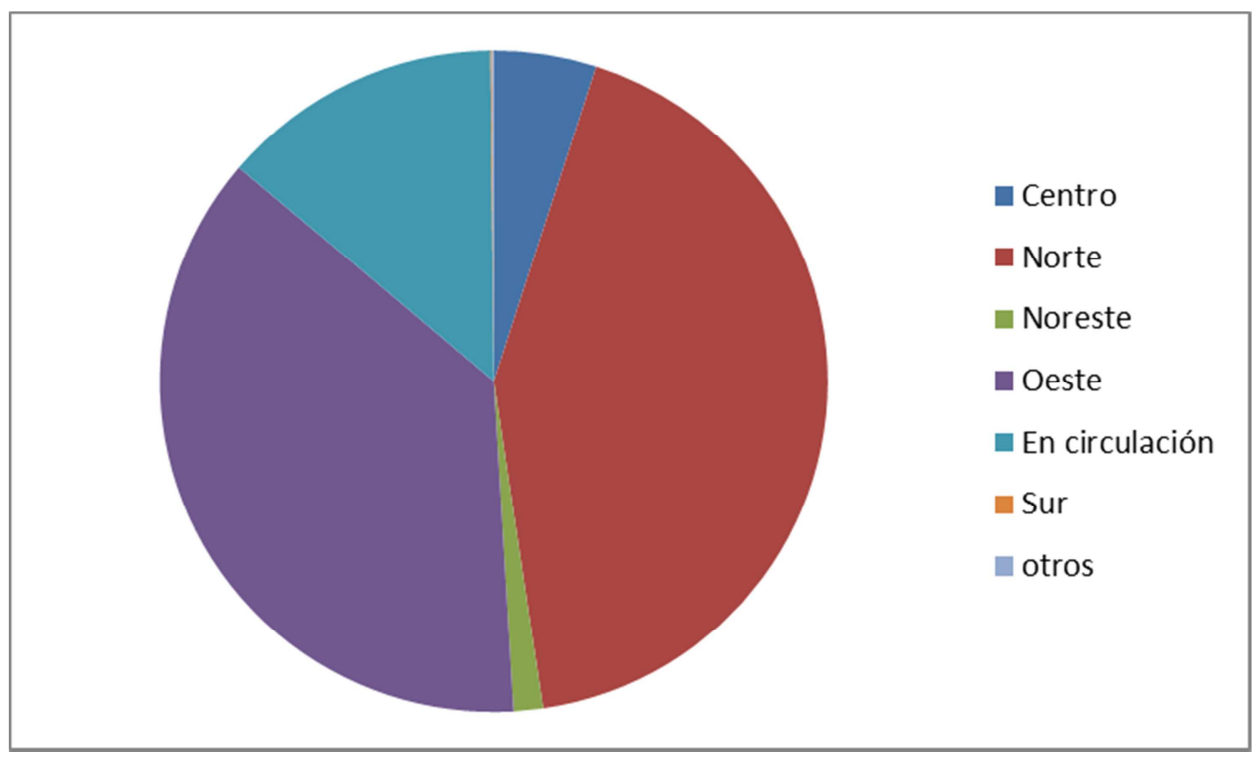

Fuente: elaboración propia a partir de los datos de Sovarzo (2014).

En este sentido, una forma de ver la importancia señalada para la región de Mendoza y Chile es considerar las rutas por donde pasaron los esclavizados. Vemos claramente, así, que la ruta de Córdoba hacia el Norte fue reemplazada por la Cuyo. Vemos claramente así que la ruta de Córdoba hacia el Norte fue reemplazada por la de Cuyo. Desde esta perspectiva se puede observar que más del $67 \%$ estuvieron vinculadas a esta ruta, dejando en un $12 \%$ a la del norte. 
Gráfico V. 4

Rutas de los esclavos salidos desde Buenos Aires (1779-1783)

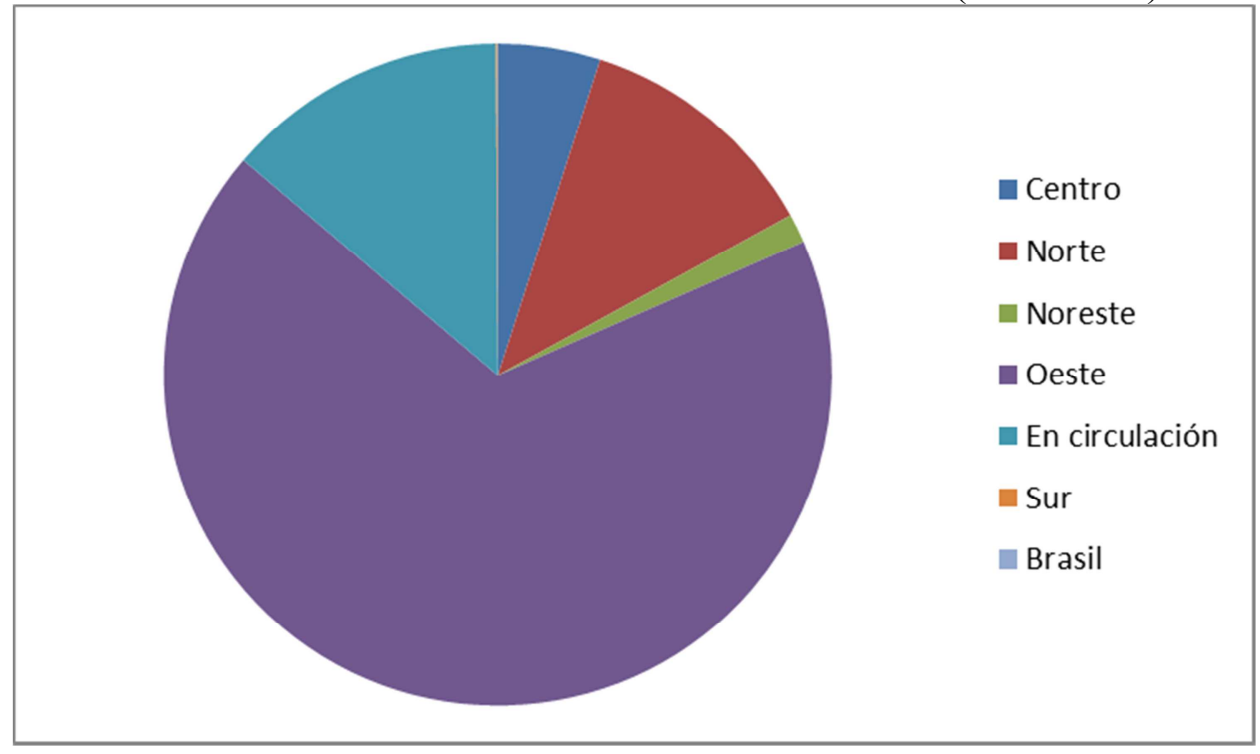

Fuente: elaboración propia a partir de los datos de Sovarzo (2014).

Tenemos, entonces, que el comercio de esclavizados fue muy importante para la dinámica económica y demográfica en todo el espacio que, durante el siglo XVII y la primera mitad del siglo XVIII, estuvo orientado al consumo interno, hacia Córdoba y al Alto Perú. A su vez, en la segunda mitad del siglo, como producto del crecimiento de la región Río de la Plata, se dividieron los esclavizados entre los que quedaban en la región y los que iban hacia el Alto Perú por la ruta de Mendoza y Chile.

A continuación se realizará un aporte en relación a la vinculación de las cifras de los esclavizados con el resto de mercancías, la participación en torno a los orígenes de los comerciantes y la intervención de los actores regionales.

\section{La circulación de navíos con esclavizados}

Con respecto al comercio de esclavizados durante el siglo XVIII, se desarrollaron tres tipos: los asientos de la primera mitad del siglo XVIII, el comercio con Brasil y el directo con África. Durante la primera mitad del siglo 
XVIII se produjo el asiento del comercio de esclavos de Francia (La compañía francesa de Guinea) e Inglaterra (la South Sea Company). El comercio de esclavizados provenientes de Brasil se articuló como producto de la posesión portuguesa de Colonia do Sacramento hasta su expulsión en 1777 y luego a partir del contacto comercial con Río de Janeiro y Bahía. Por último, se encuentra el comercio directo de los americanos en África a partir de la compra de navíos o su alquiler y previa carga de plata y cueros, se embarcaban desde el complejo portuario rioplatense hacia ultramar.

El comercio ultramarino de esclavizados en manos de españoles se desarrolló durante la segunda mitad del siglo XVIII, a partir de la aplicación de mecanismos legales en donde se les permitía realizarlo. Con dificultades para su concreción, la Corona permitió a la Compañía Gaditana de Negros y a la Real Compañía de Filipinas el comprar en África esclavizados, transportarlos a Hispanoamérica y comercializarlos. Arturo Bentancur (1997) planteó que, dada la falta de experiencia, estas compañías solo se ofrecieron de intermediarias entre los consumidores y los comerciantes extranjeros. En la Real Cedula del 24 de noviembre de 1791 se decretó la libre introducción de esclavos, permitiendo, por lo tanto, que cualquier español y extranjero pudiera comercializar.

El total de navíos que llegó con esclavizados a las costas del Río de la Plata entre los años 1779 a 1812 fue de $712^{62}$, esto nos da muestra de la importancia que tuvo a nivel regional este comercio. Encontramos que un total de 551 navíos, el 77\%, 1legaron desde Brasil. Si bien el tamaño de los navíos (en su mayoría zumacas) que cubrían esa travesía no permitía que el número de esclavizados fuera comparable con los llegados desde

${ }^{62}$ En base a la consulta de Fuente: elaboración propia a partir de (Studer,1958) AGN-A IX, 18-811; 2-9-1; 2-9-6; 10-4-7; 45-2-6. AGN-U, EGH, 28, 80, 40, 89, 95 AGI, Indiferente 2824, 2825, Buenos Aires 483. 
África, sí nos marca la pauta de la importancia que continuaba teniendo el comercio con Brasil, ya que solo 161 provenían de África en forma directa.

La regularidad del flujo comercial de estos dos espacios con la región Río de la Plata fue similar, salvando las distancias con respecto a la cantidad de los navíos. Hubo un primer momento de crecimiento a partir del acuerdo de paz en 1783 y luego a partir de los permisos que posibilitaban la compra de navíos y de las expediciones americanas hacia África, se dio un nuevo incremento, acelerado con el ingreso de banderas neutrales en el comercio a raíz del nuevo conflicto armado de 1796.

\section{Gráfico V. 5}

Entrada y salida de navíos con esclavizados del complejo portuario rioplatense por origen (1777-1811)

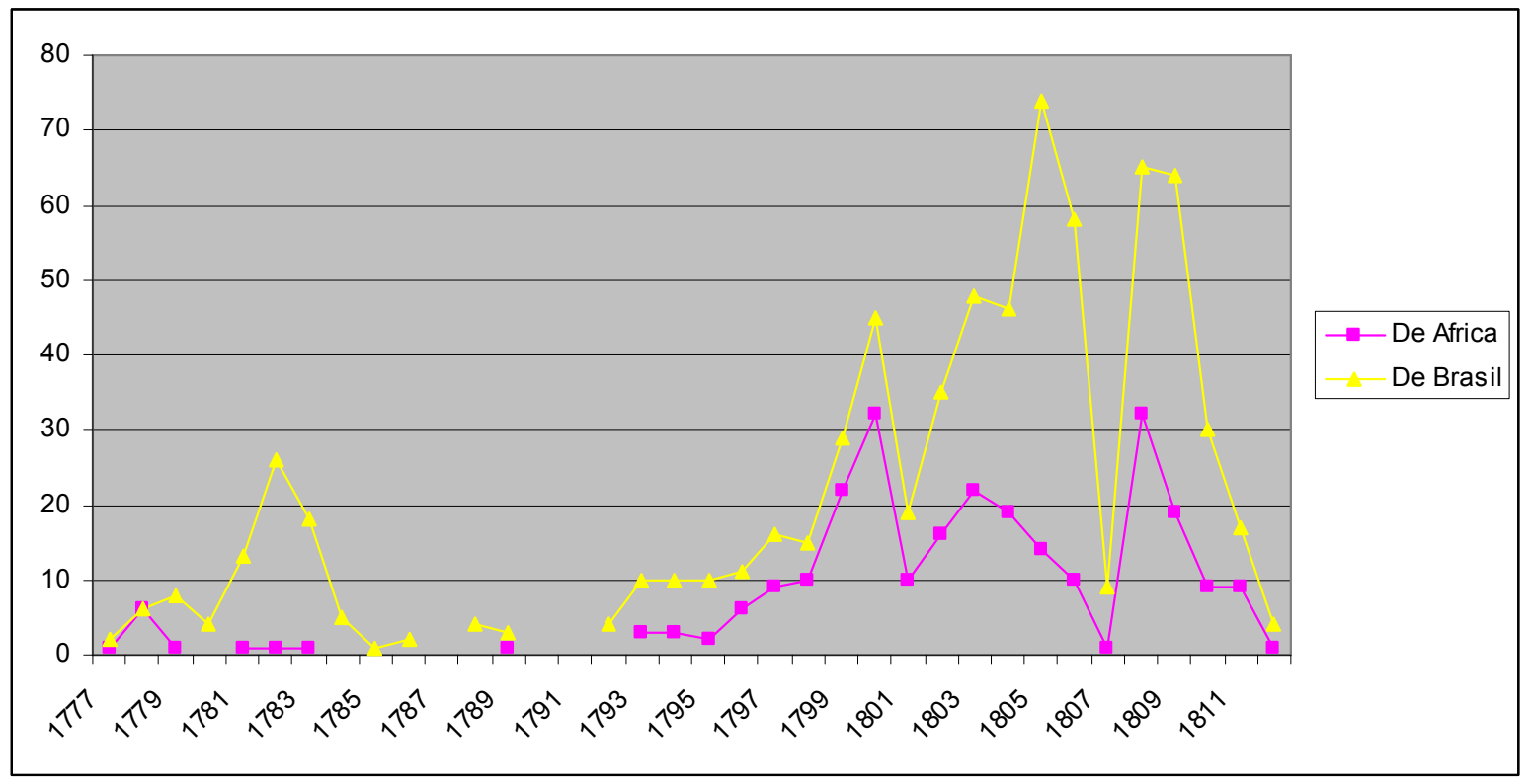

Fuente: elaboración propia a partir de Studer (1958) y AGN-A IX, 18-8-11; 2-91; 2-9-6; 10-4-7; 45-2-6. AGN-U, EGH, 28, 80, 40, 89, 95 AGI, Indiferente 2824, 2825, Buenos Aires 483.

El análisis de las banderas de los navíos dedicados a este comercio nos arroja resultados interesantes ya que, pese a lo que marcaría el sentido común historiográfico respecto a que el comercio se encontraba en manos extranjeras, 
numerosos barcos que surcaron las aguas atlánticas con esclavizados eran de bandera española. El predominio, como sucedió en toda América, era de los brasileños quienes tuvieron en el comercio de esclavizados una de sus actividades más importantes y, como ya se ha planteado, la toma de Colonia do Sacramento no fue un impedimento para las vinculaciones comerciales. Muy cercanos en cuanto al número total de embarcaciones se encuentran los españoles, quienes lograron, a partir de 1792, la compra de una flota naviera comercial.

Gráfico V. 6

Navíos llegados a la región Río de la Plata según bandera (1779-1812)

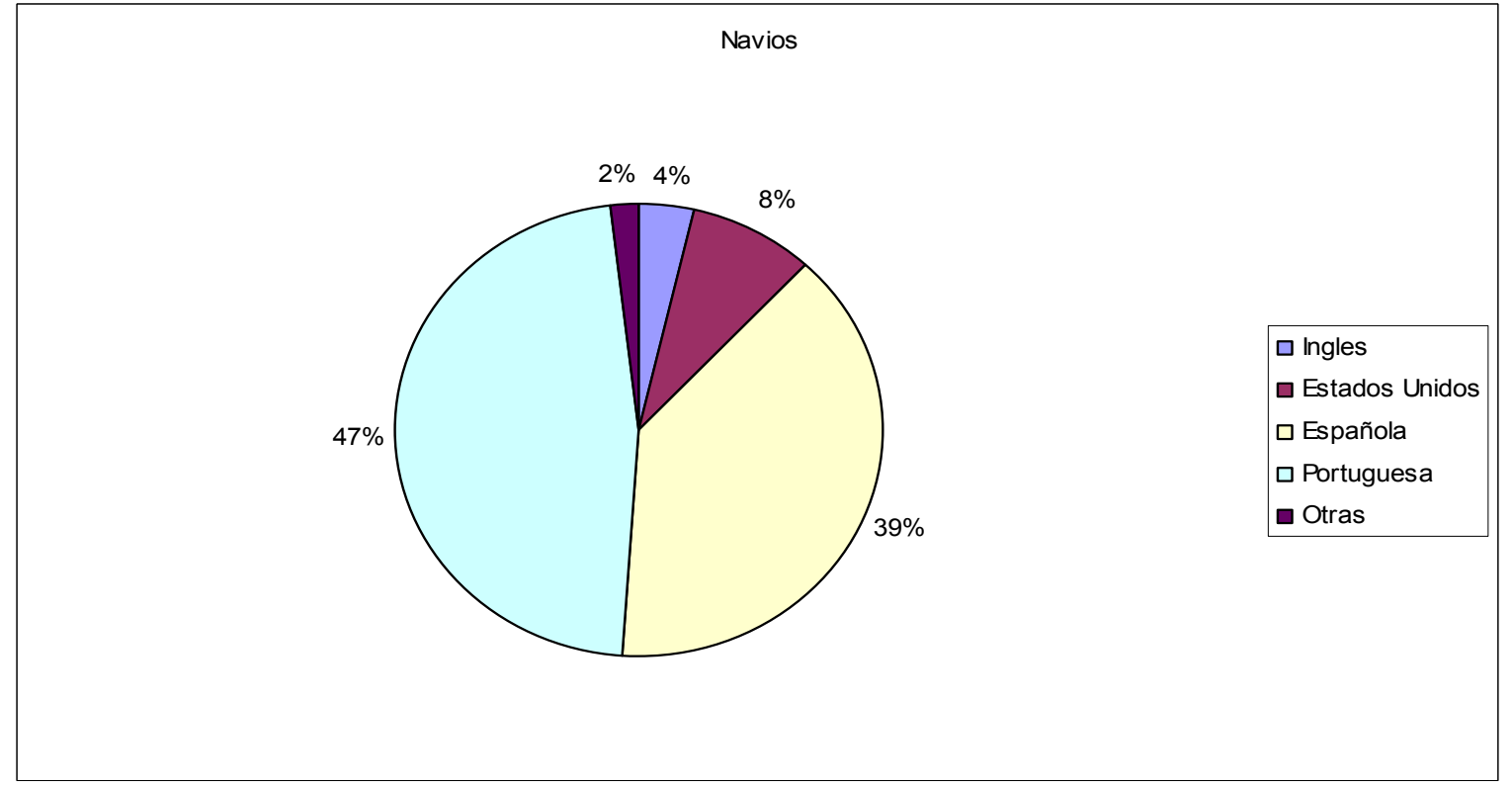

Fuente: Elaboración propia a partir de Studer (1958) AGN-A IX, 18-8-11; 2-9-1; 2-9-6; 10-4-7; 45-2-6. AGN-U, EGH, 28, 80, 40, 89, 95 AGI, Indiferente 2824, 2825, Buenos Aires 483.

La compra de navíos por parte de los criollos fue uno de los mecanismos de inversión más importantes desarrollado entre 1787 y 1805, alcanzando un total de 184 adquisiciones que fueron patentadas. Algunos de los actores implicados se dedicaron fundamentalmente a esta actividad, como Francisco Del Sar o Manuel Pinedo quienes, si bien comercializaban cueros $\mathrm{y}$ fueron comisionistas que enviaron remesas de plata a la península española, concentraron su actividad 
económica fundamentalmente en la compra y puesta en funcionamiento de embarcaciones destinadas al comercio del Atlántico, las cuales partieron a cuenta y riesgo de terceros.

Otro grupo de actores, en cambio, combinó la compra de embarcaciones con el comercio ultramarino de cueros, esclavizados y tasajo. Dentro de este grupo se encontraron Tomas Romero, Pedro Duval, Josep Milá de la Roca, entre otros.

Pero además existió un grupo de actores que compraron una embarcación como inversión y la arrendaron a un tercero quien desarrolló el comercio hacia Brasil, el Callao, La Habana o África. Estos últimos son los casos mayoritarios numéricamente, dando cuenta de que, si bien existió una concentración de capital económico en pocas manos, la posibilidad de acceder al comercio y a bienes de alto valor no se encontró vedado para gran parte de la población de la región Río de la Plata.

La compra de navíos por parte de rioplatenses se encuentra registrada desde el año 1787, si bien es cierto que el número de transacciones en estos primeros años fue bajo, anteriormente, el mercado de embarcaciones solo estuvo compuesto por lanchas y botes. Esto da muestra de la alta monetarización y de la intención por parte de los rioplatenses en invertir en embarcaciones.

El 14 de diciembre de 1794 la Monarquía dio curso a una Real Orden en donde se facilitaba la compra de navíos en colonias extranjeras que, a partir de allí, se incrementó notablemente. En 1800 se acrecentaron las exigencias para erradicar mecanismos fraudulentos de evasión y que los rioplatenses sean meros testaferros de terceros. Varios casos analizados por Arturo Bentancur (1997) y Elena Studer (1958) dan cuenta de que las medidas regulatorias en este sentido 
fueron insuficientes. Uno de los mecanismos que generaba dudas sobre las transacciones, era realizar una declaración jurada plasmando en las escrituras que el navío no pertenecía a extranjeros y que se dedicaba al comercio de esclavizados. Otra estrategia que generaba dudas en las autoridades era la contratación de la totalidad de los marineros extranjeros de las embarcaciones.

Pese a los potenciales fraudes, estimo que el alto número de navíos adquiridos por rioplatenses da cuenta de un proceso de inversión y un interés de inaugurar circuitos por parte de los mismos.

\section{Gráfico V.7}

Navíos comprados por rioplatenses (1787-1805)

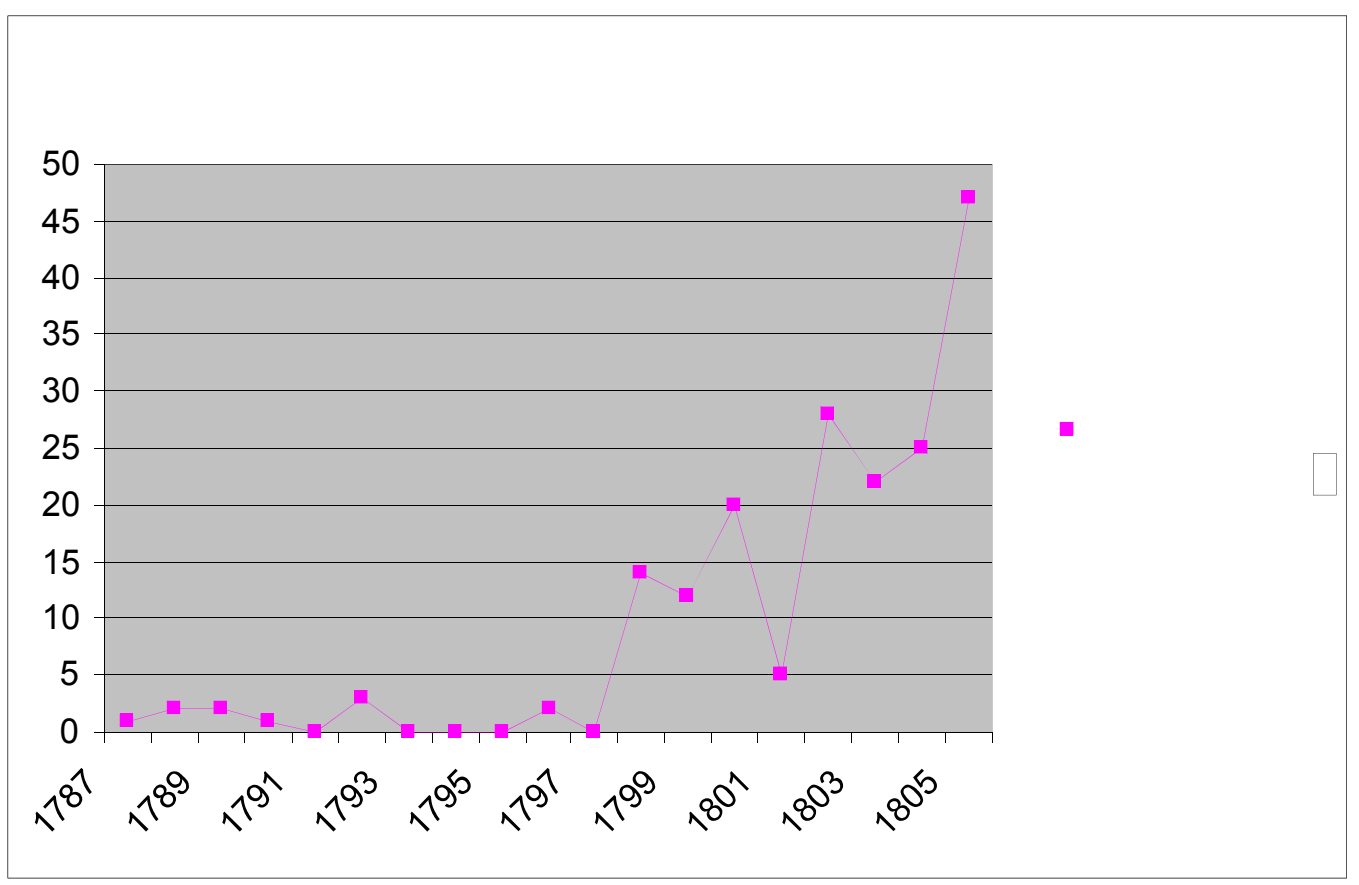

Fuente: Elaboración propia a partir de AGN. Alcabala de Buenos Aires sala IX desde 9-3-9 a 13-7-8. Alcabala de Montevideo Sala XIII desde 15-6-5 a 16-6-1.

El circuito de los navíos adquiridos por los rioplatenses oscilaba entre tres destinos: Brasil, África y Cuba. La vinculación con los dos primeros tuvo como 
fin el intercambio de esclavizados por metales preciosos y cueros y, con Cuba, la venta de tasajo.

\section{Cuadro V. 1}

Mayores propietarios de embarcaciones del Río de la Plata (1787- 1806)

\begin{tabular}{|c|c|}
\hline Nombre & Total de Navíos \\
\hline Aguirre, Manuel & 6 \\
\hline Añorga, Martin & 3 \\
\hline Baudrix, José & 4 \\
\hline Belaustegui, Francisco & 4 \\
\hline Costa, Antonio & 4 \\
\hline Del Sar, Francisco & 4 \\
\hline Duval, Pedro & 4 \\
\hline Elordi, Martin & 5 \\
\hline García, Agustín & 3 \\
\hline Juanico, Francisco & 3 \\
\hline Maciel, Francisco & 7 \\
\hline Magariños, Mateo & 4 \\
\hline María, José & 2 \\
\hline Milá de la Roca, José & 4 \\
\hline Pacheco, Manuel & 4 \\
\hline Patron, Juan Bautista & 3 \\
\hline Pinedo, Manuel & 3 \\
\hline Romero, Tomas & 11 \\
\hline Rosiana, Bartolomé & 2 \\
\hline Silva Cordeiro, Juan & 2 \\
\hline Ugarte, Francisco & 4 \\
\hline Vidal, Felipe & 5 \\
\hline
\end{tabular}

Fuente: Elaboración propia a partir de AGN. Alcabala de Buenos Aires sala IX desde 9-3-9 a 13-7-8. Alcabala de Montevideo Sala XIII desde 15-6-5 a 16-6-1.

\section{Los esclavizados ingresados a la región Río de la Plata}


En este apartado se analizarán las cifras de ingreso de esclavizados. Como se podrá apreciar, se encuentran diferencias en torno a las cantidades de navíos y de esclavizados llegados. Esto es producto de la variación de los tamaños de los navíos ya que, si bien desde África el contacto naviero fue menor, las embarcaciones que optaban por cruzar el Atlántico eran, en su mayoría, de gran tamaño.

Con respecto al total de esclavizados, en el gráfico V-8 se pueden apreciar que a partir de 1791, se da un incremento muy por encima en relación a los años previos. Esta transformación en cuanto a la cantidad de esclavizados ingresados estuvo marcada por dos cuestiones. Una posible "legalización" del comercio directo con Brasil, el cual hasta 1777 se producía por Colonia do Sacramento y luego por vía terrestre, a partir de que la Corona permitió el comercio de esclavizados en forma libre. Una segunda causa posible es el ingreso de nuevos actores al mercado de esclavizados. A partir de la Reglamentación de 1792 se dio permiso a los hispanoamericanos a que, a través del arrendamiento de navíos o por medio de los suyos propios, pudieran comercializar esclavizados en África y Brasil. Este proceso, que inauguró un nuevo mercado para los españoles radicados en América y los norteamericanos, trajo consigo el incremento de la competencia, la subsiguiente bajada de los precios de los esclavizados y de los actores que poseyeron esclavizados, tanto en las zonas urbanas como rurales. 
Gráfico V. 8

Esclavizados introducidos al Río de la Plata (1777-1812)

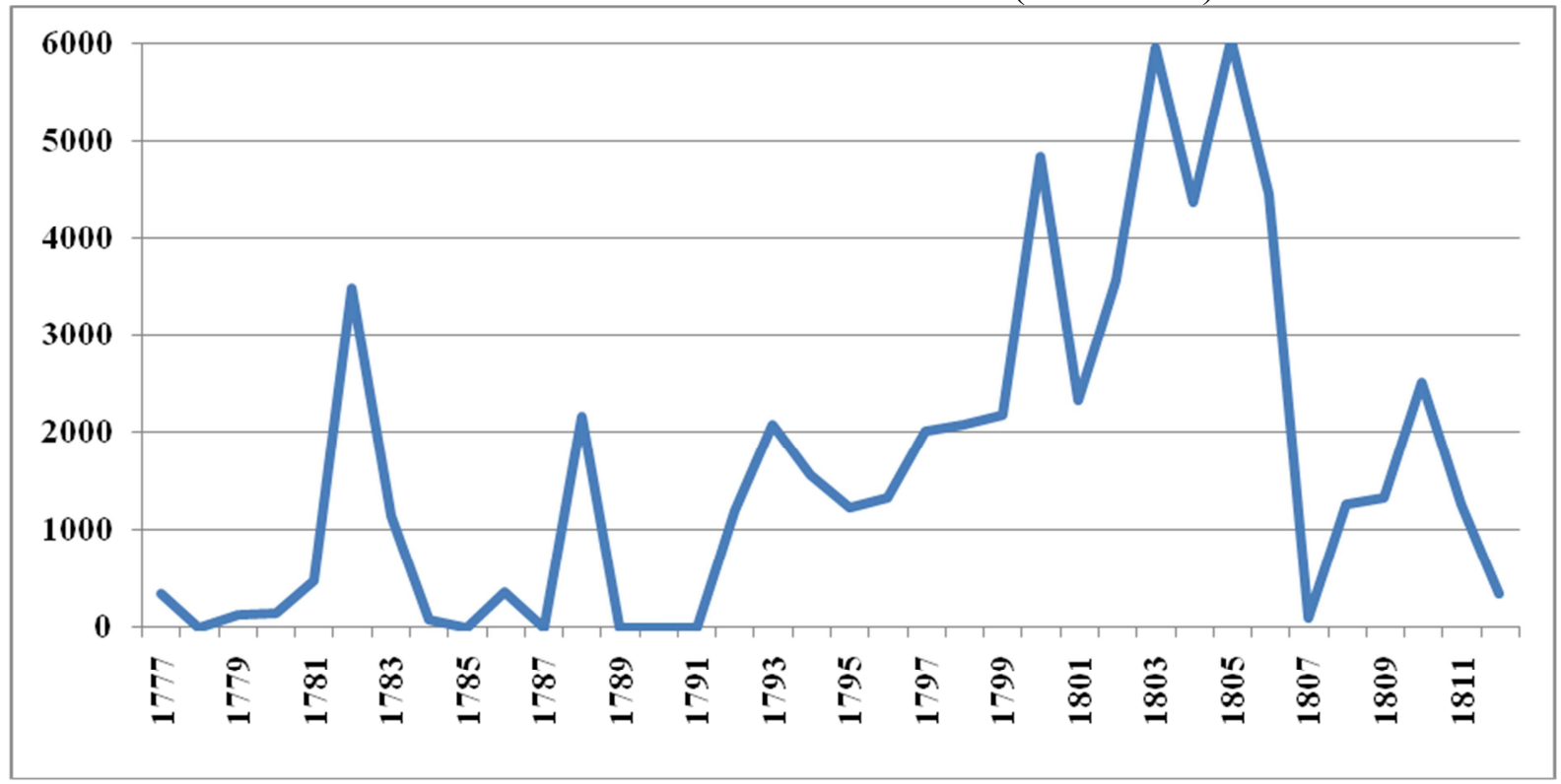

Fuente: elaboración propia a partir de Studer (1958) AGN-A IX, 18-8-11; 2-9-1; 2-9-6; 10-4-7; 45-2-6. AGN-U, EGH, 28, 80, 40, 89, 95 AGI, Indiferente 2824, 2825, Buenos Aires 483.

Como se puede observar en el gráfico V-8 el incremento de esclavizados provenientes de Brasil se mantuvo constante hasta las invasiones inglesas, en donde se produjo un freno del comercio ultramarino en general y de esclavizados en particular ya que se hizo efectiva la ruptura del comercio con Inglaterra y sus socios (en este caso Portugal). La masiva llegada de esclavizados desde África fue el principal vehículo para el incremento durante los últimos años del siglo XVIII y los primeros del XIX. 
Gráfico V.9

Esclavizados introducidos al Río de la Plata desde África y Brasil (1777-1812)

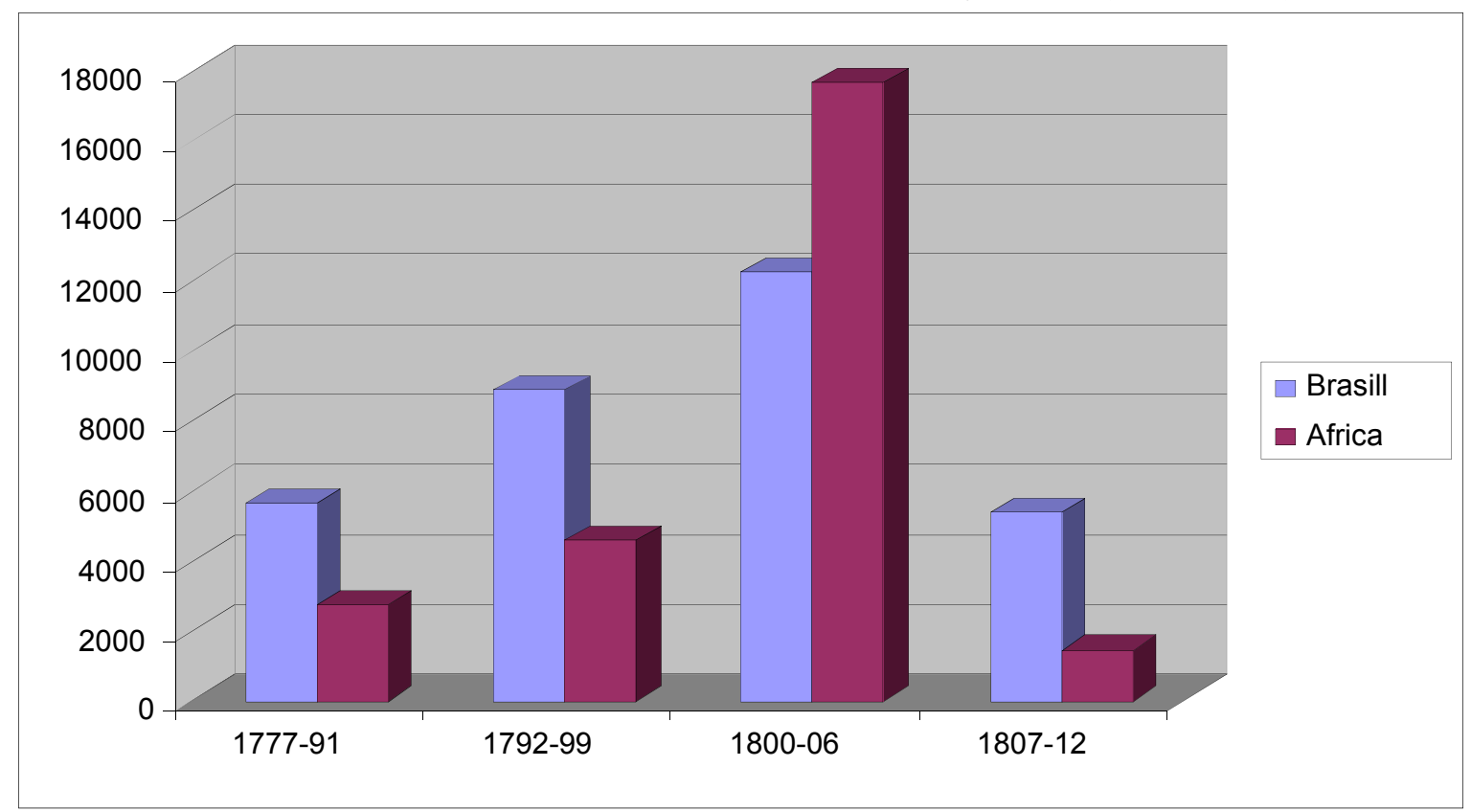

Fuente: elaboración propia a partir de Studer (1958) AGN-A IX, 18-8-11; 2-9-1; 2-9-6; 10-4-7; 45-2-6. AGN-U, EGH, 28, 80, 40, 89, 95 AGI, Indiferente 2824, 2825, Buenos Aires 483.

Si tomamos los datos del total de esclavizados introducidos al Río de la Plata desde África y Brasil, 1777-1812, encontramos que un 40\% correspondieron al primero y un $60 \%$ a Brasil. ${ }^{63}$ En relación al total de esclavizados en las dos rutas, se puede observar en el gráfico V-9 un predominio no tan marcado de Brasil en relación a África. Esto, como ya habíamos anticipado, fue producto de la variación del tamaño de los navíos destinados a una y otra ruta. Por otro lado, si bien el riesgo era mucho mayor a la hora de desarrollar un viaje hacia África, las ganancias y la capacidad de introducirse en el mercado también se incrementaban. A su vez, el mercado brasileño se encontraba consolidado en manos de los comerciantes locales, lo que dificultaba la posibilidad de obtener un circuito fluido en manos de los criollos o norteamericanos interesados.

${ }^{63}$ Estos datos fueron extraídos de Studer (1958) AGN-A IX, 18-8-11; 2-9-1; 2-9-6; 10-4-7; 45-2-

6. AGN-U, EGH, 28, 80, 40, 89, 95 AGI, Indiferente 2824, 2825, Buenos Aires 483. 
El comercio de esclavizados provenientes de Brasil estuvo dominado por los portugueses quienes tuvieron los dos mayores asentamientos en América y dedicaron grandes esfuerzos en convertirse en los mejores en el arte del transporte y comercialización. Río de Janeiro y Bahía eran polos de atracción en donde se concentraban los navíos esclavistas y a partir de estos puertos se redistribuían al resto de los territorios americanos. El número de esclavizados que llegaron a estos dos puertos brasileños fue el más importante durante todo el período de dominio hispano-portugués de América. Las cifras estimadas eran de alrededor de los 2,5 millones de esclavizados en Río de Janeiro y 1,7 millones en Bahía y, con respecto a los llegados al complejo portuario rioplatense, un 47\% (15.155) provinieron de Río de Janeiro, y un 25\% (7.955) de Bahía (Borucki, 2011:14).

El origen de los comerciantes que introdujeron los esclavizados no se redujo, sin embargo, a los portugueses, ya que la ruta Áfricana fue dominada por distintos grupos de comerciantes durante el período estudiado. Como ya se dijo y se puede observar en el gráfico $\mathrm{V}-10$, los portugueses mantuvieron un control del mercado muy importante durante todo el período a partir de la ruta brasileña del comercio de esclavizados. Ahora bien, a partir de 1792, se produjo un crecimiento muy marcado de los comerciantes españoles y, con el inicio del siglo XIX, se sumaron los estadounidenses. Durante este periodo es cuando se produjo un transformación en el comercio de esclavizados. 
Totales de esclavizados introducidos al Río de la Plata en relación al origen del navío, 1777-1812

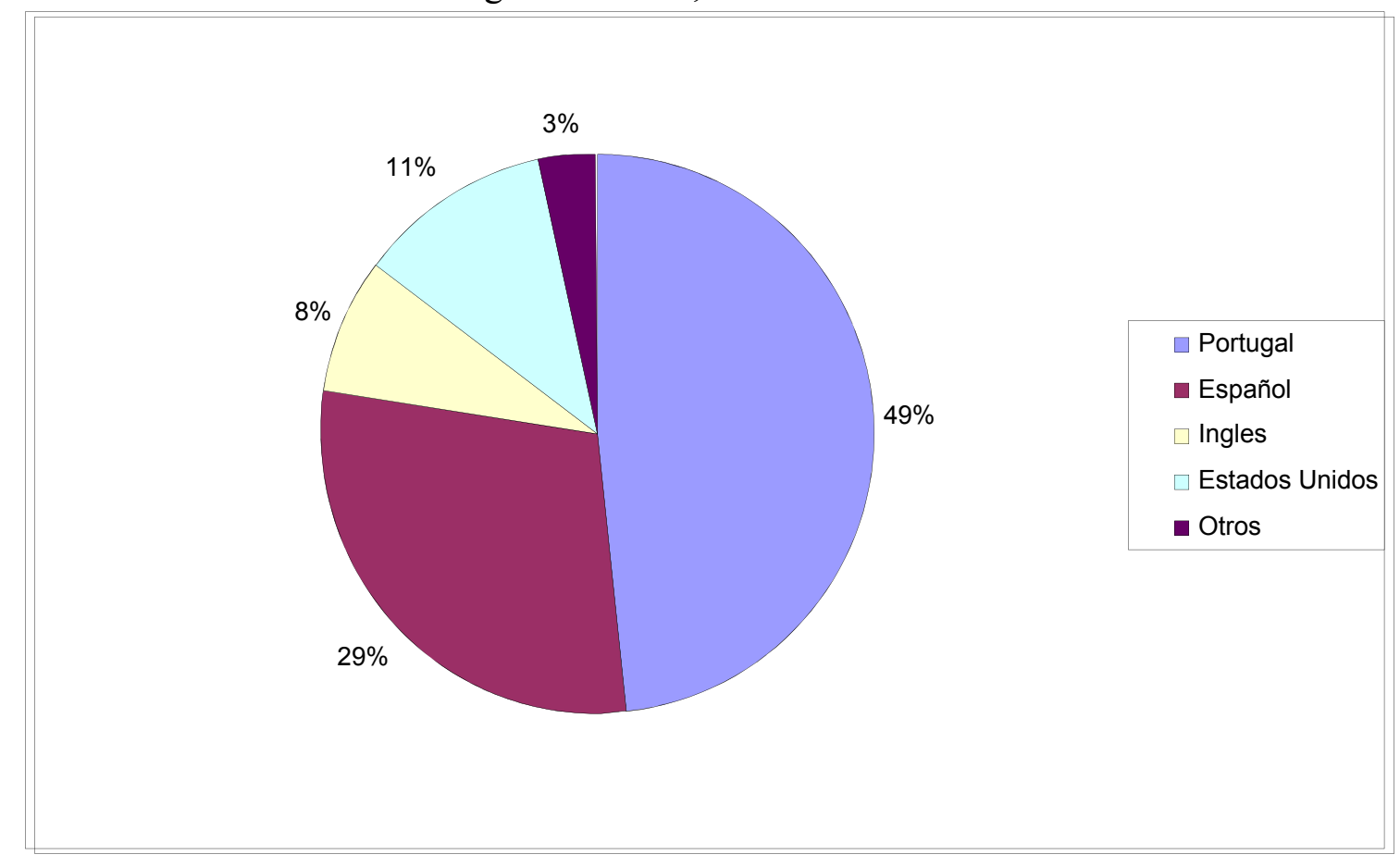

Fuente: Elaboración propia a partir de (Studer,1958) AGN-A IX, 18-8-11; 2-9-1; 2-9-6; 10-4-7; 45-2-6. AGN-U, EGH, 28, 80, 40, 89, 95 AGI, Indiferente 2824, 2825, Buenos Aires 483.

La posibilidad de los hispanoamericanos de comprar, transportar y vender esclavizados en el complejo portuario rioplatense fue una meta que se logró tras varios intentos fallidos y a pesar de la oposición de un sector de los comerciantes que no veía con buenos ojos que esto se produjese. La Corona, a partir del tratado de San Ildefonso en 1777, obtuvo un territorio en África que le permitía asentar navíos españoles y comprar esclavos para su transporte. Desde allí, se intentó con mayor ahínco introducir españoles en el comercio de esclavizados.

Como se puede observar en las Reales Cedulas y Reales Ordenes ${ }^{64}$, fue muy importante la preocupación de la Corona con respecto al comercio de esclavos durante este período, siendo las únicas directrices comerciales que se

${ }^{64}$ AGN sala IX 25-4-33. 
desarrollaron. Una primera señal de ello se dio en el año 1779, cuando se permitió que Tomas Romero ingresara 1000 esclavizados desde África como compensación a las pérdidas que tuvo en el Alto Perú por el levantamiento de Túpac Amaru.

En el año 1789 se impartieron instrucciones para regular los navíos extranjeros y el posible contrabando, se estableció que un oficial montara guardia en el navío. Como se puede ver en la Real Cédula, el 24 de noviembre de 1791 comenzó una nueva etapa, debido a que se dejó de dar permisos a actores individuales y se extendieron los mismos tanto a hispanoamericanos como a extranjeros (haciendo foco en los primeros).

A partir de última década del siglo XVIII, los rioplatenses lograron enviar navíos con cueros y metales preciosas a las costas Áfricanas y traerlos con esclavizados. Esto impactó en dos aspectos. En primer lugar, la apertura de una ruta comercial nueva permitió nuevas inversiones a aquellos que habían tenido fortuna con el crecimiento comercial de las décadas pretéritas. Esto es, quienes habían pasado de ser comisionistas a enviar grandes cantidades de cueros, logrando abrir un camino, vedado hasta entonces, que rompía con el circuito clásico hacia la península ibérica. En segundo lugar, la autorización de la compra de navíos para esta ruta les daba una independencia comercial muy importante, ya que estos navíos podían ser utilizados hacia otras rutas y también podían destinarse para fletes. Por lo tanto, se trató de un rasgo comercial distintivo de este período que influyó en las redes comerciales y políticas de los actores rioplatenses más importantes.

Este proceso va a tener un brusco freno a partir del permiso de ingreso de navíos neutrales, en especial norteamericanos, los cuales van a ofrecerse como 
una competencia muy dura para los navíos hispanoamericanos. Como planteó Josep Ramón Milá de la Roca, la llegada de los navíos neutrales perjudicó a aquellos actores que habían comenzado a intervenir en el comercio ultramarino hacia las islas Áfricanas, Cuba (con tasajo) y la península ibérica.

El descenso del ingreso de esclavizados se produjo a partir de las invasiones inglesas. Acaso una de las posibles causas haya sido el crecimiento de Norteamérica en el mercado hispanoamericano que iban en contra de sus intereses y los de sus aliados (Portugal). Lo cierto es que el impacto dejó en mínimos la llegada de navíos desde África, manteniéndose en muy bajo número los llegados desde Brasil. Durante este período de retracción del comercio, los actores que intervinieron fuertemente redireccionaron sus inversiones en tierras y propiedades urbanas fundamentalmente.

\section{Los actores regionales intervinientes}

Las licencias se otorgaron en la segunda mitad del siglo XVIII a los súbditos de la Monarquía española. En 1741 Thomas de Navarro, obtuvo una licencia para introducir dos navíos de bandera neutral provenientes de África y con un coste máximo de 24.000 pesos, en detrimento de Francisco Alzaybar. Un año y medio después ingresaron dos naves francesas con permiso Real con esclavizados. Este permiso generó una queja del Cabildo, ya que a cambio de los esclavizados se entregaron cueros de corambre sin la intervención del mismo. A partir de allí, se otorgaron varias licencias a agentes comerciales asentados en Cádiz y en Lima, con agentes en Buenos Aires. 


\section{Cuadro V. 2}

Permisos para ingresar esclavizados

\begin{tabular}{|c|c|c|}
\hline 1741 & $\begin{array}{l}\text { Licencia para ingresar en } \\
\text { dos navíos neutrales }\end{array}$ & Thomas Navarro. \\
\hline 1750 & $\begin{array}{l}\text { Permiso para ingresar } \\
2000 \text { esclavos por el Río } \\
\text { de la Plata }\end{array}$ & Ramón Palacios \\
\hline $1759-1761$ & $\begin{array}{lrr}\text { Permiso } & \text { para } & \text { ingresar } \\
\text { esclavos } & \text { con } & \text { destino } \\
\text { Lima } & & \\
& & \end{array}$ & Francisco de Mendinueta \\
\hline 1756 & $\begin{array}{l}\text { Licencia concedida por el } \\
\text { Virrey del Perú }\end{array}$ & Felipe Colmenares \\
\hline $1760-1772$ & $\begin{array}{l}\text { Asiento General para } \\
\text { toda América- Compañía } \\
\text { Gaditana }\end{array}$ & $\begin{array}{lcr}\text { Miguel } & \text { de } & \text { Uriarte- } \\
\text { Lorenzo } & \text { De } & \text { Arístigui- } \\
\text { Francisco } & \text { Aguirre- } & \text { José } \\
\text { María } & \text { Enrile- } & \text { José } \\
\text { Ortuño. } & & \end{array}$ \\
\hline 1780 & $\begin{array}{lrr}\text { Permiso } & \text { para } & \text { ingresar } \\
\text { esclavos } & \text { con } & \text { destino } \\
\text { Lima } & & \end{array}$ & Bruno Francisco Pereyra \\
\hline 1780 & $\begin{array}{lrr}\text { Permiso } & \text { para } & \text { ingresar } \\
\text { esclavos } & \text { con } & \text { destino } \\
\text { Lima } & & \\
\end{array}$ & Juan y José Gurruchaga \\
\hline 1782 & Permisos varios & $\begin{array}{l}\text { Manuel de Basavilbaso- } \\
\text { Luis de Reparaz- Pablo } \\
\text { Álvarez }\end{array}$ \\
\hline 1783 & Permisos varios & $\begin{array}{l}\text { Baltasar de Arandia- } \\
\text { Nicolás de Acha- Joseph } \\
\text { Oliveira Pedroso }\end{array}$ \\
\hline 1784 & Permisos varios & $\begin{array}{l}\text { Jerónimo Hijosa- } \\
\text { Gregorio Álvarez- Matías } \\
\text { López- Tomas Romero }\end{array}$ \\
\hline 1785 & Permisos varios & $\begin{array}{l}\text { Manuel López- Diego } \\
\text { Cantero- }\end{array}$ \\
\hline 1787 & $\begin{array}{l}\text { Real Compañía de } \\
\text { Filipinas }\end{array}$ & $\begin{array}{l}\text { Particulares varios. En } \\
\text { Buenos Aires Martín de } \\
\text { Sarratea. }\end{array}$ \\
\hline
\end{tabular}

Fuente: Elaboración propia a partir de los datos varios de Studer (1958).

En 1782 se dio entonces comienzo a la participación de los rioplatenses en el comercio de esclavizados. A partir de una rebaja de la presión fiscal la Monarquía buscó que se desarrollara el ingreso de esclavizados desde África. Sin embargo como, Studer afirma "los viajes de las naves negreras a Río de Janeiro y 
otros puertos brasileños continuaron siendo corrientes debido a que allí se conseguían los negros relativamente baratos y porque suministraban excelentes oportunidades para el contrabando" (Studer, 1958: 268).

El mecanismo, para que se produjera el desarrollo del comercio en manos de los rioplatenses, estuvo unido durante los siguientes años a los actores portugueses que ya operaban en la región desde hacía muchas décadas.

En el cuadro V-3 se puede apreciar a los mayores cargadores de esclavizados rioplatenses en relación al comercio con Brasil y con África. Algunos actores estuvieron vinculados a las dos plazas comerciales. La mayoría también fueron grandes cargadores de cueros y operaron, aunque en menor medida, como comisionistas de metales preciosos hacia la península. Además compraban navíos al tiempo que algunos de ellos, comercializaban tasajo hacia Cuba. Este grupo de comerciantes, acaso el más beneficiado por las transformaciones económicas e institucionales de la segunda mitad del siglo XVIII, fue el que logró consolidar, junto a otros actores vinculados, una suerte de hegemonía regional. Este grupo no fue el único que intervino en el comercio de esclavizados, existió otro que, circunstancialmente, intentó realizarlo pero con disímil suerte ${ }^{65}$.

${ }^{65}$ AGN, sala IX 25-06-02 y 25-04-33 
Cuadro V. 3

Algunos de los grandes cargadores de esclavizados rioplatenses

\begin{tabular}{|l|r|r|r|}
\hline Nombre & Brasil & África & Total \\
\hline Dubal, Pedro & 1.506 & 323 & 1829 \\
\hline Cagigas, Antonio & 206 & 0 & 206 \\
\hline Rusiano, Bartolomé & 89 & 0 & 89 \\
\hline Baudrix, Juan & 605 & 0 & 605 \\
\hline Belaustegui, Francisco & 918 & 0 & 918 \\
\hline Romero, Tomas & 1152 & 830 & 1982 \\
\hline Marco de Pont, Ventura & 16 & 58 & 74 \\
\hline Elordi, Martin & 92 & 0 & 92 \\
\hline Aguirre, Manuel & 122 & 0 & 122 \\
\hline Silva, Juan & 354 & 0 & 354 \\
\hline Joanicó, Francisco & 53 & 162 & 215 \\
\hline Olazabal, Benito & 0 & 200 & 200 \\
\hline Patron, Benito & 0 & 680 & 680 \\
\hline Salvañach, Cristóbal & 0 & 177 & 177 \\
\hline Vidal, Felipe & 682 & 0 & 682 \\
\hline Maciel, Francisco & 535 & 195 & 730 \\
\hline Belaustegui, Francisco & 551 & 0 & 551 \\
\hline Milá de la Roca, Josep & 13 & 1473 & 1486 \\
\hline
\end{tabular}

Fuente: elaboración propia a partir de (Studer,1958) AGN-A IX, 18-8-11; 2-9-1; 2-9-6; 10-4-7; 45-2-6. AGN-U, EGH, 28, 80, 40, 89, 95 AGI, Indiferente 2824, 2825, Buenos Aires 483.

La participación de Martín de Alzaga en el comercio de esclavizados es un ejemplo de la dificultad que esta actividad representó para los rioplatenses. Elena Studer (1958) trabajó sobre el esclavista Martín de Alzaga, quien en 1802 fletó un navío portugués hacia Mozambique. Este barco partió de África el 19 de noviembre de 1803 con 376 esclavizados de los cuales 60 llegaron a las costas rioplatenses, el resto pereció en alta mar. Por ello, quedó incomunicado el barco y no se le permitió el descenso de los integrantes de la nave viéndose obligado a partir del puerto. Finalmente, una tormenta destruyó en buena medida la nave y esta encalló en la Playa de la Aguada. 
A partir de allí, se generó un conflicto entre Alzaga y el Gobernador Ruiz Huidobro, el médico que intervino y el Virrey Sobremonte. Se sucedieron los petitorios, escritos, junta de sanidad, declaración de los tripulantes de la nave, entre otras cuestiones. Finalmente, se estableció que la muerte de los esclavos fue por la falta de agua y de apiñamiento en la bodega. Alzaga no siguió adelante con la acción por daños y prejuicios y no se le cubrieron las pérdidas ocasionadas. Alex Borucky plantea que posiblemente algunos esclavizados fueron descargados en Brasil sin el conocimiento de Alzaga ya que no tenía ningún representante.

Casos como el señalado fueron bastantes comunes, en particular como producto de la falta de conocimiento de aquellos que invirtieron ocasionalmente, ya que, en general, alquilaban un navío y contrataban a un capitán y marineros sin tener un representante que financiara la travesía. Además, como consecuencia de ser un viaje muy largo, era necesario saber el momento en el cual se debía realizar y la velocidad de llegada ya que la proliferación de enfermedades por el clima era una de las causas más importantes del incremento de la mortandad.

\section{7- La triangulación del comercio de esclavizados con el tasajo: el caso de Mila de la Roca.}

José Ramón Milá de la Roca fue un migrante catalán, quien nació en San Sebastián de Guipúzcoa en el año 1769, su padre era catalán y su madre vasca de origen noble ${ }^{66}$. Fue educado en Cataluña y, en 1790, producto de su orientación liberal y afrancesada, partió de la península (desde Barcelona) hacia el Río de la Plata, tras la derrota de José I, a la edad de 21 años, con un cargamento

\footnotetext{
${ }^{66}$ Itamar Olivares plantea que el linaje de Milá de la Roca se remonta a los tiempos de Carlomagno manteniendo un gran poder en Cataluña y Aragón.
} 
perteneciente a su casa paterna. Se asentó, así, en Montevideo y mantuvo vinculación con actores sociales franceses durante la república, sosteniendo una regular correspondencia con ellos y participando en diversas operaciones comerciales de estos en la América Hispana (Olivares, 1988: 10).

Como él mismo describió, las dos actividades económicas que desempeñó desde su llegada a Buenos Aires fueron: comisionista e inversor. Por lo tanto, se centró en:

el despacho de esas mismas expediciones y otras, que sucesivamente mi referido padre y otros pusieron a mi cuidado, me situé en el puerto de Montevideo por contemplarlo a propósito, así para la atención de los buques, que se me asignaban, como para dar curso a las ideas que había concebido, que al mismo tiempo que su asistencia me fuese benéfica, lo fuera también a esta provincia y sus habitantes. ${ }^{67}$

Desde su llegada a la región Río de la Plata en 1790, José Ramón Milá de la Roca, comenzó enviando cueros a los puertos de Barcelona y Cádiz, probablemente como intercambio de mercancías comisionadas por él. Solo dos años después de su arribo, en 1792, dio impulso al envío de tasajo y cebo a La Habana que había comenzado paulatinamente.

Además, Milá de la Roca fue uno de los más activos en el comercio del tasajo. En cinco años, desde 1792 a 1796, este catalán envió veintitrés cargamentos con un total de 114.026 qq. El primer año solo envió un barco, dos al año siguiente, seis en 1794, cinco en 1795 y ocho el último año que envió tasajo a La Habana. Milá de la Roca se expresó en relación a la producción y planteó:

En los años de 1795 y 1796 ver establecidos once saladeros a expensas mías, que solo trabajaban para las expediciones que yo dirigía para el puerto de la Habana, donde a fuerza de mi cuidado y de mi anhelo por la perfección del indicado fruto, consiguieron los tasajos de esta provincia la preferencia sobre quantos le remitían de otras partes del continente septentrional; llevando a tal puerto su

${ }^{67}$ AGN. Comerciales, Legajo 27, Expediente 3 
perfección en la fábrica, y en su modo de conducirlo, que la considerable pérdida en las mermas del 30 y mas por ciento, que en los principios sufría solo llegó a un $6 \%$ consiguiendo los hacendados fabricantes también la extraordinaria ventaja de hacer rendir 150 libras de tasajo en lugar de 100 libras que les redituable. ${ }^{68}$

En el gráfico siguiente se puede observar el crecimiento del tasajo a lo largo de los años. El mismo pasó de menos de 10.000 qq a casi 45000 qq en 1796. De un total de 22 salidas de barcos en este período, solo uno partió en 1792 y ocho en 1796, lo que da muestras del crecimiento de la circulación y aumento de las ganancias. Milá de la Roca afirmó que fueron “los mejores años” en el comercio ya que le permitieron construir con las ganancias varios saladeros y comprar varios barcos, llegando a tener, en los últimos años de este período, seis barcos: Reina de los Ángeles, Nuestra Señora de los Ángeles, Número siete, Número ocho, Astigarraga y Elisa.

\section{Gráfico V. 11}

Exportación de tasajo a Cuba realizada por J. R. Milá de la Roca (1792 a 1796)

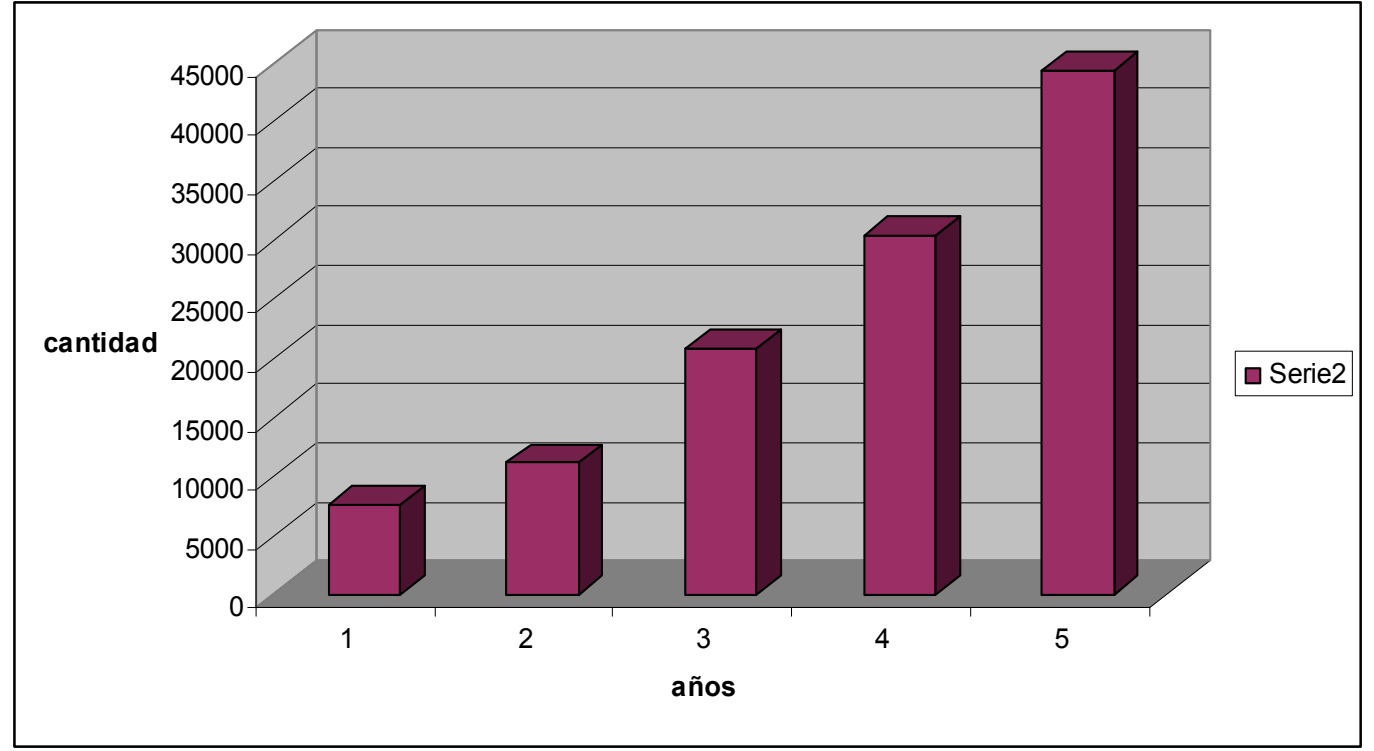

Fuente: elaboración propia a partir de AGN Comerciales Legajo 27 Expediente 3.

${ }^{68}$ AGN. Comerciales, Legajo 27, Expediente 3 
En 1796 se intensificó la guerra con Gran Bretaña, lo que provocó cambios en la circulación comercial ya que, como planteó Silva, tanto la acción de la armada inglesa como los corsarios, incidieron duramente sobre el comercio de Ultramar. Cercaron los puertos y efectivizaron un fuerte control en las más importantes rutas (Silva, 1994). Esto influyó, por lo tanto, el comercio rioplatense con la Isla de Cuba.

Así, a partir de 1797, Milá de la Roca, comenzó a dedicarse a dos nuevos emprendimientos: en primer lugar, buscar nuevos mercados para el tasajo y, en segundo lugar, insertarse en el comercio de esclavos. En los tres años siguientes, intermitentemente, comercializó tasajo, cebo y otros productos hacia mercados que no había contactado con anterioridad, como Bahía de Todos los Santos, Chile y Lima.

A su vez, comenzó a incursionar en el comercio de esclavos y ya en 1795 obtuvo su primera compra a partir, como describió Alex Borucki, de que la fragata de su propiedad:

Reina Luisa partió de Montevideo rumbo a La Habana con carnes saladas. Al llegar a la altura de Río de Janeiro entró a puerto para hacer reparaciones. Allí, su capitán fletó un bergantín para que la carga continuara a Cuba. Una vez realizadas las reparaciones, la fragata salió de Río de Janeiro hacia Montevideo. A los cinco días de navegación, la Reina Luisa encontró dos fragatas portuguesas que venían de Benguela, y en alta mar compró 359 Áfricanos con los que llegó a Montevideo en enero de 1796. (2009: 6).

Esta primera experiencia, a partir de los beneficios generados, dio pie a que Milá de la Roca comenzara a enviar sus barcos a las costas Áfricanas para comprar esclavizados a partir de la apertura económica que se produjo en los años precedentes, producto de la motivación que llevó a cabo la Corona en 1791 de liberar el ingreso de esclavos hacia el Virreinato del Río de la Plata teniendo como 
lugar de ingreso el puerto de Montevideo. Si bien, según este comerciante, no fue beneficioso este comercio por la pérdida de barcos en diversas circunstancias, en 1797 envió tres expediciones, en 1798 dos y en 1799 nuevamente tres expediciones (con un incremento de la cantidad de esclavizados respecto de la primera expedición) como podemos observar en el gráfico siguiente.

\section{Gráfico V. 12}

Comercio de esclavizados introducidos por Milá de la Roca (1797 a 1799).

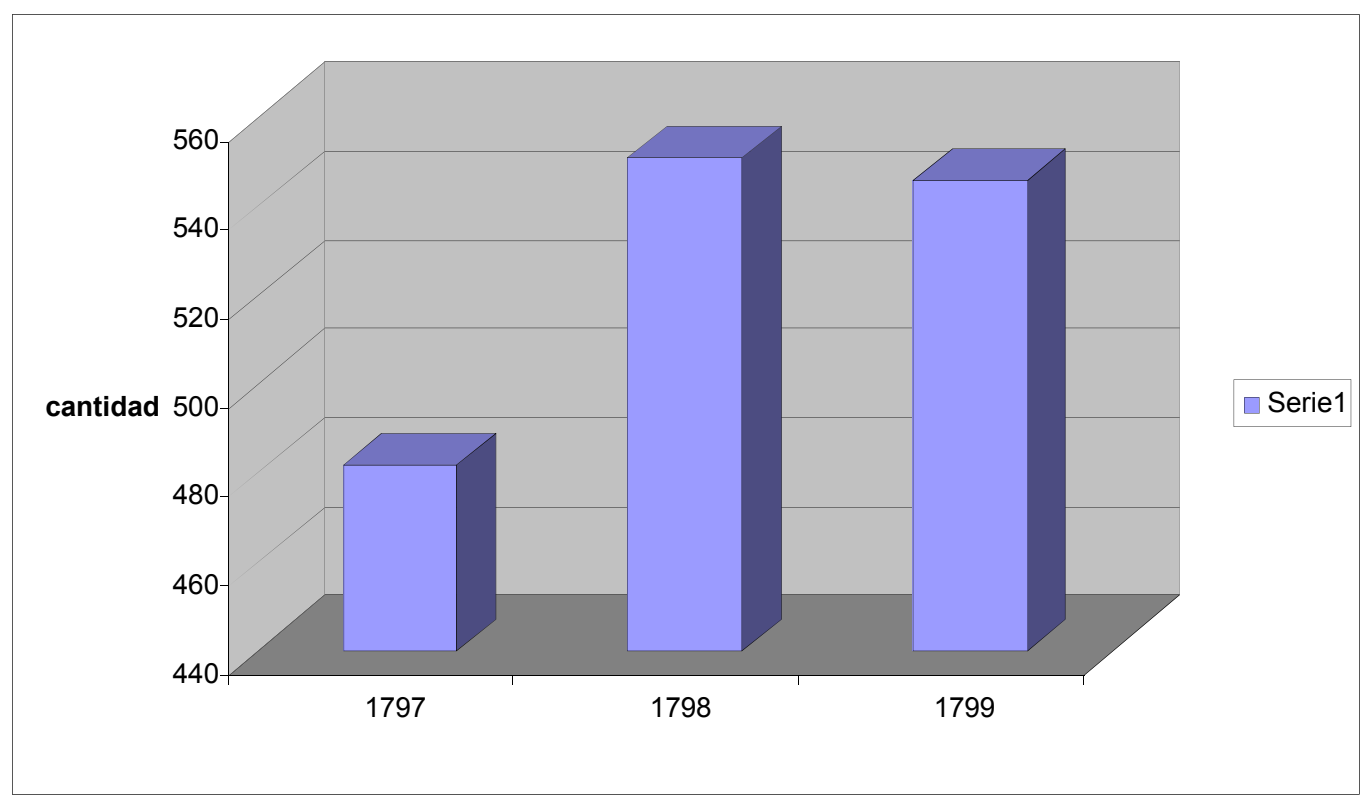

Fuente: AGN Comerciales Legajo 27 Expediente 3.

El comercio de esclavizados fue, para este actor social, una alternativa que reemplazó durante un breve período el comercio de tasajo como eje central, permitiéndole continuar con el funcionamiento de sus barcos, alternando nuevos destinos (fundamentalmente colonias extranjeras) y mercancías (jabón, cacao, cascarilla, entre otras). Sin embargo, a partir de diversos inconvenientes acontecidos con sus embarcaciones como consecuencia de la guerra, tuvo que optar por contratar navíos de bandera neutra que fletaban sus productos, dejando 
aparcado su ímpetu naviero en el período posterior que coincidió con el nacer del nuevo siglo.

Durante los primeros años del nuevo siglo, continuó entonces con la producción de tasajo y cebo. En 1805 presentó la instancia en donde expresa que:

Para seguir el fomento del tasajo y sebos, y con particularidad las carnes y tocinos en barril y harinas no solo con destino al tráfico en general, sino también para proveer la Real Armada; al efecto tengo meditado la compra del terreno más aparente que pueda pensarse en toda esta provincia, que es la Estancia de Haedo, colocada en la península que forman los ríos Uruguay y Negro, cuyos herederos tratan de vender y me han ofrecido la preferencia; pero como mis fondos ya no pueden soportar unas tan crecidas anticipaciones según son necesarias, es indispensable ocurrir al Rey N. Señor a fin de conseguir sus auxilios, que al mismo tiempo los necesito, así para proveerme de sujetos aparentes para mis empresas, como para traher las maquinas e instrumentos necesarios a ellas, y también introducir los negros bozales dirigiendo mis expediciones directamente a la África, evitando en quanto sea posible que el extranjero lleve nuestras riquezas. $^{69}$

$\mathrm{Su}$ objetivo era, durante ese período, el de comprar tierras y no el de continuar con la producción de los saladeros ya que durante ese mismo año estos fueron vendidos a Francisco Antonio Maciel y solo un par de años después, en 1807, le serán entregadas por medio de la mediación “del Corregidor y Cabildo de Yapeyú las tierras comprendidas entre el Guaviyú, el Uruguay, el arroyo San José y las tres puntas al este siguiendo en línea recta hasta las puntas de Sarandí" (Sala de Touron, De la Torre y Rodríguez, 1967: 56).

Desde su llegada a la región Río de la Plata mantuvo una actividad política muy activa: epistolario con representantes de la República Francesa, participación en las Invasiones Inglesas, diputado en Bayona y benefactor durante los primeros años de la Revolución de Mayo. Durante los siguientes años, mantuvo correspondencia epistolar con varios de los máximos dirigentes franceses con el

${ }^{69}$ AGN. Comerciales, Legajo 27, Expediente 3 
objetivo de conectar comercialmente con las posesiones francesas en América y enviar mercancías a Francia.

Con respecto a la vinculación de Milá de la Roca con Francia, Itamar Olivares (1988) realizó un análisis puntilloso de este proceso. Su vinculación se produjo a partir de que la población de las islas del Índico de posesión francesa, entró en una hambruna durante 1792. A raíz de esto, los representantes institucionales de las mismas, gobernador M. de Malartic e Intendente Dupuy, decidieron comprar un gran cargamento de trigo en el Río de la Plata. A finales de ese año enviaron un navío que, tras dos meses de travesía, llegó al complejo portuario rioplatense. Sin embargo, a raíz de las problemáticas existentes en las relaciones diplomáticas entre España y Francia (que desembocaron en la declaración de guerra a mediados de ese mismo año), la fragata y sus mercancías fueron confiscadas por orden del virrey español. La fragata y sus mercancías fueron confiscados por orden del virrey. Tras la detención de su tripulación, Milá de la Roca se ofició de intermediario con gran éxito, ya que se les permitió zarpar, llevando el trigo comprado.

Durante las invasiones inglesas (1806-1807) Milá de Roca se distinguió por su participación en la defensa y reconquista de Buenos Aires. Tras la derrota de los ingleses, fue enviado a la península ibérica para desarrollar un plan de defensa regional. Luego de la invasión de Napoleón en la península ibérica, formó parte como miembro de la Asamblea de Bayona. Planteó, junto a Nicolás Herrera, entre otras cuestiones, la abolición del diezmo y la igualdad de derechos entre las regiones de la Península y de América ${ }^{70}$.

\footnotetext{
70 "Memoria presentada en Bayona por José R. Mila de la Roca y Nicolás Herrera sobre el Virreinato del Río de la Plata para lograr su progreso" (Bayona, 28 de junio de 1808), en Mayo Documental, Bs. As. 1962, Tomo II, pp. 19-21
} 
Durante el inicio del proceso revolucionario, se mantuvo activo en forma constante a favor del Cabildo de Buenos Aires. Mantuvo esta actividad política a favor de los revolucionarios, no solo a partir de donaciones sino con la participación de su único familiar directo, que se llamó Josep Milá de la Roca, quien fue secretario de Manuel Belgrano en la campaña de Paraguay, amigo personal de José de San Martín (fue el intermediario en el epistolario entre estos dos revolucionarios) y uno de los que firmó el testamento de Belgrano. Las causas de que este actor social, recientemente llegado al Río de la Plata y con una participación activa dentro de la estructura institucional, se mantuviese a favor de un proceso secesionista se explican entonces a partir de su actividad económica y de su posicionamiento ideológico.

\section{Consideraciones finales}

En este capítulo se analizó el comercio ultramarino de esclavizados de las últimas décadas del siglo XVIII. En primer lugar, se abordó la dinámica del comercio de esclavizados en América en su generalidad, los lugares de origen y las reformas institucionales de la Monarquía española. En segundo lugar, se establecieron las cifras de navíos y esclavizados que ingresaron, los circuitos, las banderas y el impacto de este comercio en la totalidad del complejo portuario. Por último, se desarrolló la participación de los actores regionales en las últimas décadas tomando un caso particular: Josep Ramón Milá de la Roca.

Sobre la vinculación del complejo portuario con Brasil, se puede afirmar que, pese a las prohibiciones y conflictos armados que se sucedieron, este tuvo continuidad durante las últimas décadas del siglo XVIII. La afluencia de navíos de este espacio fue constante a lo largo de los años ya que, si bien la carga por navíos 
era menor, la sumatoria anual de esclavizados era mayor a los llegados desde África y, a su vez, si bien, su precio era mayor, gozaba de menor riesgo su traslado.

La dinámica de la ruta Áfricana, en cambio, era diametralmente opuesta: los impuestos que se pagaban y el coste de los esclavizados era menor, pero el riesgo aumentaba notablemente. Aquellos que lograban pasar esa travesía exitosamente eran quienes tenían navíos en su propiedad y contaban con los conocimientos necesarios. El análisis del caso del barco enviado por Alzaga da cuenta de las complicaciones que se generaban si no se contaba con esos requisitos.

Por otro lado, durante gran parte del siglo XVIII, este comercio estuvo en manos de actores de otras regiones, ya sea por medio de los Asientos, como del comercio directo con Brasil. Esto permitía a los actores regionales el control de la distribución de los esclavizados en el territorio, el mercado tierra adentro, sin tener la capacidad de intervenir más allá de los límites del Río de la Plata.

$\mathrm{S}$ in embargo, durante las dos últimas décadas del siglo, se produjeron cambios que permitieron que los actores locales pudieran intervenir fuertemente en el comercio ultramarino de esclavizados: el crecimiento del comercio ultramarino de cueros, la llegada de migrantes, reformas institucionales y coyunturas internacionales.

Los actores regionales tuvieron la capacidad económica de invertir, la posibilidad de comprar embarcaciones para la travesía, un marco legal que avalaba el contacto en tierras Áfricanas y las redes internas para su posterior venta. Esto llevó a que muchos de los actores comerciales más importantes 
desarrollaran estrategias vinculadas a este comercio, como así también que otros con menos fortuna y en forma esporádica también participaran del mismo.

La existencia de este comercio y la participación de actores regionales en el mismo, como así también el alto número de navíos matriculados y la articulación con el comercio del tasajo hacia Cuba, dan cuenta de la diversificación económica que se desarrolló en este período por parte de los mismos. Este proceso, sumado a lo analizado en los capítulos anteriores en torno al notable incremento del comercio ultramarino de cueros, la región orientada al comercio atlántico, el estancamiento económico de los actores que hicieron solamente de comisionistas de casas comerciales de Cádiz y la dinámica comercial global permite un retrato del proceso analizado y que, a continuación, en las conclusiones se dará un cierre parcial. 


\section{CONCLUSIONES}

A lo largo de esta tesis demostramos que los cambios económicos en la región Río de la Plata se produjeron a partir de mediados del siglo XVIII, debido a una serie de transformaciones articuladas que pusieron en relieve la necesidad de atender a diversas escalas analíticas. Ello es porque percibimos clivajes dentro de la propia región, en el comercio interno y externo de la Monarquía española y en la dinámica comercial ultramarina del complejo portuario.

Confirmamos que en este proceso se conjugaron el crecimiento de la producción y comercialización de los cueros, el incremento de la población regional, el aumento del mercado inmobiliario y naviero, la acentuación de los intercambios de mercancías provenientes de la península española por metales preciosos y el ingreso de esclavizados.

Todo ello favoreció que un grupo de actores comerciales, cuya renta principal era extraída de la comercialización ultramarina de cueros lograran una preeminencia económica regional. Hemos podido dar cuenta gracias al cruce de diversos registros documentales de un complejo mecanismo: intercambiaban las mercancías que les enviaban desde la península en el interior americano por metales preciosos y cueros, enviando como pago de las mercancías hacia la península fundamentalmente cueros, y lograban así acumular mediante este mecanismo los metales preciosos. Esto le representó una mayor ganancia, y en metálico, con lo que pudieron desarrollar inversiones inmobiliarias, en navíos, tierras o en expediciones hacia África por esclavizados. 
Para confirmar esta hipótesis analizamos las características de la región, del comercio ultramarino en general, de la salida de metales preciosos y cueros y del ingreso de esclavizados durante las últimas décadas del siglo XVIII. Para llevarlo a cabo se analizaron unos 30.000 registros fiscales. Este ejercicio fue sumamente fructífero ya que nos permitió establecer las cifras del comercio, los circuitos y los actores que intervinieron, aspectos que eran poco conocidos y que dan cuenta de un panorama más complejos de la economía regional.

Con el fin de definir la región Río de la Plata tomamos la conceptualización de Fernando Jumar en tanto espacio económico homogéneo. Este concepto, fue un vector fecundo para abordar los flujos mercantiles sin las restricciones de los límites políticos y destacar el hecho de que la circulación interna fue mayor que los intercambios con otros espacios. Además, la potencialidad de pensar en su particularidad de ser homogéneo, implicó que la región como un todo se pueda transformar en un polo de atracción de un espacio mayor.

Dividimos su análisis en dos sub. zonas, la sur y norte. Verificamos que durante la segunda mitad del siglo XVIII se incrementó la producción y comercialización de cueros, esto se produjo por la demanda externa y, también, por la oferta, en particular por los cambios en los mecanismos de producción. Esto, sumado a una serie de transformaciones internas como la expulsión de los jesuitas, generó una reconfiguración espacial. Esta región se articuló en torno a dos espacios, con algunas particularidades y complementariedades. Comprobamos así que los límites de la región planteados por Fernando Jumar son similares a lo que establecimos a partir de las zonas de donde provinieron los cueros que llegaban a Buenos Aires y Montevideo. 
La región Río de la Plata contaba en su territorio con un complejo portuario rioplatense que era la puerta de entrada de intercambios a nivel regional y de la zona sur del territorio americano con otros ultramarinos. Para su análisis se partió de dividir el comercio ultramarino en dos grupos: el desarrollado con otras unidades políticas, el externo, y otro con los territorios que compusieron la Monarquía española, el interno.

El comercio exterior de la Monarquía española se desarrolló a partir de dos grandes puertas: Manila con el comercio con China y la península española con el resto de Europa. Además, se vinculaban distintos espacios con potencias extranjeras a partir de Asientos comerciales particulares.

El comercio interno durante las primeras décadas del siglo XVIII estuvo centrado fundamentalmente en la articulación de algunos puertos americanos y uno en la península: el circuito Cádiz- Portovelo- Veracruz- La Habana. El Río de la Plata lograba conectarse el resto de las regiones a partir de algunos registros de navíos o compañías comerciales que obtuvieron permisos especiales por algunas décadas. La finalidad de este sistema era el producir un gran control sobre la salida y entrada de mercancías y actores. La dificultad de conectar comercialmente a algunas regiones que, en principio, no tendrían gran importancia económica, se solventaba con el comercio directo el cual era permitido de hecho por las autoridades de la monarquía.

Propusimos entonces que este modelo era el que predominó y que el mismo moduló temporalidades. Las transformaciones económicas externas e internas fueron en buena medida las que forzaron a los cambios que se desarrollaron en la segunda mitad de siglo. 
Por un lado, tenemos el proceso de industrialización que provocó la búsqueda de nuevas mercancías como insumos (palo Brasil, cueros, etc.) y otras para su consumo (te, café, azúcar, etc). Por otro lado, la invasión de Inglaterra a la Isla de Cuba forzó a establecer cambios defensivos en los territorios. Esto permitió el desarrollo de varias regiones hispanoamericanas tanto en lo económico como en lo demográfico.

Las regiones productoras de materias primas, se volcaron al comercio ultramarino y tuvieron un proceso de aceleración económico que sedujo la llegada de migrantes. Los cuales aumentaron la densidad población regional e insertaron a estas regiones en un círculo virtuoso: a mayor demanda externa, más producción, más migración y más población. El hecho de tener una mayor población permitió una mejor defensa regional ya que los sujetos que estuvieron a cargo de la defensa conformaron milicias.

El ingreso al comercio ultramarino de nuevos actores y la mayor vinculación entre las distintas regiones fueron elementos centrales en este proceso. Los pequeños y medianos, y no tan medianos, productores industriales que no podían comercializar en Cádiz por lo costoso de mantener una casa comercial allí, sumado a los productores hispanoamericanos que tenían la capacidad de producir más, fueron los artífices y beneficiados de las reformas comerciales que se desarrollaron. Esto se debe a que lograron insertarse en un circuito que hasta ese momento les había sido vedado y con la oposición de quienes hasta ese momento concentraban este comercio. Este es el motivo por el cual se produjo la apertura a otros puertos que ocuparon una porción muy grande del comercio de América con la península. 
Este proceso se expresó en el complejo portuario rioplatense, en donde se generó un crecimiento de la llegada de navíos a partir de la década de 1760. Este incremento estuvo marcado por la pluralidad de puertos de destino ya que se pasó de la centralidad previa de Cádiz, a una atomización de los destinos.

En suma, a partir de una serie de transformaciones en la economía global (la necesidad de mercancías como insumos para el proceso de industrialización), en el régimen monárquico (la expulsión de los Jesuitas, la creación de milicias, la fundación de Villas y Poblados, entre otros) y en lo regional, se dio una reconfiguración espacial en donde la región Río de la Plata se reorientó hacia el mercado ultramarino. La mercancía que acusó de eslabón imprescindible fue el cuero vacuno, el cual permitió el desarrollo económico de la región. A partir de ello, se produjo entonces un círculo virtuoso de crecimiento comercial y demográfico constante.

El crecimiento del comercio ultramarino durante la segunda mitad del siglo XVIII se expresó en la salida de los cueros, los metales preciosos y el ingreso de esclavizados. Llegaban mercancías de la península española que se distribuían en todo el territorio sur americano (con un crecimiento muy importante del consumo de la región Río de la Plata) por los cuales llegaban al complejo portuario rioplatense grandes cantidades de metales preciosos. El envío de cueros por las mercancías produjo una mayor acumulación de metales preciosos, los cuales fueron destinados, por los comerciantes a la compra de navíos, casas, tierras y esto permitió que los rioplatenses envíen navíos a África en busca de esclavizados.

El proceso señalado se produjo por el ingreso de mercancías provenientes de distintas regiones de la península española y de comerciantes vinculados a esas 
regiones. La salida de cueros y metales preciosos durante las últimas décadas del XVIII estuvo marcada por ser recibidas en el resto de puertos de la península, siendo esto la principal transformación comercial de este período.

Los actores que intervinieron en el comercio estuvieron lejos de ser monopolizados por un grupo en particular que no permitía el envío de cueros o metales preciosos al resto de la población. Hemos podido advertir un registro social mucho más amplio del circuito comercial, que complejiza el conocimiento sobre la dinámica de la región.

Gran parte de la población con posibilidades de realizar envíos (sujetos hombres -aunque algunas mujeres también participaron- provenientes de la península y adultos) los efectuaron. Un gran número de actores que participaron como cargadores lo realizaron en forma circunstancial producto, posiblemente, como retribución por las mercancías que trajeron cuando llegaron o por una oportunidad puntual de comerciar.

Otro grupo de actores que intervinieron, eran pequeños y medianos comerciantes que participaron en forma regular pero con envíos pequeños. Este sector fue muy beneficiado por la posibilidad de conectar en forma directa con distintas regiones y que no era necesario que envíen grandes cantidades.

Por último se encuentran los grandes comerciantes, los cuales en la tesis dividimos en tres grandes grupos: los cargadores de metales, de cueros y los mixtos. Los grandes comerciantes conformaban un grupo de unos cien actores que participaban masivamente en el comercio interno y externo, su participación estuvo determinada por las redes externas que le enviaban mercancías para introducir internamente. 
Los comerciantes que enviaban solamente metales preciosos como intercambio por mercancías proveniente de la península española tenían, en su mayoría, vinculación con grandes comerciantes de Cádiz. Su beneficio radicaba en que quienes podían ingresar mercancías eran pocos actores, por ello, tenían un control muy importante del comercio legal hasta mediados del siglo y se fue reduciendo gradualmente su importancia con el correr de las décadas. Además, los envíos que realizaban eran a cuenta y riesgo de los comerciantes gaditanos, basando por lo tanto la ganancia en las comisiones. Las inversiones que realizaban con su ganancia eran en inmuebles urbanos y accesorios de lujo. Si bien, lograban manejar grandes volúmenes de metales preciosos su enriquecimiento fue menor a los dos otros grupos de grandes comerciantes.

El segundo grupo de grandes comerciantes eran aquellos que solo enviaron cueros al comercio ultramarino. Estos actores eran, en su mayoría, de reciente migración procedentes de Galicia, Cataluña y el País Vasco, zonas en donde la demanda de cueros rioplatenses aumentó notablemente en este período. Una vez llegados, estos actores se vincularon con los productores pecuarios y lograron una dinámica comercial muy activa a partir de tener tiendas en Buenos Aires y/o Montevideo, además de enviar mercancías al interior. Obtenían gran rentabilidad de su actividad y en muchos de los casos invertían sus ganancias en el resto de eslabones de la cadena productiva o comercial del cuero, compraban tierras y/o navíos con lo que lograban consolidad su actividad.

El último grupo de comerciantes eran aquellos que participaban tanto en el envío de metales preciosos como de cueros. Estos actores eran los que mayores redes establecidas tenían, logrando un incremento mayor de su patrimonio. No solo se dedicaban al comercio, posiblemente esta no era su actividad más 
importante, sino que eran hacendados, logrando con ello incrementar sus ganancias notablemente. Además, invertían en navíos y propiedades urbanas, prestaban dinero, entre otras. Posiblemente hayan sido el sector más dinámico de la economía regional y en los conflictos políticos eran quienes inclinaban la balanza hacia uno de los dos lados.

Durante la segunda mitad del siglo XVIII, también, se desarrollaron diversas pujas institucionales para modificar las regulaciones comerciales que cristalizaron el lugar que ocuparon los distintos grupos de comerciantes. Como caso testigo de dichas pujas, examinamos con detalle un conflicto con Lima producto del proceso de expansión comercial que se comenzaba a desarrollar. En particular se produjo por la disputa de introducir mercancías legalmente internamente hacia Chile y el norte. En este conflicto, los rioplatenses resultaron victoriosos. En este conflicto, se unieron los comerciantes vinculados a Cádiz y los hacendados, representados por el Cabildo, ya que compartían los beneficios que se producirían de poder expandir el comercio legal a esos lugares.

A partir de allí, se puede apreciar, que se fueron distanciando cada vez más los intereses de los comerciantes monopolistas y los empresarios ganaderos y comerciantes vinculados a ellos. La llegada de las fragatas correo, el reglamento de libre comercio, el ingreso de navíos neutrales, la salida de cueros a potencias extranjeras, la salida de cueros para el comercio de esclavizados, entre otros dieron cuenta de la disociación de los intereses de estos dos grupos. La dinámica económica y las resoluciones institucionales favorecieron al grupo de actores vinculados al comercio de cueros en detrimento de aquellos que enviaban metales preciosos hacia Cádiz. 
En el año 1794 se creó el Consulado de Comercio de Buenos Aires, el cual contenía a los tres grupos de comerciantes que se describió. En el año 1797 se permitió el ingreso de los empresarios ganaderos a dicho Consulado. Esto da cuenta de la importancia que lograron obtener este grupo de actores que tenían intereses en común y que regionalmente no tenían oposición. Si bien, no contamos con suficiente evidencia para afirmarlo, los indicios que pudimos reconstruir permiten pensar que para las últimas décadas del siglo XVIII se consolidó un grupo conformado por empresarios ganaderos y comerciantes que tuvieron una hegemonía económica y política durante las siguientes décadas.

En suma, fueron determinantes para las transformaciones las causas externas a la región Río de la Plata: transformaciones en la dinámica económica global, incremento de los conflictos con Inglaterra de mediados de siglo, reformas institucionales de la Monarquía con el fin de conservar los territorios y la integración comercial de otras regiones peninsulares y el Río de la Plata; internas, el incremento de la atlantización de la región Río de la Plata y la expansión comercial legal hacia el interior.

Estos cambios dieron como resultado un círculo virtuoso en donde a mayor comercio, más población y nuevamente más comercio. Dado que la rentabilidad del cuero era muy alta, los actores que intervinieron lograron acumular metales preciosos que invirtieron en el mercado inmobiliario, en navíos y en expandir el comercio hacia África, por esclavizados, y Cuba, por el tasajo. Este grupo de actores no solo fue favorecido en lo económico por su actividad, sino que las transformaciones institucionales que se fueron produciendo los favoreció notablemente y las trabas que intentaron imponer otros sectores comerciales no dieron resultado. 
Por último, pensamos que la situación examinada fue proyectiva al período posterior. La década siguiente al período estudiado estuvo marcado por conflictos militares muy importantes, las invasiones inglesas, la invasión de Francia a la península y el apresamiento del Rey y el inicio del proceso de Mayo. La consolidación de este grupo de actores, la centralidad del complejo portuario rioplatense como puerta de entrada del comercio y el crecimiento de la economía de la región Río de la Plata estuvieron dentro de las causas de algunos de los conflictos señalados.

A saber, que se produjesen dos invasiones inglesas, y su posterior expulsión, en el Río de la Plata estuvo marcado por lo floreciente y neurálgico del complejo portuario rioplatense en los territorios del sur de América. Además el proceso revolucionario de mayo estuvo marcado por la participación de los actores que se consideró más importante a nivel regional dos décadas atrás.

Por último, la invasión de Francia y el inicio de los conflictos armados en América que produjeron la independencia de gran parte de los territorios americanos estuvieron marcados por la dinámica económica y política de los dos siglos anteriores. Las causas que produjeron la edad de oro de España contuvieron su decadencia.

Claro que lo desarrollado en esta tesis nos invitó a pensar en muchas problemáticas para continuar con la investigación. Los resultados obtenidos resultaron centrales para ampliar el conocimiento sobre la economía de la región Río de la Plata y en tanto plataforma analítica para profundizar en la dinámica y redes de los actores más importantes.

Una primera es establecer la dinámica comercial interna, tanto en la región Río de la Plata como los circuitos comerciales que se conformaron en el interior. 
En este sentido, bajo la dirección de Fernando Jumar nos encontramos trabajando con la salida de mercancías desde Buenos Aires hacia el interior a partir de la información que nos ofrece las notas de aduana y la utilización de una base de datos, CADO, que permite una sistematización de toda la información que contiene.

En segundo lugar, hemos establecido los actores económicos más importantes, y resultará fructífero avanzar en sus redes comerciales, personales y políticas a lo largo del tiempo, con el objetivo de aportar a la reflexión sobre el carácter hegemónico en lo económico y político de este grupo de actores.

Por último, el establecer la dinámica comercial ultramarino de los distintos puertos de la Monarquía española permitiría dar cuenta de la importancia de las dinámicas internas en las transformaciones institucionales comerciales. En este sentido, las reformas en el complejo portuario acompañaron los cambios económicos regionales y por lo tanto se podría establecer que la tendencia política regional dio cuenta de ello, pero para que se produzcan transformaciones como, por ejemplo, el Reglamente de Libre Comercio, la persuasión de las regiones para que esto se produzca tuvo que ser muy importante e implicó a gran parte de las mismas. Por ese motivo para poder determinar que, las transformaciones económicas antecedieron a las institucionales es necesario un estudio de todas las regiones que conformaban la Monarquía española.

Retornando a los resultados de la tesis, los aportes que se desarrollaron estuvieron marcados por la sistematización de un número muy importante de documentos que permitió establecer las cifras, los circuitos y los actores que intervinieron. 


\section{FUENTES}

$\underline{\text { Inéditas }}$

Archivo General de la Nación Argentina

Sala IX

02-03-03; 02-03-04; 02-03-05; 02-03-06; 02-03-07; 02-04-01; 02-04-02; 02-0403; 02-04-04; 02-04-05; 02-04-06; 02-05-01; 02-05-02; 02-05-03; 02-05-04; 0205-05; 02-05-06; 02-06-01; 02-06-02; 02-06-03; 02-06-04; 02-06-05; 02-06-06; 02-06-07; 02-06-08; 02-07-01; 02-07-02; 02-07-03; 02-07-04; 02-07-05; 02-0706; 02-07-07; 02-08-01; 02-08-02; 02-08-03; 02-08-04; 02-08-05; 02-08-06; 0208-07; 02-08-08; 02-09-01; 02-09-02; 02-09-03; 02-09-04; 02-09-05; 02-09-06; 02-09-07; 02-09-08; 02-10-01; 02-10-02; 02-10-03; 02-10-04; 02-10-05; 02-1006; 02-10-07; 03-01-01; 03-01-02; 03-01-03; 03-01-04; 03-01-05; 03-01-06; 0301-07; 03-01-08; 03-02-01; 03-02-02; 03-02-03; 44-03-02; 44-03-03; 44-03-04; 44-03-05; 44-03-06; 44-03-07; 44-03-08; 44-03-09; 44-03-10; 43- 05- 11; 43- 0601; 43- 06- 02; 43- 06- 03; 43- 06- 04; 43- 06- 05; 43- 06- 06; 43- 06- 07; 43- 0608; 43- 06- 09; 43- 07- 01; 43- 07- 02; 43- 07-03; 43- 07- 04; 43- 07- 05; 43- 0706; 43- 07- 07; 43- 07-08; 43- 07-09; 43- 07- 10; 43- 07- 11; 43- 07- 12; 43-0801; 43- 08- 02; 43- 08- 03; 43- 08- 04; 43- 08- 05; 43- 08- 06; 43- 08- 07; 43- 0808; 43- 08- 09; 43- 08- 10; 43- 08- 11; 43- 08- 12; 43- 09- 01; 43- 09- 02; 43- 0903; 43-09- 04; 43-09- 05; 43- 09- 06; 43- 09- 07; 43- 09- 08; 43- 09- 09; 43- 09$10 ; 43-09-11 ; 25-4-33$

\section{Sala XIII}

$15-10-3 ; 37-6-4 ; 37-10-5 ; 37-10-6-; 38-8-3 ; 38-8-4 ; 38-1-1 ; 38-1-3 ; 38-2-3 ; 38-3-$ 4 ; 38-4-4; 38-5-3; 38-6-4; 38-1-3; 39-1-3; 39-2-1; 39-2-2; 39-3-1; 39-3-2; 39-3-3; $39-4-3$; 39-5-4; 39-6-2; 39-8-4; 39-9-3; 39-10-1; 39-10-4; 39-7-4; 15-10-3; 37-93 ; 37-9-4; 38-10-3; 38-6-3. 14-9-5; 14-10-1; 14-10-2; 14-10-3; 14-10-4; 15-10-1; $15-10-2 ; 15-10-3$.

\section{Sala IX}

Cartas comerciales y personales.

Sucesiones. 
Testamentos.

Protocolos Notariales.

Comerciales Legajo 27 Expediente 3.

Alcabala de Buenos Aires sala IX desde 9-3-9 a 13-7-8.

Alcabala de Montevideo Sala XIII desde 15-6-5 a 16-6-1.

Archivo General de la Nación. Montevideo

Registros de navíos

Cajas desde: 218 a 354

Padrones y censos.

Archivo Judicial del Archivo General de la Nación. Montevideo

Protocolos Notariales

Juzgado de Primera instancia

Hacienda.

Archivo del Museo Histórico Nacional. Montevideo

Arxiu d'Catalunya (en la localidad de Sant Cugat del Vallès.)

Fondo de los corredores comerciales de Barcelona.

Arxiu de la Ciutat d'Barcelona

Registros comerciales

Diarios de Bitácora

Diario de la Ciudad de Barcelona

Archivo General de Indias

Buenos Aires 484. 


\section{$\underline{\text { Editas }}$}

Acuerdos del extinguido Cabildo de Buenos Aires. Buenos Aires, 1925-1934. Tomos IX, X y XI.

Acuerdos del extinguido Cabildo de Montevideo. Montevideo. 1941. tomos XII, XIII, XIV y XV.

Almanak Mercantil o Guía de Comerciantes. Madrid. Imprenta de Vega y Compañía. Años: 1795, 1796, 1797, 1798, 1799, 1800, 1801, 1802, 1803, 1804 y 1805.

Apolant, Juan A. Génesis de la familia uruguaya. Los habitantes de Montevideo en sus primeros 40 años. Filiaciones. Ascendencias. Entronques. Descendencias. Montevideo. Instituto Histórico y Geográfico del Uruguay. 1966.

Aguirre, Juan F. Diario histórico. Buenos Aires. Biblioteca Nacional de Buenos Aires. MS. No 9. 1973.

Bandos de Buen Gobierno del Río de la Plata, Tucumán y Cuyo (época hispánica). Edición y Estudio de Tau Anzoategui, Vicotr. Buenos Aires. Dunken. 2004.

Censo de la Riqueza Territorial e Industrial de España en el año de 1799.Madrid. Imprenta Real. 1803.

Corcolocorvo. El lazarillo de ciegos caminantes (1773). Buenos Aires. Ed. Espasa-Calpe. 1946.

Documentos y planos relativos al periodo edilicio colonial de la ciudad de Buenos Aires. Buenos Aires. Talleres Casa Jacobo Peuser. 1910.

Documentos para la Historia Argentina; tomo V, Comercio de Indias, Antecedentes Legales (1713-1778); tomo VI, Comercio de Indias, Comercio Libre (1778-1791); Facultad de Filosofia y Letras, Universidad de Buenos Aires, Buenos Aires, 1915-1916.

Haenke, Tadeo. Viaje por el Virreinato del Río de la Plata. Buenos Aires. Emecé editores. 1943.

Malaspina, A. "Viaje al Río de la Plata en el siglo XVIII". Reedición de los documentos relativos al viaje de las corbetas Descubierta y Atrevida e informes de sus oficiales sobre el virreinato. Buenos Aires, 1938.

Millau, Francisco. Descripción de la Provincia del Rio de la Plata (1774). Argentina. Espasa- Calpe.1947. 
Muhn, Juan S. J. La Argentina vista por viajeros del siglo XVIII. Buenos Aires. Ed. Huarpes S. A. 1946.

Parras, Fray Pedro José Diario y derrotero de sus viajes 1749/1753. Buenos Aires. Ed. Solar.

Ravignani, Emilio. Documentos para la historia Argentina. UBA: Facultad de Filosofía y Letras. Buenos Aires. 1939. tomo X y XI.

Reglamento y Aranceles Reales para el Comercio Libre de España e Indias del 12 de Octubre de 1778. Madrid. Imprenta de Pedro Marin. 1778.

Sanchez de Thompson, Mariquita Recuerdos del Buenos Aires Virreinal. Buenos Aires. ENRE. 1953.

Memoria presentada en Bayona por José R. Mila de la Roca y Nicolás Herrera sobre el Virreinato del Río de la Plata para lograr su progreso" (Bayona, 28 de junio de 1808), en Mayo Documental, Bs. As. 1962, Tomo II. 


\section{Bibliografía}

AA. VV. (2004) "Para seguir con el debate en torno al colonialismo ... », Nuevo Mundo Mundos Nuevos [En ligne], Débats, mis en ligne le 08 février 2005, consulté le 05 avril 2015. URL: http://nuevomundo.revues.org/430; DOI : 10.4000 /nuevomundo.430

AA. VV. (2012). La Ruta del Esclavo en el Río de la Plata: su historia y sus consecuencias. Montevideo: UNESCO.

Acemoglu, Daron, Simon Johnson y James Robinson (2005) "The Rise of Europe: Atlantic Trade, Institutional Change and Economic Growth." En The American Economic Review, 95: 03. June.

Acemoglu, Daron, Simon Johnson \& James Robinson (2001). "The Colonial Origins of Comparative Development: An Empirical Investigation". The American Economic Review, December. 95:05.

Acevedo Tarazona (2005). "La historia regional: Un campo abierto de problemas". Revista de Ciencias Humanas. UTP No 35 Enero- junio.

Aguirrezabala, Marcela (2001)"El comportamiento económico de las mujeres en el área portuaria rioplatense de fines del siglo XVIII y principios del XIX a través del concepto de género como categoría analítica", ponencia presentada en las Jornadas empresarios y empresas en la historia argentina, la Universidad Argentina de la Empresa (UADE), 20 al 21 de noviembre.

Aguirrezabala, Marcela (2003) "Las viudas de dos grandes empresarios del siglo XVIII" En: Asociación Uruguaya de Historia Económica (AUDHE) Terceras Jornadas de Historia Económica Montevideo, 9 al 11 de julio.

Aguirrezabala, Marcela (2011) "La dinámica mercantil de las mujeres rioplatenses frente al resquebrajamiento del Antiguo Régimen (1806-1810)”. En Anuario del Instituto de Historia Argentina, N 11.

Agulhom, Maurice (1994). Política, imágenes y símbolos en la Francia posrevolucionaria, Historia. Vagabunda. México: Instituto Mora.

Agulhom, Maurice (2009) El círculo burgués. La sociabilidad en Francia, 18101848. Siglo XXI. $1^{\circ}$ edición en español.

Acha, Omar y Nicolás Quiroga (2012). El hecho maldito. Conversaciones para otra historia del peronismo. Rosario: Prohistoria.

Aimé Césaire (2006) Discurso sobre el colonialismo. Barcelona: Ed. Akal.

Alfonso Mola, Marina y Carlos Martinez Shaw (2000) El Galeón de Manila. Madrid: Museo Nacional del Prado. 
Alonso Álvarez, Luis (1984). Comercio colonial y crisis del Antiguo Régimen en Galicia (1778-1818). Resumen de la tesis presentada para aspirar al grado de doctor en Geografía e Historia. Universitat de Barcelona: Barcelona.

Alonso Álvarez, Luis (1999). "Comercio exterior e atraso económico. Os intercambios de Galicia con Latinoamérica, 1764- 1868". En Alonso Álvarez, Luis (coord.) Os intercambios entre Galicia e América Latina. Ed. Por la Universidad de Santiago de Compostela: Santiago de Compostela.

Amaral, Samuel (1984) "Producción y mano de obra en la estancia colonial. Magdalena 1785- 1795". Ponencia presentada en las VI Jornadas de Historia Económica, Vaquerías, Córdoba.

Amaral, Samuel (1987) "Rural production and labour in Late Colonial Buenos Aires" Journal of Latin America Sudies. Noviembre.

Amaral, Samuel (1998) The Rise of Cpitalism on the Pampas. The Estancias of Buenos Aires, 1785- 1870. Cambridge University Press.

Amaral, Samuel (2011) "Las finanzas arcaicas: La atención del déficit fiscal en la Real Caja de Buenos Aires, 1789- 1811”. En Investigaciones y Ensayos. N 60

Arce Facundo (1979). "El poblamiento: 1573-1776". en Enciclopedia de Entre Ríos, J. Pedrazzoli (Dir.), Edit. Arozena. Paraná.. T.1

Ardit Lucas, Manuel (1977). Revolución liberal y revuelta campesina. Un ensayo sobre la desintegración del Régimen Feudal en el país valenciano (1793-1840). España: Ariel.

Apolant, J. A. (1966a). Padrones Olvidados de Montevideo del siglo XVIII. Montevideo, Imprenta Letras.

Apolant, J. A. (1966b). Génesis de la familia uruguaya. Los habitantes de Montevideo en sus primeros 40 años. Filiaciones. Ascendencias. Entronques. Descendencias. Montevideo, Instituto Histórico y geográfico del Uruguay.

Assadourian, C. S. (1982). El sistema de la economía colonial. Mercado interno, regiones y espacio económico. Lima, Instituto de Estudios Peruano.

Assadourian, Carlos Sempat (2006) "La economía del Río de La Plata durante el siglo XIX”, Illes e Imperis 9. Diciembre: Barcelona.

Assadourian, Carlos Sampat (1983). El sistema de la economía colonial. El mercado interior. Regiones y espacio económico. México: Ed. Nieva Imagen.

Assadourian, Carlos Sampat, Beato, Guillermo, y Chiaramonte, J. C. (1986). Argentina de la conquista a la independencia. Buenos Aires: Hispamérica.

Azara, Félix de (1953). "Viajes por la América Meridional.”. Madrid, Ed. Espasa. 1969.; 
Anónimo (1953) "Noticias sobre los campos de Buenos Aires y Montevideo para su arreglo, 1794". Estudio preliminar de Rogelio Brito Stefano, En Revista Histórica. Tomo XVIII. Montevideo.

Azcona Guerra, Ana M (1996). Comercio y comerciantes en la Navarra del siglo XVIII. Editado por el Gobierno de Navarra: Navarra.

Azcuy Ameghino, E. (1995). El latifundio y la gran propiedad colonial rioplatense. Buenos Aires, F. García Cambeiro.

Azcuy Ameghino, Eduardo (1997). La otra historia. Economía, Estado y Sociedad en el Río de la Plata Colonial. Buenos Aires: Imago Mundi.

Azúa, Carlos Real de (1991). Los orígenes de la nacionalidad uruguaya. Montevideo: Arca.

Bagú, Sergio (1952). Estructura social de la colonia: Ensayo de historia comparada de América Latina. Buenos Aires: Ateneo.

Banzato, Guillermo (2002a). "Grandes estancias en la provincia de Buenos Aires, formación y consolidación del patrimonio rural en los partidos de Chascomús, Ranchos y Monte, 1780- 1880." En Casado Alonso, Hilario y Robledo Hernández, Ricardo. Fortuna y negocios: Formación y gestión de los grandes patrimonios (siglos XVI-XX). Valladolid. Universidad de Valladolid.

Banzato, G. (2002b). Ocupación y acceso a la propiedad legal de la tierra en el nordeste del río Salado: Chascomús, Ranchos y Monte, 1780-1880. Tesis de doctorado, Facultad de Humanidades y Ciencias de la Educación, Universidad Nacional de La Plata, 2002.

Banzato, Guillermo y Lanteri, Sol. (2007) "Forjando la frontera. Políticas públicas y estrategias privadas en el Río de la Plata, 1780- 1860”. Historia Agraria, año XVII. No 43.

Barba, Enrique M. (1978) Don Pedro de Ceballos. Buenos Aires: Rioplatense. Barba, F. E. (1997). Frontera ganadera y guerra con el indio. La frontera y la ocupación ganadera en Buenos Aires entre los siglos XVIII y XIX, La Plata, UNLP.

Barba, Fernando Enrique y Mamblona, María del Carmen (2005) "El Resguardo de Buenos Aires en 1817. Noticias sobre el comercio de importación y exportación". Anuario del Instituto de Historia Argentina. N 5.

Barcos, F. (2010). De cada labrador un soldado y de cada agricultor un propietario: Economía, sociedad y política en el ejido de la guardia de Luján (Mercedes), 1810-1870. Tesis de doctorado, Facultad de Humanidades y Ciencias de la Educación, Universidad Nacional de La Plata.

Barrán, J. P. (1998). La espiritualización de la riqueza. Catolicismo y economía en Uruguay (1730-1900). Montevideo, Ediciones de la Banda Oriental. 
Barrán, J. P. y Nahum, B. (1964). Bases económicas de la revolución artiguista. Montevideo, Ediciones de la Banda Oriental.

Barros, Carlos (2006). "La historia mixta como una historia global". Enfoques. Año/Vol. XVIII, número 1-2. Universidad Adventista del Plata: Buenos Aires.

Basurto Larrañaga, Román (1983). Comercio y burguesía mercantil de Bilbao en la segunda mitad del siglo XVIII. Bilbao: Servicio Editorial del País Vasco.

Beckles, Hilary y Verene Shepherd (ed.) (2002) "Las voces de los esclavizados, los sonidos de la libertad.” Kingston: UNESCO.

Becerra, María José (2008) "Estudios sobre esclavitud en Córdoba: Análisis y perspectivas" En Lechini, Gladys (Comp.) Los estudios Afroamericanos y Áfricanos en América Latina, herencia, presencia y visiones del otro. Argentina: Consejo Latinoamericano de Ciencias Sociales.

Benavent, Ricard. (2008) "El comercio en el mediterráneo español durante la edad moderna: del estudio del tráfico a su vinculación con la realidad productiva y el contexto social". Revista Obradoiro de Historia Moderna. № 17.

Besio Moreno, Nicolás (1939). Buenos Aires, Puerto del Río de da Plata, Capital de la Argentina, Estudio crítico de su Población, 1536-1936. Buenos Aires. Talleres Gráficos Tuduri.

Betancur, Arturo (1997). El Puerto Colonial de Montevideo. Guerra y apertura comercial: tres lustros de crecimiento económico 1791-1806. Montevideo: FaHCE.

Biangardi, Nicolás (2010) "Indagaciones en torno al Río de la Plata como región, 1778-1816" XXII Jornadas de Historia Económica Río Cuarto, 20 al 22 de octubre.

Biangardi, Nicolás (2013a). Poblamiento, crecimiento económico y poderes locales en un área de la región Río de la Plata. Maldonado 1755-1814. Tesis de Maestría. UTREF, Mimeo.

Biangardi, N. (2013b) "Una nueva área para la región. Poblamiento y crecimiento económico en Maldonado (1755-1814)". Revista Uruguaya de Historia Económica, Vol. III, № 4.

Biangardi, Nicolás (2015). Expansión territorial, producción ganadera y relaciones de poder en la región Río de la Plata. Montevideo y Maldonado a fines del siglo XVIII Tesis de Doctorado. UNLP, Mimeo.

Bonialian, Mariano (2012). El Pacífico Hispanoamericano. Política y comercio asiático en el imperio español (1680-1784). La centralidad de lo marginal. México: El Colegio de México.

Bonilla, Heraclio (ed.) (2011) La cuestión colonial, Bogotá. Universidad Nacional de Colombia. 
Borges, Jorge Luis (1985) "Prólogo". En Melville Herman, Benito Cereno, Billy Budd y Bartleby, el escribiente. Buenos Aires: Hyspamérica.

Birocco, Carlos María (1996). "Historia de un Latifundio rioplatense: Las estancias de Riglos en Areco, 1713- 1813". Anuario de Estudios Americanos. Tomo LIII, $\mathrm{N}^{\mathrm{o}}$ I.

Birocco, Carlos María. (1998) "La estructuración de un espacio de poder local en la campaña bonaerense: Las Alcaldías de la Santa Hermandad de los partidos de Areco y la Cañada de la Cruz (1700-1790)" Cuadernos del PIEA, № 5.

Bloch, Marc (2006). Los reyes taumaturgos: estudio sobre el carácter sobrenatural atribuido al poder real, particularmente en Francia e Inglaterra. México: FCE.

Borucky, Alex; Chagas, Karla y Stalla, Natalia (2005). "Debates y problemas sobre los estudios recientes en torno a la esclavitud en el Río de la Plata (17501850)", en Segundas Jornadas de Historia Regional Comparada / Primeras Jornadas de Economía Regional Comparada, Porto Alegre, Pontifícia Universidade Católica do Río Grande do Sul, octubre.

Borucky, Alex (2009) "Las rutas brasileñas del tráfico de esclavos hacia el Río de la Plata, 1777-1812", 26 en $4^{\circ}$ Encontro Escravidão e Liberdade no Brasil Meridional, Curitiba, Universidade Federal do Paraná Centro - Apicuri, , mayo. En línea:

http://www.labhstc.ufsc.br/ivencontro/pdfs/comunicacoes/AlexBorucki.pdf; [última fecha de consulta: 8 de abril].

Borucky, Alex (2011) "The Slave Trade to the Río de la Plata, 1777-1812: Transimperial Networks and Atlantic Warfare", en Colonial Latin American Review, v. $20, n^{\circ} 1$, abril.

Braudel, Fernand (2002 -1985). La dinámica del capitalismo. México. FCE.

Brown, Johnatan (1979). Socioeconómic History of Argentina, 1776- 1860. Canedo, M. (2001). Propietarios, ocupantes y labradores. San Nicolás de los Arroyos 1600-1860. Mar del Plata, Universidad Nacional de Mar del Plata.

Canedo, Mariana Poderes intermedios en la frontera. Buenos Aires, siglo XVIIIXIX. Canedo, Mariana (Comp.) Mar del Plata. EUDEM. 2013.

Nueva York: New York University Press.

Camarda, Maximiliano. (2014). El comercio ultramarino de cueros del complejo portuario rioplatense, 1779-1799. Tesis de maestría, Universidad Nacional de Mar del Plata.

Camarda, Maximiliano (2014) "De comerciante exitoso a hacendado y revolucionario. La estrategia económica de fines del siglo XVIII en el Complejo Portuario Rioplatense a partir de un actor: José Ramón Milá de la Roca". En 
Revista Naveg@merica Asociación Española de Americanistas. Universidad de Murcia. $\mathrm{N}^{\mathrm{o}} 12$.

Camarda, Maximiliano (2013). "Circulación Ultramarina de Navíos del Complejo Portuario Rioplatense (1779-1806)" en evaluación externa de la revista Anuario del Instituto de Historia Argentina, $\mathrm{N}^{\mathrm{o}} 13$.

Camarda Maximiliano (2006). Un hogar alquilado. Las unidades domésticas y la renta urbana en la ciudad de Buenos Aires a mediados del siglo XVIII. Tesis propuesta para la Licenciatura en historia. UNMdP.

Canedo, Mariana (1993). "Propiedades, propietarios y ocupantes. La tierra y la familia en la campaña de Buenos Aires. El Pago de los Arroyos, 1650- 1750". Boletín del Ravignani. No 7, FCE- UBA.

Canedo, Mariana (2000). Propietarios, ocupantes y pobladores. San Nicolás de los Arroyos, 1600- 1860. Mar del Plata: UNMdP- GIHRR.

Cardim, P., Herzog, T., Ruiz Ibáñez, J. J., y Sabatini, G. (ed.) (2012). Polycentric monarchies. How early modern Spain and Portugal achieve and maintain a global hegemony?. Brighton, Sussex Academic Press.

Cansanello, Carlos O. (1998) "Pueblos, lugares y fronteras de la provincia de Buenos Aires en la primera parte del siglo XIX”. Jahrbuch für Geschichte Lateinamerikas. Número 35.

Castro-Gómez, Santiago (2000). "Ciencias sociales, violencia epistémica y el problema de la "invención del otro". En La colonialidad del saber: eurocentrismo y ciencias sociales. Perspectivas Latinoamericanas. Edgardo Lander (comp.) CLACSO, Consejo Latinoamericano de Ciencias Sociales, Buenos Aires, Argentina.

Caula, Elsa (2001) "1Jurisdicciones en Tensión Poder patriarcal, legalidad monárquica y libertad eclesiástica en las dispensas matrimoniales del Buenos Aires virreinal". En Prohistoria N 5.UNR.

Caula, Elsa (2011) "Las configuraciones mercantiles a escala de imperio a finales del período colonial: pautas de comportamiento, circulación de recursos y experiencias". En Anuario del Instituto de Historia Argentina, N 11.

Cervera, Manuel (1907). Historia de la ciudad y provincia de Santa Fe, 15731853, Santa Fe, Imprenta La Unión.

Chakrabarty, Dipesh (2000) Provincializing Europe: Postcolonial Thought and Historical Difference. Cambridge: Cambridge Press.

Chaunu, Pierre y Chaunu Hugette (1969). Sevilla y el Atlántico. Sevilla: Universidad de Sevilla.

Ciliberto, Valeria (2005). "Entre el campo y la ciudad: población y producción en los entornos agrarios de Buenos Aires." Nuevo Mundo. Mundos Nuevos. 
Ciliberto, Valeria (2007). "Patrimonio y producción en los entornos rurales de Buenos Aires. San José de Flores, 1800-1875”. Mundo Agrario: La Plata.

Ciliberto, Valeria (2010). "La tierra pública periurbana: arrendamiento, enfiteusis y ventas en el entorno agrario de Buenos Aires (San José de Flores, 1800-1862)." Trabajos y Comunicaciones: La Plata.

Comadrán Ruiz, Jorge (1964). Evolución demográfica argentina durante el período hispánico (1535-1810). Buenos Aires.

Cuesta, M. (2006a). El crecimiento de una economía colonial: el caso de Buenos Aires en el siglo XVIII. Tesis de doctorado inédita, Facultad de Filosofía y Letras, Universidad Nacional de Buenos Aires.

Cuesta, M. (2006b). "Evolución de la población y estructura ocupacional de Buenos Aires, 1700-1810”. Papeles de población, vol. 12, núm. 49.

Cuesta, M. (2007). "Precios y mercados en Buenos Aires en el siglo XVIII". América Latina en la Historia Económica, nº 28.

Dalla Corte, Gabriela (2000). Vida i mort d'una aventura al Riu de la Plata, Jaime Alsina i Vergés, 1770-1836. Barcelona: Abadia de Monserrat.

Das, Veena y Deborah Poole (2008). "El estado y sus márgenes. Etnografías comparadas". En Revista Académica de Relaciones Internacionales. Número 8 Marzo. UAM-AEDRI.

De Cristóforis, Nadia (2001). Migraciones de gallegos y asturianos a Buenos Aires a fines del siglo XVIII y comienzos del siglo XIX. Tesis de Maestría. Universidad de San Andrés.

De Cristóforis, Nadia (2002). "La conformación de una temprana identidad postmigratoria: gallegos en el Buenos Aires tardo-colonial". En III Jornadas de Historia Moderna y Contemporánea: Rosario.

De la Serna, Juan M. (2004). "Cambio y continuidad en el comercio esclavista. Una perspectiva desde el puerto de Veracruz a finales del siglo XVIII”. Boletín $A G N 6^{\text {a }}$ época, número 6 , oct-nov.

De Vries, Gerard (2010). "The limits of globalization in the early modern world" en The Economic History Review, 63, 2: pp. 710-733.

Delgado Ribas, Josep (1981). "La inmigración española a América Latina durante la época del comercio libre (1765- 1820) el ejemplo catalán”. En: Boletín Americanista $\mathrm{N}^{\mathrm{o}} 31$. Any XXIII.

Delgado Ribas, Joseph (1982a). "El impacto de las crisis coloniales en la economía catalana (1787-1807)." En: Fontana, Joseph (Comp.) La economía española al final del antiguo régimen. Madrid: Alianza Editorial. 
Delgado Ribas, Josep (1982b). "El impacto de las crisis coloniales en la economía catalana (1787- 1807)”. En: Fontana, Josep (ed.) La economía española al final del Antiguo Régimen. Comercio y colonias. Madrid. Alianza Editorial.

Delgado Ribas, Josep (1983). "Política Ilustrada, Industria española y Mercado Americano (1720-1820)". Revista Pedralbes. No 3.

Delgado Ribas, Josep (1987) "El modelo catalán, dentro del sistema de Libre Comercio (1765-1820)." En Fontana, Joseph (Comp.) Comercio Libre entre España y América Latina, 1765-1824. Fundación Banco Exterior: Madrid.

Delgado Barrado, Jose Miguel (1997) "Ideas y escritos sobre la formación de la Compañía Privilegiada de Filipinas (1724- 1753).” En Elizalde, Dolores (Ed.) Las relaciones internacionales en el Pacifico (siglos XVIII-XX), Madrid: Consejo Superior de Investigaciones Científicas.

Djenderedjian, J. (2008c) "Roots of Revolution: Frontier Settlement Policy and the Emergence of New Spaces of Power in the Río de la Plata Borderlands, 17771810", en Hispanic American Historical Review, vol. 88, nro. 4.

Djenderedjian, J. (2004), “¿Un aire de familia? Producción ganadera y sociedad en perspectiva comparada: las fronteras rioplatenses a inicios del siglo XIX”, en Jahrbuch für Geschichte Lateinamerikas, vol. 41, Köln - Weimar - Wien, Alemania-Austria.

Djenderedjian, Julio (2003). Economía y sociedad en la Arcadia criolla. Formación y desarrollo de una sociedad de frontera en Entre Rios, 1750- 1820. Tesis Doctoral: UBA.

Djenderedjian, J. y R. Schmit (2007) "La empresa rural en el largo plazo. Cambios en la explotación de una gran estancia rioplatense entre el orden colonial y el nacimiento del capitalismo, 1780-1870" en Boletín del Instituto de Historia Argentina y Americana "Dr. Emilio Ravignani”, 3ra. serie, nro. 29.

Díaz, Marisa M. (1998) "Las migraciones internas a la ciudad de Buenos Aires, 1744-1810." En Boletín del Instituto de Historia "E. Ravignani. Tercera serie, números 16 y $17,2^{\circ}$.

Douglass C. North, William Summerhill \& Barry R. Weingast (2000). Order, Disorder and Economic Change: Latin America vs. North America, Bruce Bueno de Mesquita and Hilton Root, eds., Governing for Prosperity Yale University Press.

Douglas Inglis, Gregory y Allan J. Kuethe (1984) "El Consulado de Cádiz y el Reglamento de comercio libre de 1765" En Actas de la 4 Jornadas de Andalucía y América. Andalucía y América en el siglo XVIII. La Rábida

Dussel, Enrique (1992). Europa, modernidad y eurocentrismo. Madrid: Nueva Utopía.

Elias, Norbert (1996). La sociedad cortesana. México: FCE. 
Eliott, John (2006). Imperios del mundo Atlántico. Madrid: Taurus.

Escobedo Romero, Rafael (2000). El contrabando y la crisis del Antiguo Régimen en Navarra (1778-1808). Navarra: Príncipe de Viana.

Espanha, Antonio M. (1989) Visperas del Leviatán. Instituciones y poder político (Portugal, siglo XVII). Madrid: Taurus Humanidades.

Fanon, Franz (1973). Piel negra, mascaras blancas. Buenos Aires: Ed. Abraxas.

Fanon, Franz (1983). Los condenados de la tierra. México: FCE.

Fazio Vengoa, Hugo (2009). "La historia global y su convivencia para el estudio del pasado y del presente" Historia Crítica Edición Especial. Bogotá. Noviembre.

Fernández Albadalejo, Pablo (1975). La crisis del Antiguo Régimen en Guipuzcoa, 1766- 1833. Cambio Económico e Historia. España: Espasa Akal.

Ferreyra, Silvana (2011). La libertad del dogma. Un análisis del proyecto mariateguiano a la luz de sus vínculos con la Internacional comunista (19261930). Lima: Librería Editorial Minerva.

Fisher, John (1993). El comercio entre España e Hispanoamérica (1797-1820). España. Banco de España.

Fisher, John (1985). Commercial Relations between Spain and Spanish America in the Era of Free Trade, 1778-1796. Liverpool.

Fontana, Josep y José María Delgado Ribas (2000) "La política colonial española 1700-1808”, en Tandeter, Enrique Historia General de América Latina, Procesos americanos hacia la redefinición colonial, Vol. IV. España: UNESCO- TROTTA.

Fradkin, Raúl Osvaldo (1995) “El Gremio de Hacendados en Buenos Aires durante la segunda mitad del siglo XVIII." Cuadernos de Historia Regional. Luján. V. III

Fradkin, Raúl Osvaldo (1993). “¿Estancieros, hacendados o terratenientes? La formación de la clase terrateniente porteña y el uso de las categorías históricas y analíticas (Buenos Aires, 1750- 1850)", en Marta Bonaudo y Alfredo Pucciarelli (comps.) La problemática agraria. Nuevas aproximaciones. Buenos Aires: CEAL.

Fradkin, Raúl, Mariana Canedo y José Mateo (1999) Tierra, población y relaciones sociales en la campaña bonaerense (siglo XVIII y XIX). Fradkin, Raúl, Mariana Canedo y José Mateo (Comp.) Mar del Plata. EUDEM.

Frega, Ana (2007). Pueblos y soberanía en la revolución artiguista. La región de Santo Domingo Soriano desde la colonia a la ocupación portuguesa. Montevideo: Banda Oriental.

Furlong, Guillermo (1936). "Mapa del P. Cardiel de 1752”. Cartografía Jesuítica del Río de la Plata, Publicaciones del Instituto de Investigaciones Históricas de la UBA. 
Fuster, Joan (1962). Nosaltres, els valencians. Barcelona: Edicions 62.

Galarza, Antonio (Comp.) (2010). Debates y diagnósticos sobre las sociedades coloniales latinoamericanas. Mar del Plata: GIHRR.

Galmarini, Hugo (2000). Los negocios del poder. Reforma y crisis del Estado, 1776- 1826. Argentina: Corregidor.

Garavaglia, Juan Carlos (1987). Economía, Sociedad y Regiones. Buenos Aires: De La Flor.

Garavaglia, Juan Carlos (1989). "Ecosistemas y tecnología agraria: elementos para una historia social de los ecosistemas agrarios rioplatenses (1700-1830)." Desarrollo Económico. V. 28, No 112 (enero- Marzo).

Garavaglia, Juan Carlos (1999a). Pastores y labradores de Buenos Aires. Una historia agraria de la campaña bonaerense 1700-1830, Buenos Aires: De la Flor.

Garavaglia, Juan Carlos (1999b). "Un siglo de estancias en la campaña de Buenos Aires: 1751 a 1853” The Hispanic American Historical Review, Duke University Press, V. 79. No. (nov).

Garavaglia, Juan Carlos y Gelman, Jorge (1995). "Rural history of the Río de la Plata, 1600-1850: Results of a Historiographical Renaissance" en Latin America Research Review, Latin American Studies Asociation, Baltimore, 30:3.

García-Baquero González, Antonio (2002). “Andalucía y la carrera de Indias”. Granada. Universidad de Granada.

García- Baquero González, Antonio(1976). Cádiz y el Atlántico (1717-1778). 2 Vols. Sevilla: Universidad de Sevilla.

García- Baquero González, Antonio (1975). "Comercio colonial y producción industrial en Cataluña a fines del siglo XVIII", en Actas del I Coloquio de Historia Económica de España, Barcelona.

García- Baquero González, Antonio (1972). Comercio colonial y guerras revolucionarias: la decadencia económica de Cádiz a raíz de la emancipación americana. Sevilla: Universidad de Sevilla.

García-Baquero González, Antonio (1974) “Comercio colonial y producción industrial en Catalunya a fines del siglo XVIII”, En: García-Baquero González, Antonio (compilador) Agricultura, comercio colonial y crecimiento de España: Barcelona.

García Belsunce, César y Susana Frías (1996). De Navarra a Buenos Aires: 1580-1810, Buenos Aires, Instituto Americano de Estudios Vascos,

García Belsunce, César (1982). "Los vascos en Buenos Aires en 1810", en VI Congreso de Historia de América. Vol. 2, Buenos Aires. pp. 143-157.

García Fuentes, Lutgardo (1980). El Comercio español con América, 1650- 1700. Sevilla. Universidad de Sevilla. 
García Del Pino, César (2002). Toma de La Habana por los ingleses y sus antecedentes. Ed. Ciencias Sociales. La Habana.

Gelman, Jorge (2012). "La economía de Buenos Aires". En: Fradkin, R. (dir.). Historia de laprovincia de Buenos Aires. Tomo 2. De la conquista a la crisis de 1820. Edhasa. Buenos Aires.

Gelman, (1996). De mercachifle gran comerciante. Los caminos del ascenso en el Río de la Plata. Universidad Internacional de Andalucía. Sevilla.

Gelman, Jorge (1993). "Los caminos del mercado. Campesinos, estancieros y pulperos en una región del Río de la Plata colonial". Latin American Research Review. 1993. Vol. 28, No 2, pp. 89-118.

Gelman, Jorge (1992). "Producción campesina y estancias en el Río de la Plata Colonial. La región de Colonia a fines del Siglo XVIII". En Boletín del Instituto de Historia Argentina y Americana "Dr. E. Ravignani” Tercera serie, número 6 $2^{\circ}$ semestre de.

Gelman, Jorge (1989). "Una región y una chacra en la campaña rioplatense: Las condiciones de la producción triguera a fines de la época colonial”. En Desarrollo económico, v 28, № 112 (enero- marzo 1989).

Gelman, Jorge (1998). Campesinos y estancieros. Una región del Río de la Plata a fines de la época colonial. Buenos Aires. Los libros del riel. 1998.

Giberti, Hugo C. (1954). "Historia Económica de la ganadería argentina". Argentina, Ed. Hyspamerica.

Giralt, Ernest (1970). L'estructura económica del País Valencià. Valencia. Edic. L'Estel.

Girbal- Blacha, Noemí (2010). "La historia regional argentina en tiempos del bicentenario de la revolución de mayo de 1810". En Mundo Agrario. Vol.10 número 20.

Goldberg, Marta B. y Silvia C. Mallo (1994). "La población Áfricana en Buenos Aires y su campaña. Formas de vida y subsistencia, en: Temas de África y Asia 2, Facultad de Filosofía y Letras, UBA, Buenos Aires.

Goldman, Noemí (comp.) (1998). Revolución, Republica, Confederación (18061852). Buenos Aires. Sudamericana.

González Bernardo de Quirós, Pilar (2001). Civilidad y política en los orígenes de la Nación Argentina. Las sociabilidades en Buenos Aires, 1829- 1862. Buenos Aires. FCE.

González, Rafael (2014). "La globalización hispana del comercio y el arte en la Edad Moderna”. En Estudios de Economía Aplicada, 32, 1, enero. 
Grafe, Regina \& Alejandra Irigoin (2008). "A Stakeholder Empire: The Political Economy of Spanish Imperial Rule In America", College of New Jersey, Working Papers No. 111/08.

Guerra, Françoise-Xavier (1992). Modernidad e Independencias. Ensayos sobre las revoluciones hispánicas. España. Ed. MAPFRE.

Guimerá Ravina, Agustín (2002). "Puertos y Ciudades Portuarias (Ss. XVIXVIII), una aproximación metodológica". Revista O litoral em Perspectiva Hitórica (Séc. XVI a XVIII). Porto. Instituto de História Moderna.

Guzmán, María Florencia (1993). "Los mulatos-mestizos en la jurisdicción riojana a fines del siglo XVIII: El caso de los Llanos". en: Temas de Asia y África, 2, Buenos Aires, Sección de Asia y África, Facultad de Filosofía y Letras.

Haring, Clarence H. (1939). Comercio y Navegación entre España y las Indias. México. FCE.

Halperín Donghi, Tulio (1972). Revolución y guerra. Formación de una elite dirigente en la Argentina criolla. Buenos Aires. Siglo XXI.

Hamilton, Erl (1934). El tesoro americano y la revolución de los precios en España, 1501- 1650. Barcelona. Ariel.

Hausberger, Vernard. (s/f). Historia global y los orígenes de la globalización. Miméo.

Hormaechea, Cayetano (2012). "la construcción naval española del siglo XVIIII a través de algunos modelos de arsenal del museo naval de Madrid" A.A.M.M.B.Visita colectiva al Museo Naval de Madrid, Enero.

Ibarra, Antonio (2013). "Crecimiento y desigualdad de la economía novohispana en la crisis imperial hispanoamericana, 1780-1810", en Reina, Leticia y Ricardo Pérez Montfort eds., Fin de siglo ¿fin de ciclos?, Siglo XXI eds., México.

Ibarra, Antonio (1994). "La organización regional del mercado interno colonial novohispano: la economía de Guadalajara", 1770-1804. Anuario IEHS, pp. 127168 .

Imizcoz Beunza, José María (1996). “Comunidad, red social y élites. Un análisis de la vertebración social en el Antiguo Régimen”. En Imizcoz Beunza, José María (Director) Elites, poder y red social. Las élites del país Vasco y Navarra en la Edad Moderna (estado de la cuestión y perspectivas). País Vasco. Ed. De la Universidad del País Vasco.

Jackson, Robert H. (2004). "Una mirada a los patrones demográficos de las misiones jesuíticas de Paraguay" Fronteras de la Historia, núm. 9.

Jeffrey G. Williamson (2001). "After Columbus: Explaining the Global Trade Boom 1500-1800". Working Paper Series no. 8186, National Bureau of Economic Research. 
Johnson Lyman L. (1979). "Estimaciones de la población de Buenos Aires en 1744, 1778 y 1819”. En Desarrollo Económico, Vol. 19. número 73.

Johnson, L. y Socolow Susan Migden (1980). "Población y espacio en el Buenos Aires del siglo XVIII”. En Desarrollo Económico, v 20, número 79.

Jumar, Fernando. (2002a). Le comerce atlantique au Río de la Plata 1680-1778, Tesis de doctorado, École des Hautes Études Sciences Sociales, París.

Jumar, Fernando (2002b). "Algunas cifras del comercio ultramarino del Río de la Plata en el siglo XVIII”. En XVIII Jornadas de Historia Económica. Mendoza, septiembre.

Jumar, Fernando (2001). "Los comerciantes rioplatenses: su participación en el comercio legal español. 1720- 1778”. Coloquio Internacional Mercantilismo y Comercio en el Mundo Ibérico, septiembre.

Jumar, F., Biangardi, N., Bozzo, J., Orlowski, S., Sandrín, M. E. y Querzoli, R. (2006). "El comercio ultramarino y la economía local en el complejo portuario rioplatense. Siglo XVIII". Anuario IEHS, nº 21.

Jumar, Fernando y Javier Kraselsky (2007). "Las esferas del poder. Hacendados y comerciantes de Buenos Aires frente a los cambios de la segunda mitad del siglo XVIII", Anuario del Instituto de Historia Argentina, número 7, pp. 31-58.

Jumar, Fernando y Paredes, I. (2008a) "El comercio intrarregional en el complejo portuario rioplatense: el contrabando visto a través de los comisos, 1693-1777”. América Latina en la Historia Económica, no 29.

Jumar, Fernando (2008b). "El primer boom de la exportación de cueros y la sociedad local. Río de la Plata. Fines del siglo XVII, comienzos del siglo XVIII". Caseros, XXI Jornadas de Historia Económica.

Jumar, Fernando y María Emilia Sandrín (2011a). “¿A panza llena corazón contento? La economía rioplatense, el estado llano y general del pueblo y la adhesión a la revolución" en I Jornadas Internacionales Independencia, historia y memoria. Hacia una reflexión sobre los procesos revolucionarios en Iberoamérica.

Jumar, Fernando (2011b). "Lo que la revolución se llevó: la región del Río de la Plata com espacio económico". Boletín del Instituto de Historia Argentina y Americana Dr. Emilio Ravignani, n 33.

Jumar, Fernando (2011c). "Presentación del Dossier: Comerciantes en Hispanoamérica durante el Antiguo Régimen y su crisis.” En Anuario del Instituto de Historia Argentina. No 11.

Jumar, Fernando (2012). "La región Río de la Plata y su complejo portuario durante el Antiguo Régimen" en Fradkin, Raúl (dir.). Historia de la provincia de Buenos Aires. Tomo 2. De la conquista a la crisis de 1820. Buenos Aires: Edhasa. 
Jumar, Fernando y Biangardi, Nicolás (2013). "La conjunción entre espacio económico y territorialidad. Río de la Plata. Siglo XVIII". III Jornadas Interdisciplinarias de Investigaciones Regionales. Enfoques para la historia. Siglos XVIII-XX, Mendoza, CCT Mendoza.

Klein, Herbert S. (1986). La esclavitud Áfricana en América Latina y el Caribe. Madrid: Alianza.

Kraselsky, Javier (2005). "Los actores locales y su representación corporativa. Las Juntas de Comercio y su dinámica de funcionamiento, Buenos Aires 1779-1794”. Anuario del Instituto de Historia Argentina, número 5, pp. 65-92.

Kraselsky, Javier (2011). Las estrategias de los actores del Río de La Plata: Las juntas y el Consulado de Comercio de Buenos Aires a fines del Antiguo Régimen 1748-1809 Tesis Doctoral inédita: UNLP.

Künh, Fábio (2011). "Clandestino e ilegal: notas sobre o contrabando de escravos na Colonia del Sacramento". In: $5^{\circ}$ Encontro Escravidão e Liberdade no Brasil Meridional. Porto Alegre: UFRGS,. Disponible en: http://www.labhstc.ufsc.br/vencontro/pdf/KUHN,\%20Fabio.pdf Acceso el 10 de julio de 2011.

La Piñera y Rivas (2002). "La construcción naval en España durante el siglo XVIII". Revista de Historia Naval. Núm. 79 (cuarto trimestre), p. 17-33.

Lemperière, Annick (2004). "El paradigma colonial en la historiografía latinoamericanista” Istor V. 19.

Levene, Raul (1952). Investigaciones acerca de la historia económica del Virreinato del Rio de la Plata. Argentina: Hyspamerica.

Llimargas, Jordi (1992). Guerra i revolución. La crisi de l’Antic Regim (17881833). Barcelona: Barcanova.

Llopis Agelán, Enrique (1996). "La formación del "desierto manufacturero" extremeño, el declive de la pañería tradicional al final del Antiguo Régimen". En Zapata Blanco, Santiago (ed.) La industria de una región no industrializada: Extremadura, 1750- 1990. Cáceres: Universidad de Cáceres.

Lluch, Ernest (2003). La via Valenciana. Recerca i pensament. Barcelona: Afers. Catarroja.

Lynch, John (2000). "Las revoluciones hispanoamericanas. 1808- 1826". Barcelona. Ed. Ariel. 1976.

Malamud, Carlos (1982). "España, Francia y el «comercio directo» con el espacio peruano (1695-1730): Cádiz y Saint Malo”, en J. Fontana, ed., La economía española al final del Antiguo Régimen, III. Comercio y colonias, Madrid.

Malamud, Carlos (1981). "El comercio directo de Europa con América en el siglo XVIII. Algunas consideraciones.” Revista Quinto Centenario. Volumen 1. 
Mallo, Silvia (1997). "Población afroargentina. Del peculio al patrimonio y la propiedad." En Actas del XII Congreso Nacional de Arqueología. Facultad de Ciencias Naturales. Universidad Nacional de La Plata, Facultad de Ciencias Naturales, La Plata, t. II.

Mallo, Silvia (1991). "La libertad en el discurso del Estado, de amos y esclavos. 1780-1830." Revista de Historia de América, $\mathrm{N}^{\mathrm{o}}$ 112, México. Instituto Panamericano de Geografía e Historia, julio-diciembre.

Mallo, Silvia C. y Beatriz I. Moreyra (coord.). (2008) Miradas sobre la historia social en la Argentina en los comienzos del siglo XXI. Córdoba: Centro de Estudios Históricos, Prof. S. A, Segreti, La Plata: Centro de Estudios de Historia Americana Colonial.

Maquiavelo, Nicolás (2006). El Príncipe. Buenos Aires: El Aleph.

Mariategui, Juan Carlos (1984). 7 ensayos de interpretación de la realidad peruana. Lima: Biblioteca Amauta.

Marichal, Carlos (2006). "The Spanish-American Silver Peso: Export Commodity and Global Money of the Ancien Regime, 1550-1800". En Topik, S., Marichal, C. y Frank, Z. (eds.) From Silver to Cocaine (pp. 25-52). Durham. Duke University Press.

Marrero, Leví (1978). Cuba economía y sociedad, vol. 7. Madrid: Playor.

Martinez Shaw, Carlos (1986). El comerç Catalá, del Mediterrani a L’Atlantic”. En: AA. VV. El comerç entre Catalunya i America, 1680- 1898. Barcelona: L’avenç.

Martínez Shaw, Carlos (1987). "El libre comercio y Cataluña: contribución a un debate". En: AA VV El comercio libre entre España y América Latina, 1765 1824. Barcelona. Fundación Banco Exterior.

Martínez Shaw, Carlos (1975). El comercio entre Cataluña y América (16801756). Barcelona: Crítica.

Matas, Sara E. (2006). "Hacer Historia Regional: temas, enfoques, posibilidades". Ponencia presentada en las Primeras Jornadas Internacionales de Historiografía Regional. Resistencia, Chaco, 9 y 10 de noviembre.

Mateo, José. (2001). Población, parentesco y red social en la frontera. Lobos (Provincia de Buenos Aires) en el siglo XIX. Mar del Plata. GIHRR.

Marrero, Leví. (1978). Cuba economía y sociedad, vol. 7. Madrid: Playor.

Mayo, Carlos (1984a). Convento, economía y sociedad en el Río de la Plata, 1748-1822. Tesis doctoral. Los Angeles: University of California.

Mayo, Carlos (1984b). "Estancias y peonaje en la región pampeana en la segunda mitad del siglo XVIII”. Desarrollo económico. V. 23, No 92 (Enero- Marzo). 
Mayo, Carlos (1993). "Inmigración Áfricana”, en: Temas de África y Asia, 2, Buenos Aires, Sección de Estudios de Asia y África. Facultad de Filosofía y Letras, Universidad de Buenos Aires.

Maeder Ernesto y Alfredo Bolsi (1976) Evolución y características de la población guaraní de las misiones jesuíticas, Bs. As. Historiográfica,

Maeder, Ernesto J. (1981) Historia Económica de Corrientes en el Período Virreinal. Buenos Aires. Academia Nacional de la Historia.

Miguel López, Isabel (1996). "El censo de manufacturas de 1784. Una nueva fuente para el análisis de la industria catalana". Revista Historia Económica. Año $\mathrm{XIV}, \mathrm{N}^{\mathrm{o}} 1$.

Miguel Lopez, Isabel (2000) El mundo del comercio en Castilla y león al final del Antiguo Régimen. Valladolid: Universidad de Valladolid.

Mitre, Bartolomé (1927). Historia de Belgrano. Buenos Aires: Editorial científica y literaria.

Montoya, Alberto (1957). Historia de los saladeros argentinos. Argentina: Hyspamerica.

Moraes, Maria Inés (2007). "Crecimiento del Litoral rioplatense colonial y decadencia de la economía misionera: un análisis desde la ganadería” en: Investigaciones de Historia Económica, $N^{o}$ 9; Universidad Complutense de Madrid.

Moraes, María Inés. (2011) Las economías agrarias del litoral rioplatense en la segunda mitad del siglo XVIII. Paisajes y desempeños. Tesis de doctorado inédita. Facultad de Ciencias Sociales y Empresariales: Universidad Complutense de Madrid.

Moraes, María Inés (2014) "Tendencias y coyunturas agrarias del Litoral rioplatense, 1760-1800: un análisis cuantitativo." En Investigaciones en Historia Económica, v.: 1 3Página $\mid 285$

Morineau, Michel (1984). Incroyables Gazettes et fabuleux métaux. Les retours des trésors américains dans les gazettes hollandaises XVI - XVIII siècles. Paris: Maison des Sciences de l'Homme et Cambridge University Press.

Morineau, Michel. (1968) “D'Amsterdam á Seville. De quelle réalité 1'histoire des Prix selélle le miroir?”. Annales. E.S.C. 178- 205.

Morineau, Michel (1971). "Bayonne et Saint Jean de Luz relais du comerse neerlandais vers 1'Espagne au début du XVII siécle. Aces du 94 congrés nacional des societés savantes (Pau 1969) Section d'histoire moderne et contemporaine. Paris. Bibliotheque Nationale.

Moutoukias, Zacarías (1988). Contrabando y control colonial. Buenos Aires, el Atlántico y el espacio peruano en el siglo XVII., Buenos Aires: Centro Editor de América Latina. 
Moutoukias, Zacarías (1995). "El crecimiento en una economía colonial de antiguo régimen: Reformismo y sector externo en el Río de la Plata, 1760-1795." Arquivos do Centro Cultural Calouste Gulbekian XXIV, pp. 771-813.

Moutoukias, Zacarías (1999). "Comercio y producción”. En Nueva Historia de la Nación Argentina. Academia Nacional de la Historia. 3- período español (16001810). Buenos Aires: Planeta.

Moutoukias, Zacarías (2000). "Gobierno y sociedad en el Tucumán y el Río de la Plata, 1550- 1800" En Tandeter, Enrique (dir.) La Sociedad Colonial, Nueva Historia Argentina. Tomo 2. Buenos Aires: Sudamericana.

North, Douglass (1993). Instituciones, cambio institucional y desempeño económico. México: FCE.

Oliva Melgar, José María (1996). Cataluña y el comercio privilegiado con América en el siglo XVIII. Barcelona: Temes Història.

O'Rourke, Kevin, Leandro Prados de la Escosura \& Guillaume Daudin (2008) "Trade and Empire, 1700-1870", Trinity Economic Papers, Working Paper No. 208 May.

Olivares, Itamar (1988). "José Ramón Milá de la Roca, un afrancesado du Río de la Plata”. CMHLB CARAVELLE. N 51. Toulouse.

Palacio Atard, Vicente. El comercio de Castilla y el Puerto de Santander en el siglo XVIII. Notas para su estudio. Concejo superior de investigaciones científicas escuela de historia moderna. Madrid. 1960.

Palacios, Juan José (1983). "El concepto de región, la dimensión espacial de los proceso sociales" Revista Interamericana de Planificación, México D.F. № 66. Junio.

Palti, Elías (2007) El tiempo de la política, el siglo XIX reconsiderado. Buenos Aires: Siglo XXI.

Parcero Torre, Celia (2005). "La alimentación en Cuba en el siglo XVIII" Revista de Humanidades, Tecnológico de Monterrey, número 19 ITESM, Monterrey, México.

Pérez Colman, Carlos. (1936) Historia de Entre Ríos, Imprenta de la Provincia de Entre Ríos. Paraná. Tomo II. Imprenta de la Provincia de Entre Ríos.

Pérez, Osvaldo (1996) "Tipos de producción ganadera en el Río de la Plata colonial." En Azcuy Ameghino (ed.) Poder terrateniente, relaciones de producción y orden colonial, Buenos Aires: Fernando García Cambeiro, pp. 151184.

Pietschmann, Horst (1985). "La marginación de Andalucía en el comercio transatlántico de las ciudades Hanseáticas en el primer tercio del siglo XIX. Un aporte historiográfico" En: Andalucía y América en el siglo XIX. Universidad 
Hispanoamericana Santa María de la Rábida, Jornadas de Andalucía y América, pp.247-267.

Pivel Devoto, Juan (1952) Raíces coloniales de la revolución oriental de 1811. $1^{\mathrm{a}}$ ed. Montevideo: Editorial Medina.

Pollero, Raquel, y Carolina Vicario (2009). "Informe demográfico sobre la región platense, 1760-1860." 57: Facultad de Ciencias Sociales, Universidad de la República.

Punta, Ana Ines (1994), "Los intercambios comerciales de Córdoba con el puerto de Buenos Aires en la segunda mitad del siglo XVIII. El sector de los comerciantes." Anuario del IEHS 9, Tandil.

Ravignani, Emilio (1952). "El volumen del comercio del Río de la Plata a comienzos del Virreinato (1779- 1781)". En Boletín del Instituto de Investigaciones Históricas. Universidad Nacional de Buenos Aires, Facultad de Filosofía y Letras. Tomo XV, año XI, No 54. Buenos Aires.

Reid Andrews, George (1980). "The Afro-Argentines of Buenos Aires: 18001900”. Wisconsin: University of Wisconsin Press.

Reitano, Emir (2003) Los portugueses del Buenos Aires tardocolonial: Inmigración, sociedad, familia, vida cotidiana y religión. [En línea] Tesis de doctorado. Universidad Nacional de La Plata. Facultad de Humanidades y Ciencias de la Educación. Disponible en: http:// www.fuentesmemoria.fahce.unlp.edu.ar/tesis/te.237/te.237.

Reitano, Emir (2012) "Los extranjeros de Buenos Aires en los albores del siglo XIX. Algunos rasgos de su composición”. En Anuario del Instituto de Historia Argentina. N 12.

Rey Castelao, Ofelia (2001). "Los gallegos en el Río de la Plata durante la época colonial." En Xosé Nuñez Seijas (coord.), La Galicia Austral. La inmigración gallega en la Argentina. Buenos Aires: Biblos.

Rey Castelao, Ofelia (2013) "Del noreste español a America: oportunidades y medios de fraude y de corrupción”. En Revista E-spania. Diciembre.

Ribes, Vicent (1985). Los valencianos y América. El comercio valenciano con Indias en el siglo XVIII. Valencia: Diputació Provincial de Valencia

Rivero Scirgalea, Sebastián (2009). Los procesos y la larga duración en la historia regional. Estudios Históricos-CDHRP- Mayo No 1.

Rodríguez Molas, Ricardo (1958). La Música y la Danza de los Negros en el Buenos Aires de los Siglos XVIII y XIX. Buenos Aires: Editorial Clío

Rodríguez Molas, Ricardo (1959). "El Hombre de Color en la Música Rioplatense" en Revista de la Universidad (La Plata) No 6, pp. 133-136; 
Rodríguez Molas, Ricardo (1959). "El Negro en la Sociedad Porteña después de Caseros", Comentario, Buenos Aires, № 22.

Rodríguez Molas, Ricardo (1961) "Negros Libres Rioplatenses" en Revista de Humanidades, Ministerio de Educación de la Provincia de Buenos Aires, No 1, pp. 133- 171.

Rodríguez Molas, Ricardo (1988) "Esclavitud Áfricana, Religión y Origen Étnico", en Ibero-Amerikanisches Archiv, No 14(2), pp. 125-147.

Rodríguez Molas, Ricardo (1993) “Aspectos ocultos de la identidad nacional: Los negros y el origen del tango" Ciclos, N ${ }^{\mathrm{o}} 3(5)$, pp. 147-161.

Rodríguez Molas, Ricardo (1999) "Presencia de África Negra en la Argentina" DesMemoria, № 21/22, pp. 33-70;

Rodríguez Molas, Ricardo (2000) "Los afroargentinos y los orígenes del tango" DesMemoria, No 27, pp. 87-132.

Román Alarcón, Rigoberto Arturo (2002). "La región y su análisis: teorías para su estudio". Revista Clío, Nueva época, Vol. 1 número 28.

Roman, Cesar (2012) "Agentes del Imperio, autoridades locales y trabajo coactivo en el proceso de fundación de villas. Los "entrerianos" en el último tercio del siglo XVIII" En Canedo, Mariana (Comp.) Poderes intermedios en la frontera. Buenos Aires, siglo XVIII- XIX. Mar del Plata: EUDEM.

Rosal, Miguel Ángel y Schmit, Roberto (1999). "Del reformismo colonial borbónico al libre comercio: las exportaciones pecuarias del Río de la Plata (17681854)", Boletín del Instituto de Historia Argentina Dr. Emilio Ravignani, Tercera Serie, núm. 20, Buenos Aires.

Rosal, Miguel y Roberto Schmit (2004). "Las exportaciones pecuarias bonaerenses y el espacio mercantil rioplatense (1768- 1854)". En Juan Carlos Garavaglia y Raúl Fradkin (ed.) En busca del tiempo perdido. La economía de Buenos Aires en el país de la abundancia 1750-1865. Buenos Aires: Prometeo.

Ruiz i Pablo, Ángel. (1994) Historia de la Real Junta particular de comercio de Barcelona (1758-1847). Menorca: Nura.

Sánchez Suarez, A. "La formación de una política económica prohibicionista en Cataluña, 1760- 1840”. Lleida. Ed Espai/Temps. 1988.

Sandrín María Emilia (2008). "El abasto y la provisión de bienes y servicios en el Sitio de Colonia del Sacramento, 1735-1737”, en: XXI Jornadas de Historia Económica, Caseros, 23 al 26 de septiembre. En línea: http://xxijhe.fahce.unlp.edu.ar.

Sandrín, María Emilia (2011). Bizcocheras, lancheros y demás... Los estímulos de la guerra para los sectores medios y bajos del complejo portuario rioplatense, 1735-1737. Madrid: Editorial Académica Española. 
Sandrín, Maria Emilia (2014). "Los carpinteros, calafates, herreros, faroleros y demás trabajadores de las fragatas correo en Montevideo y su posible participación en el proceso emancipador". Revista Naveg@mérica. Revista electrónica editada por la Asociación Española de Americanistas, n. 12.

Santilli, Daniel (2013) “¿Perjudiciales o beneficiosas? La discusión sobre el impacto económico de las reformas borbónicas en Buenos Aires y su entorno". Revista Fronteras de la Historia. Vol. 18, número 2, julio- diciembre. Instituto Colombiano de Antropología e Historia. Bogotá. Colombia.

Santos, Corcino Medeiros dos (2010). O Tráfico de escravos do Brasil para o Rio da Prata. Brasília: Edições do Senado Federal.

Santos, Corcino Medeiro dos (2005). "Negros e tabaco nas relações hispanolusitanas do Río da Plata". In: Actas do Congresso Internacional "Espaço Atlântico de Antigo Regime: poderes e sociedades. Lisboa, 2 a 5 de noviembre. Disponible en: http://cvc.institutocamoes.pt/eaar/coloquio/comunicacoes/corcino_medeiros_santos.pdf

Sarreal, Julia (2009). Globalization and the Guarani: From Missions to Modernization in the Eighteenth Century." Harvard. Harvard.

Saguier, Eduardo (1989). "La naturaleza estipendiaria de la esclavitud urbana colonial. El caso de Buenos Aires en el siglo XVIII". Revista Paraguaya de Sociología, Año 26, № 74. enero-abril.

Saguier, Eduardo. (2015) Un debate inconcluso en la América Latina (16002000). Cuatro Siglos de lucha en el espacio colonial peruano y rioplatense y la argentina moderna y contemporánea. 16 tomos. En línea: http://www.ersaguier.org/obras/udhielal/indice.php.

Schmit, R. (2004) Ruina y resurrección en tiempos de guerra. Sociedad, economía y poder en el oriente entrerriano posrevolucionario, 1810-1852. Buenos Aires, Prometeo.

Schlez, Mariano (2010) Dios, Rey y Monopolio. Los comerciantes monopolistas y la contrarrevolución en el Río de la Plata tardo colonial. Buenos Aires, Ediciones RyR.

Schlez, Mariano (2014) Entre Dios y la Revolución. El clero rioplatense frente a la Revolución de Mayo de 1810. Los casos de Julián Segundo de Agüero y Juan Manuel Fernández de Agüero Naveg@mérica; Lugar: Murcia; p. 1 -35

Schlez, Mariano (2014) La medición de la ganancia mercantil en el Río de la Plata colonial: el caso de Diego de Agüero y Compañía (Río de la Plata, 1770-1820) Revista de Indias; Lugar: Madrid.

Schlez, Mariano (2014) Buenos Aires versus Lima. La estrategia reformista de los comerciantes porteños (1770-1794). Illapa. Revista Latinoamericana de Ciencias Sociales; Lugar: Lima; p. 43 - 64 
Silva, Hernán Asdrúbal (1993) El comercio entre España y el Río de la Plata (1778-1810). España: Banco de España.

Silva, Hemán Asdrúbal (1979). "Los norteamericanos y el tráfico entre el Río de la Plata y La Habana." XIII Jornadas de la Asociación Argentina de Estudios Americanos. Termas de Río Hondo.

Silva, Hernán Asdrúbal (1994). "La estructuración del comercio y la navegación desde el Río de la Plata a Cuba" Anuario de Estudios Americanos. Tomo LI, núm. 2.

Socolow, Susan (1978). "La burguesía comerciante de Buenos Aires en el siglo XVIII". Desarrollo Económico. Vol. 18, No 70. Jul. Sep.

Socolow, Susan (1975). "Economic activities of the porteño Merchants: the Viceregal period". HAHR, 55.1.

Socolow, Susan (1988). Los mercaderes del Buenos Aires virreinal. Familia y Comercio. Buenos Aires: Ediciones de la Flor.

Studer, Elena (1958). La trata de negros en el Río de la Plata durante el siglo XVIII. Buenos Aires: Universidad de Buenos Aires.

Taracena Arriola, Arturo (2008). "Propuesta de definición histórica para región", en Estudios de Historia Moderna y Contemporánea de México, n. 35. enero-junio.

Tarragó, Griselda (1993)"Los Diez de Andino: un linaje colonial santafesino. 1660-1822", en Cuadernos de Historia Regional, $n^{\circ} 16$, Universidad Nacional de Luján/Editorial Biblos,

Tarragó, Griselda (1994) "Elite, parentesco y comercio en Santa Fe, siglo XVIII", en Anuario de la Escuela de Historia, ${ }^{\circ} 16$, Rosario, UNR.

Tarragó, Griselda (2006) "De las montañas al Río de la Plata: gobernadores cántabros en Buenos Aires (primera mitad del siglo XVIII), en Monte Buciero, 12, Santoña, Ayuntamiento de Santoña.

Tarragó, Griselda y Elsa Caula (2003). "Cuando el mañana sólo era desamparo. Comerciantes rioplatenses en tiempos de guerra, 1806-1820." Prohistoria $\mathrm{N}^{\mathrm{o}} 7$.

Ternavasio, Marcela (2002). La revolución del voto. Política y elecciones en Buenos Aires, 1810- 1852. Buenos Aires: Siglo XXI.

Tejerina Garza, Eliézer (2008). "Evaluación crítica del neoinstitucionalismo de D. C. North" Revista Denarius. Instituciones y desarrollo: diagnostico y evaluación. Año. Vol. 15. No 1.

Tejerina, Marcela (2002). Luso-brasileños en el Buenos Aires virreinal: trabajo, negocios e intereses en la plaza naviera y comercial. Bahía Blanca: De la Universidad Nacional del Sur.

Thompson, E. P. (2001). La formación de la clase obre en Inglaterra. Barcelona: Crítica. 
Thompson, E. P. (1998) Costumbres en común. Barcelona: Crítica.

Thompson, E. P. (1992) Tradición, revuelta y conciencia de clase. Barcelona: Crítica.

Tornero, Pablo. (1996) "Comercio colonial y proyección de la población: La emigración Catalana a Cuba en la época del crecimiento azucarero (1790- 1817)". Boletín Americanista. Año XXXI Sevilla.

Torras Elias, Jauma (2007). Fabricants sense fàbrica, els Torelló d'igualada (1691- 1794). Vic. Ed. EUMO.

Undurraga, C., Maureira, F., Santibañez, E y Zuleta, J. (1990). Investigación en educación popular. Santiago: CIDE.

Van Young, Eric (1987). "Haciendo historia regional consideraciones metodológicas y teóricas" Anuario IEHS, 2.

Vicens i Vives, Jaume (1974). Coyuntura económica y reformismo burgués. Ed. Ariel. Barcelona..

Vicens i Vives, Jaume (1958). Historia Social y Económica de España y América. Barcelona, tomo IV.

Vilar, Pierre (1988). Cataluña en la España Moderna. La formación del capital comercial. Barcelona: Crítica.

Villalobos, Sergio (1965). Comercio y contrabando en el Río de la Plata y Chile, 1700-1811. Buenos Aires: EUDEBA.

Wetzel, Claudia (1988) "El comercio del Litoral de los Ríos con Buenos Aires: El aria del Paraná, 1783-1821”. Anuario del IHES 3. Tandil. 


\section{Anexos}

Anexo I: Grandes cargadores de metales preciosos (1779- 1794) y cueros (1779-

1799)

\begin{tabular}{|c|c|c|c|c|c|}
\hline Nombre & Metales & Años & Envios & Cueros & Años \\
\hline $\begin{array}{l}\text { Abaroa } \\
\text { Barrena, } \\
\text { Matias }\end{array}$ & 176526 & 1783-1794 & 77 & 7100 & 1787 \\
\hline $\begin{array}{l}\text { Agüero, } \\
\text { Diego }\end{array}$ & 513587 & 1783-1794 & 205 & 15130 & 1784-92 \\
\hline $\begin{array}{l}\text { Aguirre, } \\
\text { Agustin } \\
\text { Casimiro }\end{array}$ & 258755 & 1783-1789 & 93 & 316.990 & 1779-94 \\
\hline $\begin{array}{l}\text { Aguirre, } \\
\text { Cristobal }\end{array}$ & 181048 & $1783-1790$ & 87 & 0 & 0 \\
\hline Aguirre, Juan & 108727 & $1785-1791$ & 27 & 0 & 0 \\
\hline Alsina, Jaime & 188201 & $1783-1794$ & 153 & 5948 & $1784-96$ \\
\hline $\begin{array}{l}\text { Alvarado, } \\
\text { Pedro }\end{array}$ & 125145 & 1783-1793 & 101 & 19339 & 1786-92 \\
\hline $\begin{array}{l}\text { Alvarez, } \\
\text { Saturnino } \\
\end{array}$ & 59454 & 1783-1794 & 80 & 0 & 0 \\
\hline $\begin{array}{l}\text { Alzaga, } \\
\text { Martin }\end{array}$ & 192858 & $1784-1790$ & 53 & 72890 & $1789-96$ \\
\hline $\begin{array}{l}\text { Amenabar, } \\
\text { Josep }\end{array}$ & 66777 & $1783-1794$ & 63 & 0 & 0 \\
\hline $\begin{array}{l}\text { Anchorena, } \\
\text { Juan Esteban }\end{array}$ & 321179 & 1783-1794 & 58 & 0 & 0 \\
\hline $\begin{array}{l}\text { Aramburu, } \\
\text { Adrian }\end{array}$ & 52776 & $1783-1790$ & 90 & 0 & 0 \\
\hline $\begin{array}{l}\text { Arana, } \\
\text { Joaquin }\end{array}$ & 176026 & 1783- 1794 & 57 & 0 & 0 \\
\hline $\begin{array}{l}\text { Arana, } \\
\text { Manuel }\end{array}$ & 975440 & 1783-1794 & 223 & 0 & 0 \\
\hline $\begin{array}{l}\text { Arguibel, } \\
\text { Felipe }\end{array}$ & 84234 & 1783-1794 & 83 & 201733 & $1784-96$ \\
\hline $\begin{array}{l}\text { Avecilla, } \\
\text { Cristobal }\end{array}$ & 123990 & 1786-1793 & 107 & 11896 & $1791-93$ \\
\hline $\begin{array}{l}\text { Belanzategui, } \\
\text { Tomas }\end{array}$ & 424587 & 1783-1794 & 170 & 180493 & $1784-97$ \\
\hline $\begin{array}{l}\text { Balbastro, } \\
\text { Isidro }\end{array}$ & 428372 & 1783-1794 & 168 & 18222 & 1785 \\
\hline $\begin{array}{l}\text { Basavilbaso, } \\
\text { Manuel }\end{array}$ & 3877686 & 1783-1794 & 2050 & 4310 & $1784-89$ \\
\hline $\begin{array}{l}\text { Basualdo, } \\
\text { Manuel }\end{array}$ & 127279 & $1783-1790$ & 37 & 0 & 0 \\
\hline $\begin{array}{l}\text { Baudrix, } \\
\text { Juan }\end{array}$ & 61850 & $1783-1786$ & 30 & 6213 & 1784 \\
\hline $\begin{array}{l}\text { Belgrano } \\
\text { Perez, } \\
\text { Domingo }\end{array}$ & 94230 & 1783-1792 & 61 & 49740 & $1784-93$ \\
\hline
\end{tabular}




\begin{tabular}{|c|c|c|c|c|c|}
\hline $\begin{array}{l}\text { Bosch, } \\
\text { Francisco }\end{array}$ & 71499 & 1784-1794 & 87 & 27752 & $1788-96$ \\
\hline $\begin{array}{l}\text { Cerro Sanz, } \\
\text { Manuel }\end{array}$ & 83208 & $1783-1793$ & 80 & 1827 & 1784 \\
\hline $\begin{array}{l}\text { Diaz de } \\
\text { Vivar, Pedro }\end{array}$ & 133240 & 1783-1794 & 93 & 2832 & $1790-93$ \\
\hline $\begin{array}{l}\text { Diaz Velez, } \\
\text { Francisco }\end{array}$ & 211147 & $1783-1794$ & 101 & 0 & 0 \\
\hline Dubal, Pedro & 107268 & 1783-1794 & 114 & 159329 & $1788-99$ \\
\hline $\begin{array}{l}\text { Echeñique, } \\
\text { Juan }\end{array}$ & 161246 & $1783-1793$ & 95 & 132115 & $1779-89$ \\
\hline $\begin{array}{l}\text { Erezcano, } \\
\text { Agustin }\end{array}$ & 161439 & 1783-1794 & 100 & 0 & 0 \\
\hline Euba, Juan & 208836 & 1783-1794 & 133 & 0 & 0 \\
\hline Ezcurra, Juan & 99521 & 1783-1793 & 57 & 0 & 0 \\
\hline $\begin{array}{l}\text { Fernandez, } \\
\text { Tomas }\end{array}$ & 91636 & $1783-1793$ & 69 & 0 & 0 \\
\hline $\begin{array}{l}\text { Flotat, } \\
\text { Santiago }\end{array}$ & 69454 & 1783-1794 & 43 & 5180 & 1791-93 \\
\hline $\begin{array}{l}\text { Gainza, } \\
\text { Josep }\end{array}$ & 611110 & $1783-1794$ & 267 & 1408 & $1784-93$ \\
\hline $\begin{array}{l}\text { Garcia } \\
\text { Lopez, } \\
\text { Antonio }\end{array}$ & 129085 & 1783-1793 & 27 & 0 & 0 \\
\hline $\begin{array}{l}\text { Gardeazabal, } \\
\text { Luis }\end{array}$ & 269300 & 1783-1794 & 169 & 4700 & 1794 \\
\hline $\begin{array}{l}\text { Gonzalez } \\
\text { Bolaños, } \\
\text { Josep } \\
\end{array}$ & 374068 & 1783-1794 & 200 & 197973 & $1779-96$ \\
\hline $\begin{array}{l}\text { Gonzalez } \\
\text { Cortina, } \\
\text { Pedro }\end{array}$ & 51520 & 1784-1794 & 24 & 0 & 0 \\
\hline $\begin{array}{l}\text { Gonzalez, } \\
\text { Domingo }\end{array}$ & 53804 & 1783-1794 & 64 & 1000 & $1794-96$ \\
\hline $\begin{array}{l}\text { Gonzalez, } \\
\text { Gregorio }\end{array}$ & 88639 & 1783-1794 & 57 & 0 & 0 \\
\hline $\begin{array}{l}\text { Gonzalez, } \\
\text { Josep }\end{array}$ & 74878 & 1783-1794 & 62 & 0 & 0 \\
\hline $\begin{array}{l}\text { Hernandez, } \\
\text { Julian }\end{array}$ & 54309 & 1783-1789 & 49 & 0 & 0 \\
\hline Insua, Tomas & 150510 & 1783-1794 & 91 & 1393 & 1784 \\
\hline $\begin{array}{l}\text { Lagraba, } \\
\text { Juan }\end{array}$ & 60532 & 1784-1794 & 17 & 3496 & $1792-95$ \\
\hline $\begin{array}{l}\text { Larrea, } \\
\text { Bernardo }\end{array}$ & 185856 & $1783-1786$ & 53 & 8534 & 1784 \\
\hline $\begin{array}{l}\text { Larrea, } \\
\text { Miguel }\end{array}$ & 87365 & $1783-1791$ & 27 & 0 & 0 \\
\hline $\begin{array}{l}\text { Las Heras, } \\
\text { Bernardo }\end{array}$ & 205302 & 1783-1794 & 103 & 26872 & 1784-94 \\
\hline $\begin{array}{l}\text { Lerdo de } \\
\text { Tejada, } \\
\text { Eugenio }\end{array}$ & 245878 & 1783-1791 & 120 & 0 & 0 \\
\hline
\end{tabular}




\begin{tabular}{|c|c|c|c|c|c|}
\hline Lesica, Josep & 235501 & $1783-1794$ & 77 & 836 & $1779-88$ \\
\hline Lesica, Juan & 2396590 & 1783-1794 & 1072 & 168101 & $1784-97$ \\
\hline $\begin{array}{l}\text { Llano, } \\
\text { Francisco }\end{array}$ & 73776 & $1783-1794$ & 88 & 7550 & $1789-95$ \\
\hline $\begin{array}{l}\text { Llorente } \\
\text { Romero, } \\
\text { Ventura }\end{array}$ & 52279 & $1783-1791$ & 44 & 4297 & $1785-91$ \\
\hline $\begin{array}{l}\text { Martinez de } \\
\text { Hoz, Josep }\end{array}$ & 187303 & 1784-1794 & 73 & 312 & 1784 \\
\hline Maza, Mateo & 287256 & 1783-1791 & 71 & 0 & 0 \\
\hline $\begin{array}{l}\text { Molino, } \\
\text { Julian }\end{array}$ & 197117 & 1784-1794 & 118 & 0 & 0 \\
\hline $\begin{array}{l}\text { Nadal y } \\
\text { Guarda, } \\
\text { Jaime }\end{array}$ & 191902 & 1784-1794 & 165 & 1254 & 1784-1794 \\
\hline $\begin{array}{l}\text { Necochea, } \\
\text { Casimiro }\end{array}$ & 622205 & $1783-1794$ & 367 & 585701 & 1784-99 \\
\hline $\begin{array}{l}\text { Novales, } \\
\text { Manuel }\end{array}$ & 86399 & 1783- 1788 & 33 & 1779 & 3382 \\
\hline $\begin{array}{l}\text { Obligado, } \\
\text { Antonio }\end{array}$ & 191346 & 1783- 1794 & 84 & 0 & 0 \\
\hline Orueta, Luis & 80530 & 1784- 1790 & 24 & 0 & 0 \\
\hline Osorio, Juan & 55292 & $1783-1790$ & 19 & 0 & 0 \\
\hline $\begin{array}{l}\text { Pinto, } \\
\text { Joaquin }\end{array}$ & 594062 & 1783- 1794 & 177 & 2100 & 1793 \\
\hline $\begin{array}{l}\text { Pita de la } \\
\text { Vega, } \\
\text { Pascual } \\
\end{array}$ & 51554 & $1783-1790$ & 24 & 0 & 0 \\
\hline $\begin{array}{l}\text { Pueyrredon, } \\
\text { Juan }\end{array}$ & 119421 & 1783- 1791 & 63 & 1883 & 1787-89 \\
\hline $\begin{array}{l}\text { Quintana, } \\
\text { Antonio }\end{array}$ & 52025 & 1784 & 12 & 0 & 0 \\
\hline $\begin{array}{l}\text { Rodriguez de } \\
\text { la Vega, } \\
\text { Manuel }\end{array}$ & 460258 & 1783- 1794 & 135 & 0 & 0 \\
\hline $\begin{array}{l}\text { Romero, } \\
\text { Tomas } \\
\end{array}$ & 112413 & 1783- 1794 & 150 & 113792 & 1788-99 \\
\hline $\begin{array}{l}\text { Ruiz de } \\
\text { Gaona, Pablo }\end{array}$ & 260901 & 1783- 1794 & 180 & 0 & 0 \\
\hline $\begin{array}{l}\text { Santa } \\
\text { Coloma, } \\
\text { Gaspar }\end{array}$ & 884810 & 1783- 1794 & 246 & 12424 & $1789-92$ \\
\hline Sanz, Miguel & 92822 & 1783- 1794 & 56 & 2000 & 1783 \\
\hline $\begin{array}{l}\text { Sarasa, } \\
\text { Saturnino }\end{array}$ & 95158 & $1783-1790$ & 44 & 0 & 0 \\
\hline $\begin{array}{l}\text { Sarratea, } \\
\text { Martin }\end{array}$ & 349758 & 1783- 1794 & 141 & 0 & 0 \\
\hline $\begin{array}{l}\text { Segurola, } \\
\text { Francisco }\end{array}$ & 523255 & 1783- 1794 & 224 & 0 & 0 \\
\hline $\begin{array}{l}\text { Ugarte, } \\
\text { Francisco }\end{array}$ & 792535 & $1783-1794$ & 147 & 44033 & $1784-96$ \\
\hline
\end{tabular}




\begin{tabular}{|c|c|c|c|c|c|}
\hline $\begin{array}{l}\text { Ugarte, } \\
\text { Julian }\end{array}$ & 144623 & 1785- 1792 & 106 & 95834 & $1786-92$ \\
\hline $\begin{array}{l}\text { Ugarteche, } \\
\text { Josep }\end{array}$ & 96128 & 1784- 1794 & 34 & 27048 & 1794-97 \\
\hline $\begin{array}{l}\text { Villaboa, } \\
\text { Juan }\end{array}$ & 58401 & 1784- 1794 & 54 & 920 & 1794-95 \\
\hline $\begin{array}{l}\text { Villanueba, } \\
\text { Esteban }\end{array}$ & 116248 & 1784- 1794 & 83 & 0 & 0 \\
\hline Zelaya, Juan & 173511 & 1784-1794 & 103 & 1600 & 1793 \\
\hline $\begin{array}{l}\text { Zubiria, } \\
\text { Miguel }\end{array}$ & 57948 & 1783- 1792 & 23 & 0 & 0 \\
\hline $\begin{array}{l}\text { Monfort, } \\
\text { Miguel }\end{array}$ & 18111 & 1784 & 6 & 96699 & $1779-84$ \\
\hline $\begin{array}{l}\text { Conet, } \\
\text { Miguel }\end{array}$ & 0 & 0 & 0 & 102911 & $1789-96$ \\
\hline $\begin{array}{l}\text { De la Peña, } \\
\text { Francisco }\end{array}$ & 15099 & 1784-1794 & 17 & 109020 & $1786-97$ \\
\hline $\begin{array}{l}\text { Martinez, } \\
\text { Juan }\end{array}$ & 2945 & $1783-92$ & 10 & 174360 & $1779-98$ \\
\hline $\begin{array}{l}\text { Ulibarri, } \\
\text { Lorenzo }\end{array}$ & 0 & 0 & 0 & 295297 & $1780-96$ \\
\hline $\begin{array}{l}\text { Diago, } \\
\text { Manuel }\end{array}$ & 4027 & $1783-84$ & 8 & 174245 & $1779-1784$ \\
\hline $\begin{array}{l}\text { Belaustegui, } \\
\text { Francisco }\end{array}$ & 799 & 1783 & 1 & 305412 & $1786-97$ \\
\hline
\end{tabular}


Anexo II: cargadores de metales preciosos, 1779- 1794

\begin{tabular}{|l|r|r|}
\hline Nombre & cantidad & años \\
\hline Acha, Nicolas & 125 & 1786 \\
\hline Acuña. Francisco & 108 & 1783 \\
\hline Agar, Francisco & 15398 & $1786-94$ \\
\hline Agote, Francisco & 18936 & $1786-94$ \\
\hline Aguada, Juan & 487 & 1783 \\
\hline Aguiar, Andres & 70 & 1783 \\
\hline Aguilera, Manuel & 300 & 1784 \\
\hline Aguirre, Francisco & 1792 & 1783 \\
\hline Ahumada, Francisco & 6528 & 1784 \\
\hline Albuerne, Antonio & 1641 & 1784 \\
\hline Alcain, Eugenio & 11648 & $1786-94$ \\
\hline Alcalde, Francisco & 1000 & 1783 \\
\hline Alcalde, Francisco & 1000 & 1783 \\
\hline Aliaga, Martin & 304 & 1785 \\
\hline Allende, Santiago & 20134 & 1786 \\
\hline Almandoz, Francisco & 10925 & $1784-86$ \\
\hline Almandoz, Josep & 1288 & $1784-92$ \\
\hline Almeida, Maria & 914 & $1786-93$ \\
\hline Alonso, Juan & 6125 & 1785 \\
\hline Alonso, Manuel & 8750 & $1783-90$ \\
\hline Alsina, Tirso & 1300 & $1784-85$ \\
\hline Altamira, Manuel & 2000 & 1784 \\
\hline Altoaguirre, Leon & 7200 & 1786 \\
\hline Alvarez, Alberto & 2000 & 1783 \\
\hline Alvarez, Antonio & 1350 & $1783-94$ \\
\hline Alvarez, Ermenegildo & 1377 & 1786 \\
\hline Alvarez, Francisco Antonio & 1100 & 1783 \\
\hline Alvarez, Jacobo & 8000 & 1785 \\
\hline Alvarez, Josep & 400 & 1784 \\
\hline Alvarez, Miguel & 320 & 1786 \\
\hline Alvarez, Pedro & 110 & $1784-86$ \\
\hline Alvarez, Saturnino & 12151 & $1784-94$ \\
\hline Alvear, Diego & 59454 & $1783-94$ \\
\hline Alzaga, Blas & 6000 & $1783-84$ \\
\hline Alzaga, Mateo & 10806 & $1783-85$ \\
\hline Alzaga, Ramon & 100 & $1785-86$ \\
\hline Amenabar, Francisco & 1785 \\
\hline Andrade, Antonio & $1784-94$ \\
\hline Andrade, Juan & 1784 \\
\hline Ano, Juan Bautista & 1784 \\
\hline Ansede y Graña, Francisco & 1783 \\
\hline Antecha, Antonio & 178 \\
\hline Antela, Manuel & 178 \\
\hline Añores, Miguel & 178 \\
\hline
\end{tabular}




\begin{tabular}{|c|c|c|}
\hline Aramburu, Adrian & 52776 & $1783-90$ \\
\hline Aramburu, Juan & 7950 & 1784-89 \\
\hline Arancivia, Cristobal & 1000 & 1785 \\
\hline Aran Saenz, Antonio & 182 & 1784 \\
\hline Arana, Tomas & 30050 & 1784 \\
\hline Arancia, Baltazar & 192 & 1784 \\
\hline Aransacovi, Antonio & 8768 & $1784-85$ \\
\hline Arce, Manuel & 100 & 1786 \\
\hline Arco, Jose & 1600 & 1783 \\
\hline Arechaga, Geronimo & 1750 & 1784-1794 \\
\hline Arias de Saavedra, Baltasar & 270 & 1786 \\
\hline Arias, Francisco & 650 & 1784 \\
\hline Ariza, Alejandro & 2646 & $1786-91$ \\
\hline Armengol, Ignacio & 4600 & 1784 \\
\hline Arois, Petrona & 2500 & $1784-85$ \\
\hline Arquer, Juan Bautista & 133 & 1784 \\
\hline Arrechaga, Geronimo & 400 & 1786 \\
\hline Arrechea, Antonio & 1950 & 1784 \\
\hline Arredondo, Manuel & 1863 & $1784-85$ \\
\hline Arriaga, Josep & 1100 & $1784-85$ \\
\hline Arriola, Juan & 100 & 1785 \\
\hline Arrivillaga, Agustin & 35696 & 1783 \\
\hline Arroyo, Juan & 2169 & $1784-90$ \\
\hline Artechea, Antonio & 47333 & 1784-91 \\
\hline Artes, Juan & 1900 & 1785 \\
\hline Arueta, Fernando & 2200 & 1784 \\
\hline Aruza, Alejandro & 300 & 1784 \\
\hline Asturiz, Cristobal & 2000 & 1786 \\
\hline Atalay, Tomas & 600 & 1786 \\
\hline Aurel, Miguel & 20000 & 1783 \\
\hline Azcuenaga, Miguel & 51188 & $1783-91$ \\
\hline Azcuenaga, Vicente & 46826 & $1783-87$ \\
\hline Azcueta, Nicolas & 4588 & 1783 \\
\hline Azcurra, Juan & 11600 & 1785 \\
\hline Azteaga, Francisco & 300 & 1783 \\
\hline Baca, Francisco & 80 & 1785 \\
\hline Badiola, Diego & 24165 & 1784 \\
\hline Balbastro, Eugenio Josep & 2000 & 1784 \\
\hline Balbastro, Maria & 4500 & $1783-85$ \\
\hline Balbastro, Ramon & 60 & 1786 \\
\hline Baldeon, Asencio & 600 & 1784 \\
\hline Baldovinos, Francisco & 17580 & $1783-91$ \\
\hline Ballesteros, Pedro & 6650 & $1785-91$ \\
\hline Balvin Vallejos, Juan & 3500 & $1783-86$ \\
\hline Baquijano, Mariana & 2500 & 1786 \\
\hline Barbosa, Josep Teniente de Dragones & 6000 & 1783 \\
\hline Barcela, Cristobal & 400 & 1784 \\
\hline Barguin, Manuel Antonio & 512 & 1784 \\
\hline
\end{tabular}




\begin{tabular}{|c|c|c|}
\hline Barnero, Manuel & 500 & 1784 \\
\hline Barquez, Francisco Antonio & 200 & 1784 \\
\hline Barrena, Manuel & 1500 & 1784 \\
\hline Barrera, Josep & 25835 & $1784-86$ \\
\hline Barrios, Josep & 150 & 1786 \\
\hline Barron, Gregorio & 18450 & $1784-90$ \\
\hline Barua, Josep & 39303 & $1783-90$ \\
\hline Basualdo, Antolin & 260 & $1786-88$ \\
\hline Basualdo, Antonio & 8290 & $1786-88$ \\
\hline Basualdo, Manuel & 127279 & $1783-90$ \\
\hline Battle, Ramon & 30200 & $1783-86$ \\
\hline Baudrix, Juan & 62921 & $1783-86$ \\
\hline Bazarez, Ignacio & 160 & 1786 \\
\hline Becar, Cosme & 1320 & $1784-91$ \\
\hline Bedoya, Ramon & 5507 & 1784 \\
\hline Bejarano, Manuel & 2137 & $1786-89$ \\
\hline Belanzategui, Tomas & 799 & 1783 \\
\hline Belarde, Josep & 1000 & 1784 \\
\hline Belaustegui, Josep & 34104 & $1782-83$ \\
\hline Belderrain, Josep & 9000 & 1786 \\
\hline Bergareche, Nicolas & 6816 & $1784-92$ \\
\hline Bernal, Matias & 958 & 1786-89 \\
\hline Berreondo, Pedro & 64 & 1783 \\
\hline Bersiano, Miguel & 1250 & 1784 \\
\hline Beruti, Pablo & 40976 & 1784-94 \\
\hline Bezoquince, Faustino & 15196 & 1783 \\
\hline Boedo, Manuel & 11033 & $1784-86$ \\
\hline Bofill, Buenaventura & 1080 & $1786-87$ \\
\hline Bonifaci, Josep & 225 & 1784 \\
\hline Borda, Manuel & 2727 & 1783 \\
\hline Boreo, Martin & 316 & 1786 \\
\hline Borja, Francisco & 1147 & 1784 \\
\hline Bosch, Gerardo & 13233 & $1784-85$ \\
\hline Bozo, Faustino & 25512 & $1783-94$ \\
\hline Braco, Fernando & 200 & 1785 \\
\hline Braco, Nicolas & 2870 & $1786-88$ \\
\hline Brunce, Manuel & 1000 & 1783 \\
\hline Bruñel, Manuel & 1000 & 1784 \\
\hline Buceta, Carlos & 100 & 1786 \\
\hline Busogorri, Roque & 547 & 1785 \\
\hline Bustillo, Josep & 810 & $1783-90$ \\
\hline Busto, Francisco & 1386 & 1785 \\
\hline Caballero, Pedro & 491 & $1786-89$ \\
\hline Cabañas, Salvador & 280 & 1786 \\
\hline Cabrera, Francisco & 20915 & $1784-94$ \\
\hline Cajasaville, Andres & 112 & 1786 \\
\hline Calbo, Rafael & 5435 & $1784-1785$ \\
\hline Calcena, Josep & 7600 & $1786-93$ \\
\hline
\end{tabular}




\begin{tabular}{|c|c|c|}
\hline Calleja Sandoval, Juan Antonio & 64 & 1784 \\
\hline Calleja, Josep & 8559 & $1783-92$ \\
\hline Calleja, Marcelino & 21715 & $1783-89$ \\
\hline Calvo, Rafael & 23275 & $1783-88$ \\
\hline Camacho, Francisco & 2800 & $1784-92$ \\
\hline Campos, Andres & 1040 & 1786 \\
\hline Campos, Lorenzo & 19850 & $1783-90$ \\
\hline Camps, Bernardo & 6000 & 1784 \\
\hline Canilla, Santiago & 2500 & 1784 \\
\hline Cano, Francisco & 864 & 1784 \\
\hline Caohe, Mateo & 4600 & 1786 \\
\hline Capdevilla, Josep & 4785 & $1784-94$ \\
\hline Capellan Francisco Domingo & 250 & 1784 \\
\hline Capellan Manuel Varela & 800 & 1783 \\
\hline Capello, Ignacio & 100 & 1784 \\
\hline Capitan Antonio Estrimiana & 500 & 1783 \\
\hline Capitan Leandro Badaran & 1000 & 1784 \\
\hline Carado, Ignacio & 420 & 1784 \\
\hline Carballo, Domingo & 800 & 1785 \\
\hline Cardenas, Rufino & 6272 & $1783-90$ \\
\hline Cardona, Miguel & 1504 & $1784-86$ \\
\hline Casas, Pedro & 907 & 1784 \\
\hline Castañeda, Martin & 1036 & 1784 \\
\hline Castellanos, Rafael & 110 & 1784 \\
\hline Castilla, Santiago & 31876 & $1783-86$ \\
\hline Castillo, Ignacio & 300 & 1783 \\
\hline Castillo, Juan & 17900 & $1784-90$ \\
\hline Castro, Blas & 928 & 1783 \\
\hline Castro, Felipe & 12144 & $1784-87$ \\
\hline Castro, Jacinto & 450 & $1785-87$ \\
\hline Castro, Joaquin & 171 & 1786 \\
\hline Castro, Julian & 114 & 1785 \\
\hline Cavallero, Pedro & 3100 & $1784-86$ \\
\hline Celiser, Bruno & 236 & 1785 \\
\hline Cerafin, Francisco & 2445 & 1783 \\
\hline Cevallos, Josep & 511 & 1784 \\
\hline Chabarria, Matias & 4500 & $1784-86$ \\
\hline Chapeli, Jaime & 3000 & 1783 \\
\hline Chavarria, Matias & 2000 & $1784-94$ \\
\hline Cima, Josep & 4808 & $1784-92$ \\
\hline Cires, Eusebio & 39137 & $1783-86$ \\
\hline Colobran, Francisco & 3054 & $1783-84$ \\
\hline Comesaña, Pedro & 30 & 1786 \\
\hline Cometa, Fernando & 356 & 1785 \\
\hline Compta, Josep & 6824 & 1783 \\
\hline Cordoba, Fermin & 7000 & $1783-84$ \\
\hline Cordoba, Juan & 297 & 1783 \\
\hline Correa, Antonio & 1258 & $1783-86$ \\
\hline
\end{tabular}




\begin{tabular}{|c|c|c|}
\hline Cot, Josep & 7500 & 1785 \\
\hline Cristino, Lorenzo & 1462 & $1785-87$ \\
\hline Cubelo, Luis & 3740 & 1786 \\
\hline Cuebas, Manuel & 696 & 1785 \\
\hline Cueli, Juana Petrona & 20200 & $1783-94$ \\
\hline Cueto, Pedro & 300 & 1784 \\
\hline $\begin{array}{l}\text { Cura de NN de la Piedad de Bs As Francisco } \\
\text { Zamudio }\end{array}$ & 500 & 1784 \\
\hline De Acha, Nicolas & 379 & 1783 \\
\hline De Basa, Manuel & 2123 & 1784 \\
\hline de Cuba Juan Bautista & 2800 & 1784 \\
\hline De la Barca, Pedro & 1779 & 1783 \\
\hline De la Concha, Agustin & 27780 & $1783-84$ \\
\hline De la Concha, Domingo & 6764 & $1783-93$ \\
\hline De la Cruz, Nicolas & 10000 & 1783 \\
\hline De la Cruz, Vicente & 13000 & 1783 \\
\hline De la Graba, Juan & 8500 & 1785 \\
\hline De la Guarda, Domingo & 200 & 1784 \\
\hline De la Mata, Bartolome & 8500 & $1783-85$ \\
\hline De la Mata, Pedro & 30887 & $1783-89$ \\
\hline De la Peña, Francisco & 15110 & $1784-94$ \\
\hline De la Peña, Josep & 10064 & $1786-88$ \\
\hline De la Prava, Juan & 100 & 1783 \\
\hline De la Quinta, Josefa & 600 & 1784 \\
\hline De la Rosa, Vicente & 600 & $1786-94$ \\
\hline De la Torre, Bernardo & 5423 & $1785-92$ \\
\hline De la Torre, Josep & 2174 & 1785 \\
\hline De la Torre, Manuel & 12000 & 1783 \\
\hline De la Vega, Manuel & 2000 & 1785 \\
\hline De la Vega, Pascual & 7980 & $1786-90$ \\
\hline De la Vega, Pedro & 56 & 1786 \\
\hline De las Cagigas, Juan & 1000 & 1785 \\
\hline De las Carreras, Josep & 200 & 1784 \\
\hline De las Heras, Bernardo & 6284 & 1784 \\
\hline De los Rios, Alonso & 1325 & $1785-86$ \\
\hline De Mata, Fernando & 420 & 1783 \\
\hline de Mora, Manuel & 1755 & $1784-87$ \\
\hline De Murga, Gabriel & 5410 & $1783-91$ \\
\hline De Murga, Miguel & 1000 & 1784 \\
\hline De Paula Saubidet, Francisco & 2403 & $1783-91$ \\
\hline de Prieto y Pulido, Facundo & 208 & 1784 \\
\hline Decima y Ocampo, Jose & 100 & 1786 \\
\hline Del Campo, Nicolas & 17685 & 1784-89 \\
\hline Del Molino Torres, Julian & 15841 & $1786-87$ \\
\hline Del Portal, Manuel & 15546 & $1783-86$ \\
\hline Del Rincon, Andres & 9036 & 1785 \\
\hline Del Rio, Antonio & 1163 & 1786 \\
\hline Del Valle, Francisco & 4080 & 1784 \\
\hline
\end{tabular}




\begin{tabular}{|c|c|c|}
\hline Diago, Manuel & 4027 & $1783-84$ \\
\hline Diaz de Arenas, Francisco & 150 & 1785 \\
\hline Diaz de Vedoya, Manuel & 2500 & $1783-86$ \\
\hline Diaz Mendez, Francisco & 2000 & 1783 \\
\hline Diaz Perafan, Francisco & 812 & 1784 \\
\hline Diaz Saravia, Mateo & 6049 & 1785 \\
\hline Diaz, Josep & 11854 & 1785 \\
\hline Diaz, Lorenzo & 2931 & $1783-94$ \\
\hline Diaz, Ramon & 43122 & $1783-94$ \\
\hline Dulon, Juan & 460 & 1786 \\
\hline Echapera, Jaime & 800 & 1783 \\
\hline Echeverria, Josep & 10847 & $1783-90$ \\
\hline Echevarria, Matias & 3500 & 1783 \\
\hline Echeverria, Pedro & 4125 & 1784 \\
\hline Elguera, Juan & 2000 & 1784 \\
\hline Elia, Juan Ignacio & 676 & 1784 \\
\hline Elizalde, Francisco & 13905 & $1786-93$ \\
\hline Ellaurdi, Manuel & 17192 & $1783-85$ \\
\hline Elortondo, Blas & 109 & 1785 \\
\hline Elzaurdi, Antonio & 1750 & 1784 \\
\hline Endeiza, Juan & 5066 & $1785-94$ \\
\hline Ensena, Josep & 306 & 1783 \\
\hline Erreno, Francisco & 217 & 1786 \\
\hline Escalada, Antonio & 20408 & $1783-89$ \\
\hline Escalada, Felipe & 5193 & $1786-90$ \\
\hline Escalada, Francisco & 41562 & $1784-94$ \\
\hline Escalada, Josep & 3282 & $1783-88$ \\
\hline Escudero, Josep & 20012 & $1784-92$ \\
\hline Espinosa, Domingo & 100 & 1786 \\
\hline Espinosa, Francisco & 1000 & $1785-86$ \\
\hline Esteves, Pedro & 12460 & $1784-87$ \\
\hline Estevez, Domingo & 1400 & 1784 \\
\hline Ezpeleta, Juan & 30011 & 1784 \\
\hline Fabro Palacios, Bartolome & 33183 & 1786 \\
\hline Fajardo, Joaquin & 1125 & 1785 \\
\hline Febrer Brigadier de los Ejercitos, Miguel & 1500 & 1784 \\
\hline Feijo, Francisco & 2000 & 1783 \\
\hline Fernandez, Tomas & 5000 & 1785 \\
\hline Fernandez de Acevedo, Miguel & 12124 & $1786-90$ \\
\hline Fernandez de la Barca, Ramon & 970 & 1784 \\
\hline Fernandez de la Peña, Francisco & 3008 & 1784 \\
\hline Fernandez de Paredes, Tomas & 1129 & 1784 \\
\hline Fernandez Muñiz, Josep & 800 & 1783 \\
\hline Fernandez Portal, Manuel & 1550 & 1784 \\
\hline Fernandez Trelles, Manuel & 2529 & 1785 \\
\hline Fernandez, Francisco & 8400 & $1784-88$ \\
\hline Fernandez, Ildefonso & 548 & 1783 \\
\hline Fernandez, Josep & 14795 & $1783-92$ \\
\hline
\end{tabular}




\begin{tabular}{|c|c|c|}
\hline Fernandez, Juan & 14415 & $1783-94$ \\
\hline Fernandez, Julian & 2000 & 1784 \\
\hline Fernandez, Lucas & 47045 & $1783-84$ \\
\hline Fernandez, Manuel & 4307 & $1785-89$ \\
\hline Fernandez, Melchor & 500 & $1785-90$ \\
\hline Fernandez, Pedro & 14523 & $1783-94$ \\
\hline Fernandez, Ventura & 604 & $1783-94$ \\
\hline Ferreira, Manuel & 14711 & $1784-94$ \\
\hline Ferreira, Vicente & 750 & 1786 \\
\hline Ferrero, Joaquin & 5600 & $1783-91$ \\
\hline Ferreto, Josep & 100 & 1784 \\
\hline Ferreyra, Fray Juan Nicolas & 208 & 1784 \\
\hline Ferros, Domingo & 20 & 1786 \\
\hline Figueiro, Antonio & 961 & $1786-87$ \\
\hline Firmat, Manuel & 440 & $1784-85$ \\
\hline Flotat, Santiago & 69454 & $1784-93$ \\
\hline Frai Tomas Donoso Pajuelo & 2480 & 1783 \\
\hline Frasqueri, Jaime & 21475 & 1785 \\
\hline Fray Mayor & 2106 & 1783 \\
\hline Fresno, Gabriel & 21000 & 1784 \\
\hline Fresno, Juan & 97 & 1786 \\
\hline Frontera, Josep & 900 & 1786 \\
\hline Frucios, Nicolas & 1600 & 1783 \\
\hline Gabuzo, Miguel & 4000 & 1785 \\
\hline Gallardo, Placido & 5817 & $1783-86$ \\
\hline Gallego, Manuel & 220 & 1786 \\
\hline Galves, Vicente & 6400 & 1783 \\
\hline Galvez, Pedro & 3101 & $1784-87$ \\
\hline Gandara, Julian & 6025 & 1783 \\
\hline Gandia, Domingo & 1325 & 1784 \\
\hline Gandoli, Martin & 3815 & $1785-94$ \\
\hline Gandoqui, Juan & 425 & 1785 \\
\hline Garate, Agustin & 100 & 1785 \\
\hline Garcia Bermudez & 5941 & 1783 \\
\hline Garcia Bustamante, Manuel & 8020 & 1785 \\
\hline Garcia Bustamante, Miguel & 20493 & $1786-91$ \\
\hline Garcia de Gazeta, Francisco & 4499 & $1784-87$ \\
\hline Garcia de la Mata, Josep & 1720 & 1786 \\
\hline Garcia Gaceta, Francisco & 1000 & 1786 \\
\hline Garcia Perea, Carlos & 300 & 1786 \\
\hline Garcia Pumariño, Manuel & 6153 & $1784-86$ \\
\hline Garcia, Agustin & 25654 & $1785-94$ \\
\hline Garcia, Barbara & 634 & 1786 \\
\hline Garcia, Carlos & 10000 & 1783 \\
\hline Garcia, Francisca & 2493 & 1783 \\
\hline Garcia, Francisco & 659 & $1783-84$ \\
\hline Garcia, Ildefonso & 970 & 1783 \\
\hline Garcia, Isidro & 3545 & $1783-87$ \\
\hline
\end{tabular}




\begin{tabular}{|c|c|c|}
\hline Garcia, Joaquin & 2200 & 1785 \\
\hline Garcia, Josep & 8959 & $1784-94$ \\
\hline Garcia, Juan & 37249 & $1784-91$ \\
\hline Garcia, Lorenzo & 17684 & 1784-94 \\
\hline Garcia, Manuel & 4950 & $1786-90$ \\
\hline Garcia, Miguel & 11384 & $1783-94$ \\
\hline Garcia, Ramon & 1605 & $1784-85$ \\
\hline Gardeazabal, Manuel & 35900 & 1784-89 \\
\hline Gardoqui, Francisco & 90 & 1786 \\
\hline Gardoqui, Juan & 679 & $1784-86$ \\
\hline Garre, Antonio & 2200 & 1785 \\
\hline Garviso, Josep & 3000 & 1785 \\
\hline Gascon, Gabriel & 390 & 1785 \\
\hline Gaspar Hernandez, Juan & 2840 & 1784 \\
\hline Gavera, Pedro & 100 & 1783 \\
\hline Gaviria, Jose & 9551 & 1785 \\
\hline Gayoso, Bartola & 80 & 1784 \\
\hline Gazeta, Francisco & 100 & 1786 \\
\hline Gil, Bartolome & 13855 & $1784-88$ \\
\hline Gil, Isabel & 5536 & $1784-94$ \\
\hline Giles Bravo, Fernando & 671 & $1783-84$ \\
\hline Gimarra, Francisco & 2500 & 1785 \\
\hline Godoy, Juan & 108 & 1785 \\
\hline Gogenola, Gregoria & 100 & 1784 \\
\hline Goicoelea, Manuel & 2000 & 1786 \\
\hline Golobardes, Juan & 6025 & $1783-90$ \\
\hline Gomez y Cosio, Manuel & 630 & 1786 \\
\hline Gomez, Domingo & 700 & 1784 \\
\hline Gomez, Francisco & 1169 & $1784-94$ \\
\hline Gomez, Josefa & 1849 & 1784 \\
\hline Gomez, Narciso & 4000 & 1784 \\
\hline Gomez, Pedro & 483 & 1785 \\
\hline Gonzalez Bodallo, Juan & 2000 & 1785 \\
\hline Gonzalez Bueno, Bernabe & 200 & 1784 \\
\hline Gonzalez Cortina, Pedro & 51955 & $1784-94$ \\
\hline Gonzalez de Cueto, Pedro & 29481 & $1784-89$ \\
\hline Gonzalez de Noriega, Miguel & 32069 & $1783-90$ \\
\hline Gonzalez de Rivadavia, Benito & 5083 & $1783-93$ \\
\hline Gonzalez de Sandoval, Carlos & 2300 & $1786-89$ \\
\hline Gonzalez Santander, Francisco & 505 & 1784 \\
\hline Gonzalez, Alonso & 288 & 1785 \\
\hline Gonzalez, Antonio & 3145 & $1785-91$ \\
\hline Gonzalez, Bernardo & 17174 & $1783-91$ \\
\hline Gonzalez, Carlos & 2500 & 1785 \\
\hline Gonzalez, Felipe & 12824 & $1784-89$ \\
\hline Gonzalez, Francisco & 24159 & $1783-91$ \\
\hline Gonzalez, Juan & 4825 & $1783-93$ \\
\hline Gonzalez, Manuel & 2720 & 1783-91 \\
\hline
\end{tabular}




\begin{tabular}{|c|c|c|}
\hline Gonzalez, Miguel & 13836 & $1783-92$ \\
\hline Gonzalez, Pedro & 74878 & $1783-94$ \\
\hline Gonzalez, Santiago & 3652 & 1783 \\
\hline Goñavens, Cayetano & 576 & 1785 \\
\hline Gorriaran, Juan & 5000 & $1785-88$ \\
\hline Goycoechea, Francisco & 7080 & 1784 \\
\hline Goytia, Domingo & 49 & 1783 \\
\hline Granados, Juan & 708 & 1784 \\
\hline Grandoli, Martin & 4180 & $1785-93$ \\
\hline Guerra, Josep & 64 & 1786 \\
\hline Guerreros, Rafael & 330 & 1786 \\
\hline Guevara, Joaquin & 1000 & 1784 \\
\hline Guido, Pedro & 7000 & 1785 \\
\hline Guimara, Francisco & 10302 & $1785-87$ \\
\hline Gurruchaga, Josep & 11495 & $1783-90$ \\
\hline Gurruchaga, Juan & 45066 & $1783-93$ \\
\hline Gurruchaga, Pedro & 7888 & 1785 \\
\hline Gutierrez, Juan & 674 & $1783-86$ \\
\hline Gutierrez, Luis Antonio & 4587 & $1783-84$ \\
\hline Gutierrez, Simon & 20000 & 1784 \\
\hline Guzman, Juan & 100 & 1786 \\
\hline Guzman, Tomas & 139 & 1786 \\
\hline Guzmara, Francisco & 4000 & 1784 \\
\hline Hano, Juan Bautista & 4672 & 1784 \\
\hline Herrero, Francisco & 3946 & $1784-94$ \\
\hline Herrero, Joaquin & 1350 & 1784-89 \\
\hline Hoyo, Miguel & 400 & 1784 \\
\hline Huarriz, Manuel & 9236 & 1784-89 \\
\hline Huguet, Esteban & 28350 & $1783-94$ \\
\hline Hurramendi, Juan & 802 & 1784 \\
\hline Hurtado, Josep & 3081 & $1783-93$ \\
\hline Ibañez, Josep & 3081 & $1786-87$ \\
\hline Ibañez, Pascual & 200 & $1784-86$ \\
\hline Ibare, Pedro & 4000 & 1783 \\
\hline Ibarra, Matias & 3114 & 1783 \\
\hline Idalgo, Juan & 680 & 1783 \\
\hline Idaurren, Juan & 2314 & 1783 \\
\hline Iglesia, Josep & 2908 & $1785-86$ \\
\hline Illarramendi, Juan Francisco & 1000 & 1784 \\
\hline Imaña, Ventura & 2210 & 1785 \\
\hline Inchauraga, Martin & 6000 & 1784 \\
\hline Infante, Juan & 106 & 1784 \\
\hline Iparraguirre, Juan & 4940 & 1784 \\
\hline Iraga, Sebastian & 664 & 1783 \\
\hline Irramendi, Francisco & 1000 & 1784 \\
\hline Irramendi, Juan & 7088 & $1784-94$ \\
\hline Irrimendi, Josep & 1956 & $1783-86$ \\
\hline Iturrigaray, Maria & 2500 & 1784 \\
\hline
\end{tabular}




\begin{tabular}{|c|c|c|}
\hline Iurramande, Francisco & 1200 & 1785 \\
\hline Jaramillo, Pedro & 7000 & 1783 \\
\hline Jazmin, Juan & 1130 & $1784-86$ \\
\hline Jimenez, Alonso & 14000 & 1783 \\
\hline Jimenez, Bartolome & 11000 & $1783-85$ \\
\hline Jimenez, Claudio & 1200 & 1783 \\
\hline Jimenez, Francisco & 33131 & $1783-88$ \\
\hline Jimenez, Gaspar & 15783 & 1784 \\
\hline Jimenez, Josep & 12318 & $1784-86$ \\
\hline Jimenez, Ramon & 6817 & $1783-88$ \\
\hline Jofre, Clemente & 24376 & $1784-94$ \\
\hline Jordan, Josep & 8900 & $1784-86$ \\
\hline Juarez, Miguel & 4000 & 1783 \\
\hline Junco, Pedro & 31524 & 1785 \\
\hline La Madrid, Bernardo & 35000 & 1786 \\
\hline Labander, Francisco & 63404 & 1783 \\
\hline Lagna, Miguel & 1000 & 1784 \\
\hline Lago, Domingo & 3100 & $1783-84$ \\
\hline Lago, Maria & 637 & 1785 \\
\hline Lagraba, Juan & 56808 & $1784-94$ \\
\hline Landa, Julian & 869 & 1783 \\
\hline Landaeta, Juan Jose & 350 & 1784 \\
\hline Larrazabal, Marcos & 235 & 1786 \\
\hline Lascano, Juan & 3925 & $1784-93$ \\
\hline Lati, Manuel & 474 & 1786 \\
\hline Latorriente, Jacinto & 100 & 1784 \\
\hline Lazcano, Agustin & 18092 & $1783-85$ \\
\hline Lazcano, Josep & 14025 & $1783-90$ \\
\hline Lazcano, Placido & 100 & 1784 \\
\hline Legarza, Josep & 32488 & $1784-85$ \\
\hline Lesica, Francisco & 45117 & $1783-91$ \\
\hline Lesica, Manuel & 14076 & $1784-92$ \\
\hline Leyba, Miguel & 800 & 1786 \\
\hline Lezama, Francisco & 200 & $1786-88$ \\
\hline Linda, Juan & 107 & 1784 \\
\hline Lindeso, Francisco & 2500 & 1783 \\
\hline Lino de Leon, Josep & 349 & 1784 \\
\hline Liseras, Josep & 6000 & 1783 \\
\hline Lizarazu, Miguel & 5008 & 1783-89 \\
\hline Llano, Josep & 18759 & $1785-94$ \\
\hline Llano, Manuel & 2000 & 1786 \\
\hline Llano, Tiburcio & 26500 & $1785-91$ \\
\hline Llano, Tomas & 2135 & 1786 \\
\hline Llanos, Miguel & 912 & 1785 \\
\hline Llorente, Josep & 4800 & $1783-86$ \\
\hline llovet, Jaime & 500 & 1786 \\
\hline Lopez, Antonio & 24048 & $1785-93$ \\
\hline Lopez, Gabriel & 9847 & $1786-90$ \\
\hline
\end{tabular}




\begin{tabular}{|c|c|c|}
\hline Lopez, Juan & 335 & $1786-88$ \\
\hline Lopez, Manuel & 25571 & $1785-91$ \\
\hline Lorente, Josep & 2368 & 1784 \\
\hline Lores, Juan & 2500 & 1785 \\
\hline Luaces, Francisco & 3151 & $1786-87$ \\
\hline Lynch, Domingo & 22807 & $1783-94$ \\
\hline Maca, Mateo & 3000 & 1784 \\
\hline Machado, Cayetana & 190 & 1786 \\
\hline Madariaga, Joaquin & 17871 & $1784-92$ \\
\hline Marce, Manuel & 600 & 1784 \\
\hline Marco de Pont, Buenaventura & 10000 & 1784 \\
\hline Marenco, Diego & 674 & 1784-93 \\
\hline Margarit, Manuel & 4900 & $1784-87$ \\
\hline Marimon, Antonio & 800 & 1783 \\
\hline Mariño, Josep Ramon & 1700 & 1784 \\
\hline Marquesa de Casa Real Vesina de Santiago & 3768 & 1785 \\
\hline Marquez de la Plata, Josep & 18144 & $1783-87$ \\
\hline Marquez de la Plata, Miguel & 548 & 1784 \\
\hline Marquez de Roca & 1008 & 1786 \\
\hline Marquez, Josep & 1000 & 1785 \\
\hline Marti, Francisco & 2148 & $1783-94$ \\
\hline Martin, Juan & 2000 & 1784 \\
\hline Martin, Pablo & 208 & 1783 \\
\hline Martinez de Ochagavia, Manuel & 3032 & 1784 \\
\hline Martinez, Antonio & 617 & $1783-90$ \\
\hline Martinez, Felipe & 1500 & $1786-89$ \\
\hline Martinez, Josep & 755 & 1786 \\
\hline Martinez, Juan & 2945 & $1783-92$ \\
\hline Martinez, Manuel & 14341 & $1783-86$ \\
\hline Martinez, Pedro & 8000 & 1783 \\
\hline Martinez, Rafael & 8125 & $1783-86$ \\
\hline Marull, Francisco & 11640 & $1786-94$ \\
\hline Mata, Bartolome & 8000 & $1784-85$ \\
\hline Mata, Pedro & 45023 & $1784-90$ \\
\hline Mateauda, Manuel & 4000 & 1784 \\
\hline Matuliche, Simon & 216 & 1783 \\
\hline Maurin, Domingo & 12400 & $1783-89$ \\
\hline Maurion, Francisco & 5000 & 1784 \\
\hline Maza, Felix & 1500 & 1786 \\
\hline Medina, Francisco & 1246 & 1784 \\
\hline Medrano, Pedro & 1800 & $1786-93$ \\
\hline Mendinueta, Jose & 2987 & 1785 \\
\hline Menendez, Josep & 800 & 1786 \\
\hline Merino, Lazaro & 592 & 1785 \\
\hline Migoya, Francisco & 22 & 1784 \\
\hline Migoya, Juan & 600 & 1785 \\
\hline Millan, Antonio & 25 & 1783 \\
\hline Miranda, Antonio Rodrigo & 250 & 1784 \\
\hline
\end{tabular}




\begin{tabular}{|c|c|c|}
\hline Molas, Maria & 4000 & $1785-86$ \\
\hline Molder, Juan & 150 & 1786 \\
\hline Molina, Felix & 11000 & 1783 \\
\hline Molina, Josef & 10000 & 1783 \\
\hline Moncada, Carmen & 3975 & 1784 \\
\hline Monfort, Miguel & 18115 & 1783 \\
\hline Montada, Mariano & 275 & 1783 \\
\hline Montells, Josep & 14000 & $1784-85$ \\
\hline Montero, Marcos & 1655 & $1785-86$ \\
\hline Moral, Manuel & 30515 & $1783-92$ \\
\hline Moreira, Juan & 28777 & $1783-93$ \\
\hline Moreno de Tejada, Francisco & 130 & $1784-90$ \\
\hline Moreno, Antonio & 105 & $1786-91$ \\
\hline Moreno, Francisco & 100 & 1783 \\
\hline Morillas, Francisco & 80 & 1784 \\
\hline Morrell, Josep & 955 & 1784 \\
\hline Moscoso, Josep & 4000 & $1783-92$ \\
\hline Mota, Salvador & 1000 & 1785 \\
\hline Moya, Felipe & 20 & $1786-92$ \\
\hline Moya, Ramon & 3812 & $1785-88$ \\
\hline Muñoz de Ochogavia, Manuel & 1000 & 1786 \\
\hline Muñoz, Bartolome & 658 & $1784-94$ \\
\hline Murieta, Juan & 1396 & 1786 \\
\hline Muxica, Miguel & 14725 & 1785 \\
\hline Navarro, Josep & 1000 & 1783 \\
\hline Navarro, Juan & 1115 & $1784-88$ \\
\hline Navarro, Miguel & 12000 & 1784 \\
\hline Nebares, Josep & 170 & 1786 \\
\hline Nevares, Pedro & 1080 & $1784-88$ \\
\hline Nolasco, Pedro & 8444 & 1783-94 \\
\hline Novales, Manuel & 71643 & $1783-88$ \\
\hline Nuñez, Felipe & 500 & 1786 \\
\hline Nuñez, Josep & 5745 & $1784-87$ \\
\hline Nuñez, Juan & 20123 & $1785-93$ \\
\hline Nuñez, Manuel & 1005 & $1783-84$ \\
\hline Nuñez, Matias & 155 & $1784-86$ \\
\hline Obligado, Josep & 11820 & 1783 \\
\hline Obregon, Joaquin & 35079 & $1783-88$ \\
\hline Ocampo, Luis & 5000 & 1786 \\
\hline Ocampo, Manuel & 5000 & 1786 \\
\hline Ocampo, Sebastian & 113388 & $1786-90$ \\
\hline Ochagavia, Manuel & 13033 & $1783-93$ \\
\hline Olariaga, Francisco & 20546 & $1783-84$ \\
\hline Olave, Andres & 372 & 1784 \\
\hline Oliver, Mateo & 3000 & 1784 \\
\hline Oliver, Matias & 4000 & 1784 \\
\hline Oliveros, Josep & 13671 & $1783-86$ \\
\hline Ordaurre, Juan Ignacio & 1077 & 1784 \\
\hline
\end{tabular}




\begin{tabular}{|c|c|c|}
\hline Orion, Domingo & 500 & 1784 \\
\hline Orrismendi, Josep & 11306 & $1784-85$ \\
\hline Ortega, Francisco & 11148 & $1784-87$ \\
\hline Ortiz, Josep & 1687 & $1786-93$ \\
\hline Orueta, Fernando & 2112 & $1783-90$ \\
\hline Orueta, Luis & 80480 & $1784-90$ \\
\hline osandabaras, Juan & 108 & 1785 \\
\hline Osorio, Juan & 55292 & 1784-89 \\
\hline Otamendi, Juan & 2000 & 1783 \\
\hline Otecia, Simon & 42 & 1784 \\
\hline Paez Jaramillo, Pablo & 2006 & 1784 \\
\hline Palacios, Francisco & 37500 & 1784 \\
\hline Palacios, Josep & 2147 & $1783-86$ \\
\hline Palacios, Pedro & 4000 & 1785 \\
\hline Palacios, Prudencio & 3782 & 1784 \\
\hline Pallares, Domingo & 5111 & $1784-86$ \\
\hline Palmero, Bernardo & 32 & 1786 \\
\hline Palomeque, Tomas & 5983 & $1784-86$ \\
\hline Paramo Benitez, Tomas & 600 & 1786 \\
\hline Parcero, Jacinto & 138 & 1783 \\
\hline Pardo, Josep & 500 & 1785 \\
\hline Paredes, Maria Ignacia & 573 & 1784 \\
\hline Pareja, Josep & 221 & 1786 \\
\hline Pascual, Andres & 600 & 1783 \\
\hline Paso, Domingo & 469 & $1786-87$ \\
\hline Pasos, Leonardo & 1150 & 1786 \\
\hline \begin{tabular}{|l|} 
Pastor, Blas \\
\end{tabular} & 747 & $1786-90$ \\
\hline Pazano, Joaquin & 110 & 1786 \\
\hline Pazos, Leonardo & 54 & 1786 \\
\hline Peirano, Tomas & 5925 & $1783-87$ \\
\hline Pellares, Domingo & 280 & 1786 \\
\hline Peña Fernandez, Francisco & 3004 & 1784 \\
\hline Pereira, benito & 512 & 1784 \\
\hline Pereyra, Sabastian & 1700 & 1783 \\
\hline Perez, Agustin & 1000 & 1786 \\
\hline Perez, Alberto & 14767 & 1783 \\
\hline Perez, Josep & 6733 & $1783-92$ \\
\hline Perez, Manuel & 4000 & 1784 \\
\hline Perez, Marcos & 6465 & 1783 \\
\hline \begin{tabular}{|l|} 
Perez, Sebastian \\
\end{tabular} & 18030 & $1784-94$ \\
\hline Pita de la Vega, Pascual & 58789 & $1783-92$ \\
\hline Picazarri, Pedro & 22061 & $1783-89$ \\
\hline Pinedo, Antonio & 2938 & $1783-89$ \\
\hline Pinedo, Damaso & 400 & 1784 \\
\hline Pios, Andres & 301 & 1786 \\
\hline Piran, Antonio & 18500 & $1786-93$ \\
\hline Planes, Miguel & 1000 & 1783 \\
\hline Pome y Lobaton, Juan & 1250 & 1783 \\
\hline
\end{tabular}




\begin{tabular}{|c|c|c|}
\hline Pons, Juan & 3861 & $1784-87$ \\
\hline Poppe, Jacobo & 28515 & $1786-88$ \\
\hline Portal, Manuel & 6887 & 1786 \\
\hline Pose, Gerardo & 355 & $1785-94$ \\
\hline Prast y Guerra, Ignacio & 112 & 1784 \\
\hline Prast, Francisco & 22876 & $1783-85$ \\
\hline Presbitero Antonio Gomez & 500 & 1783 \\
\hline Presbitero De la Rosa Olerigo, Hermenegildo & 5100 & 1784 \\
\hline Presbitero Juan Otano & 1258 & 1783 \\
\hline Prieto, Facundo & 3850 & $1784-93$ \\
\hline Pujato, Quirce & 13392 & $1784-88$ \\
\hline Pumariño, Manuel & 1200 & 1784 \\
\hline Quintana, Antonio & 52025 & 1784 \\
\hline Quintana, Josep & 6000 & 1784-91 \\
\hline Quintana, Juan & 48409 & $1783-84$ \\
\hline Quintana, Nicolas & 1000 & 1783 \\
\hline Rajon, Baltasar & 1341 & $1784-86$ \\
\hline Ramirez Bedoya, Antonio & 200 & 1786 \\
\hline Ramirez, Fernando & 10654 & $1784-88$ \\
\hline Ramos, Ignacio & 2520 & $1786-91$ \\
\hline Real, Lorenzo & 12834 & $1784-94$ \\
\hline Rebuelta, Joaquin & 8095 & 1786 \\
\hline Reguero, Domingo & 20210 & $1784-86$ \\
\hline Rejo, Juan & 520 & 1784 \\
\hline Requejo, Ramon & 2892 & $1784-85$ \\
\hline Requena, Josep & 53 & 1783 \\
\hline Revuelta, Vicente & 18111 & $1786-91$ \\
\hline Reyes, Ramon & 120 & 1784 \\
\hline Rezabal, Ignacio & 4049 & $1784-91$ \\
\hline Ribas, Juan & 605 & 1783 \\
\hline Ribas, Nicolas & 5785 & 1784 \\
\hline Ribera, Lazaro & 300 & 1785 \\
\hline Ribes, Andres & 1225 & 1783 \\
\hline Ridameta, Francisco & 6600 & 1784 \\
\hline Riera, Josep & 46005 & $1783-94$ \\
\hline Riesco, Manuel & 2580 & 1785 \\
\hline Riglos, Francisco & 19880 & $1783-90$ \\
\hline Riglos, Marcos Josep & 500 & 1784 \\
\hline Riglos, Mateo & 500 & 1784 \\
\hline Riguero, Domingo & 6000 & $1784-86$ \\
\hline Rincon, Andres & 5844 & $1783-93$ \\
\hline Rius, Antonio & 714 & 1784 \\
\hline Rivarola, Francisco & 5000 & 1784 \\
\hline Rivarola, Pantaleon & 210 & 1784 \\
\hline Rivera, Ramon & 22500 & 1784 \\
\hline Rivero, Antonio & 6902 & $1784-94$ \\
\hline Rivero, Felix & 64 & 1784 \\
\hline Rivero, Juana & 70 & 1784 \\
\hline
\end{tabular}




\begin{tabular}{|c|c|c|}
\hline Robles, Cristobal & 8300 & $1784-92$ \\
\hline Roca, Antonio & 5000 & 1783 \\
\hline Rocha, Juan & 1200 & $1786-93$ \\
\hline Rocha, Miguel & 6000 & 1783 \\
\hline Rodriguez, Angel & 535 & 1786 \\
\hline Rodriguez, Antonio & 1873 & $1786-91$ \\
\hline Rodriguez, Cristobal & 1200 & $1784-86$ \\
\hline Rodriguez, Domingo & 354 & 1784-92 \\
\hline Rodriguez, Fernando & 150 & 1784 \\
\hline Rodriguez, Gaspar & 12480 & 1783 \\
\hline Rodriguez, Ignacio & 4104 & $1784-91$ \\
\hline Rodriguez, Lucas & 30 & 1784 \\
\hline Rodriguez, Melchor & 550 & $1784-85$ \\
\hline Rodriguez, Policarpo & 300 & 1785 \\
\hline Roger, Jaime & 9180 & 1784 \\
\hline Roig, Bernardo & 665 & $1784-90$ \\
\hline Rojas, Juan & 689 & $1783-87$ \\
\hline Roldan, Antonio & 13312 & $1783-92$ \\
\hline Roldan, Justo & 930 & $1786-90$ \\
\hline Roman y Cabezalez, Josep & 100 & 1784 \\
\hline Romero y Espinola, Francisco & 385 & 1785 \\
\hline Romero, Josep & 30577 & $1784-94$ \\
\hline Romero, Juan & 14871 & $1784-87$ \\
\hline Romero, Manuel & 200 & 1784 \\
\hline Romeu, Miguel & 2000 & 1785 \\
\hline Roque, Francisco & 2248 & 1783 \\
\hline Ros, Cornelio Matias & 32 & 1784 \\
\hline Ros, Juan & 19885 & $1783-86$ \\
\hline Rosa, Antonio & 5000 & 1783 \\
\hline Rosales, Juan Enrique & 800 & 1784 \\
\hline Rosales, Manuel & 14408 & $1783-88$ \\
\hline Rosas, Miguel & 150 & 1783 \\
\hline Rospiglio, Claudio & 8460 & $1785-86$ \\
\hline Roza, Josep & 3840 & 1783 \\
\hline Roza, Pedro & 108 & 1785 \\
\hline Rubio, Josep & 10879 & $1786-94$ \\
\hline Rubio, Manuel & 1231 & $1783-84$ \\
\hline Ruiz de la Peña, Martin & 200 & 1785 \\
\hline Ruiz de Sorzano, Josep & 32318 & $1783-84$ \\
\hline Rusell, Miguel & 20000 & 1783 \\
\hline Sabatini, Luis & 499 & 1783 \\
\hline Sabid, Antonio & 1101 & 1786 \\
\hline Saenz de la Maza, Manuel & 1900 & 1783 \\
\hline Saenz, Tomas & 616 & $1785-87$ \\
\hline Sagasta, Francisco & 20437 & $1783-84$ \\
\hline Sagasti, Juan & 100 & 1785 \\
\hline Saint Paul, Francisco & 79 & 1784 \\
\hline Saizan, Josep & 6060 & $1783-85$ \\
\hline
\end{tabular}




\begin{tabular}{|c|c|c|}
\hline Salou, Tomas & 1500 & 1783 \\
\hline Salvañach, Cristobal & 8200 & $1786-87$ \\
\hline Samaniego, Lorenzo & 6419 & $1784-88$ \\
\hline San Martin, Juan & 1500 & 1783 \\
\hline Sanchez de Celis, Felix & 1416 & 1784 \\
\hline Sanchez de Velasco, Cecilio & 14339 & 1784-92 \\
\hline Sanchez, Antonio & 4759 & $1785-90$ \\
\hline Sanchez, Bernardo & 28226 & 1783 \\
\hline Sanchez, Felix & 19075 & $1783-92$ \\
\hline Sanchez, Francisco & 2260 & 1784 \\
\hline \begin{tabular}{|l|} 
Sanchez, Isidoro \\
\end{tabular} & 7426 & $1784-87$ \\
\hline Sanchez, Manuela & 188 & 1786 \\
\hline Sanchez, Miguel & 1200 & $1783-87$ \\
\hline Sanchez, Roque & 22660 & $1783-85$ \\
\hline Sandobal, Carlos & 4392 & $1784-87$ \\
\hline Sandobal, Juan & 22958 & $1783-90$ \\
\hline Sanjurjo, Antonio & 2225 & $1783-87$ \\
\hline Santa Cruz, Diego & 10028 & $1784-91$ \\
\hline Santibañez, Francisco & 6861 & $1786-91$ \\
\hline Santimayor, Juan & 10000 & 1784 \\
\hline Santome, Domingo & 1000 & 1783 \\
\hline Sanz de la Peña, Tomas & 2739 & $1786-88$ \\
\hline Saraza, Lorenzo & 2000 & 1785 \\
\hline Saubidet, Francisco & 1249 & $1784-93$ \\
\hline Saubidet, Tomas & 288 & 1783 \\
\hline Saviola, Diego & 10000 & 1784 \\
\hline Sayzas, Josep & 11604 & 1784 \\
\hline Scontoner, Pablo & 3300 & 1783 \\
\hline Sierra, Josep & 7156 & $1783-86$ \\
\hline Signo, Francisco & 900 & $1784-89$ \\
\hline \begin{tabular}{|l|} 
Silva, Josep \\
\end{tabular} & 4552 & $1784-87$ \\
\hline Silva, Juan & 600 & 1783 \\
\hline Sistiaga, Josep Ignacio & 2158 & 1784 \\
\hline Soexe, Manuel & 5345 & 1784 \\
\hline Sola, Miguel & 1500 & 1786 \\
\hline Solanas, Josep & 108 & 1783 \\
\hline Solobardes, Juan & 5000 & 1786 \\
\hline Sorarte, Francisca & 1200 & 1783 \\
\hline Sorarte, Sabina & 1095 & 1786 \\
\hline Soto, Felipe & 20902 & $1783-93$ \\
\hline Soto, Jose & 6436 & 1784 \\
\hline Sotomayor, Martin & 1839 & 1784 \\
\hline Suarez, Bernabe & 3074 & 1784 \\
\hline Suarez, Francisco & 171 & 1783 \\
\hline Suarez, Manuel & 3250 & $1784-87$ \\
\hline Suarez, Miguel & 1300 & 1784 \\
\hline Suliban, Pedro & 110 & 1784 \\
\hline Suora, Manuel & 3000 & 1784 \\
\hline
\end{tabular}




\begin{tabular}{|c|c|c|}
\hline Tagle, Miguel & 12377 & $1784-91$ \\
\hline Taibo, Josep & 1000 & 1784 \\
\hline Tapia, Pablo & 8000 & 1783 \\
\hline Tejada, Manuel & 70 & 1786 \\
\hline Tejerina, Joaquin & 4950 & 1785 \\
\hline Tellechea, Francisco & 16381 & $1785-94$ \\
\hline Teniente de navio Diego Albera & 1700 & 1783 \\
\hline Teniente Manuel Gallego & 300 & 1784 \\
\hline Tercio, Joaquin & 1000 & 1784 \\
\hline Terrero, Joaquin & 11822 & $1783-88$ \\
\hline Thompson, Pablo & 1504 & 1784 \\
\hline Tillo, Domingo & 490 & 1785 \\
\hline Tirado, Maria & 200 & 1783 \\
\hline Tobal, Francisco & 4336 & $1784-94$ \\
\hline Tompson, Pablo & 25611 & $1783-90$ \\
\hline Toribio, Manuel & 8022 & 1784 \\
\hline Torres, Andres & 33027 & $1786-89$ \\
\hline Torres, Julian & 486 & 1786 \\
\hline Tortosa, Juan & 322 & 1783 \\
\hline Tries, Eusebio & 2000 & 1784 \\
\hline Trigo, Jose & 800 & 1783 \\
\hline Trillo, Domingo & 423 & $1785-92$ \\
\hline Trillo, Maria & 2096 & 1784 \\
\hline Trustan, Mariano & 8000 & 1784 \\
\hline Tuarriz, Manuel & 1000 & 1783 \\
\hline Ubeda, Mariano & 230 & $1784-86$ \\
\hline Ugarte, Josep & 30993 & $1785-94$ \\
\hline Urcullo, Mateo & 5323 & 1784 \\
\hline Urdaneta, Francisco & 63304 & $1783-93$ \\
\hline Ureta y Mena, Josep & 326 & 1785 \\
\hline Urien, Domingo & 59955 & $1783-85$ \\
\hline Urien, Francisco & 1108 & 1783 \\
\hline Uriza, Antonio & 32600 & 1783 \\
\hline Urizmendi, Josep & 520 & 1785 \\
\hline Urtuzan, Juan & 2000 & 1785 \\
\hline Valdez, Francisco & 1055 & $1783-94$ \\
\hline Valdez, Lucas & 224 & $1786-87$ \\
\hline Valdivieso, Ignacio & 2104 & $1786-91$ \\
\hline Valdovinos, Francisco & 14801 & $1783-91$ \\
\hline Valiño, Juan & 191 & 1785 \\
\hline Valle, Maria Ana & 500 & 1784 \\
\hline Valle, Ramon & 2000 & 1784 \\
\hline Valomategui, Tomas & 6000 & 1783 \\
\hline Varela, Manuel & 1674 & $1785-89$ \\
\hline Vascani, Juan & 438 & 1784 \\
\hline Vazquez, Juan & 830 & $1784-92$ \\
\hline Vazquez, Manuel & 41442 & $1783-93$ \\
\hline Velarde, Fray Leandro & 500 & 1783 \\
\hline
\end{tabular}




\begin{tabular}{|c|c|c|}
\hline Velasco, Sebastian & 20761 & $1784-92$ \\
\hline Velazco, Angelo & 2800 & 1784 \\
\hline Vial, Santiago & 8908 & $1786-87$ \\
\hline Viana, Andres & 3200 & $1784-86$ \\
\hline Viana, Melchor & 4300 & $1783-87$ \\
\hline Vidal, Josep & 2400 & 1785 \\
\hline Vidaurri, Juan & 3761 & $1783-84$ \\
\hline Videla, Agustin & 6000 & $1785-90$ \\
\hline Videla, Juan & 22435 & $1783-94$ \\
\hline Viedma, Antonio & 1500 & $1784-86$ \\
\hline Vigil, Antonio & 2000 & 1784 \\
\hline Vila, Josep & 24683 & 1784-94 \\
\hline Vilanova, francisco & 500 & 1783 \\
\hline Vilanova, Juan & 4923 & $1783-87$ \\
\hline Vilera, Domingo & 30 & 1784 \\
\hline Villa, Josep & 1130 & $1786-87$ \\
\hline Villabaso, Andres & 3600 & 1786-89 \\
\hline Villaboa, Tomas & 300 & 1785 \\
\hline Villalba, Andres & 9010 & 1784 \\
\hline Villamil, Ignacio & 3220 & $1786-88$ \\
\hline Villapol, Agustin & 270 & 1786 \\
\hline Villar, Josep & 4305 & $1783-93$ \\
\hline Villaraso, Andres & 7500 & $1784-86$ \\
\hline Villaraso, Andres & 3631 & $1786-94$ \\
\hline Villegas, Francisco & 1158 & $1786-93$ \\
\hline Villegas, Manuel & 30240 & $1785-91$ \\
\hline Villota, Cipriano & 2486 & $1784-86$ \\
\hline Villota, Tomas & 1050 & 1783 \\
\hline Viola, Juan & 25665 & $1783-94$ \\
\hline Visaurre, Juan Ignacio & 5000 & 1784 \\
\hline Vivar, Pedro & 7070 & $1783-93$ \\
\hline Viudo de Mendoza, Josep & 50 & 1784 \\
\hline Warnes, Manuel & 8404 & 1784-94 \\
\hline Wight, Agustin & 10885 & $1785-92$ \\
\hline Xado, Casimiro & 7821 & 1789 \\
\hline Xibirell, Jose & 8900 & 1790 \\
\hline Yaneti, Bernardo & 98 & 1784 \\
\hline Yañez, Josep & 2807 & $1784-89$ \\
\hline Yañez, Martin & 650 & 1794 \\
\hline Yarza, Francisco & 348 & $1786-93$ \\
\hline Yepe, Antonio & 60 & 1790 \\
\hline Yoldi, Joaquin & 34572 & $1786-89$ \\
\hline Yolis, Juan & 650 & 1789 \\
\hline Yosti, Antonio & 50 & 1788 \\
\hline Yurramendi, Juan & 5000 & 1784-89 \\
\hline Zaballa, Francisco & 20572 & $1783-91$ \\
\hline Zadis, Gabriel & 372 & 1784 \\
\hline Zelis, Bruno & 402 & 1784 \\
\hline
\end{tabular}




\begin{tabular}{|l|r|r|}
\hline Zemborain, Felix & 1000 & 1784 \\
\hline Zendijo, Julian & 1125 & $1790-94$ \\
\hline Zañartu, Manuela & 200 & 1790 \\
\hline Zengoitia, Martin & 7112 & 1789 \\
\hline Zuizan, Josep & 7734 & $1784-86$ \\
\hline Zulaica, Antonio & 11337 & $1784-94$ \\
\hline Zulueta, Ignacio & 162 & 1792 \\
\hline Zulueta, Manuel & 1552 & 1786 \\
\hline Zuñiga, Barbara & 100 & 1784 \\
\hline Zuñiga, Rafael & 5416 & $1784-86$ \\
\hline Zuzur, Pablo & 1079 & 1787 \\
\hline
\end{tabular}

Anexo III: Navios de bandera española con esclavizados

\begin{tabular}{|r|l|l|r|l|}
\hline años & $\begin{array}{l}\text { Tipo de } \\
\text { navio }\end{array}$ & Nombre & $\begin{array}{c}\text { cantida de } \\
\text { esclavizados }\end{array}$ & Origen \\
\hline 1778 & zumaca & S José & 33 & Brasil \\
\hline 1778 & Paquebot & S Teresa & 104 & Brasil \\
\hline 1778 & zumaca & La Madre de Dios & 26 & Brasil \\
\hline 1778 & Polacra & Purísima Concepción & 24 & Brasil \\
\hline 1778 & zumaca & & 30 & Brasil \\
\hline 1778 & zumaca & N Sa del Carmen & 35 & Brasil \\
\hline 1779 & Fragata & S Pedro & 36 & África \\
\hline 1781 & Fragata & N Sa del Rosario & 27 & Brasil \\
\hline 1781 & zumaca & N Sa del Carmen & 16 & Brasil \\
\hline 1782 & zumaca & N Sa del Carmen & 40 & Brasil \\
\hline 1783 & Fragata & S Tiago & 24 & Árica \\
\hline 1789 & Fragata & N Sa La Madre de Dios & 1 & Brasil \\
\hline 1792 & bergantín & Animas & 220 & Brasil \\
\hline 1792 & balandra & N Sa del Carmen & 27 & Brasil \\
\hline 1792 & Fragata & S Ana & 425 & África \\
\hline 1793 & bergantín & N Sa de la Piedad, S Antonio & 341 & Brasil \\
\hline 1793 & balandra & N Sa del Carmen & 45 & Brasil \\
\hline 1794 & balandra & N Sa del Carmen & 48 & Brasil \\
\hline 1794 & zumaca & Rosa & 118 & Brasil \\
\hline 1794 & bergantín & N sa de la Concepción & 255 & Brasil \\
\hline 1795 & zumaca & N Sa de la Guía & 30 & Brasil \\
\hline 1795 & bergantín & Buen Jardín & 220 & África \\
\hline 1796 & zumaca & Lunes & 213 & Brasil \\
\hline 1796 & zumaca & N Sa del Rosario & 2 & Brasil \\
\hline 1796 & zumaca & S Pío & 191 & Brasil \\
\hline 1796 & zumaca & S Pío Quinto & 55 & Brasil \\
\hline 1796 & zumaca & N Sa de la Guía & 319 & África \\
\hline 1796 & Fragata & Reina Luisa & 250 & Brasil \\
\hline 1797 & bergantín & Jesús María y José Rivera & Brasil \\
\hline 1797 & bergantín & N Sa de la Piedad & \\
\hline
\end{tabular}




\begin{tabular}{|c|c|c|c|c|}
\hline 1797 & zumaca & El Lunes & 184 & Brasil \\
\hline 1797 & lancha & N Sa de la Concepción & 67 & Brasil \\
\hline 1797 & zumaca & $\begin{array}{l}\text { N Sa de la Concepción, San Antonio y } \\
\text { Animas }\end{array}$ & 193 & Brasil \\
\hline 1797 & Fragata & Faustina de Buenos Aires & 161 & África \\
\hline 1797 & bergantín & Reyna de los Angeles & 29 & África \\
\hline 1797 & bergantín & $\begin{array}{l}\text { S Cristo de la Pasión, S Antonio y } \\
\text { Animas }\end{array}$ & 169 & África \\
\hline 1797 & Fragata & S Felipe Neri & 230 & África \\
\hline 1798 & zumaca & S Pío & 245 & Brasil \\
\hline 1798 & Paquebot & El Miércoles & 462 & Brasil \\
\hline 1798 & bergantín & La Flor del Mar & 117 & Brasil \\
\hline 1798 & bergantín & La Madre de los Hombres & 2 & Brasil \\
\hline 1798 & zumaca & N Sa de Aranzanzú & 157 & Brasil \\
\hline 1798 & zumaca & N Sa de Monserrat & 89 & Brasil \\
\hline 1798 & bergantín & S Francisco de Paula & 59 & Brasil \\
\hline 1798 & zumaca & S Pío & 240 & Brasil \\
\hline 1798 & Fragata & Trinidad & 21 & Brasil \\
\hline 1798 & Fragata & Faustina de Buenos Aires & 284 & África \\
\hline 1799 & bergantín & S Francisco de Paula & 90 & Brasil \\
\hline 1799 & bergantín & Brillante & 12 & Brasil \\
\hline 1799 & Fragata & Ceres & 25 & Brasil \\
\hline 1799 & bergantín & N Sa de Aranzanzú & 25 & Brasil \\
\hline 1799 & bergantín & $\begin{array}{l}\text { N Sa de la Concepción y S Francisco de } \\
\text { Asís }\end{array}$ & 12 & Brasil \\
\hline 1799 & zumaca & N Sa de la Estrella & 1 & Brasil \\
\hline 1799 & Polacra & N Sa del Pilar & 91 & Brasil \\
\hline 1799 & Polacra & N Sa del Rosario & 7 & Brasil \\
\hline 1799 & zumaca & S Antonio & 60 & Brasil \\
\hline 1799 & bergantín & El Tigre & 20 & Brasil \\
\hline 1799 & zumaca & Joven & 2 & Brasil \\
\hline 1799 & zumaca & N Sa de Begoña & 5 & Brasil \\
\hline 1799 & Corbeta & N Sa de la Concepción & 12 & Brasil \\
\hline 1799 & bergantín & N Sa de la Concepción & 191 & Brasil \\
\hline 1799 & zumaca & $\begin{array}{l}\text { N Sa de la Concepción y el S del Buen } \\
\text { Fin }\end{array}$ & 1 & Brasil \\
\hline 1799 & zumaca & N Sa del Rosario & 8 & Brasil \\
\hline 1799 & zumaca & N Sa del Rosario & 1 & Brasil \\
\hline 1799 & bergantín & N Sa la Madre de los Hombres & 3 & Brasil \\
\hline 1799 & zumaca & S Ana & 126 & Brasil \\
\hline 1799 & bergantín & S Francisco Solano & & Brasil \\
\hline 1799 & Fragata & Astirraga & 276 & África \\
\hline 1799 & zumaca & N Sa de la Concepción & 58 & África \\
\hline 1800 & bergantín & Miércoles & 119 & Brasil \\
\hline 1800 & Polacra & S Cruz & 246 & Brasil \\
\hline
\end{tabular}




\begin{tabular}{|c|c|c|c|c|}
\hline 1800 & zumaca & Estrella & 66 & Brasil \\
\hline 1800 & zumaca & N Sa de la Lapa & 7 & Brasil \\
\hline 1800 & zumaca & S Antonio & 8 & Brasil \\
\hline 1800 & bergantín & S Francisco de Paula & 119 & Brasil \\
\hline 1800 & lancha & Concepción & 14 & Brasil \\
\hline 1800 & bergantín & Resoluto & 345 & Brasil \\
\hline 1800 & Fragata & Joaquina & 24 & Brasil \\
\hline 1800 & lancha & Concepción & 138 & Brasil \\
\hline 1800 & lancha & Concepción & 142 & Brasil \\
\hline 1800 & bergantín & Fama del Sur & 44 & Brasil \\
\hline 1800 & bergantín & Joven & 70 & Brasil \\
\hline 1800 & zumaca & Pura Concepción & 30 & Brasil \\
\hline 1800 & zumaca & Maravilla & 172 & Brasil \\
\hline 1800 & zumaca & N Sa de Begoña & 74 & Brasil \\
\hline 1800 & zumaca & N Sa de Begoña & 24 & Brasil \\
\hline 1800 & bergantín & N Sa de la Concepción & 31 & Brasil \\
\hline 1800 & zumaca & N Sa de la Concepción & 157 & Brasil \\
\hline 1800 & bergantín & N Sa de la Concepción & 16 & Brasil \\
\hline 1800 & bergantín & N Sa de la Estrella & 332 & Brasil \\
\hline 1800 & zumaca & N Sa de la Maravilla & 22 & Brasil \\
\hline 1800 & bergantín & N Sa del Pilar & 222 & Brasil \\
\hline 1800 & zumaca & N Sa del Pilar y SS Sacramento & 190 & Brasil \\
\hline 1800 & bergantín & Rosario & 113 & Brasil \\
\hline 1800 & zumaca & S Antonio & 3 & Brasil \\
\hline 1800 & Fragata & S Buenaventura & 8 & Brasil \\
\hline 1800 & Goleta & S Fortunata & 250 & Brasil \\
\hline 1800 & bergantín & S Francisco Solano & 354 & Brasil \\
\hline 1800 & zumaca & S José & 6 & Brasil \\
\hline 1800 & zumaca & SS Trinidad & 26 & Brasil \\
\hline 1800 & zumaca & SS Trinidad & 32 & Brasil \\
\hline 1800 & Fragata & S Teresa & 7 & África \\
\hline 1801 & zumaca & Estrella & 137 & Brasil \\
\hline 1801 & zumaca & Estrella & 30 & Brasil \\
\hline 1801 & Fragata & La Fama del Sur & 25 & Brasil \\
\hline 1801 & zumaca & N Sa del Pilar & 34 & Brasil \\
\hline 1801 & zumaca & N Sa del Pilar & 89 & Brasil \\
\hline 1801 & bergantín & N Sa del Pilar & 249 & Brasil \\
\hline 1801 & zumaca & Piedad & 6 & Brasil \\
\hline 1801 & zumaca & S Francisco Xavier & 4 & Brasil \\
\hline 1801 & Fragata & S Teresa & 2 & Brasil \\
\hline 1801 & Fragata & S Jose & 213 & África \\
\hline 1802 & Fragata & La Joven María Josefa & 4 & Brasil \\
\hline 1802 & zumaca & N Sa de la Peña de Francia & 8 & Brasil \\
\hline 1802 & bergantín & S Ana y San Feliú & 53 & Brasil \\
\hline 1802 & bergantín & El Resoluto & 9 & Brasil \\
\hline
\end{tabular}




\begin{tabular}{|c|c|c|c|c|}
\hline 1802 & bergantín & La Peña de Francia & 94 & Brasil \\
\hline 1802 & zumaca & N Sa de Begoña & 9 & Brasil \\
\hline 1802 & zumaca & N Sa de la Concepción & 137 & Brasil \\
\hline 1802 & zumaca & N Sa de los Remedios & 13 & Brasil \\
\hline 1802 & zumaca & N Sa del Rosario & 40 & Brasil \\
\hline 1802 & bergantín & N Sa del Rosario & 3 & Brasil \\
\hline 1802 & Fragata & S Antonio & & Brasil \\
\hline 1802 & bergantín & S Antonio & 304 & Brasil \\
\hline 1802 & Fragata & S Francisco de Asís & 29 & Brasil \\
\hline 1802 & bergantín & S Francisco de Paula & 3 & Brasil \\
\hline 1802 & bergantín & S Juan & 18 & Brasil \\
\hline 1802 & zumaca & N Sa del Pilar & 29 & Brasil \\
\hline 1802 & bergantín & N Sa del Juncal & 66 & África \\
\hline 1803 & bergantín & Buen Jardín & 40 & Brasil \\
\hline 1803 & bergantín & Estrella & 76 & Brasil \\
\hline 1803 & balandra & N Sa de la Concepción & 2 & Brasil \\
\hline 1803 & zumaca & S Ana & 15 & Brasil \\
\hline 1803 & bergantín & S Antonio Volador & 198 & Brasil \\
\hline 1803 & bergantín & Ulises & 50 & Brasil \\
\hline 1803 & bergantín & N Sa del Buen Viaje & 18 & Brasil \\
\hline 1803 & zumaca & S Ana & 24 & Brasil \\
\hline 1803 & bergantín & S Antonio & 59 & Brasil \\
\hline 1803 & Fragata & S Feliciano & 133 & Brasil \\
\hline 1803 & bergantín & S Rosa & 27 & Brasil \\
\hline 1803 & bergantín & Ulises & 11 & Brasil \\
\hline 1803 & bergantín & S Antonio & 198 & Brasil \\
\hline 1803 & balandra & Castor & 185 & Brasil \\
\hline 1803 & Fragata & S Juan Bautista & 151 & África \\
\hline 1803 & Fragata & Retiro de Buenos Aires & 265 & África \\
\hline 1803 & bergantín & Rio & 200 & África \\
\hline 1803 & Fragata & Minerva & 282 & África \\
\hline 1803 & Fragata & N Sa de las Nieves & 233 & África \\
\hline 1803 & bergantín & & 93 & África \\
\hline 1803 & bergantín & Angela & 108 & África \\
\hline 1803 & bergantín & S Ignacio & 67 & África \\
\hline 1803 & & Tártaro & 263 & África \\
\hline 1804 & bergantín & Buen Viaje & 32 & Brasil \\
\hline 1804 & Fragata & Delfina & 135 & Brasil \\
\hline 1804 & zumaca & Estrella & 89 & Brasil \\
\hline 1804 & bergantín & La Flor de Mayo & 90 & Brasil \\
\hline 1804 & bergantín & La Marcelina & 55 & Brasil \\
\hline 1804 & bergantín & N Sa de Aranzanzú & 93 & Brasil \\
\hline 1804 & bergantín & N Sa de Begoña & 3 & Brasil \\
\hline 1804 & zumaca & N Sa de la Concepción & 10 & Brasil \\
\hline 1804 & Fragata & N Sa de la Concepción & 3 & Brasil \\
\hline
\end{tabular}




\begin{tabular}{|c|c|c|c|c|}
\hline 1804 & bergantín & S Juan & 8 & Brasil \\
\hline 1804 & bergantín & $\mathrm{N}^{\mathrm{o}} 6$ & 108 & Brasil \\
\hline 1804 & zumaca & S Ana & 7 & Brasil \\
\hline 1804 & bergantín & S Antonio & 37 & Brasil \\
\hline 1804 & bergantín & S Antonio & 18 & Brasil \\
\hline 1804 & bergantín & S Ignacio & 2 & Brasil \\
\hline 1804 & bergantín & S José & 22 & Brasil \\
\hline 1804 & bergantín & S Vicente Ferrer & 4 & Brasil \\
\hline 1804 & bergantín & S Antonio & 14 & Brasil \\
\hline 1804 & Fragata & N Sa del Juncal & & África \\
\hline 1804 & bergantín & Belisario & 104 & África \\
\hline 1804 & zumaca & S Ana & 81 & África \\
\hline 1805 & Fragata & Hermenegilda & 11 & Brasil \\
\hline 1805 & Fragata & Estrella & 6 & Brasil \\
\hline 1805 & bergantín & S Antonio & 11 & Brasil \\
\hline 1805 & Goleta & Marcelina & 60 & Brasil \\
\hline 1805 & zumaca & S Ana & 2 & Brasil \\
\hline 1805 & zumaca & S Ana & 8 & Brasil \\
\hline 1805 & bergantín & S Juan & 2 & Brasil \\
\hline 1805 & bergantín & Turboada & 7 & Brasil \\
\hline 1805 & bergantín & Ulises & 11 & Brasil \\
\hline 1805 & zumaca & Turboada & 10 & Brasil \\
\hline 1805 & balandra & Castor & 19 & Brasil \\
\hline 1805 & Fragata & Buena Madre & 130 & África \\
\hline 1805 & bergantín & S Pedro & 172 & África \\
\hline 1806 & bergantín & Bentura & 26 & Brasil \\
\hline 1806 & bergantín & Encarnación & 9 & Brasil \\
\hline 1806 & bergantín & S Antonio & 3 & Brasil \\
\hline 1806 & bergantín & S José & 10 & Brasil \\
\hline 1806 & bergantín & Begoña & 2 & Brasil \\
\hline 1806 & bergantín & El Belisario & 10 & Brasil \\
\hline 1806 & bergantín & N Sa Buen Viaje & 12 & Brasil \\
\hline 1806 & zumaca & N Sa del Rosario & 22 & Brasil \\
\hline 1806 & zumaca & Turboada & 10 & Brasil \\
\hline 1806 & bergantín & S Francisco Xavier & 16 & Brasil \\
\hline
\end{tabular}

